Final Report

FHWA/IN/JTRP-2005/5

\title{
Technical Issues Related to the Use of Fly Ash and Slag During Late-Fall (Low Temperature) Construction Season
}

\author{
By \\ Anand Krishnan \\ Jinesh K. Mehta \\ Graduate Research Assistants \\ Jan Olek \\ Professor of Civil Engineering \\ Principal Investigator \\ and \\ W. J. Weiss \\ Professor of Civil Engineering \\ Co-Principal Investigator \\ School of Civil Engineering \\ Purdue University \\ Joint Transportation Research Program \\ Project Number: C-36-19I \\ File Number: $5-5-9$ \\ SPR-2475 \\ Prepared in Cooperation with the \\ Indiana Department of Transportation and the \\ U. S. Department of Transportation \\ Federal Highway Administration
}

The contents of this report reflect the views of the authors, who are responsible for the facts and the accuracy of the data presented herein. The contents do not necessarily reflect the official views and policies pf the Indiana Department of Transportation or Federal Highway Administration at the time of publication. The report does not constitute a standard, specification or regulation.

Purdue University

West Lafayette, IN 47907

June 2006 


\section{TECHNICAL Summary}

INDOT Research

Technology Transfer and Project Implementation Information

\section{Technical Issues Related to the Use of Fly Ash and Slag During the Late-Fall (Low Temperature) Construction Season}

\section{Introduction}

Current INDOT specifications (Section 501.03) permit the use of fly ash and slag in concrete pavement only between April 1 and October 15 of the same calendar year. This limitation is intended to address concerns regarding the potential for inadequate durability performance of concrete containing such materials when the concrete is placed in the late fall construction season. The objective of this research was to evaluate whether concrete pavements containing fly ash (FA) or ground, granulated blast furnace slag (GGBFS) can be constructed under conditions typical of those expected in the late fall in Indiana to provide adequate durability to freeze-thaw and salt scaling resistance.

The project is broadly divided in to two phases. Phase I contains the results of preliminary studies on materials and concrete properties influencing scaling. In the Phase II, a more focused study on scaling of concrete containing supplementary cementitious materials (SCM) was performed. The whole project was divided in to six tasks. The first task focused on compilation of published data on the topics of freeze-thaw and scaling resistance, air-void analysis in hardened concrete, and maturity and strength development of concretes containing fly ash and slag. The second task focused on characterization of cements, fly ashes and slags from INDOT's list of approved materials for selection of representative materials and formulating a logical method to be used in the subsequent experiments. Preliminary tests on various mortar and concrete mixture combinations were performed in Task 3. After initial tests on paste and mortar specimens, binder compositions were selected to prepare concrete mixtures.

Based on these three primary tasks, the need for a more focused study on scaling behavior of concrete was identified. In Phase II, the entire study was conducted on the worst performing cement and fly ash combination identified in Phase I. The fourth and fifth tasks covered the study of factors influencing the scaling resistance of concrete. In addition, a microstructure and chloride ion penetration study was performed to assist in the interpretation of results. Finally, in task six, the discrepancy between laboratory results and field observations was addressed and summary of results from the entire study was prepared.

\section{Findings}

Models can be developed for strength prediction of cement mortars and Strength Activity Index (SAI) predictions for fly ashes using the supplier's data on chemical composition and physical properties of the materials. These models can be successfully used to forecast the expected changes in strength (for cements) and SAI (for fly ashes) as a result of changes in properties of the material.
The maturity method could be used to effectively predict the age required to attain a given strength level for mortar mixtures cured under any temperature history.

Concrete containing fly ash or slag can be exposed to freeze and thaw cycles at relatively early ages without significant reduction in durability factor provided that it reaches compressive strength of at least 3500 psi and has

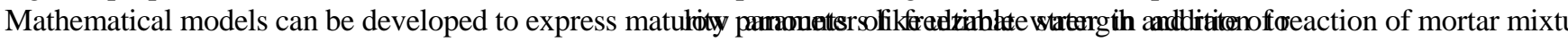


minimum air contents of $6 \%$ and air-void spacing less than 0.008”.

Since all concrete mixtures tested were supposed to represent slowest hydrating systems under low temperature conditions, it is believed that mixtures prepared with similar fly ashes or slag, but using other cements, would also pass the freeze-thaw durability test.

\section{Implementation}

Based on the study on scaling in concrete containing fly ash, it can be recommended that the use of supplementary materials with current replacement levels and current INDOT temperature guidelines can be extended throughout the year for climatic conditions of Indiana for pavement construction. The reasons for this conclusion are evident in the entire study and have also been briefly listed below.

Experimental results showed that adequate $\mathrm{F}-\mathrm{T}$ resistance can be obtained when concrete has a compressive strength of at least 3500 psi and has low amounts of freezable water in addition to minimum air contents of $6 \%$ and airvoid spacing less than 0.008 inch.

In regard to scaling, the ASTM C 672 was found to be too severe and does not represent the climatic conditions observed in Indiana. Risk analysis indicated that the overall probability of scaling to initiate in any typical pavement in Indiana is very low.

The scaling resistance of concrete in actual pavement is most likely to be better than that of the corresponding laboratory specimens. This can be attributed to low slump, better finishing with slip-form paver, and most-favorable temperature profile developed during freezing due to a higher thickness of pavement compared to laboratory specimens.

Out of the total of seven different combinations of cementitious materials studied in this research, only one combination showed a scaled mass higher than the specified limit when studied as per ASTM C672. Moreover, when the tests were repeated using second shipment of the "worst" performing materials from the same source, even the laboratory specimens did not develop any scaling. This indicates that the probability of getting the worst performing combination of materials is very low.

The worst performing combination of materials that showed severe scaling damage in the laboratory did not show any scaling when attempt was made to simulate the actual field conditions in the laboratory.

Survey information showed that out of 12 states having similar or more severe climatic conditions than Indiana, nine states allow the use of fly ash or slag throughout the entire year. None of these states reported having any major scaling resulting from the use of these materials during the late fall construction season.

Based on the results of this research study, it is recommended that INDOT should revise their standard specifications to allow slag and fly ash in concrete pavements to be placed after October $15^{\text {th }}$, providing that the contractor understands the risk involved when the target strength for adequate $\mathrm{F}-\mathrm{T}$ resistance $(3500 \mathrm{psi})$ is not achieved.

\section{Contacts}

\section{For more information:}

\section{Prof. Jan Olek}

Principal Investigator

School of Civil Engineering

Purdue University

West Lafayette, IN 47907-2051

Phone: (765) 494-5015

Fax: (765) 496-1364

E-mail: olek@ecn.purdue.edu

\author{
Indiana Department of Transportation \\ Division of Research \\ 1205 Montgomery Street \\ P.O. Box 2279 \\ West Lafayette, IN 47906 \\ Phone: (765) 463-1521 \\ Fax: (765) 497-1665

\section{Purdue University} \\ Joint Transportation Research Program \\ School of Civil Engineering \\ West Lafayette, IN 47907-1284 \\ Phone: (765) 494-9310 \\ Fax: (765) 496-7996 \\ E:mail: jtrp@ecn.purdue.edu \\ http://www.purdue.edu/jtrp
}


TABLE OF CONTENTS

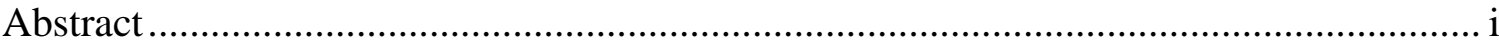

List of Figures ................................................................................................ vii

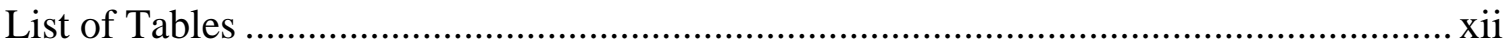

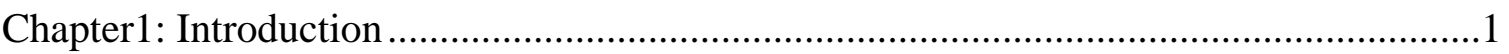

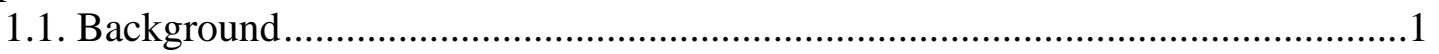

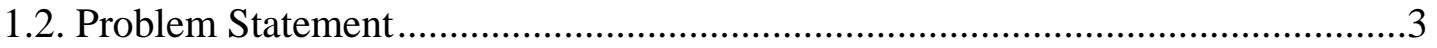

1.3. Research Objective and Scope of Project .....................................................

1.4. Organization of Report .......................................................................

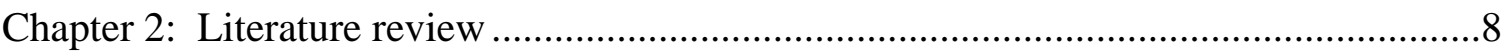

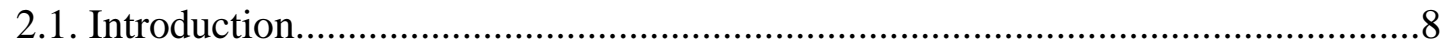

2.2. Studies of F-T and Deicer Salt Scaling of Concrete Containing SCM.................8

2.3. Current Understanding of the Influence of Various Materials on Scaling ...........11

2.3.1. Cementitious Materials Types and Contents ............................................11

2.3.2. Coarse and Fine Aggregates ................................................................13

2.4. Concrete Properties, Preparation, and Characteristics Influencing Scaling

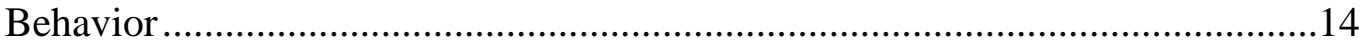

2.4.1. Air Void Content, Spacing Factor, and Carbon Content of Fly Ash ...........15

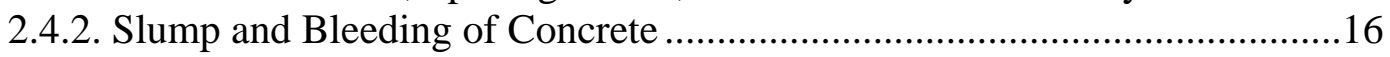

2.4.3. Placing and Finishing of Concrete .........................................................17

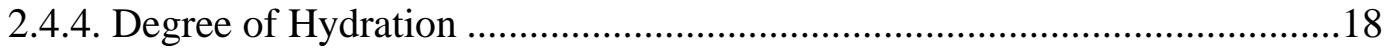

2.4.5. Early and Later Age Strength of Concrete................................................19

2.4.6. Porosity, Pore Size Distribution, and Sorptivity of Concrete ......................20

2.5. Environmental and Other Parameters Influencing Durability of Concrete under

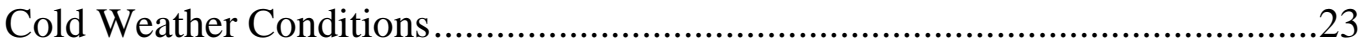

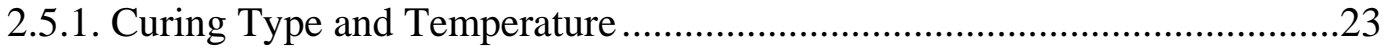

2.5.2. Rate of Freezing and Minimum Temperature.........................................26

2.5.3. De-icing Salt Solutions; Types and Concentration ....................................27

2.6. Summary of Proposed Mechanisms of Scaling of Concrete ..............................29

2.6.1. Hydraulic Pressure Mechanism ..............................................................30

2.6.2. Osmotic Pressure Mechanism....................................................................31

2.6.3. Combined Hydraulic and Osmotic Pressure Mechanism ............................32

2.6.4. Crystal Growth Mechanism .................................................................33

2.6.5. Thermal Shock, Thermal Incompatibility or Thermal Mismatch................34

2.6.6. A Case-Specific Approach Based on Summary of Various Mechanisms ...35

2.7. Maturity Method 
Chapter 3: Selection of Cements and Supplementary Cementing Materials.................. 41

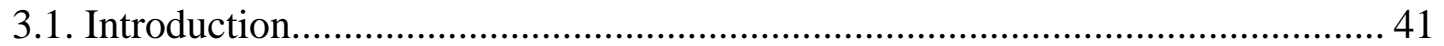

3.2. Development of Mathematical Model for Strength Prediction of Cement Mortars

3.3. Development of Mathematical Model for Strength Activity Index (SAI)

Prediction for Fly Ashes .............................................................................. 46

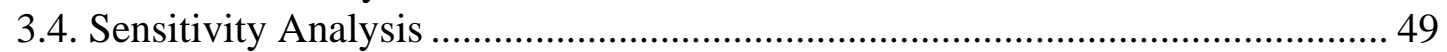

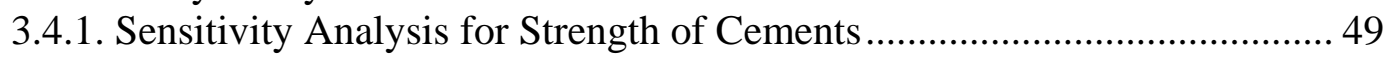

3.4.2. Summary of Sensitivity Analysis for Cements ........................................ 52

3.4.3. Sensitivity Analysis for Class C Fly Ash.................................................. 53

3.4.4. Summary of Sensitivity Analysis for Class C Fly Ash.............................. 55

3.5. Identification of Cements for Further Study .................................................... 55

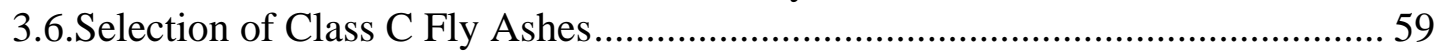

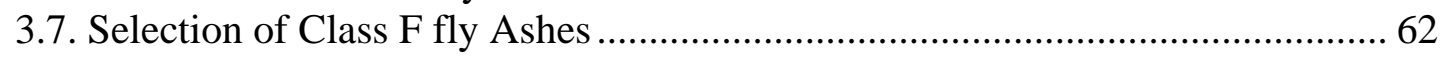

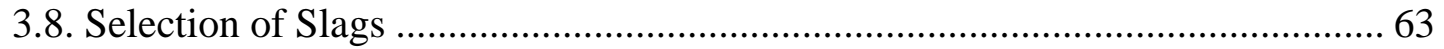

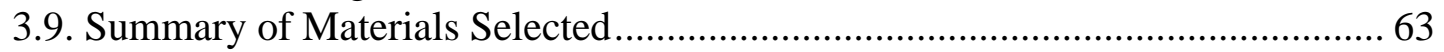

Chapter 4: Development of Procedures for Identifying Material Combinations that may

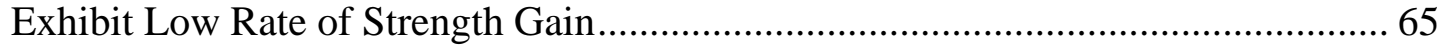

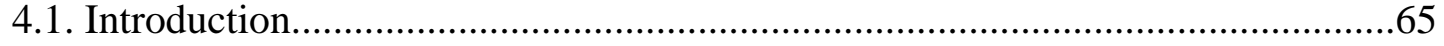

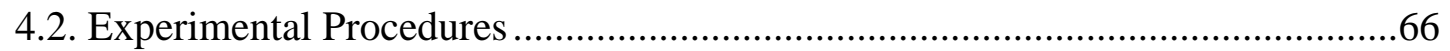

4.2.1. Preparation of Mortar Test Specimens ...................................................66

4.2.2. Curing and Test Procedures for Maturity and Compressive Strength Tests67

4.2.3. Preparation of Paste Specimens ............................................................. 70

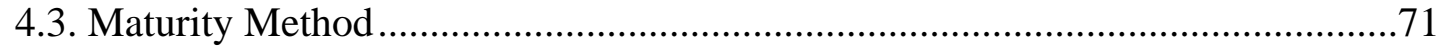

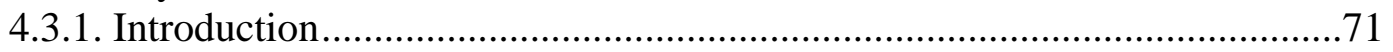

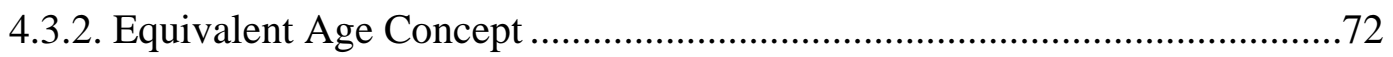

4.3.3. Hyperbolic Strength Maturity Relationship............................................73

4.3.4. Determination of Ultimate Strength........................................................75

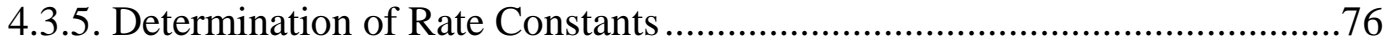

4.3.6. Determination of Activation Energy......................................................77

4.4. Approach for Development Strength Models and Binder Selection ...................78

4.4.1. Summary of Values of Ultimate Strength, Rate of Reaction and Energy

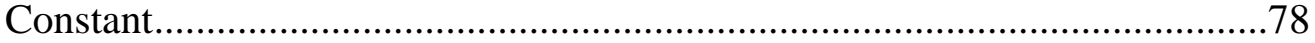

4.4.2. Development of Mathematical Model for Strength Prediction in Mortars..80

4.4.3. Comparison of Actual Strength Results with Results Predicted from the

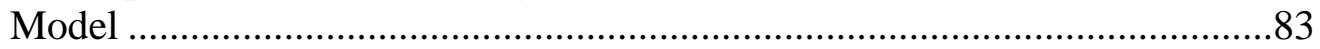

4.4.4. Non-Evaporable Water Content Determination.......................................86

4.4.5. Summary of Results from Non-Evaporable Water Content tests ................88

4.4.6. Late Fall Temperatures in the State of Indiana........................................89

4.4.7. Identification of Slow Strength Gaining Mortar Mixtures .........................93

4.4.8. Selection of Concrete Mixture Composition Based on Material Tests and

Trends from Time-temperature Contour Plots .............................................99

4.5. Summary. 
Chapter 5: Evaluation of Properties of Concrete Mixtures..........................................103

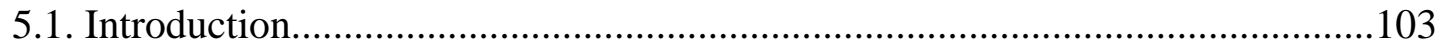

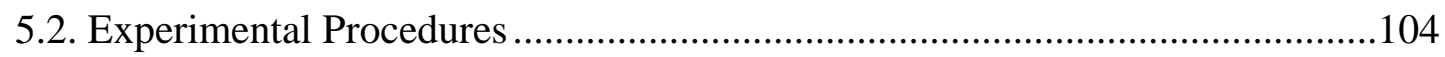

5.2.1. Preparation of Concrete ........................................................................104

5.2.2. Curing and Test Procedures for Compressive, and Flexural Strength of

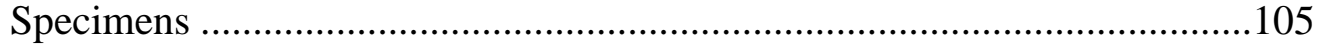

5.2.3. Curing and Testing of Specimens Subjected to Freeze-Thaw Cycling .....106

5.2.4. Curing and Testing of Specimens for Salt Scaling Tests...........................107

5.2.5. Test Procedure for Determining Sorptivity..............................................108

5.2.6. Test Procedure for Air void Analysis on Hardened Concrete Sections.....109

5.2.7. Test Procedure for Determination of Resonant Frequency of Concrete....110

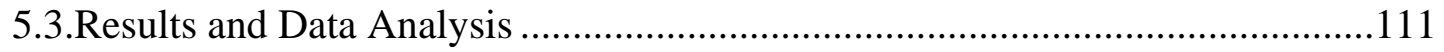

5.3.1. Compressive Strength Tests.............................................................111

5.3.2. Flexural Strength Tests ...........................................................................112

5.3.3. Comparison of Rate Constants for Concrete Mixtures with Companion Mortar Mixtures .....................................................................................115

5.3.4. Freeze-Thaw Durability and Air Void Analysis....................................116

5.3.5. Sorptivity Tests and Weight Loss on Drying.........................................119

5.3.7. Resonant Frequency Development Over Time.......................................125

5.3.9. Observations from Scaling Tests .........................................................130

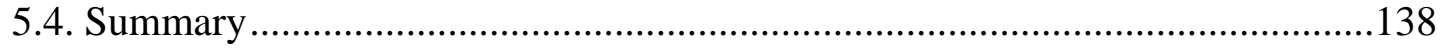

Chapter 6: Summary and Conclusions for Phase I of the Research Objectives and Scope of Work for Extended Study (Phase II) on Scaling Behavior of Concrete Containing SCM

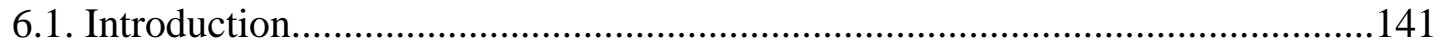

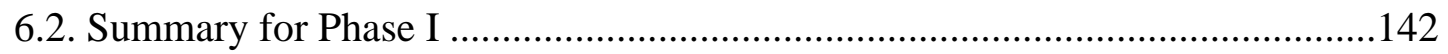

6.2.1. Summary of Analysis and Selection of Cementitious Systems .................142

6.2.2. Summary of Tests Procedures and Results of Mortar Tests......................143

6.2.3. Summary of Analysis of Concrete Test Results .......................................145

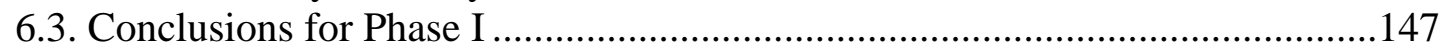

6.4. Research Objectives and Scope of Work for Phase II ....................................148

Chapter 7: Constituent Materials and Their Influence on Scaling Resistance of

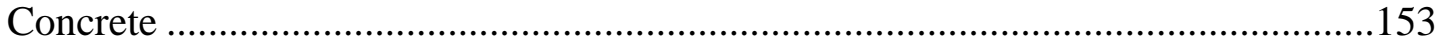

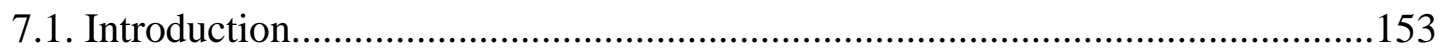

7.2. Constituent Materials ..................................................................................... 153

7.3. Study of Influence of Individual Constituent Materials on Scaling

Performance 156

7.3.1. Influence of Chemical Admixtures and Fly Ash on Near-Surface Region

Density of Hydrated Paste.......................................................................156

7.3.2. Role of Deleterious Aggregates .............................................................161

7.3.3. Influence of Variability of Cementitious Materials on Scaling Behavior .164

7.4. Summary. 
Chapter 8: Influence of Length and Type of Curing on Salt Penetration and Scaling ...174

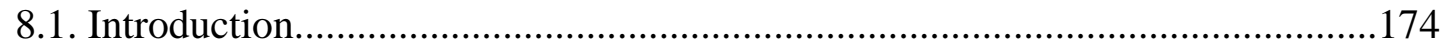

8.2. Specimen Preparation and Experimental Procedures ......................................177

8.2.1. Influence of the Length of Moist-Curing and Drying on Scaling..............178

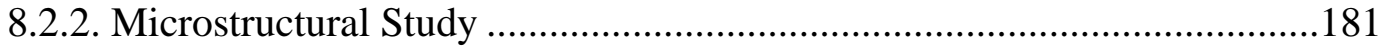

8.2.3. Study of Chloride Ion Penetration .......................................................189

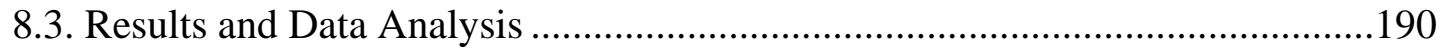

8.3.1. Rate of Scaling and Probable Governing Parameters ...............................191

8.3.2. Influence of the Moist-Curing and Drying Periods on Scaling of Low

Slump Mixtures ........................................................................................192

8.3.3. Influence of Moist-Curing and Drying on Scaling for High Slump

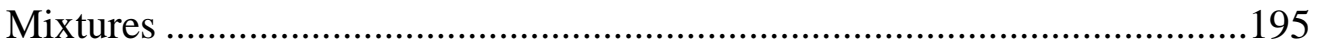

8.3.4. Scaling Rate of Specimens Conditioned for More Than 28 Days ..............197

8.3.5. Porosity of Specimens Exposed to Different Curing Regimes ...................199

8.3.6. Study of Chloride Ion Penetration ........................................................2202

8.3.7. Differential Salt Concentration Study...................................................205

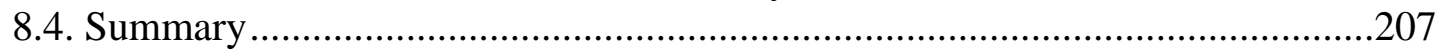

Chapter 9: Influence of Low Temperature Curing on Fresh Properties and Scaling of

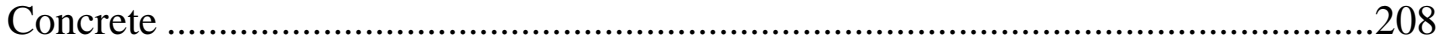

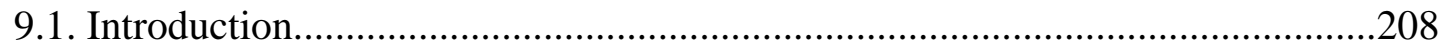

9.2. Preparation of Specimens and Experimental Procedure..................................210

9.2.1. General Parameters and Procedures for Low Temperature Study .............210

9.2.2. Setting time Measurement at Low Temperature........................................212

9.2.3. Bleeding of Concrete and Effect of Evaporation Rate at

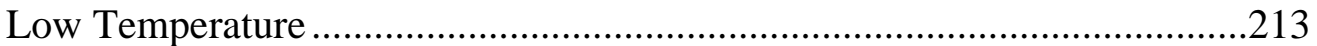

9.2.4. Scaling of 75-mm Deep Specimens Cured at Low Temperature ..............214

9.2.5. Scaling of Concrete With Different Early Age Evaporation (Drying Periods) 215

9.2.6. Scaling and Other Relevant Studies for 300-mm Deep Specimens...........216

9.2.7. Porosity Determination in Field and Laboratory Specimens .....................221

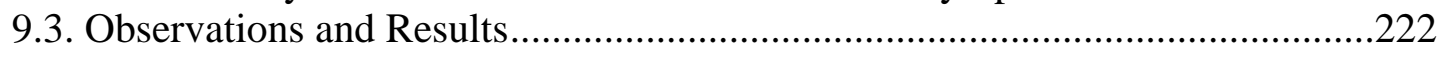

9.3.1. Setting Time Measurement at Low Temperature ....................................222

9.3.2. Bleeding of Concrete and Effect of Evaporation at Low Temperature .....224

9.3.3. Scaling of Normal Size Specimens Cured at Low Temperature ...............227

9.3.4. Scaling of Concrete With Different Early Age Drying Periods ................229

9.3.5. Low Temperature Curing of Large Size Specimens..................................230

9.3.6. Porosity Determination in Field and Laboratory Specimens .....................241

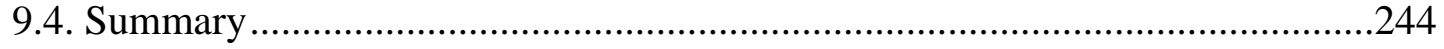

Chapter 10: Discrepancies Between Laboratory Results and Field Observations Relating

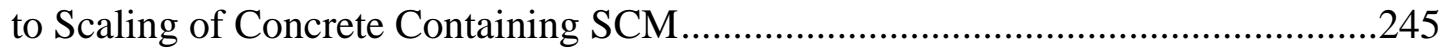

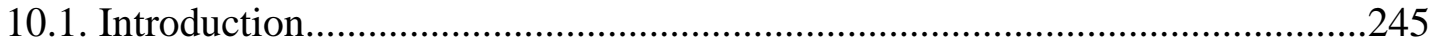


10.2. Literature Review Expressing Discrepancy Between Laboratory and Field Performance for Scaling of Concrete Containing SCM.....................................246

10.3. Survey of Field Performance of Concrete Containing SCM in Different States

Relating to Issues of Scaling..............................................................................248

10.4. Parameters Responsible for Discrepancy Related to Fresh Concrete...............257

10.4.1. Influence of Early Age Evaporation on Scaling and Surface Porosity ....258

10.4.2. Finishing Operation- Hand Finishing Versus Machine Finishing ............264

10.5. Parameters Responsible for Discrepancy Related to Hardened Concrete.......267

10.5.1. Influence of Size of the Specimen on Minimum Surface Temperature,

Rate of Freezing and Scaling ..................................................................267

10.5.2. Study of the Cumulative F-T Cycles and Intermediate Drying ................274

10.5.3. Current Practices for the Use of De-icing Salts ......................................280

10.6. Determination of Probability of Scaling in the Field.........................................281

10.6.1. Determination of Detrimental Event that Could Cause Scaling in Concrete

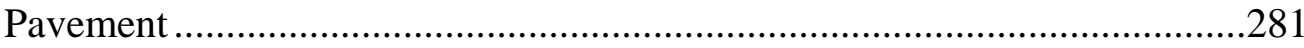

10.6.2. Monte Carlo Simulation and Risk Analysis for Scaling Probability

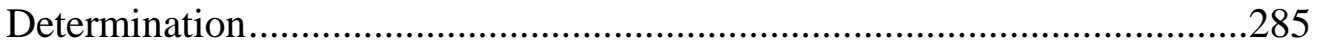

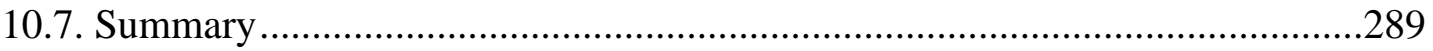

Chapter 11: Summary, Conclusions and Recommendations...........................................291

11.1. Introduction...............................................................................................291

11.2. Summary and Conclusions from Experimental Studies ...................................291

11.2.1. Materials Selection and its Influence on Scaling Performance ................291

11.2.2. Studies of Different Conditioning Periods and Slumps ............................292

11.2.3. Influence of Low Temperature Curing on Early Age Properties and Scaling ...................................................................................................292

11.2.4. Discrepancy Between Laboratory Scaling Results and Field

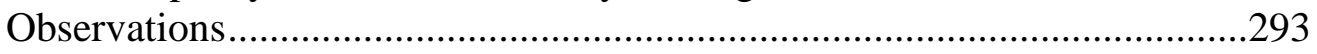

11.2.5. Summary and Conclusion Derived from Linking Together all the

Parameters Studied...................................................................................294

11.3. Overall Conclusions from the Research Project..............................................296

11.3.1. Guidelines for Materials, Mixing and Slump of Concrete........................298

11.3.2. Guidelines for Placement, Finishing and Curing...................................299

11.3.3. Temperature Guidelines.........................................................................300

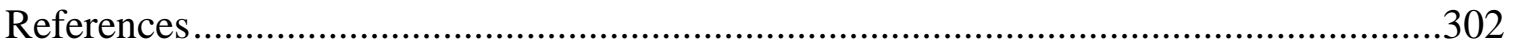

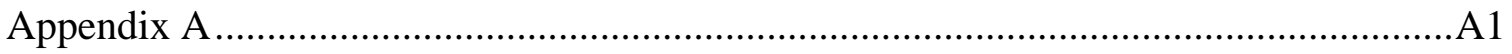

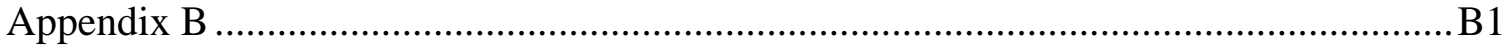

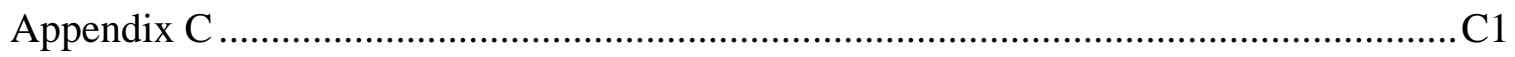




\section{LIST OF FIGURES}

Figure 1.1: Flowchart of activities in various tasks ..................................................6

Figure 2.1: Relationship between air content and spacing factor (Saucier et al., 1991)...16

Figure 2.2: Relation of scaled mass to MIP porosity of 50 and 75 MPa strength

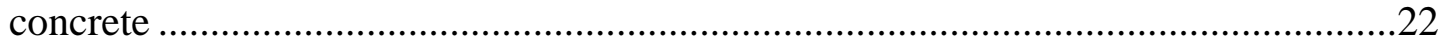

Figure 3.1: Actual versus predicted compressive strength ........................................45

Figure 3.2: Actual versus predicted SAI for Class C fly ash ......................................48

Figure 3.3: Actual versus predicted SAI for Class F fly ash .......................................49

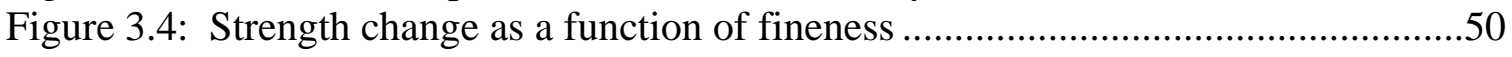

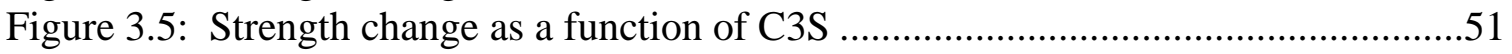

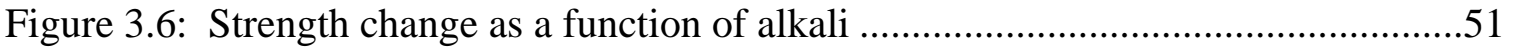

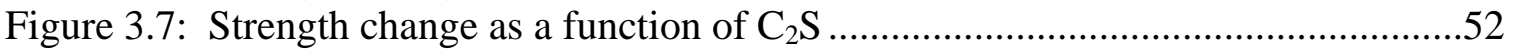

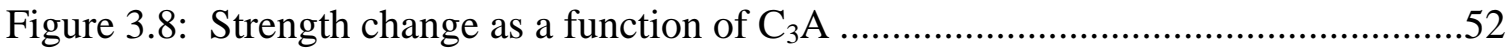

Figure 3.9: SAI sensitivity by varying lime content of fly ash .....................................54

Figure 3.10: SAI sensitivity by varying alkali content of fly ash ..................................54

Figure 3.11: SAI sensitivity by varying fineness (\% retained on $45 \mu \mathrm{m}$ sieve) of fly ash 55

Figure 3.12: C3S content comparison for screened cements .........................................58

Figure 3.13: Alkali content comparison for screened cements .......................................58

Figure 3.14: Fineness comparison for screened cements..............................................59

Figure 3.15: Lime content comparison for Class C fly ashes ......................................61

Figure 4.1: Data logger for temperature determination ...............................................68

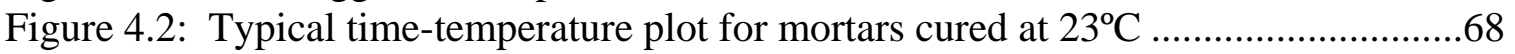

Figure 4.3: Strength versus equivalent age plot at different temperatures for mixture M12

Figure 4.4: Relative strength gain versus equivalent age plot for mixture M12 (@23ํ)..

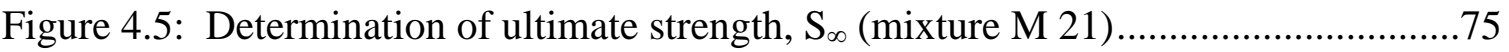

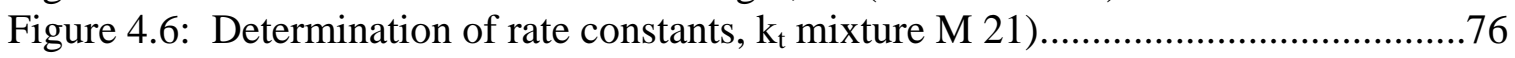

Figure 4.7: Determination of activation energy/gas constant, Q (mixture M 21)............77

Figure 4.8: Actual versus predicted ultimate strength ................................................81

Figure 4.10: Actual versus predicted strength at $23^{\circ} \mathrm{C}$..............................................83

Figure 4.13: Non-evaporable water content for pastes cured at $23^{\circ} \mathrm{C}$.............................86

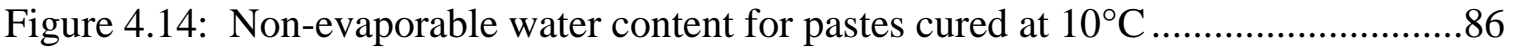

Figure 4.15: Non-evaporable water content for pastes cured at $1^{\circ} \mathrm{C}$...............................87

Figure 4.16: Minimum and maximum temperatures in Indiana (Years 1997 through 1999)

Figure 4.17: Pavement temperature at varying depths in the month of October ..............91

Figure 4.18: Temperature gain due to hydration at $1 / 4$ inch depth from pavement surface 
Figure 4.19: Simulated values of time and temperature required by all mortar mixtures to

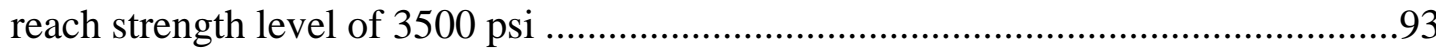

Figure 4.20: Simulated values of time and temperature required by all control mixtures to reach strength level of 3500 psi .........................................................................94

Figure 4.21: Simulated values of time and temperature required by all mixtures containing Rockport fly ash to reach strength level of 3500 psi...............................94

Figure 4.22: Simulated values of time and temperature required by all mixtures containing Clifty Creek fly ash to reach strength level of 3500 psi..........................96

Figure 4.23: Simulated values of time and temperature required by all mixtures containing Miami Fort fly ash to reach strength level of 3500 psi ..........................96

Figure 4.24: Simulated values of time and temperature required by all mixtures containing Will County fly ash to reach strength level of 3500 psi..........................97

Figure 4.25: Simulated values of time and temperature required by all mixtures containing slag to reach strength level of 3500 psi ..............................................98

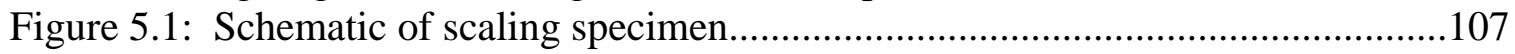

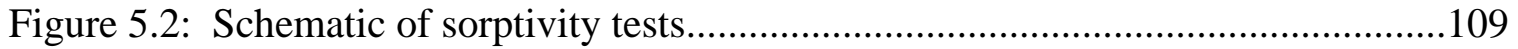

Figure 5.3: Variation in compressive strength with age ...........................................112

Figure 5.4: Comparison of rate constants for concrete and mortar mixtures.................115

Figure 5.5: Durability factors after different curing periods.......................................117

Figure 5.6: Temperature cycles of a specimen in the freeze-thaw chamber...................118

Figure 5.7: Weight gain during sorptivity for samples conditioned for 14 days ............120

Figure 5.8: Weight gain during sorptivity for samples conditioned for 28 days ............121

Figure 5.9: Determination of sorptivity for specimen conditioned for 28 days (C02) ...123

Figure 5.10: Percent weight loss on drying with age (\% of original weight) .................124

Figure 5.11: Resonant frequency development with time .........................................125

Figure 5.12: Average scaled weight for different concrete mixtures after different conditioning periods after 50 cycles

Figure 5.13: Comparison of scaled weight per unit surface area for different concrete mixtures after different conditioning periods.

Figure 5.14: Average scaled weight for different concrete mixtures and curing conditions coated with curing compound after 50 cycles.....................................................130

Figure 5.15: Amount of scaling at 5-cycle intervals................................................131

Figure 5.16: SEM image of surface layer of C02 specimen (I) ...................................133

Figure 5.17: SEM image of bulk (away from the surface) region of C02 specimen (I).133

Figure 5.18: SEM image of surface layer of C02 specimen (II)..................................134

Figure 5.19: SEM image of bulk (away from the surface) region of C02 specimen (II)134 Figure 5.20: SEM image of surface layer of C02 specimen before and after segmentation

Figure 5.21: SEM image of bulk (away from the surface) region of C02 specimen before

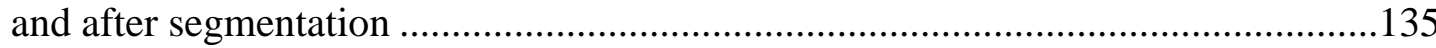

Figure 5.22: SEM image of surface layer of C01 specimen before and after segmentation

.

Figure 5.23: Correlation between amount of scaling and slump ................................137

Figure 6.1: Outline of the objectives and relevant actions for the scaling study ............150

Figure 7.1: Particle size distribution for the cement and fly ash .................................155 
Figure 7.2: Influence of WRA and AE on separation into two layers with different density; (a) measured densities of top and bottom portions for paste with WRA and AEA, and (b) Photos of paste separation

Figure 7.3: (a) Change in volume of separated surface, and ratio of density of the separated regions with change in w/cm for pastes containing $20 \%$ fly ash, and (b) Change in volume of separated surface and ratio of density of the separated regions with change in $\mathrm{w} / \mathrm{cm}$ for pastes containing cement only

Figure 7.4: X-ray diffraction pattern of weathered shale particles

Figure 7.5: Scaling of concrete surface around deleterious sand particles....

Figure 7.6: Scaled surfaces after 50 F-T cycles, (a) btch-00 (worst performing) combination of cement and fly ash, and (b) btch-03 (better performing) combination of cement and fly ash

Figure 7.7: X-ray diffraction of btch-03 fly ash

Figure 7.8: Scaled mass of concrete containing different cement-fly ash combinations plotted against their (a) (C2S-C3S) values, (b) (C2S + SAI7) values, and (c) (C2SC3S + SAI7)

Figure 8.1: Typical temperature profile inside the freeze-thaw room

Figure 8.2: Schematic diagram of specimen selection and orientation for SEM study..182

Figure 8.3: Arrangement of SEM images taken at different depths .....

Figure 8.4: Images taken at 500X magnification from the surface (left) and bulk (right) regions of the concrete, respectively.

Figure 8.5: Images acquired for 1-3-a sample at 500X from top towards center . 186

Figure 8.6: (a) Steps in image analysis and (b) calculation of percentage of porosity ...188

Figure 8.7: Cumulative scaled mass after 10 cycles normalized with respect to total scaled mass

Figure 8.8: Influence of wet curing and drying on scaling of low slump mixture; (a) total scaled mass (after 50 F-T cycles) for different conditioning periods, (b) cumulative scaled mass for specimens exposed to 5 different lengths of moist-curing and 1 day of drying, and (c) cumulative scaled mass for specimens exposed to 5 different lengths of moist-curing and 7 days of drying.

Figure 8.9: Influence of wet curing and drying on scaling of low slump mixture; (a) total scaled mass (after 50 F-T cycles) for different conditioning periods, and (b) cumulative scaled mass for 1 day moist-curing and all the different drying periods

Figure 8.10: Scaled mass for specimens with conditioning periods longer than 28 days

Figure 8.11: Normalized porosity for 1 day moist-cured and 3 days dried sample........200 Figure 8.12: Influence of moist-curing periods on microstructure and porosity of concrete; (a) micrographs (500X) of the surface and bulk regions of the samples and (b) changes in porosity with time

Figure 8.13: Influence of drying period on microstructure and porosity of concrete; (a) micrographs (500X) of surface and bulk regions of the samples and (b) changes in porosity with time.

Figure 8.14: Depth of salt penetration for different conditioning periods .203

Figure 8.15: Relation of salt penetration depth with scaling for highly scaled specimens 
Figure 9.1: Outline of low temperature curing study.....................................................209

Figure 9.2: Picture showing covered (right) and uncovered segment (left) of scaling

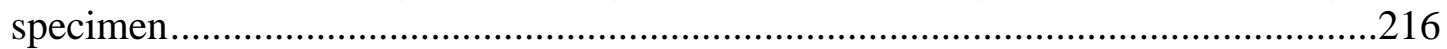

Figure 9.3: Process of preparation of large size specimen...............................................218

Figure 9.4: Results of calculations for prediction of flexural strength for control

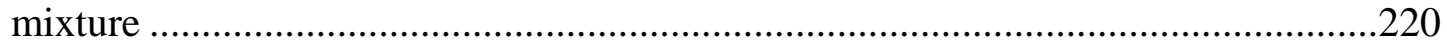

Figure 9.5: Data for setting time of concrete containing fly ash at $23^{\circ} \mathrm{C}$ and $1^{\circ} \mathrm{C}$..........223

Figure 9.6: Surface of 6” 12 " cylinders at various intervals after finishing ..................225

Figure 9.7: Loss of water versus time with constant wind effect of 9 mph for fly ash and

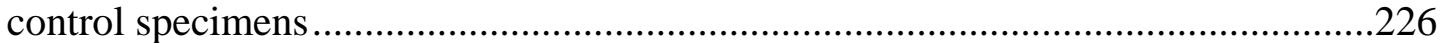

Figure 9.8: Scaling results for concrete cured at different temperatures ........................228

Figure 9.9: Time of prevention of evaporation after finishing versus scaled mass ........229

Figure 9.10: Time temperature profile for all the specimens immediately after casting until they were moved to F-T room ......................................................................232

Figure 9.11: Surfaces of the fly ash 1 specimen after 50 F-T cycles ..............................233

Figure 9.12: Time temperature profile for F-T room and respective temperature profile obtained using thermocouples placed at different locations ......................................235

Figure 9.13: Time temperature profile in PCC pavement in Indiana ..............................237

Figure 9.14: Time-temperature profile in PCC pavement in Quebec, Canada................238

Figure 9.15: Effect of wind in the rate of heat transfer in the large slab ........................240

Figure 9.16: Representative images for different concrete cured at low temperature....242

Figure 9.17: Ratio of surface to bulk porosity for different concrete ..............................243

Figure 10.1: Results from field observation of scaling of concrete containing fly ash

(Thomas, 1997) …………..............................................................................247

Figure 10.2: (a) Lansing bridge constructed in 1977 with $20 \%$ class F fly ash and

(b) U.S. Highway 52 constructed in 1992 with 33\% fly ash (Thomas, 2000) ..........248

Figure 10.3: States selected for scaling problem survey................................................249

Figure 10.4: Total mass scaled for samples exposed to different wind velocities...........260

Figure 10.5: (a) Scaled mass for different wind speeds and (b) scaled mass for different

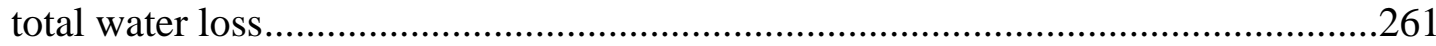

Figure 10.6: Porosity gradient for evaporation specimens, normalized against minimum

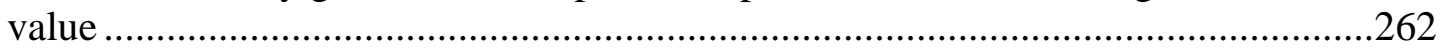

Figure 10.7: Segmentation of images at lower threshold ...........................................263

Figure 10.8: Modified porosity gradients for high and no evaporation specimens ........264

Figure 10.9: Parking slab with differential scaling performance (Thomas, 2000) .........266

Figure 10.10: Partitioned mold for size effect study.....................................................268

Figure 10.11: Final mold before mixing, with 1" thick base of aggregates.....................2270

Figure 10.12: F-T cycle temperatures (room and $2 \mathrm{~mm}$ below surface of all six

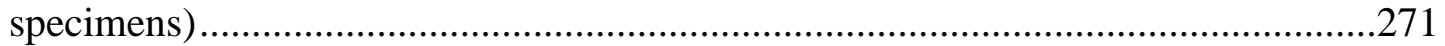

Figure 10.13: Thermal massing effect of large size specimens ......................................272

Figure 10.14: Total hours of wetting event at each time with sub-zero temperature .....276

Figure 10.15: Results of evaporation and intermittent drying study ..............................279

Figure 10.16: Snapshot of the program prepared for data analysis for event determination 
Figure 10.17: Summary of simulation results, with \% of probability for all months .....287

Figure 10.18: Simulation results showing probability for scaling for flat works ...........288

Figure 11.1: Relative importance of all parameters studied .........................................294 


\section{LIST OF TABLES}

Table 2.1: General information about prevalent salt** .29

Table 2.2: Summary showing applicability to each mechanism to specific type of

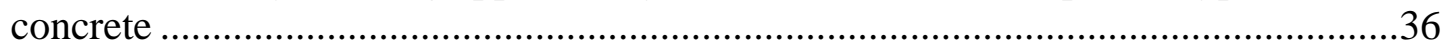

Table 2.3: Critical summary of various mechanisms using “A case specific approach”.38

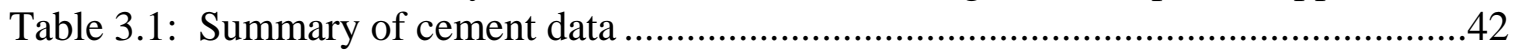

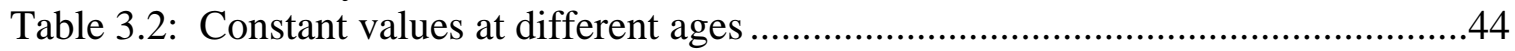

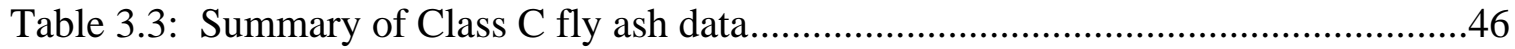

Table 3.4: Summary of Class F fly ash data ............................................................46

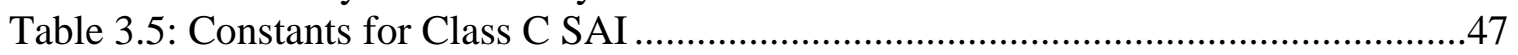

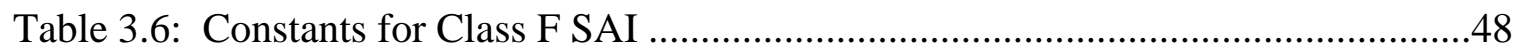

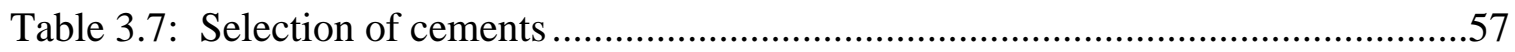

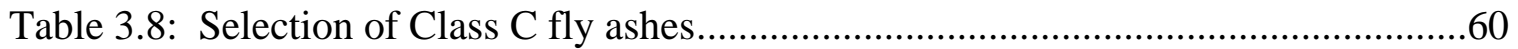

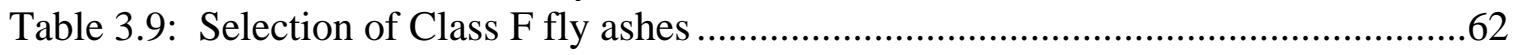

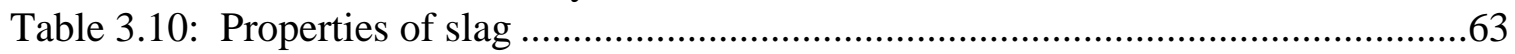

Table 3.11: Summary of materials selected ...............................................................63

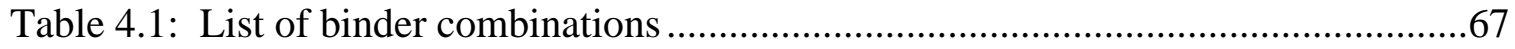

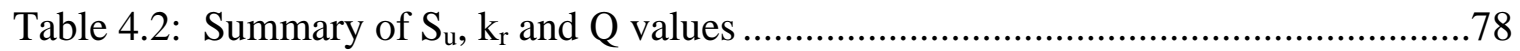

Table 4.3: Average minimum temperatures.............................................................89

Table 4.4: Summary of selected mixtures for tests on concrete ..................................102

Table 5.1: Compressive strength data at different ages (Moist room curing at $21^{\circ} \mathrm{C}$ )....111

Table 5.2: Flexural strength results for 6" x 6" x 21" beams .......................................113

Table 5.3: Flexural strength results for 3" x 3" x 15” beams at various ages.................113

Table 5.4: Comparison of flexure strength results at 7 days........................................114

Table 5.5: Data after 300 cycles of freeze-thaw for 3-day moist cured specimens ........117

Table 5.6: Data after 300 cycles of freeze-thaw for 14-day moist cured specimens ......117

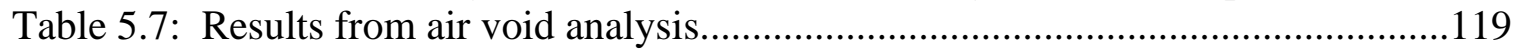

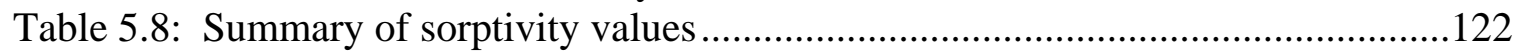

Table 5.9: Compilation of information for various mixtures........................................138

Table 7.1: Mixture Proportions and fresh concrete properties .....................................154

Table 7.2: List of paste samples prepared to study influence of fly ash and admixture.157

Table 7.3: Properties of deleterious particles present in sand.....................................163

Table 7.4: Comparison of various component and properties old and new cements .....167

Table 7.5: Comparison of various components and properties of old and new fly ashes

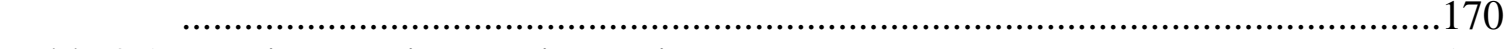

Table 8.1: Testing matrix -- curing regimes ...........................................................176

Table 8.2: List of SEM specimens obtained from 25-mm slump concrete ....................182

Table 8.3: Details of total and analyzed specimens ....................................................190

Table 8.6: Summary of study of effect of salt concentration front on scaling................206

Table 9.1: Summary of various test specimens and experimental procedures ...............213

Table 9.2: Details 300 mm deep specimens prepared for lower temperature study .......221 
Table 9.3: Results for initial and final setting time

.223

Table 10.1: Summary of information on scaling obtained from 12 states surrounding Indiana

250

Table 10.2: Mass of specimens before and after evaporation......................................259

Table 10.3: Summary of specimens and results of size effect study ............................270

Table 10.4: Data for freezing and wetting event for a typical year ...............................275

Table 10.5: Determination of number of events for different locations ........................284

Table 10.6: Probability distribution assigned to each factor under study......................286

Table 10.7: Simulation settings for Monte Carlo simulation.........................................286 


\section{CHAPTER1: INTRODUCTION}

\subsection{Background}

Supplementary cementitious materials such as fly ash and slag are commonly incorporated in concrete pavements, bridges, residential and commercial buildings. Use of these materials can result in considerable cost savings as well as provide potential improvements to durability, strength and permeability of concrete. These materials are used either as inclusions or replacements by weight of cement. When used as inclusions, fly ash or slag is interground with the cement clinker during the cement manufacturing process to obtain blended cements. Up to $50 \%$ fly ash or slag has been used in the preparation of blended cements. When used as replacements, some part of the cement by weight used in the concrete mixture is replaced with either fly ash or slag. Typically, the level of replacement ranges from 15 to $35 \%$ of the total cementitious material, but can be as high as $70 \%$ in mass concrete construction like dams.

Slag is a by-product of the iron industry. Chemically, slag is a mixture of lime, silica, alumina and magnesia. When granulated blast furnace slag is ground to an appropriate fineness, it can be used either as a separate binder which is capable of reacting hydraulically with water or as a component added to Portland cement (either by inter-grinding or by blending) to produce slag cement. In the latter case, the calcium hydroxide and alkalis released by hydrating Portland cement act as activators that accelerate the hydration of slag. Fly ash is a by-product of the coal combustion process. 
The reactivity of fly ash used in concrete is classified (according to ASTM C618) as either Class F or Class C. This classification is based in the cumulative content of silicon dioxide $\left(\mathrm{SiO}_{2}\right)$, aluminum oxide $\left(\mathrm{Al}_{2} \mathrm{O}_{3}\right)$ and iron oxide $\left(\mathrm{Fe}_{2} \mathrm{O}_{3}\right)$. The sum of these oxides has to be a minimum of $50 \%$ for Class $\mathrm{C}$ fly ash and a minimum of $70 \%$ for Class $\mathrm{F}$ fly ash. Class $\mathrm{C}$ fly ashes generally contain more than $10 \%$ of lime $(\mathrm{CaO})$ and are known to be more reactive than low calcium (ASTM Class F) fly ashes in which the lime content is typically lower than 10\% (Mehta, 1989). The degree of reactivity of fly ash is also influenced by its glass content, carbon content, particle size and shape distribution. Class C fly ash is normally produced from lignite or sub-bituminous coal, whereas Class F fly ash is normally produced from burning anthracite or bituminous coal.

As a result of fly ash variability, the properties of the concrete mixtures incorporating these materials can also vary. The use of fly ash and slag typically improves the workability of the concrete mixture, but it can make it more cohesive. Although the addition of these mineral admixtures often leads to a retardation of early age strength of concrete, strengths higher than that of plain concrete are typically observed at later ages. This improvement in strength can be attributed to the pozzolanic reaction described by equation 1.2. Typical cements react with water to form calcium silicate hydrate (C-S-H) and calcium hydroxide $(\mathrm{CH})$ as shown in equation 1.1. The pozzolans take part in a secondary reaction (equation 1.2) with the calcium hydroxide produced by the hydration of cement to form additional calcium silicate hydrate, as shown in equation 1.2 .

$$
\begin{aligned}
& \mathrm{C}_{n} \mathrm{~S}+\mathrm{H} \rightarrow \mathrm{C}-\mathrm{S}-\mathrm{H}+\mathrm{CH} \\
& \text { Pozzolans }+\mathrm{CH}+\mathrm{H} \rightarrow \mathrm{C}-\mathrm{S}-\mathrm{H}
\end{aligned}
$$


The increase in the amounts of C-S-H gel due to pozzolanic reaction is known to be beneficial to the strength. Also, the use of supplementary materials in concrete leads to pore refinement, thereby making the concrete less penetrable. This reduction in permeability has been the main motivation for using these materials in applications where increased durability is required.

There have been concerns about the slow strength development of concrete mixtures containing fly ash or slag when the ambient temperatures are low. These concerns arise mainly due to the fact that the ability of fly ash and slag to undergo reaction described by equation 1.2, depends on the availability of $\mathrm{CH}$ (calcium hydroxide) in the system. This coupled with the fact that lower temperatures significantly slow the rate of the pozzolanic reaction can make the concrete made with fly ash and slag susceptible to durability problems when exposed to freeze-thaw conditions.

\subsection{Problem Statement}

Current INDOT specifications (Section 501.03) permit the use of fly ash and slag in concrete pavement only between April 1 and October 15 of the same calendar year. This limitation is intended to address concerns regarding the potential for inadequate durability performance of concrete containing such materials when the concrete is placed during the late fall construction season. Due to slow strength gain, the concrete containing these materials may be susceptible to freezing and thawing cycles and scaling in the presence of deicing salts. There are also misgivings regarding the compatibility of many high carbon fly ashes with the air-entraining agents. Moreover, for scaling resistance, discrepancies are observed between laboratory results and field observations, 
which need to be substantiated by in-depth studies. Therefore understanding scaling mechanism and parameters, which can influence scaling performance, is essential.

\subsection{Research Objective and Scope of Project}

The objective of this research was to evaluate whether concrete pavements prepared with fly ash or GGBFS can be constructed under conditions typical of those expected in the late fall in Indiana to provide adequate durability to freeze-thaw and salt scaling resistance. This research also aims at providing valuable information for developing a rationally based approach for the use of supplementary materials in concrete pavements constructed during the late fall construction season. The scope of this project is diverse in that it requires an understanding of the mechanisms of concrete to freezethaw and scaling resistance, the role of the air-void system and other factors that can affect durability such as strength, water ingress and presence of internal water gradient. Also, properties such as setting time and bleeding need to be studied specifically at low temperature as they can influence the quality of surfaces exposed to deicing chemicals. Prediction models are needed to characterize low strength development in certain binary mixture combinations under temperatures typically expected during late fall construction season.

The project is broadly divided in to two phases. In the first phase, primary studies were conducted and the main problems were identified. In the second phase, a more focused study on scaling of concrete containing SCM was performed. The entire project was divided into six tasks. The first task focused on compilation of data published in various journals on the topics of freeze-thaw and scaling resistance, air-void analysis in 
hardened concrete, and maturity and strength development of concretes containing fly ash and slag. Topics related to degree of hydration and micro structural changes in hydrated paste were also analyzed as were the issues dealing with curing and exposure and their influence on F-T and scaling resistance of concrete. The second task focused on characterizing cements, fly ashes and slags from INDOT’s list of approved materials, and formulating a logical method for the selection of representative materials to be used in the subsequent experiments. Preliminary tests on various mortar and concrete mixture combinations were performed in Task 3. These included strength evaluation, maturity tests on mortars and non-evaporable water content determination on pastes. Mixture combinations were selected after this phase for further tests on concrete in this task. It involved tests on the durability of concrete subjected to various curing conditions such as fog-curing and air-drying under controlled temperature and relative humidity. Based on these three primary tasks, conclusions were formulated and need for more focused study on scaling behavior of concrete have been identified. The fourth and fifth tasks were preformed to determine parameters influencing scaling resistance and the role of low temperature curing. The detailed objectives and scope of this study are discussed in Chapter 6. Finally, in task six, the discrepancy between laboratory results and field observations was addressed and conclusions based on entire study were prepared. Figure 1.1 shows the flowchart of activities involved in both phases of this research. 


\begin{tabular}{|c|c|}
\hline \multicolumn{2}{|c|}{ Overview of the Entire Research Program } \\
\hline & $\nabla$ \\
\hline $\begin{array}{l}\text { Phase-I: Primary studies and } \\
\text { identification of main problem }\end{array}$ & $\begin{array}{l}\text { Phase-II: Extended studies } \\
\text { concerning scaling of concrete }\end{array}$ \\
\hline$\checkmark$ & \\
\hline $\begin{array}{l}\text { Task } 1 \text { - Literature Review and } \\
\text { Database Development }\end{array}$ & $\begin{array}{l}\text { Task } 4 \text { - Study of parameters to } \\
\text { improve scaling resistance of concrete }\end{array}$ \\
\hline $\begin{array}{l}\text { - Literature review on use of SCM in } \\
\text { concrete and durability performance } \\
\text { - Summary of influence of concrete } \\
\text { properties, preparation and exposure } \\
\text { conditions on F-T and scaling } \\
\text { resistance } \\
\text { - Summary of mechanisms for scaling }\end{array}$ & $\begin{array}{l}\text { - Influence of materials variability } \\
\text { on scaling } \\
\text { - Influence of moist curing and } \\
\text { drying periods on scaling and } \\
\text { determination of optimum moist } \\
\text { curing and drying periods } \\
\text { - Influence of slump and salt conc. }\end{array}$ \\
\hline & \\
\hline $\begin{array}{l}\text { Task } 2 \text { - Preliminary Material } \\
\text { Characterization and Mixture } \\
\text { Development }\end{array}$ & $\begin{array}{l}\text { Task 5- Influence of low } \\
\text { temperature curing on early age } \\
\text { properties and scaling }\end{array}$ \\
\hline $\begin{array}{l}\text { - Elemental analysis on cement, fly } \\
\text { ash, slag and their combinations } \\
\text { - Maturity, degree of hydration and } \\
\text { compressive strength tests for each } \\
\text { mixture } \\
\text { - Screening of mixtures from the above } \\
\text { tests }\end{array}$ & $\begin{array}{l}\text { - Influence of low temperature } \\
\text { curing on setting time and bleeding } \\
\text { - Influence of low temperature } \\
\text { curing on scaling of regular and } \\
\text { large size specimens } \\
\text { - Study of surface porosity of } \\
\text { laboratory and field specimens }\end{array}$ \\
\hline & \\
\hline $\begin{array}{l}\text { Task } 3 \text { - Correlation of Material } \\
\text { Characteristics and Maturity with } \\
\text { Durability }\end{array}$ & $\begin{array}{l}\text { Task } 6 \text { - Determination of reasons } \\
\text { for discrepancy between laboratory } \\
\text { results and field observations with }\end{array}$ \\
\hline - Maturity tests & \\
\hline $\begin{array}{l}\text { - Compressive strength tests }(1,7,28 \\
\text { days) } \\
\text { - Flexure tests (1, 7, } 28 \text { days) } \\
\text { - Freeze thaw tests to determine } \\
\text { durability factors using the resonant } \\
\text { frequency method at } 300 \text { cycles } \\
\text { - Preliminary salt scaling resistance } \\
\text { tests by visual rating, scaled weight }\end{array}$ & $\begin{array}{l}\text { - Substantiating and understanding } \\
\text { the discrepancy with literature } \\
\text { review and telephonic survey } \\
\text { - Study of parameters which could } \\
\text { create the discrepancy in the scaling } \\
\text { results } \\
\text { - Risk analysis for scaling probability } \\
\text { - Conclusions and recommendations }\end{array}$ \\
\hline
\end{tabular}

Figure 1.1: Flowchart of activities in various tasks 


\subsection{Organization of Report}

This report contains two phases; the first phase is divided into six chapters, while the second part which is extended work on scaling, is divided into five chapters. Chapter 1 provides background information about the research and presents objectives and scope of this research. A detailed literature review is presented in Chapter 2. Chapter 3 describes how all the approved material sources namely, cement, fly ash and slag are used in the preliminary characterization and screening of materials for further tests. Preliminary screening of mortar mixture combinations is discussed in Chapter 4. The screening process involved analysis of strength-maturity relationships for all mixture combinations tested, non-evaporable water content determination on pastes and mathematical models developed for strength prediction at varying temperatures and ages. Chapter 5 includes results and analysis of test data for tests like durability of concrete to freeze-thaw and scaling resistance. This chapter also includes results and analysis of mechanical tests including compressive strength, flexural strength, maturity data and results of air void analysis on hardened concrete. Chapter 6 presents conclusions derived from experimental and analytical work and also elaborate on the need for focused study on the scaling performance of concrete containing SCM. The objective and scope of extended work on scaling is also mentioned in this chapter. The descriptions for five more chapters following Chapter 6, which are part of Phase II of this report, are outlined in Chapter 6. 


\section{CHAPTER 2: LITERATURE REVIEW}

\subsection{Introduction}

Concrete containing supplementary cementitious materials (SCM), such as fly ash and slag has numerous advantages over plain cement concrete in terms of durability and cost effectiveness. However, there are a few issues related to the use of SCM in concrete, that must be addressed for its use in late fall paving applications. These issues include a slower rate of strength gain, delayed setting time with a longer bleeding period, and reduced effectiveness of the air-entraining agent due to the presence of carbon in fly ash. All of the above could influence durability issues like freeze-thaw (F-T) and the scaling performance of concrete. This literature review will focus on various case studies performed regarding F-T and scaling performance of concrete containing cementitious materials, with special concentration being on scaling of concrete containing fly ash. Moreover, to understand the role of a particular parameter, the findings regarding individual parameters are also discussed. Finally, a literature review of the effects of various proposed mechanisms on scaling is provided, based on which a "case-specific approach" is suggested for this scaling study.

\subsection{Studies of F-T and Deicer Salt Scaling of Concrete Containing SCM}

This section reviews the investigations conducted on the scaling studies by various researchers mainly in laboratory and sometimes in the actual field. 
Various binary and ternary blends were tested in a study at Virginia Department of Transportation (VDOT) and all combinations showed satisfactory durability factors after 300 cycles of freezing and thawing and only one binary blend (having $60 \%$ slag) showed mass loss in excess of 7\% (Lane and Ozyildirim, 1999). In yet another study, Langan et al. (1990) observed poor scaling resistance in concrete with $50 \%$ fly ash in his laboratory study. All four fly ash paving mixtures tested in this study showed visual ratings of 5 (worst rating) for scaling resistance after five or ten cycles of freeze-thaw. It was observed that the addition of a superplasticizer resulted in an increase in the spacing factor, which corresponds to reduced durability factors.

Marchand et al. (1992) found that only blended silica fume cement with fly ash or slag concrete, cured with a membrane-forming curing compound, displayed a mass of scaled-off particles below $1.5 \mathrm{~kg} / \mathrm{m}^{2}(0.31 \mathrm{psf})$. None of the water-cured specimens exhibited satisfactory scaling resistance. Addition of fly ash or slag resulted in poorer resistance to scaling compared to the blended silica fume cement.

Bilodeau et al. (1991) found that increasing the water to cementitious materials $(w / \mathrm{cm})$ ratio resulted in an increased amount of scaling. They observed a lot of variability in the results from scaling tests on fly ash concretes and showed that concrete incorporating up to $30 \%$ fly ash performed satisfactorily under the scaling test with some minor exceptions. Also, increased replacement levels of cement with fly ash resulted in an increase in the amount of scaling. Concrete with a higher $w / \mathrm{cm}$ was more susceptible to problems related to deicer salt scaling and internal micro-cracking due to the freeze and thaw cycles (Bilodeau et al., 1991). For most of the mixtures tested, good scaling 
resistance (less than $0.8 \mathrm{~kg} / \mathrm{m}^{2}$ or $0.16 \mathrm{psf}$ recommended by the Ministry of Transportation of Ontario, Toronto) was observed only after three days of moist curing.

Whiting (1989) performed a study for the Portland Cement Association on the strength and durability of residential concretes containing fly ash. She reported that all of the concrete mixtures containing fly ash showed a greater rate of early age scaling than the companion concretes mixtures prepared without fly ash. In some instances, relatively good resistance to deicer scaling was obtained when the total cementitious materials content was fairly high, the fly ash chosen exhibited a relatively low demand for an airentraining admixture and the replacement level was limited to $25 \%$.

Naik et al. (1995) found that two properly cured air-entrained concrete mixtures, one containing 40\% Class F fly ash and the other containing 50\% Class C fly ash, had excellent resistance to freezing and thawing. The $40 \%$ Class $\mathrm{F}$ fly ash concrete showed moderate scaling, but the $50 \%$ class $\mathrm{C}$ fly ash concrete showed severe scaling after 50 cycles of freezing and thawing. A long-term performance study of high volume fly ash concrete (Naik et al., 2003) reported that except for surface scaling of all the concrete containing high volume fly ash, the long-term performance of concrete was improved by addition of high volume fly ash (HVFA). In another study, Bouzoubaâ (2002) showed that HVFA-blended cement concrete that contain fly ash in excess of 50\% replacement, exhibited improvements in all properties except scaling resistance, when compared to the concrete in which the fly ash and cement were added separately at the mixer

The primary details about scaling resistance of concrete seem to show poor scaling performance of concrete containing supplementary materials. However, there was a significant difference observed in various findings and in their reasoning about the 
scaling. Therefore, it is essential to take a comprehensive look at these findings to arrive at a meaningful correlation and a holistic view. Thus, regarding the durability of concrete under cold weather condition, the various parameters were divided into three main classifications, which were described in subsequent sections.

\subsection{Current Understanding of the Influence of Various Materials on Scaling}

Scaling resistance of the concrete is one of the tests, which has a very high degree of variation (20 - 25\%; Marchand, 1996) associated with the results, a major portion of which can be attributed to variability of the constituent materials and the composition of the concrete. Hence, a brief summary of the literature current addressing the influence of constituent materials on scaling was necessary.

\subsubsection{Cementitious Materials Types and Contents}

The type and composition of cementitious materials in the mixtures seem to have a significant influence on the durability performance of concrete. It is believed that finer cements can improve concrete durability due to the reduction in the average size of the capillary pores. There have also been reports of the detrimental influence of high alkali/high $\mathrm{C}_{3} \mathrm{~A}$ cements on the scaling resistance of concrete (Marchand et al., 2000). Marchand also mentioned that the use of finer cement could improve the F-T durability of concrete. Similar to other recent studies, Jackson (1958) reported that the scaling of concrete increased with the $\mathrm{C}_{3} \mathrm{~A}$ and alkali contents and mentioned that long-term exposure to low-sodium chloride solutions was found to significantly reduce the salt scaling resistance of air-entrained concretes made with high $\mathrm{C}_{3} \mathrm{~A}$ cements. Girodet et al. 
(1997) studied the influence of cement on F-T resistance and reported that for plain cement mortars the best behavior was obtained for a low Blaine-specific surface area, a low $\mathrm{C}_{3} \mathrm{~A}$ content, and a high $\mathrm{C}_{2} \mathrm{~S}$ content. This shows that criterion for good F-T durability and scaling performance might be contradictory as the former requires low Blaine specific surface area while later is improved with high Blaine surface area. Therefore, care should be taken in evaluating the performance of concrete for a particular durability issue.

To study the influence of that fly ash on scaling, Marchand et al. (1997) investigated the scaling of sawed surfaces of concrete containing fly ash. He observed that the negative effect of fly ash on scaling resistance is not solely related to the surface microstructure of concrete. The use of fly ash appeared to have an intrinsic effect on the deterioration mechanisms. He also experimentally disproved the argument, that due to the slower hydration of the fly ash, at early ages reduction in effective cementitious materials would cause increase in effective $\mathrm{w} / \mathrm{cm}$ and would decrease the durability of concrete. For this purpose he compared fly ash concrete with high w/c plain cement concrete in regard to scaling performance. Barrow et al. (1989) found that neither the strength nor the water to cementitious materials ratio is a governing factor in determining the scaling resistance of concrete containing fly ash for typical quality concrete construction. They observed that for a given curing temperature, the best scaling resistance was exhibited by concrete that did not contain any fly ash. Klieger and Gebler (1987) showed that in general air-entrained concretes with or without fly ash exhibited good resistance to freezing and thawing when moist-cured at $23^{\circ} \mathrm{C}\left(73^{\circ} \mathrm{F}\right)$, but the Class $\mathrm{F}$ fly ash showed lower resistance when it was compared to concrete made with Class C fly 
ash cured at low temperatures. No such observation was reported for scaling results. Rodway (1998) tested five different fly ashes covering a wide range of lime contents, which were used as $25 \%$ replacement in concrete mixtures. It was found that regardless of the lime content of the fly ash, a satisfactory air void size and spacing values could be obtained to produce durable fly ash concrete. Also, studies have shown that lower replacement levels of cement with fly ash or slag, in the range of $20-35 \%$, are optimal for satisfactory durability to frost conditions (Nasser and Lai, 1993). There also have been recommendations that a minimum cementitious material of $335 \mathrm{~kg} / \mathrm{m}^{3}\left(564 \mathrm{lb} / \mathrm{yd}^{3}\right)$ and a maximum water to cementitious material ratio of 0.45 should be adopted for satisfactory performance of concrete when it is subjected to deicer salts (Kosmatka et al., 2002).

\subsubsection{Coarse and Fine Aggregates}

It has been observed that similar concrete mixtures using different types of coarse aggregates exhibit difference in resistance to F-T or scaling. Thermal incompatibility or freezing of the moisture within the aggregates were considered major parameters that influences the scaling results. In addition, in the laboratory and the field it was observed that scaling often involves a fracture plane at the interface between the coarse aggregate and the surface mortar. Sometimes deleterious chert or shale type aggregates showed poor interface and increased the overall scaling damage by weakening the aggregate paste bond in the surface region.

Klieger (2003) reported that the optimum concrete air requirement for frost resistance increased as the maximum size of aggregate decreased. For the air-dried concretes at a particular maximum size of aggregate, the cement content appeared to have 
little effect on the optimum concrete air content. Jansen (2000) showed that the salt scaling resistance of concrete specimens using a vitrified coarse aggregate was poor due to the reduced bond of the aggregates with the paste. This poor bond not only allowed the top layer of mortar to spall very quickly, but subsequent damage continued at an accelerated rate even after the coarse aggregates were completely exposed. In the late 1940s, extensive studies of coarse aggregate (Indiana Limestone) as a component of concrete was conducted by several researchers. The pavement distress observed in Indiana due to blowups and frost action were attributed to coarse aggregates (Slate, 1949). It was reported that the coarse aggregates with poor performances had higher values of porosity, absorption, and vacuum saturation and lower values of bulk density. No cases of scaling were reported due to such coarse aggregates.

\subsection{Concrete Properties, Preparation, and Characteristics Influencing Scaling Behavior}

There are several critical factors associated with the properties of concrete that influence the durability of concrete that under cold weather conditions. Some of the very important early age properties, i.e., air void content and spacing factor, slump, finishing etc., are primarily discussed here. Other important properties like degree of hydration, early and later age strength and porosity, which would determine the amount of freezable water and the degree of resistance provided by the concrete, are also discussed in this section. 


\subsubsection{Air Void Content, Spacing Factor, and Carbon Content of Fly Ash}

Research has shown that proper air void spacing is the most critical factor determining the resistance of concrete to freezing and thawing (Marchand et al., 1996, Pigeon et al., 1987 and 1996). When the air voids were close together, the surrounding cement paste does not expand when it is frozen, thereby preventing crack formation and scaling. ASTM C 457 (1998) specifies a maximum air-void spacing of 0.008 inch $(200 \mu \mathrm{m})$ for concrete exposed to freezing and thawing cycles. It has been shown that the carbon content in fly ash reduces the effectiveness of the air-entraining agent. Sturrup et al. (1983) found that doubling the carbon content required doubling the air-entraining admixture to entrain about $6.5 \pm 1 \%$ air. They mentioned in their findings that as long as the required air contents were obtained, the carbon content in the fly ash did not adversely affect the performance of fly ash concrete during freezing and thawing. Klieger and Gebler (1987) observed that the organic matter content in fly ash was the most significant factor affecting the retention of air voids in fresh concrete. The total carbon content and the loss on ignition of the fly ash showed less correlation with the retention of air content in fresh concrete than did the organic matter content. Class C fly ash was found to retain a greater amount of entrained air than the Class F fly ash.

Apart from the spacing factor of $200 \mu \mathrm{m}$ (0.008 in.), which is most commonly used for specifying durability, field concrete having air content values in the range of 5$8 \%$ are also thought of as being durable. Though this is generally true, it may not always be the case. It is normally assumed that concrete containing air content of about $6 \%$ will have a spacing factor of about $200 \mu \mathrm{m}$. Figure 2.1 shows that concrete having an air content of $6 \%$ can have spacing factors ranging from $100 \mu \mathrm{m}$ to $400 \mu \mathrm{m}$ (Saucier et al., 
1991). Conversely, a spacing factor of $200 \mu \mathrm{m}$ can be obtained with concrete with an air content as low as $4 \%$ and as high as $9 \%$. Hence, when producing concretes that will be exposed to cold weather conditions, it is always safer to specify the critical spacing factor value instead of completely relying on the air content values as is done in field construction.

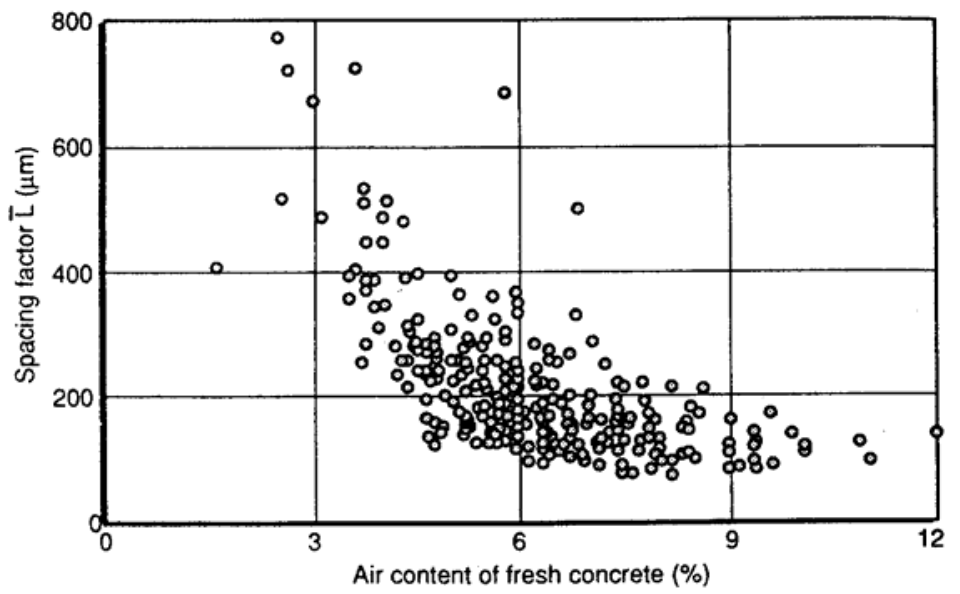

Figure 2.1: Relationship between air content and spacing factor (Saucier et al., 1991)

\subsubsection{Slump and Bleeding of Concrete}

A few studies have observed the influence of slump on the scaling performance of concrete. Fagerlund (1986) reported that normal strength concretes with very high slumps tend to have reduced scaling resistance. In such concretes, it was observed that bleeding increases permeability in the surface region and could leave bleed channels below the aggregates and weaken the bonds between the aggregate and the paste. Very high slump could result in the air void system being destabilized in certain cases (Marchand, 1994). 
Microstructural investigations have shown a higher porosity at the surface $(0-10$ $\mathrm{mm}$ ) as opposed to the bulk of the concrete (Marchand et al., 2000). Higher slump of concrete may result in higher bleed water at the top surface, rendering the surface susceptible to damage due to deicer salts. Test results indicate that the higher porosity of the surface layer tends to reduce the deicer salt scaling resistance of wood-troweled laboratory samples during the first cycles of freeze thaw. Swenson (1969) suggested some requirements for concrete to be durable to the effects of freezing and thawing and salt scaling. For example, for severe exposures, the water to cement ratio should not exceed 0.45 and slump should not exceed $88 \mathrm{~mm}(3.5 ")$.

\subsubsection{Placing and Finishing of Concrete}

The placing and finishing of concrete plays an important role in determining the air void characteristics and surface formation and thereby influence the F-T and scaling resistance. Improper placing or over-compaction could lead to a reduction in the total air content, which could then lead to F-T damage in concrete. Over-finishing could destroy the air void structure in the surface region or create a formation of high w/c paste in the surface region that could cause excessive scaling.

Klieger et al. (1955) showed that the scaling resistance of air-entrained plain concretes was not influenced by surface exposure, temperature, or time of final finishing, despite changes in bleeding of all concretes. For concrete containing slag, Luther et al. (1994) reported the effects of various finishing on scaling. No clear difference was seen between using a wooden tool and a magnesium tool for final finishing. The use of an edging tool was linked to an increase in scaling. 
Issa et al. (1994) in one of their case studies for a scaling investigation of concrete driveways reported that scaling of the concrete was mainly governed by the surface finish. They suggested that floating tends to bring the cement and water to the surface. Therefore, floating too early or too long brings an excess of fines to the surface, which damages and weakens the bond between the surface and the concrete below by the formation of a paste with w/c. This paste may not have been condensed enough because of the presence of high water content, which led to concrete scaling and flaking of the surface.

Molded surfaces as opposed to troweled surfaces could show significantly different performance in the case of scaling. There is not enough literature available on this aspect, but it can be assumed that molded surfaces would be more prone to scaling damage in comparison to trowel finished surfaces (Marchand, 1994). Swenson (1969) also mentioned that finishing is critical as excessive laitance is vulnerable to frost action, especially in the presence of de-icing salts.

\subsubsection{Degree of Hydration}

The degree of hydration is an important parameter in determining the amount of internal water present in a paste mixture, which can be useful in predicting the performance of similar concrete mixtures under freezing conditions. In a binary system containing cement and fly ash, quantifying the fly ash reaction products as well as the cement hydration products becomes essential. Selective dissolution procedures have been adopted to determine the degree of fly ash reaction. Lam et al. (2000) found that in HVFA pastes containing $45 \%$ and $55 \%$ fly ash, more than $80 \%$ of the fly ash remained 
un-reacted even at the age of 90 days. The non-evaporable water contents $\left(\mathrm{W}_{\mathrm{n}}\right)$ of fly ash pastes were also found to be lower than the plain cement pastes at a given water to cementitious materials ratio. Roy (1989) found that hydration rates are greatest in silica fume pastes, followed by OPC pastes and fly ash pastes. It was found that the degree of reaction of silica fume was much greater than fly ash pastes, even at 90 days, due to the high specific area of silica fume. Further, the overall reaction with Class $\mathrm{C}$ fly ash was greater than the Class F fly ash after a few days. The XRD patterns have shown that the hydration products of OPC with fly ash and slag were very similar and that at the age of 90 days, slags showed better pozzolanic activity than fly ash (Sharma and Pandey, 1999). It has also been verified that hydration of the fly ash causes refinement of the pore structure (Berry et al., 1994). Their SEM studies showed etching of glassy materials around the ash and at ages beyond 28 days, the fractured surface deposits were comprised of round, toroidal plates with compositions similar to C-S-H.

\subsubsection{Early and Later Age Strength of Concrete}

At low temperatures, early age strength gain is one of the important parameters in the determination of concrete performance, becoming more sensitive in the presence of supplementary cementitious materials. Slower strength gain in the presence of supplementary materials could be a concern for the durability performance of concrete, but in most cases concrete pavements are protected from freezing until enough compressive strength is achieved, lessening the chances of a detrimental effect by low temperatures on durability performance. 
Studies by Gebler and Klieger (1986) indicated that higher compressive strength is essential in improving the scaling resistance of concrete. Average compressive strengths of 24.1 MPa (3500 psi), 30.8 $\mathrm{MPa}$ (4460 psi) and $33.8 \mathrm{MPa}$ (4910 psi) were reported for three concrete mixtures (cured at $4.4^{\circ} \mathrm{C}$ or $40^{\circ} \mathrm{F}$ ); the first containing Class $\mathrm{F}$ fly ash, the second Class C fly ash and the third plain cement respectively. They reported that as the compressive strength increased, the deicer scaling resistance generally improved. The cementitious material contents were $306.7 \mathrm{~kg} / \mathrm{m}^{3}\left(517 \mathrm{lb} / \mathrm{yd}^{3}\right)$ and 281 $\mathrm{kg} / \mathrm{m}^{3}\left(474 \mathrm{lb} / \mathrm{yd}^{3}\right)$ in the fly ash mixtures and plain cement mixture, respectively. Swenson (1969) recommended that air-entrained concrete should have strengths in the range of $24.1-31 \mathrm{MPa}(3500-4500 \mathrm{psi})$ for better scale resistance in case of severe exposures.

Bilodeau et al. (1994) studied the mechanical and durability properties of concrete with eight different fly ashes and two different cements from various sources in the United States. It was reported that with an increase in compressive strength, the chloride ion permeability reduced drastically; but no relationship was observed between scaling and compressive strength. The final visual evaluation of test slabs subjected to the deicing salt scaling test showed that all of the high-volume fly ash concretes had equally poor performances in the test.

\subsubsection{Porosity, Pore Size Distribution, and Sorptivity of Concrete}

The resistance of concrete to the ingress of harmful salts or to that of water depends upon the permeability of the system. In other words, a denser microstructure of concrete not only ensures less ingress of harmful salts, but also reduces water absorption, 
which is important with respect to improving the durability of concrete to freezing and thawing cycles. Additionally, the filling of air voids with water was experimentally proven the most probable cause of high scaling in virgin concretes (Jacobsen et al., 1997). In an unsaturated system, water flows within a porous media under the action of a capillary force, which in turn depends on the pore structure of the material. Thus, the capillary force is the strongest when the material is completely dry and it reduces with saturation. In concrete, water absorption could be influenced by the porosity of the aggregate, the porosity of the cement gel matrix, the packing geometry of the constituent particles, e.g., sand, coarse aggregate, and in some cases, could be due to the inclusion of air-entraining admixtures (Hall and Yau, 1987).

The porous distribution seems to have a significant influence on the scaling resistance of concrete. For similar strength concrete mixtures, finer and more refined pores might be more detrimental to scaling because of higher stresses generated by a longer freezing time and a higher degree of saturation (Lindmark, 1999). It is difficult to determine the exact pore size distribution of concrete, however, a weak trend was observed as shown in Figure 2.2 between the MIP values and scaled mass for highstrength concrete (50 and $75 \mathrm{MPa}$ ) studied by Baroghel-Bouny et al. (1995). 


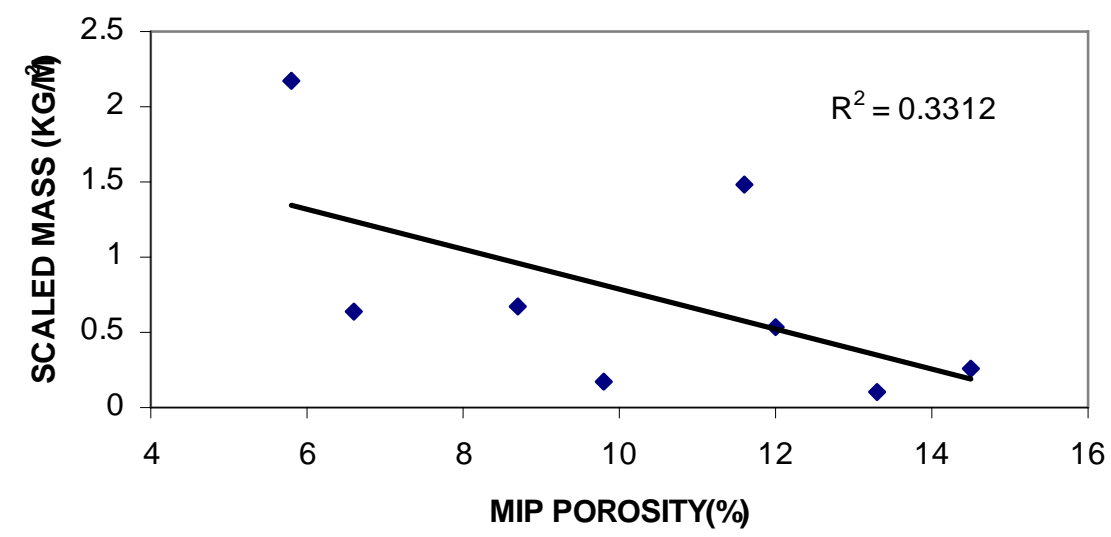

Figure 2.2: Relation of scaled mass to MIP porosity of 50 and $75 \mathrm{MPa}$ strength concrete

The sorptivity test, which involves the theory of capillary suction, can be used to determine the cumulative absorption, as well as the rate of ingress, of water into the concrete. Hence, it is useful in studying the quality of concrete surfaces subjected to wet and dry cycling (Gopalan, 1996; Hall, 1989; Hall and Yau, 1987; Martys and Ferraris, 1997). Gopalan (1996) found that when adequate curing was provided, a 37\% reduction in sorptivity was observed in a mix containing $40 \%$ fly ash. This study also reported that under fog-cured conditions, the sorptivity of fly ash concrete was lower than OPC concrete; but under dry-curing, the sorptivity of the fly ash concrete was higher than the OPC concrete. McCarter (1993) tested the top, bottom and cut surfaces for their sorptivity test and found the top surface to have the highest sorptivity values, followed by the bottom and cut surfaces. 


\subsection{Environmental and Other Parameters Influencing Durability of Concrete under Cold}

\section{$\underline{\text { Weather Conditions }}$}

Other than concrete properties, durability performance is largely dependent on conditioning of the specimens and type of exposure conditions. There have been several studies addressing curing, but there is a very little consistency observed in the results, a summary of which follows. Moreover, the effects of the rate of freezing, minimum air temperature, and salt concentration are also briefly described.

\subsubsection{Curing Type and Temperature}

Curing plays an important role in reducing the permeability of concrete. This is particularly true for concrete containing supplementary materials, as the dependence on curing increases with increased replacement levels of cement. It was found that the compressive strength of concrete with $50 \%$ fly ash was more adversely affected by inadequate curing (Thomas and Mathews, 1994). Ballim (1993) suggested that increasing the duration of moist curing was a more effective way of extending the durability of concrete than increasing the cement content.

On the other hand, Nasser and Lai (1993) reported that increasing the curing period did not increase the frost resistance. Incorporating 35 to $50 \%$ fly ash in concrete was detrimental to frost resistance even though the specimens were cured for 80 days. However, these authors found that a $20 \%$ fly ash content in concrete resulted in satisfactory performance (durability factor greater than $60 \%$ ), and $35 \%$ fly ash resulted in doubtful to satisfactory performance (durability factor between $40 \%$ and $60 \%$ ). Also they determined from SEM micrographs that a decrease in the freezing and thawing 
resistance may be due to slow displacement of microcrystalline $\mathrm{Ca}(\mathrm{OH})_{2}$ and fibrous ettringite hydrates from the dense C-S-H zones to the air voids during freeze-thaw cycling.

Bilodeau et al. (1991) found that the mass of scaling residue reduces significantly when membrane-curing was adopted instead of moist-curing. Extended moist-curing and drying periods did not affect significantly the performance ash concretes in the scaling tests, at least within the periods investigated. In the laboratory (Bilodeau, 1991) and in the field (Marchand, 1992) it has been observed that concrete cured with membraneforming curing compounds have better resistance as compared to similar water-cured concretes. The use of curing compound was observed to result in scaling resistance as good as that of concrete moist-cured for 14 days, but the results seemed to vary with the type of curing compound used (Langlois et al., 1989). They also found accelerated heatcuring of specimens had a very detrimental influence on the scaling resistance.

Stark et al. (2002) reported results of their scaling study for different concrete specimens placed for about 35 years or more in the PCA outdoor facility. This study of the effects of the season of construction clearly indicated that all the concrete specimens containing plain cement as the binder constructed in late fall, under different curing regimes, were more prone to scaling than specimens constructed in the summer. Additionally, it was shown that among all the curing treatments, the specimens cured under air showed minimal scaling, which indicated that concrete constructed without fly ash was also susceptible to scaling when constructed in late fall. To evaluate different admixtures, they found that the performance of the control mix and the mix containing $30 \%$ fly ash by weight of cement as a supplement, both showed moderate scaling 
resistance. Further, these specimens proved to be more scaling resistant then the concrete constructed in late fall with plain cement. However, in this study, fly ash was added as a supplement, which increased the cementitious materials content significantly and consequently the improved scaling resistance.

Isaac et al. (1994) reported that, irrespective of curing conditions, concrete containing $50 \%$ slag showed poor resistance to scaling, while concrete containing $25 \%$ slag behaved in a similar manner as the reference concrete. It was also observed that for different types of slag 22 and for $25 \%$ and $35 \%$ percentage replacement of fly ash, there was no specific relationship developed between the curing temperature and the amount of scaling for different curing temperatures of $10^{\circ} \mathrm{C}\left(50^{\circ} \mathrm{F}\right), 23^{\circ} \mathrm{C}\left(73^{\circ} \mathrm{F}\right)$ and $38^{\circ} \mathrm{C}\left(100^{\circ} \mathrm{F}\right)$ (Hadchiti et al., 1988).

Klieger (1957), based on his study for the Highway Research Board, developed guidelines for "Curing Requirements for Scale Resistance of Concrete". He specified that for plain air-entrained and non-air-entrained concrete, an increase in curing increased the scaling resistance of concrete. Plain concrete cured at low temperatures was more prone to scaling than that cured at room temperature. In further studies on the influence of aggregates (Klieger, 2003), it was observed that concretes moist-cured continuously required more entrained air for adequate resistance to freezing and thawing than air-dried concretes. Gunter and Hilsdorf (1987) showed that prolonged curing of Portland cement concretes in water might reduce the durability of air-entrained concrete. Concrete containing slag could be more prone to scaling at later age than at an early age because of the effect of carbonation (Gunter, 1987). 
In summary, it can be said that in most cases plain concrete, when cast and cured at low temperatures, proved more prone to scaling compared to normal temperature cured plain concrete, while no such particular trend was observed for concrete containing fly ash or slag. The use of a curing compound seems to be the most effective means of reducing scaling and no general relationship between the duration of moist-curing and scaling resistance could be developed.

\subsubsection{Rate of Freezing and Minimum Temperature}

It has been observed that the rate of freezing has very dissimilar influences resulting in internal damage due to freeze-thaw and scaling damage in the presence of a de-icing salt solution. For freeze-thaw durability, it is believed that the higher the rate of freezing, the lower the spacing factor for similar resistance should be. For concrete prepared with a w/c ratio between 0.5 and 0.6, Powers (1949) proposed a critical spacing factor value of $250 \mu \mathrm{m}$ for a freezing rate of $11^{\circ} \mathrm{C} / \mathrm{h}$. Different concrete mixtures having a constant $\mathrm{w} / \mathrm{c}$ ratio of 0.5 but having variable spacing factors were subjected to F-T cycles (Pigeon et al., 1985). The critical spacing factors for various freezing rates were evaluated from length change measurements done at the completion of 300 cycles. It was found that the critical spacing factor reduced significantly when the freezing rate was increased from 2 to $6^{\circ} \mathrm{C} / \mathrm{h}$. Malhotra (1982) reported that concretes with spacing factor values in the range of 250 to $300 \mu \mathrm{m}$ can resist 300 cycles of freezing and thawing in water when the freezing rate is $8^{\circ} \mathrm{C} / \mathrm{h}$. These results indicated that though the test results obtained from ASTM C 666 procedure B (freezing in air, thawing in water) were identical to test results from procedure A (freezing and thawing in water), concretes 
frozen in water exhibited surface scaling after 300 cycles whereas those frozen in air did not.

In case of scaling, it has been observed that increasing the freezing rate, decreases the scaling or, that there is no significant influence of rate of freezing on scaling damage. This is mainly because rapid cooling allows less time for moisture uptake during cooling thereby, reducing the development of scaling. Studer (1993) found no influence of either duration of the frost cycle or freezing rate on scaling. He varied the rate in the very narrow interval $\left(-2.0^{\circ} \mathrm{C} / \mathrm{h}\right.$ to $\left.-3.4^{\circ} \mathrm{C} / \mathrm{h}\right)$ and therefore should have very limited effect on overall results. He found that minimum temperature has much larger influence on scaling results than duration of cycle and hence, severity of temperature cycle can be well characterized by minimum temperature reached in the salt solution. Jacobsen (1995) studied effect of three different cooling rates $2.8,4.9$ and $12^{\circ} \mathrm{C} / \mathrm{h}$ on scaling for non airentrained and air entrained concrete. He observed that reducing the cooling rate with the same minimum temperature in comparison to extending the time at minimum temperature with faster cooling rate showed higher weight loss due to scaling. Lindmark (1998) reported that if the rest of the frost cycle is unchanged than scaling decreases as cooling rate increases. However, he mentioned that scaling may be repeated several times during the cooling phase, so the final result cannot be quantitatively predicted.

\subsubsection{De-icing Salt Solutions; Types and Concentration}

The use of de-icing salt has definitely been shown, in both the laboratory and the field, to increase the severity and extent of concrete scaling. In the initial studies of Verbeck and Klieger (1957), the effect of the concept of pessimum solution was shown. 
They studied the effects of four dissimilar de-icing agents $\left(\mathrm{CaCl}_{2}, \mathrm{NaCl}\right.$, urea, and ethyl alcohol) on the scaling resistance of concrete at various concentration levels. They observed greater amounts of surface scaling at relatively low intermediate concentrations ( $2-4 \%$ by weight) and that the severity concentration curves associated with the four agents were similar. Between $2-4 \% \mathrm{NaCl}$ concentrations appeared to be the most detrimental solution for scaling of concrete. Similar observations were made by Grieb et al. (1962); out of five agents he studied, calcium chloride appeared to be more effective and less harmful to the concrete, while the severity of the damage from sodium chloride and urea were found to be essentially the same. To develop a better understanding of the application of salt in the field, a summary of the various salt mixtures being applied in the field in Indiana, along with its application rate, and advantages-disadvantages are in Table 2.1. Note that these salts are being used as deicing or anti-icing agents, alone and in various combinations.

Based on the above summary of numerous studies it seems that different researchers have found different parameters to be important in the determination of total scaling. Based on their observations, several mechanisms have been suggested for the scaling of concrete. None of these mechanisms are widely accepted but summarizing then will be helpful in addressing the ensuing issues. 
Table 2.1: General information about prevalent salt**

\begin{tabular}{|c|c|c|c|c|}
\hline $\begin{array}{l}\text { Chemical } \\
\text { Name, Formula, } \\
\text { (Eutectic } \\
\text { Temperature, E. } \\
\text { T.) }\end{array}$ & Advantages & Disadvantages & $\begin{array}{l}\text { Application } \\
\text { Rates for lane } \\
\text { miles }\end{array}$ & Costs \\
\hline $\begin{array}{l}\text { Sodium } \\
\text { Chloride, } \mathrm{NaCl} \\
\text { E. T. }=-21.1^{\circ} \mathrm{C} \\
\left(-6^{\circ} \mathrm{F}\right)\end{array}$ & $\begin{array}{l}\text { Low initial cost, } \\
\text { effective above } 20^{\circ} \mathrm{F} \text {, } \\
\text { melts snow and } \\
\text { penetrates ice }\end{array}$ & $\begin{array}{l}\text { Corrosive, slow } \\
\text { below } 20^{\circ} \mathrm{F} \text {, must } \\
\text { dissolve before ice } \\
\text { melting begins. }\end{array}$ & $\begin{array}{l}30-50 \\
\text { gallons/lm, 30\% } \\
\text { (deicing - } 250 \\
\text { lbs/lm every } 3 \\
\text { hour) }\end{array}$ & $\begin{array}{l}\text { Liquid } \\
\text { salt cost } \\
4-6 \notin \text { per } \\
\text { gallon, } \$ 25 \\
\text { - } \$ 45 \text { per } \\
\text { ton. }\end{array}$ \\
\hline $\begin{array}{l}\text { Calcium } \\
\text { Chloride, } \mathrm{CaCl}_{2} \\
\text { E. T. }=-51.1^{\circ} \mathrm{C} \\
\left(-60^{\circ} \mathrm{F}\right)\end{array}$ & $\begin{array}{l}\text { Effective at lower } \\
\text { temperatures than } \\
\mathrm{NaCl} \text {, attracts } \\
\text { moisture from air } \\
\text { which hastens its } \\
\text { dissolving and } \\
\text { melting, releases heat } \\
\text { when it dissolves. }\end{array}$ & $\begin{array}{l}\text { More costly, } \\
\text { requires extra } \\
\text { handling effort, } \\
\text { very corrosive, } \\
\text { tends to keep } \\
\text { pavement wet. }\end{array}$ & $\begin{array}{l}30 \text { to } 50 \text { gallons } \\
\text { per lane mile } \\
(32 \%) \text { for anti- } \\
\text { icing. }\end{array}$ & $\begin{array}{l}\$ 150-300 \\
\text { (flake) - } \\
\$ 250- \\
400 / \text { ton } \\
\text { (pellets) - } \\
30-65 \varnothing \\
\text { per gallon } \\
\text { liquid }\end{array}$ \\
\hline $\begin{array}{l}\text { Magnesium } \\
\text { Chloride, } \mathrm{MgCl}_{2} \\
\text { E. T. }=-33.33^{\circ} \mathrm{C} \\
\left(-28^{\circ} \mathrm{F}\right)\end{array}$ & $\begin{array}{l}\text { Effective at lower } \\
\text { temperatures than salt } \\
\text { (used for less than } \\
0^{\circ} \mathrm{F} \text { ), attracts moisture } \\
\text { from air which hastens } \\
\text { its dissolving and } \\
\text { melting. }\end{array}$ & $\begin{array}{l}\text { More costly than } \\
\text { salt, corrosive, } \\
\text { may increase } \\
\text { concrete scaling } \\
\text { and spalling, tends } \\
\text { to keep pavement } \\
\text { wet. }\end{array}$ & $\begin{array}{l}30 \text { to } 50 \text { gallons } \\
\text { per lane mile for } \\
\text { anti-icing }\end{array}$ & $\begin{array}{l}50-70 \varnothing \\
\text { per gallon } \\
\text { of } 30 \% \\
\text { solution, } \\
\$ 300 \text { per } \\
\text { ton dry } \\
\text { flake. }\end{array}$ \\
\hline
\end{tabular}

**This information was compiled at the University of Wisconsin-Madison. The information was collected from numerous TRB, State DOT, and Canadian provincial reports; manufacturers product literature; trade journals; and industry sources.

\subsection{Summary of Proposed Mechanisms of Scaling of Concrete}

Based on various experimental and field results, several mechanisms have been suggested by different researchers to explain scaling behavior. A few of the relevant mechanisms are discussed here briefly, and will be discussed further in explaining the 
results in successive chapters. Since this is not the main focus of this study, brief overview is given with the details available in the cited references.

\subsubsection{Hydraulic Pressure Mechanism}

This mechanism suggested by Powers (1945) is widely accepted for F-T damage in concrete, which is based on the fact that the freezing of water causes approximately $9 \%$ expansion. The destruction of concrete by freeze-thaw is a result of the pressure generated when freezing water expands in the pores and displaces unfrozen water. The mechanism for scaling damage as explained by powers is summarized below.

The capillary voids in the surface-layer of concrete are saturated to a certain depth due to the water collecting on the surface. The surface water freezes first, effectively sealing the surface. Freezing then progresses inwardly from the surface, displacing the unfrozen water towards the interior. During thawing the ice in the less saturated interior capillary voids will tend to melt at a lower temperature. This causes melting to occur outwardly from the interior. However, due to the presence of salt in the surface solution, the surface ice might melt prior to the surface capillary ice. In such cases, an external source of moisture would be available and some of this water would be absorbed into the concrete. Thus, the overall degree of saturation and the depth of saturation would be increased by repetitions of the freeze-thaw cycle. This process would continue until some critical depth of saturation is attained, which would result in hydraulic pressures great enough to cause surface disintegration.

The governing parameters for this mechanism, is flow distance (spacing factor), degree of saturation, and rate of freezing. This mechanism does not address the 
deleterious effect of pessimum salt solution. Powers developed a mathematical formulation for determining the spacing factor but recent research has created doubt on the validity of this formulation (Lindmark, 1997).

\subsubsection{Osmotic Pressure Mechanism}

This mechanism was proposed later by Powers and Helmuth (1953) to address other observations relating to deicing salts. The osmotic pressure mechanisms are dependent on the fact that capillary voids and gel pores might be filled with a solution of water and deicing agents or to a small extent, alkali ions. Prior to freezing, the capillary voids contain an aqueous solution of deicing agents and are in equilibrium with each other. Freezing of the capillary solution, results in a mixture of relatively pure ice and a solution of higher salt concentration. It can be assumed that the gel pores surrounding this capillary cannot freeze because of their very small size. Thus, the solution in the capillary voids and gel pores cannot be in equilibrium at this point. When cooling proceeds, the unfrozen water in the smaller pores will gain more free energy than the ice already formed, which will create a potential difference, in turn creating moisture that moves out from the small pores into the large ones, where it will freeze onto the existing ice body.

Several improvements were later suggested to this mechanism. Most recently modified form of this mechanism was suggested by Lindmark (1997). He explained this phenomenon by the main premise being the osmotic ice body growth in porous systems. In a concrete specimen, osmotic ice body growth is significantly facilitated, as compared to the situation in the interior of a moisture-isolated specimen, when the pore liquid is 
connected to the reservoir of liquid in which the liquid pressure remains atmospheric. It is the central role of salt in the outer solution to provide such a reservoir of liquid at temperatures below the freezing point of the pore solution. He also pointed out the limitation that no numerical solution was obtainable because of the high degree of uncertainty associated with the pore size distribution.

\subsubsection{Combined Hydraulic and Osmotic Pressure Mechanism}

Currently, the following mechanism is widely accepted by various researchers for scaling of concrete. Powers (1965) proposed that most scaling issues could be explained by the combined effect of osmotic and hydraulic pressure. The osmotic pressure would be due to the presence of salts; and since this would draw more moisture into pores where ice and salt existed together, the subsequent increased ice formation in these pores would cause increased hydraulic pressure when water is expelled from these pores. Powers also states that deicing salts will spread much faster in the capillary pores than in the gel pores and that the salt concentration gradient thereby formed between the gel pores and the capillary pores would promote this mechanism.

Marchand and Pleau (2000) further explained that the total pressure induced in the system is the sum of the pressures generated by both phenomena and is influenced by the amount of salts dissolved in the pore solution. The higher the salt solution; the lower the amount of freezable water at a given temperature; thus, the hydraulic pressure decreases with an increase in the salt concentration. On the other hand, the osmotic pressure increases with an increase in the salt concentration. The combination of these two 
phenomena yields a moderate salt concentration (2 - 4\%), which causes maximum scaling.

\subsubsection{Crystal Growth Mechanism}

Hansen (1954) was the first to suggest the crystal growth mechanism, involving formation and growth of salt crystals, to explain severe scaling of concrete subjected to deicing agents. The process resulting in the formation of and growth of these crystals, which in turn results in surface disintegration, was visualized by Hansen as follows:

The application of the salt for the purpose of ice removal results in a salt solution covering the surface of the slab. Salt molecules from this solution tend to migrate into the concrete by either diffusion or absorption. If the surface of the concrete is then sealed by a layer of ice, separation of the salt from the solution is an expansion reaction; and since the solution cannot escape through the surface, the formation of crystals will displace the salt solution into pores that are not already filled. By this process, repeated cycles of freezing could cause the liquid in the concrete to become an aqueous solution of de-icing salts. Cooling or evaporation can cause crystallization of salt in the pores of the concrete. This action results in a condition in which the film of the solution surrounding the capillary crystal is not in equilibrium with the solution in the surrounding pores. Consequently, salt molecules diffuse into the capillaries and allow the crystal to continue to grow. After the pore is completely filled with a salt crystal, continued growth will cause the crystal to be extruded or will cause the development of pressure, which can result in scaling. 
This is considered the most likely mechanism for observed scaling behavior in the field because of the initial application of a high salt solution and the drying of the pavement between freezing cycles. However, this will not explain the results of laboratory scaling tests because there is no drying between consecutive cycles for crystallization to occur.

\subsubsection{Thermal Shock, Thermal Incompatibility or Thermal Mismatch}

Hartmann (1957) reported that damage was caused by the rapid consumption of melting heat, which results in the rapid cooling of the upper layer of the concrete when deicer is applied. This sharp change in temperature produces stresses in the already frozen surface layer of mortar. Thus, he considered thermal shock as the mechanism of scaling in field performance.

Another similar mechanism illustrates that concrete deterioration due to the freeze-thaw cycles may be attributed to the difference in the thermal incompatibility of aggregates and cement paste. Parsons and Johnson (1944) concluded that if the thermal expansion of an aggregate differs considerably from that of the paste, a potential incompatibility exists that might result in excessive internal stresses if concrete is subjected to large temperature changes.

Recently, Valenza II and Scherer (2004), with the help of a novel experiment suggested thermal mismatch as the most important mechanism. Their experimental results demonstrated the occurrence of a thermal expansion mismatch (or bi-material) mechanism explains for all of the observed salt scaling phenomenology. According to the authors, scaling occurs when the stress in the freezing layer rises above the tensile 
strength of the brine-containing ice, resulting in cracking. With the help of a visco-elastic analysis of the stresses in the brine/ice layer, it was shown that pure ice would not crack, but a layer containing more than $1 \% \mathrm{NaCl}$ would. The damage from the cracking of the ice is exacerbated by the weakening of the cement paste from exposure to concentrated brine. However, not being able to account for the effect of air voids in the concrete is the major limitation of this mechanism. Hence, it can be said that this mechanism might be considered responsible when non-air entrained concrete is studied.

\subsubsection{A Case-Specific Approach Based on Summary of Various Mechanisms}

Based on the extensive literature review, it can be assumed that scaling is not a single point process; different magnitudes of forces can be generated at different temperatures, depending on the degree of saturation and the salt concentration in the surface region. Based on the degree of resistance, a particular mechanism might govern the scaling behavior in a given case. The exact mechanism of scaling is still considered unknown because none of the mechanisms proposed to date explain all the different laboratory and field observations. However, from a holistic look at the extensive literature review and experimental results, it becomes evident that the type of concrete and other boundary conditions are not similar in all of the previous studies. Moreover, some correlation was observed for similar types of concrete or boundary conditions, in the scaling behavior and for suggested mechanisms. Based on such observations, Table 2.2 was prepared, which provides the maximum applicability of each mechanism to a specific type of concrete based on the results and reasoning provided in various studies. 
Thus, it can be said that although the damage is the same, the reason for the damage can change based on the type of concrete and the boundary conditions.

Table 2.2: Summary showing applicability to each mechanism to specific type of concrete

\begin{tabular}{|c|c|c|}
\hline No. & Governing mechanism & Most applicable type of concrete \\
\hline 1 & Hydraulic pressure mechanism & $\begin{array}{c}\text { Plain concrete or concrete with } \\
\text { higher porosity, carbonated concrete } \\
\text { containing slag }\end{array}$ \\
\hline 2 & Osmotic pressure mechanism & $\begin{array}{c}\text { Air entrained concrete with fly ash, } \\
\text { refined pore structure }\end{array}$ \\
\hline 3 & $\begin{array}{c}\text { Combined hydraulic and osmotic } \\
\text { pressure mechanism }\end{array}$ & Air entrained plain concrete \\
\hline 4 & Crystal growth mechanism & $\begin{array}{c}\text { Actual pavements exposed to drying } \\
\text { while freezing }\end{array}$ \\
\hline 5 & $\begin{array}{c}\text { Thermal shock or thermal } \\
\text { incompatibility }\end{array}$ & $\begin{array}{c}\text { Actual pavements, application of } \\
\text { sudden deicing solution }\end{array}$ \\
\hline 6 & Bi-material or thermal mismatch & Non-air-entrained plain concrete \\
\hline
\end{tabular}

"A case-specific mechanism of scaling" approach is suggested here to simplify the problem and to understand the influencing parameters. Based on the understanding developed from the detailed analysis of the results of various studies, Table 2.3 proposes such an approach for different types of concrete. Also, scaling is not a single-point process so for each scaling problem, there might be several mechanisms acting at the same time, one of which would be the governing mechanism and would influence the results significantly. Therefore, Table 2.3 provides probable governing mechanisms in the order of its importance, along with the major influencing parameters. Here it should be noted that for simplicity and better comparison, the exposure conditions and the strength of the concrete are assumed constant for all types of concrete. For this ideal condition, an approximated comparison for the types of stresses and the degree of 
resistance are shown thereby, as well as the potential for damage. It should be noted that this is just an approximate representation of extensive literature review and laboratory study. This approach should be refined further to give more precise and exact solution to individual problems.

Overall, based on all the literature, scaling could be considered as a function of the tensile strength, the salt concentration in the surface, the minimum concrete temperature, the air void structure and the degree of saturation of the concrete, the traffic movements, and many more parameters. Moreover, the surface composition, pore structure and degree of drying can influence results by changing the penetrability of salt in the concrete. Thus, it seems that scaling is the combined effect of many parameters, which make the process complex to model. Therefore, the above mentioned case-specific approach could help in reducing the complexity of the problem by pointing out important parameters for a particular type of concrete and providing the proper focus on the governing parameters. For the problem at hand, the focus will be scaling of air-entrained concrete containing fly ash in the field and laboratory. Moreover, the role of the suggested influencing parameters is verified using a few laboratory results. 
Table 2.3: Critical summary of various mechanisms using "A case specific approach"

\begin{tabular}{|c|c|c|c|}
\hline $\begin{array}{c}\text { Type of } \\
\text { concrete }\end{array}$ & $\begin{array}{c}\text { Dominating mechanism and } \\
\text { reasoning }\end{array}$ & $\begin{array}{c}\text { Degree of resistance and generated } \\
\text { stresses }\end{array}$ & Influencing parameters \\
\hline $\begin{array}{l}\text { Non-air } \\
\text { entrained, } \\
\text { plain cement } \\
\text { concrete }\end{array}$ & $\begin{array}{l}\text { Bi-material mechanism, thermal } \\
\text { mismatch, coherent layer and ice } \\
\text { cracking }\end{array}$ & $\begin{array}{l}\text { Low degree of resistance, lower stresses } \\
\text { are generated due to this mechanism }\end{array}$ & $\begin{array}{l}\text { Minimum temperature, DOH (Degree of } \\
\text { Hydration), porosity and strength, } \\
\text { surface salt concentration }\end{array}$ \\
\hline $\begin{array}{l}\text { Air entrained } \\
\text { plain cement } \\
\text { concrete }\end{array}$ & $\begin{array}{l}\text { Balance of hydraulic and osmotic } \\
\text { pressure and subsequent increase in } \\
\text { degree of saturation }\end{array}$ & $\begin{array}{l}\text { High degree of resistance and moderate } \\
\text { stresses generated due to mechanism }\end{array}$ & $\begin{array}{l}\text { Degree of saturation, minimum } \\
\text { temperature, DOH, porosity and } \\
\text { strength, surface salt concentration }\end{array}$ \\
\hline $\begin{array}{l}\text { Air } \\
\text { entrained } \\
\text { concrete } \\
\text { containing } \\
\text { fly ash }\end{array}$ & $\begin{array}{l}\text { Governed more by higher osmotic } \\
\text { pressure generated due to refined } \\
\text { pore structure and critical degree of } \\
\text { saturation }\end{array}$ & $\begin{array}{l}\text { High degree of resistance and high } \\
\text { stresses generated due to this mechanism, } \\
\text { because of presence of small pores and } \\
\text { progressive filling }\end{array}$ & $\begin{array}{l}\text { Pore size distribution, inner salt } \\
\text { concentration, length of wetting, degree } \\
\text { of saturation, minimum temperature, } \\
\text { DOH, porosity and strength, surface salt } \\
\text { concentration }\end{array}$ \\
\hline $\begin{array}{l}\text { Air entrained } \\
\text { concrete } \\
\text { containing } \\
\text { slag }\end{array}$ & $\begin{array}{l}\text { Effect of carbonation, hydraulic } \\
\text { pressure due to increased porosity, } \\
\text { degree of saturation }\end{array}$ & $\begin{array}{l}\text { Moderate degree of resistance because } \\
\text { of increase in porosity due to carbonation } \\
\text { and moderate stresses due to mechanism }\end{array}$ & $\begin{array}{l}\text { Extent of carbonation, degree of } \\
\text { saturation, minimum temperature, DOH, } \\
\text { porosity and strength, surface salt } \\
\text { concentration }\end{array}$ \\
\hline $\begin{array}{l}\text { Air entrained } \\
\text { plain cement } \\
\text { concrete in } \\
\text { the field }\end{array}$ & $\begin{array}{l}\text { More osmotic effect due to lower } \\
\text { rate of freezing, effect of traffic } \\
\text { movement, thermal shock or crystal } \\
\text { growth mechanism }\end{array}$ & $\begin{array}{l}\text { High degree of resistance when cured at } \\
\text { normal temperature, moderate resistance } \\
\text { when cured at low temperature due to } \\
\text { chances of higher porosity and degree of } \\
\text { saturation in surface region, moderate } \\
\text { stresses }\end{array}$ & $\begin{array}{l}\text { Curing temperature, vehicular } \\
\text { movement, size and rate of cooling, } \\
\text { bleeding-evaporation and surface } \\
\text { porosity, degree of saturation, minimum } \\
\text { temperature, DOH, and strength, surface } \\
\text { salt concentration }\end{array}$ \\
\hline $\begin{array}{l}\text { Air } \\
\text { entrained } \\
\text { concrete } \\
\text { containing } \\
\text { fly ash in the } \\
\text { field }\end{array}$ & $\begin{array}{l}\text { More osmotic effect due to lower } \\
\text { rate of freezing, effect of traffic } \\
\text { movement, thermal shock or crystal } \\
\text { growth mechanism }\end{array}$ & $\begin{array}{l}\text { High degree of resistance, irrespective of } \\
\text { curing temperature, moderate stresses } \\
\text { because of shorter actual length of } \\
\text { wetting, while freezing }\end{array}$ & $\begin{array}{l}\text { Vehicular movement, bleeding- } \\
\text { evaporation and surface porosity, size } \\
\text { and rate of cooling, length of wetting, } \\
\text { pore size distribution, degree of } \\
\text { saturation, min. temp., DOH, surface salt } \\
\text { concentration }\end{array}$ \\
\hline
\end{tabular}




\subsection{Maturity method}

In concrete construction, it is essential to know the in-place strength of concrete so that construction schedules could be planned in advance and executed so as to have maximum economic benefits. The maturity technique uses temperature history collected during the curing period to find an equivalent age needed to achieve desired level of strength under different temperatures. Maturity techniques are being used extensively in current pavement construction practices as a tool to predict the strength of concrete, which in turn can be useful in deciding the period of curing required before the pavement can be opened to traffic. The devices commonly used to measure temperature in concrete are thermocouples or other sensors like thermistors, which are inserted into the concrete at required depths. The temperature is collected by a data logger (which stores the temperature data), to which instructions like the time interval for temperature collection are transferred by means of a software code.

Under isothermal curing conditions, the strength gain of concrete can be described by a hyperbolic curve having three parameters:(1) the limiting long-term strength, $S_{u},(2)$ the rate constant, $k_{t}$ and (3) the age $t_{o}$ when rapid strength development is assumed to begin (Tank and Carino, 1991). Another important parameter called the activation energy, $E_{a}$. Activation energy is defined as the energy required to initiate a reaction or the minimum energy needed to form an activated complex during a collision between reactants. $E_{a}$ is related to the rate constant through the Arrhenius function, which was found to accurately account for the influence of temperature differences on strength gain (Carino, 1991 and Carino et al., 1983). The maturity method has been used to accurately monitor and predict the strength gain of rapid concrete pavement repairs during the 
curing period (Okamoto and Whiting, 1994). The prediction using the maturity method, however, seemed to underestimate strengths at early ages. Pinto and Hover (1990) found that the initial and final set times could be predicted for any mixture provided the activation energy is obtained. Early age curing temperatures have been found to influence the ultimate strength of concrete. McIntosh (1956) reported that for equal maturities, specimens exposed to low early age temperatures were weaker at early maturities but stronger at later maturities. Many other researchers also reported this "cross-over" effect where lower early age curing temperatures resulted in higher ultimate strengths. 


\section{CHAPTER 3: SELECTION OF CEMENTS AND SUPPLEMENTARY CEMENTING MATERIALS}

\subsection{Introduction}

In order to understand the complexities involved with various chemical reactions in concrete containing cement and mineral admixtures like fly ash and slag, it was decided to gather data on various cements, fly ashes and slag and study the influence of various chemical components in each of these materials on factors like rate of strength gain and strength activity index which would be essential in cold weather conditions. The material selection was conducted in conjunction with the INDOT sponsored project on the use of supplementary materials in the late fall construction season. A listing of all INDOT approved sources of cement, fly ash and slag was collected. Mill certificates were obtained from 28 sources of cement, nine sources of Class C fly ash, four sources of Class F fly ash and one source of slag. The mill certificates for cements contained data like chemical compositions of $\mathrm{C}_{3} \mathrm{~S}, \mathrm{C}_{2} \mathrm{~S}, \mathrm{C}_{3} \mathrm{~A}$, fineness $\left(\mathrm{m}^{2} / \mathrm{kg}\right)$, alkali content and strength data for tests performed at different ages. For fly ashes chemical compositions of lime, $\mathrm{SiO}_{2}, \mathrm{Al}_{2} \mathrm{O}_{3}, \mathrm{Fe}_{2} \mathrm{O}_{3}$, alkali content and strength activity index values at different ages were provided. For the slag, values of sulfide, alkali content and strength activity index were provided. The data obtained were either in the form of yearly averages or monthly averages for a period of 12 months. All the mill certificates were then used to prepare a comprehensive database of different parameters from various sources of 
Table 3.1: Summary of cement data

\begin{tabular}{|c|c|c|c|c|c|c|c|c|c|c|}
\hline \multirow[b]{2}{*}{ Cement ID } & \multirow[b]{2}{*}{ Company } & \multirow[b]{2}{*}{$\mathrm{C}_{3} \mathrm{~S}(\%)$} & \multirow[b]{2}{*}{$\mathrm{C}_{2} \mathrm{~S}(\%)$} & \multirow{2}{*}{$\begin{array}{c}\text { Alkali ( } \mathrm{Na}_{2} \mathrm{O} \\
\text { equiv.) }\end{array}$} & \multirow{2}{*}{$\begin{array}{c}\text { Blaine } \\
\text { Fineness }\left(\mathrm{m}^{2} / \mathbf{k g}\right)\end{array}$} & \multirow[b]{2}{*}{$\mathrm{C}_{3} \mathrm{~A}(\%)$} & \multicolumn{4}{|c|}{ Compressive strength, psi (MPa) } \\
\hline & & & & & & & 1 day & 3day & 7 day & 28 day \\
\hline \multicolumn{11}{|l|}{ Type I } \\
\hline C01 & Blue circle & 54 & 17 & 0.81 & 408.0 & 10 & & $3924(27)$ & $4793(33)$ & $5835(40)$ \\
\hline $\mathrm{CO2}$ & Lonestar, IN & 60.01 & 13.54 & 0.54 & 360.8 & 8.22 & $2272(16)$ & $3439(24)$ & $4390(30)$ & $5790(40)$ \\
\hline $\mathrm{C03}$ & Lonestar, IL & 52.5 & 17.2 & 0.9 & 332.3 & 10.3 & $1794(12)$ & $3441(24)$ & $4328(30)$ & $5438(37)$ \\
\hline $\mathrm{C04}$ & Holnam, MI & 54.83 & 17.08 & 0.74 & 400.8 & 9.33 & & $3400(23)$ & $4472(31)$ & \\
\hline $\mathrm{C05}$ & Holnam, MO & 58.89 & 15.09 & 0.47 & 375.5 & 8.65 & & $3356(23)$ & $4832(33)$ & \\
\hline C06 & Siam cement & 63.79 & 23.32 & 0.43 & 355.5 & 8.76 & & $4009(28)$ & $5077(35)$ & $6529(45)$ \\
\hline $\mathrm{C07}$ & Southdown (Pitts) & 51 & & 0.61 & 384.0 & 8 & $1995(14)$ & $3225(22)$ & $4365(30)$ & \\
\hline $\mathrm{C08}$ & Lonestar, MO & 51.72 & 21.47 & 0.49 & 366.0 & 6.47 & 1841 (13) & $3135(22)$ & $4172(29)$ & $6060(42)$ \\
\hline $\mathrm{C09}$ & Essroc, Logansport & 62.45 & & 0.25 & 383.9 & 8.58 & $1521(10)$ & $3293(23)$ & $5421(37)$ & $6916(48)$ \\
\hline $\mathrm{C10}$ & Essroc, Essexville & 56.58 & & 0.95 & 382.0 & 7.7 & $2681(18)$ & $3198(22)$ & $4646(32)$ & $5734(40)$ \\
\hline $\mathbf{C 1 1}$ & Lafarge, Paulding & 62.45 & & 0.45 & 358.5 & 7.9 & $1624(11)$ & $3235(22)$ & $4313(30)$ & $5864(40)$ \\
\hline $\mathrm{C12}$ & Southdown, Fairborn & 51.83 & & 0.59 & 395.1 & 6.14 & $2011(14)$ & $3454(24)$ & $4216(29)$ & $5346(37)$ \\
\hline $\mathbf{C 1 3}$ & Southdown, MI & 56.15 & 14.23 & 0.94 & 396.1 & 6.54 & & $3648(25)$ & $4375(30)$ & 5412 (37) \\
\hline C14 & Lafarge, Bath & 59.06 & & 0.65 & 373.1 & 6.59 & & $3912(27)$ & $4744(33)$ & $6044(42)$ \\
\hline C15 & Lafarge, Alpena & 63.76 & & 0.54 & 363.8 & 8 & $2074(14)$ & $3900(27)$ & $4658(32)$ & $5950(41)$ \\
\hline \multicolumn{11}{|l|}{ Type I/II } \\
\hline C16 & Lehigh portland & 49.31 & 25.85 & 0.49 & 373.4 & 6.46 & $2414(17)$ & $3765(26)$ & $4688(32)$ & \\
\hline $\mathbf{C 1 7}$ & Southdown (KY) & 51.63 & 22.59 & 0.65 & 386.4 & 6.33 & $2997(21)$ & 3957 (27) & $5600(39)$ & \\
\hline $\mathbf{C 1 8}$ & Heracles, Greece & 62.8 & 11.4 & 0.52 & 379.4 & 6 & & $3652(25)$ & $4328(30)$ & \\
\hline C19 & Essroc, Speed & 56.09 & & 0.52 & 374.6 & 6.91 & $1853(13)$ & & $4119(28)$ & $6168(43)$ \\
\hline $\mathrm{C20}$ & Lafarge, Joppa & 60 & & 0.46 & 380.2 & 7.33 & $2017(14)$ & $3728(26)$ & $4843(33)$ & $6103(42)$ \\
\hline C21 & River Cement, MO & 58.26 & 15.44 & 0.54 & 360.7 & 6.53 & $2087(14)$ & $3476(24)$ & $4685(32)$ & $6243(43)$ \\
\hline \multicolumn{11}{|l|}{ Type III } \\
\hline $\mathrm{C} 22$ & Lehigh portland & 53.15 & 25.15 & 0.49 & 610.2 & 4.93 & $4365(30)$ & $5768(40)$ & $6979(48)$ & \\
\hline $\mathrm{C23}$ & Lonestar, IN & 59 & 11.75 & 0.6 & 552.1 & 9 & $4138(29)$ & $5199(36)$ & $6030(42)$ & \\
\hline $\mathrm{C24}$ & \begin{tabular}{|l|} 
Lonestar, IL \\
\end{tabular} & 53.0 & 16.6 & 0.9 & 562.1 & 10.4 & $4348(30)$ & 5395 (37) & $6108(42)$ & \\
\hline $\mathrm{C25}$ & Holnam, MI & 53.81 & 16.94 & 0.72 & 525.3 & 9.15 & $2620(18)$ & $4470(31)$ & $5203(36)$ & \\
\hline $\mathrm{C26}$ & Essroc, Logansport & 61 & & 0.31 & 622.0 & 8.3 & $2854(20)$ & $5212(36)$ & $6679(46)$ & \\
\hline $\mathbf{C 2 7}$ & Essroc, Speed & 54.63 & & 0.51 & 593.1 & 6.74 & $3170(22)$ & $4700(32)$ & $5799(40)$ & \\
\hline $\mathrm{C28}$ & Southdown, MI & 57.33 & 14 & 0.96 & 633.3 & 6.67 & $4550(31)$ & 5207 (36) & $5993(41)$ & \\
\hline
\end{tabular}


cement, fly ash and slag. The database was prepared in such a way that it would provide an easy reference of chemical compositions, fineness and results of mechanical properties for all materials under consideration. Models were developed for strength prediction in cements and strength activity index (SAI) prediction in fly ashes. Sensitivity analyses were performed to evaluate the influence of various chemical components, fineness on the strength and SAI of cements and fly ashes respectively. Subsequent divisions in this chapter discuss models for strength, strength activity index prediction and the scientific approach involved in screening cements, fly ashes and slag for subsequent tests.

\subsection{Development of Mathematical Model for Strength Prediction of Cement Mortars}

A detailed listing of the cement information shown in Table 3.1 used in the development of mathematical models was prepared. In order to select a manageable number of cements for the subsequent tasks of the project, which involved tests on mortars and concrete, steps were taken so as to screen few cements. The approach adopted for screening the materials was such that all mixtures prepared with the screened materials would cover a wide range of possible mixture combinations in the state of Indiana. It was decided to perform some analysis, which would indicate the sensitivity of strength of cements to variation of each chemical component under consideration and fineness at varying ages. As it is known that each of $\mathrm{C}_{3} \mathrm{~S}, \mathrm{C}_{2} \mathrm{~S}, \mathrm{C}_{3} \mathrm{~A}$, fineness $\left(\mathrm{m}^{2} / \mathrm{kg}\right)$, and alkali content has a significant influence on the strength development and subsequently the ultimate strength of concrete, the compressive strength was initially expressed as a linear function of each of the above components. An initial expression shown in equation 3.1 was adopted for describing compressive strength. 


$$
\mathrm{f}_{\mathrm{c}}=\mathrm{A}(\text { Fineness })+\mathrm{B}\left(\mathrm{C}_{3} \mathrm{~S}\right)+\mathrm{C}\left(\mathrm{C}_{2} \mathrm{~S}\right)+\mathrm{D}(\text { Alkali })+\mathrm{E}\left(\mathrm{C}_{3} \mathrm{~A}\right)
$$

The square of the difference of the error between the strength values obtained from the above-predicted equation and actual strength data obtained from the mill certificates was minimized towards zero in order to obtain the values of the coefficients i.e., Assume initial values of $A, B, C, D, E \Rightarrow \Sigma\left(f_{c \text { predicted }}-f_{c \text { actual }}\right)^{2} \rightarrow 0 \Rightarrow$ obtain constants

The values of coefficients obtained at ages of $1,3,7$ and 28 days after performing iterations are shown in Table 3.2.

Table 3.2: Constant values at different ages

\begin{tabular}{|c|c|c|c|c|c|}
\hline \multicolumn{7}{|c|}{ Constants } \\
\hline Age (days) & Fineness & $\mathbf{C}_{\mathbf{3}} \mathbf{S}$ & $\mathbf{C}_{\mathbf{2}} \mathbf{S}$ & Alkali & $\mathbf{C}_{\mathbf{3}} \mathbf{A}$ \\
\hline $\mathbf{1}$ & 6.69 & -10.01 & 16.94 & 1383.80 & -98.29 \\
\hline $\mathbf{3}$ & 7.19 & 13.34 & 16.20 & -58.96 & -2.86 \\
\hline $\mathbf{7}$ & 7.44 & 31.34 & 18.45 & -680.73 & 31.99 \\
\hline $\mathbf{2 8}$ & 8.32 & 52.59 & 12.49 & -1155.45 & 53.15 \\
\hline
\end{tabular}

Since, it was desired to obtain a single expression for describing the compressive strength of concrete taking all chemical components of cement and period of curing, a relation for describing the constants of each parameter in equation 3.1 as a function of time was developed. The expressions for predicting the values of constants as a function of time are given below:

$$
\begin{aligned}
& \mathrm{A}=0.4794 * \ln (\mathrm{t})+6.646 \\
& \mathrm{~B}=18.845 * \ln (\mathrm{t})-8.2275 \\
& \mathrm{C}=-0.0204 *(\mathrm{t})^{2}+0.4485 * \mathrm{t}+15.95 \\
& D=-745.93 * \ln (\mathrm{t})+1061.3
\end{aligned}
$$




$$
E=44.128 * \ln (t)-74.351
$$

On substituting the constants given by equations 3.2 through 3.6 in equation 3.1, the expression for compressive strength of concrete as a function of parameters like $\mathrm{C}_{3} \mathrm{~S}$, $\mathrm{C}_{2} \mathrm{~S}, \mathrm{C}_{3} \mathrm{~A}$, fineness $\left(\mathrm{m}^{2} / \mathrm{kg}\right)$, alkali content and period of curing is given by:

$$
\begin{aligned}
& \mathrm{f}_{\mathrm{c}}=(0.4794 * \ln (\mathrm{t})+6.646) * \text { Fineness }+(18.845 * \ln (\mathrm{t})-8.2275) * \mathrm{C}_{3} \mathrm{~S}+ \\
& \left(-0.0204 *(\mathrm{t})^{2}+0.4485 * \mathrm{t}+15.95\right) * \mathrm{C}_{2} \mathrm{~S}+(-745.93 * \ln (\mathrm{t})+1061.3) * \text { Alkali }+ \\
& (44.128 * \ln (\mathrm{t})-74.351) * \mathrm{C}_{3} \mathrm{~A}
\end{aligned}
$$

The above equation (3.7) gave very good strength predictions when compared with the actual strength data obtained from the mill certificates. A plot of actual strength values versus strength predicted from equation (3.7) is shown in Figure 3.1. The plot had an $\mathrm{R}^{2}=0.93$.

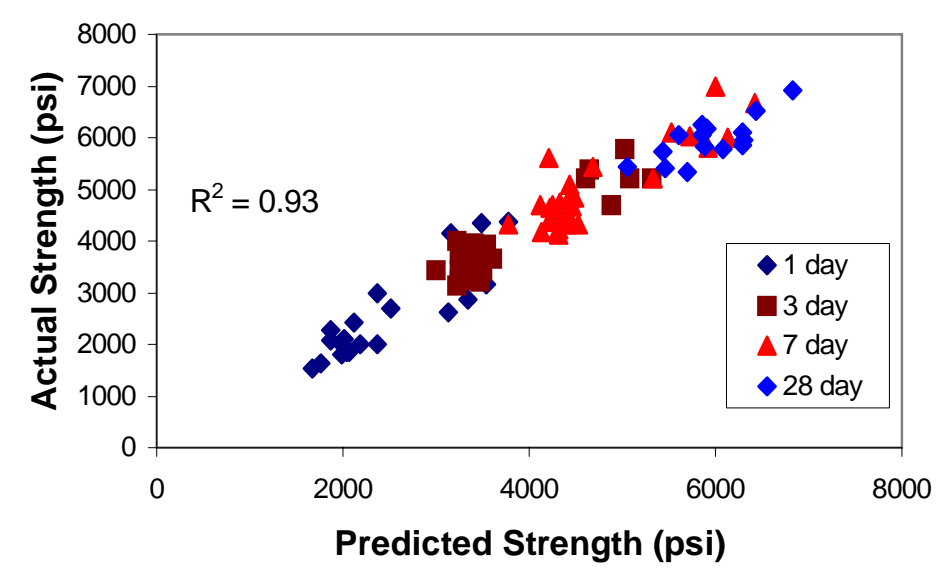

Figure 3.1: Actual versus predicted compressive strength 


\subsection{Development of Mathematical Model for Strength Activity Index (SAI) Prediction}

\section{for Fly Ashes}

A detailed compilation of information on Class $C$ fly ashes is shown in the Table 3.3 and a compilation of information on Class F fly ashes is also shown in Table 3.4. Similar to a model developed for compressive strength for cements, a model was developed for predicting the strength activity indexes (SAI) for fly ashes. An expression of the form shown in equation 3.8 was used for predicting the strength activity index for Class C fly ash.

Table 3.3: Summary of Class C fly ash data

\begin{tabular}{|l|c|c|c|c|c|c|c|}
\hline \multicolumn{1}{|c|}{ Station } & $\begin{array}{c}\text { Fly ash } \\
\text { ID }\end{array}$ & CaO (\%) & $\begin{array}{c}\text { Alkali } \\
\mathbf{( \% )}\end{array}$ & $\begin{array}{c}\text { Fineness (\% } \\
\text { retained 45 } \\
\boldsymbol{\mu m} \text { sieve) }\end{array}$ & $\begin{array}{c}\text { Carbon } \\
\mathbf{( \% )}\end{array}$ & SAI7 & SAI28 \\
\hline Mitchell & FA01 & 24.22 & 1.19 & 10.67 & 0.46 & 94.83 & 99.43 \\
\hline Schahfer & FA02 & 25.22 & 1.20 & 10.76 & 0.26 & 94.02 & 99.89 \\
\hline Clifty creek & FA03 & 18.78 & 1.09 & 13.78 & 2.19 & 96.98 & 102.15 \\
\hline Joliet & FA04 & 24.49 & 1.85 & 13.19 & 0.25 & 96.28 & \\
\hline Rockport & FA05 & 18.57 & 0.70 & 21.88 & 0.68 & 85.50 & \\
\hline Will County & FA06 & 25.80 & 1.65 & 11.52 & 0.35 & 96.85 & \\
\hline Joppa & FA07 & 25.29 & 1.40 & 17.15 & 0.36 & 93.34 & 98.45 \\
\hline St.Louis & FA08 & 24.96 & 1.40 & 13.78 & 0.34 & 88.79 & 99.15 \\
\hline Chouteau,U1 & FA09 & 25.74 & 1.28 & 14.18 & 0.16 & 91.97 & \\
\hline
\end{tabular}

Table 3.4: Summary of Class F fly ash data

\begin{tabular}{|l|c|c|c|c|c|c|c|}
\hline Station & $\begin{array}{c}\text { Fly ash } \\
\text { ID }\end{array}$ & CaO (\%) & $\begin{array}{c}\text { Alkali } \\
(\mathbf{\%})\end{array}$ & $\begin{array}{c}\text { Fineness } \mathbf{( \%} \\
\text { retained 45 } \\
\boldsymbol{\mu m} \text { sieve) }\end{array}$ & $\begin{array}{c}\text { Carbon } \\
(\%)\end{array}$ & SAI7 & SAI28 \\
\hline Miami Fort & FA10 & 2.08 & 0.68 & 26.34 & 2.38 & 80.21 & 85.83 \\
\hline Petersburg & FA11 & 2.57 & 0.48 & 24.96 & 1.67 & 79.64 & 84.07 \\
\hline Owensbury & FA12 & 5.46 & 0.93 & 14.48 & 1.63 & & 87.78 \\
\hline Coronado & FA13 & 3.85 & 0.90 & 22.30 & 0.44 & 87.10 & 91.90 \\
\hline
\end{tabular}




$$
\text { SAI }=A^{*}(\text { Lime })^{0.33}+B^{*}(\text { Alkali })^{0.33}+C^{*}(\text { Fineness })^{0.33}
$$

The values of constants obtained on minimizing the squared difference of the values between actual and predicted SAI are shown in Table 3.5 below.

Table 3.5: Constants for Class C SAI

\begin{tabular}{|c|c|c|c|}
\hline \multicolumn{4}{|c|}{ Constants } \\
\hline Age (days) & Lime & Alkali & Fineness \\
\hline $\mathbf{7}$ & 24.22 & 18.80 & -4.15 \\
\hline $\mathbf{2 8}$ & 33.20 & 1.72 & -5.37 \\
\hline
\end{tabular}

The values of the constants when plotted with respect to age were obtained as:

$$
A=(0.4277 * t+21.226)
$$

$=(0.8133 * \mathrm{t}+24.494)$

(3.10)C $=(-0.0579 * t-$

3.7435)

Hence equation (3.8) takes the form

$$
\begin{aligned}
& \text { SAI }=(0.4277 * \mathrm{t}+21.226) *(\text { Lime })^{0.33}+(0.8133 * \mathrm{t}+24.494) *(\text { Alkali })^{0.33}+ \\
& (-0.0579 * \mathrm{t}-3.7435) *(\text { Fineness })^{0.33}
\end{aligned}
$$

The above equation gave reasonable predictions when compared with the actual SAI values, which can be observed from the Figure 3.2. The coefficient of correlation was obtained as 0.87 . 


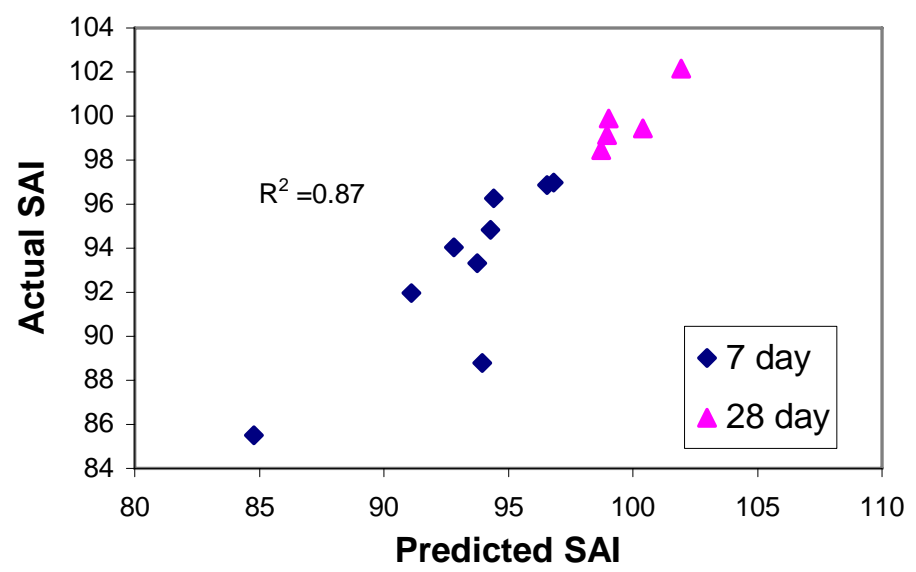

Figure 3.2: Actual versus predicted SAI for Class C fly ash

Similar to the Class $\mathrm{C}$ fly ashes, a relation of the form shown below in equation 3.13 was used to predict SAI for Class F fly ashes.

$$
\mathrm{SAI}=\mathrm{A} *(\text { Lime })+\mathrm{B} *(\text { Alkali })+\mathrm{C} *(\text { Fineness })
$$

The values of the constants obtained on minimizing the squared difference of the values of actual and predicted SAI are shown in Table 3.6:

Table 3.6: Constants for Class F SAI

\begin{tabular}{|c|c|c|c|}
\hline \multicolumn{4}{|c|}{ Constants } \\
\hline Age (days) & Lime & Alkali & Fineness \\
\hline 7 & 6.96 & 7.96 & 2.41 \\
\hline 28 & 8.03 & 10.49 & 2.30 \\
\hline
\end{tabular}

The values of constants when plotted as a function of age was obtained as

$$
\begin{aligned}
& A=(0.0509 * t+6.5998) \\
& B=(0.1206 * t+7.1127) \\
& C=(-0.0052 * t+2.4463)
\end{aligned}
$$


Equation (3.13) then takes the following form:

$$
\begin{aligned}
& \text { SAI }=(0.0509 * t+6.5998) * \text { Lime }+(0.1206 * t+7.1127) * \text { Alkali }+ \\
& (-0.0052 * t+2.4463) * \text { Fineness }
\end{aligned}
$$

The above predicted equation gave a very good relation when compared with the actual SAI values. A plot showing the comparison is shown in Figure 3.3.

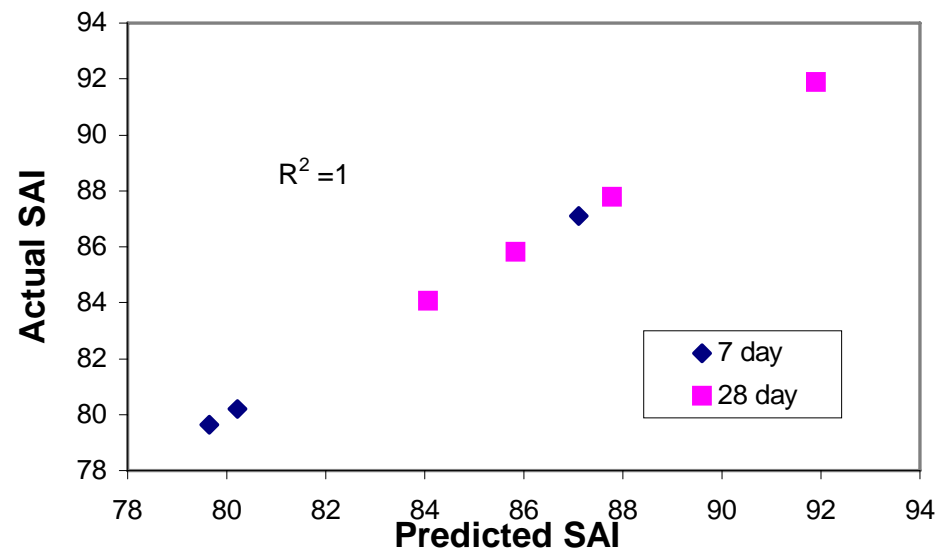

Figure 3.3: Actual versus predicted SAI for Class F fly ash

\subsection{Sensitivity Analysis}

\subsubsection{Sensitivity Analysis for Strength of Cements}

After developing a mathematical model given by equation (3.7), which can predict the compressive strength of mortars made with any cement in the range of values of chemical constituents and fineness obtained from mill certificates as well as cements having a chemical composition different from the original matrix, the next step was to determine the significance of each of the parameters involved in equation (3.7). This was required in order to select a manageable number of cements from the INDOT approved 
list for performing preliminary tests on mortars. In order to select the cements, a strength sensitivity analysis was carried out, where the average values of each parameter involved namely, $\mathrm{C}_{3} \mathrm{~S}, \mathrm{C}_{2} \mathrm{~S}, \mathrm{C}_{3} \mathrm{~A}$, fineness $\left(\mathrm{m}^{2} / \mathrm{kg}\right)$, and alkali content were computed for all cements shown in the table. In order to determine the sensitivity of strength to changes in fineness at any given age, the value for fineness was varied from 300 to $500 \mathrm{~m}^{2} / \mathrm{kg}$ keeping all other parameters, namely, $\mathrm{C}_{3} \mathrm{~S}, \mathrm{C}_{2} \mathrm{~S}, \mathrm{C}_{3} \mathrm{~A}$ and alkali content constant at their average values.

Similarly, the strength sensitivity analysis was performed for all other parameters by varying one parameter over a certain range of values while keeping all others constant at the average values. The plots of sensitivity of strength to changes in fineness, $\mathrm{C}_{3} \mathrm{~S}$, $\mathrm{C}_{2} \mathrm{~S}$, alklali and $\mathrm{C}_{3} \mathrm{~A}$ content are shown in Figures 3.4 through 3.8, respectively. $\mathrm{C}_{3} \mathrm{~S}$ content was varied from $50 \%$ to $60 \%, \mathrm{C}_{2} \mathrm{~S}$ content was varied from $15 \%$ to $25 \%$, alkali content was varied from 0.5 to $1.5 \%$ and $\mathrm{C}_{3} \mathrm{~A}$ content was varied from 5 to $10 \%$.

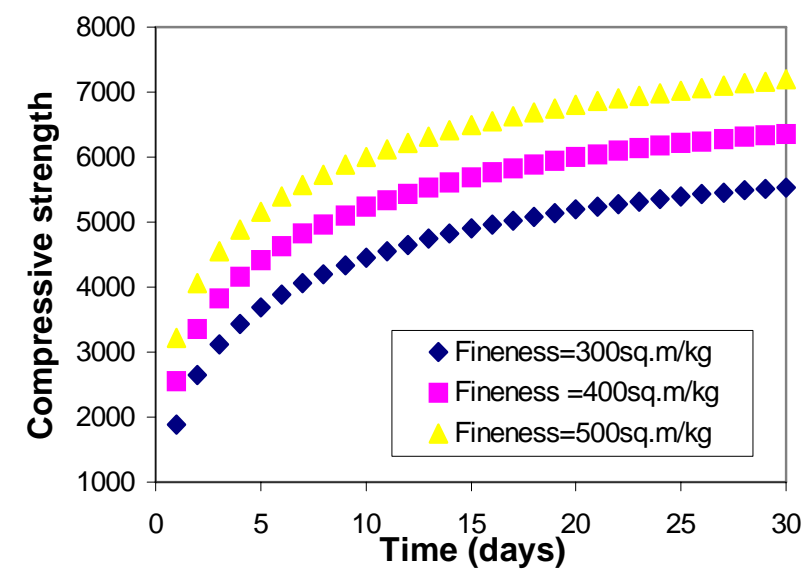

Figure 3.4: Strength change as a function of fineness 


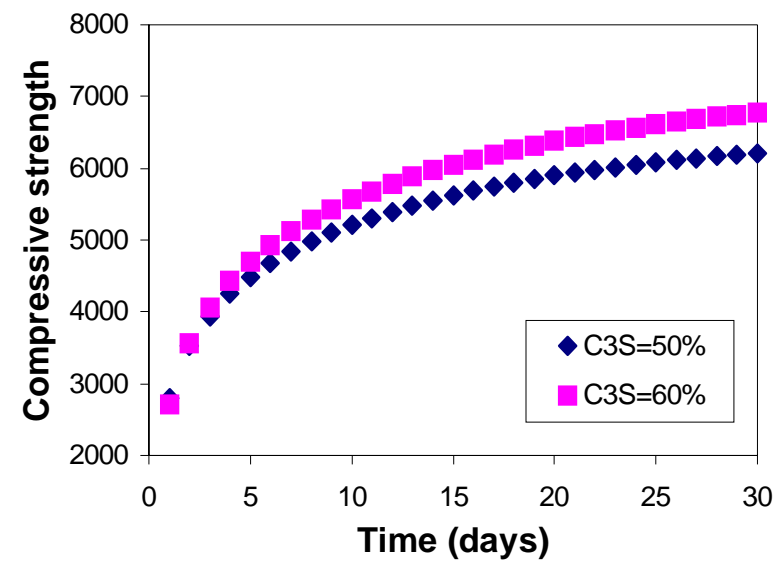

Figure 3.5: Strength change as a function of $\mathrm{C}_{3} \mathrm{~S}$

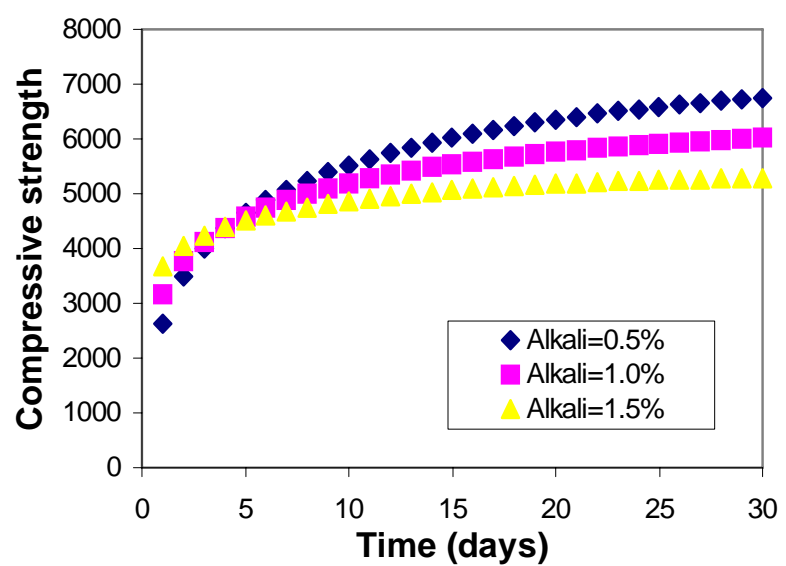

Figure 3.6: Strength change as a function of alkali 


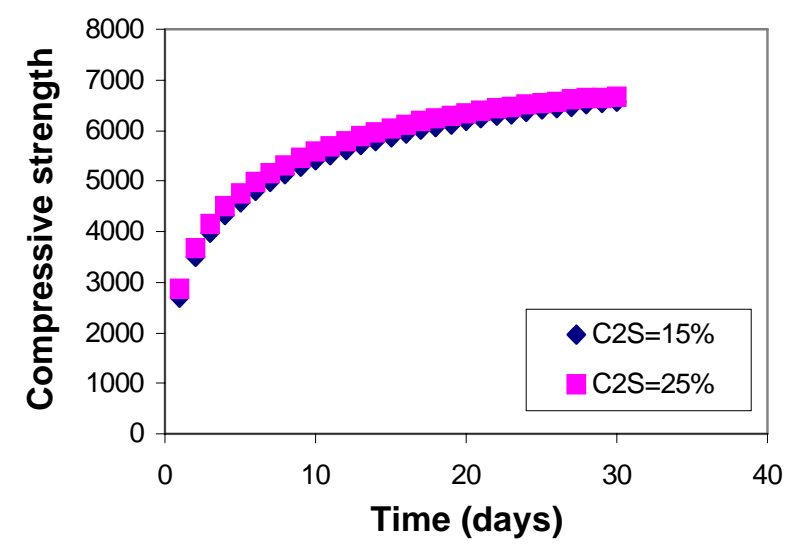

Figure 3.7: Strength change as a function of $\mathrm{C}_{2} \mathrm{~S}$

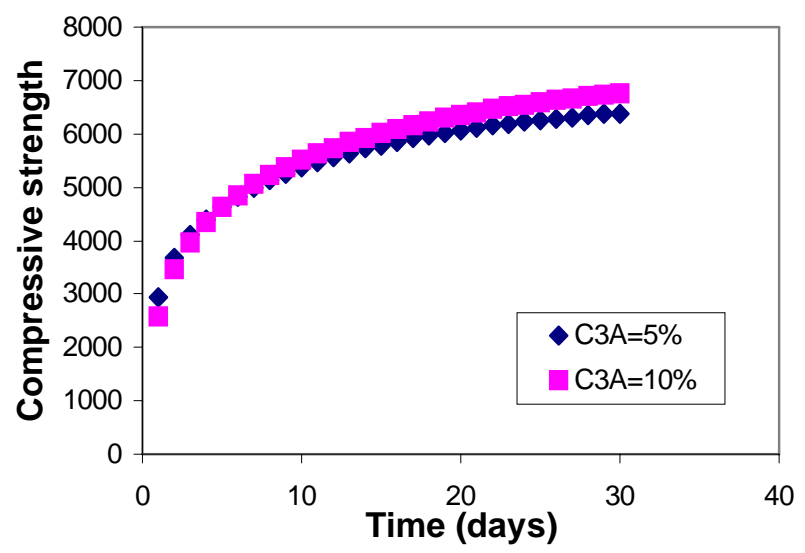

Figure 3.8: Strength change as a function of $\mathrm{C}_{3} \mathrm{~A}$

\subsubsection{Summary of Sensitivity Analysis for Cements}

From the plot for strength sensitivity to fineness (Figure 3.4), it is seen that fineness plays an important role in the strength development of concrete at all ages with a 
higher fineness value of the cement showing higher strengths at all ages. Higher $\mathrm{C}_{3} \mathrm{~S}$ content (Figure 3.5) seems to affect the strength more at later ages. An increase in the alkali content of cement increases the strength at early ages but reduces the strengths after ages of 7 days (Figure 3.6). Increase in the $\mathrm{C}_{2} \mathrm{~S}$ content (Figure 3.7) does not appear to have any affect on the strength development of concrete. Increase in $\mathrm{C}_{3} \mathrm{~A}$ content seems to increase the strength marginally at ages beyond 28 days (Figure 3.8).

\subsubsection{Sensitivity Analysis for Class C Fly Ash}

Similar to the sensitivity analysis done for cements, a similar approach was adopted for Class C fly ashes where the SAI sensitivity to variation of each parameter namely fineness, lime and alkali was determined. The average values for each of the above parameters were computed and the SAI sensitivity for each parameter was determined by varying the parameter under consideration while keeping the other parameters at their average values. Equation (3.12) was used for varying the values of various parameters under consideration and to observe the subsequent effect on the SAI values. Figure 3.9 shows the effect of varying the lime content of fly ash on the SAI when it is varied from 15 to 20 to $25 \%$. As observed from the plot, higher value of lime content results in higher SAI at all ages. In contrast, when the fineness (percent retained on $45 \mu \mathrm{m}$ sieve) of fly ash is increased from 10 to 17 to $25 \%$, the SAI of fly ash decreases at all ages (Figure 3.11). However, when the alkali content of fly ash is increased from 0.5 to 1 to $1.5 \%$, the SAI shows increased values at early ages, converging at an age of about 28 days (Figure 3.10). 


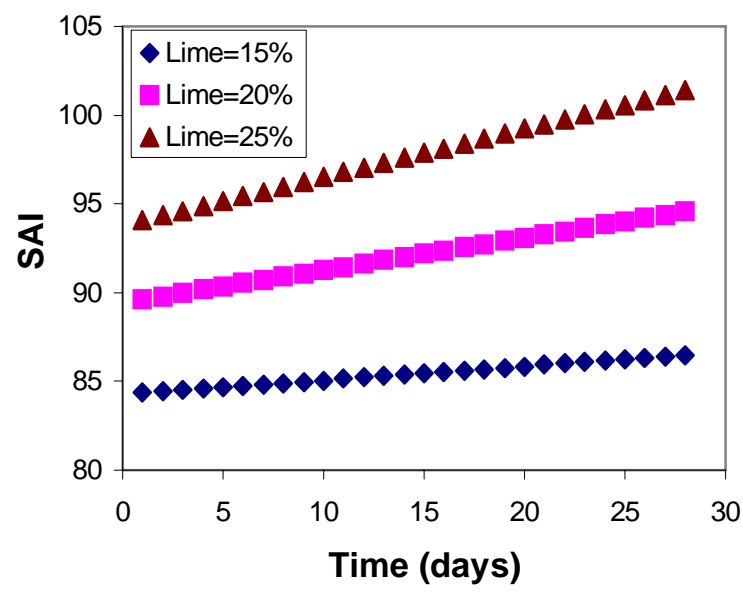

Figure 3.9: SAI sensitivity by varying lime content of fly ash

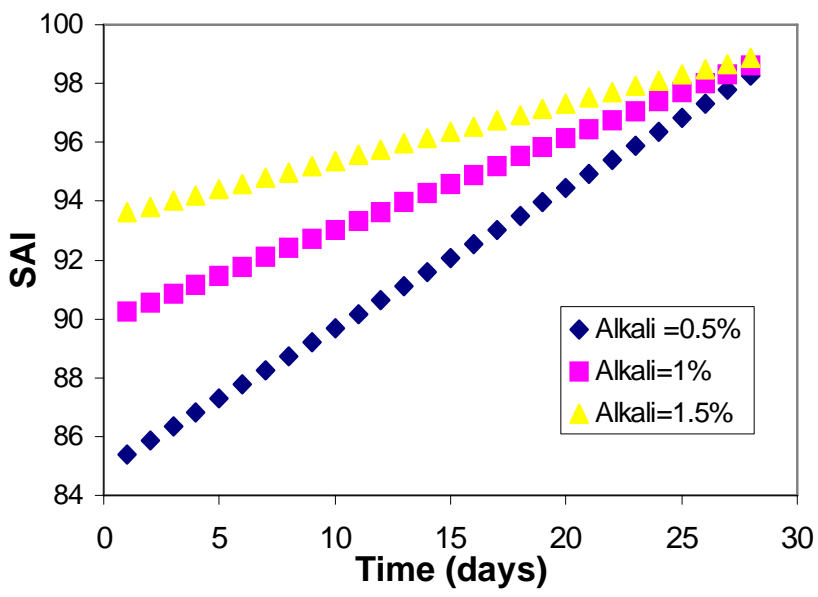

Figure 3.10: SAI sensitivity by varying alkali content of fly ash 


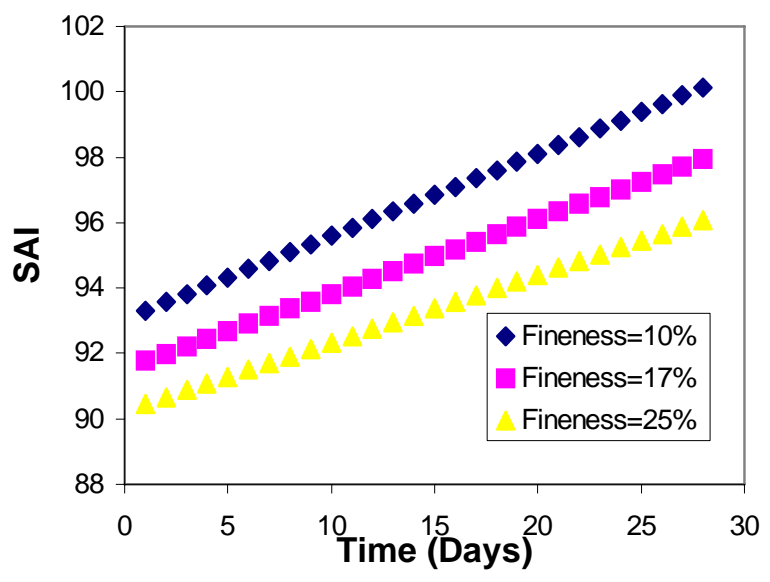

Figure 3.11: SAI sensitivity by varying fineness (\% retained on $45 \mu \mathrm{m}$ sieve) of fly ash

\subsubsection{Summary of Sensitivity Analysis for Class C Fly Ash}

From the above plots, it is observed that an increase in the lime content of fly ash from 15 to 20 to $25 \%$ increases the SAI of the fly ash, the increase being more significant at ages beyond 28 days (Figure 3.9). An increase in the fineness (\% retained on $45 \mu \mathrm{m}$ sieve) of the fly ash from 10 to 17 to $25 \%$ decreases the SAI of fly ash at all ages uniformly. The increase in the alkali content however, seems to have a different effect on the SAI of fly ash. When the alkali content of fly ash is increased from 0.5 to 1 to $1.5 \%$, the SAI shows significant increase at early ages; however, the difference in the values of SAI at the 3 alkali contents used for the analysis converges at an age of about 28 days.

\subsection{Identification of Cements for Further Study}

Since, a manageable number of cements was required for further tests, selection of cements was carried out using the information obtained from strength sensitivity 
analyses. Among all the type I cements, the average values of all sensitive parameters like $\mathrm{C}_{3} \mathrm{~S}, \mathrm{C}_{2} \mathrm{~S}, \mathrm{C}_{3} \mathrm{~A}$, fineness and alkali content were computed. Lonestar cement (C02) was observed to have all the values close to the average values computed. Since it was also the most commonly used laboratory cement at Purdue University, it was chosen as the baseline cement. Cements, which would contribute towards early age strength development, would require the presence of high amounts of alkali or higher fineness as observed from the sensitivity analysis for cements. Essroc cement (C10) had all values close the average except for the alkali content, which was a high value of $0.95 \%$. Therefore, this cement was selected. Lonestar, Type III cement was chosen as the cement with a very high fineness value of $552.10 \mathrm{~m}^{2} / \mathrm{kg}$ but all other chemical component values being close to the average. In order to look at the worst-case scenario towards strength development, Lehigh cement having a relatively low $\mathrm{C}_{3} \mathrm{~S}$ value was chosen. This cement had other values close to the average, but a high $\mathrm{C}_{2} \mathrm{~S}$ content of $25.85 \%$. Table 3.7 shows a detailed listing of all cements and the values of different strength sensitive parameters like $\mathrm{C}_{3} \mathrm{~S}, \mathrm{C}_{2} \mathrm{~S}, \mathrm{C}_{3} \mathrm{~A}$, fineness and alkali content.

The cements selected are shown in Table 3.7 by the symbol (*). Figures 3.12 through 3.14, respectively, show the comparison of selected cements C10, C16 and C23 with respect to the $\mathrm{C}_{3} \mathrm{~S}$, alkali and fineness contents of baseline cement (C02). 
Table 3.7: Selection of cements

\begin{tabular}{|c|c|c|c|c|c|c|c|c|c|c|c|}
\hline \multirow{2}{*}{ Company } & \multirow{2}{*}{ Cement ID } & \multirow{2}{*}{$\mathrm{C}_{3} \mathrm{~S}(\%)$} & \multirow{2}{*}{$\mathrm{C}_{2} \mathrm{~S}(\%)$} & \multirow{2}{*}{$\begin{array}{l}\text { Alkali } \\
\mathrm{Na}_{2} \mathrm{O} \\
\text { equiv. }\end{array}$} & \multirow{2}{*}{$\begin{array}{c}\text { Blaine } \\
\text { Fineness } \\
(\mathrm{m} 2 / \mathrm{kg})\end{array}$} & \multirow{2}{*}{$\mathrm{C}_{3} \mathrm{~A}(\%)$} & \multicolumn{4}{|c|}{ Compressive strength(psi) } & \multirow{2}{*}{ Comments } \\
\hline & & & & & & & 1 day & 3day & 7 day & 28 day & \\
\hline \multicolumn{12}{|l|}{ Type I } \\
\hline \begin{tabular}{|l|l} 
Blue circle \\
\end{tabular} & $\mathrm{C01}$ & 54.00 & 17.00 & 0.81 & 408.0 & 10.00 & & 3924 & 4793 & 5835 & \\
\hline Lonestar, IN $\left(^{*}\right)$ & $\mathrm{C02}$ & 60.01 & 13.54 & 0.54 & 360.8 & 8.22 & 2272 & 3439 & 4390 & 5790 & BASELINE \\
\hline $\begin{array}{l}\text { Lonestar, IL } \\
\end{array}$ & $\mathrm{C03}$ & 52.51 & 17.15 & 0.92 & 332.3 & 10.30 & 1794 & 3442 & 4328 & 5438 & \\
\hline Holnam, Ml & $\mathrm{C04}$ & 54.83 & 17.08 & 0.74 & 400.8 & 9.33 & & 3400 & 4472 & & \\
\hline Holnam, MO & C05 & 58.89 & 15.09 & 0.47 & 375.5 & 8.65 & & 3356 & 4832 & & \\
\hline Siam cement & $\mathrm{C06}$ & 63.79 & 23.32 & 0.43 & 355.5 & 8.77 & & 4009 & 5077 & 6529 & \\
\hline Southdown (Pitts) & $\mathrm{CO}$ & 51.00 & & 0.61 & 384.0 & 8.00 & 1995 & 3225 & 4365 & & \\
\hline Lonestar, MO & C08 & 51.72 & 21.47 & 0.49 & 366.0 & 6.47 & 1841 & 3135 & 4172 & 6060 & \\
\hline \begin{tabular}{|l} 
Essroc, Logansport \\
\end{tabular} & C09 & 62.45 & & 0.25 & 383.9 & 8.58 & 1521 & 3293 & 5421 & 6916 & \\
\hline Essroc, Essexville $\left(^{*}\right)$ & C10 & 56.58 & & 0.95 & 382.0 & 7.70 & 2681 & 3198 & 4646 & 5734 & High Alkali \\
\hline Lafarge, Paulding & C11 & 62.45 & & 0.45 & 358.5 & 7.91 & 1625 & 3235 & 4313 & 5864 & \\
\hline Southdown, Fairborn & C12 & 51.83 & & 0.58 & 395.1 & 6.14 & 2011 & 3454 & 4216 & 5346 & \\
\hline Southdown, Ml & C13 & 56.15 & 14.23 & 0.94 & 396.1 & 6.54 & & 3648 & 4375 & 5412 & \\
\hline Lafarge, Bath & C14 & 59.06 & & 0.65 & 373.1 & 6.59 & & 3912 & 4744 & 6044 & \\
\hline Lafarge, Alpena & C15 & 63.77 & & 0.54 & 363.8 & 8.00 & 2074 & 3900 & 4658 & 5950 & \\
\hline \multicolumn{12}{|l|}{ Type I/II } \\
\hline Lehigh portland $\left({ }^{*}\right)$ & C16 & 49.31 & 25.85 & 0.49 & 373.4 & 6.46 & 2414 & 3765 & 4688 & & Low $\mathrm{C}_{3} \mathrm{~S}$ \\
\hline Southdown (KY) & C17 & 51.63 & 22.59 & 0.65 & 386.4 & 6.33 & 2997 & 3957 & 5600 & & \\
\hline Heracles, Greece & C18 & 62.80 & 11.40 & 0.52 & 379.4 & 6.00 & & 3652 & 4328 & & \\
\hline Essroc, Speed & C19 & 56.09 & & 0.52 & 374.6 & 6.91 & 1853 & & 4119 & 6168 & \\
\hline Lafarge, Joppa & $\mathrm{C} 20$ & 60.00 & & 0.46 & 380.2 & 7.33 & 2017 & 3728 & 4843 & 6103 & \\
\hline \multirow[t]{2}{*}{ River Cement, MO } & C21 & 58.26 & 15.44 & 0.54 & 360.7 & 6.53 & 2087 & 3476 & 4685 & 6243 & \\
\hline & AVG Type I\& I/II & 57.01 & 17.85 & 0.59 & 375.7 & 7.66 & 2084 & 3557 & 4622 & 5962 & \\
\hline \multicolumn{12}{|l|}{ Type III } \\
\hline \begin{tabular}{|l} 
Lehigh portland \\
\end{tabular} & $\mathrm{C} 22$ & 53.15 & 25.15 & 0.49 & 610.2 & 4.94 & 4365 & 5768 & 6979 & & \\
\hline Lonestar, IN $\left(^{*}\right)$ & $\mathrm{C23}$ & 59.00 & 11.75 & 0.61 & 552.1 & 9.00 & 4138 & 5199 & 6030 & & High Fineness \\
\hline Lonestar, IL & C24 & 52.99 & $\frac{1.10}{16.59}$ & 0.91 & 562.1 & 10.40 & 4348 & 5395 & 6108 & & \\
\hline Holnam, Ml & $\mathrm{C} 25$ & 53.81 & 16.94 & 0.72 & 525.3 & 9.15 & 2620 & 4470 & 5203 & & \\
\hline Essroc, Logansport & $\mathrm{C} 26$ & 61.00 & & 0.31 & 622.0 & 8.30 & 2854 & 5212 & 6679 & & \\
\hline Essroc, Speed & $\mathrm{C} 27$ & 54.63 & & 0.51 & 593.1 & 6.74 & 3170 & 4700 & 5799 & & \\
\hline Southdown, MI & $\mathrm{C28}$ & 57.33 & 14.00 & 0.96 & 633.3 & 6.67 & 4550 & 5207 & 5993 & & \\
\hline
\end{tabular}




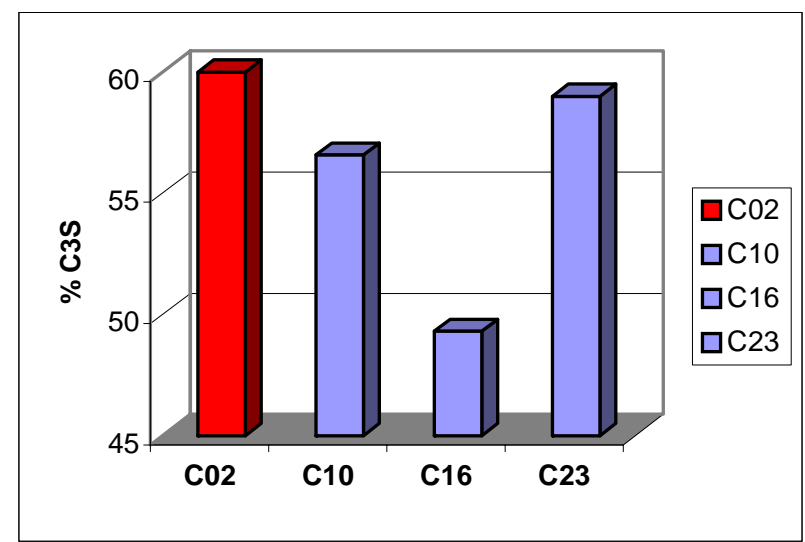

Figure 3.12: $\mathrm{C}_{3} \mathrm{~S}$ content comparison for screened cements

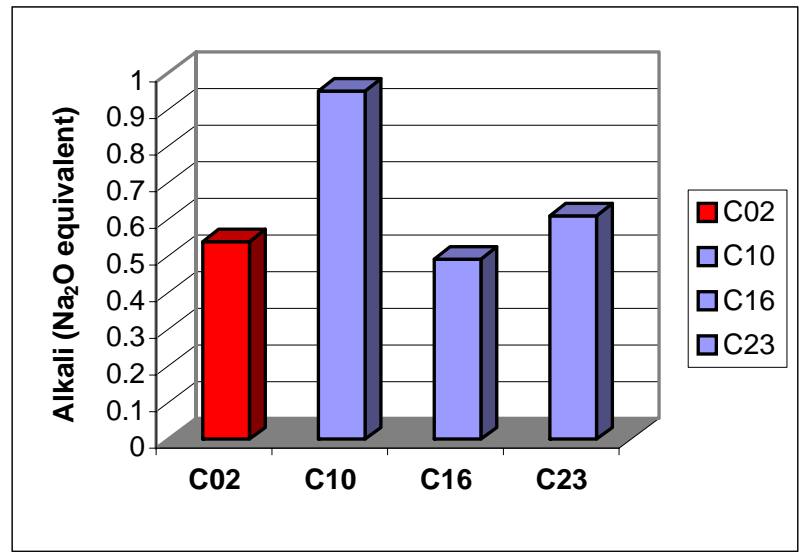

Figure 3.13: Alkali content comparison for screened cements 


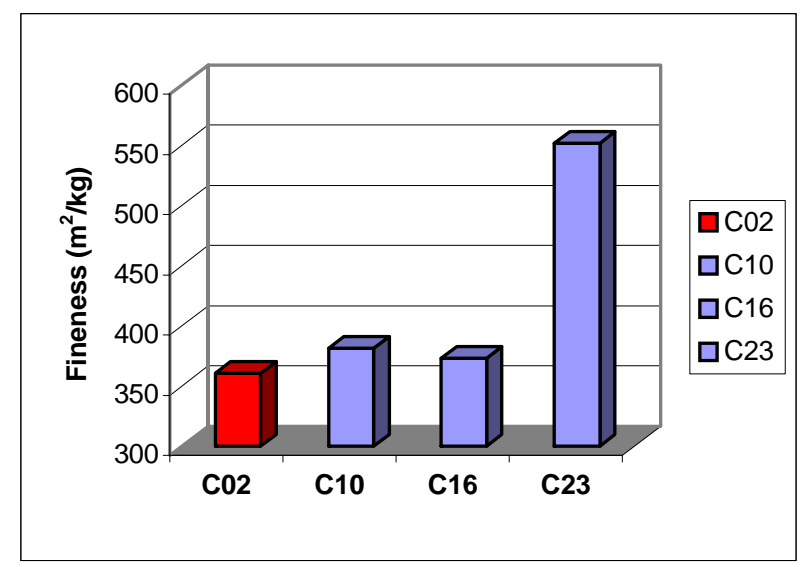

Figure 3.14: Fineness comparison for screened cements

\subsection{Selection of Class C Fly Ashes}

A compilation showing the average values of parameters like lime, fineness, alkali and carbon content along with the SAI values at 7 and 28 days for all the Class $\mathrm{C}$ fly ashes is shown in the Table 3.8 below. It is a known fact that the addition of fly ash contributes towards the later age strength development because of the pozzolanic reaction, which is responsible for the formation of additional C-S-H gel at later ages. 
Table 3.8: Selection of Class $\mathrm{C}$ fly ashes

\begin{tabular}{|c|c|c|c|c|c|c|c|}
\hline Station & $\begin{array}{c}\text { Fly ash } \\
\text { ID }\end{array}$ & CaO (\%) & Alkali (\%) & $\begin{array}{c}\text { Fineness (\% } \\
\text { retained 45 } \boldsymbol{\mu m} \\
\text { sieve) }\end{array}$ & $\begin{array}{c}\text { Carbon } \\
\text { (\%) }\end{array}$ & SAI7 & SAI28 \\
\hline Rockport (*) & FA05 & 18.57 & 0.70 & 21.88 & 0.68 & 85.50 & \\
\hline Clifty Creek (*) & FA03 & 18.78 & 1.09 & 13.78 & 2.19 & 96.98 & 102.15 \\
\hline Mitchell & FA01 & 24.22 & 1.19 & 10.67 & 0.46 & 94.83 & 99.43 \\
\hline Joliet & FA04 & 24.49 & 1.85 & 13.19 & 0.25 & 96.28 & \\
\hline St.Louis & FA08 & 24.96 & 1.40 & 13.78 & 0.34 & 88.79 & 99.15 \\
\hline Schahfer & FA02 & 25.22 & 1.20 & 10.76 & 0.26 & 94.02 & 99.89 \\
\hline Joppa & FA07 & 25.29 & 1.40 & 17.15 & 0.36 & 93.34 & 98.45 \\
\hline Chouteau,U1 & FA09 & 25.74 & 1.28 & 14.18 & 0.16 & 91.97 & \\
\hline Will County (*) & FA06 & 25.80 & 1.65 & 11.52 & 0.35 & 96.85 & \\
\hline & AVG (\#) & $\mathbf{2 5 . 1 0}$ & $\mathbf{1 . 4 2}$ & $\mathbf{1 3 . 0 3}$ & $\mathbf{0 . 3 1}$ & $\mathbf{9 3 . 7 3}$ & $\mathbf{9 9 . 2 3}$ \\
\hline
\end{tabular}

(\#) - Average of fly ashes excluding FA03 and FA05

$\left({ }^{*}\right)$ - Denotes selected fly ashes

Also, higher amount of lime results in a higher calcium to silica ratio as a result of which the fly ash becomes more self-cementing. Hence, the amount of lime was used an important parameter in the screening of Class C fly ashes. Also, from the plots for sensitivity analysis of fly ashes, it was observed that higher alkali content leads to higher SAI values at early ages. However, the presence of large amounts of carbon reduces the effectiveness air-entraining admixture in concrete mixtures. The Class $C$ fly ashes shown in the Table 3.8 could be distinctly classified in two groups with one group consisting of FA03 and FA05, which have relatively low lime contents of about 18\%. The other group of fly ashes has lime content in the range of about $25 \%$. The average values shown in the Table 3.8 were calculated for fly ashes from the high lime (above 25\%) category. A plot showing the variation in lime contents for all the Class C fly ashes is shown in Figure 3.15. 


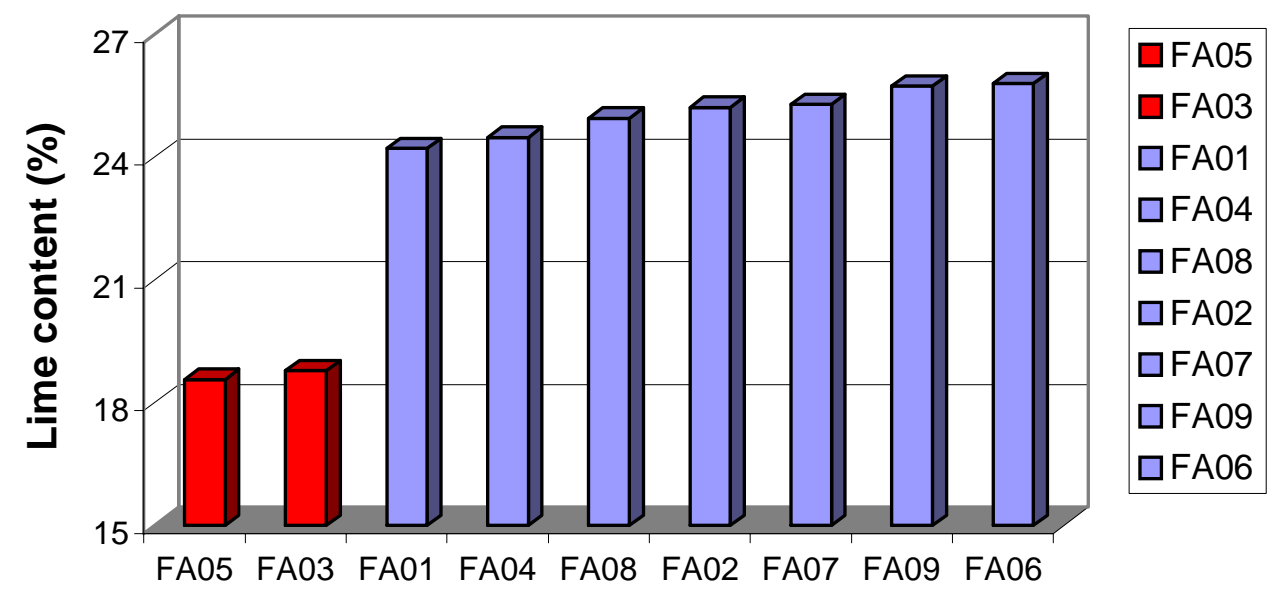

Fly Ash ID

Figure 3.15: Lime content comparison for Class C fly ashes

From the sensitivity analysis plots, it was observed that increasing the lime content from 15 to $25 \%$ increases the SAI by $12.81 \%$ at 7 days and $17.23 \% 28$ days. Hence higher lime content is important for early and late SAI. Increasing the alkali content from 0.5 to $1.5 \%$ increases the SAI by $7.4 \%$ at 7 days and $0.61 \%$ at 28 days. Hence higher alkali content is important for early SAI. Fineness was observed to be relatively unimportant for SAI. Both the fly ashes, FA03 and FA05, which represents low lime contents, were chosen for further tests to be done with mortars. Another feature of the fly ash FA03 was its high carbon content, which has a potential to reduce the effectiveness of the air-entraining admixtures. The above two fly ashes were chosen so as to represent the worst-case scenario, as low lime contents would not be beneficial towards later age strength development. The third Class C fly ash that was chosen was 
FA08 as it displayed values of fineness, lime, alkali and carbon similar to the average of all the fly ashes in the $25 \%$ lime content category.

\subsection{Selection of Class F Fly Ashes}

Table 3.9 shows a summary of lime, alkali, fineness, carbon contents and SAI values at 7 and 28 days for all Class F fly ashes considered in this project.

Table 3.9: Selection of Class F fly ashes

\begin{tabular}{|c|c|c|c|c|c|c|c|}
\hline Station & $\begin{array}{l}\text { Fly ash } \\
\text { ID }\end{array}$ & $\mathrm{CaO}(\%)$ & Alkali (\%) & \begin{tabular}{|l} 
Fineness (\% \\
retained 45 \\
um sieve)
\end{tabular} & $\begin{array}{l}\text { Carbon } \\
(\%)\end{array}$ & SAI7 & SAI28 \\
\hline Miami Fort $\left(^{\star}\right)$ & FA10 & 2.08 & 0.68 & 26.34 & 2.38 & 80.21 & 85.83 \\
\hline Petersburg & FA11 & 2.57 & 0.48 & 24.96 & 1.67 & 79.64 & 84.07 \\
\hline Owensbury & FA12 & 5.46 & 0.93 & 14.48 & 1.63 & & 87.78 \\
\hline Coronado & FA13 & 3.85 & 0.90 & 22.30 & 0.44 & 87.10 & 91.90 \\
\hline
\end{tabular}

$(*)$ - Denotes selected fly ash

Evaluation of data in Table 3.9 reveals that fly ash FA10 has the lowest lime content and relatively low SAI index at both 7 and 28 days, which is detrimental for both early and later age strength development. In addition, it also has the highest carbon content, which would reduce the effectiveness of the air-entraining admixtures. The selection of this fly ash thus represented a worst-case scenario with respect to strength development and durability. 


\subsection{Selection of Slags}

Since only one source of slag was listed in the INDOT approved list, it was decided to use this slag from Holnam Inc., for the preliminary screening tests on mortars. Some properties of this slag (Grade 100) are shown in Table 3.10.

Table 3.10: Properties of slag

\begin{tabular}{|c|c|c|c|}
\hline $\begin{array}{c}\text { Fineness } \\
\left(\mathrm{m}^{2} / \mathrm{kg}\right)\end{array}$ & $\begin{array}{c}\text { Alkali as } \\
\mathrm{Na}_{2} \mathrm{O}(\%)\end{array}$ & $\begin{array}{c}\text { SAl } \\
(7 \text { day })\end{array}$ & $\begin{array}{c}\text { SAI } \\
(28 \text { day })\end{array}$ \\
\hline 530.5 & 0.785 & 85.2 & 119.6 \\
\hline
\end{tabular}

\subsection{Summary of Materials Selected}

Table 3.11 shows a summary of all cements and supplementary cementitious materials selected for preliminary testing on mortars.

Table 3.11: Summary of materials selected

\begin{tabular}{|c|c|c|c|c|c|c|}
\hline \multirow{2}{*}{ No. } & \multicolumn{2}{|l|}{ Cement } & \multicolumn{2}{|l|}{ Fly ash } & \multicolumn{2}{|l|}{ Slag } \\
\hline & Name/Type & Location & Name/Type & Name/Type & Location & Name/Type \\
\hline 1. & $\begin{array}{l}\text { Lonestar } \\
\text { (Type I) }\end{array}$ & $\begin{array}{l}\text { Greencastle, } \\
\text { IN }\end{array}$ & $\begin{array}{l}\text { Mineral } \\
\text { Solutions } \\
\text { (Class C) }\end{array}$ & $\begin{array}{l}\text { Rockport, IN } \\
\text { (Rockport } \\
\text { Station) }\end{array}$ & $\begin{array}{l}\text { Holnam } \\
\text { Inc. }\end{array}$ & Chicago \\
\hline 2. & $\begin{array}{l}\text { Lonestar } \\
\text { (Type III) }\end{array}$ & $\begin{array}{l}\text { Greencastle, } \\
\text { IN }\end{array}$ & $\begin{array}{l}\text { Mineral } \\
\text { Solutions } \\
\text { (Class C) }\end{array}$ & $\begin{array}{l}\text { Romeoville, } \\
\text { IL (Will } \\
\text { County } \\
\text { Station) }\end{array}$ & & \\
\hline 3. & $\begin{array}{l}\text { Lehigh } \\
\text { (Type I/II) }\end{array}$ & Mitchell, IN & $\begin{array}{l}\text { ISG } \\
\text { Resources } \\
\text { Inc., (Class C) }\end{array}$ & $\begin{array}{l}\text { Madison, IN } \\
\text { (Clifty Creek } \\
\text { Station) } \\
\end{array}$ & & \\
\hline 4. & $\begin{array}{l}\text { Essroc } \\
\text { (Type I) }\end{array}$ & $\begin{array}{l}\text { Essexville, } \\
\text { MI }\end{array}$ & $\begin{array}{l}\text { ISG } \\
\text { Resources } \\
\text { Inc., (Class F) }\end{array}$ & $\begin{array}{l}\text { Northbend, } \\
\text { OH (Miami } \\
\text { Fort Station) }\end{array}$ & & \\
\hline
\end{tabular}




\title{
CHAPTER 4: DEVELOPMENT OF PROCEDURES FOR IDENTIFYING MATERIAL COMBINATIONS THAT MAY EXHIBIT LOW RATE OF STRENGTH GAIN
}

\begin{abstract}
4.1. Introduction
The objective of this chapter is to identify combinations of cement, fly ash and slag, which have the potential for slow strength gain. This is especially critical for the low temperature conditions that may be encountered during the late fall construction season in Indiana. A screening program was implemented to identify mixtures that exhibit slow strength gain. This program consisted of compressive strength tests on mortar cubes, maturity testing of mortar specimens at different ages, and non-evaporable water content determination of companion pastes. Strength-maturity relationships were developed for twenty-four mixture combinations, enabling the strength to be predicted at any age under any temperature history. This allows for identification of potentially slow strength developing material combinations for further tests in concrete. Non-evaporable water content tests on pastes helped in verifying the trends observed from actual test results as well as results obtained from mathematical, maturity based models.

This chapter provides background information on the maturity method, equivalent age, and the concept of relative strength gain. The analysis performed in this chapter is used to define three properties, rate of reaction $\left(k_{t}\right)$, activation energy $\left(E_{a}\right)$, and the ultimate strength $\left(S_{u}\right)$. These material properties were used to formulate mathematical
\end{abstract}


models that predict strength development with time, thereby providing a technique that can identify mixtures with the potential for slow strength gain.

\subsection{Experimental Procedures}

\subsubsection{Preparation of Mortar Test Specimens}

Sixty 50-mm thick (2 in.) mortar cube specimens were prepared for the binders listed in Table 4.1. Each of these binder systems had a composition comparable to that encountered in a "typical” pavement concrete mixture used in Indiana (see Appendix A). Each of the binder systems was designed to represent the mortar portion of concrete. The water to cementitious ratio $(\mathrm{w} / \mathrm{cm})$ of the mixtures was 0.41 and the total aggregate content in the mixture (by volume) was $67 \%$. In the fly ash mixtures, $20 \%$ of the cement was replaced with an equivalent weight of fly ash while replacement level for the slag mixtures was maintained at 25\%. Thermocouples for determining maturity in mortar specimens were formed by combining copper and constantan wires. The thermocouple was inserted in the center of the mortar cube (i.e., to a depth of $25 \mathrm{~mm}$ (1 inch)). The mortar mixing procedure adopted in this investigation is given below:

1. All solid materials (cement, fly ash or slag and sand) were weighed to the nearest $0.1 \mathrm{~g}$ and were placed in the bowl of a Hobart mixer with a nominal capacity of $0.00595 \mathrm{~m}^{3}\left(0.21 \mathrm{ft}^{3}\right)$. The materials were mixed for 1 minute at slow speed (140 $\pm 5 \mathrm{r} / \mathrm{min}$ ) after which the mixing was stopped.

2. The required amounts of water, water reducer, and air-entraining agent were measured. 
3. Approximately $3 / 4^{\text {th }}$ of the mix water and all of the chemical admixtures were added to the materials already in the mixer. All these materials were mixed for 30 seconds at slow speed. During this process, the remaining mix water was added to the mixer.

4. The mixing was stopped and the mixture was allowed to rest for 1 minute. During the first 15 seconds of this rest period, a spatula was used to scrape the sides and bottom of the bowl and the bell-shaped paddle of the Hobart mixer.

5. Mixing was continued at slow speed for another 30 seconds and then mixing was stopped.

6. The mixing process was completed after mixing for 30 seconds at medium speed $(285 \pm 10 \mathrm{r} / \mathrm{min})$.

7. The mortar was placed into the molds in two layers, table vibrated and finished with a steel trowel.

\subsubsection{Curing and Test Procedures for Maturity and Compressive Strength Tests}

The 60 mortar specimens were divided into three batches of 20, immediately after the specimens were finished. Twenty specimens each were cured at different temperatures of 23,10 and $1^{\circ} \mathrm{C}\left(73.4,50\right.$ and $33.8^{\circ} \mathrm{F}$, respectively). The above also included two mortar cubes at each temperature for the purpose of determining maturity. The mortar cubes were removed from the forms at an age of $24 \pm 2$ hours and transferred to sealed plastic containers. Three mortar cubes were tested from each of the three curing temperatures for their compressive strength at ages of 12 hours, 1, 3, 7, 28 and 90 days in accordance with the procedure specified in ASTM C 109. 
Table 4.1: List of binder combinations

\begin{tabular}{|c|c|l|}
\hline Mix No. & Mix ID & \multicolumn{1}{c|}{ Binder Combination } \\
\hline 1 & M01 & Lonestar cement + Rockport fly ash \\
\hline 2 & M02 & Lonestar cement + Clifty Creek fly ash \\
\hline 3 & M03 & Lonestar cement + Miami Fort fly ash \\
\hline 4 & M04 & Lonestar cement + Will County fly ash \\
\hline 5 & M05 & Lehigh cement + Rockport fly ash \\
\hline 6 & M06 & Lehigh cement + Clifty Creek fly ash \\
\hline 7 & M07 & Lehigh cement + Miami Fort fly ash \\
\hline 8 & M08 & Lehigh cement + Will County fly ash \\
\hline 9 & M09 & Essroc cement + Rockport fly ash \\
\hline 10 & M10 & Essroc cement + Clifty Creek fly ash \\
\hline 11 & M11 & Essroc cement + Miami Fort fly ash \\
\hline 12 & M12 & Essroc cement + Will County \\
\hline 13 & M17 & Lonestar III cement + Rockport fly ash \\
\hline 14 & M18 & Lonestar III cement + Clifty Creek fly ash \\
\hline 15 & M19 & Lonestar III cement + Miami Fort fly ash \\
\hline 16 & M20 & Lonestar III cement + Will County fly ash \\
\hline 17 & M13 & Lonestar cement (Control mix) \\
\hline 18 & M14 & Lehigh cement (Control mix) \\
\hline 19 & M15 & Essroc cement (Control mix) \\
\hline 20 & M16 & Lonestar III cement (Control mix) \\
\hline 21 & M21 & Lonestar cement + Holnam Slag \\
\hline 22 & M22 & Lehigh cement + Holnam Slag \\
\hline 23 & M23 & Essroc cement + Holnam Slag \\
\hline 24 & M24 & Lonestar III cement + Holnam Slag \\
\hline
\end{tabular}

The temperature history of each mortar mixture was determined using the average of two cubes. The temperature data was collected using a data logger that collected data at 30-second intervals and recorded the average temperatures at 10-minute intervals. The device for determination of temperature history of mortar specimens is shown in Figure 4.1. Typical time versus temperature plots are shown in Figure 4.2 for plain and accelerator containing mortar mixtures cured at $23^{\circ} \mathrm{C}\left(73.4^{\circ} \mathrm{F}\right)$. These plots show an increase in temperature with time during the first eleven hours, which can be attributed to the heat of hydration. After this period, the temperature stabilizes at a level close to the curing temperature. The figure also shows the influence of an accelerating admixture on 
the temperature development. It could be observed that the mixture with accelerator developed a higher peak temperature $\left(27.5^{\circ} \mathrm{C}\right.$ or $\left.81.5^{\circ} \mathrm{F}\right)$ than the mixture without accelerator $\left(25.5^{\circ} \mathrm{C}\right.$ or $\left.77.9^{\circ} \mathrm{F}\right)$.

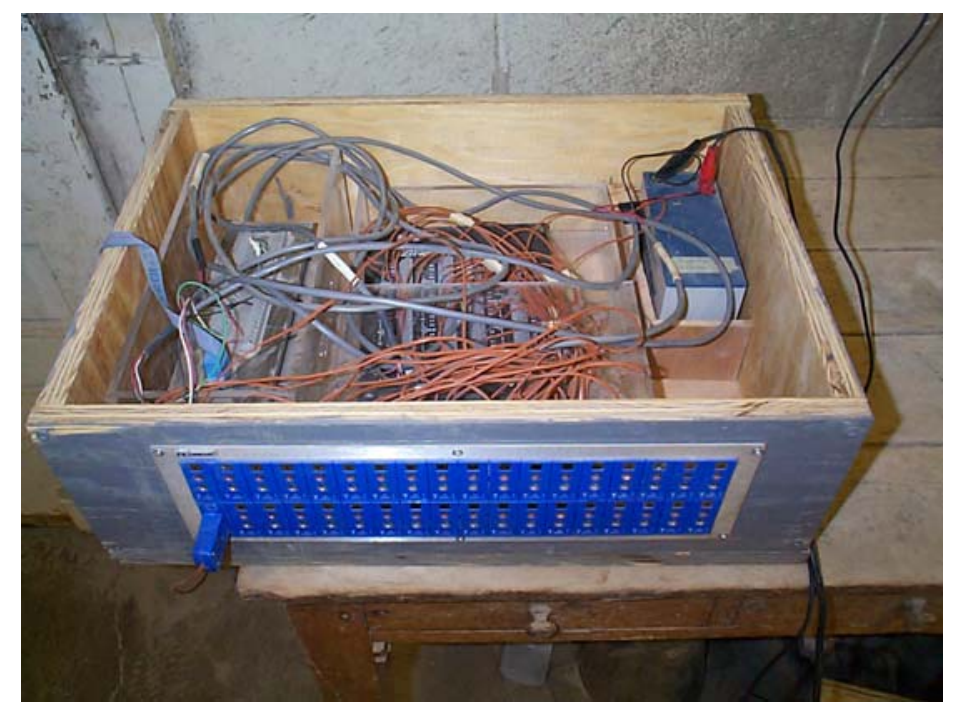

Figure 4.1: Data logger for temperature determination

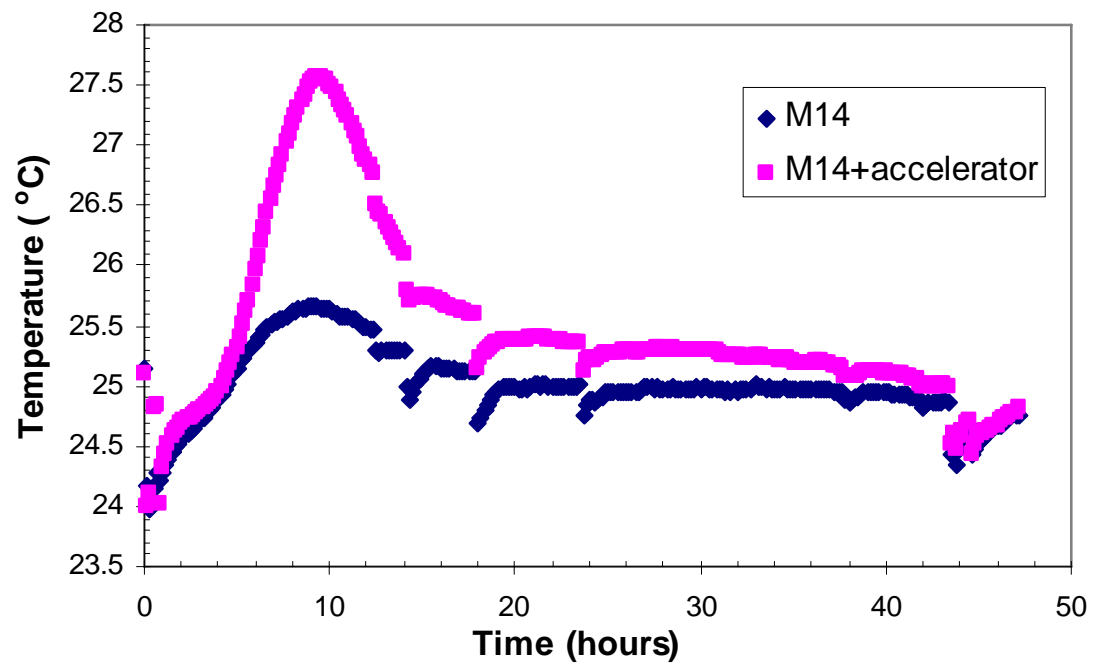

Figure 4.2: Typical time-temperature plot for mortars cured at $23^{\circ} \mathrm{C}$ 
Tests were conducted using a universal testing machine to determine compressive strength at ages of 12 hours, 1, 3, 7, 28 and 90 days. The loading rate for this test was maintained at $300 \mathrm{lb} / \mathrm{s}$. The average of three failure loads was used in computing the compressive strength at any age. The strength values for all mortar mixtures are reported in Appendix B.

\subsubsection{Preparation of Paste Specimens}

Twenty-four binder systems (Table 4.1) were used to prepare pastes with water to cementitious ratio $(\mathrm{w} / \mathrm{cm})$ of 0.41 . Paste specimens were prepared excluding the aggregates, using similar proportions adopted in making mortars. Again the replacement level of cement for mixtures containing fly ash and slag were $20 \%$ and $25 \%$, respectively. The procedure given below was adopted for preparing the paste mixtures:

1. The solid materials (cement, fly ash, or slag) were initially dry mixed for 30 seconds at slow speed (140 $\pm 5 \mathrm{r} / \mathrm{min})$ using a Hobart mixer with a nominal capacity of $0.0014 \mathrm{~m}^{3}\left(0.05 \mathrm{ft}^{3}\right)$, so as to homogenize the mixture. The mixing was stopped.

2. Measured quantities of air-entraining admixture and water reducer were then added to this homogenized mixture containing cementitious materials.

3. Approximately $3 / 4^{\text {th }}$ of the measured amount of water was added to the mixture and mixing was conducted at slow speed for 30 seconds. During this period, the remaining water was slowly added to the mixer.

4. Mixing was stopped for 1-minute interval. During this rest period, a spatula was used to scrape the paddle as well as the sides and bottom of the mixing bowl. 
5. Mixing was continued for 30 seconds at slow speed and then stopped.

6. The mixing operation was finished after mixing at medium speed (285 \pm 10 $\mathrm{r} / \mathrm{min}$ ) for a period of 30 seconds.

7. The paste mixture was placed in the molds in a single layer and table vibrated.

\subsection{Maturity Method}

\subsubsection{Introduction}

As discussed in section 2.4, the maturity method provides a tool for predicting the in-place strength of concrete. The maturity method had been used for predicting the strength gain of concrete for rapid pavement repairs (Okamoto and Whiting, 1994). Since the maturity method is useful for scheduling various construction activities, the cost of any construction project can be optimized.

Strength maturity relationships were developed for the twenty-four mortar mixtures tested for this project. Three maturity parameters were determined from experiments: the ultimate strength $\left(S_{u}\right)$, the rate of reaction $\left(k_{r}\right)$, and the energy of activation $\left(E_{a}\right)$. Determination of these parameters is discussed in Sections 4.3.4, 4.3.5 and 4.3.6. Mathematical models were developed for the prediction of $S_{u}$ and $k_{r}$. The models were developed so as to account for the composition and fineness of cement and supplementary materials. Subsequently, these models were used in the relative strength gain expression for the purposes of strength prediction of various mortar mixtures at any given age subjected to any temperature history. Strength development plots are developed for all the mortar mixture combination at several curing temperatures to indicate the potential for slow strength gain. 


\subsubsection{Equivalent Age Concept}

There have been reports by many researchers regarding difficulties in the prediction of strength using maturity concepts for concrete cured at different temperatures (Carino, 1991). Early work by Nurse-Saul showed problems especially at low maturity values. To overcome these problems, it was suggested that the Arrhenius function be used to account for the effects of initial curing temperature on the early rate

of hydration of cement. Freiesleben et al. (Carino, 1991) suggested an expression for equivalent age (equation 4.1) based on the Arrhenius expression:

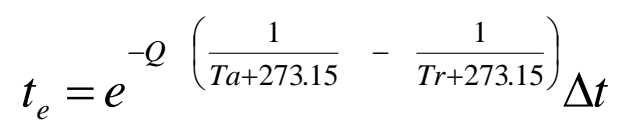

where $t_{e}=$ equivalent age

$\Delta t=$ time interval

$T_{a}=$ absolute temperature, ${ }^{\circ} \mathrm{C}$

$T_{r}=$ reference temperature, ${ }^{\circ} \mathrm{C}$

$\mathrm{Q}=$ activation energy / universal gas constant $\left(E_{a} / R\right)$ where $R=8.314 \mathrm{~J} /(\mathrm{mol} \mathrm{K})$

The reference temperature for experiments performed for this project was $23^{\circ} \mathrm{C}$

$\left(73^{\circ} \mathrm{F}\right)$. Equation 4.1 accurately accounts for the variations in temperature on strength development in mortars at the temperatures under consideration. 


\subsubsection{Hyperbolic Strength Maturity Relationship}

Although a particular mixture combination would be expected to have a unique strength-maturity relationship, it has been reported that a unique relationship does not exist for mixtures cured at different temperatures (Carino, 1991). This is verified by Figure 4.3, which shows the results of mortar tests performed using binder M12. This problem is overcome by using a relative strength gain expression suggested by Carino (Carino, 1991). When the relative strength gain (given by equation 4.2) is plotted as a function of equivalent age, the data points for mortar specimens (prepared using binder M12) cured at different temperatures fall on a single curve (Figure 4.4).

$$
\frac{S}{S_{u}}=\frac{k_{t}\left(t-t_{o}\right)}{1+k_{t}\left(t-t_{o}\right)}
$$

where $S=$ the strength at any given age,

$$
\begin{aligned}
& S_{u}=\text { the ultimate strength, } \\
& k_{t}=\text { rate constant at a given temperature } \\
& t_{o}=\text { offset time or the time at which strength gain is assumed to begin } \\
& t=\text { specimen age }
\end{aligned}
$$

The relative strength gain function can be related to the equivalent age by introducing an age conversion factor $\alpha=\frac{k_{t}}{k_{r}}$ where $k_{r}$ is the rate of reaction, which is the initial slope of the curve shown in Figure 4.4. 


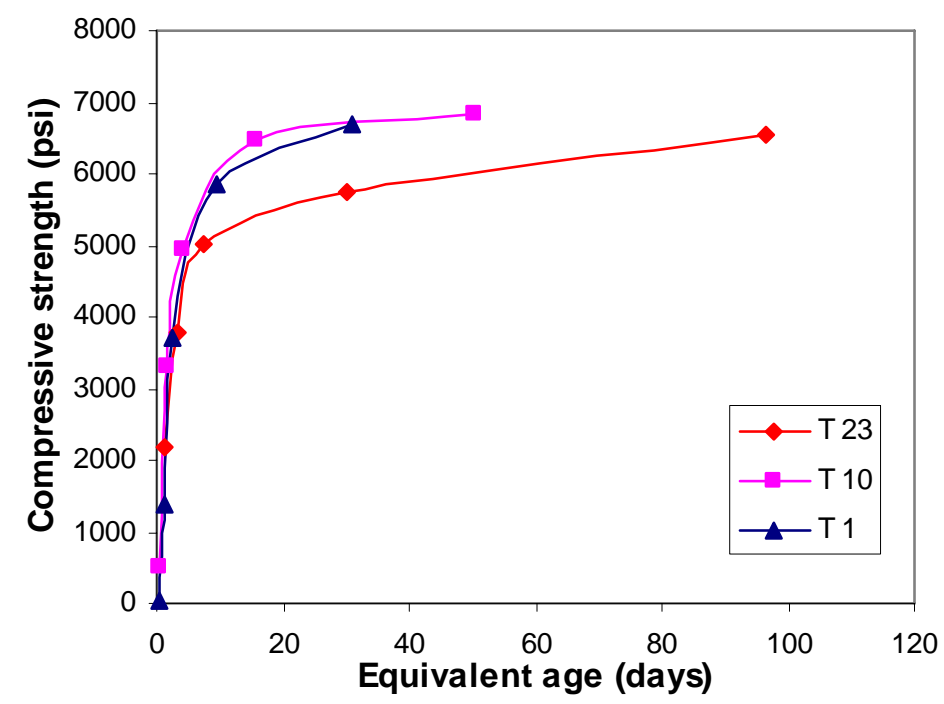

Figure 4.3: Strength versus equivalent age plot at different temperatures for mixture M12

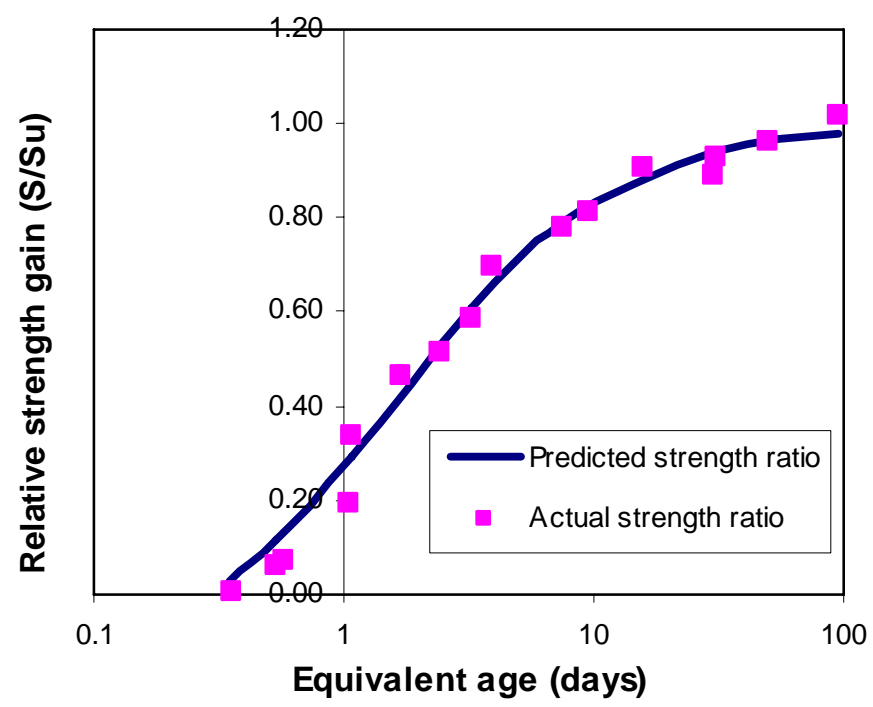

Figure 4.4: Relative strength gain versus equivalent age plot for mixture M12 (@ 23ㄷ) 
Substituting the age conversion factor $\alpha$ in equation 4.2, the relative strength gain function can be expressed in terms of equivalent age as shown in equation 4.3.

$$
\frac{S}{S_{u}}=\frac{k_{r} \alpha\left(t-t_{o}\right)}{1+k_{r} \alpha\left(t-t_{o}\right)}
$$

Also, the product $\alpha t=t_{e}$ (equivalent age), and $\alpha t_{o}=t_{1}$ (constant) hence equation 4.3 can be written as

$$
\frac{S}{S_{\infty}}=\frac{k_{r}\left(t_{e}-t_{1}\right)}{1+k_{r}\left(t_{e}-t_{1}\right)}
$$

\subsubsection{Determination of Ultimate Strength}

Ultimate strength $\left(S_{u}\right)$ is one of the important maturity parameters. Ultimate strength was determined using the last 3 testing ages (7, 28, 90 days). Ultimate strength was determined by plotting the inverse of strength versus the inverse of age for all mixtures. Figure 4.5 shows determination of ultimate strength for mixture M21. The inverse of the intercept of the plot at each temperature gives the ultimate strength for that temperature. It was observed for some of the mortar mixtures that lower curing temperatures result in higher ultimate strength values. This has also been reported in the literature (Carino, 1991). 


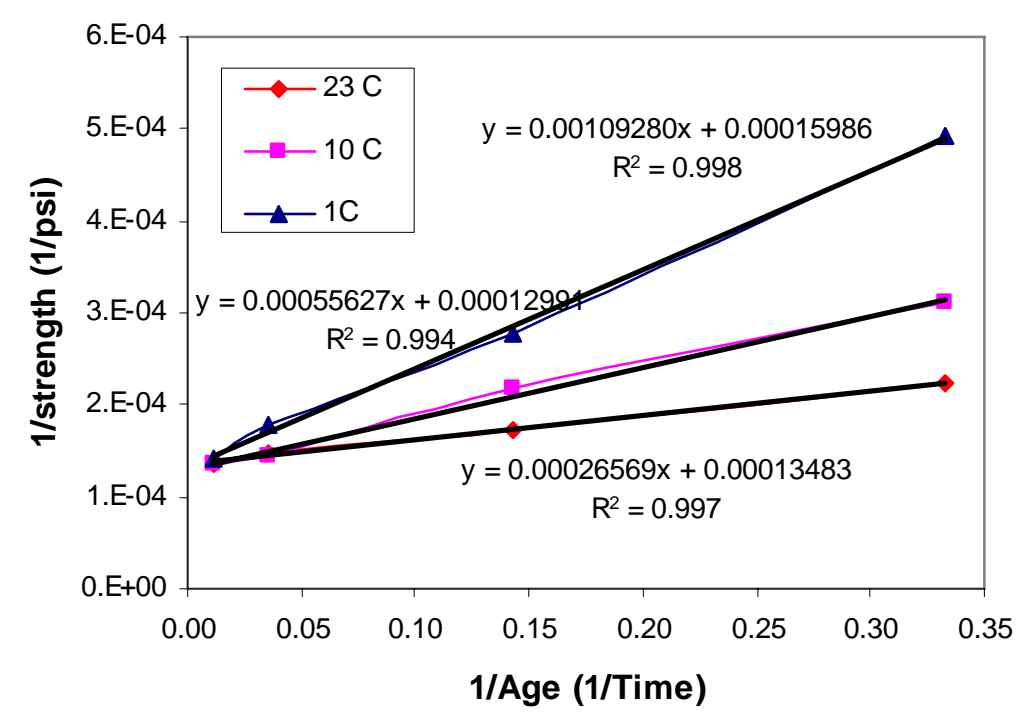

Figure 4.5: Determination of ultimate strength, $\mathrm{S}_{\infty}$ (mixture $\mathrm{M}$ 21)

\subsubsection{Determination of Rate Constants}

The second maturity parameter of interest is the rate constant, $k_{t}$, which describes the rate of reaction for a particular mixture at any given curing temperature. The rate constant was computed along the lines of the procedure specified by ASTM C1074. For each curing temperature, $A$ was computed for the earliest four ages in accordance with equation 4.5.

$$
A=\frac{S}{\left(S_{u}-S\right)}
$$

The values of $A$ were plotted versus age for each curing temperature (Figure 4.6). The rate constants $\left(k_{t}\right)$ were obtained from the slopes of the best-fit straight lines for each curing temperatures. Since the equivalent age for this research was obtained with respect to a temperature of $23^{\circ} \mathrm{C}\left(73.4^{\circ} \mathrm{F}\right)$, the rate of reaction, $k_{r}$ in this case is the rate constant 
value, $k_{t}$ at $23^{\circ} \mathrm{C}$. While plotting the relative strength gain versus equivalent age plot (Figure 4.4), the concept of the age conversion factor was introduced, where $\alpha$ is the ratio of rate constant at a particular temperature to the rate constant at which equivalent age is computed, which is $23^{\circ} \mathrm{C}$ in this case. Hence, the ratio $\alpha$ for a temperature $23^{\circ} \mathrm{C}$ would be 1.

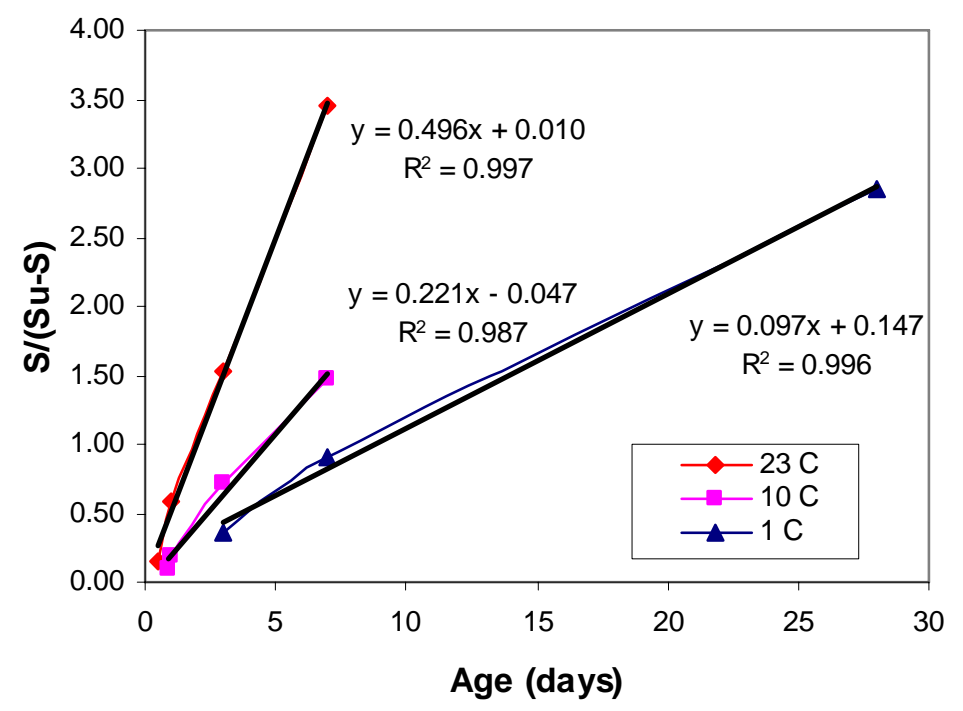

Figure 4.6: Determination of rate constants, $\mathrm{k}_{\mathrm{t}}$ (mixture $\mathrm{M} 21$ )

\subsubsection{Determination of Activation Energy}

The third maturity parameter to be determined is the activation energy, $E_{a}$. The activation energy is necessary in computation of equivalent age for mortars cured at different temperatures. The value of the activation energy $\left(E_{a}\right)$ divided by the universal gas constant $(\mathrm{R})$ is a constant $\mathrm{Q}$. In order to compute $\mathrm{Q}$, the natural logarithms of the rate constant $\left(k_{t}\right)$ values are plotted versus the inverse of temperature (in Kelvin), as shown in 
Figure 4.7. The negative of the slope of this plot is the ratio of activation energy to the gas constant, Q.

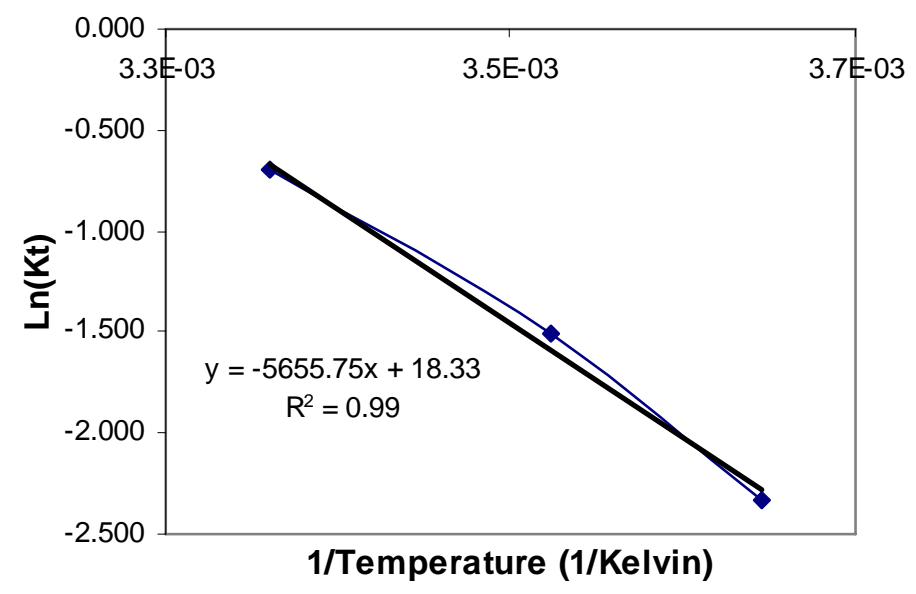

Figure 4.7: Determination of activation energy/gas constant, Q (mixture M 21)

\subsection{Approach for Development Strength Models and Binder Selection}

\subsubsection{Summary of Values of Ultimate Strength, Rate of Reaction and Energy Constant}

Table 4.2 summarizes the parameters used in the strength - maturity relationship (equation 4.4) for mortars. The values of $Q$ ranged from about 3500 to 6200. Researchers have commonly used a Q value of 5000 for strength prediction. The rate of reaction values ranged from 0.353 to 0.943 , higher values indicating a higher rate of reaction. The ultimate strengths ranged from about $5300 \mathrm{psi}(36.5 \mathrm{MPa})$ to about 8500 psi (58.6 MPa). Typically, mixtures prepared with supplementary materials showed higher ultimate strengths compared to mixtures prepared with similar control cements, confirming the beneficial effect of the pozzolanic reaction on the ultimate strength. The values of $k_{r}, S_{u}$ obtained from actual experiments were then used to develop mathematical 
models for predicting $k_{r}$ and $S_{u}$. These models and actual values of Q were used in the strength-maturity hyperbolic relationship given by equation 4.4 to predict strength of any mortar mixture at any given age and subjected to any temperature history.

Table 4.2: Summary of $S_{u}, k_{r}$ and Q values

\begin{tabular}{|c|l|c|c|c|}
\hline Mix ID & \multicolumn{1}{|c|}{ Binder Combination } & $\begin{array}{c}\mathbf{S}_{\mathbf{u}}(@ \\
\left.\mathbf{2 3}{ }^{\mathbf{}} \mathbf{C}\right)\end{array}$ & $\begin{array}{c}\mathbf{k}_{\mathbf{r}}\left(\mathbf{2 3} \mathbf{2}^{\mathbf{0}} \mathbf{C}\right) \\
\text { M01 }\end{array}$ & $\mathbf{Q}$ \\
\hline M02 & Lonestar cement + Rockport fly ash & 6337 & 0.426 & 5314 \\
\hline M03 & Lonestar cement + Clifty Creek fly ash & 7407 & 0.543 & 4606 \\
\hline M04 & Lonestar cement + Miami Fort fly ash & 5991 & 0.353 & 3674 \\
\hline M05 & Lehigh cement + Rockport fly ash & 5660 & 0.406 & 6271 \\
\hline M06 & Lehigh cement + Clifty Creek fly ash & 6916 & 0.716 & 4726 \\
\hline M07 & Lehigh cement + Miami Fort fly ash & 6276 & 0.511 & 4747 \\
\hline M08 & Lehigh cement + Will County fly ash & 6860 & 0.366 & 5543 \\
\hline M09 & Essroc cement + Rockport fly ash & 5305 & 0.493 & 4560 \\
\hline M10 & Essroc cement + Clifty Creek fly ash & 6910 & 0.470 & 5615 \\
\hline M11 & Essroc cement + Miami Fort fly ash & 5851 & 0.444 & 4021 \\
\hline M12 & Essroc cement + Will County & 6454 & 0.519 & 3971 \\
\hline M17 & Lonestar III cement + Rockport fly ash & 7515 & 0.801 & 5156 \\
\hline M18 & Lonestar III cement + Clifty Creek fly ash & 8525 & 0.719 & 3922 \\
\hline M19 & Lonestar III cement + Miami Fort fly ash & 6833 & 0.817 & 5043 \\
\hline M20 & Lonestar III cement + Will County fly ash & 7053 & 0.790 & 3513 \\
\hline M13 & Lonestar cement (Control mix) & 6405 & 0.784 & 4913 \\
\hline M14 & Lehigh cement (Control mix) & 7412 & 0.854 & 4993 \\
\hline M15 & Essroc cement (Control mix) & 6630 & 0.846 & 5277 \\
\hline M16 & Lonestar III cement (Control mix) & 7878 & 0.943 & 5277 \\
\hline M21 & Lonestar cement + Holnam Slag & 7417 & 0.496 & 5656 \\
\hline M22 & Lehigh cement + Holnam Slag & 7549 & 0.567 & 5944 \\
\hline M23 & Essroc cement + Holnam Slag & 7065 & 0.425 & 5675 \\
\hline M24 & Lonestar III cement + Holnam Slag & 8122 & 0.772 & 4021 \\
\hline
\end{tabular}




\subsubsection{Development of Mathematical Model for Strength Prediction in Mortars}

As it was earlier observed from the sensitivity analyses performed on the data from mill certificates, the strength development is mainly sensitive to the fineness, alkali content and $\mathrm{C}_{3} \mathrm{~S}$ content (section 3.4.1). It is also known that $\mathrm{C}_{2} \mathrm{~S}$ content in cement contributes primarily to the later age strength development in concrete. Higher fineness, $\mathrm{C}_{3} \mathrm{~S}$ and alkali content of the cement are also known to be responsible for a higher initial rate of reaction. The sensitivity analyses of fly ash showed that the strength activity index is dependent on the lime, fineness, and alkali content. There have been reports of problems of reduction in the air content in concrete mixtures prepared with fly ashes containing high amount of carbon. Since only one slag was tested, the chemical components of the slag were not taken into consideration in the development of mathematical models. Therefore, based on the factors mentioned above, the ultimate strength and rate of reaction for the mortars was initially expressed in a form given by equations 4.5 and 4.6 below:

$$
\begin{aligned}
& S_{u}=W_{c} *\left(C_{1} * F_{c}+C_{2} * C_{3} S+C_{3} * C_{2} S+C_{4} * A_{c}\right)+W_{f a} *\left(C_{5} * F_{f a}+C_{6} *\right. \text { Lime } \\
& \left.+C_{7} * A_{f a}+C_{8} * \text { Carbon }\right)+W_{s} * C_{9} \\
& k_{r}=W_{c} *\left(D_{1} * F_{c}+D_{2} * C_{3} S+D_{3} * C_{2} S+D_{4} * A_{c}\right)+W_{f a} *\left(D_{5} * F_{f a}+D_{6} *\right. \\
& \text { Lime } \left.+D_{7} * A_{f a}+D_{8} * \text { Carbon }\right)+W_{s} * D_{9}
\end{aligned}
$$

where $C_{n}$ and $D_{n}$ are constants to be determined by regression analysis. $W_{c}=$ wt $\%$ of cement, $W_{f a}=w t \%$ of fly ash, $W_{s}=w t \%$ of slag, $F_{c}=$ Fineness of cement, $F_{f a}=$ Fineness of fly ash, $A_{c}=$ Alkali of cement, $A_{f a}=$ Alkali of fly ash 
In this project, the data analysis was performed using the data analysis feature of Microsoft Excel $^{\circledR}$ software. The actual values of ultimate strength or rate of reaction determined from experiments were selected as the dependent variable (Y-axis input range) and the properties obtained from mill certificates including fineness, $\mathrm{C}_{3} \mathrm{~S}, \mathrm{C}_{2} \mathrm{~S}$ and alkali for cements and fineness, lime, alkali and carbon contents for fly ashes were selected as independent variables (X-axis input range). After the values of the constants were determined, the significance of each independent variable was assessed. A statistical approach was adopted where a confidence level of $95 \%$ was specified and the corresponding p-values (significance) were determined. Using this approach enabled one or more variables to be eliminated from the equations 4.5 and 4.6.

For ultimate strength, a significance level of 0.05 was specified. The variables (used in equation 4.5 ) producing a p-value $\leq 0.05$ were retained in the model and those producing values greater than 0.05 were eliminated. Further iteration or regression analysis was carried out until a point when all parameters in the modified equation for ultimate strength were statistically significant (i.e., $\mathrm{p} \leq 0.05$ ). The alkali content of cement and the alkali content of fly ash were found to be statistically insignificant for predicting the ultimate strength. The final equation for predicting ultimate strength for the mortar mixture combinations tested was of the form given in equation 4.7.

$$
\begin{aligned}
& S_{u}=W_{c} *\left(8.27 * F_{c}+46.18 * C_{3} S+61.68 * C_{2} S\right)+W_{f a} *\left(-186.10 * F_{f a}+236.80 *\right. \\
& \text { Lime }+3130.60 * \text { Carbon })+878.31 * \text { Slag }
\end{aligned}
$$

A similar procedure was adopted for eliminating insignificant parameters from the rate of reaction expression given by equation 4.6. Regression analysis was continued to a point until a reasonable value of coefficient of correlation was obtained between the 
actual rate of reaction values and the predicted values. The significance level for all parameters after repetitive regression analysis was $\mathrm{p} \leq 0.27$. The $\mathrm{C}_{3} \mathrm{~S}$ and alkali content of cement and the lime content of fly ash were parameters that were determined to be statistically insignificant. The final equation for predicting the rate of reaction for the mortar mixture combinations tested was of the form given below:

$$
\begin{aligned}
& k_{r}=\left(0.00189 * F_{c}+0.004207 * C_{2} S\right)+\left(-0.03444 * F_{f a}-0.2594 * A_{f a}+0.1515 *\right. \\
& \text { Carbon })-0.02716 * \text { Slag }
\end{aligned}
$$

The values predicted for the ultimate strength and rate of reaction using equations 4.7 and 4.8 are in very good agreement with the actual values obtained from experiments as shown in Figures 4.8 and 4.9.

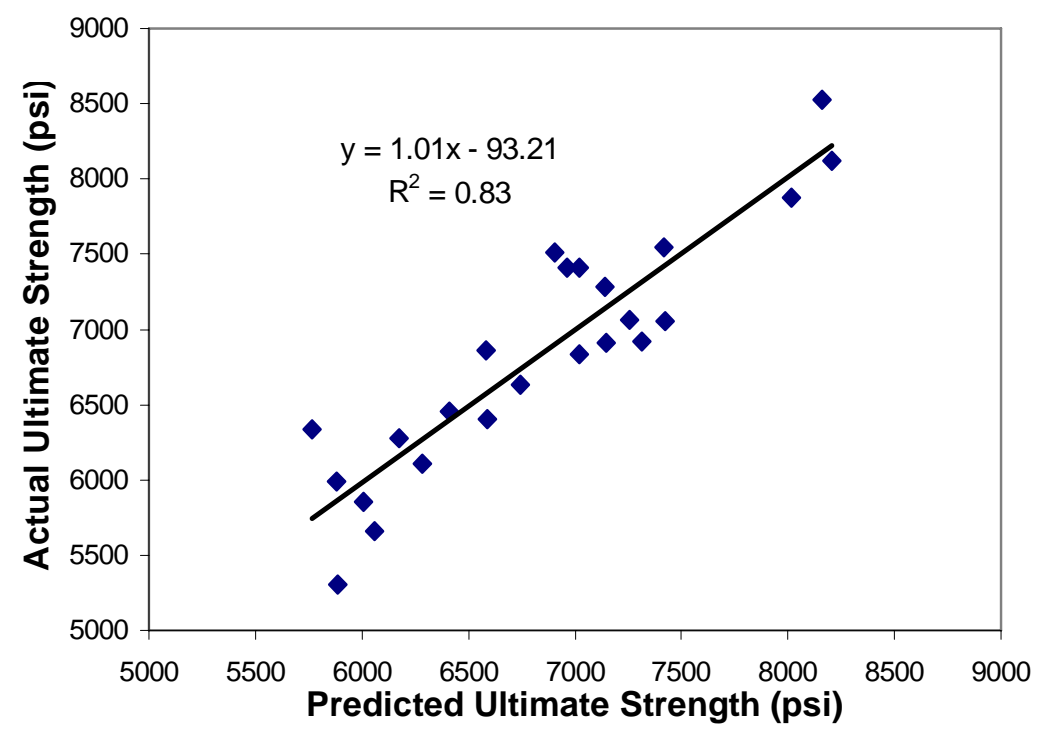

Figure 4.8: Actual versus predicted ultimate strength 


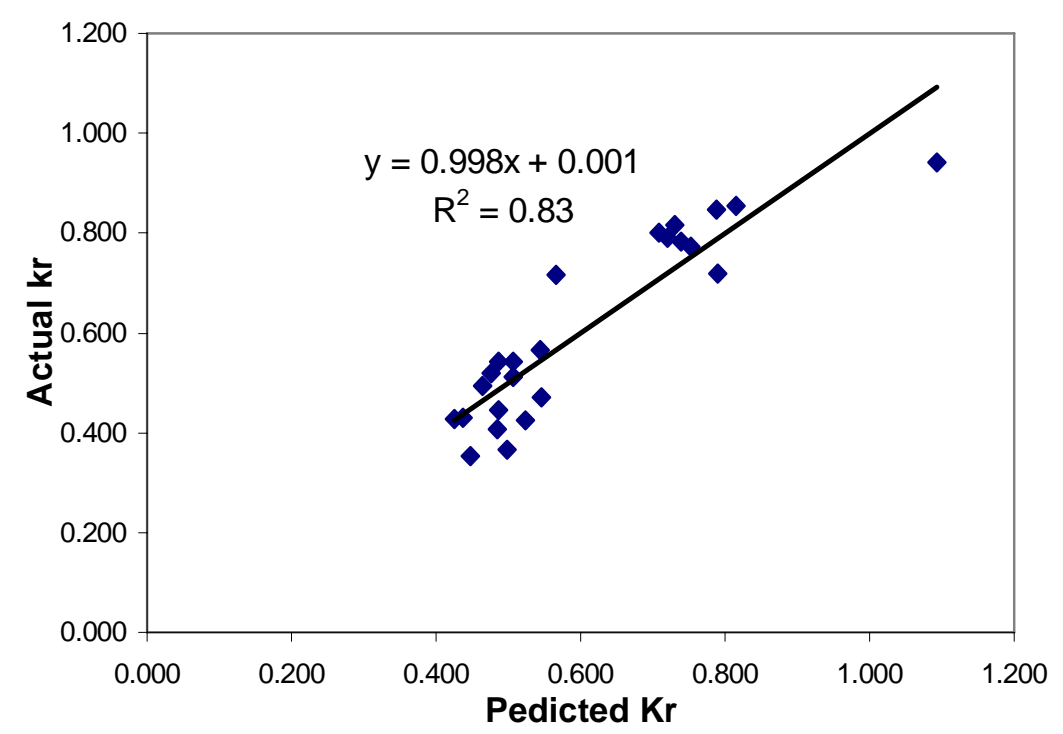

Figure 4.9: Actual versus predicted rate of reaction

\subsubsection{Comparison of Actual Strength Results with Results Predicted from the Model}

As observed from the plots shown in Figures 4.8 and 4.9, the values predicted by the mathematical models for ultimate strength and rate of reaction were in excellent agreement with the actual values obtained. These models (equations 4.7 and 4.8) were then used in equation 4.4 for strength prediction at the temperatures of 23,10 and $1^{\circ} \mathrm{C}$ (73.4, 50 and $33.8^{\circ} \mathrm{F}$ ), at which the actual strength tests on mortars were carried out. Actual values of $\mathrm{Q}$ given in table 4.2 were used in predicting strength because of difficulties in developing a mathematical model. The equivalent age term $\left(t_{e}\right)$ in equation 4.4 was computed using the Arrhenius function given by equation 4.1. The following plots (Figures 4.10 through 4.12) show the comparison between actual and predicted strength results at the three temperatures at ages of 3, 7 and 28 days. The coefficient of correlation for the plot at a temperature of $23^{\circ} \mathrm{C}$ was 0.98 . 


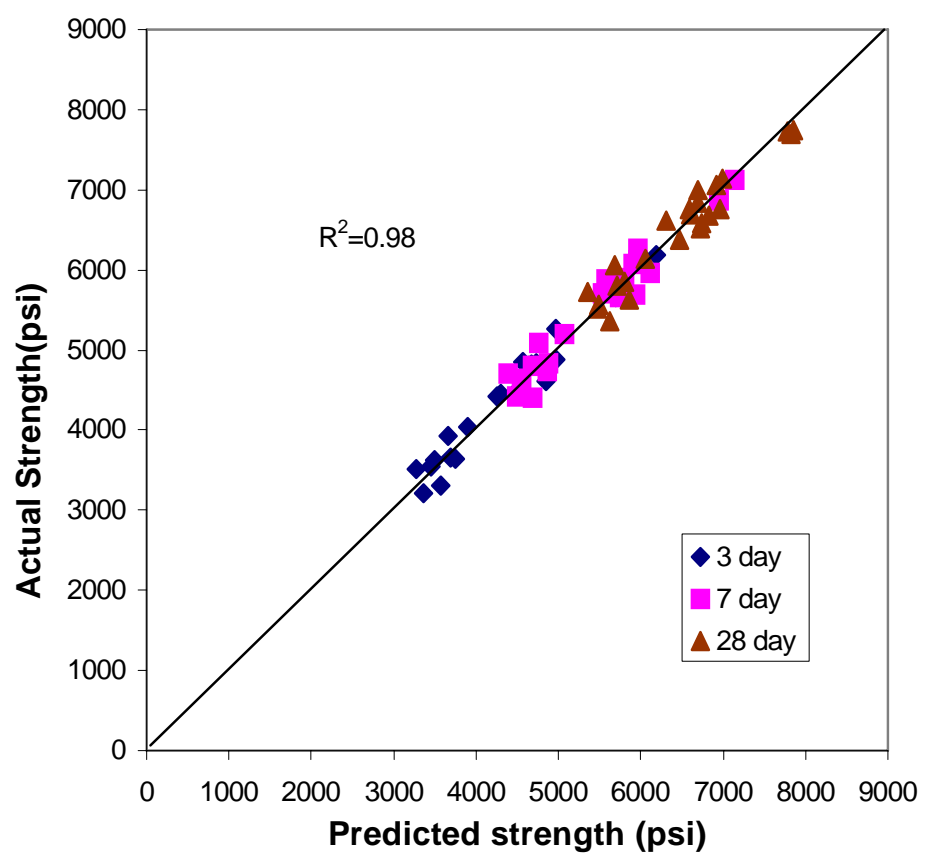

Figure 4.10: Actual versus predicted strength at $23^{\circ} \mathrm{C}$

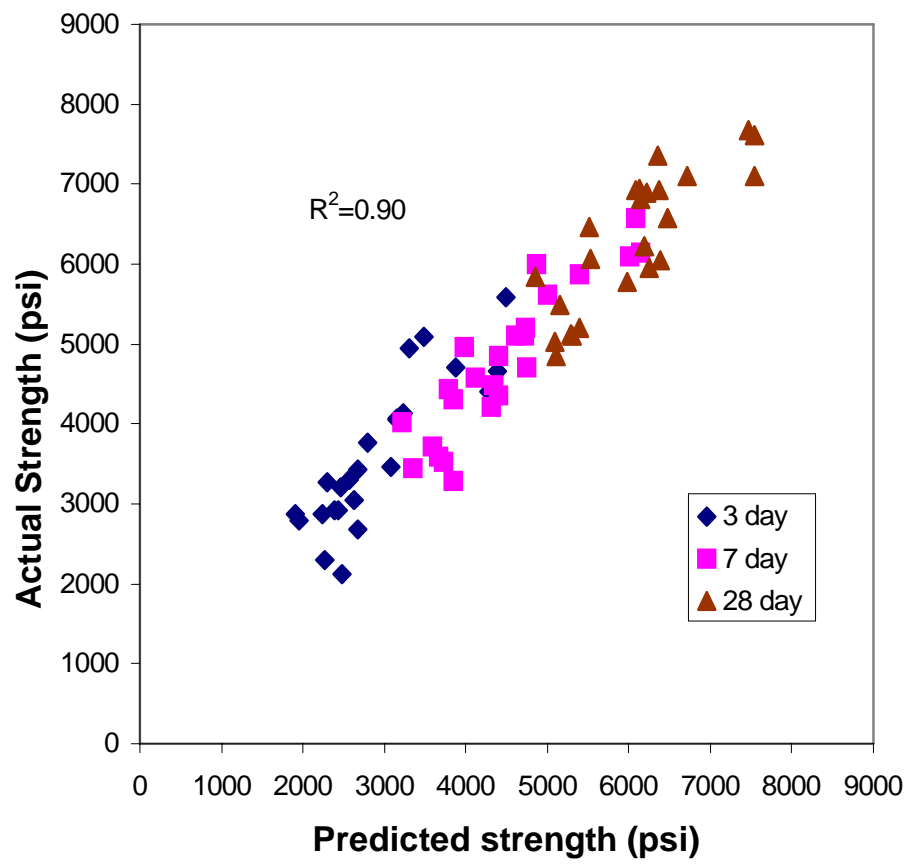

Figure 4.11: Actual versus predicted strength at $10^{\circ} \mathrm{C}$ 


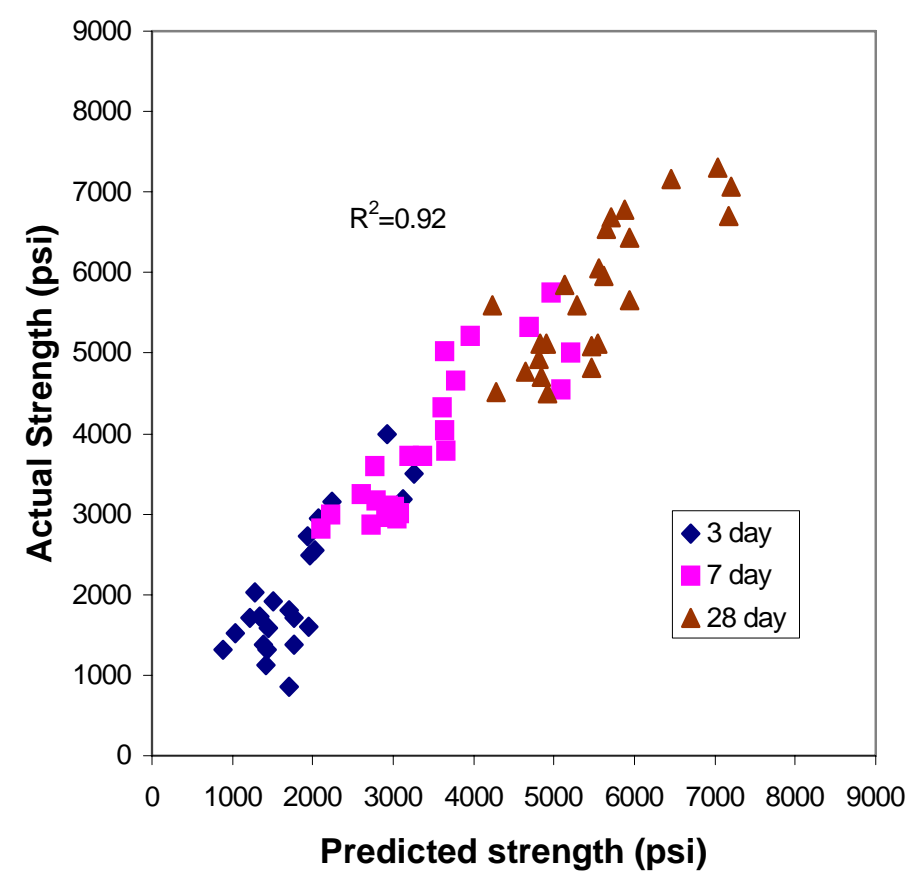

Figure 4.12: Actual versus predicted strength at $1^{\circ} \mathrm{C}$

The plot shown in Figure 4.10 indicates that predicted strength and actual strength values match most accurately. This is due to the fact that the ultimate strength and rate of reaction values were predicted using actual data results obtained at a temperature of $23^{\circ} \mathrm{C}$. McIntosh (36) and several others reported the crossover effect (Section 2.4). They found that lower initial curing temperatures result in lower degree of hydration at early ages but results in higher degrees of hydration at later ages primarily due to the better dispersion of hydration products. Consequently, lower initial curing temperatures result in higher ultimate strengths. Hence, theoretically the ultimate strength values that were computed at $23^{\circ} \mathrm{C}$ and used for development of the mathematical model might result in conservative estimates for the other two temperatures of 10 and $1^{\circ} \mathrm{C}$. This is also verified 
from Figure 4.10 in which the data points are closely spaced, but in Figures 4.11 and 4.12 the data points have a wider distribution.

\subsubsection{Non-evaporable Water Content Determination}

As discussed in section 4.2.3, twenty-four paste mixtures were prepared for determination of non-evaporable water content $\left(\mathrm{W}_{\mathrm{n}}\right)$. The paste samples were powdered by using a pestle and bowl. Water contained in pastes containing cement, mineral admixtures like fly ash, ground granulated blast furnace slag can be divided into two: evaporable water and chemically bound or non-evaporable water. The evaporable water content was determined by oven drying the paste sample to $105^{\circ} \mathrm{C}\left(221^{\circ} \mathrm{F}\right)$. The chemically bound water was determined by heating the sample in a furnace set to a temperature of $1050^{\circ} \mathrm{C}\left(1922^{\circ} \mathrm{F}\right)$. The non-evaporable water content, $\mathrm{W}_{\mathrm{n}}$ for pastes was calculated as the ratio of the difference between the weight on ignition at $1050^{\circ} \mathrm{C}$ and the weight after oven drying at $105^{\circ} \mathrm{C}$ to the weight of the sample on ignition at $1050^{\circ} \mathrm{C}$.

$$
\mathrm{W}_{\mathrm{n}}=\left(\mathrm{W}_{1050}-\mathrm{W}_{105}\right) * 100 / \mathrm{W}_{1050}
$$

where $\mathrm{W}_{105}=$ weight of sample after oven drying at $105^{\circ} \mathrm{C}$

$$
\mathrm{W}_{1050}=\text { weight of sample after ignition at } 1050^{\circ} \mathrm{C}
$$

For paste samples containing cement, fly ash and slag, necessary corrections due to the loss on ignition of cement, fly ash and slag were made based on the weight ratios of the individual components present in the mortar sample. Following plots show the comparison of non-evaporable water contents for paste mixtures containing fly ash or 
slag. Fig 4.13, 4.14 and 4.15, respectively, show the non-evaporable water contents for pastes cured at temperatures of 23,10 and $1^{\circ} \mathrm{C}\left(73.4,50,33.8^{\circ} \mathrm{F}\right.$, respectively).

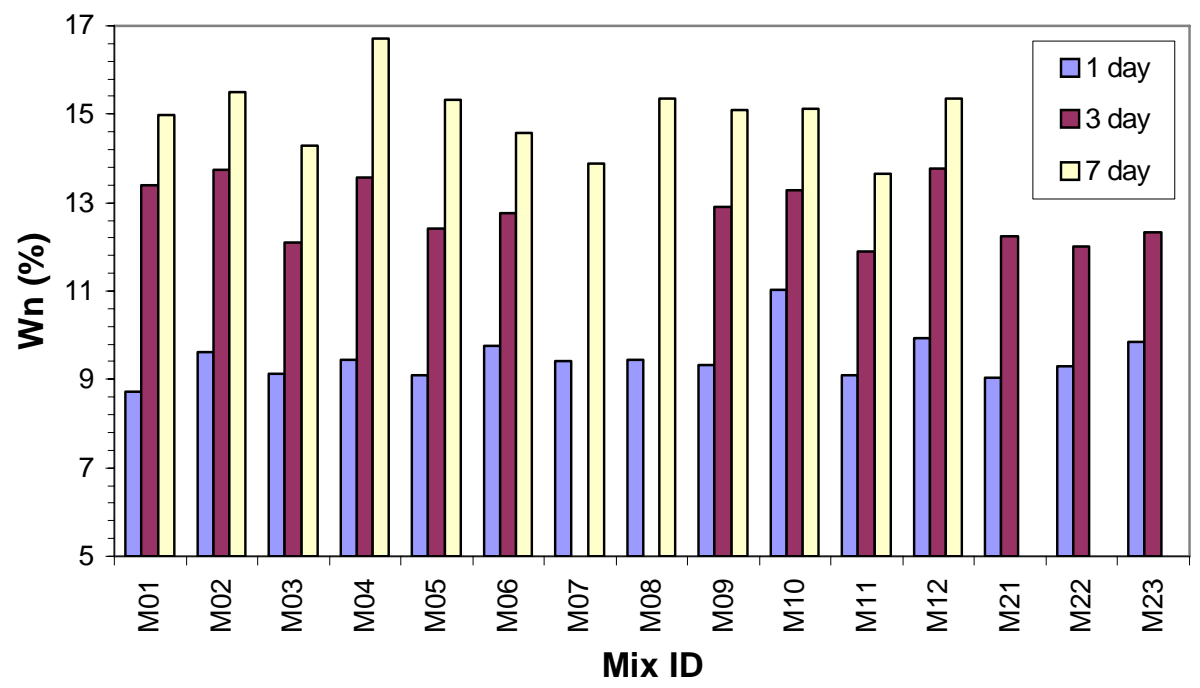

Figure 4.13: Non-evaporable water content for pastes cured at $23^{\circ} \mathrm{C}$

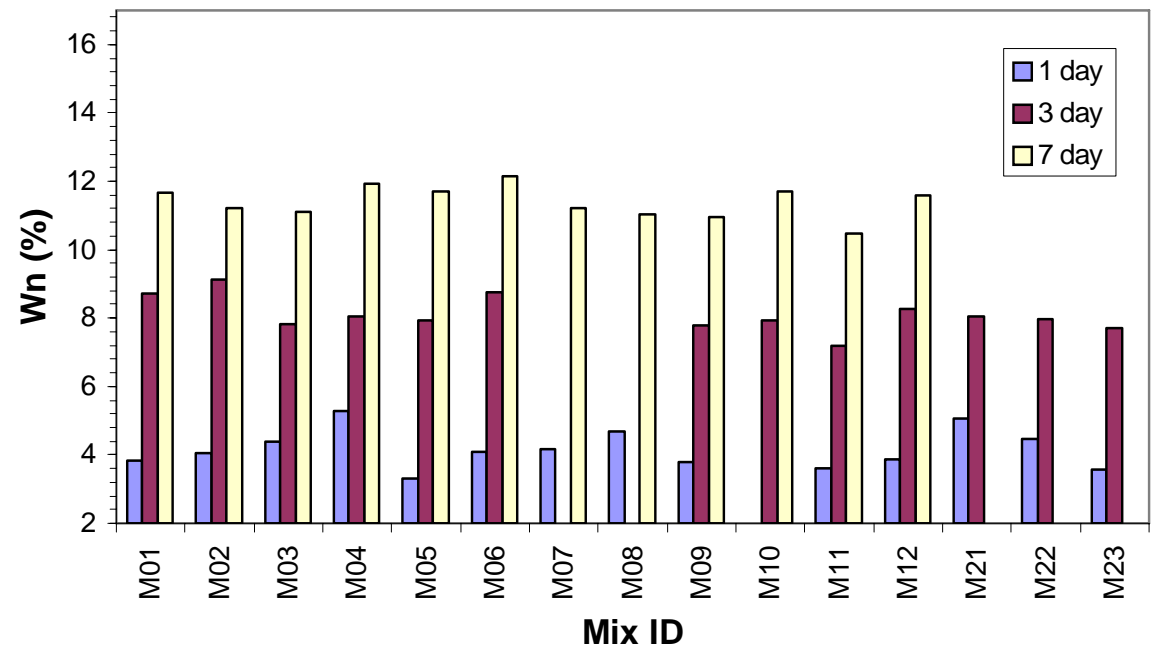

Figure 4.14: Non-evaporable water content for pastes cured at $10^{\circ} \mathrm{C}$ 


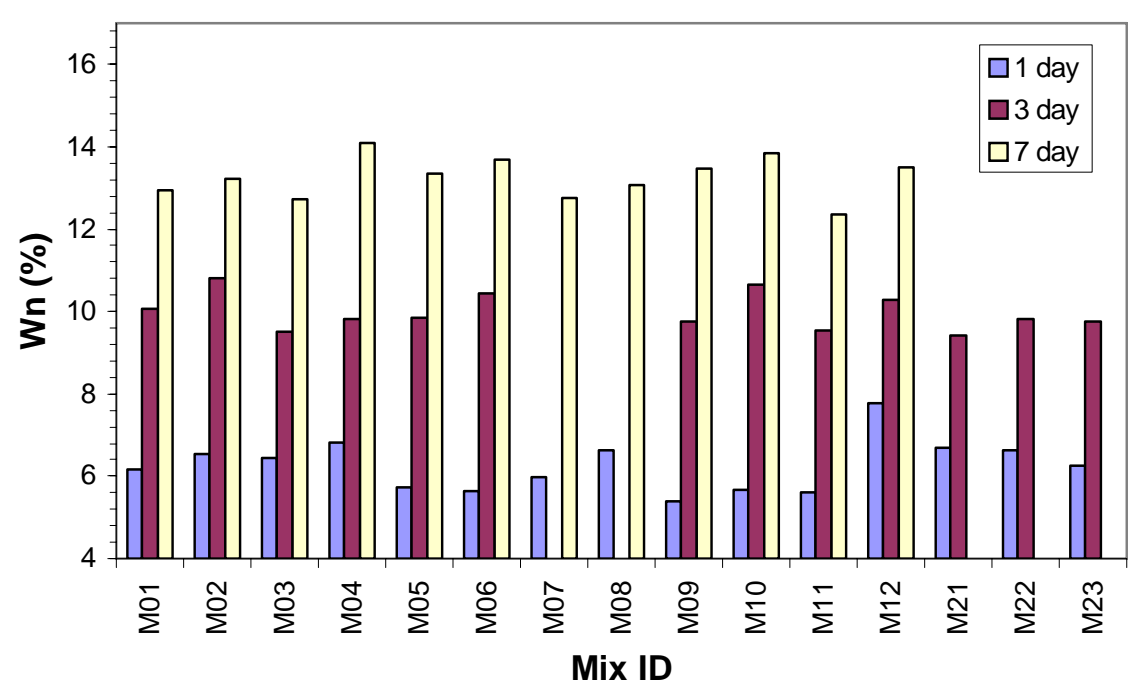

Figure 4.15: Non-evaporable water content for pastes cured at $1^{\circ} \mathrm{C}$

\subsubsection{Summary of Results from Non-Evaporable Water Content tests}

For all the mixtures evaluated, it is evident from Figures 4.13 through 4.15 that lower curing temperatures result in lower amounts of non-evaporable water especially at ages up to 3 days. Mixtures M01, M02, M03 and M04 were all prepared with Lonestar cement (Type I) but with fly ashes from the Rockport, Clifty Creek, Miami Fort and Will County plants respectively. At the three ages tested, Rockport ash showed the lowest $\mathrm{W}_{\mathrm{n}}$ value at 1 day, but the Miami Fort ash showed lowest $W_{n}$ values at 3 and 7 days. A similar trend was observed at the other two curing temperatures of 10 and $1{ }^{\circ} \mathrm{C}\left(50^{\circ} \mathrm{C}\right.$ and $33^{\circ} \mathrm{C}$, respectively). For mixtures M05, M06, M07 and M08 prepared with Lehigh cement, a similar trend was observed in which Rockport ash showed the lowest $\mathrm{W}_{\mathrm{n}}$ values at 1 day but the Miami Fort ash showed lowest values at 3 and 7 days at all three temperatures. For mixtures M09, M10, M11, M12 prepared with Essroc cement, a similar trend as observed with the other two cements was found for all fly ashes tested at 
temperatures of 23 and $10^{\circ} \mathrm{C}$. However, at $1^{\circ} \mathrm{C}$ and 1day age, the combination with Clifty Creek ash showed the lowest $\mathrm{W}_{\mathrm{n}}$ value. So, in general it is observed that Rockport ash shows the lowest $W_{n}$ value at 1 day, but the Miami Fort shows the lowest $W_{n}$ value at 3 and 7 days for all curing temperatures.

For mixtures prepared with slag, no definite trend was observed. At 1-day age, mixture with Lonestar (Type I) cement showed the lowest $\mathrm{W}_{\mathrm{n}}$ value at $23^{\circ} \mathrm{C}$, but showed the highest $\mathrm{W}_{\mathrm{n}}$ values at $10^{\circ}$ and $1^{\circ} \mathrm{C}$, respectively. At this age, mixture made with Essroc cement showed the lowest $\mathrm{W}_{\mathrm{n}}$ values at 10 and $1^{\circ} \mathrm{C}$.

\subsubsection{Late Fall Temperatures in the State of Indiana}

As this project deals with temperatures typical in the late fall construction season, the temperature history of both the atmosphere (air temperature) and freshly constructed concrete pavements during the fall season was studied. Figure 4.16 shows the air temperature in the months of October to April for years 1997, 1998 and 1999. 


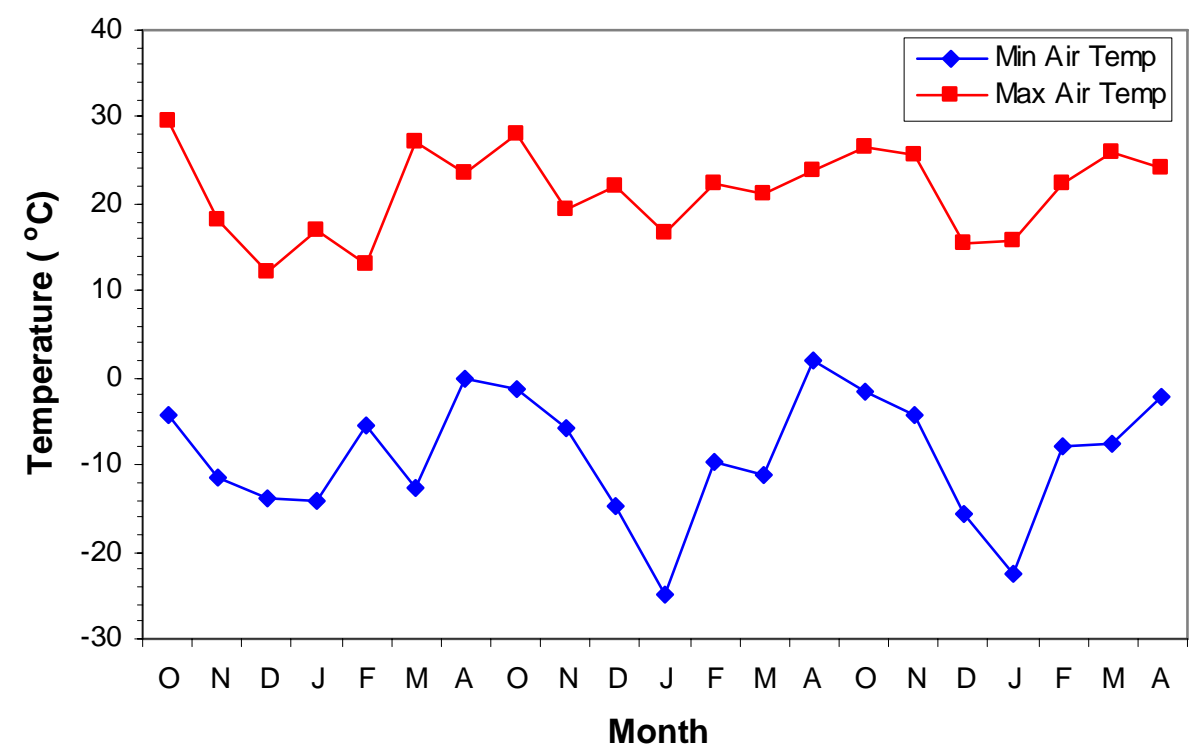

Figure 4.16: Minimum and maximum temperatures in Indiana (years 1997 through 1999)

Table 4.3: Average minimum temperatures

\begin{tabular}{|c|c|c|c|c|c|c|}
\hline \multicolumn{7}{|c|}{ Average minimum temperatures, deg C (1997 to 1999) } \\
\hline Oct & Nov & Dec & Jan & Feb & Mar & Apr \\
\hline 1.48 & -3.52 & -9.84 & -14.99 & -5.07 & -7.05 & 2.10 \\
\hline
\end{tabular}

Table 4.3 shows the average minimum temperatures for the three years 1997, 1998 and 1999. During the period studied, the lowest average minimum air temperature of $-14.99^{\circ} \mathrm{C}\left(5^{\circ} \mathrm{F}\right)$ occurred in the month of January. The second lowest average minimum air temperature of $-9.84^{\circ} \mathrm{C}\left(14.3^{\circ} \mathrm{F}\right)$ was observed in the month of December. The average minimum temperatures in the months of October and April, which mark the beginning and end, respectively, of the period during which use of supplementary materials is not permitted are $1.48^{\circ}\left(34.7^{\circ} \mathrm{F}\right)$ and $2.10^{\circ} \mathrm{C}\left(35.8^{\circ} \mathrm{F}\right)$, respectively. Figure 4.17 shows the temperature history of a freshly constructed concrete pavement at various depths from the pavement surface. The data for this plot was obtained from another 
project on performance related specifications. The plot shows the temperature history of the atmosphere as well as that of a pavement at depths of $1 / 4 \mathrm{in} .(0.635 \mathrm{~cm}), 1.5 \mathrm{in}$. (3.81 $\mathrm{cm})$ and 7 in. $(17.8 \mathrm{~cm})$ from the surface. As expected, the heat generated due to hydration during the initial period increases with an increase in pavement depth.

Figure 4.18 shows the difference between the air and concrete temperatures at a depth of $1 / 4$ in. from the surface. It can be seen that there is an increase in internal temperature due to the hydration of cement. This increase is visible for about 2 days, after which period the difference between the internal temperature and the ambient temperature is minimal. As with any chemical reaction, this higher temperature is likely to accelerate the hydration and strength gain. The shaded portions in Figure 4.18 show the maturity index, i.e., the product of temperature versus time gained due to hydration at a pavement depth of $1 / 4$ in. from the pavement surface. From the above plot, it was observed that at a pavement depth of $1 / 4$ inch, a maturity of $7.3^{\circ} \mathrm{C}$-days is gained during the initial 1.8 days after placement of concrete due to the heat liberated during hydration. Higher maturities would be gained at greater pavement depths. 


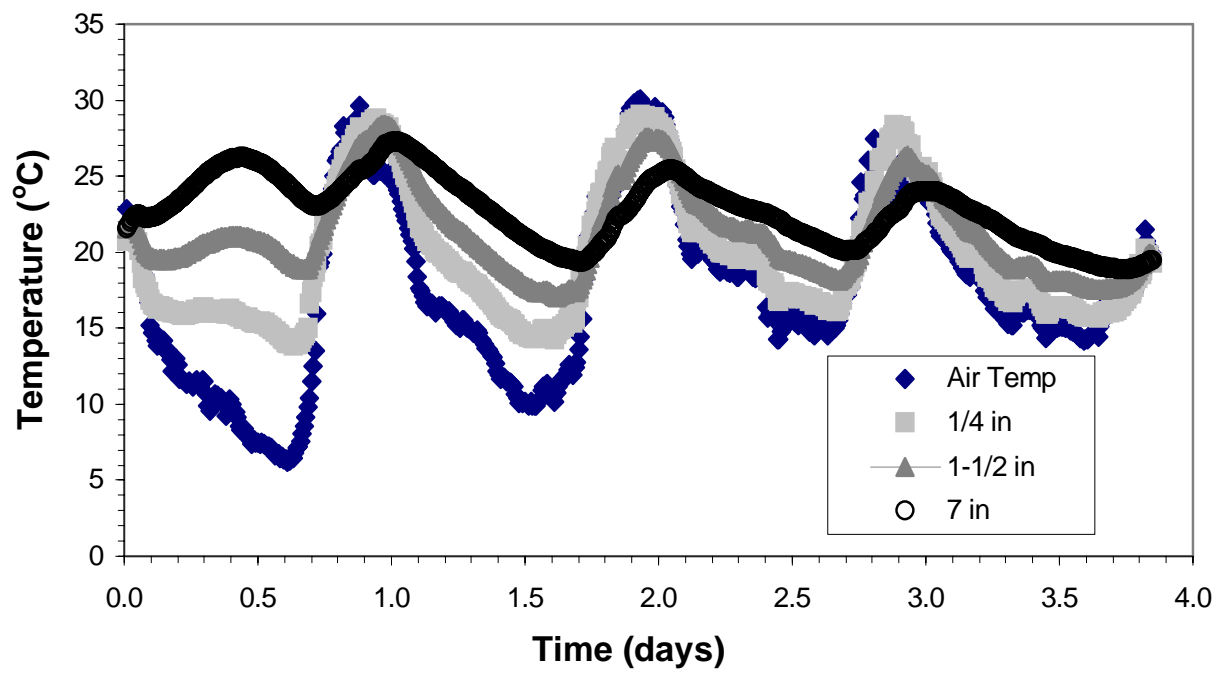

Figure 4.17: Pavement temperature at varying depths in the month of October

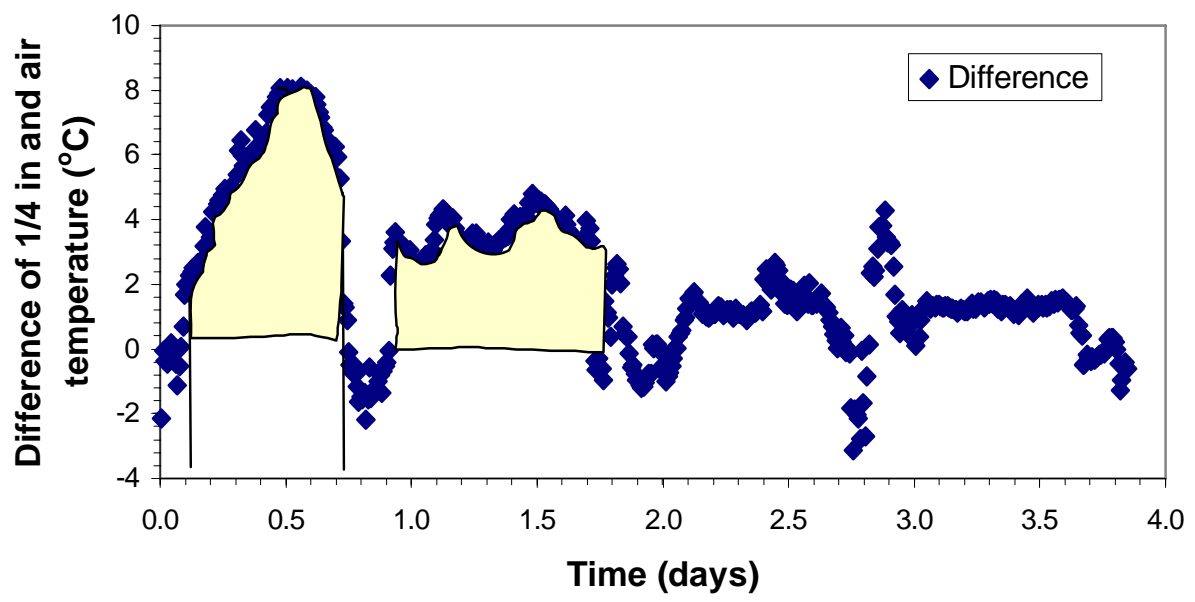

Figure 4.18: Temperature gain due to hydration at $1 / 4$ inch depth from pavement surface 


\subsubsection{Identification of Slow Strength Gaining Mortar Mixtures}

The purpose of this section was to identify binder combinations that when used in mortars would result in slow strength gain, especially under low temperature conditions. Using the mathematical models developed in section 4.4.2 that allowed prediction of the rate of reaction, $k_{t}$ and ultimate strength, $S_{\infty}$ in the hyperbolic strength gain equation (4.4), the prediction of strength $(S)$ at any age cured under any temperature for any given mixture could be made. Therefore, the time required to attain a given strength level for any binder composition subjected to a particular curing temperature could be determined. A strength level of 3500 psi (24.1 MPa) was specified for concrete to be durable when exposed to cycles of freezing and thawing. Using this strength level, contour plots were developed that show variation in age required by all the twenty-four mixtures to reach a strength of 3500 psi at 4 curing temperatures of $25,15,5$ and $0^{\circ} \mathrm{C}\left(77,59,41\right.$ and $\left.32^{\circ} \mathrm{F}\right)$. The contour plots for all mortar mixtures are shown in Figure 4.19.

Figure 4.20 shows the age required by all control mortar mixtures (plain) to reach 3500 psi. The example of how the plot can be used is also shown in Figure 4.20. One should enter the temperature axis (for example, $15^{\circ} \mathrm{C}$ ) and proceed horizontally to intercept one of the curves and then move down to the $\mathrm{X}$-axis where the time required could be obtained. Figure 4.20 shows that Lonestar ((Type I), M13) and Essroc cements (M15) are the slowest to attain strength of 3500 psi (24.1 MPa) at all temperatures. As expected, M16 containing Lonestar (Type III) cement was the fastest to reach this strength level at all temperatures. 


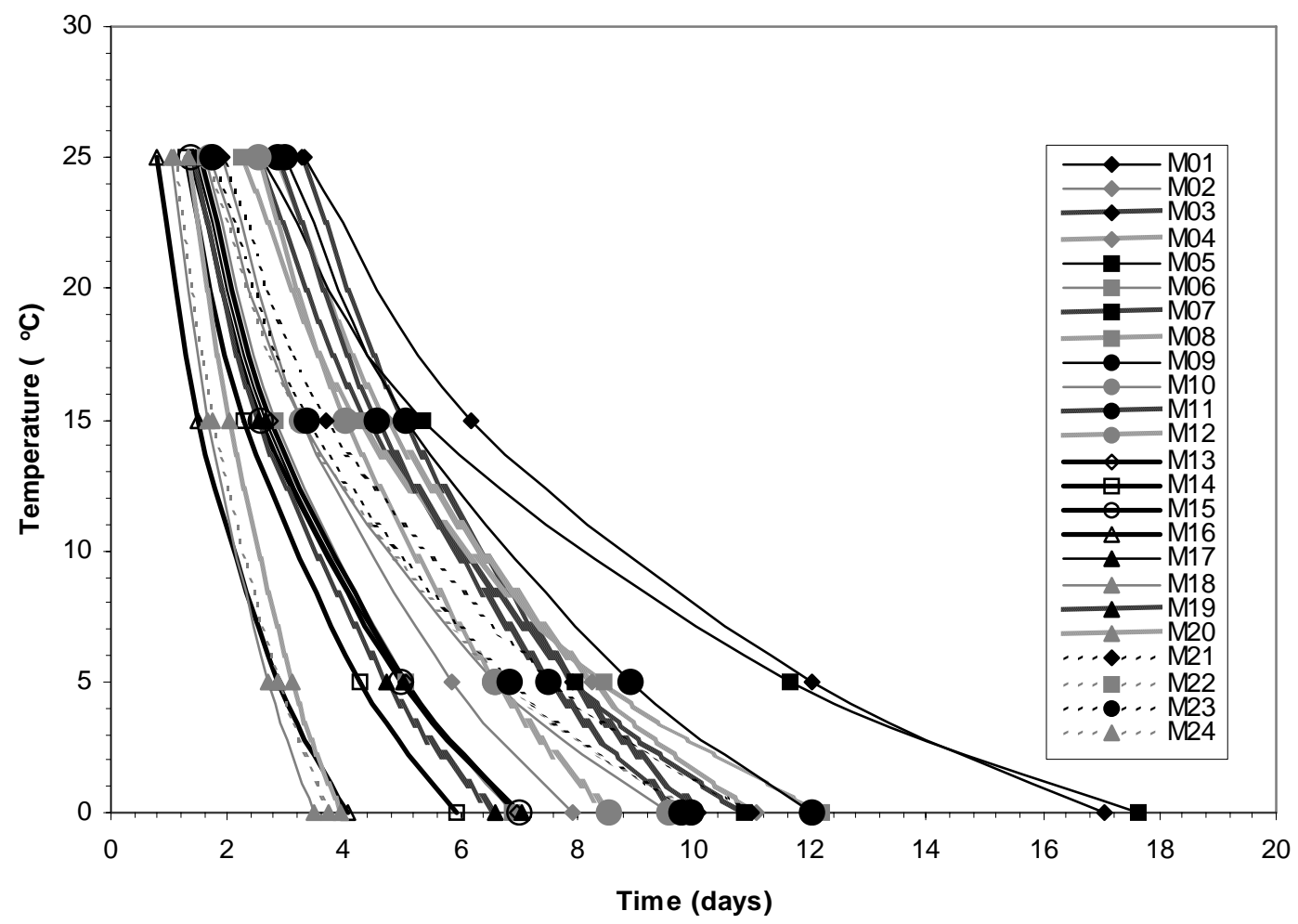

Figure 4.19: Simulated values of time and temperature required by all mortar mixtures to reach strength level of $3500 \mathrm{psi}$

Figure 4.21 shows the age required by all mixtures containing Rockport fly ash to develop strength of 3500 psi. It is observed from this figure that the combination M01 with Lonestar cement (Type I) is the slowest to develop strength of 3500 psi at all temperatures above $5^{\circ} \mathrm{C}\left(41^{\circ} \mathrm{F}\right)$. However, below $5^{\circ} \mathrm{C}$, the combination M05 with Lehigh cement seems to be slightly slower. Combination M17 containing Lonestar (Type III) cement was the fastest strength gaining at all temperatures. 


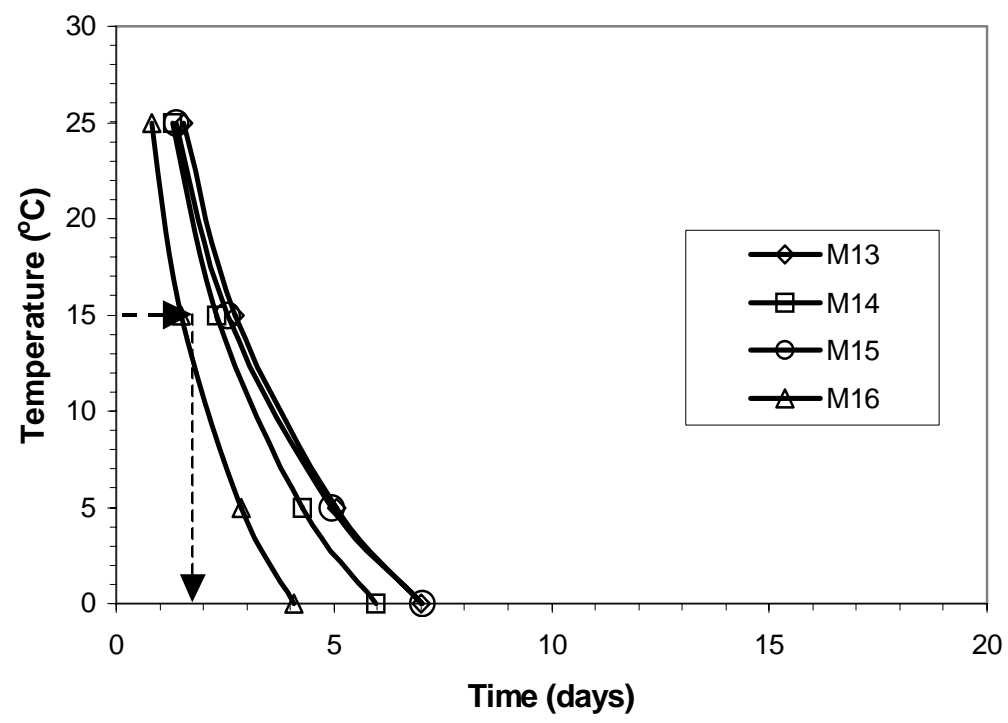

Figure 4.20: Simulated values of time and temperature required by all control mixtures to reach strength level of 3500 psi

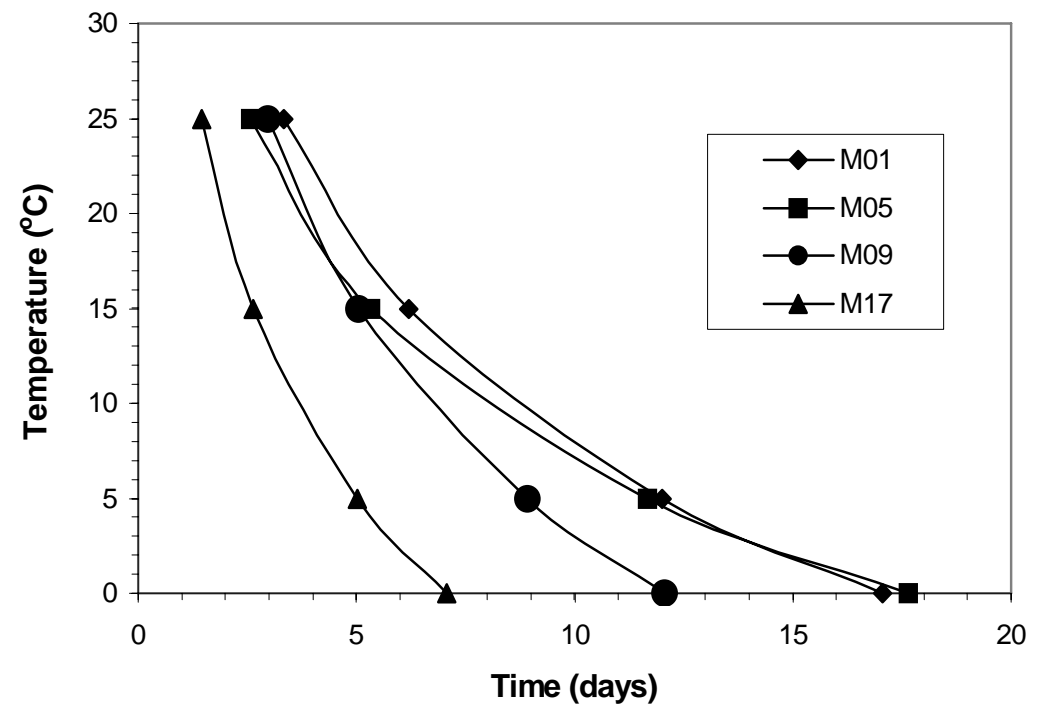

Figure 4.21: Simulated values of time and temperature required by all mixtures containing Rockport fly ash to reach strength level of 3500 psi 
Figure 4.22 shows the variation in age required by all mixtures containing Clifty Creek fly ash to develop a compressive strength of 3500 psi (24.1 MPa) at different temperatures. It is observed that the combination with Essroc cement (M10) is the slowest to develop strength of $3500 \mathrm{psi}$ at all temperatures up to $15^{\circ} \mathrm{C}\left(59^{\circ} \mathrm{F}\right)$. Above this temperature, mixtures prepared with Essroc cement (M10), Lehigh cement (M06) and Lonestar (Type I) cement (M02) showed similar trends. Again, mixture containing Lonestar (Type III) cement (M18) was the fastest at all temperatures.

Figure 4.23 shows the variation in age required to develop a compressive strength of 3500 psi at different temperatures by all mixtures containing Miami Fort fly ash. The mixture combination M03 containing Lonestar (Type I) cement was the slowest to reach 3500 psi at temperatures above $5^{\circ} \mathrm{C}$. Below this temperature, combination M07 containing Lehigh cement was the slowest. Combination M19 containing Lonestar (Type III) cement was the fastest strength developing at all temperatures.

Figure 4.24 shows the variation in age required by all mixtures containing Will County fly ash to develop a compressive strength of 3500 psi at different temperatures. It is observed that below the temperature of $5^{\circ} \mathrm{C}$, combination M08 containing Lehigh cement is the slowest strength developing. However, above this temperature, combination M04 containing Lonestar (Type I) cement is the slowest. Again, the combination M20 containing Lonestar (Type III) cement was the fastest. 


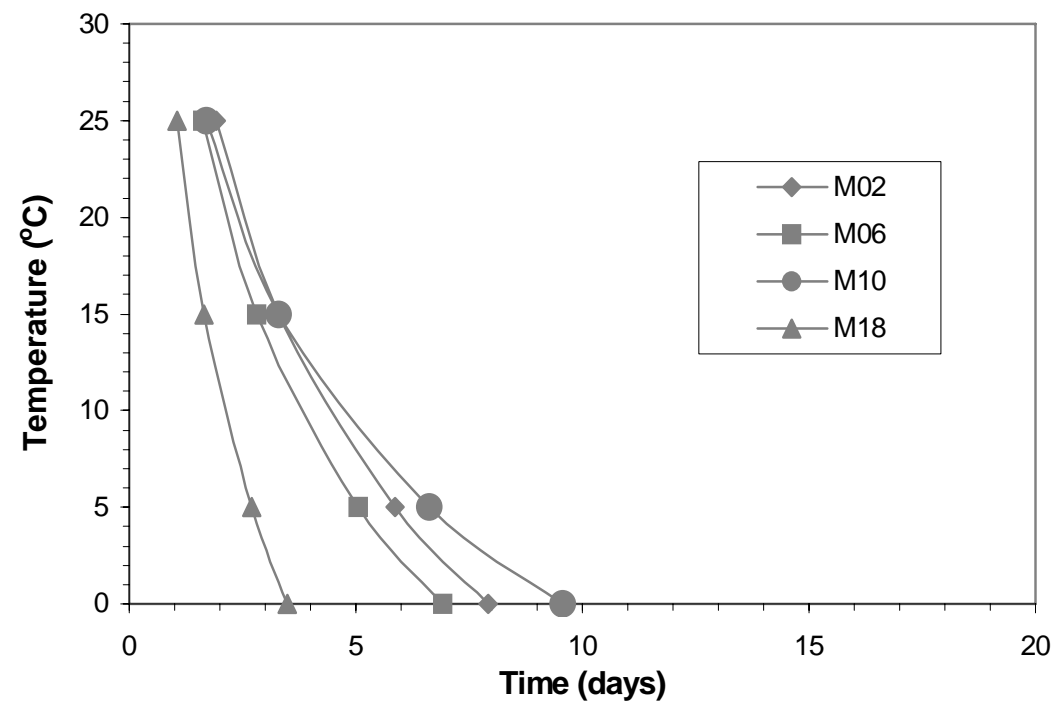

Figure 4.22: Simulated values of time and temperature required by all mixtures containing Clifty Creek fly ash to reach strength level of 3500 psi

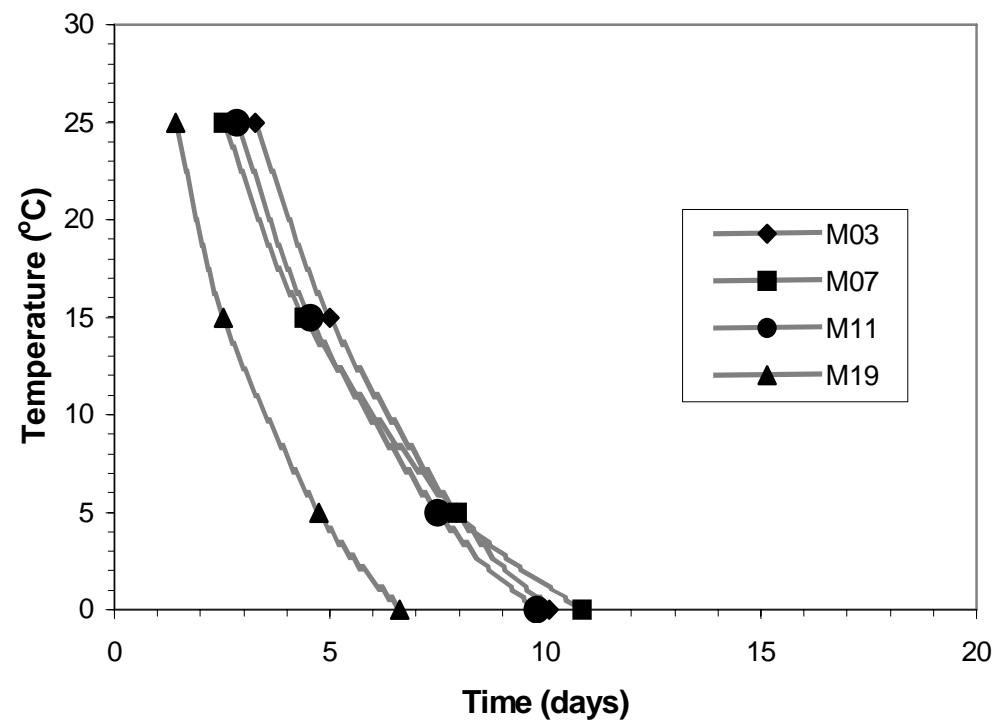

Figure 4.23: Simulated values of time and temperature required by all mixtures containing Miami Fort fly ash to reach strength level of 3500 psi 


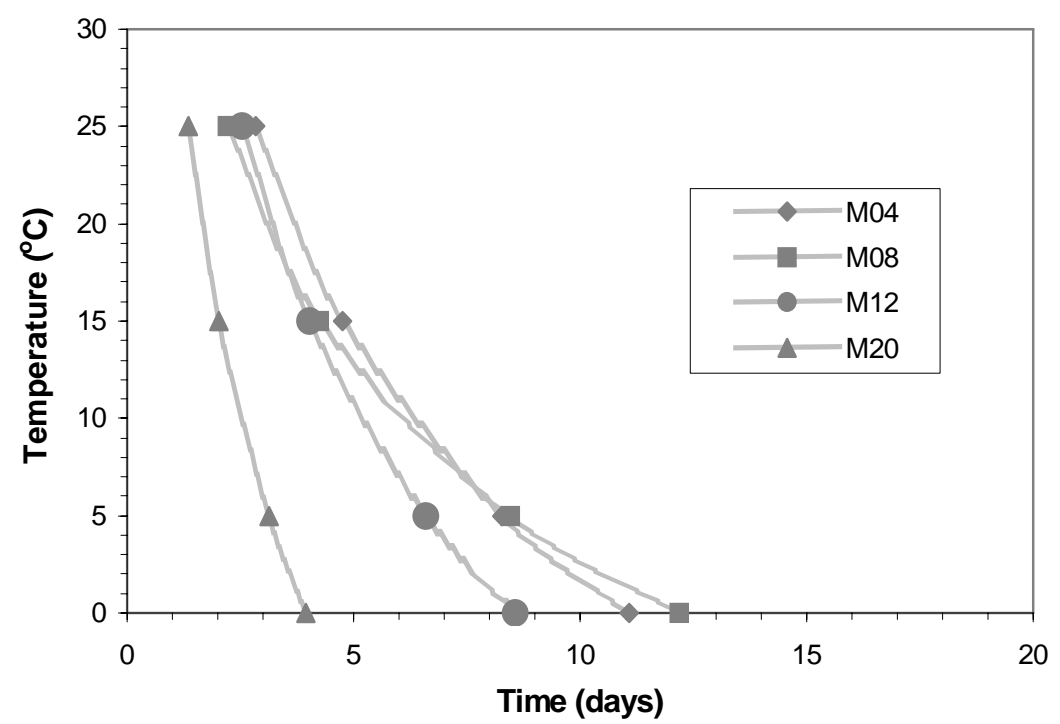

Figure 4.24: Simulated values of time and temperature required by all mixtures containing Will County fly ash to reach strength level of 3500 psi

Figure 4.25 shows the variation in age required by all mixtures containing slag to reach strength of 3500 psi when cured at different temperatures. It is observed that mixtures prepared with Essroc and Lehigh cement (M22 and M23) show identical trends at all temperatures. However, mixture M21 prepared with Lonestar (Type I) cement seemed to be the slowest strength developing mixture. Again, the combination M24 containing Lonestar (Type III) cement was the fastest strength developing at all temperatures. 


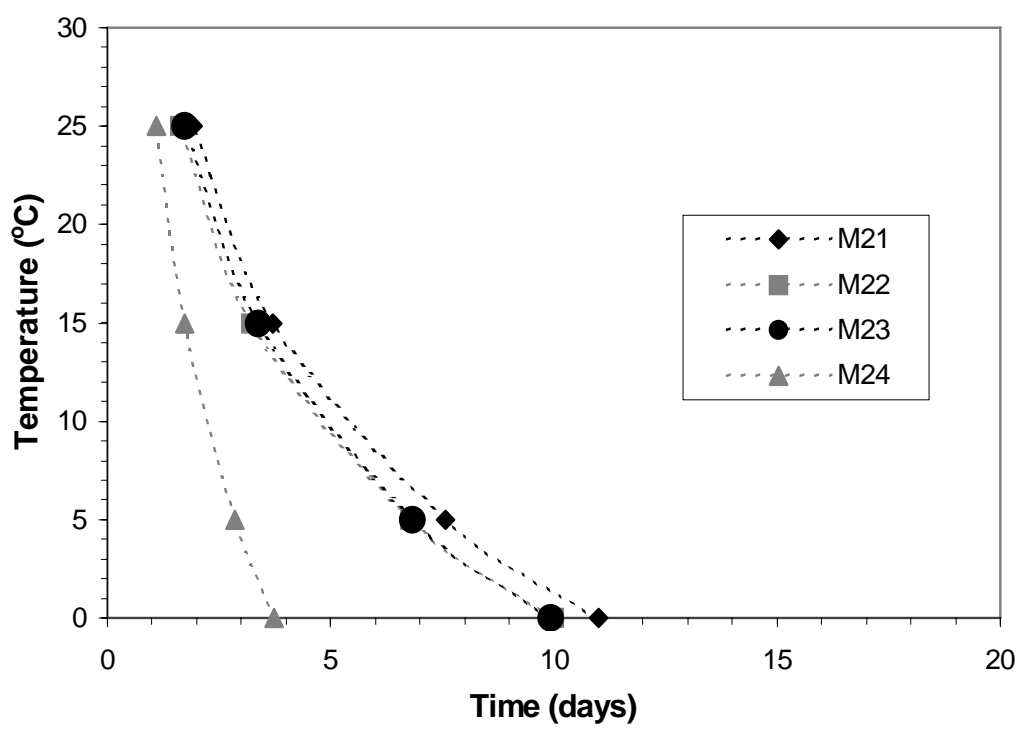

Figure 4.25: Simulated values of time and temperature required by all mixtures containing slag to reach strength level of 3500 psi

\subsubsection{Selection of Concrete Mixture Composition Based on Material Tests and Trends from Time-temperature Contour Plots}

From the data compilation for all Class C fly ashes in Table 3.8, Rockport fly ash had the lowest strength activity index value at 7 days. When all 4 fly ashes selected for tests on mortars, including Miami Fort (Class F) ash were considered, the Miami Fort fly ash showed the lowest 7-day SAI value (Table 3.8 and Table 3.9). The relative differences in SAI values of the four fly ashes used in mortar mixtures reflected in the strength predictions made using the mathematical models. According to these models, mixtures containing Rockport fly ash and Miami Fort fly ash were among the slowest to develop strength of 3500 psi especially at low temperatures. Also pastes containing Rockport and Miami Fort fly ashes had the lowest non-evaporable water content values, 
especially at low temperatures (Section 4.4.4 and 4.4.5). From the fly ash data compilation, it was observed that Clifty Creek (Class C) and Miami Fort (Class F) fly ash had the highest carbon contents (Table 3.8 and Table 3.9). The selection of candidate binder combinations for subsequent tests on concrete was carried out based on factors like potential for slow strength gain at low temperatures (observed from time-temperature contour plots), SAI values of the fly ashes used for mortar tests and high carbon contents in fly ash that could reduce the effectiveness of air-entraining agents.

Table 4.4 shows the binder systems selected for subsequent tests on concrete. Mixture M13 containing Lonestar (Type I) cement was chosen as the control (plain) mixture because this cement was found to be the slowest reacting at all temperatures considered. Among all mixtures containing Rockport fly ash, combinations with Lonestar (Type I) cement and Lehigh cement (M01 and M05) were found to be the slowest reacting below temperatures of $15^{\circ} \mathrm{C}\left(59^{\circ} \mathrm{F}\right)$. Hence these two mixtures were selected for further tests on concrete.

A mixture with high carbon Class C fly ash (Clifty Creek) that was slow reacting at temperatures below $15^{\circ} \mathrm{C}\left(59^{\circ} \mathrm{F}\right)$ was the one prepared with Essroc cement (M10). Mixture combination M07 containing Lehigh cement and Miami fort fly ash (high carbon Class F) was the slowest reacting below temperatures of $5^{\circ} \mathrm{C}$. Thus mixtures M10 and M07 were selected on the basis of slow strength gain at low temperatures and due to high contents of carbon in the fly ashes contained in them. For mixtures prepared with slag, Lonestar cement (Type I) was observed from the contour plot to be the slowest reacting especially at low temperatures. 
A compilation of all mixtures screened, based on the worst-case scenario is shown in Table 4.4. One control (plain) mixture, two mixtures with the slowest reacting Class C fly ash (Rockport), one mixture with the high carbon Class C fly ash (Clifty Creek), one mixture with the high carbon Class F fly ash (Miami Fort), and one mixture with slag were selected.

\subsection{Summary}

1. Maturity determination and strength tests were performed on twenty-four mortar mixtures at various ages.

2. Strength-maturity relationships were developed for all mixtures at different temperatures tested. Parameters like ultimate strength, rate constant and activation energy were determined.

3. These parameters were utilized to develop mathematical models to predict the ultimate strength and rate of reaction in terms of chemical components and fineness of cement and fly ash used.

4. Using the models and the maturity based hyperbolic relative strength gain equation, contour plots were developed that allow determination of age required by all mixtures to attain a strength level of 3500 psi (24.1 MPa) at various temperatures.

5. Non-evaporable water content tests on paste mixtures were carried out to verify the test results from strength, maturity tests.

6. Six different mixtures (with binder systems highlighted in Table 4.4), having the potential for slow strength gain under low temperature conditions were identified. 
These binders were then used to produce concrete specimens that were tested for durability related problems. 
Table 4.4: Summary of selected mixtures for tests on concrete

\begin{tabular}{|c|c|c|c|c|c|c|c|c|c|}
\hline Mixture & \multicolumn{4}{|c|}{ Cements } & \multicolumn{4}{|c|}{ Fly Ash/Slag } & Comments \\
\hline 1 & Lonestar & Lehigh & Essroc & Lonestar (III) & Rockport|Clifty Creek & Miami Fort & Will Co. & Slag & Control \\
\hline 2 & Lonestar & Lehigh & Essroc & Lonestar (III) & Rockport $\mid$ Clifty Creek & Miami Fort & Will Co. & Slag & Slow reacting ash \\
\hline 3 & Lonestar & Lehigh & Essroc & Lonestar (III) & 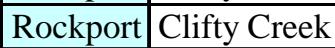 & Miami Fort & Will Co. & Slag & Slow reacting ash \\
\hline 4 & Lonestar & Lehigh & Essroc & Lonestar (III) & \begin{tabular}{|l|ll} 
Rockport & Clifty Creek \\
\end{tabular} & Miami Fort & Will Co. & Slag & Slow slag mix \\
\hline 5 & Lonestar & Lehigh & Essroc & Lonestar (III) & \begin{tabular}{|l|ll} 
Rockport & Clifty Creek \\
\end{tabular} & Miami Fort & Will Co. & Slag & Slow high carbon $\mathrm{C}$ ash \\
\hline 6 & Lonestar & Lehigh & Essroc & Lonestar (III) & \begin{tabular}{|l|ll} 
Rockport & Clifty Creek \\
\end{tabular} & Miami Fort & Will Co. & Slag & Slow high carbon $\mathrm{F}$ ash \\
\hline
\end{tabular}




\section{CHAPTER 5: EVALUATION OF PROPERTIES OF CONCRETE MIXTURES}

\subsection{Introduction}

The objective of this chapter is to describe the performance of concrete mixtures exposed to low temperatures at early ages. Concrete mixtures used in this study were selected based on results from mortar tests discussed in the previous chapter. A total of six mixtures were selected. These six mixtures were identified to have the potential for slow strength development, especially under low temperature conditions. The logic behind selecting the slowest reacting mixtures was that if the slowest reacting mixture with a particular cement and fly ash passes the durability tests, then all other mixtures made with a similar fly ash but different cements should be durable. Freeze-thaw and salt scaling tests were performed. Flexural strength and compressive strength tests were also carried out to ascertain whether the concrete mixtures satisfied strength requirements prescribed by INDOT specifications. Other tests discussed in this chapter are sorptivity, which deals with the rate of ingress of water in a particular mixture and the cumulative absorption over time. Results from tests to determine the weight loss on drying over time and the resonant frequency gained due to hydration of different mixtures are also discussed. Test results to determine the air void spacing in concrete exposed to cycles of freezing and thawing are also presented. An attempt was made relate the freeze-thaw and scaling resistance to factors like strength, air-void spacing, rate of water ingress, moisture loss on drying, and slump. 


\subsection{Experimental Procedures}

\subsubsection{Preparation of Concrete}

Concrete mixtures were prepared with water to binder ratio of 0.44 and $70 \%$ (by volume) of aggregates. Mixture proportions are shown in Appendix A. The replacement level by weight of cement with fly ash for fly ash mixtures was $20 \%$ and with slag for the slag mixture was 30\%. All solid materials were weighed to the nearest $0.1 \mathrm{~kg}$ (3.5 oz.). Following is the procedure adopted for mixing of concrete.

1. Sand and coarse aggregates were mixed with approximately $1 / 3^{\text {rd }}$ of the mixing water for one minute and the mixture was allowed to rest for a few minutes for the purpose of moisture absorption.

2. Cement and fly ash or slag was then added to the mixture of sand and coarse aggregates and mixed in order to homogenize the materials.

3. The following materials were added to the mixing pan while the mixer was in operation: (a) Measured amount of air-entraining admixture (previously diluted with $200 \mathrm{ml}$ or $6.8 \mathrm{fl}$. oz. of water), (b) another $1 / 3^{\text {rd }}$ of the mix water, (c) water reducer (previously diluted with $500 \mathrm{ml}$ or $16.9 \mathrm{fl}$. oz. of water), and (d) the remaining $1 / 3^{\text {rd }}$ of water. After the process of addition of the above materials was complete, mixing was continued for additional two minutes.

4. The mixer was stopped and the concrete mixture was allowed to rest for a period of three minutes. During the first 30 seconds of this rest period, material sticking to the sides of the mixing pan was scraped.

5. The mixing was resumed for additional two minutes. 
5.2.2. Curing and Test Procedures for Compressive, and Flexural Strength of Specimens The compressive strength was determined on 4” x 8” (10 cm x $20 \mathrm{~cm})$ cylinders. Compressive strength cylinders were prepared for testing at ages of 3, 7 and 28 days. The cylinders were de-molded after a period of $24 \pm 2$ hours and transferred to a fog room $(100 \% \mathrm{RH})$ where they were stored at a temperature of $21^{\circ} \mathrm{C}\left(69.8^{\circ} \mathrm{F}\right)$ until test time. The strength testing was performed using a 600-kip testing machine (2667 kN) and a loading rate of about $30,000 \mathrm{lb} / \mathrm{min}(133 \mathrm{kN} / \mathrm{min})$. Average of the results of three specimens tested in compression was used in the computation of compressive strength at each age.

Flexural strength tests were performed on beam specimens of dimension 15” x 3” x 3” (38 cm x $7.5 \mathrm{~cm}$ x $7.5 \mathrm{~cm})$. Flexural strength specimens were prepared for testing at ages of $12 \mathrm{~h}, 1,2,3,7,14$ and 28 days. All specimens except the ones to be tested at 12 hours were de-molded after a period of $24 \pm 2$ hours and transferred to a fog room (100\% $\mathrm{RH}$ ) maintaining a temperature of $21^{\circ} \mathrm{C}$. Average failure load from two specimens tested in third-point loading were used to calculate the flexural strength at any age. The flexural strength values until the first four test ages were used in computation of rate constant values for all mixtures. Another set of beam specimens of dimension 21 ” x 6” x 6” (53 cm x $15 \mathrm{~cm}$ x $15 \mathrm{~cm}$ ) were prepared for flexural strength determination at 7 days. This was done to determine whether the concrete specimens satisfied the INDOT flexural strength requirement (for opening to traffic) of $550 \mathrm{psi}$ (3.8 MPa) when tested at an age of 7 days. The strength testing was performed using a 60-kip (267-kN) Universal Testing Machine and the loading rate for all beams tested was maintained $1800 \mathrm{lb} / \mathrm{min}$ $(8 \mathrm{kN} / \mathrm{min})$. 


\subsubsection{Curing and Testing of Specimens Subjected to Freeze-Thaw Cycling}

The freeze thaw testing was performed in accordance with ASTM C666, procedure A which involves freezing and thawing the test specimens in water. Each freeze thaw cycle consisted of lowering the temperature of the specimens from $4.4^{\circ} \mathrm{C}$ to $-17.8^{\circ} \mathrm{C}\left(40^{\circ} \mathrm{F}\right.$ to $\left.0.04^{\circ} \mathrm{F}\right)$ and raising it from $-17.8^{\circ} \mathrm{C}$ to $4.4^{\circ} \mathrm{C}$ in a total time of about 4 hours. Four concrete prisms of dimension 16" x 4” x 3" $(40.5 \mathrm{~cm}$ x $10 \mathrm{~cm}$ x $7.5 \mathrm{~cm})$ were prepared for each of the six pre-selected concrete mixtures for the purpose of freeze thaw testing. Two prisms (specimen No. 3 and 4) were moist cured for a period of 14 days (ASTM C666 standard procedure) and two prisms (specimen No. 1 and 2) were moist cured just for 3 days before commencement of tests in order to simulate the worstcase scenario where concrete may be exposed to freezing conditions within few days after casting.

It can be observed from the contour plots in Figure 4.19 that most of the mortar mixtures cured at a temperature of $23^{\circ} \mathrm{C}\left(73.4^{\circ} \mathrm{F}\right)$ develop strength of 3500 psi (24.1 $\mathrm{MPa}$ ) within 3 to 5 days after placing. Also, a maturity gain of $7.3^{\circ} \mathrm{C}$-days due to the heat of hydration is observed close to the pavement surface (Figure 4.18) and higher maturity gains can be expected at greater pavement depths. Taking the above into account, wet curing period of 3 days was selected for freeze thaw specimens. The concrete prisms were subjected to a total of 300 cycles of freezing and thawing. The weight loss and resonant frequency of the specimens was tested after every 36 cycles (maximum) of freezing and thawing. A specimen is considered to pass the freeze thaw test if the durability factor at the end of 300 cycles is higher than $60 \%$. 


\subsubsection{Curing and Testing of Specimens for Salt Scaling Tests}

The tests for determining the resistance to salt scaling were performed using a procedure similar to that described in ASTM C672. Instead of using visual rating as the criterion for evaluating the scaling resistance, the weight loss of the scaled particles was used. Four scaling slabs of dimensions 15” x 10” x 3” (38 cm x $25 \mathrm{~cm}$ x7.5 cm) were cast for each of the six concrete mixtures. Each specimen was cut along the width into half so as to obtain two specimens of dimension 7.5” x 10” x 3” (19 cm x 25 cm x 7.5 $\mathrm{cm}$ ) as shown in Figure 5.1. Thus, a total of eight specimens were obtained.

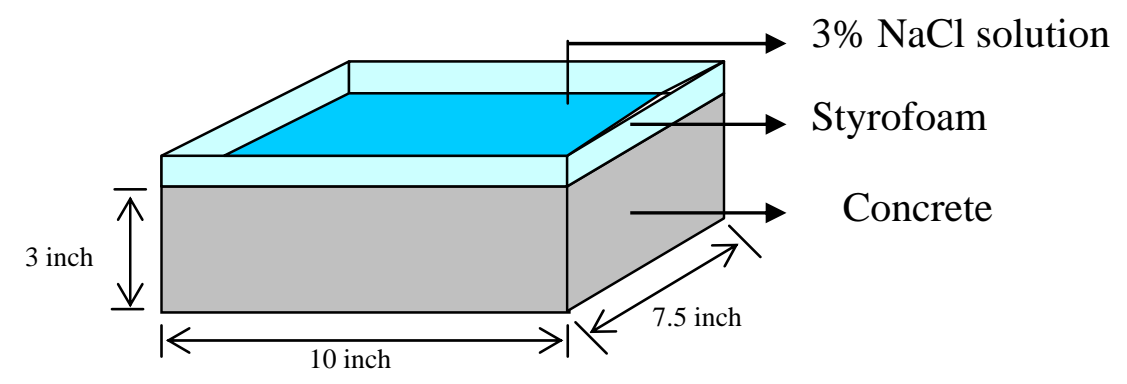

Figure 5.1: Schematic of scaling specimen

The effect of a curing compound (W.R. Meadows Inc., Sealtight 1610, White, Wax, Water-Based Concrete Curing Compound) on the resistance of concrete to deicer salts was also studied. Two specimens each, with and without curing compound were subjected to scaling tests after a moist curing period of 14 days followed by air-drying at $20 \pm 1^{\circ} \mathrm{C}\left(68 \pm 2^{\circ} \mathrm{F}\right)$ for 14 days (standard procedure). Also two specimens each, with and without curing compound were subjected to scaling tests after a moist curing period 
of 3 days followed by air drying at $20 \pm 1^{\circ} \mathrm{C}$ for 3 days (see Appendix C). These set of specimens were expected to simulate the worst case of scenario of actual pavement concrete in the field. All specimens were subjected to 50 cycles of freezing and thawing in an automatic temperature control room. Each cycle consisted of lowering the room temperature to $-18^{\circ} \mathrm{C}\left(0.4^{\circ} \mathrm{F}\right)$ for a period of 16 to 18 hours and increasing it to $23^{\circ} \mathrm{C}$ $\left(73.4^{\circ} \mathrm{F}\right)$ for a period of 6 hours. All specimens were subjected to a $3 \% \mathrm{NaCl}$ solution. An enclosure consisting of Styrofoam ${ }^{\circledR}$ was glued to the top of the specimens to contain the salt solution. After every 5 cycles of freezing and thawing, the surface of each specimen was flushed off with tap water and the scaled particles were collected and weighed. The experimental set up for a scaling specimen is shown in Figure 5.1.

\subsubsection{Test Procedure for Determining Sorptivity}

The method of capillary sorption was adopted for determining the rate of absorption as well as the cumulative amount of water absorbed by different concrete specimens. The sorptivity test was conducted on 2-in. hick discs cut from the middle portion of 4" x 8" inch cylinders. The specimens were coated with epoxy on the curved surface so as to allow water ingress into concrete only from the bottom flat surface. The specimens were immersed in a plastic container containing water and supported in such a way that about 0.4 " $(1 \mathrm{~cm})$ of the lower part of the specimens was in water. The experimental set up is shown in the Figure 5.2. 


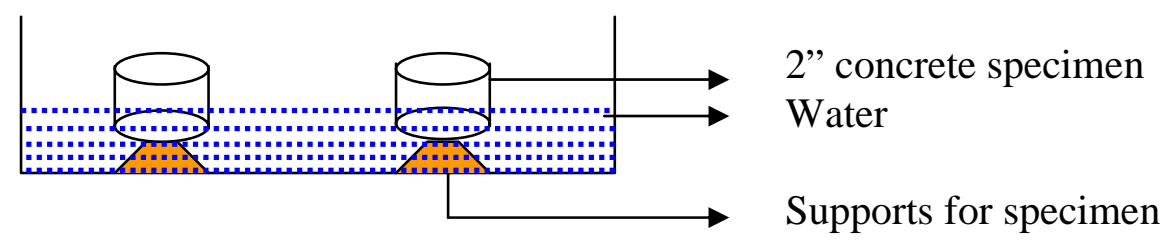

Figure 5.2: Schematic of sorptivity tests

The sorptivity was determined on specimens exposed to two different conditioning procedures. Two specimens from each concrete mixture were moist cured for a period of 3 days followed by air drying at $50 \% \mathrm{RH}$ at $20 \pm 1^{\circ} \mathrm{C}\left(68 \pm 2^{\circ} \mathrm{F}\right)$ for 11 days. Two more specimens were moist cured for 3 days followed by air-drying at 50\% $\mathrm{RH}$ at $20 \pm 1^{\circ} \mathrm{C}$ for 25 days. Two specimens were tested for their sorptivity for each conditioning procedure.

It is known that less saturated systems have more water ingress due to sorption. The purpose of having two conditioning periods was to investigate the water sorptivity in relatively saturated systems and in dry systems. By evaluating the sorptivity in all concrete mixtures conditioned for different periods, the potential for damage in concrete cured for different periods due to freeze-thaw cycles could be assessed.

\subsubsection{Test Procedure for Air void Analysis on Hardened Concrete Sections}

The tests for determination of air void content as well as the spacing between air voids was performed in accordance with ASTM C457. Rectangular specimens of dimensions 7” x 3” $(17.5 \mathrm{~cm}$ x $7.5 \mathrm{~cm})$ that were 1-in. thick $(25-\mathrm{cm})$ were cut from concrete prisms of dimension 16” x 4” x 3” (40.5 cm x $10 \mathrm{~cm}$ x $7.5 \mathrm{~cm})$ which were 
prepared in the same batch as the specimens for freeze thaw testing. The sections were cut in a direction perpendicular to the finished surface. In order to clearly distinguish between various components of concrete like paste, air void, fine aggregate and coarse aggregate, polishing of the cut section was carried out. In order to remove coarse irregularities on the specimen surface, polishing was first carried out using No.100 silicon carbide abrasive. The specimen surface was then polished with finer abrasives like No.220, No. 320, No. 600, No.800 and finally No.1000 until polished surface was able to reflect light when viewed at a low incident angle. When the abrasive was changed during the polishing process, the specimen was cleaned gently and thoroughly to remove any traces of the previous polishing abrasive. After polishing with different abrasives, hot water was run down on the polished surface to remove any traces of abrasives sticking on the surface. The polished surface was viewed under the microscope to check the quality of polishing. Microscopic determination of various components of the polished concrete surface was carried out at a magnification of 90x.

\subsubsection{Test Procedure for Determination of Resonant Frequency of Concrete}

The resonant frequency of concrete was determined as per ASTM E 1876-01. Using this values and geometric parameters dynamic young's modulus was determined. One specimen of dimension 3" x 4" x 16” $(7.5 \mathrm{~cm}$ x $10 \mathrm{~cm}$ x $40.5 \mathrm{~cm})$ was prepared for each mixture for the purpose of monitoring the resonant frequency development in the flexural mode. The first frequency was determined 24 after casting and this value was used as the original or initial frequency. The specimens were moist cured at a 
temperature of $20 \pm 1^{\circ} \mathrm{C}\left(68 \pm 3^{\circ} \mathrm{F}\right)$. The resonant frequency was determined at several ages for all mixtures.

\subsection{Results and Data Analysis}

\subsubsection{Compressive Strength Tests}

As mentioned in section 5.2.2, compressive strength tests were carried out at 3, 7 and 28 days on the 4” x 8” $(10 \mathrm{~cm}$ x $20 \mathrm{~cm})$ cylinders. The average compressive strength values were obtained from three cylinders. The test results obtained at different ages are shown in Table 5.1. Plots showing the variation in strength of the six concrete mixtures with time are shown in Figure 5.3. It is evident from the plots that mixture C03 (Lonestar + slag) has the highest strength values beyond the 3-day age and up to 28-day age. As expected, the control mixture C01 (Lonestar) shows the highest strength value at the age of 3 days. Also, after 28 days of curing, all mixtures containing fly ash or slag exhibit higher strength values than the control mixture, implying that the secondary pozzolanic reaction increases the strength at later ages. For mixtures C02, C03, C06, the beneficial effect on strength due to the pozzolanic reaction takes place as early as 7 days, but for mixtures C04 and C05, the improvement in strength is observed only at about 13 and 21 days, respectively.

Table 5.1: Compressive strength data at different ages (Moist room curing at $21^{\circ} \mathrm{C}$ )

\begin{tabular}{|c|l|c|c|c|}
\hline \multirow{2}{*}{ Mix ID } & \multirow{2}{*}{ Cementing Material } & \multicolumn{3}{|c|}{ Compressive strength, psi (MPa) } \\
\cline { 3 - 5 } & & 3 days & 7 days & 28 days \\
\hline C01 & Lonestar control & $4288(29.6)$ & $4999(34.5)$ & $5881(40.5)$ \\
\hline C02 & Lonestar + Rockport & $4093(28.2)$ & $5357(36.9)$ & $7023(48.4)$ \\
\hline C03 & Lonestar + slag & $4147(28.6)$ & $5742(39.5)$ & $7893(54.4)$ \\
\hline C04 & Lehigh + Rockport & $3558(24.5)$ & $4660(32.1)$ & $6608(45.6)$ \\
\hline C05 & Lehigh + Miami Fort & $3450(23.8)$ & $4396(30.3)$ & $6159(42.5)$ \\
\hline C06 & Essroc + Clifty Creek & $4033(27.8)$ & $4979(34.3)$ & $6812(47.0)$ \\
\hline
\end{tabular}




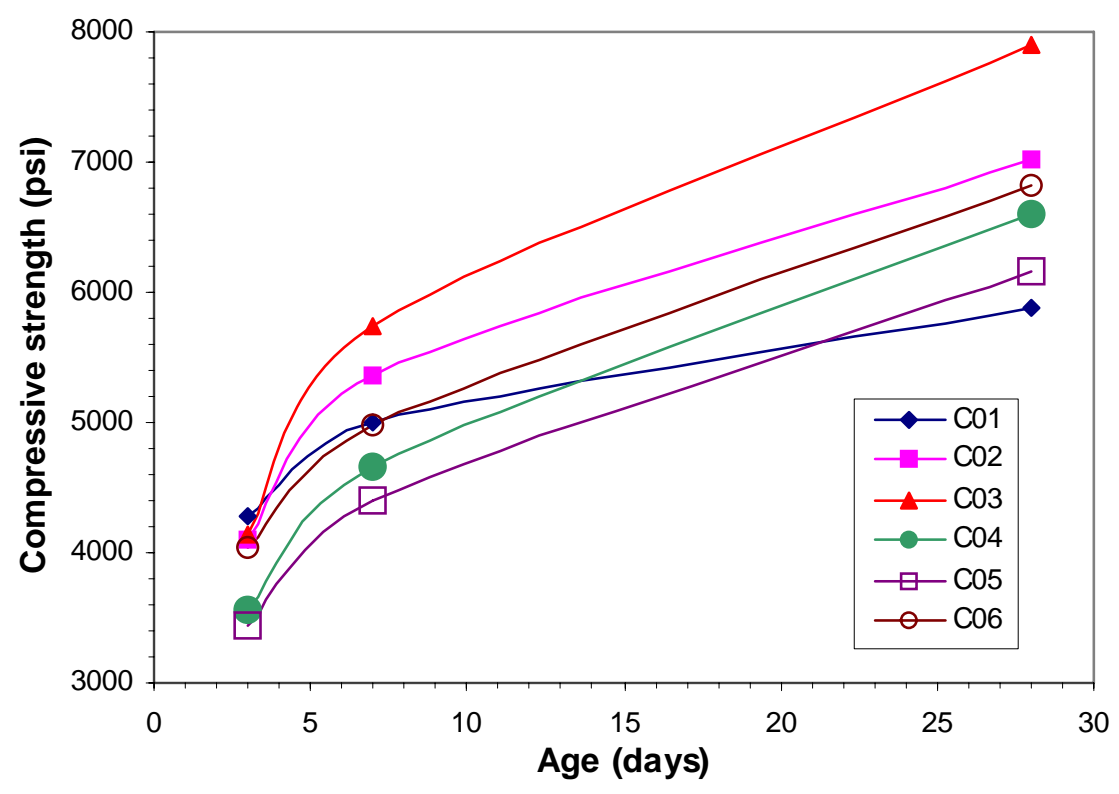

Figure 5.3: Variation in compressive strength with age

It is also to be noted that mixtures C04 and C05 contained Lehigh cement, which had the lowest $\mathrm{C}_{3} \mathrm{~S}$ content and highest $\mathrm{C}_{2} \mathrm{~S}$ content. Also, mixture $\mathrm{C} 05$ that was prepared with Miami Fort fly ash shows the lowest SAI value at 28 days compared to the other two fly ashes (Rockport and Clifty Creek) used for concrete preparation.

\subsubsection{Flexural Strength Tests}

As discussed in section 5.2.3, flexural strength tests were performed on beams of two different dimensions. The 7-day testing on 6" × 6" х 21" beams was performed to verify whether the six concrete mixtures under consideration satisfied the INDOT flexural strength requirement (for opening to traffic) of $550 \mathrm{psi}$ (3.8 MPa). 
Table 5.2: Flexural strength results for 6" x 6" x 21" beams

\begin{tabular}{|c|l|c|c|c|c|}
\hline \multirow{2}{*}{ Mix ID } & \multirow{2}{*}{ Mixture combination } & \multicolumn{2}{|c|}{ Failure load, Ib (N) } & \multirow{2}{*}{$\begin{array}{c}\text { Average failure } \\
\text { load, Ib (N) }\end{array}$} & $\begin{array}{c}\text { Flexural strength, } \\
\text { psi (MPa) }\end{array}$ \\
\cline { 3 - 4 } & Beam 1 & Beam 2 & & $797(5.5)$ \\
\hline C01 & Lonestar control & $9400(41.8)$ & $9731(43.3)$ & $9566(42.6)$ & $719(5.0)$ \\
\hline C02 & Lonestar + Rockport & $8809(39.2)$ & $8437(37.5)$ & $8623(38.6)$ & $850(5.9)$ \\
\hline C03 & Lonestar + slag & $10660(47.4)$ & $9749(43.4)$ & $10205(45.4)$ & $667(4.6)$ \\
\hline C04 & Lehigh + Rockport & $8062(35.9)$ & $7944(35.3)$ & $8003(35.6)$ & $667(4.6)$ \\
\hline C05 & Lehigh + Miami Fort & $8236(36.6)$ & $7770(34.6)$ & $8004(35.6)$ & 6 \\
\hline C06 & Essroc + Clifty Creek & $8383(37.3)$ & $8991(40.0)$ & $8687(38.7)$ & $724(5.0)$ \\
\hline
\end{tabular}

Table 5.2 shows the flexural strength results obtained from an average of two beams of dimension 6” × 6” x 21" $(15 \mathrm{~cm} \times 15 \mathrm{~cm} \times 53 \mathrm{~cm})$ tested at 7 days. The flexural strength of the beams tested in third point bending was computed as follows:

$$
f_{f^{\prime}}=\frac{\text { Average failure load } * L}{b \cdot d^{2}}
$$

where $f_{f^{\prime}}=$ modulus of rupture, $L=$ span length, $b=$ width of specimen and $d=$ depth of specimen. The span was 18 inches $(45.5 \mathrm{~cm})$. Mixture C03 had the highest flexural strength at 7 days among all concrete mixtures tested. A similar trend was observed with the compressive strength data. Also, all the six mixtures satisfied the INDOT requirement (for opening to traffic) of $550 \mathrm{psi}$ (3.8 MPa) flexural strength when tested at an age of 7 days.

Table 5.3: Flexural strength results for 3" x 3" x 15” beams at various ages

\begin{tabular}{|c|c|c|c|c|c|c|c|c|c|c|c|}
\hline \multicolumn{2}{|c|}{ Mix C01 } & \multicolumn{2}{c|}{ Mix C02 } & \multicolumn{2}{c|}{ Mix C03 } & \multicolumn{2}{c|}{ Mix C04 } & \multicolumn{2}{c|}{ Mix C05 } & \multicolumn{2}{c|}{ Mix C06 } \\
\hline Age & $\mathrm{f}_{\mathrm{f}^{\prime}}(\mathrm{psi})$ & Age & $\mathrm{f}_{\mathrm{f}^{\prime}}(\mathrm{psi})$ & Age & $\mathrm{f}_{\mathrm{f}^{\prime}}(\mathrm{psi})$ & Age & $\mathrm{f}_{\mathrm{f}^{\prime}}(\mathrm{psi})$ & Age & $\mathrm{f}_{\mathrm{f}}(\mathrm{psi})$ & Age & $\mathrm{f}_{\mathrm{f}^{\prime}}(\mathrm{psi})$ \\
\hline 0.5 & 490 & 0.5 & 437 & 0.5 & 337 & 0.5 & 276 & 0.5 & 387 & 0.5 & 319 \\
\hline 1.00 & 675 & 1.02 & 607 & 1 & 537 & 1.04 & 541 & 1.00 & 535 & 1.00 & 683 \\
\hline 2.00 & 809 & 2.08 & 668 & 2 & 744 & 2.01 & 625 & 2.00 & 719 & 2.00 & 808 \\
\hline 3.00 & 833 & 3.00 & 779 & 3 & 925 & 3.00 & 783 & 3.00 & 733 & 3.00 & 934 \\
\hline 7.00 & 983 & 7.00 & 975 & 7 & 1137 & 7.00 & 865 & 7.00 & 864 & 7.00 & 1033 \\
\hline 14.00 & 1001 & 14.00 & 1038 & 14 & 1249 & 14.00 & 959 & 14.00 & 912 & 14.00 & 1007 \\
\hline 28.00 & 1073 & 28.00 & 978 & 28 & 1118 & 28.00 & 1004 & 28.00 & 933 & 28.00 & 1086 \\
\hline
\end{tabular}


Table 5.3 shows the flexural strength results obtained by testing 3” x 3” x 15” (7.5 $\mathrm{cm} \times 7.5 \mathrm{~cm}$ x $38 \mathrm{~cm}$ ) beams at various ages. The tests on 3” x 3” x 15” beams were performed in order to determine the effect of specimen size on flexural strength at 7-day age and also to obtain the rate constants for each concrete mixture. The span length for these beams was 13 inches $(33 \mathrm{~cm})$, i.e., the supports were placed at 1 inch $(25 \mathrm{~cm})$ from either end of the beam. The results for these beams followed the same general trend as the larger beams tested. Mixture C03 showed the highest strength values at 7-day age. The lowest values were shown by mixtures C04 and C05 and this trend was also observed with the larger beams tested.

Table 5.4: Comparison of flexure strength results at 7 days

\begin{tabular}{|c|l|c|c|c|}
\hline \multirow{2}{*}{ Mix ID } & \multirow{2}{*}{ Cementing Material } & \multicolumn{2}{|c|}{ Size } & Ratio \\
\cline { 3 - 5 } & & $\mathbf{6 "} \times \mathbf{~ 6 " ~ \times ~ 2 1 " ~}$ & 3" x 3" x 15" & \\
\hline C01 & Lonestar control & 797 & 983 & 1.23 \\
\hline C02 & Lonestar + Rockport & 719 & 975 & 1.36 \\
\hline C03 & Lonestar + slag & 850 & 1043 & 1.23 \\
\hline C04 & Lehigh + Rockport & 667 & 865 & 1.3 \\
\hline C05 & Lehigh + Miami Fort & 667 & 864 & 1.3 \\
\hline C06 & Essroc + Clifty Creek & 724 & 1033 & 1.43 \\
\hline
\end{tabular}

Table 5.4 provides a comparison of strength results obtained by testing beams of dimension 6” x 6” x 21” (15 cm x $15 \mathrm{~cm}$ x $53 \mathrm{~cm})$ and 3” x 3” x 15” (7.5 cm x $7.5 \mathrm{~cm} \mathrm{x}$ $38 \mathrm{~cm}$ ) at 7 days. Except mixture C06, all other mixtures showed an increase in strength of about 23 to $30 \%$ when the tests were performed on the smaller (3”x 3” x 15”) beams. Mixture C06 showed a very high increase of 43\% when strength testing was performed on 3”x 3” x 15” beams as opposed to 6” x 6” x 21” beams. 


\subsubsection{Comparison of Rate Constants for Concrete Mixtures with Companion Mortar}

\section{Mixtures}

This section provides the analysis and comparison of the rate constants for concrete mixtures and corresponding mortar mixtures. The rate constant for concrete was computed using the flexural strength results of up to 3 days (first 4 data points from Table 5.3). The procedure for determining rate constants is discussed in section 4.3.5. Figure 5.4 shows the comparison of rate constants obtained for concrete mixtures and those obtained for companion mortar mixtures at $23^{\circ} \mathrm{C}\left(73.4^{\circ} \mathrm{F}\right)$.

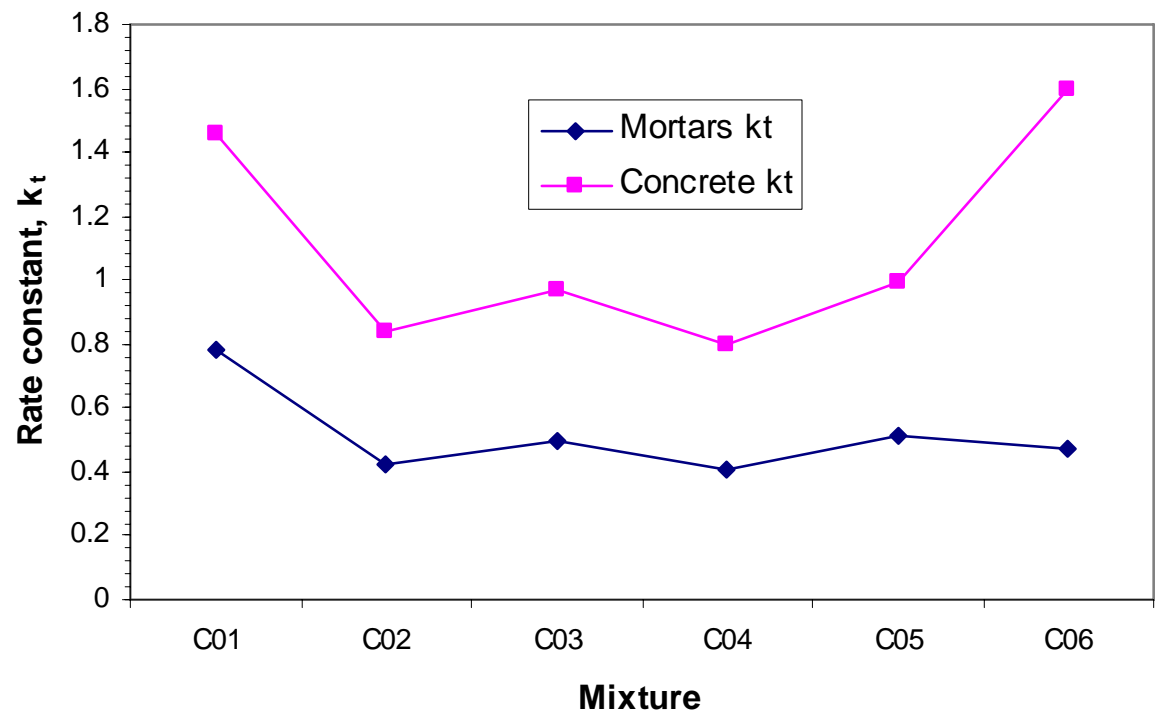

Figure 5.4: Comparison of rate constants for concrete and mortar mixtures

From this Figure, it is observed that the rate constant values for mortar and concrete prepared with similar binders are different. However, similar rate constant trends are obtained for all concrete mixtures except mixture C06, when compared to the trends from companion mortar mixtures. Also, there may be differences in the rate 
constant trends due to different testing mechanisms, i.e., compression for mortars and flexure for concrete. In general, the rate constant trends obtained from concrete mixtures justified the selection of the six binders for tests on concrete based on mortar tests.

\subsubsection{Freeze-Thaw Durability and Air Void Analysis}

As mentioned in section 5.2.3, all concrete mixtures were evaluated for their freeze-thaw resistance after being exposed to two different curing procedures. The durability factors were computed in accordance with the procedure specified in ASTM C666. Since the measured weight losses were very small (below 2\%), they were not considered in determining the durability factor. The \% weight loss and durability factors at the end of 300 cycles for specimens cured for 3 and 14 days are shown in Tables 5.5 and 5.6, respectively. Also, Figure 5.5 shows the comparison of average durability factors evaluated for all mixtures for specimens moist cured for different periods. The durability factors for freeze thaw resistance, irrespective of the length of curing for all mixtures was higher than 83\%, indicating a good performance. It was observed from experiments that for the same type of binder, specimens cured for 3 days had higher resonant frequencies at the end of 300 cycles compared to those cured for 14 days. This is most likely because mixtures, especially containing supplementary cementitious materials did not hydrate fully when cured for only 3 days and hydration process probably continued with age during the thawing phase of each cycle. 
Table 5.5: Data after 300 cycles of freeze-thaw for 3-day moist cured specimens

\begin{tabular}{|c|c|c|c|c|c|c|c|}
\hline Parameter & Specimen & C01 & C02 & C03 & C04 & C05 & C06 \\
\hline Weight Loss (\%) & 1 & 0.195 & -0.067 & 0.896 & 0.182 & 1.165 & 0.157 \\
\hline Weight Loss (\%) & 2 & 0.365 & 0.083 & 1.704 & 0.496 & 0.465 & -0.155 \\
\hline Durability Factor & 1 & 99.02 & 94.41 & 83.56 & 93.34 & 99.89 & 90.91 \\
\hline Durability Factor & 2 & 98.04 & 94.94 & 82.40 & 91.87 & 100.34 & 94.52 \\
\hline Avg Durability Factor & $1 \& 2$ & 98.53 & 94.68 & 82.98 & 92.60 & 100.11 & 92.71 \\
\hline
\end{tabular}

Table 5.6: Data after 300 cycles of freeze-thaw for 14-day moist cured specimens

\begin{tabular}{|c|c|c|c|c|c|c|c|}
\hline Parameter & Specimen & C01 & C02 & C03 & C04 & C05 & C06 \\
\hline Weight Loss (\%) & 3 & 0.182 & -0.004 & 0.434 & 0.173 & 0.100 & -0.046 \\
\hline Weight Loss (\%) & 4 & -0.071 & -0.037 & 0.070 & 0.061 & 0.070 & 0.016 \\
\hline Durability Factor & 3 & 98.73 & 99.89 & 94.39 & 98.71 & 98.13 & 98.92 \\
\hline Durability Factor & 4 & 98.64 & 99.89 & 95.42 & 99.02 & 98.78 & 99.14 \\
\hline Avg Durability Factor & $3 \& 4$ & 98.69 & 99.89 & 94.91 & 98.87 & 98.45 & 99.03 \\
\hline
\end{tabular}

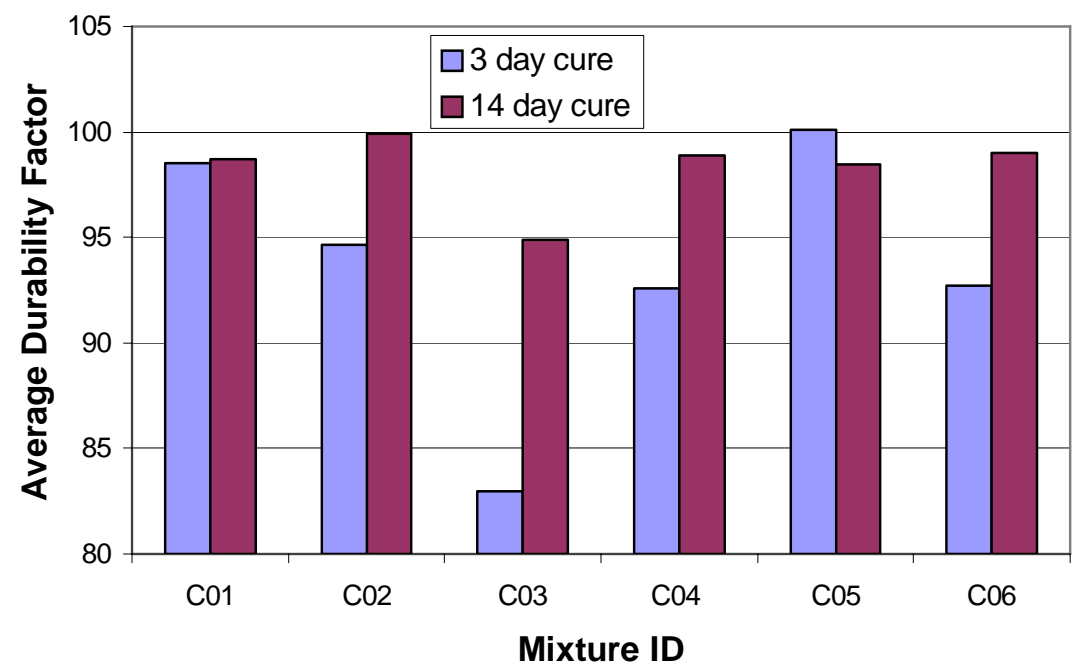

Figure 5.5: Durability factors after different curing periods

In order to account for the maturity gain of the specimens exposed to freeze-thaw cycles at early ages of curing, the maturity gain during every cycle, assuming a datum temperature of $-10^{\circ} \mathrm{C}\left(14^{\circ} \mathrm{F}\right)$ was determined. It is observed from Figure 5.6 that a 
maturity of approximately $18^{\circ} \mathrm{C}$-hrs (shown by the shaded region) is gained during every cycle. Thus, a maturity of approximately $5400^{\circ} \mathrm{C}-\mathrm{h}\left(9752^{\circ} \mathrm{F}-\mathrm{h}\right)$ or about $225^{\circ} \mathrm{C}$-days

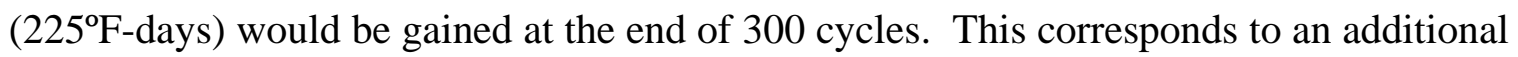
age of about 13 days when companion prisms are cured continuously at $21^{\circ} \mathrm{C}\left(69.8^{\circ} \mathrm{F}\right)$. So, the original frequencies used for computation of the durability factors for specimens moist cured for 3 days was based on a value obtained at 16 days of curing at $21^{\circ} \mathrm{C}$ (i.e., 3 +13 days). The results of resonant frequencies obtained for prisms continuously moist cured for $21^{\circ} \mathrm{C}$ were discussed in section 5.3.7.

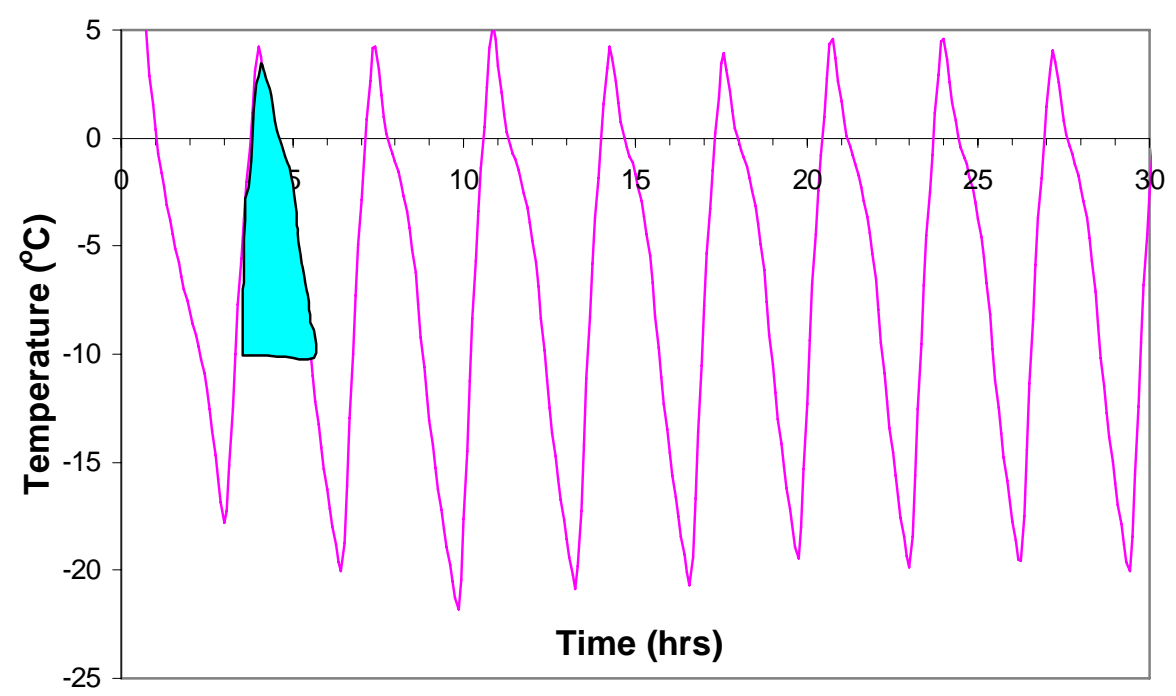

Figure 5.6: Temperature cycles of a specimen in the freeze-thaw chamber

Air void analysis was performed in accordance with the procedure specified in ASTM C457. The detailed procedure is explained in section 5.2.6. A magnification of 90x was used for all the specimens tested. One specimen was tested for determination of air void content and the spacing factor for each mixture. The sections were cut in the 
direction perpendicular to which the specimens were finished. As mentioned earlier, sections of 7-inch length and 3-inch height were used. This facilitated counting of at least 1300 points as required by the standard. Results of microscopic air-void determination performed in accordance with ASTM C457 shown in Table 5.7 indicate that most mixtures had air content over $6 \%$ with air-void spacing values less than 0.008 ” (0.203 mm). This verified the common belief that concretes having an air content of over $6 \%$ and an air-void spacing less than 0.008 " would be durable when subjected to the effects of freeze-thaw cycles. All mixtures had air contents in excess of $5.7 \%$. All mixtures except C06 had air void spacing factor less than 0.008 inch. Mixture C06 was marginally over the ASTM C457 prescribed spacing factor for concrete to be durable.

Table 5.7: Results from air void analysis

\begin{tabular}{|c|l|c|c|}
\hline Mix ID & Mixture combination & $\begin{array}{c}\text { \% Air } \\
\text { content }\end{array}$ & $\begin{array}{c}\text { Spacing factor, } \\
\text { in. (mm) }\end{array}$ \\
\hline C01 & Lonestar control & 6.4 & $0.0059(0.150)$ \\
\hline C02 & Lonestar + Rockport & 7.1 & $0.0073(0.185)$ \\
\hline C03 & Lonestar + slag & 5.9 & $0.0078(0.198)$ \\
\hline C04 & Lehigh + Rockport & 6.1 & $0.0064(0.162)$ \\
\hline C05 & Lehigh + Miami Fort & 7.1 & $0.0075(0.191)$ \\
\hline C06 & Essroc + Clifty Creek & 5.7 & $0.0089(0.226)$ \\
\hline
\end{tabular}

\subsubsection{Sorptivity Tests and Weight Loss on Drying}

As mentioned in section 5.2.4, two conditioning procedures were adopted for each of the six concrete mixtures for the purpose of determining sorptivity as well as the cumulative absorption of water over a period of time. Figure 5.7 shows the results obtained from sorptivity tests on different concrete mixtures that were moist cured for 3 days followed by air drying at $50 \% \mathrm{RH}$ at $20 \pm 1^{\circ} \mathrm{C}\left(68 \pm 2^{\circ} \mathrm{F}\right)$ for 11 days. Figure 5.7 
shows the cumulative weight gain due to capillary sorption plotted as a function of the square root of time in hours. It is clear from this figure that mixtures C01, C03 and C06 have the lowest cumulative sorption values after about 36 hours of immersion in water.

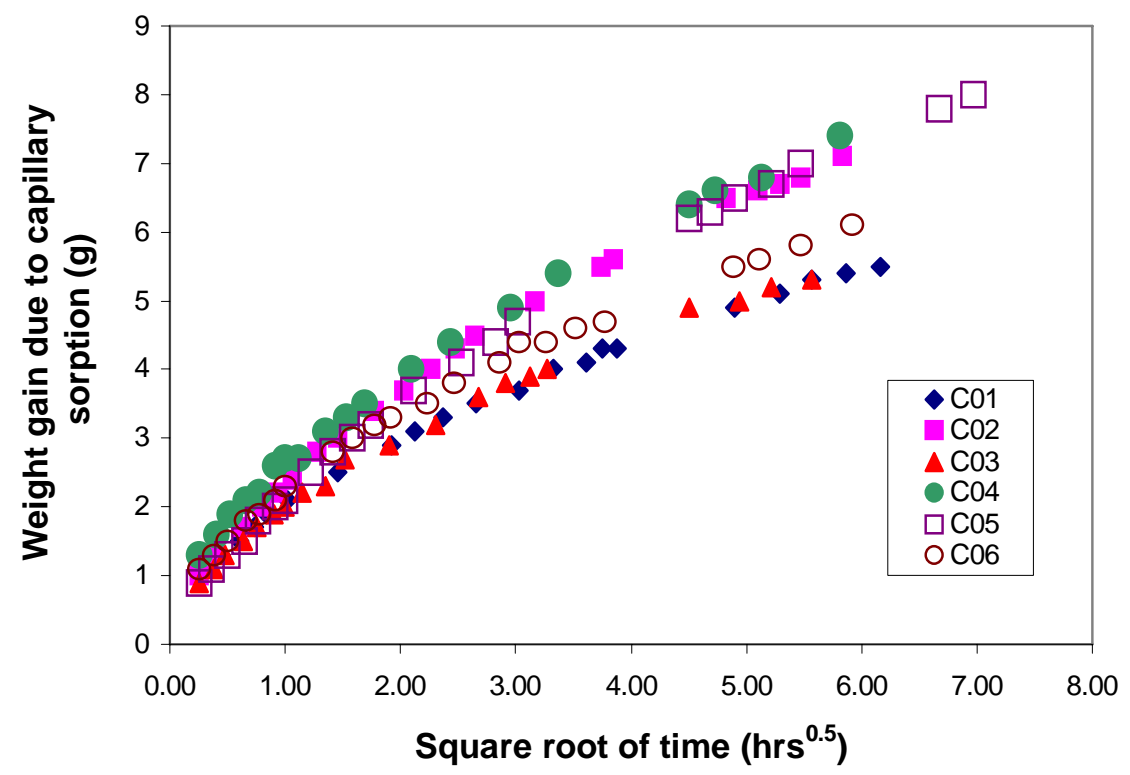

Figure 5.7: Weight gain during sorptivity for samples conditioned for 14 days

An important observation from the graph is that after a total of 14 days of conditioning, mixture C03 (Lonestar cement + slag) shows similar sorption trend as the control mixture C01. Higher sorption values might indicate higher susceptibility to damage due to freezing and thawing cycles. Also, higher sorption values indicate the higher permeability of the system, which in turn corresponds to lower strength. The capillary sorption tests were also performed on another set of specimens that were cured for a longer period of time. These set of specimens were moist cured for 3 days followed 
by air-drying at $50 \% \mathrm{RH}$ at $20 \pm 1^{\circ} \mathrm{C}\left(68 \pm 2^{\circ} \mathrm{F}\right)$ for 25 days. The results of these tests are shown in Figure 5.8.

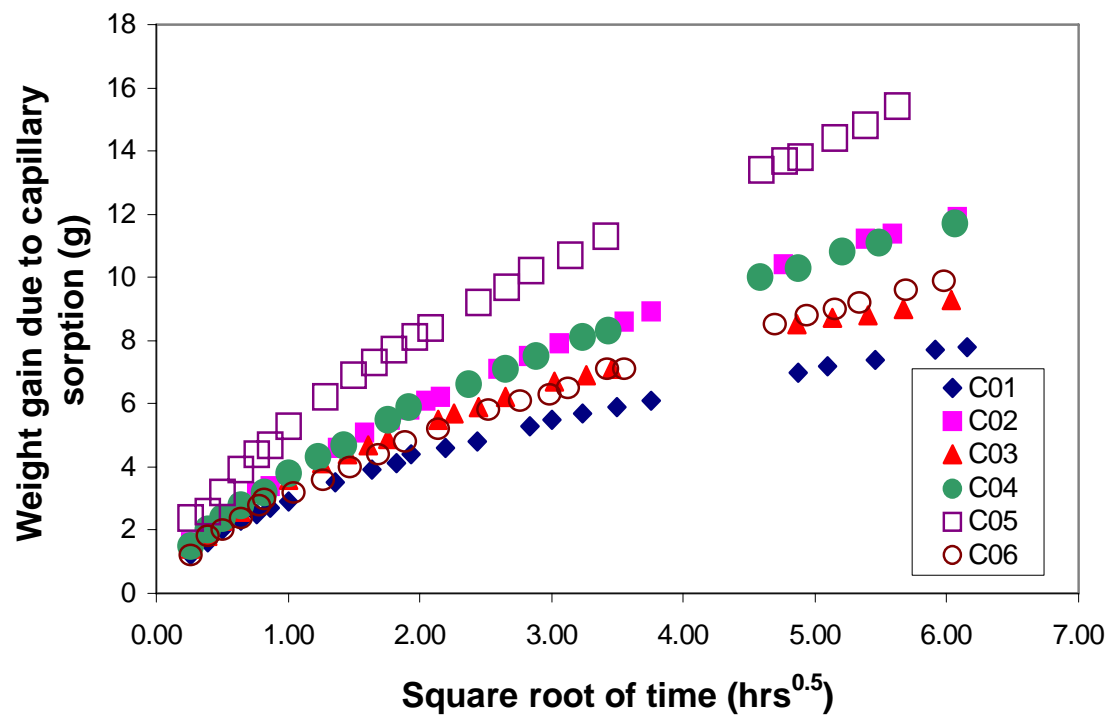

Figure 5.8: Weight gain during sorptivity for samples conditioned for 28 days

It is known that drier systems have more ingress of water due to capillary sorption compared to relatively saturated systems. Compared to the previous method of conditioning (14 days), all mixtures that were conditioned for a total of 28 days (3day moist cure and 25 day air dry) showed higher cumulative sorption values. The trends in Figure 5.8 are similar to that in Figure 5.7 with C01, C03 and C06 showing the lowest cumulative sorption values after 36 hours of immersion in water. Mixture C05 shows a significant increase in the amount of water gained after 28 days of conditioning compared to 14-day conditioning period, which suggests an increased permeability of the system. 
The rate of capillary sorption also known as the sorptivity was also determined. The cumulative water gained per unit area, $i\left(\mathrm{~g} / \mathrm{mm}^{2}\right)$ can be expressed as:

$$
i=S t^{0.5}
$$

where $S=$ sorptivity in $\mathrm{mm} /$ minute $^{0.5}$

and $t^{0.5}=$ square root of time in minutes

The sorption values for the linear portions of the plots shown in Figures 5.7 and 5.8 were plotted as a function of the square root of time. Data up to about 625 minutes was typically linear and hence all points up to this point were used in computing sorptivity. A typical plot showing computation of sorptivity is shown in Figure 5.9. Table 5.8 shows the sorptivity values obtained for all the six mixtures tested for specimens conditioned for different periods mentioned earlier.

Table 5.8: Summary of sorptivity values

\begin{tabular}{|c|l|c|c|}
\hline \multicolumn{2}{|c|}{} & \multicolumn{2}{c|}{ Sorptivity, S $\left(\mathrm{mm} / \mathrm{min}^{0.5}\right)$} \\
\hline Mixture ID & Combination & 14 day age & 28 day age \\
\hline C01 & Lonestar control & 0.0149 & 0.0230 \\
\hline C02 & Lonestar + Rockport & 0.0219 & 0.0356 \\
\hline C03 & Lonestar + slag & 0.0167 & 0.0285 \\
\hline C04 & Lehigh + Rockport & 0.0203 & 0.0347 \\
\hline C05 & Lehigh + Miami Fort & 0.0217 & 0.0455 \\
\hline C06 & Essroc + Clifty Creek & 0.0176 & 0.0282 \\
\hline
\end{tabular}

From this table, it is clear that for a particular mixture, the sorptivity increases with an increase in the duration of curing. Mixture C02 showed the highest sorptivity after 14 days of conditioning followed by mixtures C05 and C04. After 28 days of 
conditioning, C05, C02 and C04 showed the highest sorptivity values respectively. In general, mixtures C01, C03 and C06 had the lowest sorptivity values.

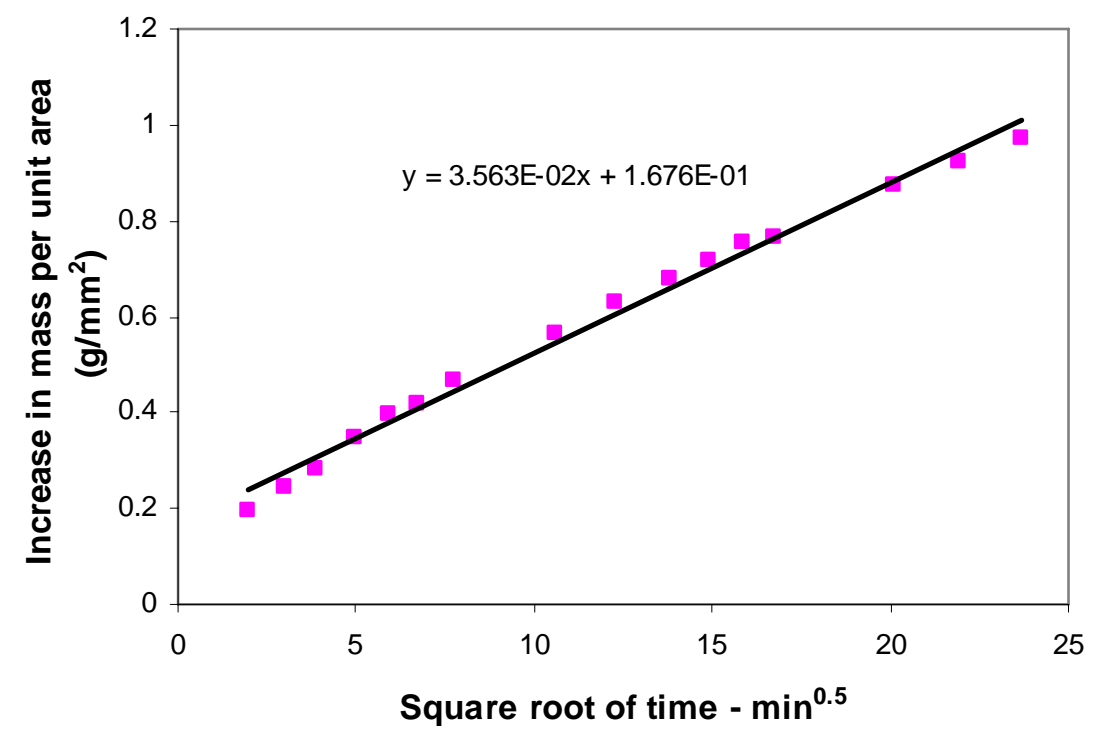

Figure 5.9: Determination of sorptivity for specimen conditioned for 28 days (C02)

Weight loss on drying tests was performed on specimens of dimension $3 \times 3 \times 11$ inches. This test was carried out in order to determine the rate at which the six concrete mixtures hydrate over time when subjected to air drying. The specimens were de-molded from the forms after 24 hours of casting and weighed. This weight was used as the base (or initial) weight. The specimens were then transferred to a drying room maintained at a temperature of $20 \pm 1^{\circ} \mathrm{C}\left(68 \pm 2^{\circ} \mathrm{F}\right)$ and relative humidity of $50 \%$. Two specimens were used for each mixture and an average value of weight loss determined at several ages was used for further analysis. Figure 5.10 shows the average percent weight loss, which was computed as a percentage of the original weight determined 24 hours after casting. 


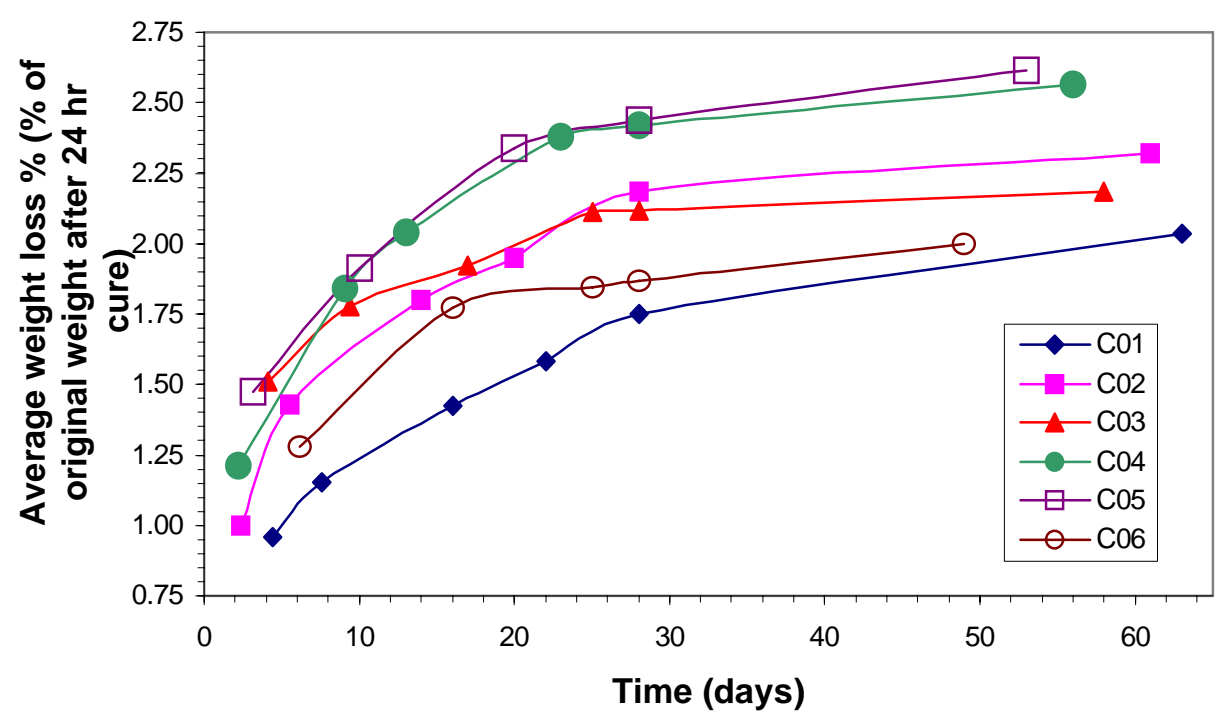

Figure 5.10: Percent weight loss on drying with age (\% of original weight)

It is evident from the figure that mixtures C04 and C05 have the highest weight loss percentages over the test period (over 50 days). This is an indication that these two mixtures show slow hydration over the period evaluated. This is believed to be primarily because of Lehigh cement with which they are prepared, having $\mathrm{C}_{2} \mathrm{~S}$ content of about 25\%. It is also well known that $\mathrm{C}_{2} \mathrm{~S}$ in cement is responsible for later age strength development. For most of the mixtures, the \% weight loss curves are steep up to about 20 days, after which they become relatively flat. Mixture C03 had a high initial weight loss, which may be due to the higher replacement level of cementitious material used. After 28 days of drying, mixtures C01, C06, C03 and C02 had the lowest drying percentages, respectively. At the same age, mixtures C04 and C05 had the highest drying percentages, which in turn would correspond to slower hydration and thus slow strength 
development. This fact was confirmed by the results of compressive and flexural strength tests discussed in earlier sections.

\subsubsection{Resonant Frequency Development Over Time}

Figure 5.11 shows the resonant frequency development as a function of the curing time. It is observed from the above plot that mixture C06 had the highest resonant frequency $(\mathrm{kHz})$ at 1 day age. Mixtures C04 and C05 showed the lowest frequencies at this age, which was in agreement with the fact that these mixtures were prepared with Lehigh cement, having a relatively low $\mathrm{C}_{3} \mathrm{~S}$ content. Mixtures C06, C03 and C02 showed similar or higher resonant frequencies compared to the control mixture C01 at about 1 day age while mixture C04 exceeds the frequency of C01 at about 10 days.

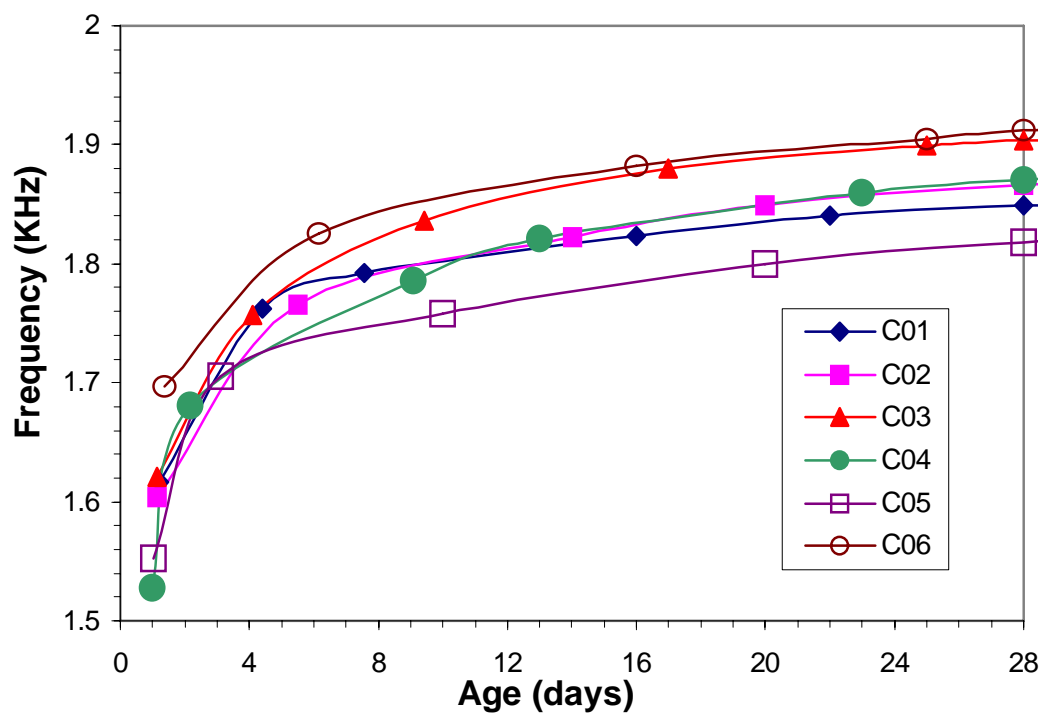

Figure 5.11: Resonant frequency development with time 
Mixture C05 prepared with a Class F fly ash never exceeds the frequency of the control mixture C01 and shows the lowest frequencies even after 28 days of moist curing.

\subsubsection{Effect of Conditioning Period on the Salt Scaling Resistance}

As discussed earlier, the scaling specimens conditioned for two different periods were subjected to cycles of freezing and thawing with $3 \% \mathrm{NaCl}$ solution on the surface for the purpose of deicing. The resistance to freeze thaw action in the presence of deicer salt solution was estimated based on the weight of scaled particles. It was mentioned in section 2.2 that concrete specimens having weight loss greater than $0.8 \mathrm{~kg} / \mathrm{m}^{2}$ after 50 cycles of freezing and thawing in the presence of salt solution is not considered to be scaling resistant. This value has been proposed by the Ministry of Transportation of Ontario (MTO) and is commonly used by researchers for evaluating the scaling resistance of concrete. ASTM C672 recommends visual rating as a criterion for evaluating the scaling resistance of concrete. However, since the method of visual rating is highly operator subjective, the scaling resistance of concrete for this research was determined on the basis of total weight of scaled particles at the end of 50 cycles of freezing and thawing.

Figure 5.12 shows the average weight of scaled particles of two specimens tested for each mixture. The figure shows the comparison when the specimens are conditioned for a total of 6 days ( 3 day moist cure followed by 3 day dry cure at $20 \pm 1^{\circ} \mathrm{C}\left(68 \pm 2^{\circ} \mathrm{F}\right)$ and $50 \% \mathrm{RH}$ ) and a total of 28 days (14 day moist cure followed by 14 day dry cure at 20 $\pm 1^{\circ} \mathrm{C}$ and $\left.50 \% \mathrm{RH}\right)$. 


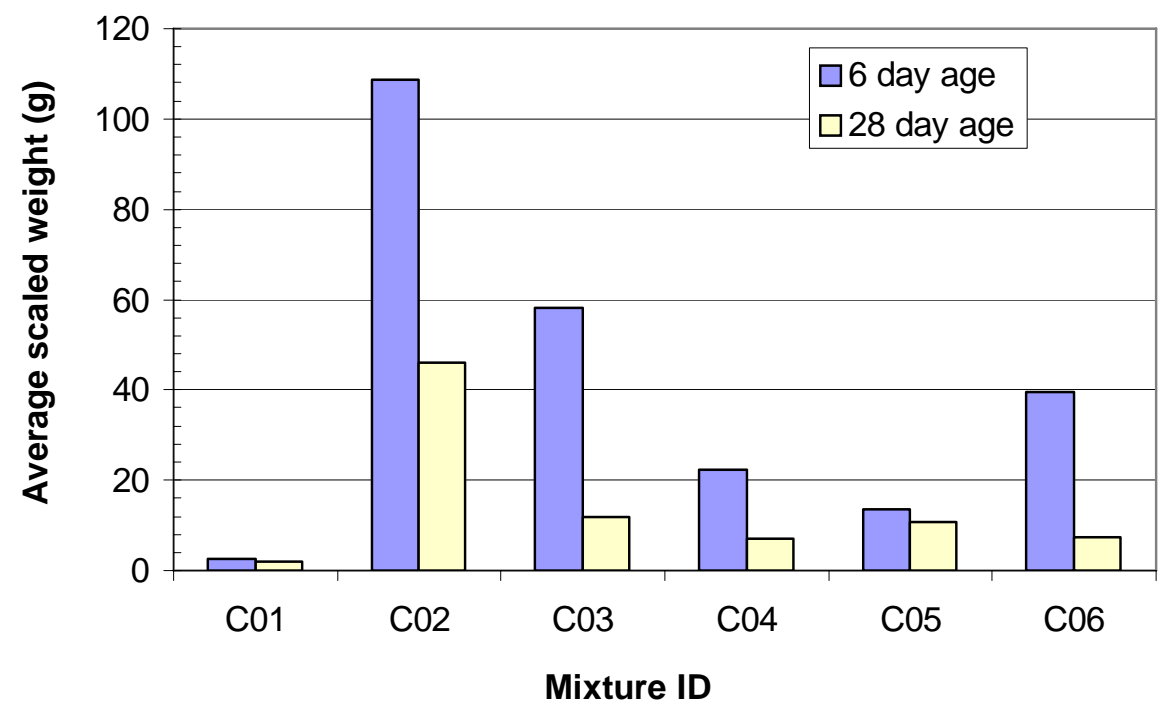

Figure 5.12: Average scaled weight for different concrete mixtures after different conditioning periods after 50 cycles

From this figure, it is clear that after a total of 6 days of conditioning, mixture C02 had the maximum weight loss due to scaling, followed by mixtures C03 and C06 after 50 cycles. Mixture C02 had an average scaled weight of 108.73 g (3.83 oz) while mixtures C03 and C06 had average scaled weights of 58.23 g (2.05 oz.) and $39.48 \mathrm{~g}$ (1.39 oz), respectively. Increasing the total conditioning period from 6 days to 28 days seemed to have a beneficial effect on the scaling resistance of mixtures C02, C03 and C06. The average scaled weights for C02, C03 and C06 after 28 days of conditioning were $46 \mathrm{~g}$ (1.62 oz), $11.73 \mathrm{~g}(0.41 \mathrm{oz})$ and $7.34 \mathrm{~g}$ (0.26 oz), respectively.

The average scaled weight per unit surface area was also computed for the purpose of comparison with the value of $0.8 \mathrm{~kg} / \mathrm{m}^{2}$, recommended by the MTO. Figure 
5.13 provides a comparison of the different concrete mixtures with respect to the total average scaled weight per unit surface area and also distinctly shows mixtures that do not satisfy the maximum scaled weight of $0.8 \mathrm{~kg} / \mathrm{m}^{2}$. After a total conditioning period of 6 days, mixtures C02, C03 and C06 failed the scaling resistance test. C02, C03 and C06 had scaled unit weights of 2.878, 1.601 and $1.085 \mathrm{~kg} / \mathrm{m}^{2}$, respectively. However, after a total conditioning period of 28 days, only mixture C02 with a scaling of $1.265 \mathrm{~kg} / \mathrm{m}^{2}$ failed the test. Pictures of scaled surfaces of specimens cured for both conditioning periods can be found in Appendix C.

Scaling resistance tests were also performed on specimens that were coated with a layer of curing compound. The purpose of this test was to determine whether or not the curing compound would have any beneficial effect on the weight loss of concrete specimens exposed to the salt solution. Figure 5.14 shows the average scaled weight per unit area for different mixtures coated with the curing compound. It is evident from Figure 5.14 that the layer of curing compound causes a significant reduction in the amount of surface scaled concrete. Except mixture C04 cured for 6 days, all other mixture combinations tested after 6 day and 28 days of conditioning showed weight loss less than $5 \mathrm{~g}(0.17 \mathrm{oz})$. All the mixtures had scaled weights much below the maximum prescribed value of $0.8 \mathrm{~kg} / \mathrm{m}^{2}$. Also, from visual observation of the surface, it was found that the layer of curing compound peels off from the surface gradually. It could be concluded that during the initial cycles, the curing compound acts a protective shield for the surface concrete layer thereby reducing the amount of scaling. Even though some of the curing compound peels off gradually, it cures the surface layer of concrete and makes it reasonably resistant to the freeze thaw action in the presence of deicing salts. The 
pictures of scaled surfaces of the specimens coated with curing compound after both conditioning periods are shown in Appendix C.

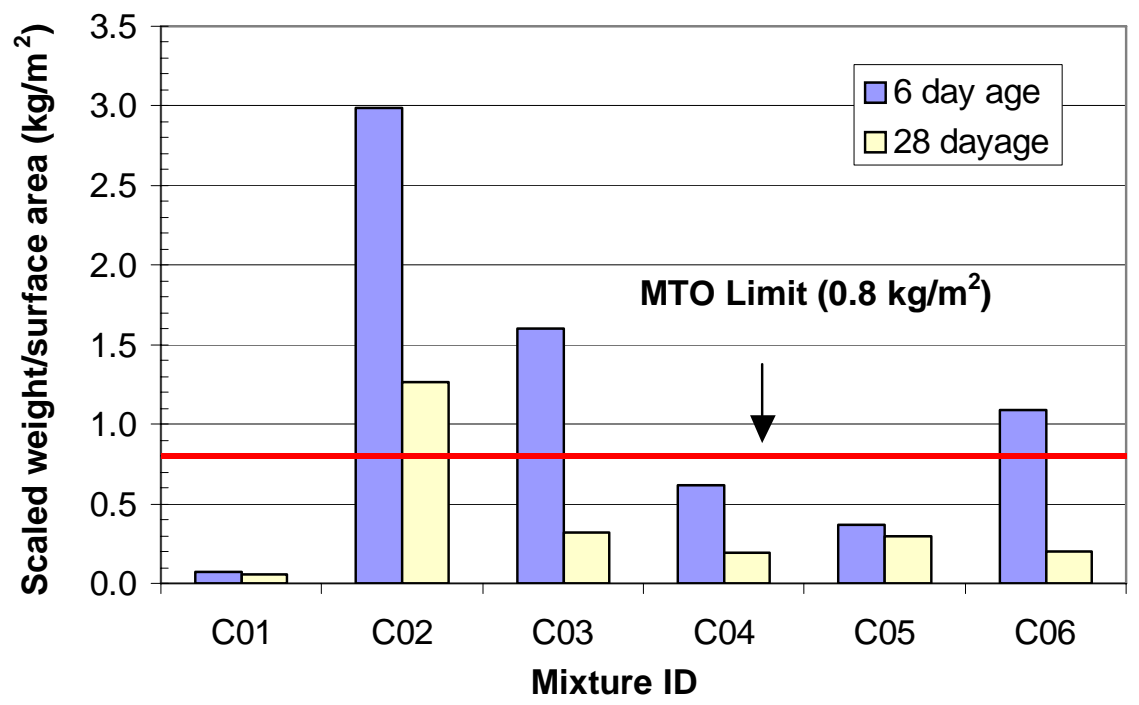

Figure 5.13: Comparison of scaled weight per unit surface area for different concrete mixtures after different conditioning periods 


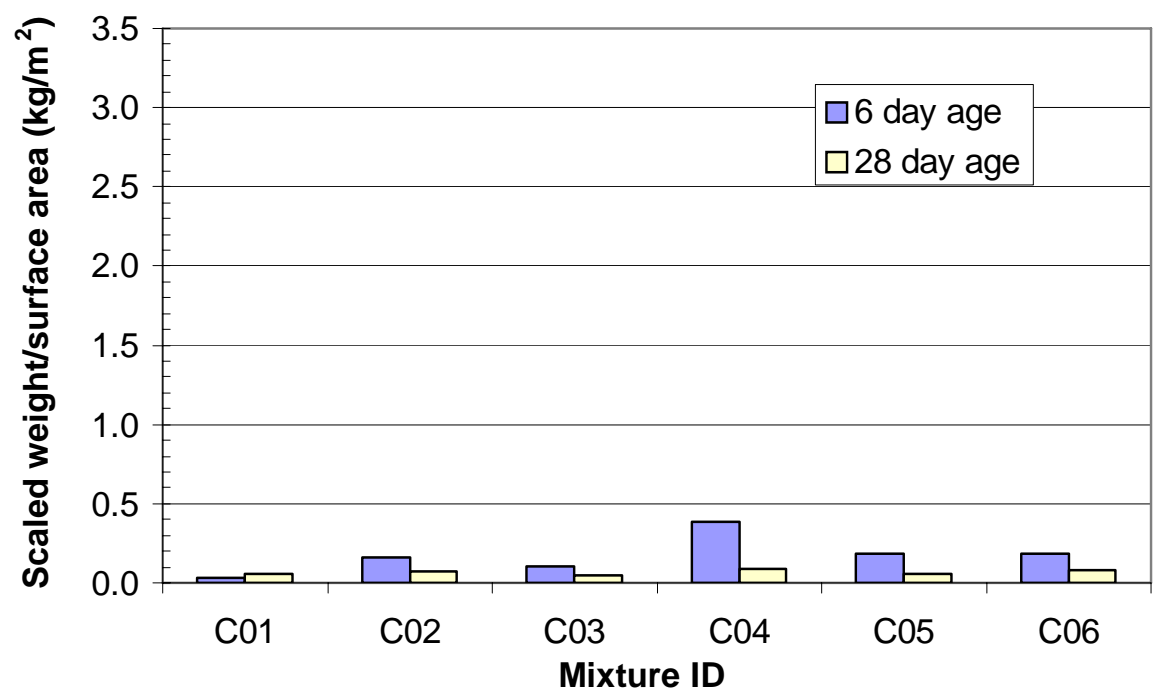

Figure 5.14: Average scaled weight for different concrete mixtures and curing conditions coated with curing compound after 50 cycles

\subsubsection{Observations from Scaling Tests}

There are several critical factors that may influence the amount of scaling in concrete. Researchers have earlier pointed out the importance of a stable air void system with a maximum air void spacing of 0.008 inches for concrete to be resistant to the effects of freezing and thawing (Marchand et al., 1996, Pigeon et al., 1987, Pigeon et al., 1996). The amount of freezable water in the system, amount of bleed water, sufficient strength of concrete and proper construction practices are some other factors governing the scaling resistance. Higher the bleeding, greater would be the porosity of the surface layer. Consequently, the ingress of salt solution into the surface layer would be greater, rendering it potentially weak against the freeze-thaw action. 
It was observed from experiments that most of the scaling occurs during the first 10 to 15 cycles. After the top layer scales off, there is very minimal scaling till the completion of the test, i.e., until the completion of 50 cycles. Figure 5.15 shows the average scaled weight of two specimens (conditioned for 6 days) tested at every 5-cycle intervals. It is observed that a bulk of the scaling occurs up to about 15 cycles.

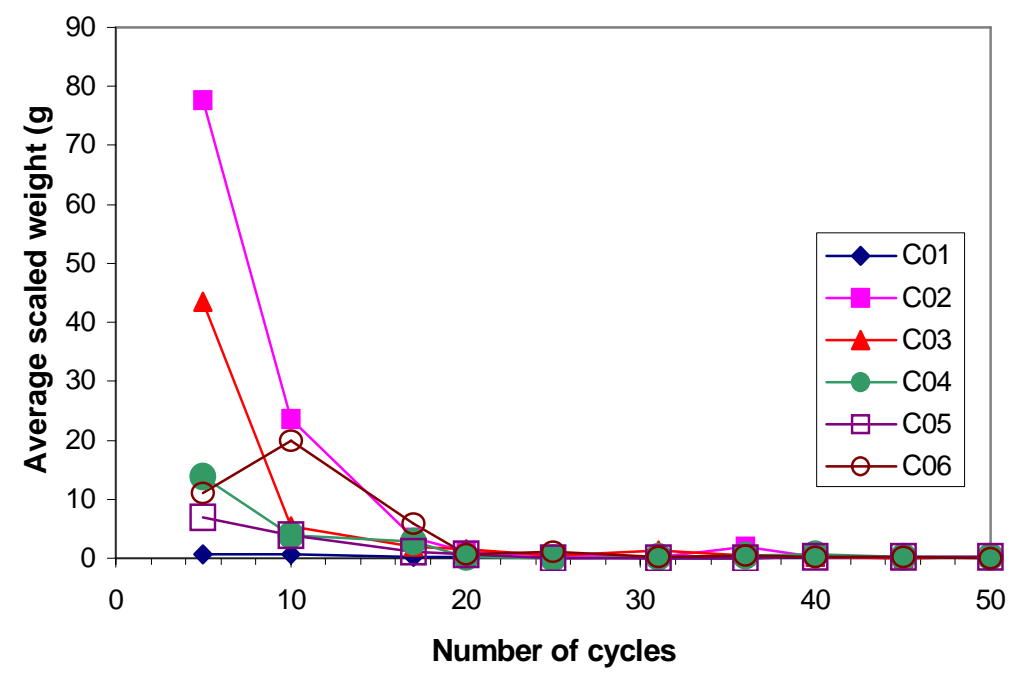

Figure 5.15: Amount of scaling at 5-cycle intervals

This Figure implies that the top few millimeters of the finished surface is the most susceptible to scaling in the presence of deicer salts. The resistance of the top layer of any concrete would depend upon factors like porosity and water absorption. Higher strength would also improve the scaling resistance of concrete. This is explained by the fact that increasing the curing period for the specimen's results in reduced scaling.

Figures 5.16 and 5.17 show images obtained using a scanning electron microscope (SEM) for the surface layer of C02 and the bulk portion of C02. It can be 
seen from Figures 5.16 and 5.17 that the surface layer of C02 has a much higher porosity compared to the bulk of C02. As a result of the increased porosity at the surface layer, the salt solution can penetrate easily into the concrete thereby resulting in damage after repeated after freeze-thaw cycles. Some additional images to confirm the difference in porosities at the surface layer and a region away from the surface are shown in Figures 5.18 and 5.19.

The difference in porosities at the surface layer and bulk region of concrete becomes more evident after segmentation of the porous regions, which is shown in Figure 5.20 and 5.21. The qualitative evaluation of these figures show that the surface layer of C02 after segmentation has more porosity (shown by dark regions) compared to the bulk region of C02 after segmentation. Also, on comparing Figures 5.20 and 5.22, it is found that C01 has a lower porosity at the surface layer compared to C02. Consequently, the amount of scaling in mixture C01 would be lower compared to C02 and this is reflected in the scaled weight per unit area plot shown in Figure 5.13. 


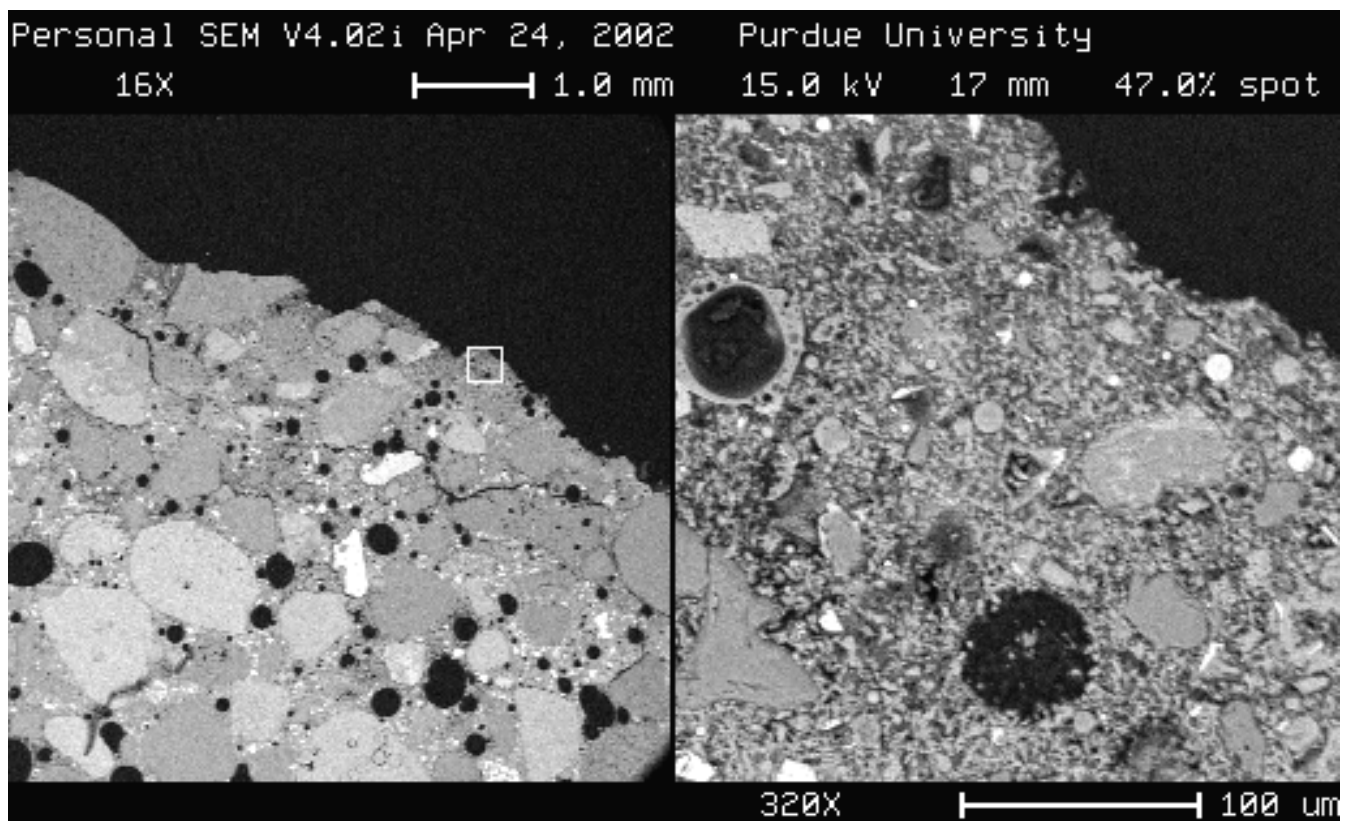

Figure 5.16: SEM image of surface layer of C02 specimen (I)

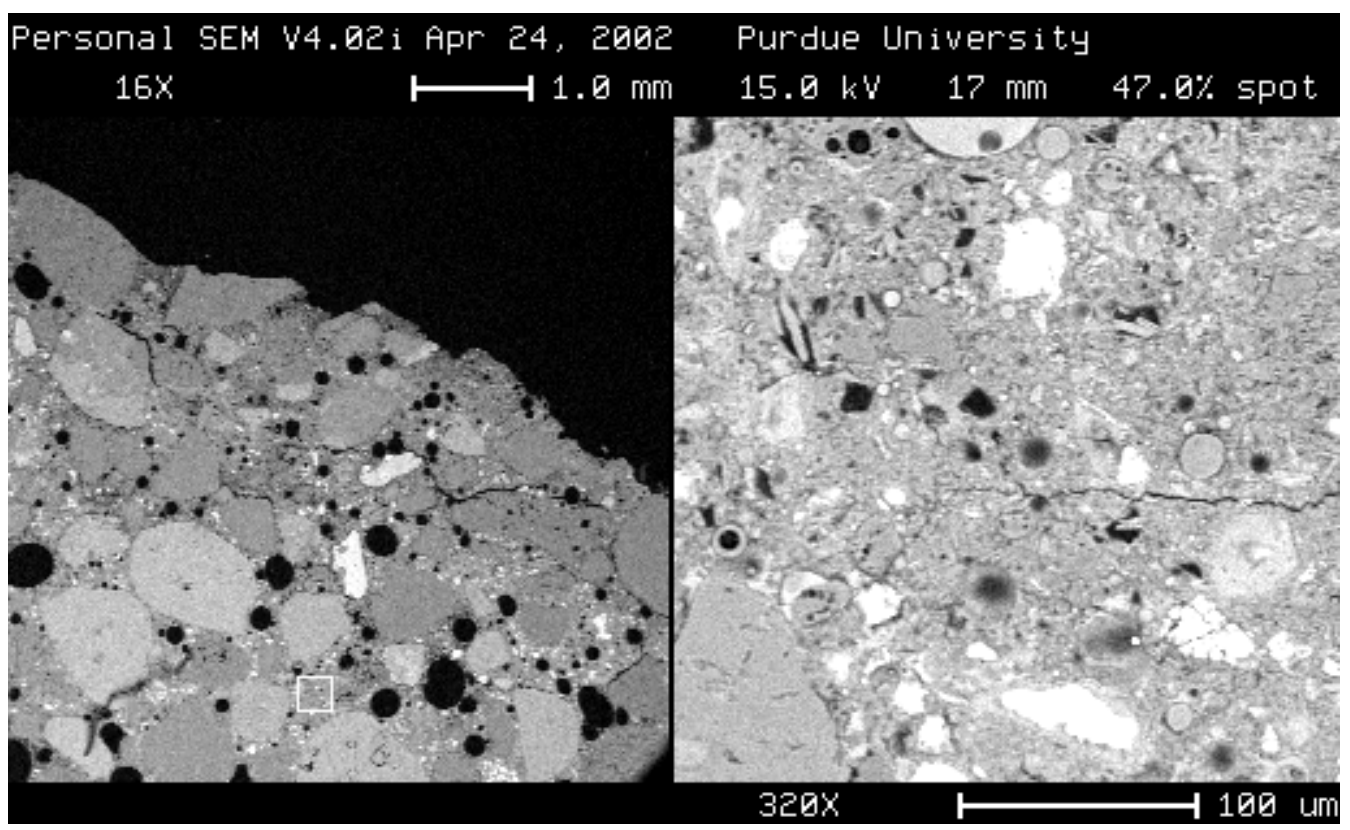

Figure 5.17: SEM image of bulk (away from the surface) region of C02 specimen (I) 


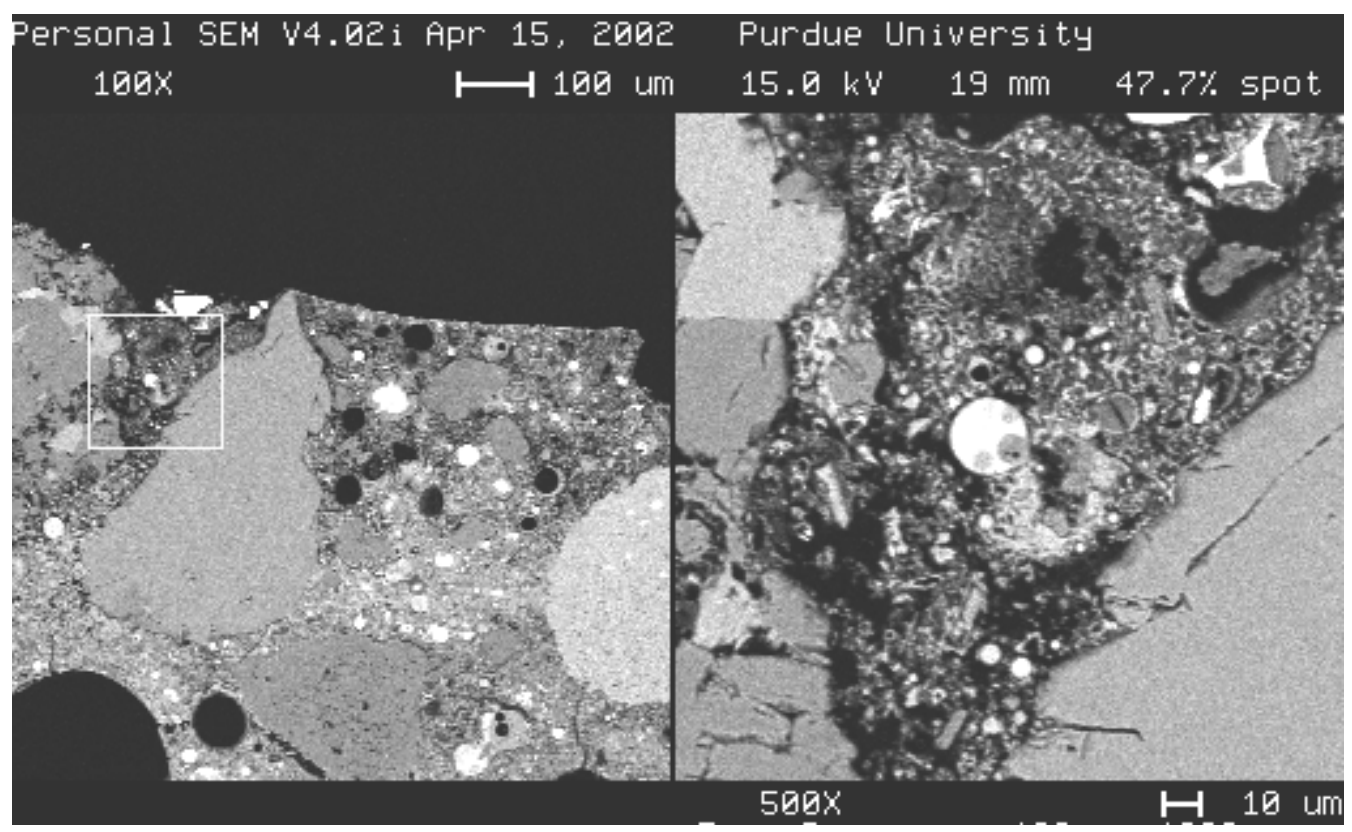

Figure 5.18: SEM image of surface layer of C02 specimen (II)

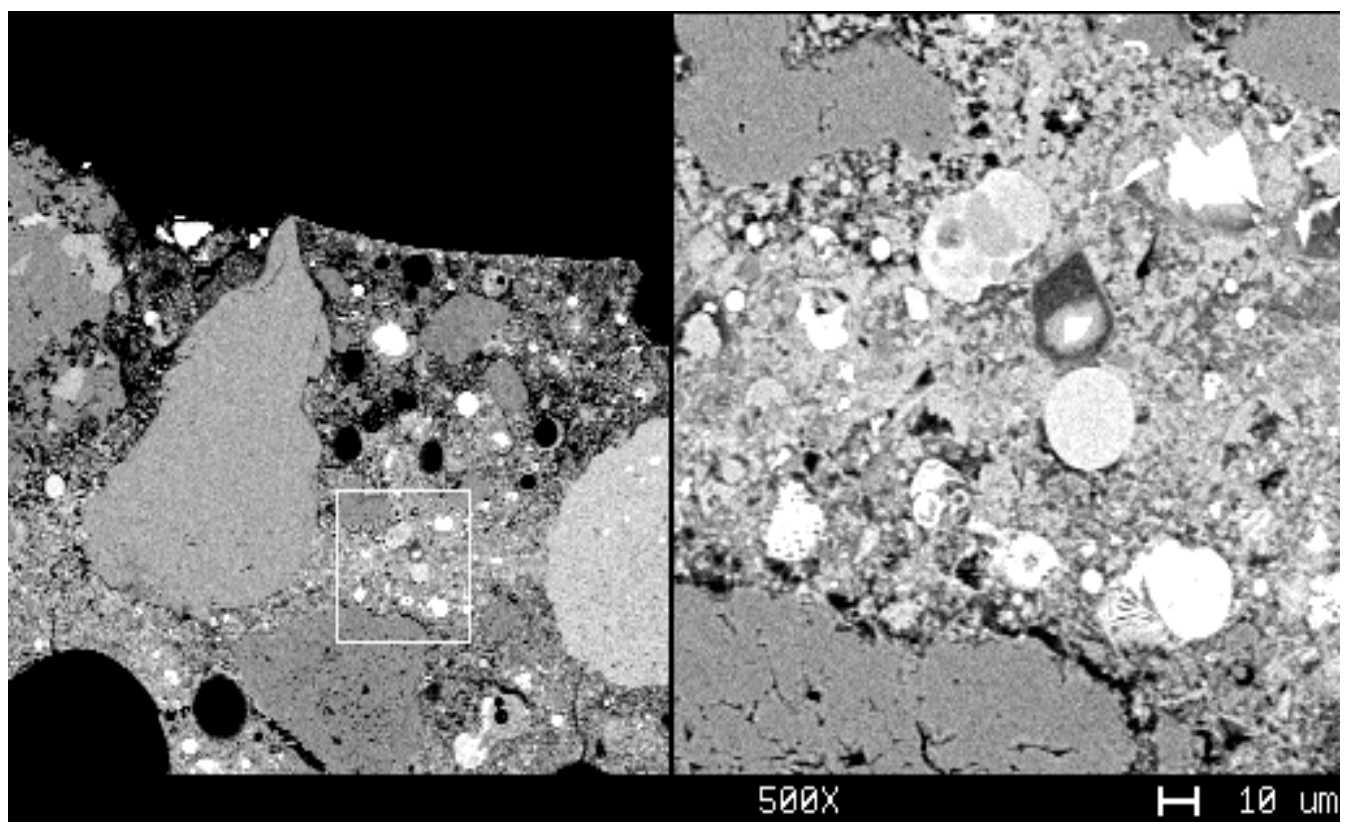

Figure 5.19: SEM image of bulk (away from the surface) region of C02 specimen (II) 

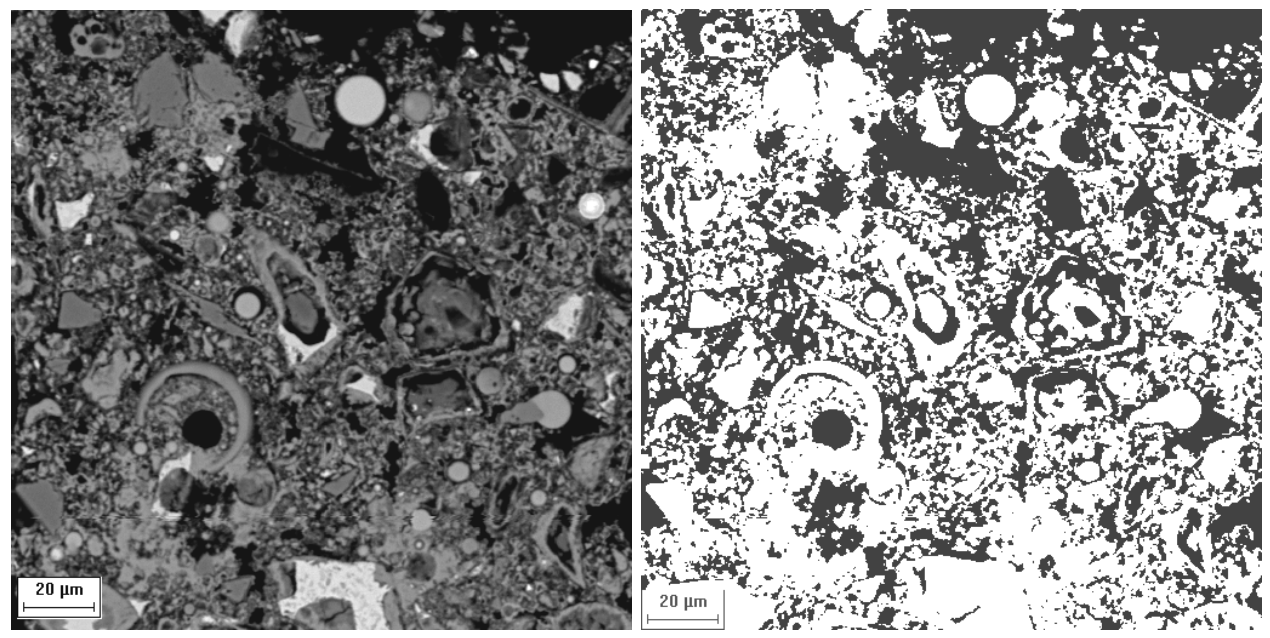

Figure 5.20: SEM image of surface layer of C02 specimen before and after segmentation
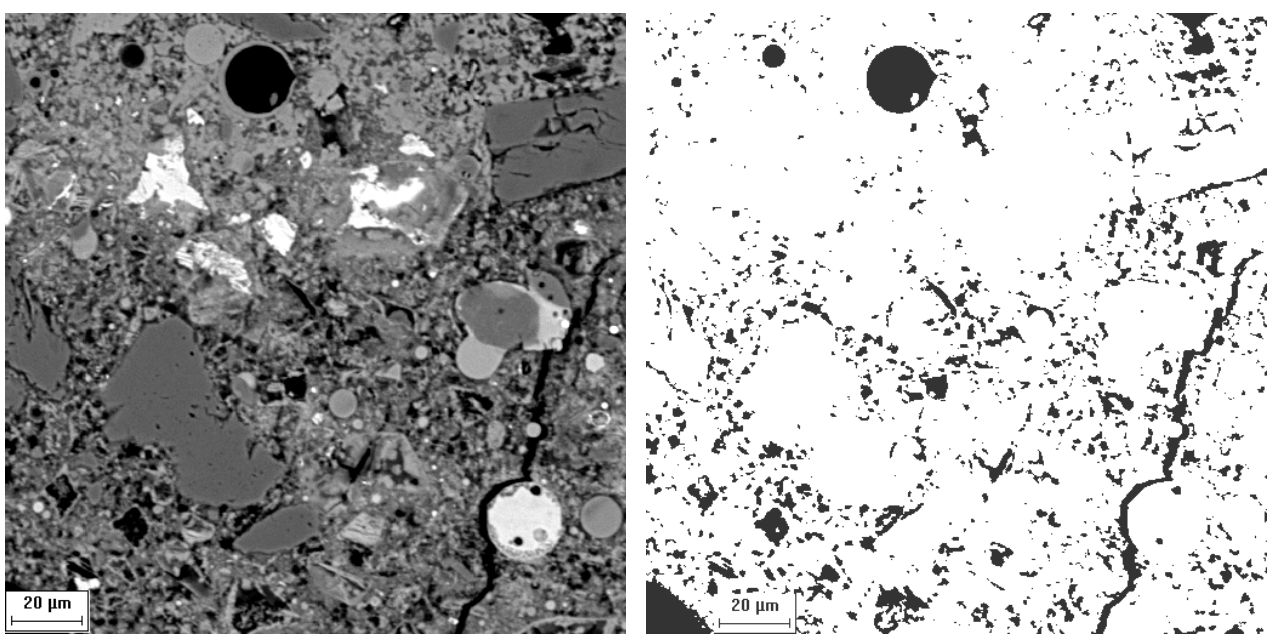

Figure 5.21: SEM image of bulk (away from the surface) region of C02 specimen before and after segmentation 

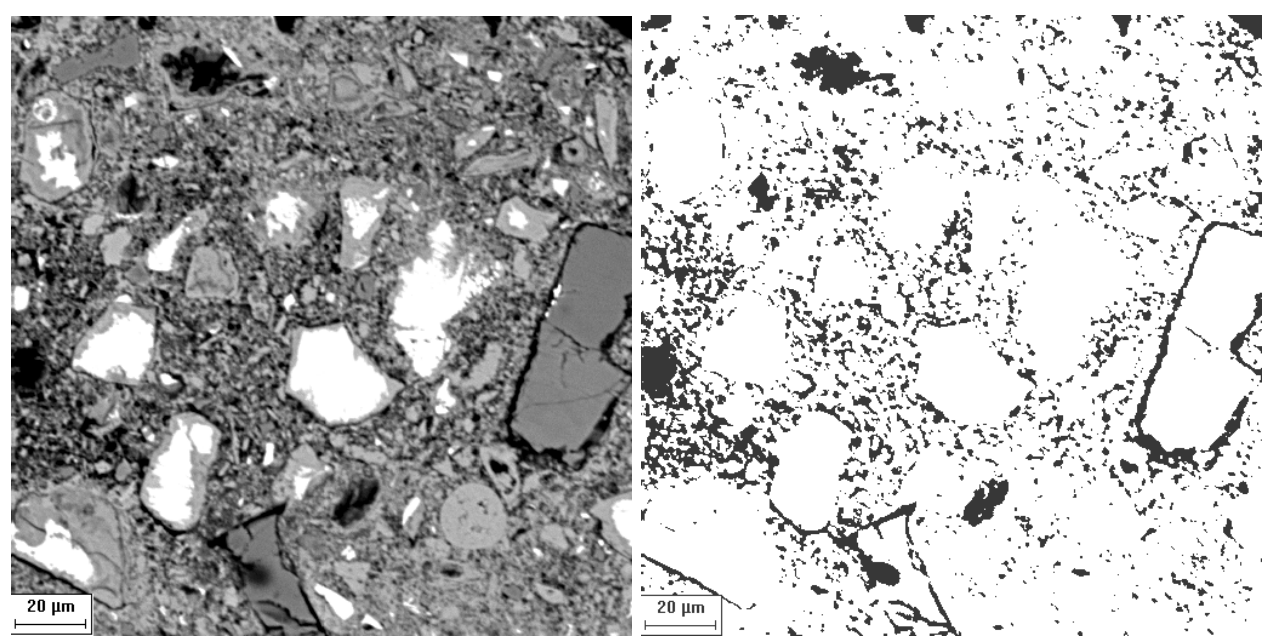

Figure 5.22: SEM image of surface layer of C01 specimen before and after segmentation

Table 5.9 compiles all possible causes that could influence the scaling of concrete. It is anticipated that higher sorptivity values would result in increased problems with regards to scaling. Mixtures C04 and C05 had similar sorptivity values after 14 days of conditioning as compared to C02, but did not scale as much as C02 after 6 days of conditioning. C05 had the highest sorptivity after 28 days of conditioning, but was among the most resistant to scaling. Hence, a definite trend could not be established between the amount of scaling and the water ingress into the concrete mixture. No particular trend was observed when the weight loss on drying data was compared with scaling. Also, higher strengths did not necessarily show improved resistance to scaling of concrete mixtures. However, some correlation existed between the slump and amount of scaling for a particular concrete mixture.

Figure 5.23 shows the amount of scaled weight plotted against the slump for all concrete mixtures tested. It is observed from this figure that higher slumps may have 
caused higher scaling in the concrete mixtures tested. Higher slumps might result in higher amount of bleed water during the process of vibration, thereby resulting in increased porosity of the top few millimeters in concrete. This is verified from Figures 5.20 and 5.22, which show the SEM images of the surface layers of mixture C02 (scaled excessively) and mixture C01 (little scaling). Further investigations need to be carried out in order to validate this trend.

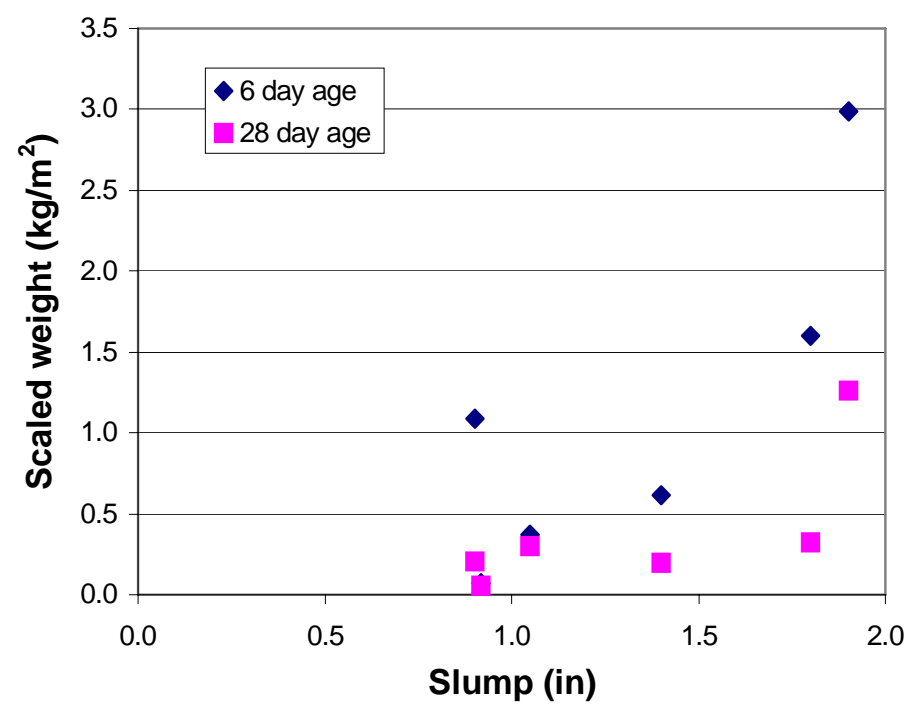

Figure 5.23: Correlation between amount of scaling and slump 
Table 5.9: Compilation of information for various mixtures

\begin{tabular}{|c|c|c|c|c|c|c|c|}
\hline Test & Remarks & $\mathrm{C01}$ & $\mathrm{C} 02$ & $\mathrm{CO3}$ & $\mathrm{CO4}$ & $\mathrm{CO5}$ & C06 \\
\hline $\begin{array}{l}\text { Compressive } \\
\text { strength (psi) } \\
4 \times 8\end{array}$ & 7 day & 4999.20 & 5357.26 & 5742.36 & 4659.85 & 4395.69 & 4978.91 \\
\hline $\begin{array}{l}\text { Compressive } \\
\text { strength (psi) } \\
4 \times 8\end{array}$ & 28 day & 5881.21 & 7022.99 & 7893.46 & 6607.65 & 6159.29 & 6812.14 \\
\hline $\begin{array}{l}\text { Flexural } \\
\text { Strength } \\
\text { (psi)-6x6x21 }\end{array}$ & 7 day & 797.13 & 718.58 & 850.38 & 666.92 & 666.92 & 723.92 \\
\hline $\begin{array}{l}\text { Sorptivity } \\
\left(\mathrm{mm} / \mathrm{min}^{0.5}\right)\end{array}$ & $\begin{array}{c}3+11 \text { day } \\
\text { cure }\end{array}$ & 0.0149 & 0.0219 & 0.0167 & 0.0203 & 0.0217 & 0.0176 \\
\hline $\begin{array}{l}\text { Sorptivity } \\
\left(\mathrm{mm} / \mathrm{min}^{0.5}\right)\end{array}$ & $\begin{array}{c}3+25 \text { day } \\
\text { cure }\end{array}$ & 0.0230 & 0.0356 & 0.0285 & 0.0347 & 0.0455 & 0.0282 \\
\hline $\begin{array}{l}\text { Weight loss } \\
\text { on drying ( } \% \\
\text { of original) }\end{array}$ & 6 day & 1.08 & 1.45 & 1.6 & 1.55 & 1.65 & 1.28 \\
\hline $\begin{array}{l}\text { Weight loss } \\
\text { on drying ( } \% \\
\text { of original) }\end{array}$ & 28 day & 1.73 & 2.18 & 2.1 & 2.41 & 2.44 & 1.86 \\
\hline $\begin{array}{l}\text { Resonant } \\
\text { frequency } \\
(\mathrm{KHz})\end{array}$ & 6 day & 1.785 & 1.795 & 1.795 & 1.745 & 1.735 & 1.82 \\
\hline $\begin{array}{l}\text { Resonant } \\
\text { frequency } \\
(\mathrm{KHz})\end{array}$ & 28 day & 1.849 & 1.866 & 1.904 & 1.87 & 1.818 & 1.912 \\
\hline $\begin{array}{l}\text { Scaled } \\
\text { weight-50 } \\
\text { cycles (g) }\end{array}$ & $\begin{array}{c}3+3 \text { day } \\
\text { age }\end{array}$ & 2.64 & 108.73 & 58.23 & 22.43 & 13.48 & 39.63 \\
\hline $\begin{array}{l}\text { Scaling (50 } \\
\text { cycles) } \\
\left(\mathrm{kg} / \mathrm{m}^{2}\right)\end{array}$ & $\begin{array}{c}3+3 \text { day } \\
\text { age }\end{array}$ & 0.073 & 2.989 & 1.601 & 0.617 & 0.370 & 1.089 \\
\hline $\begin{array}{l}\text { Scaled } \\
\text { weight-50 } \\
\text { cycles (g) }\end{array}$ & $\begin{array}{l}14+14 \\
\text { day age }\end{array}$ & 2.12 & 46.00 & 11.73 & 7.09 & 10.85 & 7.34 \\
\hline $\begin{array}{l}\text { Scaling (50 } \\
\text { cycles) } \\
\left(\mathrm{kg} / \mathrm{m}^{2}\right)\end{array}$ & $\begin{array}{l}14+14 \\
\text { day age }\end{array}$ & 0.058 & 1.265 & 0.323 & 0.195 & 0.298 & 0.202 \\
\hline $\begin{array}{l}\text { Average } \\
\text { slump (inch) }\end{array}$ & & 0.9 & 1.9 & 1.8 & 1.4 & 1.1 & 0.9 \\
\hline
\end{tabular}

Conversion: $1 \mathrm{~g}=0.035 \mathrm{oz} ; 1$ ” $=2.5 \mathrm{~cm} ; 1 \mathrm{psi}=6.9 \mathrm{kPa}$ 


\subsection{Summary}

1. All concrete mixtures prepared with supplementary materials had 28-day compressive strength in excess of 6000 psi. All mixtures except the ones prepared with Lehigh cement exceeded the strength of the control mixture after 7 days of curing.

2. All mixtures satisfied the INDOT flexural strength requirement (for opening to traffic) of 550 psi when tested at an age 7 days.

3. Most of the mixtures satisfied the maximum air-void spacing factor requirement of 0.008” (0.203 mm). Mixture C06 had a spacing factor of $0.0089 ”(0.226 \mathrm{~mm})$.

4. Freeze thaw testing for all concrete mixtures was performed after two different periods of curing. All mixtures moist cured for 3 days and 14 days satisfied the minimum durability factor requirement of $60 \%$.

5. Salt scaling resistance was evaluated by determining the scaled weight per unit surface area. Two conditioning procedures were investigated. One set of specimens was moist cured for 3 days followed by 3 days of air-drying. Mixtures C02, C03 and C06 failed the test as they had scaled particles in excess of $0.8 \mathrm{~kg} / \mathrm{m}^{2}$. Another set of specimens was moist cured for 14 days followed by 14 days of air-drying. Only mixture C02 had scaled particles in excess of $0.8 \mathrm{~kg} / \mathrm{m}^{2}$ in this case.

6. Application of curing compound reduced the amount of scaling significantly for specimens conditioned for different periods.

7. Slump appears to correlate with the amount of scaling. Higher slump corresponded to higher scaling. Higher slump might result in higher amount of bleed water at the surface layer resulting in higher porosity at the surface compared to the bulk region of 
the concrete specimen. This was verified by obtaining images using a SEM. Further investigations are required in order to explain these findings. 


\title{
CHAPTER 6: SUMMARY AND CONCLUSIONS FOR PHASE I OF THE RESEARCH AND OBJECTIVES AND SCOPE OF WORK FOR EXTENDED STUDY (PHASE II) ON SCALING BEHAVIOR OF CONCRETE CONTAINING SCM
}

\begin{abstract}
6.1. Introduction
The focus of this project was to investigate whether concrete mixtures prepared with fly ash or slag can have adequate durability and strength when exposed to low temperatures at early ages. Essentially, in this phase of research, studies were conducted in three parts, each of which has been described in detail in Chapters 3, 4 and 5. Chapter 3 described how chemical composition and physical characteristics of cements and fly ashes used in this research were analyzed in an attempt to identify parameters that may lead to low rate of strength development. Chapter 4 described the results and analysis of strength and maturity tests on mortars and non-evaporable water content on pastes. Mathematical models to predict material combinations that may result in slow strength development especially under low temperature conditions were developed. Mixtures selected during this part were used for full-scale tests on concrete as discussed in Chapter 5, which provided background for extended work on critical issue of scaling.

This chapter presents conclusions reached during each of the three parts of Phase I and provides need for further study. Based on these preliminary results, objectives of further study (Phase II) along with scope of work are also given in this chapter.
\end{abstract}




\subsection{Summary for Phase I}

\subsubsection{Summary of Analysis and Selection of Cementitious Systems}

In Chapter 3, a mathematical model was developed to predict strength for Type I, Type I/II, and Type III cements at various curing ages using information like $\mathrm{C}_{3} \mathrm{~S}, \mathrm{C}_{2} \mathrm{~S}$, $\mathrm{C}_{3} \mathrm{~A}$, fineness, alkali content, and strength provided by the cement producer on the mill certificate. Sensitivity analysis was performed to determine the influence of composition and fineness on strength. As one may expect, higher fineness was found to correlate with an increase in strength at all ages. Increasing the $\mathrm{C}_{3} \mathrm{~S}$ content had a beneficial effect on strength at later ages. Varying the $\mathrm{C}_{2} \mathrm{~S}$ and $\mathrm{C}_{3} \mathrm{~A}$ content did not seem to affect the strength development process significantly. Again as expected, increasing the alkali content had a beneficial effect on early age strength but a detrimental effect on the later age strength.

Four cements were selected for further tests on mortars based on the results from sensitivity analysis. One cement exhibited values of chemical components and fineness close to average of all the Type I and Type I/II cements. This cement (Lone Star, Type I) was selected to represent the baseline case. Three more cements were chosen, one with high alkali content (Essroc, Type I), one with a high fineness (Lone Star, Type III) and one with a low $\mathrm{C}_{3} \mathrm{~S}$ content (Lehigh, Type I/II). Similar to the analysis performed for cements, a mathematical model was also developed to characterize fly ashes using their strength activity index (SAI). The sensitivity analysis performed for all the fly ashes showed that increasing the lime content increases the SAI at all ages. The SAI also increased with alkali content at early ages, but converged at an age of about 28 days. 
Increasing the fineness (\% retained on $45 \mu \mathrm{m}$ sieve) of fly ash seemed to reduce the SAI at all ages.

Based on this analysis, four fly ashes were chosen for further study. Baseline fly ash (Will County Station) was chosen as the one that exhibited values of all of the sensitive parameters close to the average of all Class C fly ashes. Two other fly ashes (Rockport Station and Clifty Creek Station) that showed distinctly less lime content compared to other fly ashes in the Class C category were also chosen to represent the worst-case scenario with respect to their contribution to strength development. A Class F fly ash (Miami Fort Station) having the lowest lime content and the highest carbon content was also chosen. Since only one slag was approved by INDOT, this slag was also selected for further tests.

These above selections were made to facilitate testing that represents numerous mixtures having a wide range of chemical constituents, which could represent the possible mixture combinations made using materials on the current approved list in the state of Indiana.

\subsubsection{Summary of Tests Procedures and Results of Mortar Tests}

After individual materials were selected based on statistical analysis, mortar cubes were prepared using twenty-four mixture combinations. The cubes were stored at various temperatures and tested at various ages to enable strength-maturity relationships to be developed for the twenty-four mortar mixture combinations so that parameters like ultimate strength, rate of reaction and activation energy could be determined. 
The data obtained from the above tests were used to relate physical performance of the mortars to chemical compositions of the cementitious materials used in their preparation. Mortar test results were used to develop mathematical models for prediction of ultimate strength and rate of reaction. The use of the above models in a hyperbolic strength relationship showed good correlation of the actual values when compared to the predicted values. Mathematical models were used along with actual activation energy values in the relative strength gain equation for predicting the age required to attain a strength level of 3500 psi (24.1 MPa) by different mixtures under different curing temperatures.

Based on the results of the strength-maturity relationships for various mortar mixtures, six cementitious systems were selected for use in the durability study of concrete. The mixtures were selected in such a way that they represented the worst casescenario in terms of slow strength development under low temperature conditions. Two mortar mixtures (M01 and M05), which were found to be slowest strength developing at low temperatures, were selected. Both these mixtures had Rockport (Class C) fly ash as cementitious materials. Mixtures prepared with high carbon Class C fly ash (M10) and with high carbon Class F fly ash (M07) were also selected. A mixture (M21) prepared with slag and a control mixture (M13) was also selected.

Results from non-evaporable water content $\left(\mathrm{W}_{\mathrm{n}}\right)$ tests on pastes provided good verification of the trends from strength-maturity tests. For three curing temperatures of 23, 10 and $1^{\circ} \mathrm{C}\left(73.4,50,33.8^{\circ} \mathrm{F}\right.$, respectively) investigated, it was observed that Rockport ash shows the lowest $\mathrm{W}_{\mathrm{n}}$ value at 1 day, but the Miami Fort shows the lowest $\mathrm{W}_{\mathrm{n}}$ value at 3 and 7 days for all curing temperatures. 


\subsubsection{Summary of Analysis of Concrete Test Results}

All concrete mixtures containing supplementary materials had a 28-day compressive strength greater than 6000 psi (41.4 MPa). Most of the mixtures containing supplementary materials exceeded the compressive strength of the control mixture at 7 days. All six mixtures had flexural strengths in excess of 550 psi (3.8 MPa) at 7 days, which is the value adopted by INDOT for opening of pavement to traffic.

Sorptivity tests were carried out for mixtures cured for different periods. In general, for specimens cured for both 14 and 28 days, it was observed that weaker mixtures have higher sorptivity and cumulative sorption values. This may be due to higher permeability in weaker systems resulting from an undeveloped microstructure. Weight loss on drying test results showed that stronger mixtures had lower weight loss on drying. This confirms the fact the weaker mixtures have more internal water available for hydration.

All concrete mixtures (irrespective of the curing period, i.e., 3 or 14 days) prepared with supplementary materials passed the ASTM C 666 test for freeze-thaw resistance with satisfactory durability factors (generally greater than 83\%). In general, the freeze-thaw resistance seems to be correlated to the strength, i.e. stronger concretes seem to be more resistant to the effects of cyclic temperatures.

Scaling resistance tests were performed on specimens conditioned for two different periods. After a total of 6 days conditioning, mixtures C02, C03 and C06 had over 0.8 $\mathrm{kg} / \mathrm{m}^{2}$ of scaled particles. After a total of 28 days conditioning, only mixture C02 had over $0.8 \mathrm{~kg} / \mathrm{m}^{2}$ of scaled particles. Most mixtures had spacing factors smaller than 0.008” (0.203 mm) and strength values more than specified. An attempt was made to 
correlate scaling with factors like strength, sorptivity, weight loss on drying and the resonant frequency development with time. Developing a correlation to quantify the process of scaling in terms of the above factors was very difficult because of highly complicated nature of problem. Therefore some of the general trends are summarized below along with needs of further research in this area:

- In general, it was found that scaling resistance was improved by increasing the total duration of curing. But here only two curing durations were studied, so to develop proper relation of moist curing and drying on scaling and to determine optimum conditioning period for the best scaling resistance, more extensive study with variety of conditioning period is required.

- Out of six combinations studied, only one combination (C02-Lonestar cement + Rockport fly ash) showed poor scaling resistance for both curing periods. Therefore, further study with this combination should represent the worst case scenario and should help in providing more complete guidelines.

- Application of curing compound seems to significantly improve the scaling resistance of all specimens, irrespective of the conditioning period, probably due to presence of highly impermeable layer formed on the surface.

- For different mixtures tested, higher slump was found to correlate with an increase in the amount of scaling. It is not clear, however, whether increasing the duration of curing for high slump (up to about 2.5”) concrete would necessarily improve the scaling resistance. As a result, the exact relationship between conditioning periods for scaling of high slump mixtures should be determined. More research is needed on the effect of type and length of curing on scaling of high slump concrete. 
- As the issue is related to low temperature curing, influence of low temperature curing on scaling performance also needs to be studied.

- Based on the literature data and the collected field information, it was noted that the results from laboratory tests on scaling resistance may not necessarily depict a true picture of the field performance; hence better understanding of the differences between field and laboratory exposure conditions and how these differences affect scaling is essential for development of practical construction guidelines.

\subsection{Conclusions for Phase I}

Based on the analysis of all test results generated in the course of this investigation, the following conclusions are drawn:

1. Models can be developed for strength prediction of cement mortars and SAI prediction of fly ashes using the supplier's data on chemical composition and physical properties of the material. These models can be successfully used to forecast the expected changes in strength (for cements) and SAI (for fly ashes) as a result of changes in properties of the material.

2. Mathematical models can be developed to express maturity parameters like ultimate strength and rate of reaction of mortar mixture in terms of percent weight of the materials contained in them, chemical composition and physical characteristics of the materials.

3. The maturity method could be used effectively to predict the age required to attain a given strength level for mortar mixtures cured under any temperature history. 
4. Concrete containing fly ash or slag can be exposed to freeze and thaw cycles at relatively early ages without significant reduction in durability factor provided that it reaches compressive strength of at least 3500 psi (24.1 MPa) and has low amounts of freezable water in addition to minimum air contents of $6 \%$ and air-void spacing less than 0.008 ”.

5. Since all concrete mixtures tested were supposed to represent slowest hydrating systems under low temperature conditions, it is believed that mixtures prepared with similar fly ashes or slag, but using other cements would also pass the freezethaw durability test.

6. Specific conclusions regarding scaling performance of concrete and overall guidelines are presented at the end of Phase II of this project report.

\subsection{Research Objectives and Scope of Work for Phase II}

The conclusions of phase I of this research helped in formulating background for extended research on the issue of scaling. Therefore, the focus of Phase II of the research is the salt-scaling resistance of concrete containing SCM, both in the laboratory and under field conditions typically experienced in Indiana with particular attention given to pavements constructed during a season of low temperatures. To address these problems, based on background study in Phase I, three research goals were formulated as outlined in Figure 6.1. Brief listing of the tasks associated with each goal along with the description of types of specimens and other relevant details are also provided in Figure 6.1. 
The first goal of this extended study is to develop basic understanding of scaling phenomenon and determine the parameters that significantly influence scaling results. To simulate the worst-case scenario, the entire study of Phase II was conducted on the worst performing cementitious materials combination identified in Phase I (mixture C02, Lone Star cement + Rockport fly ash). This approach helped in conducting more focused study, results of which can be applicable to wide range of materials with high degree of confidence. Specimens prepared with these materials were fabricated at two different slumps and were subjected to wide range of curing conditions that are described in detail in section 8.2 (Table 8.1). In addition, a microstructure and chloride ion penetration study was performed to assist in the interpretation of results.

The second goal of the study was to evaluate the influence of low-temperature casting and curing on fresh concrete properties and scaling performance of fly ash concrete. First, various fresh concrete properties like setting time, bleeding, etc. were determined at two low temperatures $\left(1^{\circ} \mathrm{C}\right.$ and $\left.10^{\circ} \mathrm{C}\right)$. The scaling performance was evaluated for laboratory size, $250 \mathrm{~mm}$ x $190 \mathrm{~mm}$ x $75 \mathrm{~mm}$ (10” x 7.5” x 3”), regular specimens as well as large-size, 3000 mm x 1000 mm x 1000 mm (118” x 39” x 39”) insulated specimens that were assumed to simulate thermal conditions that can be encountered in the actual pavement. Temperature profiles for actual pavements located in the low temperature regions were also collected and evaluated, to determine how well the large size specimens simulate the temperature distribution in the pavement. Microstructural study was performed on some field and laboratory specimens to compare concrete bulk and surface porosities. 


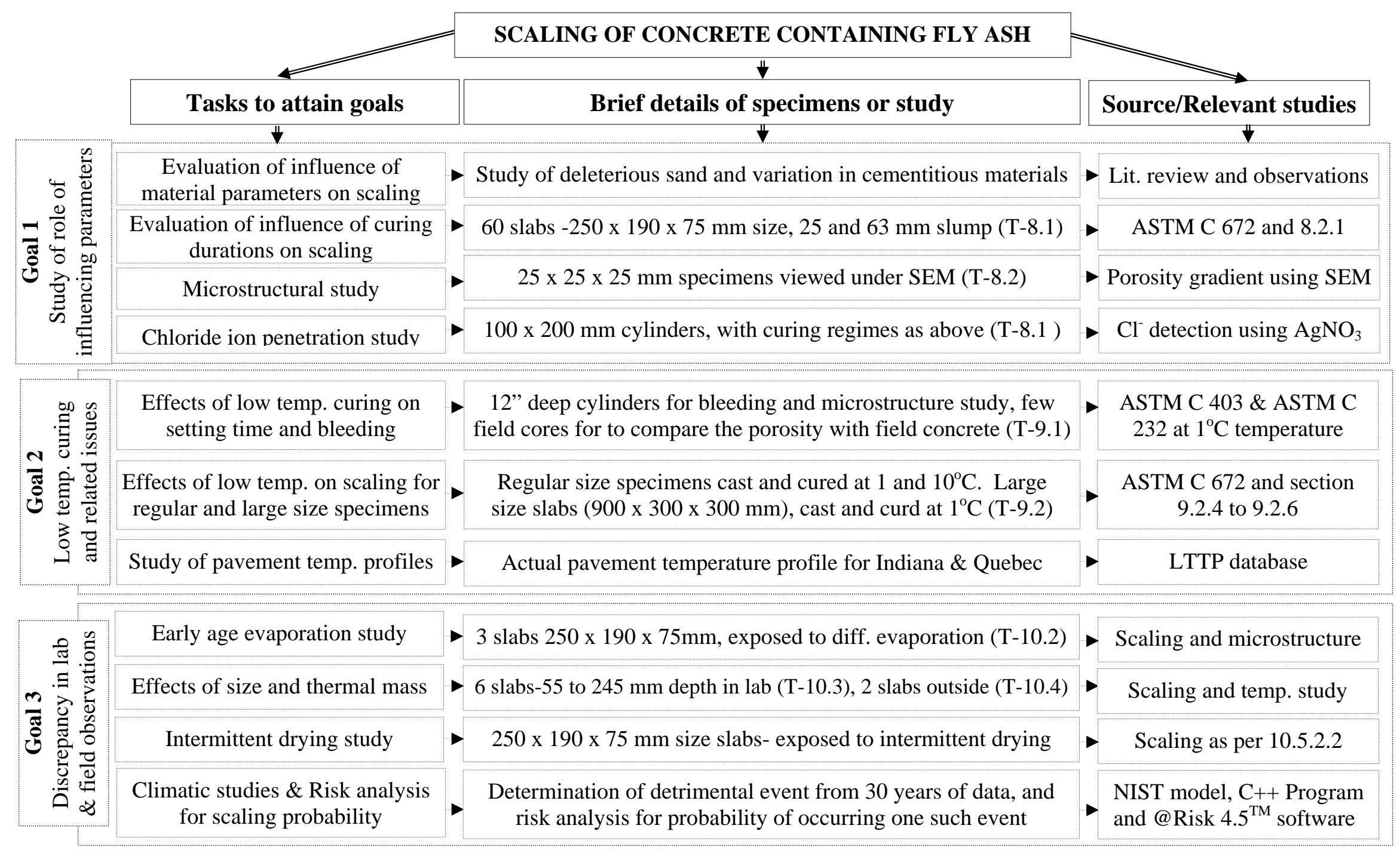

Figure 6.1: Outline of the objectives and relevant actions for the scaling study 
An extensive literature review revealed that, unlike what is observed in the laboratory, scaling of concrete containing fly ash is rare in the field. Various researchers have discussed the severity of test ASTM C 672 (Thomas, 1997 and Naik, 1995) but no firm conclusions are presented on the causes of this discrepancy between laboratory and field scaling. Therefore, the third objective of this study was to explore potential causes of discrepancy and to suggest the ways to resolve this paradox. To accomplish this goal, detailed information regarding field scaling performance of concrete was collected with the help of extensive literature review and telephone survey. This information when combined with and additional laboratory results, lead to suggestion of some parameters that may be responsible for observed discrepancy in field and laboratory scaling performance of concrete. In addition, based on these parameters and a detailed study of climatic data collected over 30 years period, the probability of scaling for a typical concrete mixture containing fly ash in Indiana was obtained using the risk analysis approach.

\subsection{Organization of the Report for Phase II}

This part of the report is divided into five chapters, which are presented in continuation of six chapters of phase I. Chapter 7 provides detailed discussion of the influence of the material parameters on scaling based on laboratory observations. The influence of various conditioning periods on scaling and chloride ion penetration is discussed in Chapter 8. This chapter also includes microstructural analysis near-surface region of concrete. Chapter 9 presents the results and analysis for fresh properties and scaling behavior of concrete cast and cured at low temperatures for two different sizes of 
specimens. The temperature profiles observed for concrete in the field obtained from the Long Term Pavement Performance (LTPP) database are also shown. Chapter 10 contains a literature review and a compilation of a survey on field scaling performance conducted in 12 mid-western and north-eastern states, including Indiana. Various suggestions are also presented regarding the discrepancy between the laboratory scaling results and the field observations. In addition, based on climatic data and risk analysis, Chapter 6 provides the probability for scaling of a typical concrete pavement for the most extreme climatic conditions of Indiana. Chapter 11 presents summary, guidelines and conclusions for phase II addressing scaling performance of concrete containing SCM. 


\section{CHAPTER 7: CONSTITUENT MATERIALS AND THEIR INFLUENCE ON SCALING RESISTANCE OF CONCRETE}

\subsection{Introduction}

The early and later age performance of concrete is highly dependent on the properties of constituent materials so an understanding of these materials is also essential for better interpretation of the results. Hence, this chapter addresses the issues related to constituent materials specifically in regard to scaling. The focus of the detailed study is to determine the potential of problems for concrete containing fly ash during late fall constructions. Therefore, the properties of the worst performing materials (Lone Star cement and Rockport fly ash), selected based on results from section 5.3, is described in this chapter. The effects of other parameters influencing performance of selected materials are studied in consecutive chapters. Additionally, the individual role of each constituent material in regard to scaling and the effects of variability in materials are discussed, with some important observations.

\subsection{Constituent Materials}

The results presented in section 5.3 .8 of this report, showed that the combination of certain cementitious materials (Lone Star cement + Rockport fly ash) exhibited the slowest strength gain and maximum scaling (in terms of mass lost). For that reason, this combination of materials was used in the current study. The typical mixture proportions 
used are shown in Table 7.1. Specimens containing plain cement (control mix) were made with Lone star type I cement for better comparison of results.

Table 7.1: Mixture Proportions and fresh concrete properties

\begin{tabular}{|c|c|c|}
\hline Materials & 25 mm (1”)Slump & 63 mm (2.5”) Slump \\
\hline Cement & $244.4 \mathrm{~kg} / \mathrm{m}^{3}\left(412 \mathrm{lb} / \mathrm{yd}^{3}\right)$ & $244.4 \mathrm{~kg} / \mathrm{m}^{3}\left(412 \mathrm{lb} / \mathrm{yd}^{3}\right)$ \\
\hline Fly Ash & $61.1 \mathrm{~kg} / \mathrm{m} 3$ (103 lb/yd3) & $61.1 \mathrm{~kg} / \mathrm{m}^{3}\left(103 \mathrm{lb} / \mathrm{yd}^{3}\right)$ \\
\hline Water & $134.1 \mathrm{~kg} / \mathrm{m}^{3}\left(226 \mathrm{lb} / \mathrm{yd}^{3}\right)$ & $134.1 \mathrm{~kg} / \mathrm{m}^{3}\left(226 \mathrm{lb} / \mathrm{yd}^{3}\right)$ \\
\hline Fine Aggregate (SSD) & $881.0 \mathrm{~kg} / \mathrm{m}^{3}\left(1485 \mathrm{lb} / \mathrm{yd}^{3}\right)$ & $881.0 \mathrm{~kg} / \mathrm{m}^{3}\left(1485 \mathrm{lb} / \mathrm{yd}^{3}\right)$ \\
\hline Coarse Aggregate (SSD) & $987.8 \mathrm{~kg} / \mathrm{m}^{3}\left(1665 \mathrm{lb} / \mathrm{yd}^{3}\right)$ & $987.8 \mathrm{~kg} / \mathrm{m}^{3}\left(1665 \mathrm{lb} / \mathrm{yd}^{3}\right)$ \\
\hline Water Reducer (WRA) & $450 \mathrm{ml}(15.2 \mathrm{oz})$ & $1250 \mathrm{ml}(42.3 \mathrm{oz})$ \\
\hline Air Entraining Agent (AE) & $79 \mathrm{ml}(2.7 \mathrm{oz})$ & $134 \mathrm{ml}(4.5 \mathrm{oz})$ \\
\hline Measured Slump & $25+/-5 \mathrm{~mm}\left(1 ”+/-0.2^{\prime \prime}\right)$ & $63+/-7 \mathrm{~mm}\left(2.5^{\prime \prime}+/-0.3 ”\right)$ \\
\hline Measured Fresh Air (\%) & $6.5+/-0.3$ & $6.5+/-0.4$ \\
\hline
\end{tabular}

A water-to-cementitious materials ratio $(\mathrm{w} / \mathrm{cm})$ of 0.44 was selected, as this is close to the maximum w/cm that INDOT permits for paving. Approximately $70 \%$ of the total concrete volume was composed of sound aggregates. Fly ash was used to replace $20 \%$ of the cement by weight, which gave the Portland cement/fly ash ratio of 4.0. TypeI Lone Star cement used in study had a Blaine fineness of $360 \mathrm{~m}^{2} / \mathrm{kg}$ and consisted of $60 \% \mathrm{C}_{3} \mathrm{~S}, 13.5 \% \mathrm{C}_{2} \mathrm{~S}, 8.2 \% \mathrm{C}_{3} \mathrm{~A}$, and $0.54 \%$ alkali $\left(\mathrm{Na}_{2} \mathrm{O}\right.$ equivalent). The class $\mathrm{C}$ (Rockport) fly ash used had a $\mathrm{CaO}$ content of $18.5 \%$, an alkali content of $0.7 \%$ and a carbon content of $0.68 \%$.

The mixture contained a Vinsol-based air entraining admixture (Daravair 1400) to create and stabilize air bubbles to meet the target air content of $6.5 \%$. A mid-range water-reducing agent (WRA), WRDA-82, was used to increase workability. This WRA is an aqueous solution of modified lignosulfonates with a hydration catalyst. Although 
most of the mixtures in this study had a slump of $25 \mathrm{~mm}$ (1”), some mixtures were produced with the slumps of $63 \mathrm{~mm}(2.5$ ”). The w/cm in the $63 \mathrm{~mm}$ slump mixtures was the same as that used in the $25 \mathrm{~mm}$ slump mixtures and the increase in slump was achieved by varying the content of WRA. The objective behind increasing the slump using the WRA content only was to study the effect of slump on scaling independent of strength of the concrete.

Figure 7.1 shows the particle size distribution of the cementitious materials as determined using a particle analyzer laser. It can be seen that the mean cement particle is approximately 22 microns while the fly ash demonstrates a well distributed range of particle sizes with a concentration of particles at slightly less than 1 micron and a concentration at approximately 18 microns.

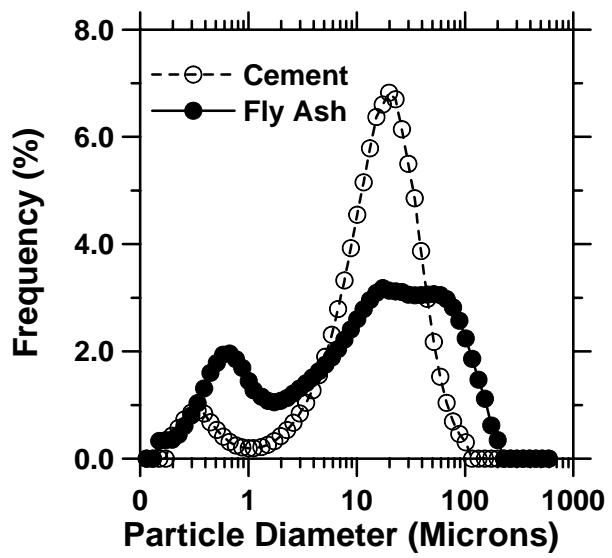

Figure 7.1: Particle size distribution for the cement and fly ash 


\subsection{Study of Influence of Individual Constituent Materials on Scaling Performance}

It is evident from the literature review that the influence of various material parameters on scaling performance was not studied extensively. In particular, none of the literature sources available examined the influence that chemical and mineral admixtures might have on the density of the near-surface region; hence, an indirect study was performed to quantify the effect of admixtures on surface density. In addition, the effects of deleterious fine aggregate particles on scaling performance are also examined in the following sections.

7.3.1. Influence of Chemical Admixtures and Fly Ash on Near-Surface Region Density of Hydrated Paste

As mentioned in the previous section, mixtures with two different slumps were used to study the scaling performance, the change of slump being the results of change in the WRA content. Many other researchers have reported that scaling increases with an increase in the slump of the concrete (section 5.3 .9 of this report, and Whiting, 1989). Therefore, it was important to identify whether the reduction in scaling resistance is related to an increased bleeding and reduction in density of near surface region (thinning) of the specimen or if there might be higher amount of admixture and fly ash in the surface region because of lower density. Additionally, buoyancy might allow more air bubbles to escape from the region of reduced density thus making it less frost resistant. 


\subsubsection{Experimental Procedures}

In an attempt to quantify the effects that chemical and mineral admixtures might have on the near-surface density, three set of experiments (studies) were performed. Three series of paste samples were prepared in each of the three studies. The paste composition is listed below in Table 7.2, illustration of which follows.

Table 7.2: List of paste samples prepared to study influence of fly ash and admixture

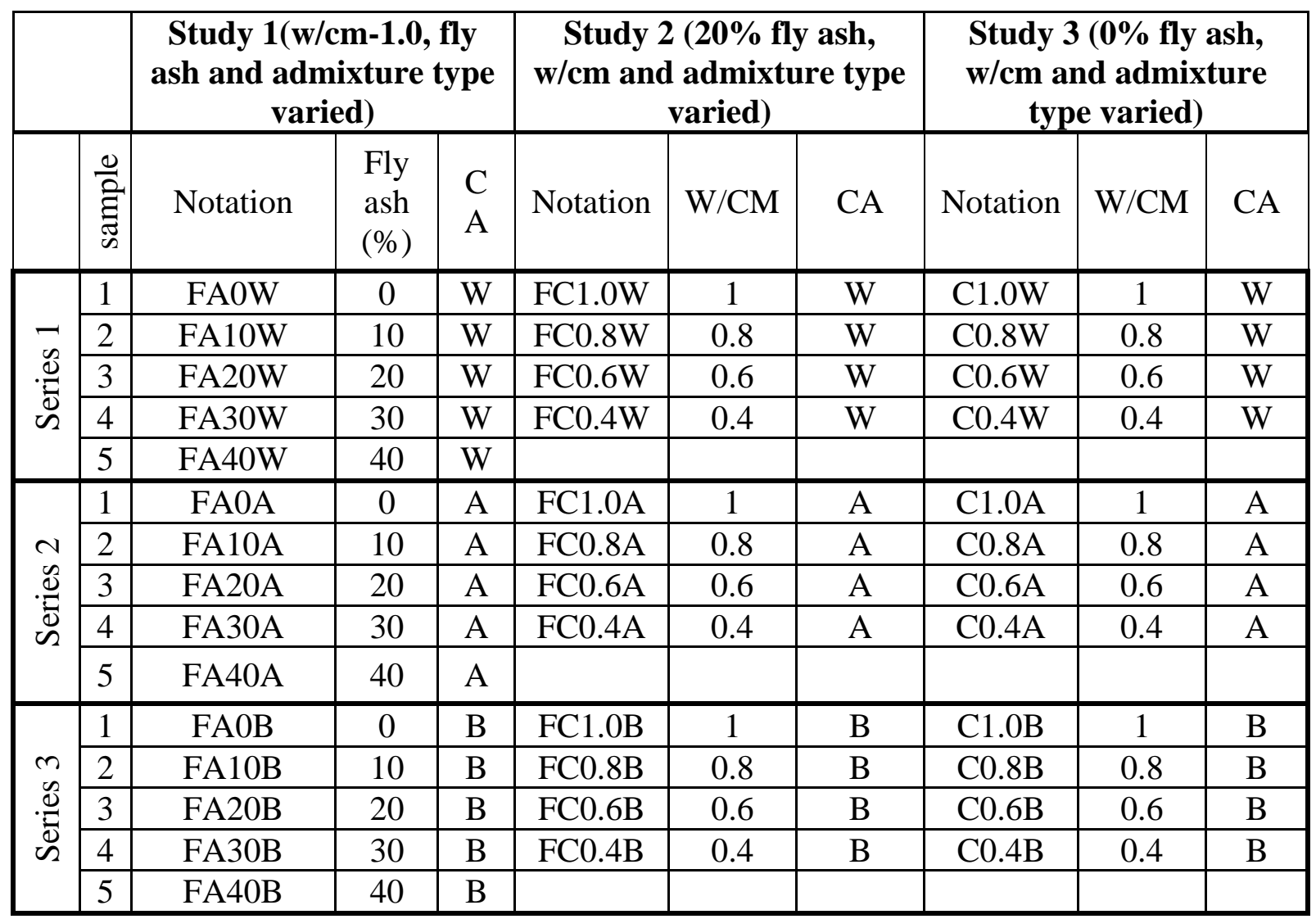

W- Water reducer, A- Air entraining agent, B-both (Water reducer + Air entraining agent), CA-Chemical Admixture

In the study 1 , liquid pastes $(\mathrm{w} / \mathrm{cm}=1)$ were prepared with different levels of supplementary cementitious materials. As mentioned earlier, three series of samples 
were prepared in this study. Each series had five samples, in which $0 \%, 10 \%, 20 \%, 30 \%$, or $40 \%$ of the cement was replaced with fly ash. Mixture proportions for the $25 \mathrm{~mm}$ slump mixture (Table 7.1) were used for proportioning the amount of WRA ( $0.22 \%$ by weight of cement) and $\mathrm{AE}$ ( $0.03 \%$ by weight of cement). The samples used in the first and second series contained only water reducing agent (WRA), and air entraining agent (AE) respectively, while samples in third series contained both WRA and AE. For each sample, all the materials including water were combined in a bottle and shaken for one minute before being allowed to settle. The paste was then poured into a clear plastic cup and allowed to set and hydrate for 48 hours, without any disturbance. In the cases, where distinct top and bottom layers were observed, they were carefully separated. Volume and mass of these sections were determined to calculate the densities.

In the study 2 , pastes were made with a $20 \%$ constant cement replacement with fly ash. In this study, three series were prepared, with four samples in each series. Each sample consisted of 500 grams $(1.1 \mathrm{lb})$ of cementitious materials, and the water was varied to achieve water to cementitious materials ratios of $1.0,0.8,0.6$, and 0.4 . Similar to previous section, first series contained only WRA, second series contained only AE and third series contained both. Thus, total of 12 paste samples were prepared for this case.

To quantify the effect of fly ash, in the study 3 another 12 samples were prepared in three different series. The third study was identical to second study, except no fly ash was added in this study. For study 2 and 3, paste samples were prepared similar to study 1. Results of all the three studies are described below. 


\subsubsection{Results and Data Analysis}

In the study 1, variables being fly ash and chemical admixture for a constant w/cm of 1.0, the following observations are made. As shown in Figure 7.2(b), all of the mixes eventually separated into two layers, a top porous layer and a denser bottom layer. This Figure shows images taken 5 minutes after the agitation. The mixtures with both admixtures had the largest top layer (by volume), while the mixtures with only air entrainment separated the least. The density of the bottom section was relatively constant while the density of the top portion decreased as the fly ash replacement increased. No distinct separation occurred when only cement and water were used, indicating that the separation was due to the use of fly ash; and the degree of separation varied as the replacement of cement with fly ash varied. At first glance it seems that mineral/chemical admixtures are responsible for low density of near-surface region, however, further studies (study 2 and 3) would help in exact quantification of the effect.

As mentioned earlier for study 2 and 3, 20 and $0 \%$ of cement was replaced with fly ash respectively and variables were w/cm and chemical admixture. The results of these two studies are summarized in Figure 7.3. Figure 7.3(a) shows the results with 20\% cement replaced by fly ash while 7.3(b) shows the results of only cement paste.

From Figure 7.3, it can be seen that when both a WRA and an AE were used in the pastes, the separated top volume was the maximum. On the other hand, the ratio of the density of the bottom to the top layer was the lowest in comparison to the pastes with only AE or only WRA. Thus, it is evident that in high w/cm mixes the combined effect of both admixtures played a major role in creating a distinct top layer but this top layer was denser in comparison to the layer generated by only air entraining agent or only 
water reducer. Therefore, the tendency of a combined effect of both admixtures could be considered such that it would provide restraint against the generation of a very high localized $\mathrm{w} / \mathrm{cm}$ ratio in the very top surface.

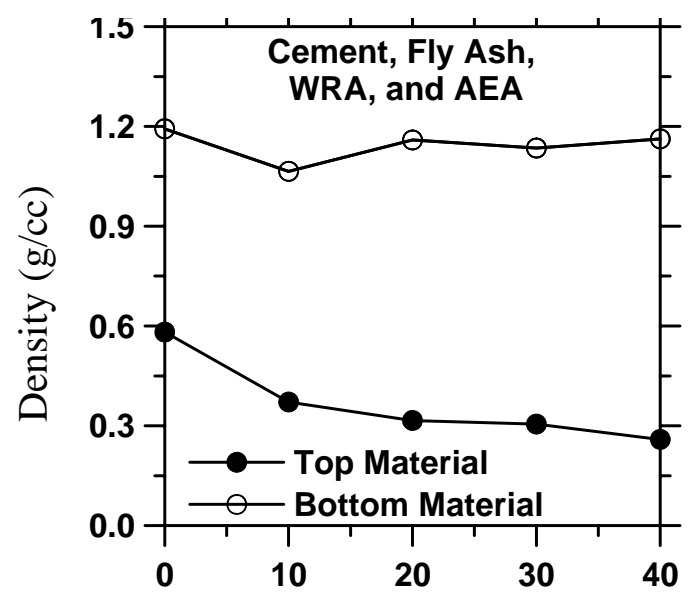

Percentage replacement of fly ash

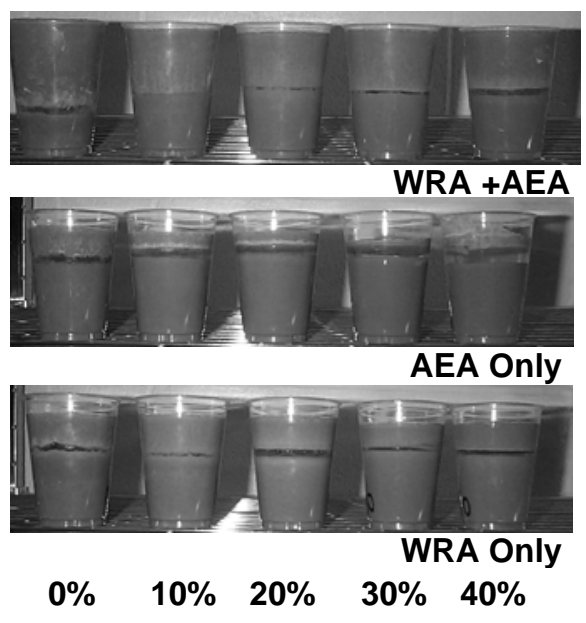

Percentage replacement of fly ash

Figure 7.2: Influence of WRA and AE on separation into two layers with different density; (a) measured densities of top and bottom portions for paste with WRA and AEA, and (b) Photos of paste separation

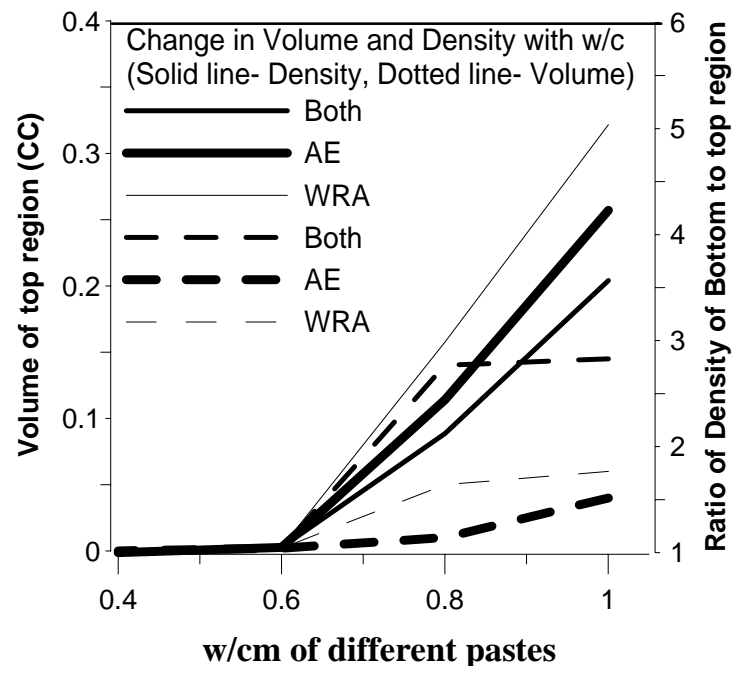

(a)

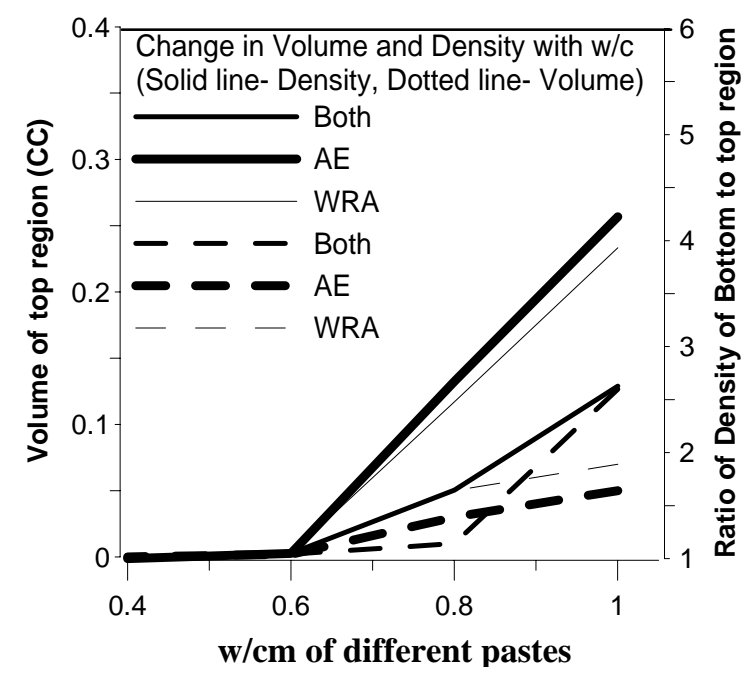

(b)

Figure 7.3: (a) Change in volume of separated surface, and ratio of density of the separated regions with change in w/cm for pastes containing $20 \%$ fly ash, and (b) Change in volume of separated surface and ratio of density of the separated regions with change in $\mathrm{w} / \mathrm{cm}$ for pastes containing cement only 
Comparing Figures 7.3(a) and (b) pastes with w/cm of 0.8 and higher, it was observed that the density of the near-surface region was lower for most pastes containing fly ash than the pastes with only cement. For a very high w/cm therefore, the presence of a higher amount of fly ash on the surface is possible, leading to layer separation and possible weakening of the surface region. However, an almost nil separation effect was observed for a w/cm of 0.6 and less. Real-life concrete mixes that contain coarse aggregate and are typically prepared at w/cm lower than 0.5 and would show a higher degree of restraint would be present towards settlement. Therefore, the presence of higher a percentage of fly ash in the surface region would not be a concern for concrete pavements containing fly ash, where the w/cm is in the range of 0.4 to 0.5 .

\subsubsection{Role of Deleterious Aggregates}

\subsubsection{Introduction and Observation}

Based on the literature review, it is evident that deleterious or porous coarse aggregates can increase scaling significantly (Klieger, 2003 and Jansen, 2000) but no such observations are available for fine aggregates. In this section an observation is reported about the influence of deleterious fine aggregate particles on scaling performance. As far as freeze-thaw resistance is concerned, fine aggregates do not have negative influence, and even the presence of a small amount of deleterious fine aggregate does not create any major damage to the concrete. In the case of scaling, however, different results are possible.

During scaling study, difference in scaled mass was observed for a few specimens that were prepared using new fine aggregate. This aggregate confirmed the INDOT 
specifications and had deleterious (non-durable) materials under the specified limit (4\% of total fine aggregates). In this case in both the fly ash and the control specimens, similar scaling behavior was observed after the first five to seven F-T cycles; scaling was initiated by the fracture of small dark grey particles on the specimens' surface. These dark grey or black particles were collected and evaluated under a scanning electron microscope and in an X-ray diffractometer. In addition, using optical microscope and specific gravity determinations were also conducted for such particles present in the fine aggregates.

\subsubsection{Results and Data Analysis}

Figure 7.4 shows the results of the $\mathrm{X}$-ray diffraction analysis, which indicate that significant amount of clay minerals (illite and kaolinite) were present in these particles. Also the EDX of the Scanning Electron Microscope (SEM) showed presence of alumina, silica, iron and oxygen in significant amounts. The above information and further petrography analysis under optical microscope to analyze the texture and grain size, revealed that these deleterious particles were weathered shale particles, which can be present in natural river sand. A few other properties for these particles were determined and are reported in the Table 7.3. 


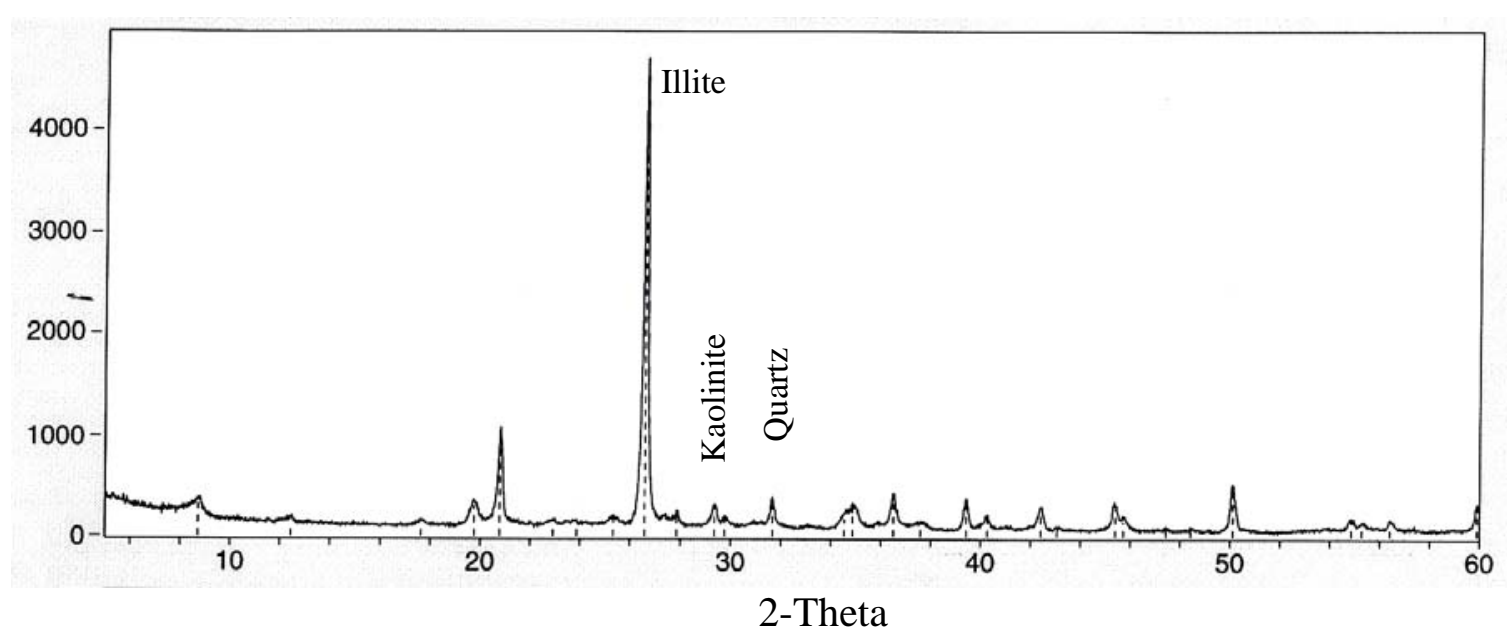

Figure 7.4: X-ray diffraction pattern of weathered shale particles

Table 7.3: Properties of deleterious particles present in sand

\begin{tabular}{|l|l|l|}
\hline Property & Technique/tools used & Observations \\
\hline $\begin{array}{l}\text { Size and shape } \\
\text { and texture }\end{array}$ & $\begin{array}{l}\text { Vernier caliper and } \\
\text { Petrographical microscope, } \\
\text { (ASTM C 295) }\end{array}$ & $\begin{array}{l}\text { Dark grey to black color, rounded or } \\
\text { flaky, } 2 \text { - 4 mm x 3.5 - 4.5 mm size, } \\
\text { plate-like structure, weathered } \\
\text { surface. }\end{array}$ \\
\hline $\begin{array}{l}\text { Percentage of } \\
\text { particles }\end{array}$ & $\begin{array}{l}\text { Random sampling as per } \\
\text { ASTM D75 }\end{array}$ & $\begin{array}{l}\text { Average 2.5\% of total weight of } \\
\text { aggregates. }\end{array}$ \\
\hline $\begin{array}{l}\text { Composition of } \\
\text { particles }\end{array}$ & $\begin{array}{l}\text { Energy Dispersive X-ray } \\
\text { (EDX) analysis using SEM }\end{array}$ & $\begin{array}{l}\text { Composed of mainly alumina, silica, } \\
\text { iron and oxygen, presence of } \\
\text { calcium and magnesium also } \\
\text { observed. }\end{array}$ \\
\hline $\begin{array}{l}\text { Mineralogical } \\
\text { analysis }\end{array}$ & X-ray diffraction & $\begin{array}{l}\text { Mainly clay minerals, such as illite, } \\
\text { kaolinite, etc., also quartz and calcite } \\
\text { observed. }\end{array}$ \\
\hline Specific gravity & ASTM C 128 & $\begin{array}{l}\text { 2.28, low in comparison to average } \\
\text { specific gravity of sand 2.64. }\end{array}$ \\
\hline
\end{tabular}

Though small in overall quantity, the weathered shale particles were lighter than other sand grains and so a greater number of these particles were visible on the surface of the specimen. Since the freeze-thaw durability of such particles is very poor, they 
fractured and caused de-lamination (scaling) of the surrounding mortar. Figure 7.5 shows the scaling caused by the presence of these particles in the surface region after $5 \mathrm{~F}-\mathrm{T}$ cycles.

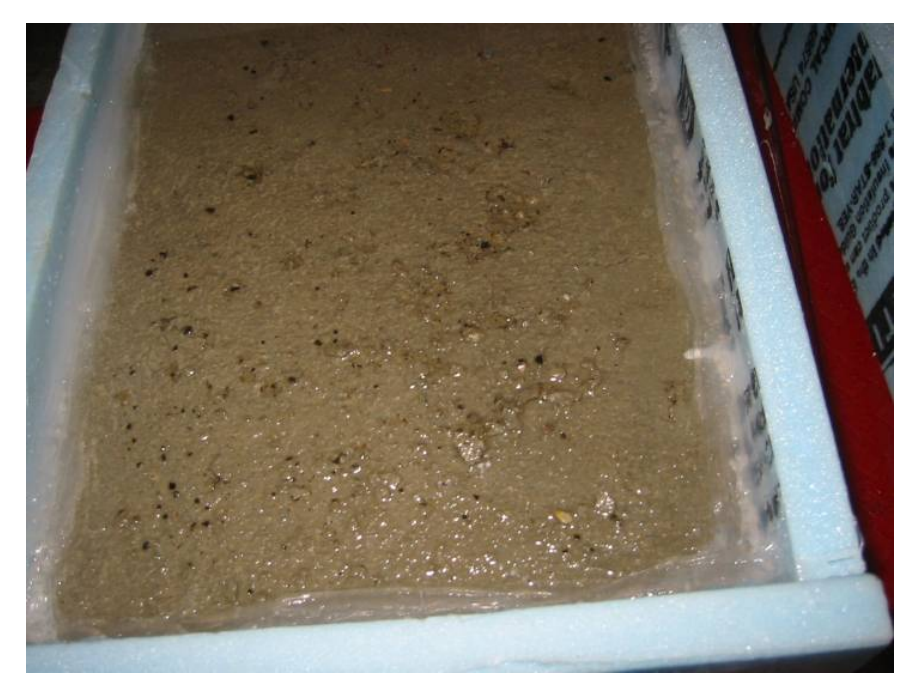

Figure 7.5: Scaling of concrete surface around deleterious sand particles

In summary, aggregate could play an important role in reducing the scaling resistance of sound concrete. As the above results confirmed the deleterious role of the fine aggregate in scaling, the source of fine aggregate was changed for further study.

\subsubsection{Influence of Variability of Cementitious Materials on Scaling Behavior}

\subsubsection{Introduction}

Based on the primary study that included various cements and fly ashes (section 5.3.8), it can be said that small changes in the chemical composition of cements can have a significant influence on scaling performance. This is evident in Figure 5.13 which shows that the scaled mass varied from $0.3 \mathrm{~kg} / \mathrm{m}^{2}$ to $3.0 \mathrm{~kg} / \mathrm{m}^{2}$, depending on combination of materials used. It should be noted that in that particular study the mixture 
proportions for all of concretes were the same except for the composition of cementitious materials.

In this study a similar variation in scaling performance was observed when the shipment of cement and fly ash were received from the same source (as used in the initial part of study), 3 years after an initial acquisition. The concrete cast from the originally acquired cement and fly ash, scaled on an average $2.5 \mathrm{~kg} / \mathrm{m}^{2}$, while the concrete prepared with new cement and fly ash scaled only $0.2 \mathrm{~kg} / \mathrm{m}^{2}$. A comparison of the scaled surfaces of the concrete containing the old (btch-00) and the new (btch-03) cement and fly ash is shown below in Figure 7.6. The properties of the old and new cements and fly ashes were compared and the probable reasons for improvement in the observed scaling results are proposed. The changes in chemical composition of both cement and fly ash are discussed in sections 7.3.3.2 and 7.3.3.3, respectively. It is strongly emphasized that to determine scaling performance, the combined influence of the cement and fly ash components should be considered. 


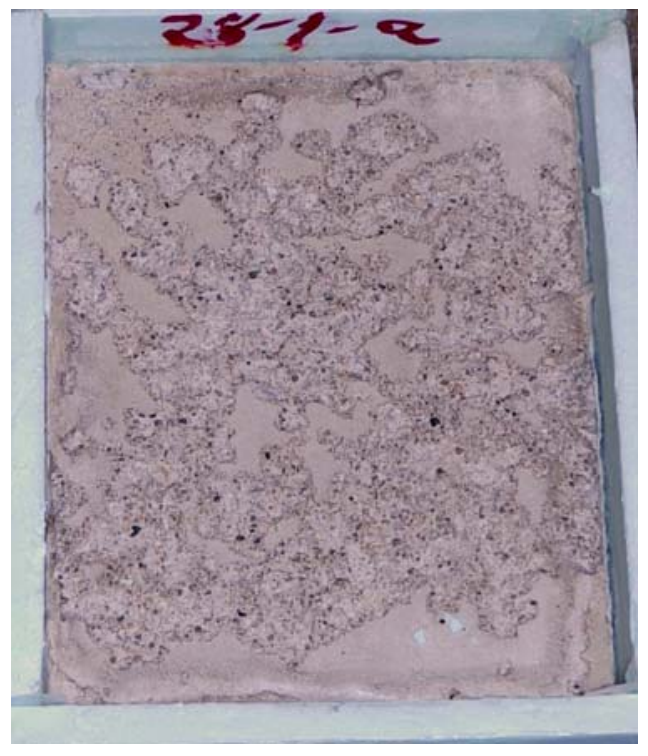

(a)

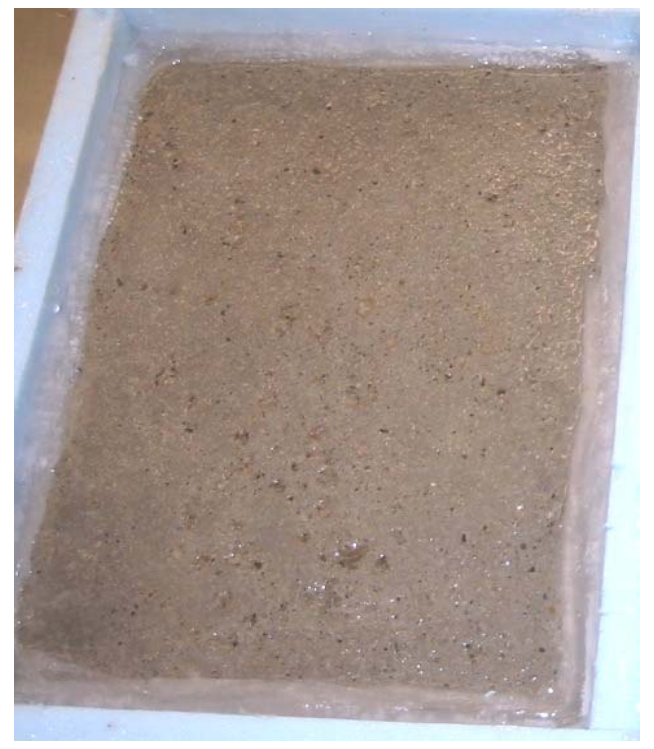

(b)

Figure 7.6: Scaled surfaces after 50 F-T cycles, (a) btch-00 (worst performing) combination of cement and fly ash, and (b) btch-03 (better performing) combination of cement and fly ash

\subsubsection{Cement}

The chemical composition of old and new cement (as reported on mill certificates) is given in Table 7.4. There is a considerable (approximately 55\%) increase in $\mathrm{C}_{2} \mathrm{~S}$ content and a corresponding $13 \%$ decrease in $\mathrm{C}_{3} \mathrm{~S}$ observed. Theoretically, the cement with higher $\mathrm{C}_{3} \mathrm{~S}$ should give higher early strength and should, therefore, show better scaling resistance. However, as shown in Figure 7.6 exactly opposite results were observed. Similarly, although btch-2003 cement has higher content of alkalis and $\mathrm{C}_{3} \mathrm{~A}$, it showed better scaling resistance, which is contradictory to what have been proposed in some other studies (Marchand et al., 2000 and Jackson, 1958). It is therefore essential to accurately interpret the results to address all of the above discrepancies. 
Table 7.4: Comparison of various component and properties old and new cements

\begin{tabular}{|c|c|c|c|c|c|c|c|c|}
\hline \multirow{2}{*}{$\begin{array}{l}\text { Lone Star cement } \\
\text { (Indiana) }\end{array}$} & \multirow{2}{*}{$\mathrm{C}_{3} \mathrm{~S}$} & \multirow{2}{*}{$\mathrm{C}_{2} \mathrm{~S}$} & \multirow{2}{*}{$\mathrm{C}_{3} \mathrm{~A}$} & \multirow{2}{*}{$\begin{array}{c}\text { Alkali } \\
\text { as } \\
\mathrm{Na}_{2} \mathrm{O} \\
\text { eq. }\end{array}$} & \multirow{2}{*}{ Fineness } & \multicolumn{3}{|c|}{$\begin{array}{l}\text { Comp. strength, psi } \\
(\mathrm{MPa})\end{array}$} \\
\hline & & & & & & 1 day & 3 day & 7 day \\
\hline $\begin{array}{l}\text { Shipment }-1 \text { btch- } \\
\text { 00: Aug } 2000\end{array}$ & 60.01 & 13.54 & 8.22 & 0.54 & 360.8 & $\begin{array}{c}2272 \\
(15.7)\end{array}$ & $\begin{array}{r}3439 \\
(23.7)\end{array}$ & $\begin{array}{r}4390 \\
(30.3)\end{array}$ \\
\hline $\begin{array}{l}\text { Shipment }-2 \text { btch- } \\
\text { 03: Sept } 2003\end{array}$ & 52 & 21 & 10 & 0.696 & 362.0 & $\begin{array}{c}2150 \\
(14.8)\end{array}$ & $\begin{array}{c}3400 \\
(23.4)\end{array}$ & $\begin{array}{c}4390 \\
(30.3)\end{array}$ \\
\hline
\end{tabular}

First, the reason for such a wide variation in $\mathrm{C}_{3} \mathrm{~S}$ and $\mathrm{C}_{2} \mathrm{~S}$ content for cements coming from the same source was explored. After the discussion with technical support personnel of Lone Star cement. It was found that when the btch-00 cement was obtained, the plant had been importing clinker from Thailand, as changes were being made in the plant. The clinker for btch-03 cement was produced in the local plant, using the local materials. Since, the sources of materials for this btch-00 and btch-03 cements were totally different, that lead to a wide differences in their chemical composition.

It is well known that $\mathrm{C}_{2} \mathrm{~S}$ produces only about half of the $\mathrm{CH}$ that is produced by the $\mathrm{C}_{3} \mathrm{~S}$ (Neville, 1996). As a result, the extent of pozzolanic reactions in the system with lower $\mathrm{C}_{3} \mathrm{~S}$ content (btch-03 concrete), therefore will be lower in comparison to btch-00 concrete.

The scaling results strongly support the hypothesis that refinement in pore structure is the major cause of increased scaling damage for laboratory concrete containing fly ash, as already noted in the case-specific literature summary of scaling. Pore refinement due to secondary reaction is widely known to be the most beneficial effect of fly ash in concrete. However, in the case of scaling that pore refinement may be detrimental under certain conditions. Specifically, it is hypothesized that pore refinement 
might increase the degree of saturation during consecutive F-T cycles because smaller pores, which might not dry out during non-freezing part of the cycle. To further investigate this hypothesis, the reactivity of fly ash in a given cementitious system was evaluated and is discussed in section 7.3.3.3. Also, the values for alkali content of cement are considered very normal for typical Type-I cement in this study, so the observation by other researchers that high alkali/high $\mathrm{C}_{3} \mathrm{~A}$ cement have poorer scaling resistance might not be applicable for this case.

\subsubsection{Fly Ash}

The available components and properties of both original and new suite of fly ashes are reported in Table 7.5. It can be seen from the data that the lime content, carbon content, and fineness (\% retained on $45 \mu \mathrm{m}$ sieve) of both fly ashes are almost identical. However, a significant increase (15\%) in the 7 days Strength Activity Index (SAI7) for btch-03 fly ash was observed. The SAI 7 of $98 \%$ is very close to the strength of plain cement (100\%), which indicates high reactivity of new fly ash (btch-03). Further analysis of the fly ash was done, therefore, to determine the exact reasons for increase in SAI7 value.

Table 7.5: Comparison of various components and properties of old and new fly ashes

\begin{tabular}{|c|c|c|c|c|c|c|}
\hline Rockport fly ash & $\begin{array}{c}\text { Lime } \\
\mathbf{( \% )}\end{array}$ & $\begin{array}{c}\text { Alkali } \\
\mathbf{( \% )}\end{array}$ & $\begin{array}{c}\text { Fineness (\% } \\
\text { retained on } \\
\mathbf{4 5} \boldsymbol{~} \mathbf{m} \text { sieve) }\end{array}$ & $\begin{array}{c}\text { Max. \% } \\
\text { frequency }\end{array}$ & $\begin{array}{c}\text { Carbon } \\
\mathbf{( \% )}\end{array}$ & SAI7 \\
\hline Batch- Aug 2000 & 18.57 & 0.70 & 21.88 & $18 \mu \mathrm{m}$ & 0.68 & 85.50 \\
\hline Batch- Aug 2003 & 18.48 & 1.0 & 20.1 & $10 \mu \mathrm{m}$ & 0.46 & 98 \\
\hline
\end{tabular}

SAI7- Strength activity index at 7 days as per ASTM C 311 
Though the percentage retained on the $45 \mu \mathrm{m}$ sieve for both fly ashes was similar, the particle size distribution for these fly ashes showed considerable difference. The maximum frequency of new (btch-03) fly ash particles was observed at $10 \mu \mathrm{m}$ versus 18 $\mu \mathrm{m}$ for the old (btch-00) fly ash, which means that a higher amount of finer particles was present in the case of btch-03 fly ash, which could increase the reactivity of fly ash at the early ages.

An increased number of finer particles and a small increase in the alkali content are probably not the only parameters that could increase the SAI of fly ash significantly. It should be remembered that SAI is the property of combined cement and fly ash system. The SAI values obtained for btch-03 fly ash, were obtained with btch-03 Lone Star type I cement. As described earlier, this cement had a comparatively low $\mathrm{C}_{3} \mathrm{~S}$ and a high $\mathrm{C}_{2} \mathrm{~S}$ content. In this combination of cement and fly ash, the self cementing properties of fly ash could play an important role in early strength development.

To develop better insight into the mineralogical characteristic of btch-03 fly ash, an X-ray diffraction analysis was performed and the results are shown in Figure 7.7. As commonly observed in reactive class $\mathrm{C}$ fly ashes a significant amount of gypsum and ettringite was observed in this fly ash. The presence of these components, along with high alkali content, could lead to significant reactivity of fly ash at early ages. 


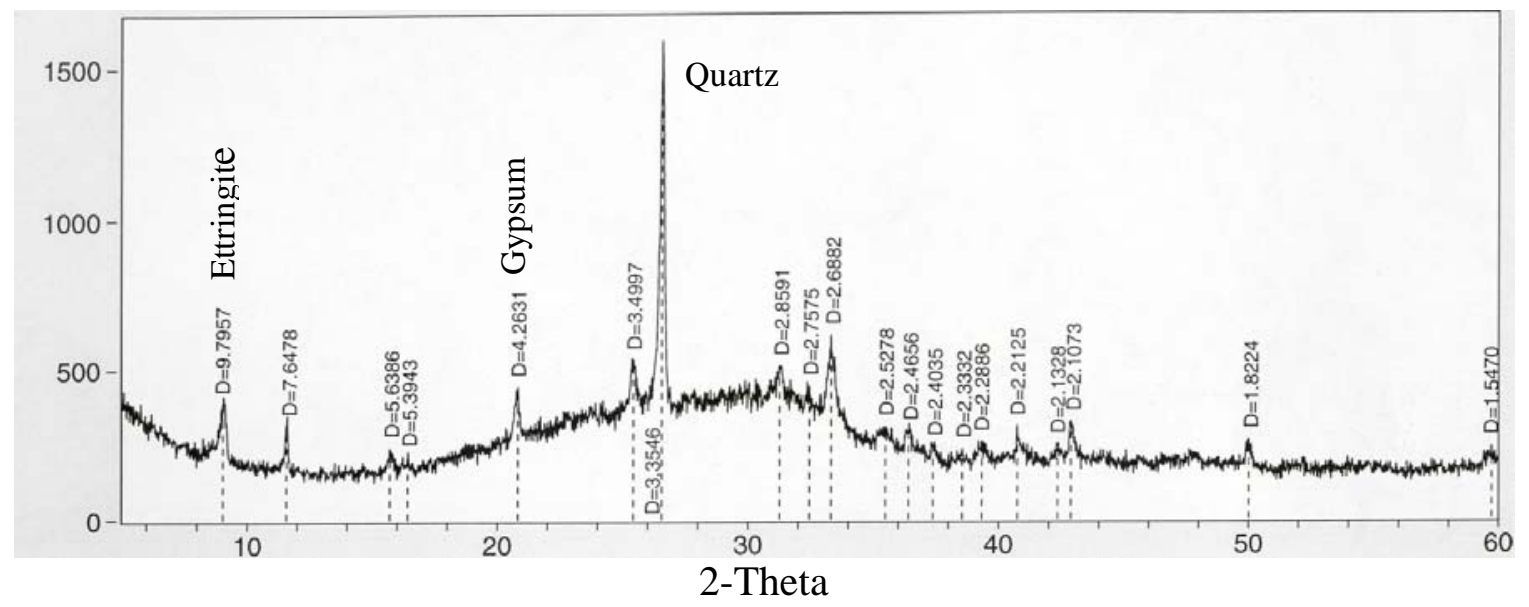

Figure 7.7: X-ray diffraction of btch-03 fly ash

\subsubsection{Data Analysis and Proposed Hypothesis}

Upon close observation of the cement and fly ash composition, it seems that a lower overall pozzolanic activity might help in improving scaling performance. To verify this hypothesis with the available results, components affecting pozzolanic activity were examined separately as mentioned below. The first component considered was the $\mathrm{C}_{2} \mathrm{~S}$ content of cement. A higher $\mathrm{C}_{2} \mathrm{~S}$ reduces the overall amount of $\mathrm{CH}$ in the system and thus the overall pozzolanic activity. The second important component that can be considered here is $\mathrm{C}_{3} \mathrm{~S}$ of cement. A higher $\mathrm{C}_{3} \mathrm{~S}$ could increase the amount of $\mathrm{CH}$ significantly and thereby help promote pozzolanic activity. Thus, the lower the $\mathrm{C}_{3} \mathrm{~S}$ in the cement, the lower should be the overall pozzolanic reaction. Thus, the SAI7 of fly ash is also one of the parameters that is related to pozzolanic activity in the system. Generally, it is believed that a minimal amount of pozzolanic activity will take place during the first seven days of hydration (Mehta, 1996). Hence, a higher value of SAI7 may be attributed primarily to the reaction of fly ash itself with water. Therefore, the 
expected overall pozzolanic activity should decrease with an increase in SAI7 value because there will be less unhydrated fly ash available in the cement-fly ash system when cement hydration generated $\mathrm{CH}$ becomes available.

Assuming that the above reasoning is correct the sum of $\mathrm{C}_{2} \mathrm{~S}-\mathrm{C}_{3} \mathrm{~S}+\mathrm{SAI7}$ should yield a factor, increase in which should yield a decrease in pozzolanic activity. Based on the earlier proposed hypothesis, the reduction in pozzolanic activity should lead to reduction in scaling. Figures 7.8(a), (b) and (c) shows $\left(\mathrm{C}_{2} \mathrm{~S}-\mathrm{C}_{3} \mathrm{~S}\right),\left(\mathrm{C}_{2} \mathrm{~S}+\mathrm{SAI7}\right)$ and $\left(\mathrm{C}_{2} \mathrm{~S}-\mathrm{C}_{3} \mathrm{~S}+\mathrm{SAI7}\right)$ values plotted against scaling results obtained from all different cement-fly ash combinations studied in this and in earlier Chapter 5. Moreover, Figure 7.8 shows scaling results plotted against $\left(\mathrm{C}_{2} \mathrm{~S}-\mathrm{C}_{3} \mathrm{~S}+\mathrm{SAI7}\right)$ value for all the different combinations. The plotted parameters show good correlation indicating that the decrease in pozzolanic activity also reduces scaling damage.

Some of the field observations reported for High Volume Fly Ash (HVFA) concrete (Thomas, 2000) indicate that at later ages scaling is usually observed in the concrete with class F fly ash. This suggests that the pozzolanic activity can be one of the parameters that controls scaling damage of field concrete. It should be noted that hypothesis presented in this section is based on the limited volume of data; further research is required to confirm the proposed reasoning. 


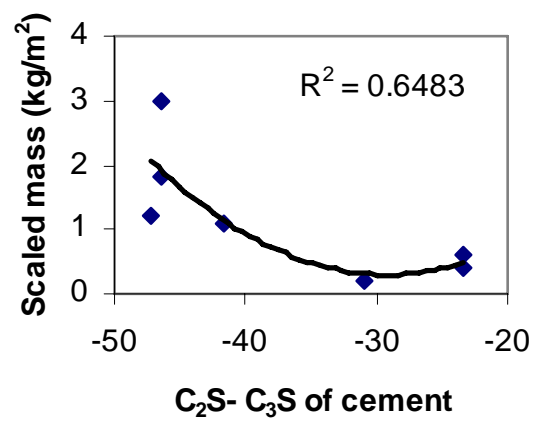

(a)

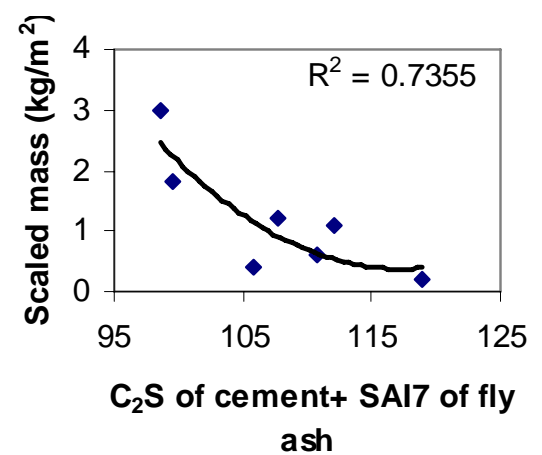

(b)

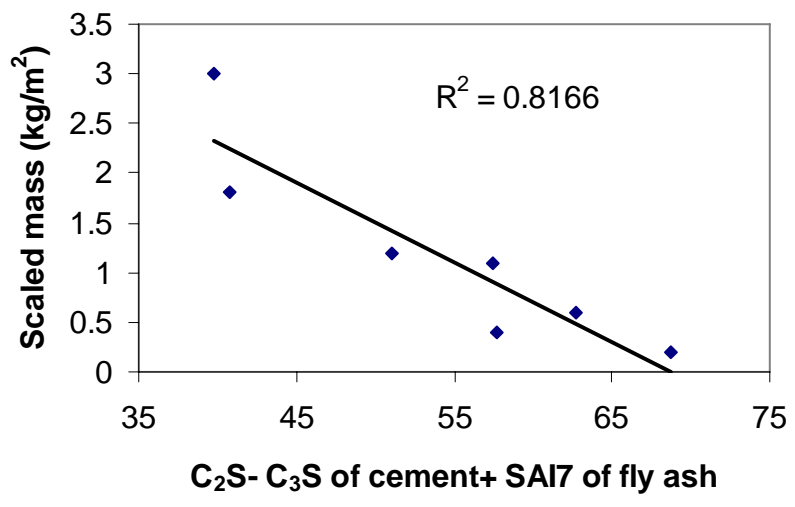

(c)

Figure 7.8: Scaled mass of concrete containing different cement-fly ash combinations plotted against their (a) $\left(\mathrm{C}_{2} \mathrm{~S}-\mathrm{C}_{3} \mathrm{~S}\right)$ values, (b) $\left(\mathrm{C}_{2} \mathrm{~S}+\mathrm{SAI}\right.$ ) values, and (c) $\left(\mathrm{C}_{2} \mathrm{~S}-\mathrm{C}_{3} \mathrm{~S}+\right.$ SAI7)

In summary, it is evident that the scaling behavior of concrete depends on the cement-fly ash interaction and how these materials influence formation of microstructure and the pore size distribution. To develop an understanding of mechanism of the scaling of fly ash concrete, it is therefore important to characterize the effect of minor changes in cementitious materials and relate these changes to scaling performance while keeping all the other parameters constant. This issue has not been addressed by researchers thus far. Therefore, a detailed systematic study is required to confirm actual importance of the above components in scaling results and to develop a more precise relationship between 
the cementitious materials components and the scaling performance of concrete. With limited availability of time and resources for this particular project, these issues could not be addressed in this research.

\subsection{Summary}

This chapter discussed studies and observations addressing the influence of various material properties on scaling performance of concrete. Role of admixtures was evaluated with the help three different studies. An observation regarding influence of deleterious fine aggregates on scaling is reported. It can be summarized that knowledge of material parameters is vital for better interpretation of results. Additionally scaling of concrete containing fly ash is highly dependent on the type of pore size distribution, and therefore the variability in cementitious materials could change scaling performance significantly. Pore refinement due to pozzolanic activity seems to be a major parameter influencing scaling results, but further study is required to confirm this hypothesis and to provide better guidelines for materials selection. 


\section{CHAPTER 7: CONSTITUENT MATERIALS AND THEIR INFLUENCE ON SCALING RESISTANCE OF CONCRETE}

\subsection{Introduction}

The early and later age performance of concrete is highly dependent on the properties of constituent materials so an understanding of these materials is also essential for better interpretation of the results. Hence, this chapter addresses the issues related to constituent materials specifically in regard to scaling. The focus of the detailed study is to determine the potential of problems for concrete containing fly ash during late fall constructions. Therefore, the properties of the worst performing materials (Lone Star cement and Rockport fly ash), selected based on results from section 5.3, is described in this chapter. The effects of other parameters influencing performance of selected materials are studied in consecutive chapters. Additionally, the individual role of each constituent material in regard to scaling and the effects of variability in materials are discussed, with some important observations.

\subsection{Constituent Materials}

The results presented in section 5.3 .8 of this report, showed that the combination of certain cementitious materials (Lone Star cement + Rockport fly ash) exhibited the slowest strength gain and maximum scaling (in terms of mass lost). For that reason, this combination of materials was used in the current study. The typical mixture proportions 
used are shown in Table 7.1. Specimens containing plain cement (control mix) were made with Lone star type I cement for better comparison of results.

Table 7.1: Mixture Proportions and fresh concrete properties

\begin{tabular}{|c|c|c|}
\hline Materials & 25 mm (1”)Slump & 63 mm (2.5”) Slump \\
\hline Cement & $244.4 \mathrm{~kg} / \mathrm{m}^{3}\left(412 \mathrm{lb} / \mathrm{yd}^{3}\right)$ & $244.4 \mathrm{~kg} / \mathrm{m}^{3}\left(412 \mathrm{lb} / \mathrm{yd}^{3}\right)$ \\
\hline Fly Ash & $61.1 \mathrm{~kg} / \mathrm{m} 3$ (103 lb/yd3) & $61.1 \mathrm{~kg} / \mathrm{m}^{3}\left(103 \mathrm{lb} / \mathrm{yd}^{3}\right)$ \\
\hline Water & $134.1 \mathrm{~kg} / \mathrm{m}^{3}\left(226 \mathrm{lb} / \mathrm{yd}^{3}\right)$ & $134.1 \mathrm{~kg} / \mathrm{m}^{3}\left(226 \mathrm{lb} / \mathrm{yd}^{3}\right)$ \\
\hline Fine Aggregate (SSD) & $881.0 \mathrm{~kg} / \mathrm{m}^{3}\left(1485 \mathrm{lb} / \mathrm{yd}^{3}\right)$ & $881.0 \mathrm{~kg} / \mathrm{m}^{3}\left(1485 \mathrm{lb} / \mathrm{yd}^{3}\right)$ \\
\hline Coarse Aggregate (SSD) & $987.8 \mathrm{~kg} / \mathrm{m}^{3}\left(1665 \mathrm{lb} / \mathrm{yd}^{3}\right)$ & $987.8 \mathrm{~kg} / \mathrm{m}^{3}\left(1665 \mathrm{lb} / \mathrm{yd}^{3}\right)$ \\
\hline Water Reducer (WRA) & $450 \mathrm{ml}(15.2 \mathrm{oz})$ & $1250 \mathrm{ml}(42.3 \mathrm{oz})$ \\
\hline Air Entraining Agent (AE) & $79 \mathrm{ml}(2.7 \mathrm{oz})$ & $134 \mathrm{ml}(4.5 \mathrm{oz})$ \\
\hline Measured Slump & $25+/-5 \mathrm{~mm}\left(1 ”+/-0.2^{\prime \prime}\right)$ & $63+/-7 \mathrm{~mm}\left(2.5^{\prime \prime}+/-0.3 ”\right)$ \\
\hline Measured Fresh Air (\%) & $6.5+/-0.3$ & $6.5+/-0.4$ \\
\hline
\end{tabular}

A water-to-cementitious materials ratio $(\mathrm{w} / \mathrm{cm})$ of 0.44 was selected, as this is close to the maximum w/cm that INDOT permits for paving. Approximately $70 \%$ of the total concrete volume was composed of sound aggregates. Fly ash was used to replace $20 \%$ of the cement by weight, which gave the Portland cement/fly ash ratio of 4.0. TypeI Lone Star cement used in study had a Blaine fineness of $360 \mathrm{~m}^{2} / \mathrm{kg}$ and consisted of $60 \% \mathrm{C}_{3} \mathrm{~S}, 13.5 \% \mathrm{C}_{2} \mathrm{~S}, 8.2 \% \mathrm{C}_{3} \mathrm{~A}$, and $0.54 \%$ alkali $\left(\mathrm{Na}_{2} \mathrm{O}\right.$ equivalent). The class $\mathrm{C}$ (Rockport) fly ash used had a $\mathrm{CaO}$ content of $18.5 \%$, an alkali content of $0.7 \%$ and a carbon content of $0.68 \%$.

The mixture contained a Vinsol-based air entraining admixture (Daravair 1400) to create and stabilize air bubbles to meet the target air content of $6.5 \%$. A mid-range water-reducing agent (WRA), WRDA-82, was used to increase workability. This WRA is an aqueous solution of modified lignosulfonates with a hydration catalyst. Although 
most of the mixtures in this study had a slump of $25 \mathrm{~mm}$ (1”), some mixtures were produced with the slumps of $63 \mathrm{~mm}(2.5$ ”). The w/cm in the $63 \mathrm{~mm}$ slump mixtures was the same as that used in the $25 \mathrm{~mm}$ slump mixtures and the increase in slump was achieved by varying the content of WRA. The objective behind increasing the slump using the WRA content only was to study the effect of slump on scaling independent of strength of the concrete.

Figure 7.1 shows the particle size distribution of the cementitious materials as determined using a particle analyzer laser. It can be seen that the mean cement particle is approximately 22 microns while the fly ash demonstrates a well distributed range of particle sizes with a concentration of particles at slightly less than 1 micron and a concentration at approximately 18 microns.

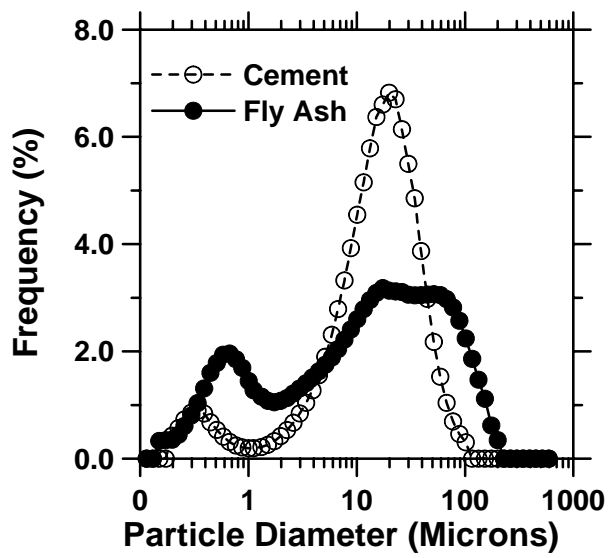

Figure 7.1: Particle size distribution for the cement and fly ash 


\subsection{Study of Influence of Individual Constituent Materials on Scaling Performance}

It is evident from the literature review that the influence of various material parameters on scaling performance was not studied extensively. In particular, none of the literature sources available examined the influence that chemical and mineral admixtures might have on the density of the near-surface region; hence, an indirect study was performed to quantify the effect of admixtures on surface density. In addition, the effects of deleterious fine aggregate particles on scaling performance are also examined in the following sections.

7.3.1. Influence of Chemical Admixtures and Fly Ash on Near-Surface Region Density of Hydrated Paste

As mentioned in the previous section, mixtures with two different slumps were used to study the scaling performance, the change of slump being the results of change in the WRA content. Many other researchers have reported that scaling increases with an increase in the slump of the concrete (section 5.3 .9 of this report, and Whiting, 1989). Therefore, it was important to identify whether the reduction in scaling resistance is related to an increased bleeding and reduction in density of near surface region (thinning) of the specimen or if there might be higher amount of admixture and fly ash in the surface region because of lower density. Additionally, buoyancy might allow more air bubbles to escape from the region of reduced density thus making it less frost resistant. 


\subsubsection{Experimental Procedures}

In an attempt to quantify the effects that chemical and mineral admixtures might have on the near-surface density, three set of experiments (studies) were performed. Three series of paste samples were prepared in each of the three studies. The paste composition is listed below in Table 7.2, illustration of which follows.

Table 7.2: List of paste samples prepared to study influence of fly ash and admixture

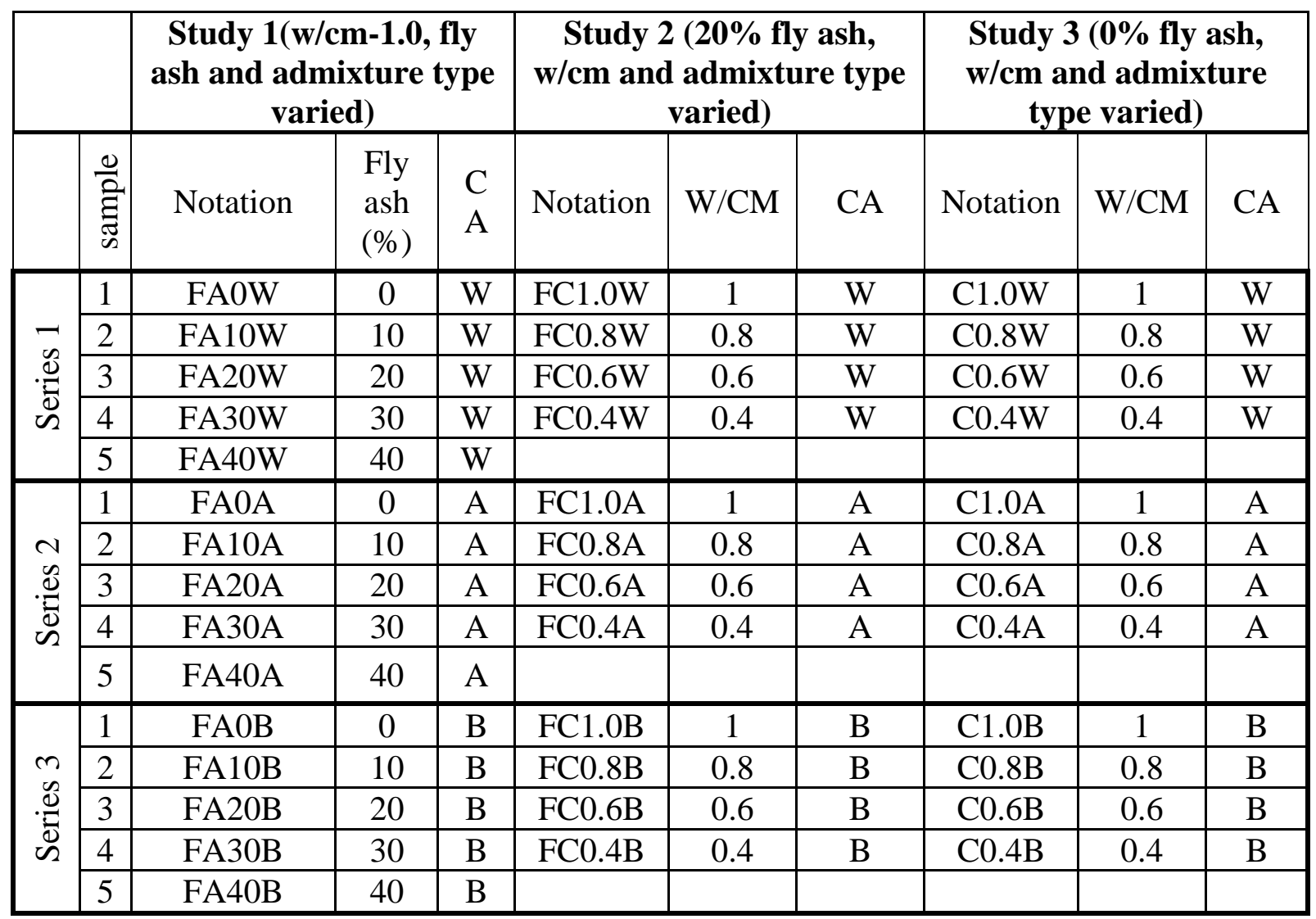

W- Water reducer, A- Air entraining agent, B-both (Water reducer + Air entraining agent), CA-Chemical Admixture

In the study 1 , liquid pastes $(\mathrm{w} / \mathrm{cm}=1)$ were prepared with different levels of supplementary cementitious materials. As mentioned earlier, three series of samples 
were prepared in this study. Each series had five samples, in which $0 \%, 10 \%, 20 \%, 30 \%$, or $40 \%$ of the cement was replaced with fly ash. Mixture proportions for the $25 \mathrm{~mm}$ slump mixture (Table 7.1) were used for proportioning the amount of WRA ( $0.22 \%$ by weight of cement) and $\mathrm{AE}$ ( $0.03 \%$ by weight of cement). The samples used in the first and second series contained only water reducing agent (WRA), and air entraining agent (AE) respectively, while samples in third series contained both WRA and AE. For each sample, all the materials including water were combined in a bottle and shaken for one minute before being allowed to settle. The paste was then poured into a clear plastic cup and allowed to set and hydrate for 48 hours, without any disturbance. In the cases, where distinct top and bottom layers were observed, they were carefully separated. Volume and mass of these sections were determined to calculate the densities.

In the study 2 , pastes were made with a $20 \%$ constant cement replacement with fly ash. In this study, three series were prepared, with four samples in each series. Each sample consisted of 500 grams $(1.1 \mathrm{lb})$ of cementitious materials, and the water was varied to achieve water to cementitious materials ratios of $1.0,0.8,0.6$, and 0.4 . Similar to previous section, first series contained only WRA, second series contained only AE and third series contained both. Thus, total of 12 paste samples were prepared for this case.

To quantify the effect of fly ash, in the study 3 another 12 samples were prepared in three different series. The third study was identical to second study, except no fly ash was added in this study. For study 2 and 3, paste samples were prepared similar to study 1. Results of all the three studies are described below. 


\subsubsection{Results and Data Analysis}

In the study 1, variables being fly ash and chemical admixture for a constant w/cm of 1.0, the following observations are made. As shown in Figure 7.2(b), all of the mixes eventually separated into two layers, a top porous layer and a denser bottom layer. This Figure shows images taken 5 minutes after the agitation. The mixtures with both admixtures had the largest top layer (by volume), while the mixtures with only air entrainment separated the least. The density of the bottom section was relatively constant while the density of the top portion decreased as the fly ash replacement increased. No distinct separation occurred when only cement and water were used, indicating that the separation was due to the use of fly ash; and the degree of separation varied as the replacement of cement with fly ash varied. At first glance it seems that mineral/chemical admixtures are responsible for low density of near-surface region, however, further studies (study 2 and 3) would help in exact quantification of the effect.

As mentioned earlier for study 2 and 3, 20 and $0 \%$ of cement was replaced with fly ash respectively and variables were w/cm and chemical admixture. The results of these two studies are summarized in Figure 7.3. Figure 7.3(a) shows the results with 20\% cement replaced by fly ash while 7.3(b) shows the results of only cement paste.

From Figure 7.3, it can be seen that when both a WRA and an AE were used in the pastes, the separated top volume was the maximum. On the other hand, the ratio of the density of the bottom to the top layer was the lowest in comparison to the pastes with only AE or only WRA. Thus, it is evident that in high w/cm mixes the combined effect of both admixtures played a major role in creating a distinct top layer but this top layer was denser in comparison to the layer generated by only air entraining agent or only 
water reducer. Therefore, the tendency of a combined effect of both admixtures could be considered such that it would provide restraint against the generation of a very high localized $\mathrm{w} / \mathrm{cm}$ ratio in the very top surface.

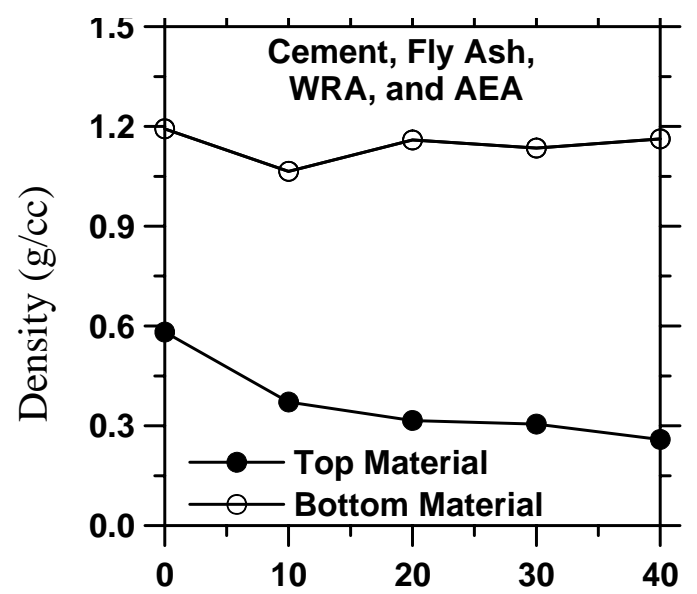

Percentage replacement of fly ash

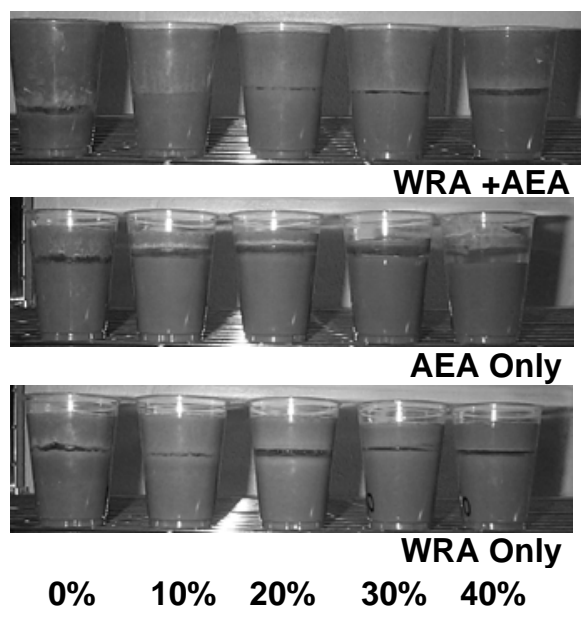

Percentage replacement of fly ash

Figure 7.2: Influence of WRA and AE on separation into two layers with different density; (a) measured densities of top and bottom portions for paste with WRA and AEA, and (b) Photos of paste separation

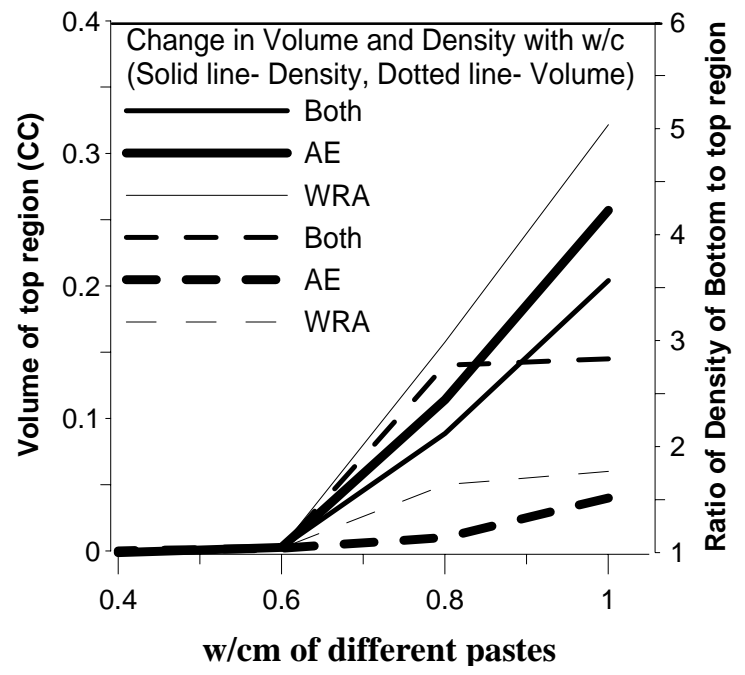

(a)

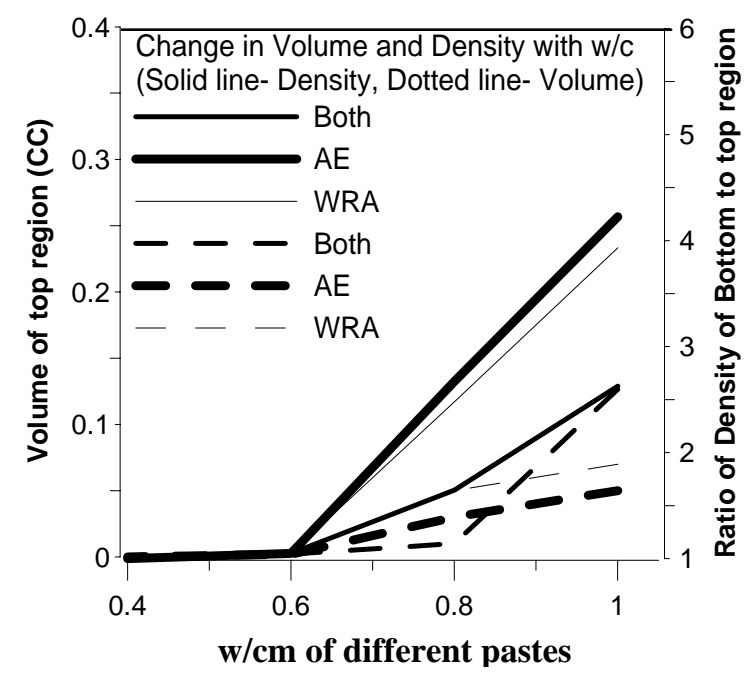

(b)

Figure 7.3: (a) Change in volume of separated surface, and ratio of density of the separated regions with change in w/cm for pastes containing $20 \%$ fly ash, and (b) Change in volume of separated surface and ratio of density of the separated regions with change in $\mathrm{w} / \mathrm{cm}$ for pastes containing cement only 
Comparing Figures 7.3(a) and (b) pastes with w/cm of 0.8 and higher, it was observed that the density of the near-surface region was lower for most pastes containing fly ash than the pastes with only cement. For a very high w/cm therefore, the presence of a higher amount of fly ash on the surface is possible, leading to layer separation and possible weakening of the surface region. However, an almost nil separation effect was observed for a w/cm of 0.6 and less. Real-life concrete mixes that contain coarse aggregate and are typically prepared at w/cm lower than 0.5 and would show a higher degree of restraint would be present towards settlement. Therefore, the presence of higher a percentage of fly ash in the surface region would not be a concern for concrete pavements containing fly ash, where the w/cm is in the range of 0.4 to 0.5 .

\subsubsection{Role of Deleterious Aggregates}

\subsubsection{Introduction and Observation}

Based on the literature review, it is evident that deleterious or porous coarse aggregates can increase scaling significantly (Klieger, 2003 and Jansen, 2000) but no such observations are available for fine aggregates. In this section an observation is reported about the influence of deleterious fine aggregate particles on scaling performance. As far as freeze-thaw resistance is concerned, fine aggregates do not have negative influence, and even the presence of a small amount of deleterious fine aggregate does not create any major damage to the concrete. In the case of scaling, however, different results are possible.

During scaling study, difference in scaled mass was observed for a few specimens that were prepared using new fine aggregate. This aggregate confirmed the INDOT 
specifications and had deleterious (non-durable) materials under the specified limit (4\% of total fine aggregates). In this case in both the fly ash and the control specimens, similar scaling behavior was observed after the first five to seven F-T cycles; scaling was initiated by the fracture of small dark grey particles on the specimens' surface. These dark grey or black particles were collected and evaluated under a scanning electron microscope and in an X-ray diffractometer. In addition, using optical microscope and specific gravity determinations were also conducted for such particles present in the fine aggregates.

\subsubsection{Results and Data Analysis}

Figure 7.4 shows the results of the $\mathrm{X}$-ray diffraction analysis, which indicate that significant amount of clay minerals (illite and kaolinite) were present in these particles. Also the EDX of the Scanning Electron Microscope (SEM) showed presence of alumina, silica, iron and oxygen in significant amounts. The above information and further petrography analysis under optical microscope to analyze the texture and grain size, revealed that these deleterious particles were weathered shale particles, which can be present in natural river sand. A few other properties for these particles were determined and are reported in the Table 7.3. 


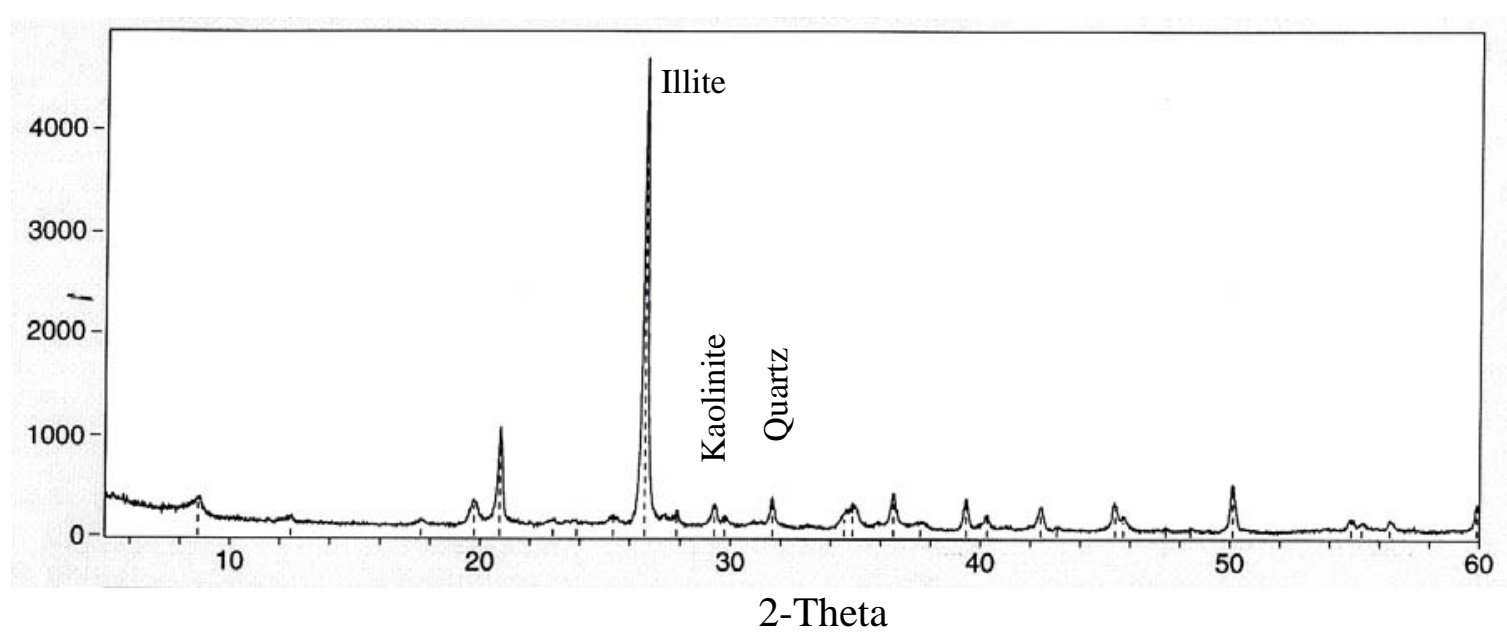

Figure 7.4: X-ray diffraction pattern of weathered shale particles

Table 7.3: Properties of deleterious particles present in sand

\begin{tabular}{|l|l|l|}
\hline Property & Technique/tools used & Observations \\
\hline $\begin{array}{l}\text { Size and shape } \\
\text { and texture }\end{array}$ & $\begin{array}{l}\text { Vernier caliper and } \\
\text { Petrographical microscope, } \\
\text { (ASTM C 295) }\end{array}$ & $\begin{array}{l}\text { Dark grey to black color, rounded or } \\
\text { flaky, } 2 \text { - 4 mm x 3.5 - 4.5 mm size, } \\
\text { plate-like structure, weathered } \\
\text { surface. }\end{array}$ \\
\hline $\begin{array}{l}\text { Percentage of } \\
\text { particles }\end{array}$ & $\begin{array}{l}\text { Random sampling as per } \\
\text { ASTM D75 }\end{array}$ & $\begin{array}{l}\text { Average 2.5\% of total weight of } \\
\text { aggregates. }\end{array}$ \\
\hline $\begin{array}{l}\text { Composition of } \\
\text { particles }\end{array}$ & $\begin{array}{l}\text { Energy Dispersive X-ray } \\
\text { (EDX) analysis using SEM }\end{array}$ & $\begin{array}{l}\text { Composed of mainly alumina, silica, } \\
\text { iron and oxygen, presence of } \\
\text { calcium and magnesium also } \\
\text { observed. }\end{array}$ \\
\hline $\begin{array}{l}\text { Mineralogical } \\
\text { analysis }\end{array}$ & X-ray diffraction & $\begin{array}{l}\text { Mainly clay minerals, such as illite, } \\
\text { kaolinite, etc., also quartz and calcite } \\
\text { observed. }\end{array}$ \\
\hline Specific gravity & ASTM C 128 & $\begin{array}{l}\text { 2.28, low in comparison to average } \\
\text { specific gravity of sand 2.64. }\end{array}$ \\
\hline
\end{tabular}

Though small in overall quantity, the weathered shale particles were lighter than other sand grains and so a greater number of these particles were visible on the surface of the specimen. Since the freeze-thaw durability of such particles is very poor, they 
fractured and caused de-lamination (scaling) of the surrounding mortar. Figure 7.5 shows the scaling caused by the presence of these particles in the surface region after $5 \mathrm{~F}-\mathrm{T}$ cycles.

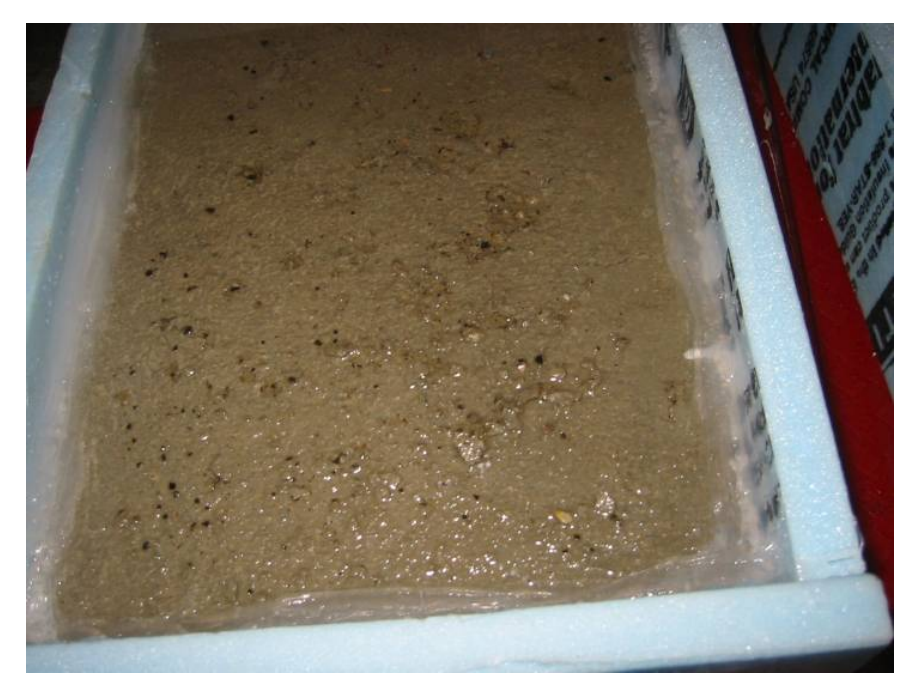

Figure 7.5: Scaling of concrete surface around deleterious sand particles

In summary, aggregate could play an important role in reducing the scaling resistance of sound concrete. As the above results confirmed the deleterious role of the fine aggregate in scaling, the source of fine aggregate was changed for further study.

\subsubsection{Influence of Variability of Cementitious Materials on Scaling Behavior}

\subsubsection{Introduction}

Based on the primary study that included various cements and fly ashes (section 5.3.8), it can be said that small changes in the chemical composition of cements can have a significant influence on scaling performance. This is evident in Figure 5.13 which shows that the scaled mass varied from $0.3 \mathrm{~kg} / \mathrm{m}^{2}$ to $3.0 \mathrm{~kg} / \mathrm{m}^{2}$, depending on combination of materials used. It should be noted that in that particular study the mixture 
proportions for all of concretes were the same except for the composition of cementitious materials.

In this study a similar variation in scaling performance was observed when the shipment of cement and fly ash were received from the same source (as used in the initial part of study), 3 years after an initial acquisition. The concrete cast from the originally acquired cement and fly ash, scaled on an average $2.5 \mathrm{~kg} / \mathrm{m}^{2}$, while the concrete prepared with new cement and fly ash scaled only $0.2 \mathrm{~kg} / \mathrm{m}^{2}$. A comparison of the scaled surfaces of the concrete containing the old (btch-00) and the new (btch-03) cement and fly ash is shown below in Figure 7.6. The properties of the old and new cements and fly ashes were compared and the probable reasons for improvement in the observed scaling results are proposed. The changes in chemical composition of both cement and fly ash are discussed in sections 7.3.3.2 and 7.3.3.3, respectively. It is strongly emphasized that to determine scaling performance, the combined influence of the cement and fly ash components should be considered. 


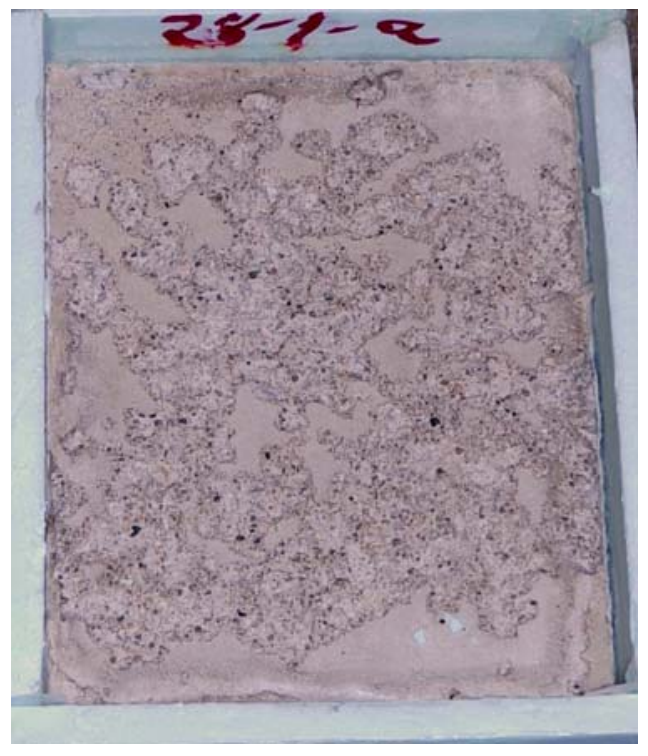

(a)

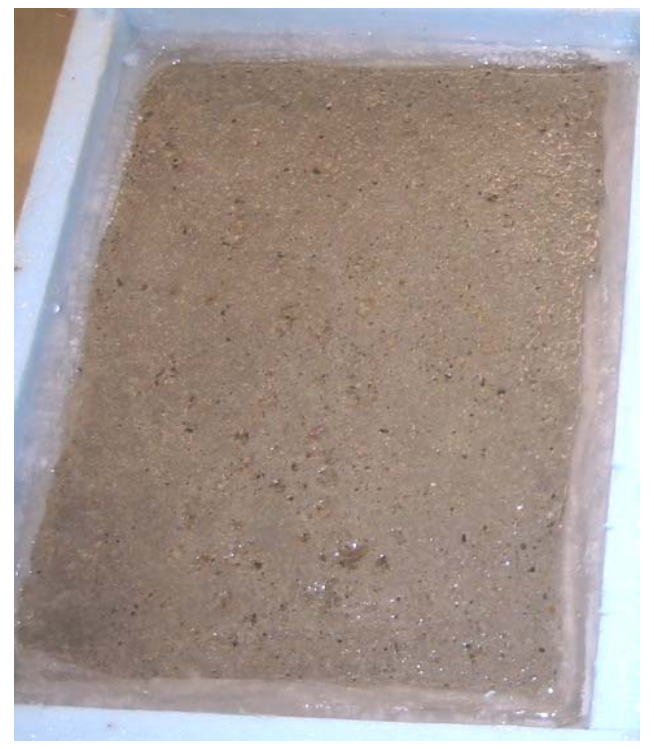

(b)

Figure 7.6: Scaled surfaces after 50 F-T cycles, (a) btch-00 (worst performing) combination of cement and fly ash, and (b) btch-03 (better performing) combination of cement and fly ash

\subsubsection{Cement}

The chemical composition of old and new cement (as reported on mill certificates) is given in Table 7.4. There is a considerable (approximately 55\%) increase in $\mathrm{C}_{2} \mathrm{~S}$ content and a corresponding $13 \%$ decrease in $\mathrm{C}_{3} \mathrm{~S}$ observed. Theoretically, the cement with higher $\mathrm{C}_{3} \mathrm{~S}$ should give higher early strength and should, therefore, show better scaling resistance. However, as shown in Figure 7.6 exactly opposite results were observed. Similarly, although btch-2003 cement has higher content of alkalis and $\mathrm{C}_{3} \mathrm{~A}$, it showed better scaling resistance, which is contradictory to what have been proposed in some other studies (Marchand et al., 2000 and Jackson, 1958). It is therefore essential to accurately interpret the results to address all of the above discrepancies. 
Table 7.4: Comparison of various component and properties old and new cements

\begin{tabular}{|c|c|c|c|c|c|c|c|c|}
\hline \multirow{2}{*}{$\begin{array}{l}\text { Lone Star cement } \\
\text { (Indiana) }\end{array}$} & \multirow{2}{*}{$\mathrm{C}_{3} \mathrm{~S}$} & \multirow{2}{*}{$\mathrm{C}_{2} \mathrm{~S}$} & \multirow{2}{*}{$\mathrm{C}_{3} \mathrm{~A}$} & \multirow{2}{*}{$\begin{array}{c}\text { Alkali } \\
\text { as } \\
\mathrm{Na}_{2} \mathrm{O} \\
\text { eq. }\end{array}$} & \multirow{2}{*}{ Fineness } & \multicolumn{3}{|c|}{$\begin{array}{l}\text { Comp. strength, psi } \\
(\mathrm{MPa})\end{array}$} \\
\hline & & & & & & 1 day & 3 day & 7 day \\
\hline $\begin{array}{l}\text { Shipment }-1 \text { btch- } \\
\text { 00: Aug } 2000\end{array}$ & 60.01 & 13.54 & 8.22 & 0.54 & 360.8 & $\begin{array}{c}2272 \\
(15.7)\end{array}$ & $\begin{array}{r}3439 \\
(23.7)\end{array}$ & $\begin{array}{r}4390 \\
(30.3)\end{array}$ \\
\hline $\begin{array}{l}\text { Shipment }-2 \text { btch- } \\
\text { 03: Sept } 2003\end{array}$ & 52 & 21 & 10 & 0.696 & 362.0 & $\begin{array}{c}2150 \\
(14.8)\end{array}$ & $\begin{array}{c}3400 \\
(23.4)\end{array}$ & $\begin{array}{c}4390 \\
(30.3)\end{array}$ \\
\hline
\end{tabular}

First, the reason for such a wide variation in $\mathrm{C}_{3} \mathrm{~S}$ and $\mathrm{C}_{2} \mathrm{~S}$ content for cements coming from the same source was explored. After the discussion with technical support personnel of Lone Star cement. It was found that when the btch-00 cement was obtained, the plant had been importing clinker from Thailand, as changes were being made in the plant. The clinker for btch-03 cement was produced in the local plant, using the local materials. Since, the sources of materials for this btch-00 and btch-03 cements were totally different, that lead to a wide differences in their chemical composition.

It is well known that $\mathrm{C}_{2} \mathrm{~S}$ produces only about half of the $\mathrm{CH}$ that is produced by the $\mathrm{C}_{3} \mathrm{~S}$ (Neville, 1996). As a result, the extent of pozzolanic reactions in the system with lower $\mathrm{C}_{3} \mathrm{~S}$ content (btch-03 concrete), therefore will be lower in comparison to btch-00 concrete.

The scaling results strongly support the hypothesis that refinement in pore structure is the major cause of increased scaling damage for laboratory concrete containing fly ash, as already noted in the case-specific literature summary of scaling. Pore refinement due to secondary reaction is widely known to be the most beneficial effect of fly ash in concrete. However, in the case of scaling that pore refinement may be detrimental under certain conditions. Specifically, it is hypothesized that pore refinement 
might increase the degree of saturation during consecutive F-T cycles because smaller pores, which might not dry out during non-freezing part of the cycle. To further investigate this hypothesis, the reactivity of fly ash in a given cementitious system was evaluated and is discussed in section 7.3.3.3. Also, the values for alkali content of cement are considered very normal for typical Type-I cement in this study, so the observation by other researchers that high alkali/high $\mathrm{C}_{3} \mathrm{~A}$ cement have poorer scaling resistance might not be applicable for this case.

\subsubsection{Fly Ash}

The available components and properties of both original and new suite of fly ashes are reported in Table 7.5. It can be seen from the data that the lime content, carbon content, and fineness (\% retained on $45 \mu \mathrm{m}$ sieve) of both fly ashes are almost identical. However, a significant increase (15\%) in the 7 days Strength Activity Index (SAI7) for btch-03 fly ash was observed. The SAI 7 of $98 \%$ is very close to the strength of plain cement (100\%), which indicates high reactivity of new fly ash (btch-03). Further analysis of the fly ash was done, therefore, to determine the exact reasons for increase in SAI7 value.

Table 7.5: Comparison of various components and properties of old and new fly ashes

\begin{tabular}{|c|c|c|c|c|c|c|}
\hline Rockport fly ash & $\begin{array}{c}\text { Lime } \\
\mathbf{( \% )}\end{array}$ & $\begin{array}{c}\text { Alkali } \\
\mathbf{( \% )}\end{array}$ & $\begin{array}{c}\text { Fineness (\% } \\
\text { retained on } \\
\mathbf{4 5} \boldsymbol{~} \mathbf{m} \text { sieve) }\end{array}$ & $\begin{array}{c}\text { Max. \% } \\
\text { frequency }\end{array}$ & $\begin{array}{c}\text { Carbon } \\
\mathbf{( \% )}\end{array}$ & SAI7 \\
\hline Batch- Aug 2000 & 18.57 & 0.70 & 21.88 & $18 \mu \mathrm{m}$ & 0.68 & 85.50 \\
\hline Batch- Aug 2003 & 18.48 & 1.0 & 20.1 & $10 \mu \mathrm{m}$ & 0.46 & 98 \\
\hline
\end{tabular}

SAI7- Strength activity index at 7 days as per ASTM C 311 
Though the percentage retained on the $45 \mu \mathrm{m}$ sieve for both fly ashes was similar, the particle size distribution for these fly ashes showed considerable difference. The maximum frequency of new (btch-03) fly ash particles was observed at $10 \mu \mathrm{m}$ versus 18 $\mu \mathrm{m}$ for the old (btch-00) fly ash, which means that a higher amount of finer particles was present in the case of btch-03 fly ash, which could increase the reactivity of fly ash at the early ages.

An increased number of finer particles and a small increase in the alkali content are probably not the only parameters that could increase the SAI of fly ash significantly. It should be remembered that SAI is the property of combined cement and fly ash system. The SAI values obtained for btch-03 fly ash, were obtained with btch-03 Lone Star type I cement. As described earlier, this cement had a comparatively low $\mathrm{C}_{3} \mathrm{~S}$ and a high $\mathrm{C}_{2} \mathrm{~S}$ content. In this combination of cement and fly ash, the self cementing properties of fly ash could play an important role in early strength development.

To develop better insight into the mineralogical characteristic of btch-03 fly ash, an X-ray diffraction analysis was performed and the results are shown in Figure 7.7. As commonly observed in reactive class $\mathrm{C}$ fly ashes a significant amount of gypsum and ettringite was observed in this fly ash. The presence of these components, along with high alkali content, could lead to significant reactivity of fly ash at early ages. 


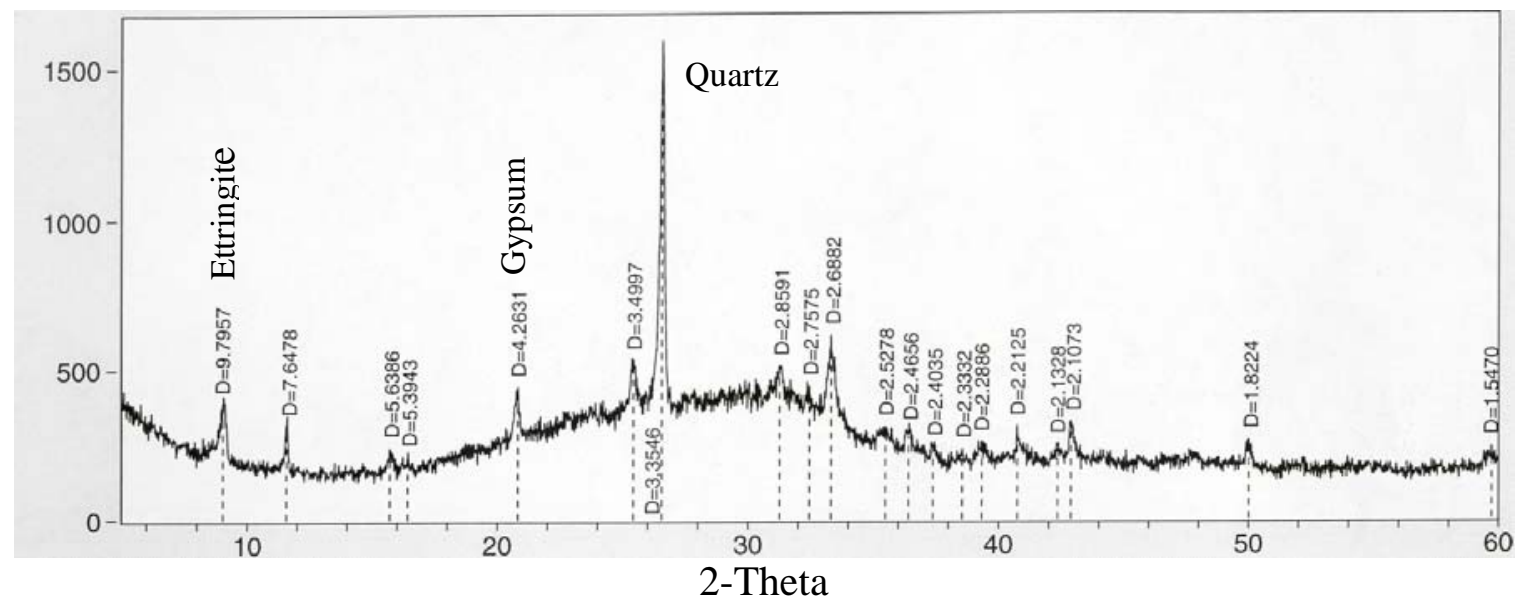

Figure 7.7: X-ray diffraction of btch-03 fly ash

\subsubsection{Data Analysis and Proposed Hypothesis}

Upon close observation of the cement and fly ash composition, it seems that a lower overall pozzolanic activity might help in improving scaling performance. To verify this hypothesis with the available results, components affecting pozzolanic activity were examined separately as mentioned below. The first component considered was the $\mathrm{C}_{2} \mathrm{~S}$ content of cement. A higher $\mathrm{C}_{2} \mathrm{~S}$ reduces the overall amount of $\mathrm{CH}$ in the system and thus the overall pozzolanic activity. The second important component that can be considered here is $\mathrm{C}_{3} \mathrm{~S}$ of cement. A higher $\mathrm{C}_{3} \mathrm{~S}$ could increase the amount of $\mathrm{CH}$ significantly and thereby help promote pozzolanic activity. Thus, the lower the $\mathrm{C}_{3} \mathrm{~S}$ in the cement, the lower should be the overall pozzolanic reaction. Thus, the SAI7 of fly ash is also one of the parameters that is related to pozzolanic activity in the system. Generally, it is believed that a minimal amount of pozzolanic activity will take place during the first seven days of hydration (Mehta, 1996). Hence, a higher value of SAI7 may be attributed primarily to the reaction of fly ash itself with water. Therefore, the 
expected overall pozzolanic activity should decrease with an increase in SAI7 value because there will be less unhydrated fly ash available in the cement-fly ash system when cement hydration generated $\mathrm{CH}$ becomes available.

Assuming that the above reasoning is correct the sum of $\mathrm{C}_{2} \mathrm{~S}-\mathrm{C}_{3} \mathrm{~S}+\mathrm{SAI7}$ should yield a factor, increase in which should yield a decrease in pozzolanic activity. Based on the earlier proposed hypothesis, the reduction in pozzolanic activity should lead to reduction in scaling. Figures 7.8(a), (b) and (c) shows $\left(\mathrm{C}_{2} \mathrm{~S}-\mathrm{C}_{3} \mathrm{~S}\right),\left(\mathrm{C}_{2} \mathrm{~S}+\mathrm{SAI7}\right)$ and $\left(\mathrm{C}_{2} \mathrm{~S}-\mathrm{C}_{3} \mathrm{~S}+\mathrm{SAI7}\right)$ values plotted against scaling results obtained from all different cement-fly ash combinations studied in this and in earlier Chapter 5. Moreover, Figure 7.8 shows scaling results plotted against $\left(\mathrm{C}_{2} \mathrm{~S}-\mathrm{C}_{3} \mathrm{~S}+\mathrm{SAI7}\right)$ value for all the different combinations. The plotted parameters show good correlation indicating that the decrease in pozzolanic activity also reduces scaling damage.

Some of the field observations reported for High Volume Fly Ash (HVFA) concrete (Thomas, 2000) indicate that at later ages scaling is usually observed in the concrete with class F fly ash. This suggests that the pozzolanic activity can be one of the parameters that controls scaling damage of field concrete. It should be noted that hypothesis presented in this section is based on the limited volume of data; further research is required to confirm the proposed reasoning. 


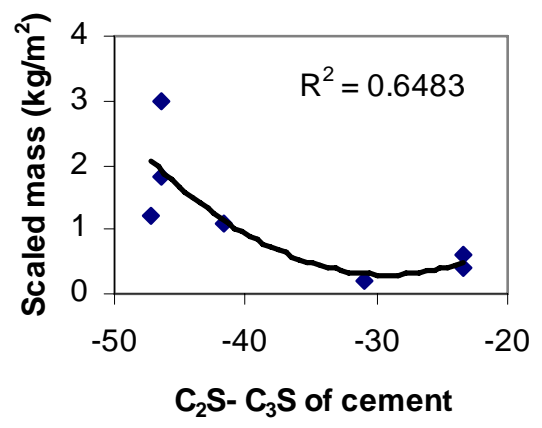

(a)

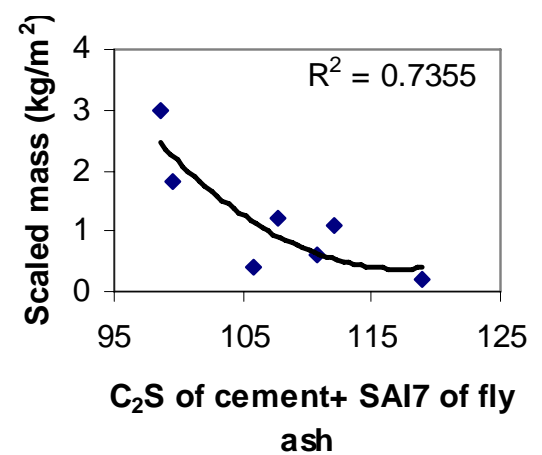

(b)

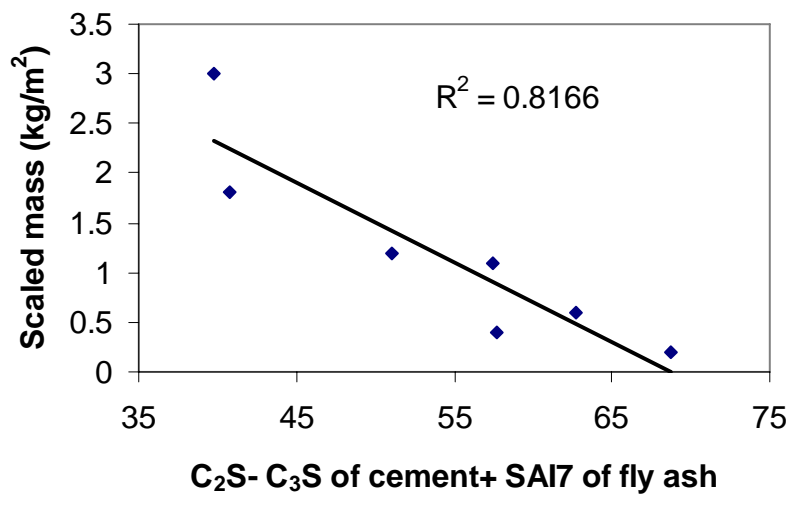

(c)

Figure 7.8: Scaled mass of concrete containing different cement-fly ash combinations plotted against their (a) $\left(\mathrm{C}_{2} \mathrm{~S}-\mathrm{C}_{3} \mathrm{~S}\right)$ values, (b) $\left(\mathrm{C}_{2} \mathrm{~S}+\mathrm{SAI}\right.$ ) values, and (c) $\left(\mathrm{C}_{2} \mathrm{~S}-\mathrm{C}_{3} \mathrm{~S}+\right.$ SAI7)

In summary, it is evident that the scaling behavior of concrete depends on the cement-fly ash interaction and how these materials influence formation of microstructure and the pore size distribution. To develop an understanding of mechanism of the scaling of fly ash concrete, it is therefore important to characterize the effect of minor changes in cementitious materials and relate these changes to scaling performance while keeping all the other parameters constant. This issue has not been addressed by researchers thus far. Therefore, a detailed systematic study is required to confirm actual importance of the above components in scaling results and to develop a more precise relationship between 
the cementitious materials components and the scaling performance of concrete. With limited availability of time and resources for this particular project, these issues could not be addressed in this research.

\subsection{Summary}

This chapter discussed studies and observations addressing the influence of various material properties on scaling performance of concrete. Role of admixtures was evaluated with the help three different studies. An observation regarding influence of deleterious fine aggregates on scaling is reported. It can be summarized that knowledge of material parameters is vital for better interpretation of results. Additionally scaling of concrete containing fly ash is highly dependent on the type of pore size distribution, and therefore the variability in cementitious materials could change scaling performance significantly. Pore refinement due to pozzolanic activity seems to be a major parameter influencing scaling results, but further study is required to confirm this hypothesis and to provide better guidelines for materials selection. 


\section{CHAPTER 8: INFLUENCE OF LENGTH AND TYPE OF CURING ON SALT PENETRATION AND SCALING}

\subsection{Introduction}

It is well known that for portland cement to properly hydrate, moisture loss must be prevented. This is typically achieved by proper curing conditions. Since pozzolanic reactions are generally slower than the standard portland cement reactions, proper curing conditions are especially important for concrete containing supplementary materials. As mentioned earlier (section 2.5.1), researchers have reported contradictory results regarding the influence of the length of the moist-curing and drying periods on scaling performance of the fly ash concrete. To develop a better understanding of how sensitive scaling resistance is to the moist-curing and drying periods and to the age of fly ash concrete, a series of moist-curing and drying regimes (Table 8.1) were investigated using $25 \mathrm{~mm}$ (1”) and $63 \mathrm{~mm}$ (2.5”) slump mixtures (Table 7.1). Thus, the effects of various combinations of three variables; length of the moist-curing period, length of the drying period and the slump on scaling performance was evaluated.

One of the questions that exist in testing concrete is whether the properties of concrete near the surface represent the properties of bulk concrete. Several researchers have suggested that surface concrete is defined as the portion of the concrete that is influenced by curing. Jacobsen et al. (1997) reported that scaling is most influenced by "both the air void characteristics and the pore structure of the surface layer". When 
evaluating scaling potential, it is important to study the structure of concrete in the surface layer because that layer will be most vulnerable to scaling when concrete is constructed during a period of falling temperatures.

Scanning electron microscopy (SEM) evaluation was performed to investigate the structure of near-surface layers of the laboratory concrete. This study was performed to verify the existence of a thin porous region at the surface of the concrete at the early ages, which, if present, may initiate the scaling process or reduce the forces required to cause scaling. To quantify the variation in porosity between the bulk and surface regions of the concrete, porosity gradients (normalized porosity at various depths) were developed for various ages from the surface towards the core of the concrete for different specimens.

Salt concentration in the surface region is one of the important parameters in determining total scaling damage at early and later ages (Lindmark, 1997). The rate of salt penetration depends on the pore structure and the degree of saturation of the concrete. During early ages, the combined effect of hydration of cement and the secondary reaction of fly ash changes the pore structure significantly. In addition, the effect of different drying periods changes the relative humidity (degree of saturation) inside the concrete and makes it difficult to predict the chloride penetration. Therefore, to quantify the salt penetration ingress and to obtain correlation with scaling, 4" x 8” (100 mm x $200 \mathrm{~mm})$ cylindrical specimens were prepared and analyzed for salt penetration depth. Additional tests were also performed (using variable salt concentrations) to quantify the effect of the salt concentration on scaling behavior of concrete. Moreover, the microstructure and salt penetration study helped in understanding the scaling results from different conditioning periods. 
Table 8.1: Testing matrix -- curing regimes

\begin{tabular}{|c|c|c|c|c|c|}
\hline \multicolumn{6}{|c|}{25 mm (1") nominal slump mixtures } \\
\hline Number & $\begin{array}{l}\text { Specimen } \\
\text { ID }\end{array}$ & $\begin{array}{l}\text { Length of moisture } \\
\text { curing ( } 98 \% \text { RH, } \\
\left.23^{\circ} \mathrm{C}\right) \text { after } 1 \text { day } \\
\text { sealed curing }\end{array}$ & $\begin{array}{c}\text { Dry curing } \\
(50 \% \mathrm{RH}, \\
\left.21^{\circ} \mathrm{C}\right)\end{array}$ & $\begin{array}{c}\text { Fresh } \\
\text { concrete } \\
\text { air content } \\
(\%)\end{array}$ & $\begin{array}{l}\text { Measured } \\
\text { slump, in. } \\
\text { (mm) }\end{array}$ \\
\hline 1 & $1-1-\mathrm{a}$ & & 1 day & \multirow{6}{*}{6.2} & \multirow{6}{*}{$0.8(20.3)$} \\
\hline 2 & $1-2-a$ & & 2 days & & \\
\hline 3 & $1-3-a$ & & 3 days & & \\
\hline 4 & $1-7-\mathrm{a}$ & & 7 days & & \\
\hline 5 & $1-14-\mathrm{a}$ & & 14 days & & \\
\hline 6 & $1-28-\mathrm{a}$ & & 28 days & & \\
\hline 7 & 3-1-a & 2 days & 1 day & \multirow{6}{*}{6.5} & \multirow{6}{*}{0.9 (22.9) } \\
\hline 8 & $3-2-a$ & 2 days & 2 days & & \\
\hline 9 & 3-3-a & 2 days & 3 days & & \\
\hline 10 & 3-7-a & 2 days & 7 days & & \\
\hline 11 & $3-14-\mathrm{a}$ & 2 days & 14 days & & \\
\hline 12 & $3-28-a$ & 2 days & 28 days & & \\
\hline $13^{*}$ & 5-1-a & 4 days & 1 day & \multirow{6}{*}{6.2} & \multirow{6}{*}{0.9 (22.9) } \\
\hline $14^{*}$ & 5-2-a & 4 days & 2 days & & \\
\hline $15^{*}$ & 5-3-a & 4 days & 3 days & & \\
\hline $16^{*}$ & 5-7-a & 4 days & 7 days & & \\
\hline $17^{*}$ & 5-14-a & 4 days & 14 days & & \\
\hline $18^{*}$ & 5-28-a & 4 days & 28 days & & \\
\hline 19 & 7-1-a & 6 days & 1 day & \multirow{6}{*}{6.8} & \multirow{6}{*}{$1.0(25.4)$} \\
\hline 20 & $7-2-a$ & 6 days & 2 days & & \\
\hline 21 & $7-3-a$ & 6 days & 3 days & & \\
\hline 22 & $7-7-a$ & 6 days & 7 days & & \\
\hline 23 & $7-14-a$ & 6 days & 14 days & & \\
\hline 24 & $7-28-a$ & 6 days & 28 days & & \\
\hline 25 & 14-1-a & 13 days & 1 day & \multirow{6}{*}{6.4} & \multirow{6}{*}{$0.9(22.9)$} \\
\hline 26 & 14-2-a & 13 days & 2 days & & \\
\hline 27 & 14-3-a & 13 days & 3 days & & \\
\hline 28 & $14-7-a$ & 13 days & 7 days & & \\
\hline 29 & 14-14-a & 13 days & 14 days & & \\
\hline 30 & 14-28-a & 13 days & 28 days & & \\
\hline 31 & 28-1-a & 27 days & 1 day & \multirow{6}{*}{6.6} & \multirow{6}{*}{0.9 (22.9) } \\
\hline 32 & $28-2-a$ & 27 days & 2 days & & \\
\hline 33 & $28-3-a$ & 27 days & 3 days & & \\
\hline 34 & $28-7-a$ & 27 days & 7 days & & \\
\hline 35 & 28-14-a & 27 days & 14 days & & \\
\hline 36 & 28-28-a & 27 days & 28 days & & \\
\hline
\end{tabular}

* Results not analyzed due to problem with finishing 
Table 8.1 continued

\begin{tabular}{|c|c|c|c|c|c|}
\hline \multicolumn{6}{|c|}{63 mm (2.5”) nominal slump mixture } \\
\hline Number & $\begin{array}{l}\text { Specimen } \\
\text { ID }\end{array}$ & $\begin{array}{l}\text { Length of moisture } \\
\text { curing ( } 98 \% \mathrm{RH}, \\
\left.23^{\circ} \mathrm{C}\right) \text { after } 1 \text { day } \\
\text { sealed curing }\end{array}$ & $\begin{array}{c}\text { Dry curing } \\
(50 \% \mathrm{RH}, \\
\left.21^{\circ} \mathrm{C}\right)\end{array}$ & $\begin{array}{c}\text { Fresh } \\
\text { concrete } \\
\text { air content } \\
(\%)\end{array}$ & $\begin{array}{l}\text { Measured } \\
\text { slump, in. } \\
\text { (mm) }\end{array}$ \\
\hline 1 & $1-1-b$ & & 1 day & \multirow{6}{*}{6.3} & \multirow{6}{*}{$2.2(55.9)$} \\
\hline 2 & 1-2-b & & 2 days & & \\
\hline 3 & 1-3-b & & 3 days & & \\
\hline 4 & $1-7-b$ & & 7 days & & \\
\hline 5 & 1-14-b & & 14 days & & \\
\hline 6 & 1-28-b & & 28 days & & \\
\hline 7 & 3-1-b & 2 days & 1 day & \multirow{6}{*}{6.5} & \multirow{6}{*}{$2.5(63.5)$} \\
\hline 8 & 3-2-b & 2 days & 2 days & & \\
\hline 9 & 3-3-b & 2 days & 3 days & & \\
\hline 10 & 3-7-b & 2 days & 7 days & & \\
\hline 11 & 3-14-b & 2 days & 14 days & & \\
\hline 12 & 3-28-b & 2 days & 28 days & & \\
\hline 13 & 5-1-b & 4 days & 1 day & \multirow{6}{*}{6.4} & \multirow{6}{*}{$2.1(53.3)$} \\
\hline 14 & 5-2-b & 4 days & 2 days & & \\
\hline 15 & 5-3-b & 4 days & 3 days & & \\
\hline 16 & 5-7-b & 4 days & 7 days & & \\
\hline 17 & 5-14-b & 4 days & 14 days & & \\
\hline 18 & 5-28-b & 4 days & 28 days & & \\
\hline 19 & $7-1-b$ & 6 days & 1 day & \multirow{6}{*}{6.8} & \multirow{6}{*}{$2.6(66.0)$} \\
\hline 20 & $7-2-b$ & 6 days & 2 days & & \\
\hline 21 & 7-3-b & 6 days & 3 days & & \\
\hline 22 & $7-7-b$ & 6 days & 7 days & & \\
\hline 23 & 7-14-b & 6 days & 14 days & & \\
\hline 24 & 7-28-b & 6 days & 28 days & & \\
\hline
\end{tabular}

Note: The actual slump of the test specimens varied slightly from the nominal values reported in the Table, but the nominal (target) slump values are used in this report to distinguish between low and high slump mixes.

\subsection{Specimen Preparation and Experimental Procedures}

The mixture proportions for the concrete used in the scaling study were described in the previous chapter (Table 7.1). Prior to mixing, the weight of all the constituent 
materials was determined within $0.1 \%$ accuracy. All mixtures were prepared in a counter-current pan mixer with an effective capacity of $1.8 \mathrm{ft}^{3}\left(0.051 \mathrm{~m}^{3}\right)$. The size of the individual batches for most of the studies was $1.5 \mathrm{ft}^{3}\left(0.042 \mathrm{~m}^{3}\right)$. The following mixing sequence was followed in the preparation of all mixtures. First, sand and coarse aggregates were mixed with approximately one third of the mixing water for one minute and the mixture was allowed to rest for three minutes for the purpose of moisture absorption. Then, the mixer was started again and cement and fly ash were added, followed by the addition of another one third of the mixing water. This was followed by addition of an air entraining admixture (previously diluted in $200 \mathrm{ml}$ water) and the water reducer (previously diluted in $500 \mathrm{ml}$ water). Finally, the remaining water was added to the mixture. After all the materials were added, the mixing continued for an additional two minutes. The mixer was then stopped for three minutes, after which the mixing was resumed for additional two minutes. Once the mixing was completed, fresh properties (slump and air content) were assessed, and slab scaling specimens and cylinders for chloride ion penetration were prepared. Specimens for microstructure study were obtained from either cylindrical or slab specimens. Further details regarding experimental procedures are described in consecutive sections.

\subsubsection{Influence of the Length of Moist-Curing and Drying on Scaling}

The slab specimens for scaling test were prepared by placing concrete in $75 \mathrm{~mm} \mathrm{x}$ $380 \mathrm{~mm}$ x $250 \mathrm{~mm}$ (3” x 15” x 10”) forms. The concrete was rodded and then vibrated for 15 - 20 seconds. The excess concrete was screeded off the surface of the specimens which stayed uncovered for 30 minutes. The specimens were then finished using the 
steel trowel. Great care was taken to avoid over-finishing of the surface. After the finishing operation was completed, the specimens were covered with plastic lids to seal them; however, the lids did not touch the surface. The slabs were stored under plastic sheets (covering the entire specimen, including the lids), until the time at which they were demolded (24 \pm 2 hours after casting). Care was taken to avoid any kind of evaporation from the specimens during the first 24 hours, and this curing procedure is considered to represent sealed curing.

After demolding, each slab was cut into halves using a diamond saw to create two 75 mm x 190 mm x 250 mm (3” x 7.5” x 10”) test specimens. In some cases, the scaling specimens were shorter (165 mm instead of $190 \mathrm{~mm}$ ) as a 25-mm wide strip was removed from one end for microscopic observations described in section 8.2.2. Once cut, each specimen was either moist-cured in a fog room $\left(>98 \% \mathrm{RH}, 23^{\circ} \mathrm{C} / 73.4^{\circ} \mathrm{F}\right)$ for two, six, thirteen or twenty seven days (the period of moist-curing excluded the first 24 hours when specimens were in the molds) or taken to the controlled humidity room (50\% RH, $21^{\circ} \mathrm{C} / 69.8^{\circ} \mathrm{F}$ ) for drying. At specified times, the most-cured specimens were also removed from the fog room and allowed to dry cure in a temperature and relative humidity controlled room $\left(50 \% \mathrm{RH}, 21^{\circ} \mathrm{C}\right)$. Table 8.1 provides a complete list of the specimens prepared, along with the details of curing. Suffixes "a" and "b" used in this Table refer to specimen with a slump of $25 \mathrm{~mm}$ (1”) and $63 \mathrm{~mm}$ (2.5”), respectively. For example, specimen 3-7-a was stored for the first 24 hours in a sealed mold. After demolding, it was moist-cured at $98 \% \mathrm{RH}$ for an additional two days, and dried in a 50\% $\mathrm{RH}$ environment for seven days. At the end of the drying period, the sides of the specimens were covered with epoxy and outfitted with a solution reservoir, which was 
created by attaching either a rubber membrane or Styrofoam ${ }^{\mathrm{TM}}$ sheets around the top perimeter of each slab. The interfaces between the membranes/Styrofoam and the sides of the specimens were carefully sealed with silicone caulk to prevent leakage of the solution. The caulk was permitted to cure for at least six hours and then the specimens were moved to an automatically-controlled, variable temperature chamber (F-T room) where 50 cycles of freezing and thawing were applied to a specimen ponded with a 3\% solution of sodium chloride on the surface.

The typical daily temperature profile inside the F-T room is shown in Figure 8.1. Each daily temperature cycle consisted of the room's temperature being maintained at $-16^{\circ} \mathrm{C}\left(3.2^{\circ} \mathrm{F}\right)$ for a period of five hours before the temperature was raised at a rate of $6.3^{\circ} \mathrm{C} / \mathrm{hr}$ to $22^{\circ} \mathrm{C}\left(71.6^{\circ} \mathrm{F}\right)$. That temperature was then maintained for a period of five hours. At the end of five hours the room was cooled at a rate of $7.5^{\circ} \mathrm{C} / \mathrm{hr}$ until it reached approximately $-8^{\circ} \mathrm{C}$ and then cooled at a slower rate of $1.55^{\circ} \mathrm{C} / \mathrm{hr}$ until it reached $-16^{\circ} \mathrm{C}$.

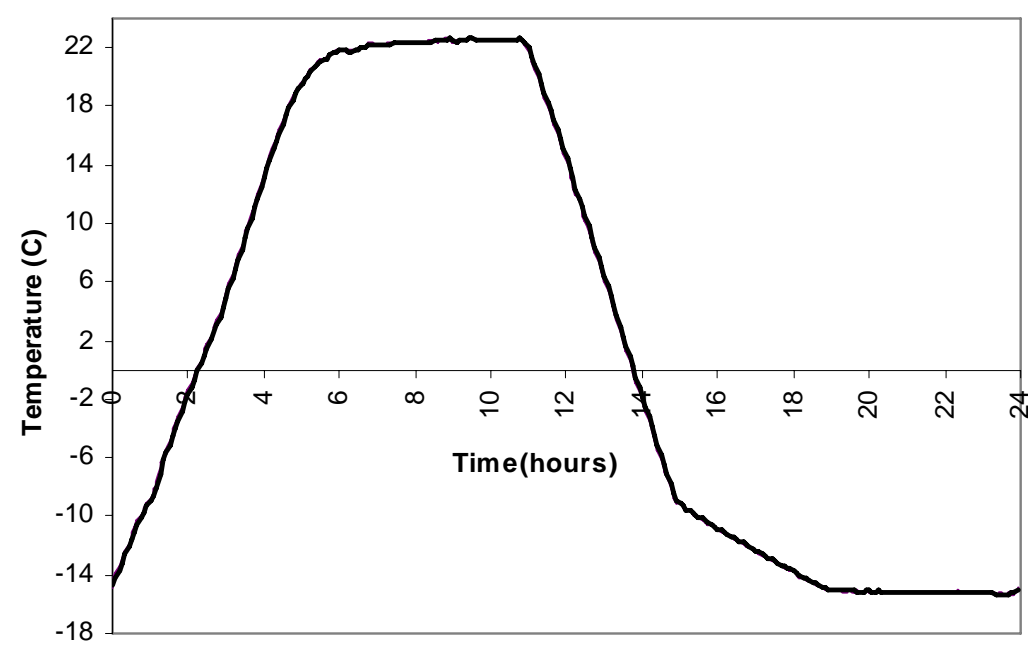

Figure 8.1: Typical temperature profile inside the freeze-thaw room 
The adopted scaling test procedure differs from the ASTM C 672 standard in the following three aspects. First, ASTM recommends visual rating as a criterion for evaluating the scaling resistance of concrete. However, since the method of visual rating is highly operator-subjective, monitoring of the weight of the scaled materials was adopted in this research. The top surface of a specimen was gently flushed with water after every five cycles and the scaled particles were collected, dried, and weighed. This procedure was repeated for up to $50 \mathrm{~F}-\mathrm{T}$ cycles. In addition to providing an unbiased measure of the extent of scaling, the weight measurements also provided information on the rate of damage development. Second, ASTM refers to the use of calcium chloride as the de-icing salt, but based on findings from previous studies (Verbeck and Klieger, 1956 and Setzer, 1997), it was clear that sodium chloride at 3\% concentration was the most detrimental salt for concrete scaling. Therefore, in order to represent the worst-case scenario with respect to scaling, a solution of $\mathrm{NaCl}$ was used in this study. In addition, ASTM specifies analysis of two specimens for each condition but due to the large volume of specimens involved and the limited resources available, only one specimen was evaluated for each test condition.

\subsubsection{Microstructural Study}

This section discusses the application of the scanning electron microscope (SEM) for the quantification of differences in the porosities of surface and bulk portions of the 1-in. (25-mm) slump scaling specimens. The specimens for SEM studies measured 25 mm x 25 mm x 25 mm (1” x 1” x 1”) and were cut from the central portion of the scaling slabs, as described in section 8.2.1 and shown in Figure 8.2. For selected curing regimes, 
separate cylinders were cast and exposed to same curing conditions as the scaling slabs.

These cylinders were then used to obtain the $25 \mathrm{~mm}$ x $25 \mathrm{~mm}$ x $25 \mathrm{~mm}$ samples for microscopic studies. Table 8.2 shows the total number of specimens prepared for microscopic study.

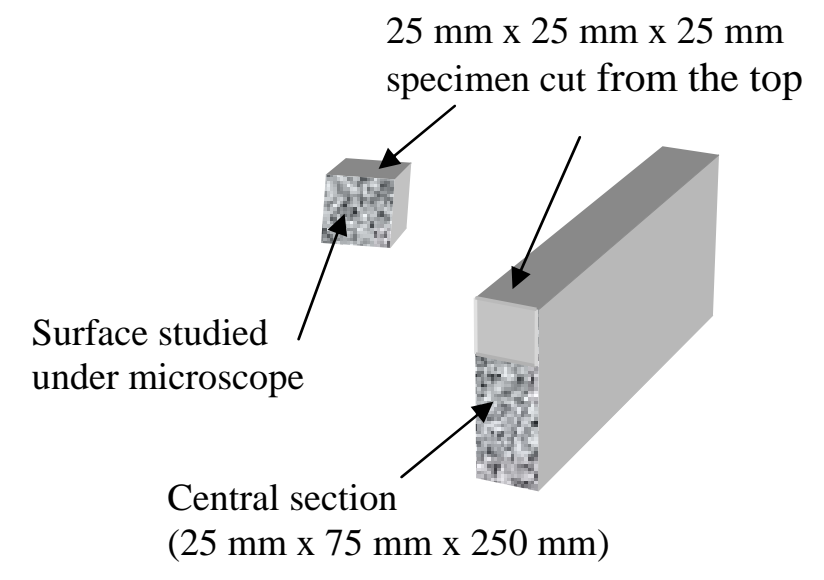

Figure 8.2: Schematic diagram of specimen selection and orientation for SEM study

Table 8.2: List of SEM specimens obtained from 25-mm slump concrete

\begin{tabular}{|c|c|c|c|c|}
\hline No & Sample name & $\begin{array}{c}\text { Moist-curing } \\
\text { period (days) }\end{array}$ & $\begin{array}{c}\text { Drying period } \\
\text { (days) }\end{array}$ & $\begin{array}{c}\text { Analysis (no. of images } \\
\text { and magnifications used) }\end{array}$ \\
\hline 1 & $1-1-\mathrm{a}$ & 0 & 1 & $90(500 \mathrm{x})$ \\
\hline 2 & $1-3-\mathrm{a}$ & 0 & 3 & $90(500 \mathrm{x})$ \\
\hline 3 & $7-1-\mathrm{a}$ & 6 & 1 & $90(500 \mathrm{x})$ \\
\hline 4 & $3-1-\mathrm{a}$ & 2 & 1 & $30(500 \mathrm{x})$ \\
\hline 5 & $3-3-\mathrm{a}$ & 2 & 3 & $30(500 \mathrm{x})$ \\
\hline 6 & $3-7-\mathrm{a}$ & 2 & 7 & $30(500 \mathrm{x})$ \\
\hline 7 & $3-14-\mathrm{a}$ & 2 & 14 & $30(500 \mathrm{x})$ \\
\hline 8 & $3-28-\mathrm{a}$ & 2 & 28 & $30(500 \mathrm{x})$ \\
\hline 9 & $7-3-\mathrm{a}$ & 6 & 3 & $30(500 \mathrm{x})$ \\
\hline
\end{tabular}


Once obtained, the $25 \mathrm{~mm}$ x $25 \mathrm{~mm}$ x $25 \mathrm{~mm}$ (1” x 1” x 1”) specimens were submerged in acetone for at least three days to stop the hydration. They were then dried for about 10 hours in an oven set to $105^{\circ} \mathrm{C}\left(221^{\circ} \mathrm{F}\right)$ to remove any evaporable water present in the samples. The dried samples were then placed in small cylindrical molds and impregnated with an ultra-low viscosity epoxy. A vacuum was applied to the molds for at least three hours to facilitate extrusion of the air and penetration of the epoxy. The specimens were then kept at atmospheric pressure for six more hours. They were then placed in a $70^{\circ} \mathrm{C}\left(158^{\circ} \mathrm{F}\right)$ oven for 8 to 10 hours to allow the epoxy to harden. After that they were cooled down in the air and demolded. After demolding, a diamond-blade saw, cooled by propylene glycol, was used to remove excess epoxy layer and to expose a fresh concrete surface for microscopic evaluation. The specimens were polished on a lapping wheel using successive finer grades (45, 30 and $15 \mu \mathrm{m})$ of diamond grit. Final polishing was done on polishing wheels with diamond paste of successively finer sizes of $3 \mu \mathrm{m}, 1$ $\mu \mathrm{m}$ and $0.25 \mu \mathrm{m}$. A very thin palladium coating was then applied to the polished samples using sputter coater. The specimens were evaluated in a scanning electron microscope operated in backscatter mode, to study the surface characteristics.

\subsubsection{Image Acquisition}

As shown in Figure 8.3, the images were taken from the top 10 - $12 \mathrm{~mm}$ of the 25 mm x 25 mm specimen at 500x (a few times at 100x magnification) using scanning electron microscope. It was observed that 500x magnification (size of the frame $0.17 \mathrm{~mm}$ x $0.17 \mathrm{~mm}$ ) was giving better resolution of air voids and capillary porosity, hence most of the study was performed at this magnification. To account for the localized variation in 
concrete microstructure, the entire surface of the SEM specimen was examined first using 500x magnification to identify unusual clustering of specific features (aggregate, cement grain, pores, etc.) that could potentially bias the results of image analysis. Representative images (9 - 10 images) were then taken, without including any extreme features, throughout the whole length at each depth. A series of 40 - 50 consecutive images was

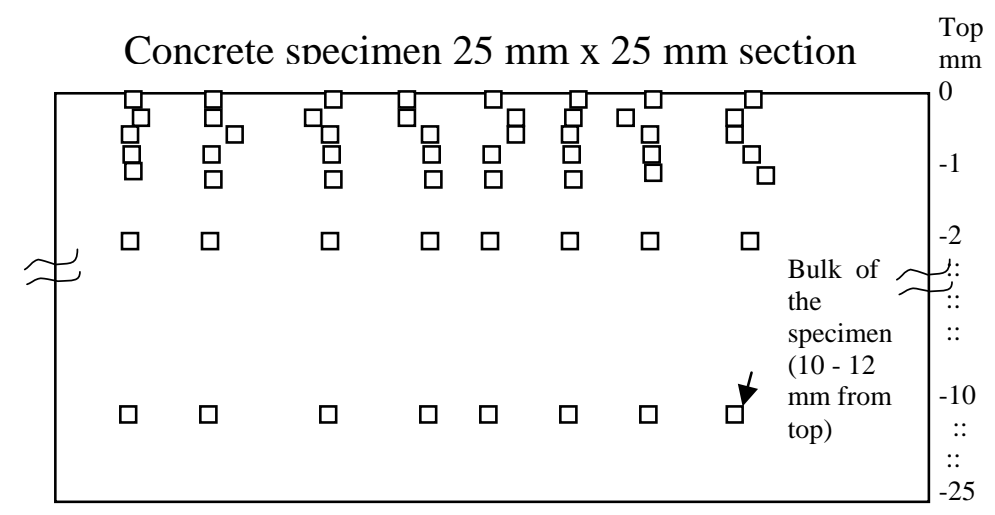

taken in the top one millimeter of the sample. The next set of about 10 images was taken at the depth of $2 \mathrm{~mm}$ and an additional set of 10 images was taken at the depth of $10-12$ $\mathrm{mm}$ from the top.

Figure 8.3: Arrangement of SEM images taken at different depths

In the backscatter mode, the porosity appears as black areas whereas; the white bright angular scattered features are the unhydrated cement grains (maximum specific gravity). Various sand grains are visible with different grayscale tones depending on the specific chemical composition. Few cement grains are surrounded by the hydration product (C-S-H), visible as off-white colored areas. The fly ash particles are distinctly visible at early ages because of their circular shape and off-white color. Moreover, quite a few cenospheres (completely empty) and plerospheres (packed with numerous small 
spheres) are visible among fly ash particles. Figure 8.4 shows two sample images obtained for specimen 1-3-a. It is very apparent that the microstructure of the bulk concrete looks much denser than that of the surface layer.
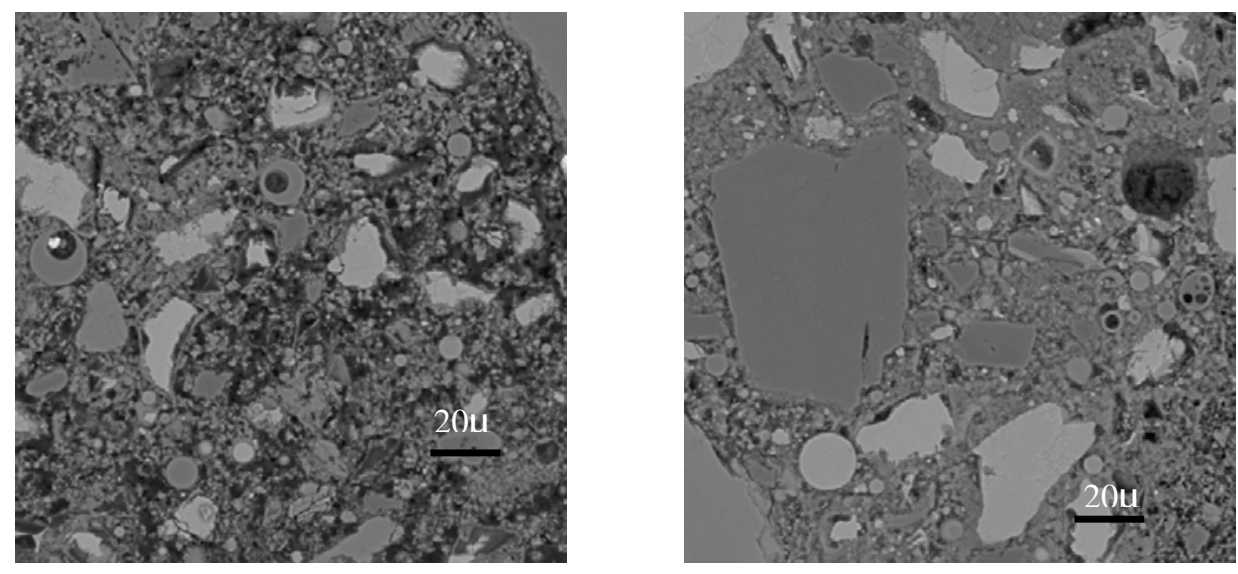

Figure 8.4: Images taken at 500x magnification from the surface (left) and bulk (right) regions of the concrete, respectively

For the purpose of porosity determination, the location of the area from which the images were acquired was carefully selected to avoid unusually high concentration of aggregates. Some of the representative images acquired are shown in the Figure 8.5. Clearly evident from these images is a great degree of heterogeneity of the microstructure. Even with extreme care exercised while obtaining the images, porosity varied significantly, depending on the local microstructure of the specimen. Therefore, rather than plotting individual porosity, normalized porosity with respect to bulk was used for entire analysis. Since the real purpose of this experiment was to examine the differences in porosity between top and bulk zones of these specimens, this approach should be satisfactory. 

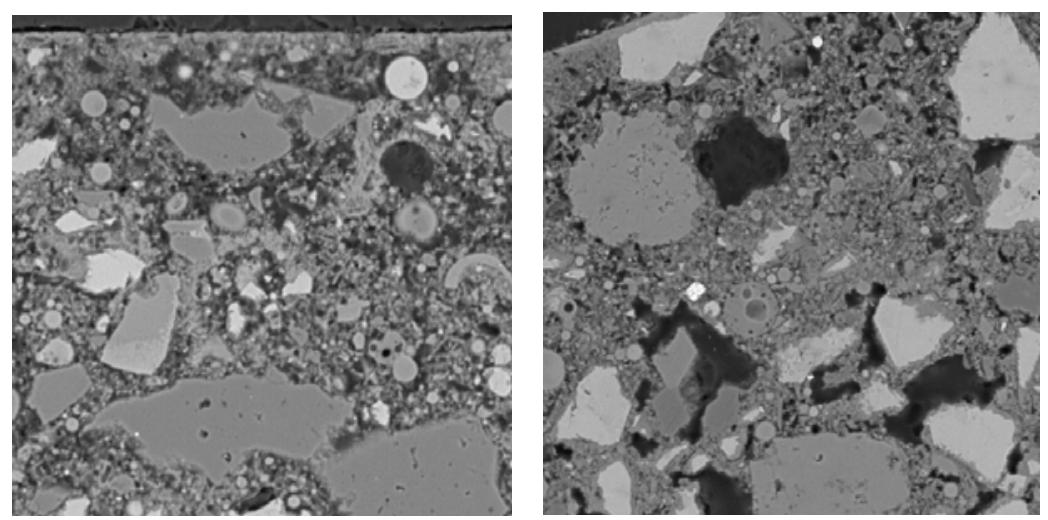

$$
0.0 \text { to } 0.17 \mathrm{~mm}
$$
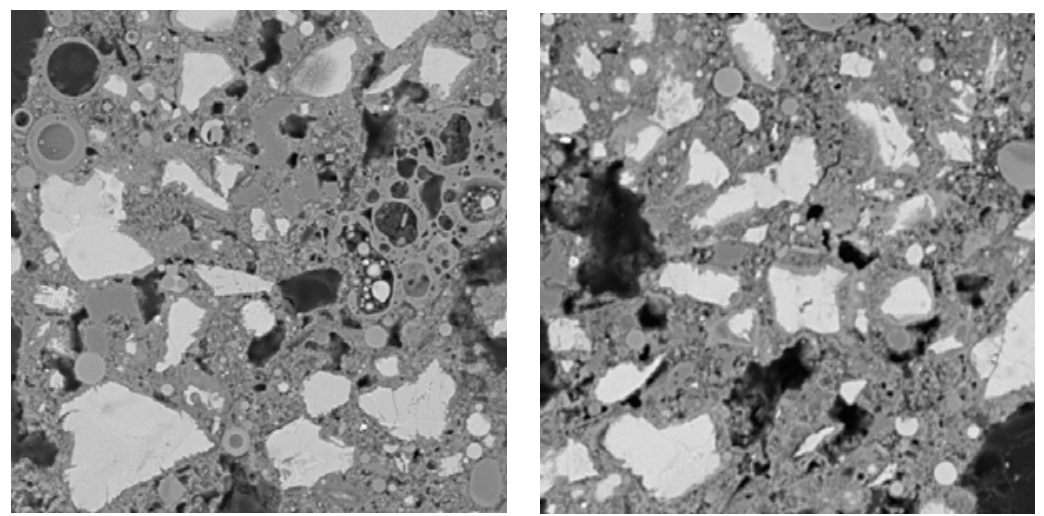

0.18 to $0.34 \mathrm{~mm}$
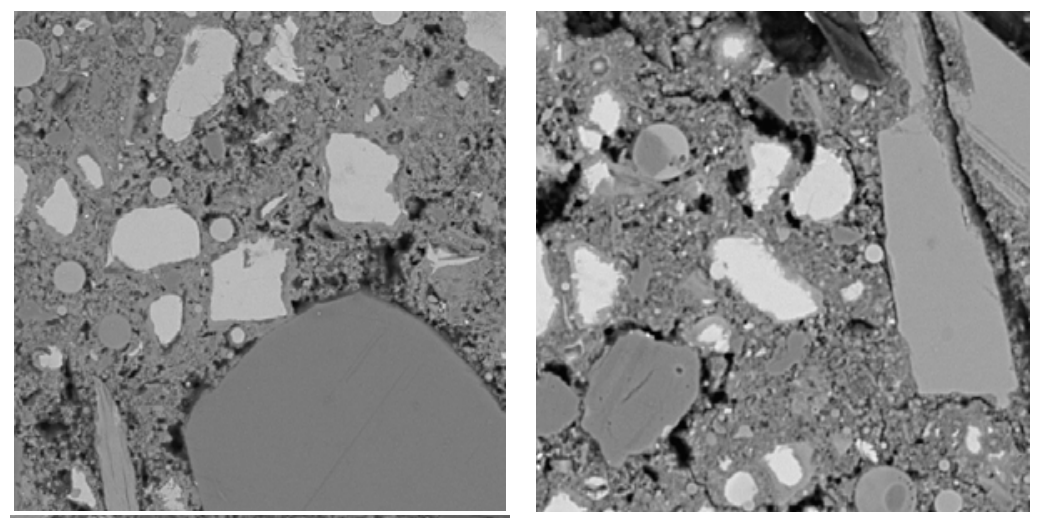

0.35 to $0.51 \mathrm{~mm}$
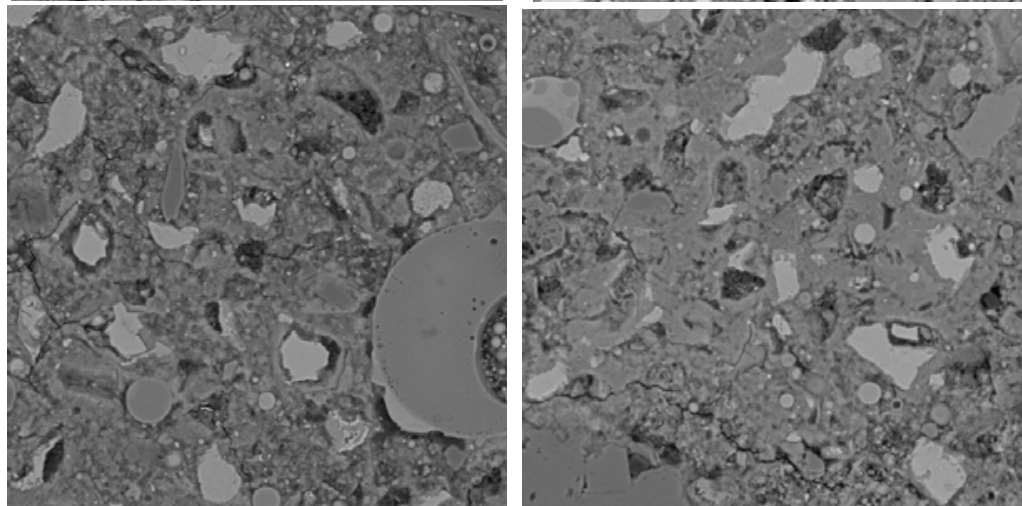

10 - $12 \mathrm{~mm}$ from

top (bulk)

Figure 8.5: Images acquired for 1-3-a sample at 500x from top towards center 


\subsubsection{Image Analysis and Determination of Porosity}

Image Pro Plus ${ }^{\mathrm{TM}}$ software was used to clean and analyze acquired images. First, images were segmented into a black (pore) and white (solid) image to differentiate the porous regions. Pixels of different grayscale were analyzed and, using a certain threshold value, the black portions (porosity) was separated from all other components. Then the properties such as area and percentage area of the pores were obtained by counting the separated features after filtering. The percentage of area was obtained using the built-in feature called "per area”, which represented percentage of porosity in each image at particular threshold. After a number of trials with different thresholding, it was concluded that when normalized against the minimum value (bulk region), the variation in normalized porosity at different thresholds was insignificant when the images were acquired with the same settings (e.g., same brightness, contrast, and focus).

Figure 8.6 shows the whole process of image segmentation and quantification. By taking 9 - 10 images at each depth, the average value of the porosity at each depth was obtained and then normalized value was plotted against the depth of the specimen. After this process was completed, the effects of moist-curing and drying on surface porosity was quantified using these normalized porosity values of specimens with different conditioning periods. 


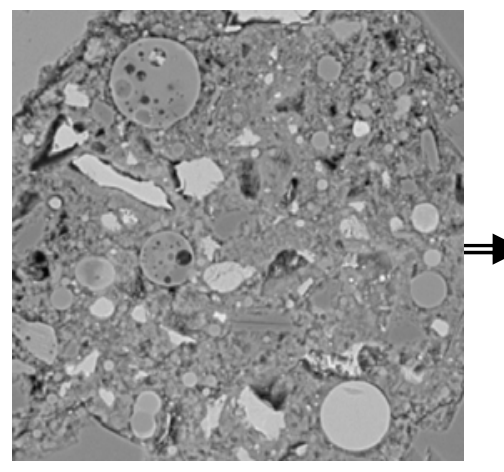

Image enhanced using contrast and brightness features

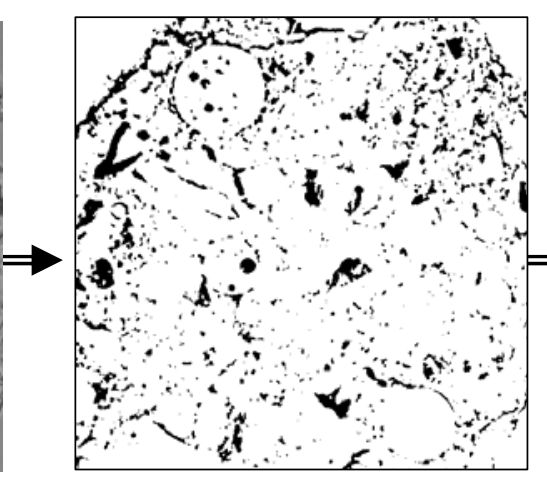

Threshold applied to separate the features of interest

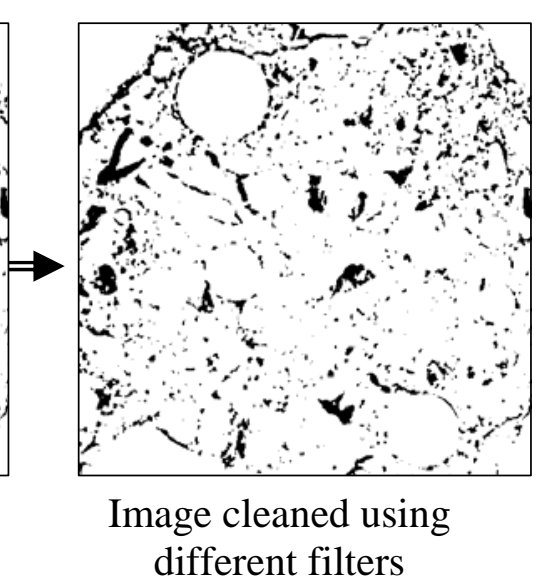

(a)

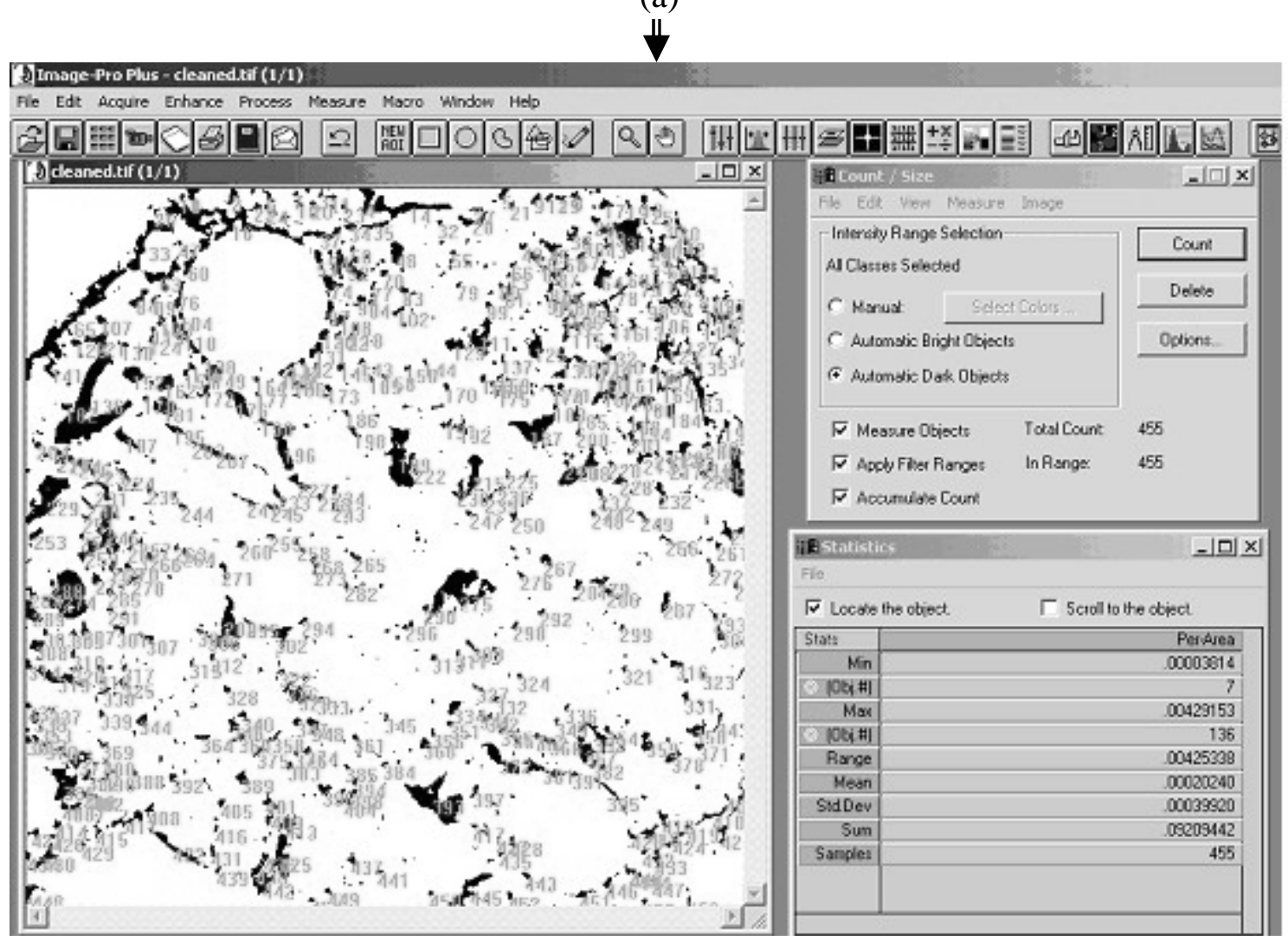

(b)

Figure 8.6: (a) Steps in image analysis and (b) calculation of percentage of porosity 


\subsubsection{Study of Chloride Ion Penetration}

As mentioned earlier in section 8.1, to obtain the salt penetration depth that can be correlated to the scaling of the specimens, a series of 4” x 8” (100 mm x $200 \mathrm{~mm})$ cylinders was prepared with the same $25 \mathrm{~mm}$ (1”) slump mixture proportions as shown in Table 7.1. To minimize the variability of the results, the specimen preparation, including finishing, was identical to that used in scaling specimens. The cylinders were covered with plastic lids until the time at which they were demolded (24 \pm 2 hours after casting). The same conditioning period was used as shown in Table 8.1 for $25 \mathrm{~mm}$ slump specimens. The notation used was also similar to that used in Table 8.1, but no suffixes were used as only single slump specimens were prepared. At the end of the drying period a reservoir was created on the surface of each cylinder by covering its sides with a waterproof epoxy and attaching duct tape around the top perimeter. A 3\% $\mathrm{NaCl}$ solution (200 $\mathrm{ml}$ ) was ponded on the top surface of each specimen for $24 \pm 1$ hours while they were kept at room temperature. After the solution was removed, each cylinder was split in accordance with specification ASTM C496. After splitting, the specimens were sprayed with a solution of $\mathrm{AgNO}_{3}$ (Collepardi, et al., 1972) and the depth of chloride penetration was measured with a micrometer by taking an average of 7 readings across the face of the specimen to the nearest $0.01 \mathrm{~mm}$. The readings were taken at least $10 \mathrm{~mm}$ away from edge and readings were not taken from the points where penetration was obstructed by the presence of coarse aggregates.

To study the effect of high a chloride concentration on scaling, a total of three large slabs (250 mm x $390 \mathrm{~mm}$ x $75 \mathrm{~mm}$ ) were cast similar to other scaling specimens. These slabs were exposed to 3 days of moist-curing and 3 days of drying. At the end of 
that curing regime, the slabs were cut in halves and used to prepare six scaling slabs. After installing a solution confining dam on the surface, each set of two slabs was exposed to $10 \%, 6 \%$ and $3 \%$ solution of sodium chloride respectively and kept inside F-T chamber for two weeks. After 15 F-T cycles, four slabs that were exposed to $10 \%$ and $6 \%$ solution were removed out of the chamber. The solution was removed and thoroughly. Following that, 3\% solution was placed on their surfaces and they continued to be exposed to an additional 35 F-T cycles with other set of scaling slabs.

\subsection{Results and Data Analysis}

The following sections describe the scaling response of the concrete containing fly ash when exposed to different conditioning periods. Table 8.3 provides summary of total number of specimens produced and number of specimens that were analyzed. The set of specimens having 1” (25 mm) slump and moist-cured for five days (see Table 8.1, 1” slump, specimens 13 - 18) are excluded from detailed analysis because of difficulties with finishing. The results of microstructure study are also analyzed in view of the observed scaling. The results of chloride ion penetration study and its correlation to scaling are also presented in this section.

Table 8.3: Details of total and analyzed specimens

\begin{tabular}{|c|c|c|}
\hline Slump & $\begin{array}{l}\text { Total conditioning periods for all the } \\
\text { specimens }(36+24=60 \text { slabs })\end{array}$ & $\begin{array}{l}\text { Specimen dat } \\
\text { conditioning p }\end{array}$ \\
\hline $\begin{array}{c}25 \\
\mathrm{~mm} \\
(1 ”)\end{array}$ & $\begin{array}{l}1,3,5,7,14 \text { and } 28 \text { days of moist- } \\
\text { curing and } 1,2,3,7,14 \text { and } 28 \text { days } \\
\text { of drying. Total } 6 \text { x } 6=36 \text { slabs }\end{array}$ & $\begin{array}{r}1,3,7,14 \text { and } \\
1,2,3,7,1 \\
\text { Tota }\end{array}$ \\
\hline $\begin{array}{c}63 \\
\mathrm{~mm} \\
(2.5 ”)\end{array}$ & $\begin{array}{c}1,3,5 \text {, and } 7 \text { days of moist-curing } \\
1,2,3,7,14 \text { and } 28 \text { days of dryi } \\
\text { Total } 4 \text { × } 6=24 \text { slabs }\end{array}$ & $\begin{array}{c}1,3,5 \text { and } 7 \text { days of moist-curing and } 1,2 \text {, } \\
3,7,14 \text { and } 28 \text { days of drying. } \\
\text { Total } 4 \text { x } 6=24 \text { slabs }\end{array}$ \\
\hline
\end{tabular}




\subsubsection{Rate of Scaling and Probable Governing Parameters}

As mentioned in the Table 8.3 not all the results are used for detailed analysis. However, one observation can be made from all the specimens very noticeably. From all the 60 slabs, where substantial scaling occurred (i.e., the specimens with a total scaled mass of greater than $0.8 \mathrm{~kg} / \mathrm{m}^{2}$ ), $52-94 \%$ of the scaled mass was measured during the first 10 F-T cycles. It was also observed that if a specimen did not develop any major scaling problems during the first $10 \mathrm{~F}-\mathrm{T}$ cycles it would generally remain lightly scaled even if exposed to the total of 100 cycles.

Figure 8.7 illustrates rate of scaling for highly scaled specimens. It shows scaled mass at 10 cycles normalized against the total scaled mass of each specimen. For easy understanding of reader, the zone of scaling pattern is shown with a dark band covering all the specimens. It can be seen that rate of scaling is very high for first 10 cycles, and reduces significantly after that. Moreover, it was noted that most of the highly scaled specimens (lines light in color) belonged to mixture with $63 \mathrm{~mm}$ (2.5”) slump. This observation confirms the findings presented earlier in this report (section 5.3.9), that higher slump could lead to increased scaling by increasing the porosity of top region due to increase in bleeding. However, it was also observed that many $63 \mathrm{~mm}$ slump specimens showed low scaling. This supports the notion that other parameters, in addition to weak microstructure and high surface porosity, control scaling behavior of concrete containing fly ash. It is hypothesized that one such parameter could be salt penetration profile in the surface region of the specimen. Thus, in the subsequent sections further explanation is provided as to the influence of both the above factors on scaling results. 


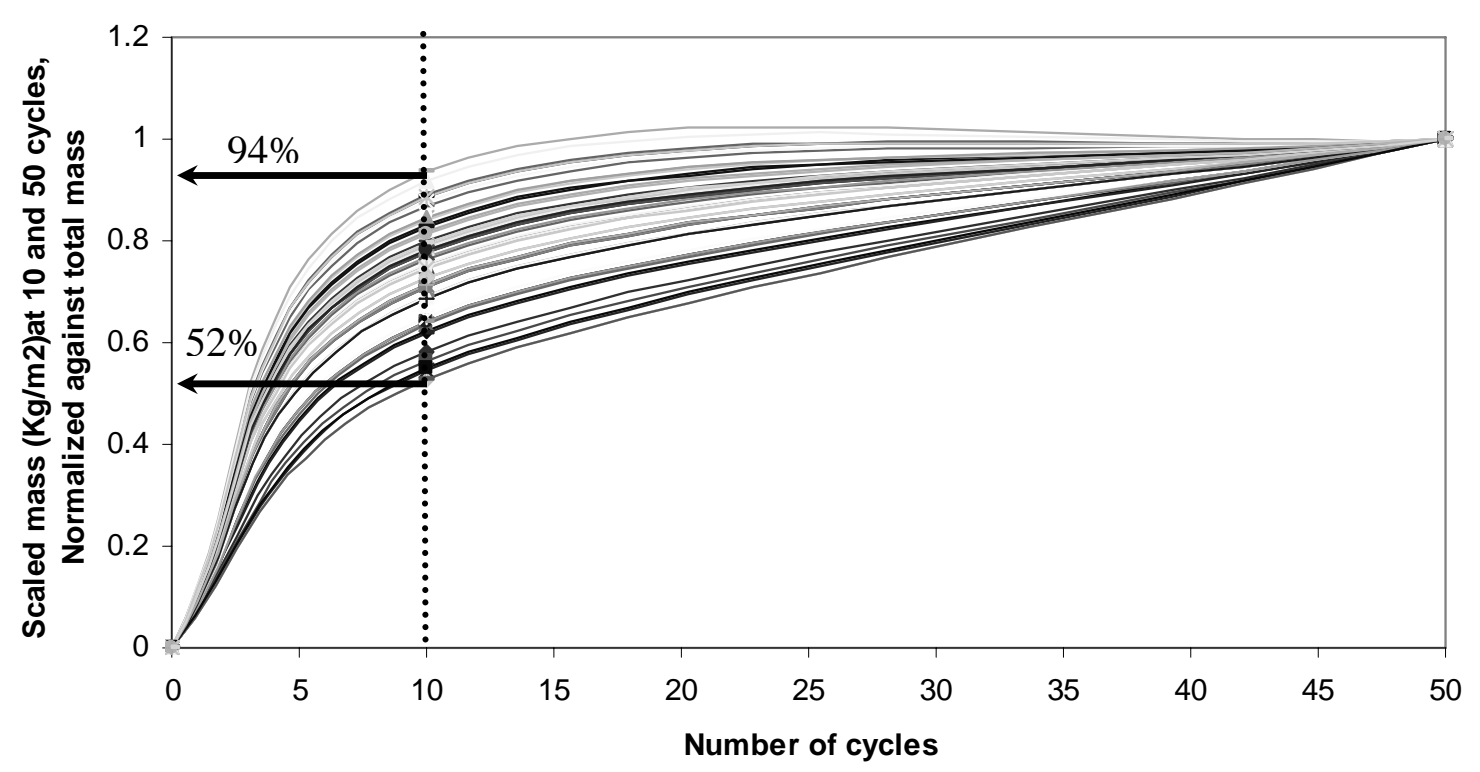

Figure 8.7: Cumulative scaled mass after 10 cycles normalized with respect to total scaled mass

\subsubsection{Influence of the Moist-Curing and Drying Periods on Scaling of Low Slump}

\section{Mixtures}

The influence of the length and type of conditioning period that the scaling specimens were subjected to before being exposed F-T cycles on the observed amount of scaling (as measured by the total scaled off mass) is summarized in Figure 8.8. Specifically Figure 8.8(a) shows total scaled mass for all five series of wet curing after 50 cycles of freezing and thawing as a function of total length of conditioning period (wet + dry). Each point (total scaled mass) shown in Figure 8.8(a) represents scaled mass for each specimen subjected to a specific conditioning (wet and dry periods), details of which can be found in Table 8.1. Figures 8.8(b) and (c) show cumulative scaled mass with 
increase in number of F-T cycles, for all wet cured specimens that were subjected to 1 day and 7 days of drying, respectively, at the end of the wet curing period.

Figure 8.8(a) shows that 7 days of moist-curing is the most beneficial with respect to reducing scaling, irrespective of the length of the drying period. However, for each of the moist-curing periods the subsequent drying of 1 to 3 days resulted in lowest scaling. At the same time scaling increased dramatically for all the wet cured specimens that were subsequently dried for 7 days. This behavior is illustrated in detail in Figure 8.8(c), which shows that the mass lost by all five sets of wet cured specimen was noticeably higher than for cases where these specimens were dried for 7 days as opposed to 1 day (Figure 8.8(b)).

The overall scaling for even longer drying periods (14 and 28 days) remained very similar to that observed at 7 days (Figure 8.8(a)). The only exception was observed for point representing specimen subjected to 14 days of wet curing and 14 days of drying. Since this is the only point that does not follow what otherwise appears to be a consistent pattern observed for all other specimen, it is assumed that it represents an experimental error rather than real phenomenon. 


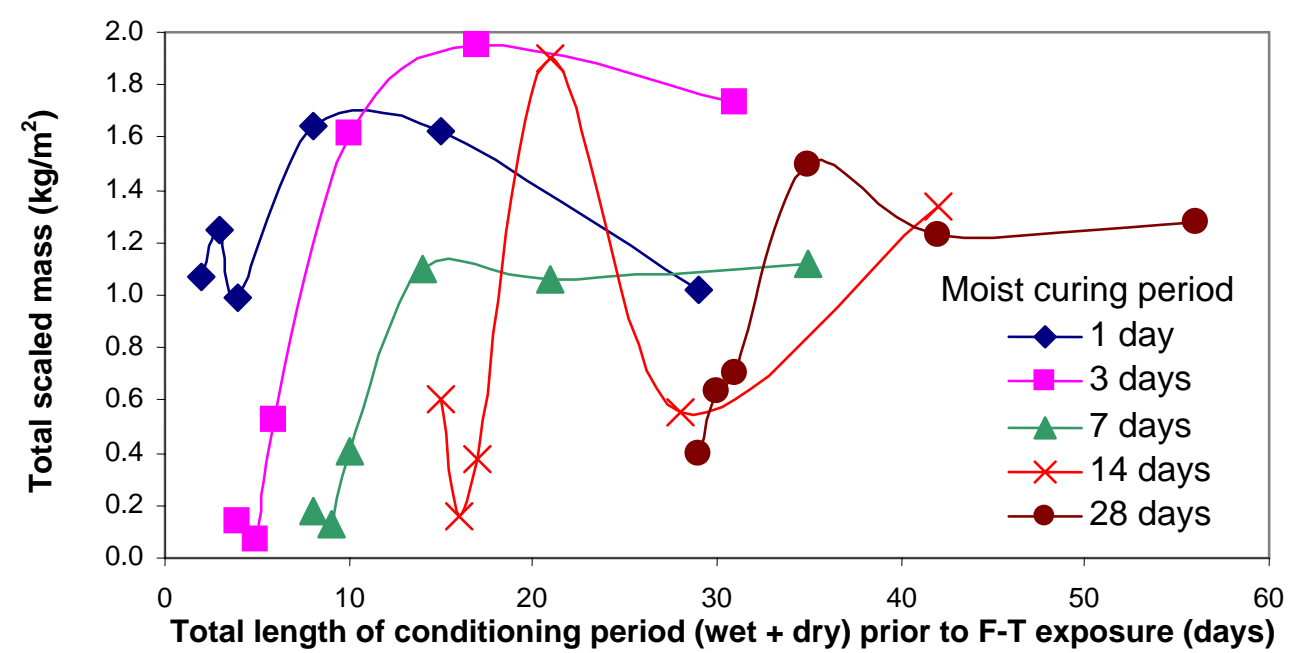

(a)

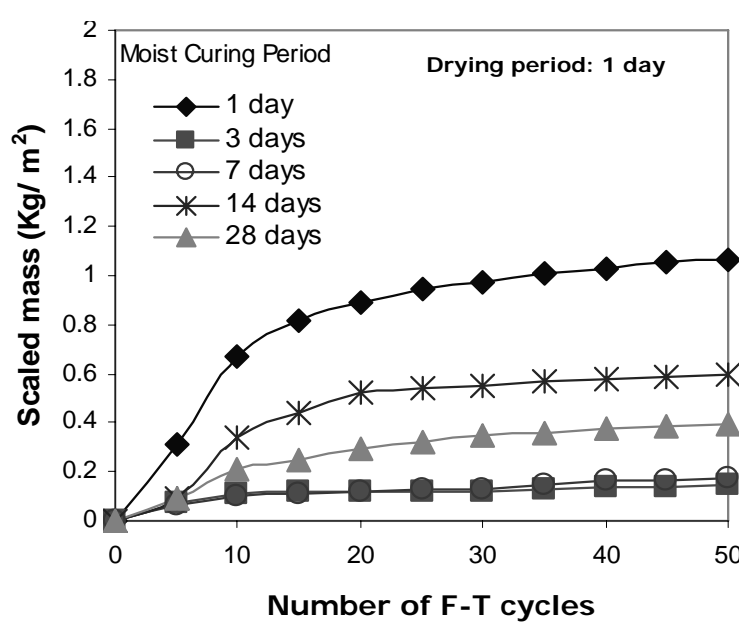

(b)

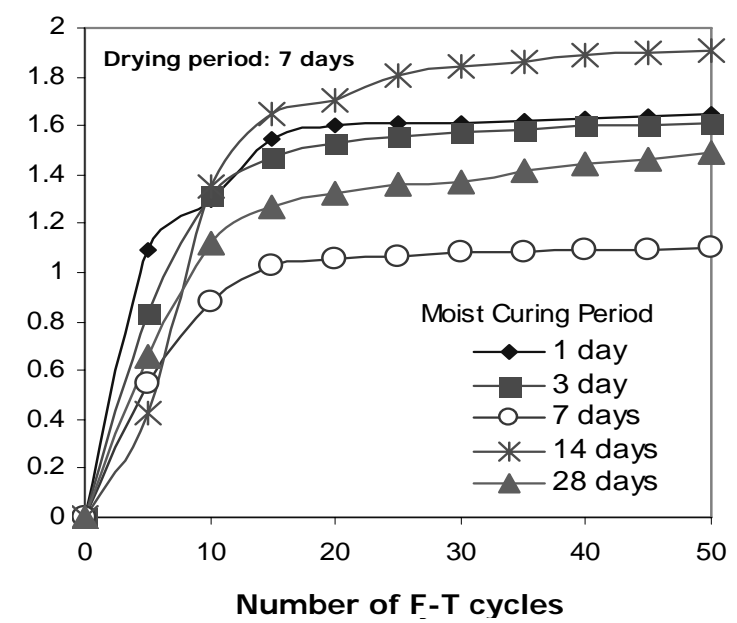

(c)

Figure 8.8: Influence of wet curing and drying on scaling of low slump mixture; (a) total scaled mass (after 50 F-T cycles) for different conditioning periods, (b) cumulative scaled mass for specimens exposed to 5 different lengths of moist-curing and 1 day of drying, and (c) cumulative scaled mass for specimens exposed to 5 different lengths of moistcuring and 7 days of drying 


\subsubsection{Influence of Moist-Curing and Drying on Scaling for High Slump Mixtures}

For the $63 \mathrm{~mm}$ (2.5”) slump specimens, the trends were minimally different from those observed for low slump mixtures. This might be attributed to the fact that the surface microstructure and the pore size distribution were most likely different for specimens with higher slump. Although water-cementitious ratio of the higher slump mixtures was essentially the same as that of the lower slump mixtures (the increase in slump was achieved by the use of water-reducing admixtures), there is a possibility that higher slump mixtures may have more bleeding channels near the surface and thus higher chloride intake.

Figure 8.9 shows the effects of moist-curing and drying on the $63 \mathrm{~mm}$ slump specimens. Similar to Figure 8.8(a), Figure 8.9(a) shows scaled mass after 50 cycles against the total length of the conditioning period prior to exposure to F-T cycles. It is apparent that after 3 days of moist-curing, the effect of moist-curing does not seem to help in improving scaling resistance of concrete. This is a different behavior than that observed in 1” (25 mm) slump specimens where 7 days of moist-curing appeared to be most beneficial. Also, it should be noted that, although for 3 days moist-curing the scaled mass is minimum, it is still higher than the scaled mass for 3 day moist-cured specimens of $25 \mathrm{~mm}$ slump mixtures. This indicates that at early age, the effect of hydraulic pressure, which is dependent on total amount of freezable water in the surface region, dominates the scaling results. Thus, it can be said that optimum moist-curing and drying period with respect to scaling resistance could be the function of mixture proportion and slump of the concrete. 
Figure 8.9(b) showed that for one day moist-cured specimens, effect of drying became insignificant after three days of drying, however 28 days dried specimen showed exceptionally low scaling. Figure 8.9(a) show scaled mass after 50 cycles against the total length of the conditioning period prior to exposure to F-T cycles. It is apparent that after 3 days of moist-curing the effect of moist-curing does not seem to help in improving the scaling resistance of concrete. This is a different behavior from that observed in 1-in. (25-mm) slump specimens, where 7 days of moist-curing appeared to be most beneficial. Also, it should be noted that although for 3 days of moist-curing the scaled mass is at minimum, it is still higher than the scaled mass for 3 days moist cured specimens of 1-in. slump mixtures. This indicates that at early age the effect of hydraulic pressure, which is dependent on total amount of freezable water in the surface region, dominates the scaling results. Thus, it can be said that the optimum moist-curing and drying period with respect to scaling resistance could be the function of mixture proportions and slump of the concrete.

Moreover, in Figure 8.9(a) it can be noticed that the peaks are shifting for total scaled mass (marked with circles), with increase in moist-curing period. The longer the specimen was moist-cured, the longer it took to create drying front for maximum scaling damage. Thus, it can be seen that the scaling is maximum for specimens exposed to 1 and 3 days of moist-curing after 7 days of drying whereas, for specimens moist-cured for 5 to 7 days, it is maximum after 14 and 28 days of drying, respectively. For specimens (both, low and high slump) conditioned for longer period of time, little difference in scaled mass and rate of scaling was observed. These results are described in the next section. 


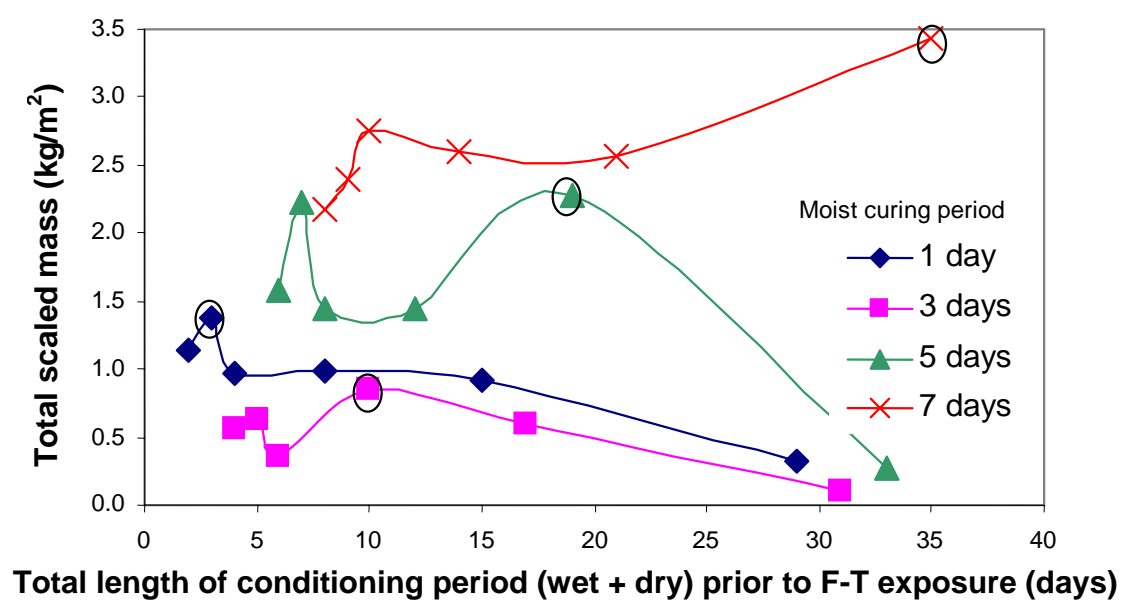

(a)

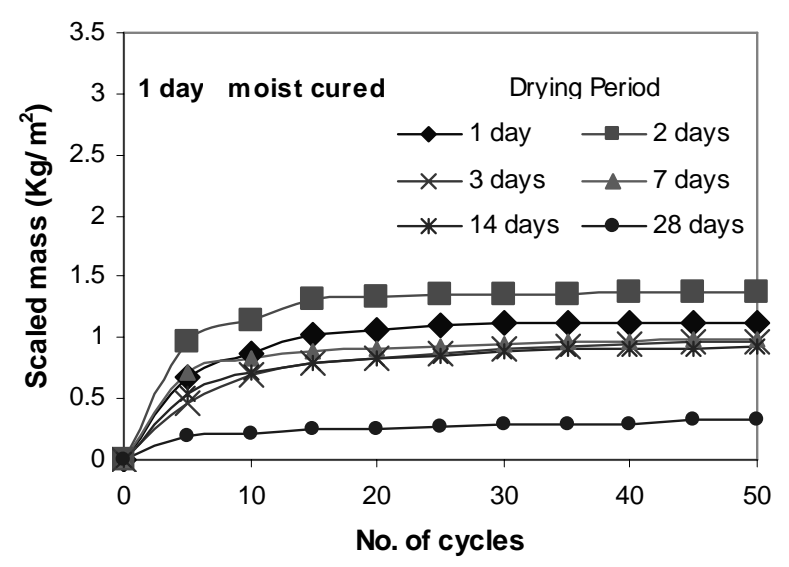

(b)

Figure 8.9: Influence of wet curing and drying on scaling of low slump mixture; (a) total scaled mass (after 50 F-T cycles) for different conditioning periods, and (b) cumulative scaled mass for 1 day moist-curing and all the different drying periods

\subsubsection{Scaling Rate of Specimens Conditioned for More Than 28 Days}

Figure 8.10 shows scaled mass for specimens conditioned for more than 28 days. Unlike what was observed in specimens conditioned for shorter periods of time, in these specimens lower amount of scaling was observed during the first five F-T cycles than 
during the next cycles. Thus, it becomes evident that for longer conditioned specimens the onset of scaling is delayed. However, upon further exposure the rate of scaling is significantly increased. This indicates that with improvement in surface strength, higher salt concentration (osmotic pressure) generated at particular plane governs the scaling behavior. This has been confirmed by the fact that that average size (area and thickness) of the scaled particles increased with the increase in conditioning time. Since the longer conditioning times result in overall improvement of the strength of the surface regions of the specimens, the scaled particles are more resistant to breaking into small pieces and tend to peel off in bigger chunks. Based on results presented here and in the preceding section, it can be hypothesized that scaling mechanism might change depending on age and degree of curing of given specimen.

To further investigate this hypothesis, results of microstructural and chloride ion penetration studies are presented in consecutive sections.

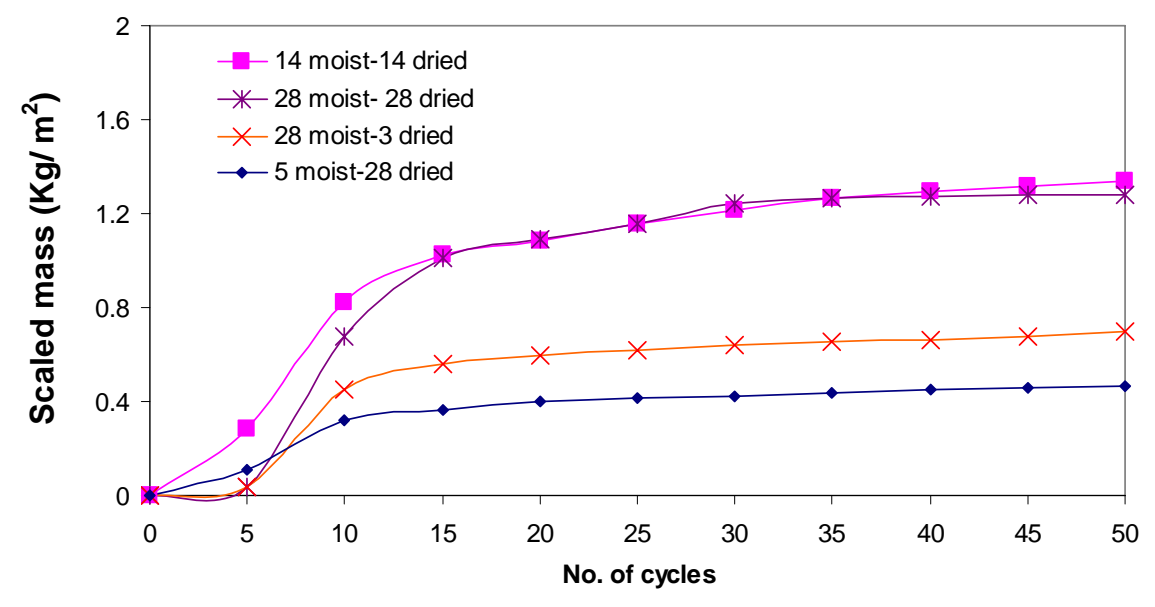

Figure 8.10: Scaled mass for specimens with conditioning periods longer than 28 days 


\subsubsection{Porosity of Specimens Exposed to Different Curing Regimes}

As described in section 8.2.2.2, the changes in porosity with depth from the surface were determined for specimens exposed to different curing regimes. As an example, Figure 8.11 shows the results of normalized porosity obtained from specimen 1-3-a. As mentioned earlier, the normalized value of porosity yields an unbiased indication of change in porosity from the surface to bulk regions of the particular specimen. It can be seen that the porosity of the top $2 \mathrm{~mm}$ of the specimen is much higher than that of the bulk of the concrete. Especially high values of porosity are observed in the top $0.7 \mathrm{~mm}$ of the concrete. It appears that for the laboratory specimens (see box in the top portion of Figure 8.11) that have been exposed to freezing and thawing cycles at early ages, higher porosity and lower tensile strength of concrete might be considered as an important parameter contributing to scaling damage. It should be remembered, however, that this data is for 4 days old concrete and that the surface porosity will reduce with further hydration. Individual effects of moist-curing and drying on surface and bulk porosity are described in subsequent sections. 


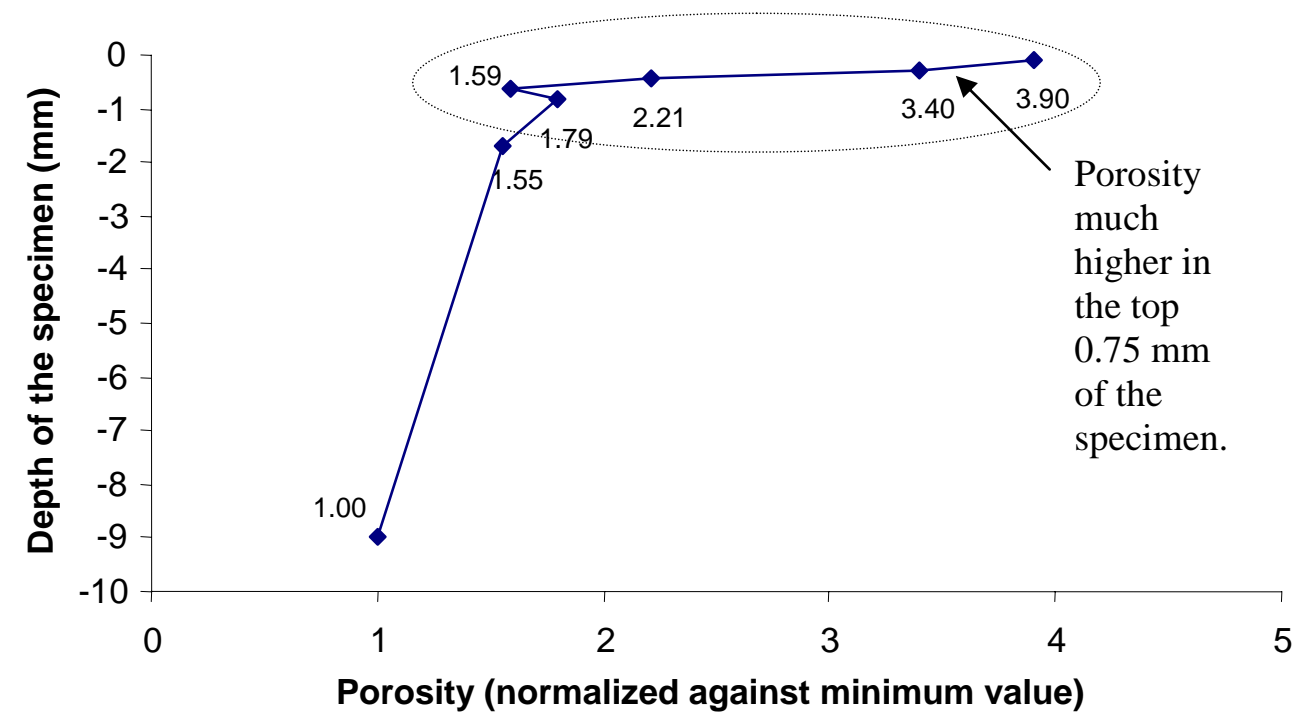

Figure 8.11: Normalized porosity for 1 day moist-cured and 3 days dried sample

\subsubsection{Influence of Moist-Curing Period on Porosity}

Figure 8.12 illustrates the changes in the microstructure and porosity of the specimens with an increase in the moist-curing period. Shown in Figure 8.12(a) are typical examples of scanning electron micrographs obtained from the vicinity of sample surface and the bulk regions of the 1-in. slump concrete after three different moist-curing periods. It can be seen that as the time of the moist-curing increases, the microstructure densifies. Figure 8.12(b) provides a comparison between the relative porosity and its changes over time at the surface of the concrete. At one day the surface of the specimen is nearly 12 times more porous than the bulk concrete at 7 days. While hydration reduces this porosity, the porosity at the surface remains approximately 3 times greater than the bulk concrete at 7 days. This is consistent with the influence of the moist-curing period on scaling described in section 8.3.2, in which a significant reduction in scaling was 
observed for moist-curing period of 1 to 7 days. It can be seen that after 7 days of moistcuring there is no significant reduction in the surface porosity observed, which suggests that for a 25-mm slump specimen, the optimum moist-curing period is 7 days, after which no significant effect of moist-curing on the surface microstructure is evident .

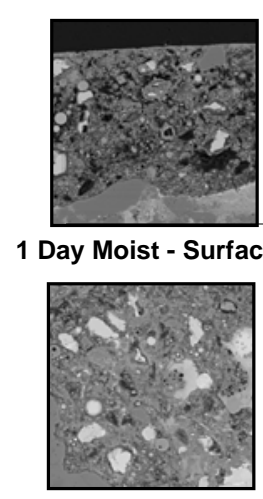

1 day moist bulk

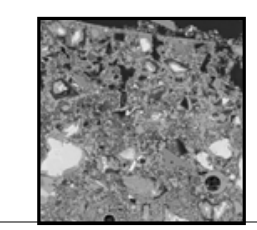

3 Day Moist - Surface

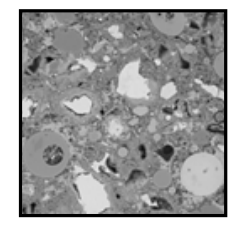

: 3 day moist bulk

(a)

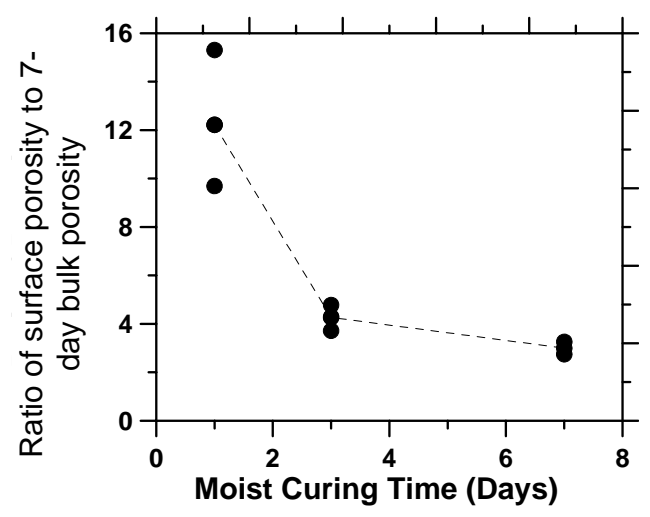

(b)

Figure 8.12: Influence of moist-curing periods on microstructure and porosity of concrete; (a) micrographs (500X) of the surface and bulk regions of the samples and (b) changes in porosity with time.

\subsubsection{Influence of Drying Period and Porosity}

To verify the influence of the drying period on the change of surface porosity, the specimens with a 3 day moist-curing period and different drying periods (listed in Table 8.2) are viewed under SEM using 500x magnification. The porosity was determined for each specimen and average porosity near the surface (top $2 \mathrm{~mm}$ ) and in the bulk (10 - 12 mm from top) of the specimen was computed. Typical images are shown in Figure 8.13(a), and the ratio of surface region porosity to the bulk porosity at 7 days is plotted in the Figure 8.13(b). During early days (1 - 2 days) of drying, when influence of drying was not significant even at the top surface, a significant decrease in porosity in the 
surface (in comparison to bulk concrete) was observed. As the drying period was increased, the decrease in the surface porosity with respect to bulk became insignificant. At longer drying periods, it can even be seen that the surface porosity increases slightly, which could probably be attributed to the hypothesis that longer drying coarsens the microstructure. However, that effect can be considered as very minor in comparison to the accuracy of the microstructural analysis of porosity.
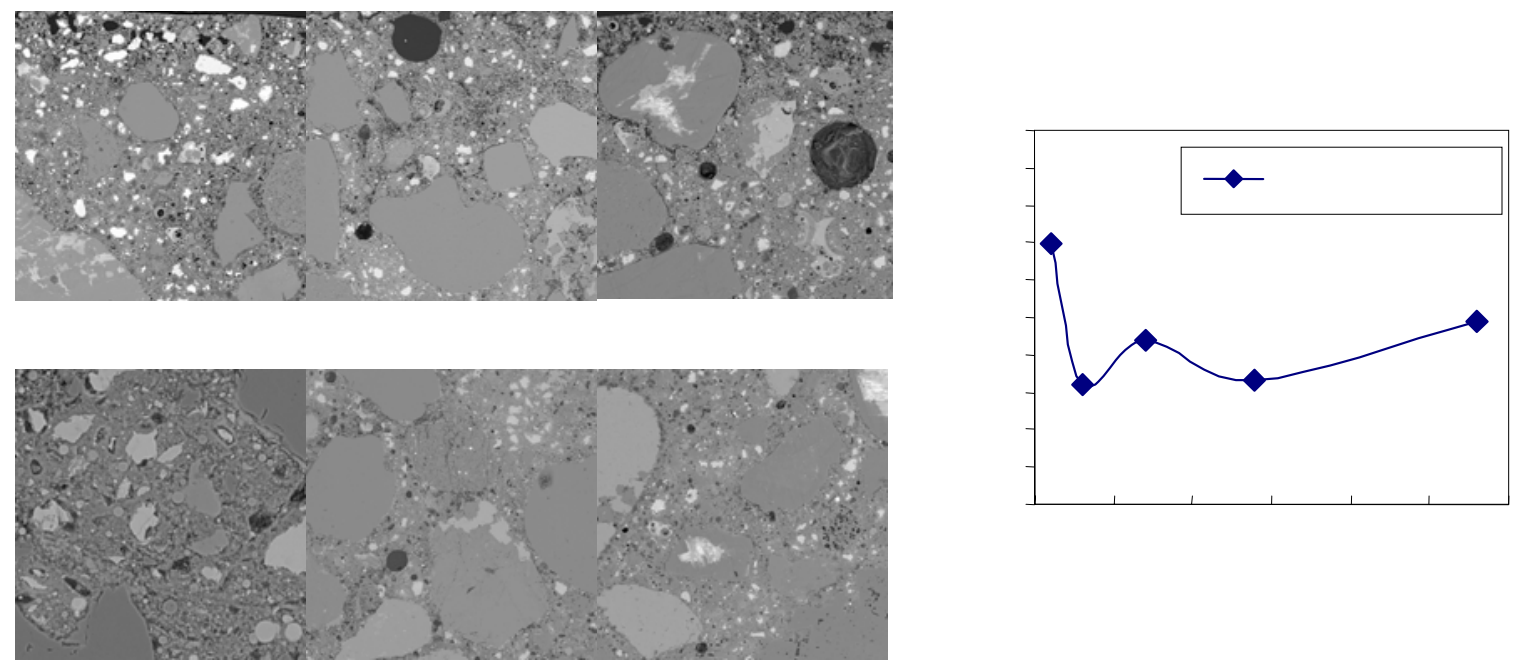

Figure 8.13: Influence of drying period on microstructure and porosity of concrete; (a) micrographs (500X) of surface and bulk regions of the samples and (b) changes in porosity with time.

\subsubsection{Study of Chloride Ion Penetration}

To obtain information on how moist-curing and drying time influences the depth of salt penetration, $100 \mathrm{~mm}$ x $200 \mathrm{~mm}$ (4” x 8”) cylinders were prepared using the $25 \mathrm{~mm}$ slump mixture (Table 7.1) as mentioned in section 8.2.3. A total of 36 specimens were investigated in this study. 
Figure 8.14 shows the depth of the salt penetration for different moist-curing and drying periods. Each line represents the total number of days of drying while the different points on the lines represent different moist-curing periods (1, 2, 3, 7, 14 and 28 days). The salt penetration depth is plotted against the total age of the specimen so that the effect of hydration can be accounted for along with the length of moist-curing and drying periods. As a general trend it can be said that, at any age as the drying time increases (different solid lines in Figure 8.14), the salt penetration depth increases. At the same time for any particular drying period, an increase in the duration of moist-curing (individual symbols) the salt penetration depth decreases. It is evident that with continued hydration, the pore structure becomes more refined and reduces the salt penetration depth significantly. In general, the effect of moist-curing reduces salt penetration significantly, especially for shorter drying periods.

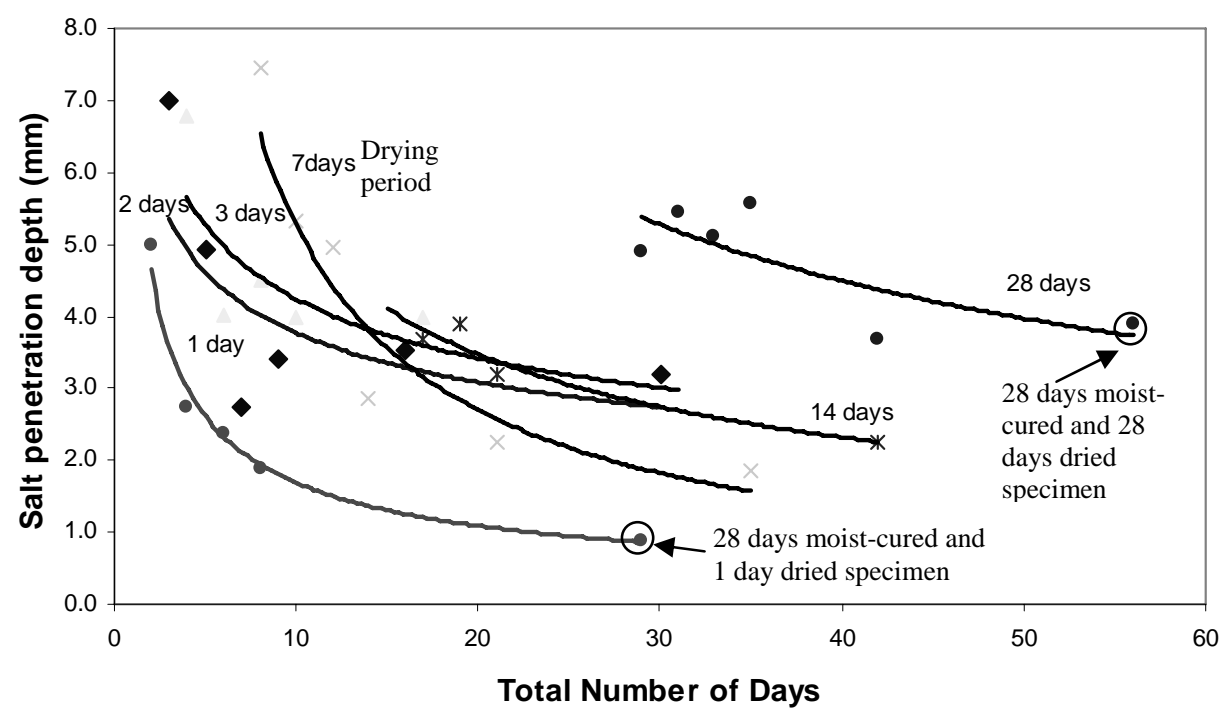

Figure 8.14: Depth of salt penetration for different conditioning periods 
The effect of the drying on salt penetration is distinctly evident for very long conditioning periods. For 28-day moist cured specimen, the salt penetration depth is almost 4 times higher for the 28-day dried specimen than for the 1-day dried specimen (marked with dots).

The salt penetration inside the specimen can be considered as a combined function of moist-curing and drying with an ongoing hydration effect, which is the reason why the data is so scattered in the case of the salt penetration depth with respect to total curing time. To further explore the relationship between the extent of scaling and the depth of chloride penetration, Figure 8.15 is plotted for the specimens that had total scaled mass more than $0.8 \mathrm{~kg} / \mathrm{m}^{2}$. The Figure shows very weak trend that with increase in salt penetration depth of scaling decreases.

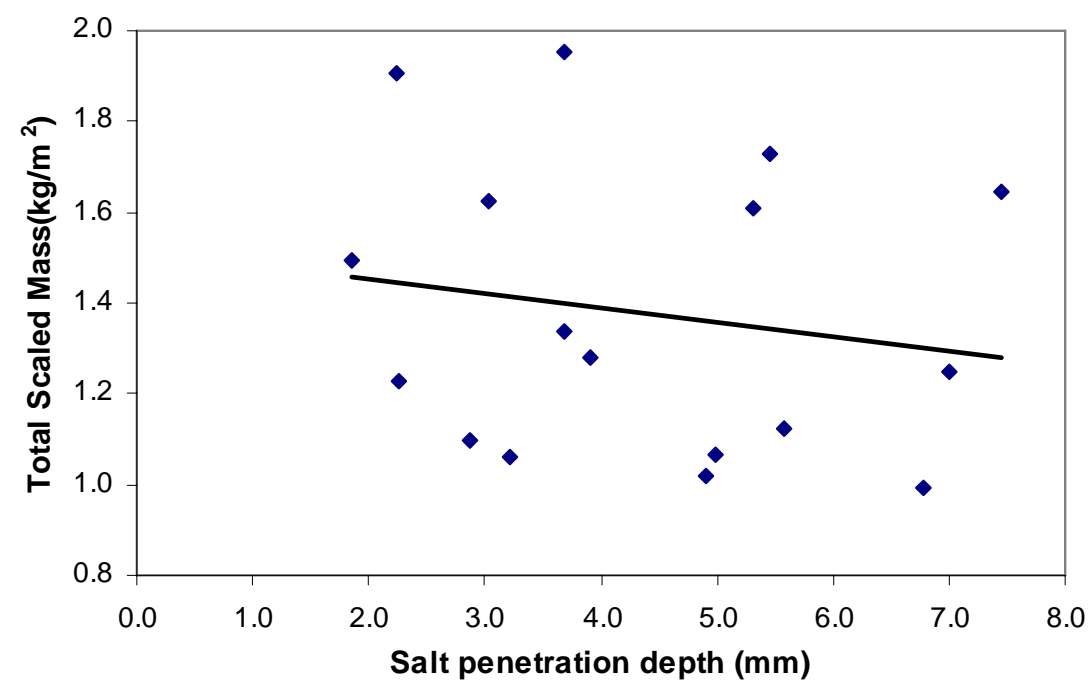

Figure 8.15: Relation of salt penetration depth with scaling for highly scaled specimens 
To further address the issue of this variability, a small study with different percentage of salt was conducted to capture the effect of salt penetration during freezing and thawing, the results of which are described below.

\subsubsection{Differential Salt Concentration Study}

The specimen preparation and experimental procedure for this study are described at the end of section 8.2.3. When the slabs were exposed to the first 15 F-T cycles with different surface concentrations, scaling was observed only in the specimen with $3 \%$ surface concentration. Surface solutions of $6 \%$ and $10 \%$ did not freeze for these specimens for the minimum room temperature of $-16^{\circ} \mathrm{C}\left(3.2^{\circ} \mathrm{F}\right)$ and therefore, no scaling was observed for these slabs. However, when these specimens were once again exposed to a $3 \%$ salt solution a distinct behavior was observed after 5 more cycles. It was observed that, for these specimens a relatively thick layer of concrete came off the surface. The scaled mass, for specimens previously exposed to high concentration solution, was composed of flakes of concrete with 1 to $1.5 \mathrm{~mm}$ thickness in comparison to usual scaled mass of $0.2-1.0 \mathrm{~mm}$ thick. This indicates that the plane of higher chloride concentration moves further down with increase in surface concentration and thereby creates more scaling in the specimen, which is reflected in the larger sizes of scaled mass. Typical observation about scaled mass for all the three sets is reported below in Table 8.6. 
Table 8.6: Summary of study of effect of salt concentration front on scaling

\begin{tabular}{|l|l|l|l|}
\hline \multirow{2}{*}{ Characteristics } & \multicolumn{3}{|l|}{ Specimens with different initial exposure } \\
\cline { 2 - 4 } & $\begin{array}{l}\mathbf{3 \%} \\
\text { concentration }\end{array}$ & $\begin{array}{l}\mathbf{6 \%} \\
\text { concentration }\end{array}$ & $\begin{array}{l}\mathbf{1 0 \%} \\
\text { concentration }\end{array}$ \\
\hline $\begin{array}{l}\text { Freezing of surface at } \\
\text { minimum temp. }\end{array}$ & $\begin{array}{l}\text { Solid ice } \\
\text { formation on the } \\
\text { surface }\end{array}$ & $\begin{array}{l}\text { Very weak ice } \\
\text { formation }\end{array}$ & $\begin{array}{l}\text { No formation of } \\
\text { ice, most liquid } \\
\text { phase }\end{array}$ \\
\hline $\begin{array}{l}\text { Initial scaled mass after } \\
15 \text { cycles }\end{array}$ & $0.9 \mathrm{~kg} / \mathrm{m}^{2}$ & None & None \\
\hline $\begin{array}{l}\text { Scaled mass after } 20 \\
\text { cycles }\end{array}$ & $1.05 \mathrm{~kg} / \mathrm{m}^{2}$ & $0.6 \mathrm{~kg} / \mathrm{m}^{2}$ & $0.75 \mathrm{~kg} / \mathrm{m}^{2}$ \\
\hline $\begin{array}{l}\text { Characteristics of } \\
\text { scaled mass } \\
\text { between } 15-20 \text { cycles }\end{array}$ & $\begin{array}{l}\text { Small flakes of } \\
0.2 \mathrm{to} 1 \mathrm{~cm}^{2} \text { area } \\
\text { and } 0.2-1.0 \mathrm{~mm} \\
\text { thickness }\end{array}$ & $\begin{array}{l}\text { Medium flakes of } \\
0.5 \text { to } 3 \mathrm{~cm}^{2} \text { area } \\
\text { and } 0.5-2.0 \mathrm{~mm} \\
\text { thickness }\end{array}$ & $\begin{array}{l}\text { Large flakes of } 0.5 \\
\text { to } 5.8 \mathrm{~cm} 2 \text { area } \\
\text { and } 0.6-3.0 \mathrm{~mm} \\
\text { thickness }\end{array}$ \\
\hline $\begin{array}{l}\text { Image showing scaled } \\
\text { mass in each case }\end{array}$ & & & \\
\hline
\end{tabular}

These results clearly explain detrimental effect of high chloride concentration in the surface region. This implies that plane of high stress concentration is governed by osmotic pressure generated due to high salt concentration during freezing. Therefore it can be summarized that for early ages, low degree of stresses generated by hydraulic pressure can easily create scaling but for longer conditioned and stronger matrix, high degree of stresses generated by osmotic pressure are required to create substantial scaling in the specimens. 


\subsection{Summary}

This chapter addressed the influence of conditioning periods and slump on the scaling results. Based on a study of a wide range of conditioning periods for the typical pavement mixture studied (25 mm slump), it can be said that 7 days of moist-curing and 1 - 3 days of drying are the optimum period that ensure the best scaling performance, while four $63 \mathrm{~mm}$ specimens 3 days of moist-curing proved the most beneficial. A microstructural study confirmed early age surface of laboratory concrete is highly porous and leads to substantial scaling during the first few cycles of freezing and thawing. The direct salt penetration measurements did not lead to any conclusive results; however study with high concentration solution confirmed that the effect of chloride ion concentration profile in the surface region is more important for specimens conditioned for longer periods. In general, it can be said that the scaling results at early age are governed by hydraulic pressure while osmotic pressure governs the overall process at later ages. 


\section{CHAPTER 9: INFLUENCE OF LOW TEMPERATURE CURING ON FRESH PROPERTIES AND SCALING OF CONCRETE}

\subsection{Introduction}

The previous chapter showed that fly ash concrete can be more susceptible to scaling than plain concrete, cast at $23^{\circ} \mathrm{C}\left(73.4^{\circ} \mathrm{F}\right)$ and tested as per ASTM C672, after exposure to different conditioning periods (up to 56 days). The focus of this research was to determine whether concrete pavements constructed using fly ash and placed in environmental conditions similar to those experienced during the late fall or early spring in Indiana, would show increased susceptibility to scaling. Specifically, more data was needed on how lower temperatures encountered during the late fall or early spring construction season influence fresh properties such as slump, setting time and bleeding of fly ash concrete, and how changes in these properties can influence changes in these properties can influence scaling. These issues are addressed in this chapter.

Fresh properties (setting time and bleeding) were first evaluated for concrete mixed at low temperature. Two types of slabs (250 mm x $190 \mathrm{~mm}$ x $75 \mathrm{~mm}$ and $900 \mathrm{~mm}$ x $300 \mathrm{~mm}$ x $300 \mathrm{~mm}$ ) were prepared at low temperatures for the scaling study. Figure 9.1 outlines the various specimens studied and the tests performed for the low temperature cured concrete. 


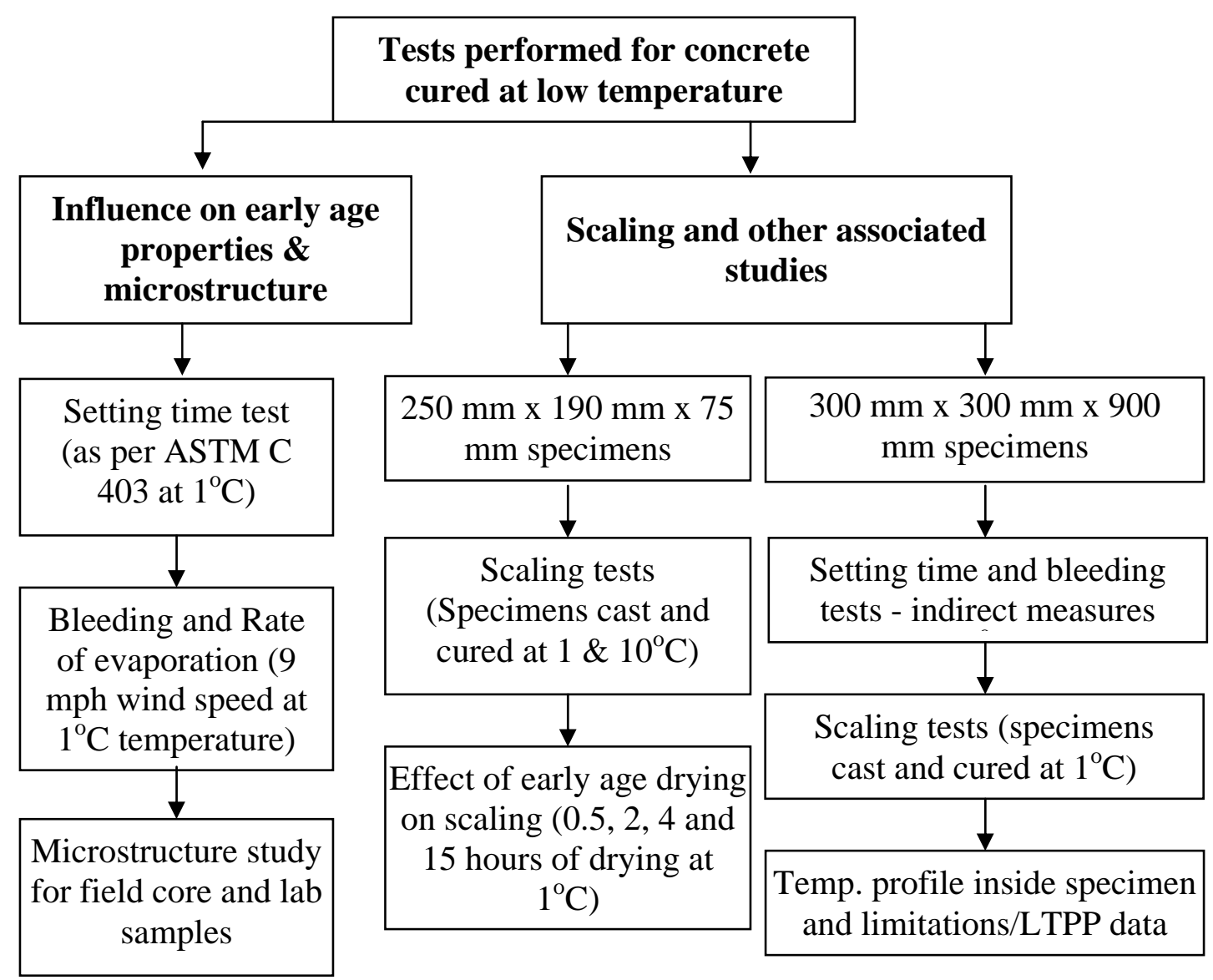

Figure 9.1: Outline of low temperature curing study

The setting time of plain and fly ash concrete was measured at $1^{\circ} \mathrm{C}\left(33.8^{\circ} \mathrm{F}\right)$. Additionally, bleeding tests were also performed at $1^{\circ} \mathrm{C}$. To obtain more information about the rate of bleeding, the rate of evaporation was measured at constant wind speed. To determine the effect of casting/curing temperature on scaling, a scaling test was performed using standard 75-mm deep (250 mm x $190 \mathrm{~mm}$ x $75 \mathrm{~mm}$ ) specimens that were cast and cured at both $1^{\circ} \mathrm{C}$ and $10^{\circ} \mathrm{C}\left(33.8^{\circ} \mathrm{F}\right.$ and $\left.50^{\circ} \mathrm{F}\right)$. To establish the appropriate time for applying the curing compound the effect of early age evaporation was evaluated using scaling specimens. 
For the low temperature study, the specimen size and degree of hydration can influence the performance of the concrete. Therefore, to simulate a large thermal mass of actual pavement, 300-mm deep (900 mm x 300 mm x 300 mm) specimens were prepared for scaling and other relevant studies. Moreover, the temperature profiles were developed for actual pavements using the Long Term Pavement Performance (LTPP) database and the limitations of laboratory testing for large size scaling specimens are discussed. Concrete microstructure was studied for field and laboratory specimens cured at low temperature as well.

\subsection{Preparation of Specimens and Experimental Procedure}

The focus of this study was to address issues associated with concrete pavements that are constructed at low temperatures. Therefore, selection of the various parameters required careful consideration of the practical aspects of the low temperature construction season to simulate the worst case scenario. To avoid repetition of the same information in various sections of the report, section 9.2.1 outlines the selection of the various parameters and procedures specific to all low temperature studies.

\subsubsection{General Parameters and Procedures for Low Temperature Study}

The average minimum temperature that was measured between 1971 and 2000 in the month of November in West Lafayette area was $1^{\circ} \mathrm{C}$ (Indiana Climate Page). Moreover, INDOT specification (Section 502.11) stipulates that "PCCP shall not be placed on frozen sub-grade or sub-base. PCCP shall be placed when the ambient temperature is $2^{\circ} \mathrm{C}\left(35^{\circ} \mathrm{F}\right)$ and above, unless the procedures outlined in the QCP for lower 
temperatures are followed. PCCP operations shall be discontinued when the ambient temperature is descending and is $4^{\circ} \mathrm{C}\left(40^{\circ} \mathrm{F}\right)$ or below." As a result, $1^{\circ} \mathrm{C}$ can be considered the minimum expected temperature during pavement construction in the late fall or early spring.

Based on this information, $1^{\circ} \mathrm{C}$ was selected as the mixing and curing temperature for most of the studies. Consequently, the constituent materials were weighed and stored in a constant temperature chamber $\left(1 \pm 1^{\circ} \mathrm{C}\right.$ and $\left.35 \pm 5 \% \mathrm{RH}\right)$ for 48 hours before mixing. Final moisture correction was performed using a sample that was taken from the cold room before mixing. To minimize the time of exposure to higher temperatures, the materials were taken to the laboratory only during mixing and after mixing they were once again returned to the cold room for finishing and curing.

The mixture proportions for this study were similar to the proportions given in Table 7.1, except for the amount of water reducer. This was the same worst performing combination of materials (Lone Star cement + Rockport fly ash) that was evaluated in section 5.3 .8 of this report. It was observed that for mixtures prepared at $1^{\circ} \mathrm{C}$, the quantity of water reducer was reduced to half (i.e., $225 \mathrm{ml} / \mathrm{yd}^{3}$ ) of the original quantity given in Table 3.1. For one of the study at $10^{\circ} \mathrm{C}$ the water reducer was reduced to $75 \%$ (i.e., $337.5 \mathrm{ml} / \mathrm{yd}^{3}$ ) of its original quantity to achieve the same 1 inch slump. The mixing sequence and procedures were identical to the procedures described in section 8.2.1.

The specimens were stored in the cold room until the minimum flexural strength requirement was achieved. A master curve was developed for this mixture using flexural strength and maturity data obtained earlier (Table 8.3). It was assumed that there was no significant variation in the composition and properties of materials. Using software 
developed for maturity calculation (Barde, 2004, and Graveen, Barde and Weiss, 2003), with time-temperature data, the strength of the specimens were back calculated.

According to INDOT (Specification Section 501.23) the minimum flexural strength requirement for pavements for opening to traffic, is $550 \mathrm{psi}$ (3.8 $\mathrm{MPa}$ ). That requirement effectively stipulates that no pavement can be exposed to de-icing salts until it achieves 550 psi flexural strength. Therefore, the specimens were stored in the cold room until they achieved maturity equivalent to a flexural strength of 550 psi. To simulate the worst possible case, it was decided to expose these slabs to a scaling test as soon as maturity equivalent to a flexural strength of 550 psi was achieved.

Table 9.1 provides the specific details of the tests performed along with the number and type of specimens prepared. A description of the tests can be found in the experimental procedure for the individual tests in the following sections.

\subsubsection{Setting time Measurement at Low Temperature}

To quantify the influence of fly ash on the setting time of concrete at low temperatures, the setting time was measured at $1^{\circ} \mathrm{C}$ for concrete with and without fly ash, as per ASTM C403. Immediately after mixing, the concrete was taken into the cold room and the coarse aggregates were removed by sieving the concrete using standard $4.75 \mathrm{~mm}$ (no. 4) sieve. Due to the lower ambient temperature, the penetration readings were taken at 2 hour intervals until the penetration resistance exceeded 4000 psi (27.6 MPa). Additionally, the setting time of the concrete containing fly ash was also measured at $23^{\circ} \mathrm{C}$ as per ASTM C403. The interval between consecutive readings was maintained as 1 hour during that study. 
Table 9.1: Summary of various test specimens and experimental procedures

\begin{tabular}{|c|c|c|c|c|}
\hline $\begin{array}{l}\text { Test } \\
\text { Name }\end{array}$ & $\begin{array}{l}\text { Number and type } \\
\text { of specimens }\end{array}$ & $\begin{array}{c}\text { Temperature } \\
\text { (cast \& } \\
\text { cured) } \\
\end{array}$ & $\begin{array}{l}\text { Specimen } \\
\text { details }\end{array}$ & $\begin{array}{l}\text { Procedure/ } \\
\text { Comments }\end{array}$ \\
\hline $\begin{array}{l}\text { Setting } \\
\text { time }\end{array}$ & $\begin{array}{l}2 \text { - specimens with } \\
\text { and without fly ash; } 1 \\
\text { - speciemen with fly } \\
\text { ash }\end{array}$ & $\begin{array}{l}\text { Performed at } \\
1^{\circ} \mathrm{C} \text {; Performed } \\
\text { at } 23^{\circ} \mathrm{C}\end{array}$ & $\begin{array}{l}\text { Concrete } \\
\text { sieved } \\
\text { from } 4.75 \\
\text { mm sieve }\end{array}$ & $\begin{array}{c}\text { ASTM C } 403 \text { with } \\
\text { reading interval of } 2 \\
\text { hours due to low } \\
\text { temperature }\end{array}$ \\
\hline Bleeding & $\begin{array}{l}\text { 2- Specimens with } \\
\text { and without fly ash } \\
\text { for each slump }\end{array}$ & $\begin{array}{l}\text { All the tests } \\
\text { performed at } \\
1^{\circ} \mathrm{C}\end{array}$ & $\begin{array}{c}\text { Concrete } \\
\text { with } 25,50 \\
\text { and } 100 \\
\text { mm slump }\end{array}$ & $\begin{array}{c}\text { Test performed in } \\
\text { accordance to ASTM } \\
\text { C } 232\end{array}$ \\
\hline $\begin{array}{l}\text { Scaling } \\
\text { of } 75 \mathrm{~mm} \\
\text { deep } \\
\text { specimen }\end{array}$ & $\begin{array}{l}2 \text { - slabs with and } \\
\text { without fly ash; } 2 \text { - } \\
\text { slabs with and } \\
\text { without fly ash }\end{array}$ & $\begin{array}{c}\text { Cast and cured } \\
\text { at } 1^{\circ} \mathrm{C} \text {; Cast } \\
\text { and cured at } \\
10^{\circ} \mathrm{C}\end{array}$ & $\begin{array}{c}250 \mathrm{~mm} \mathrm{x} \\
190 \mathrm{~mm} \mathrm{x} \\
75 \mathrm{~mm} \\
\text { slabs }\end{array}$ & $\begin{array}{c}\text { ASTM C } 672 \\
\text { Specimen preparation } \\
\text { and experimental } \\
\text { procedure identical to } \\
\text { previous studies }\end{array}$ \\
\hline $\begin{array}{l}\text { Scaling } \\
\text { (early } \\
\text { age } \\
\text { drying) }\end{array}$ & $\begin{array}{l}\text { 2- slabs with fly ash } \\
\text { each having } 0.5,2,4 \\
\text { and } 15 \text { hours of early } \\
\text { age drying }\end{array}$ & $\begin{array}{c}\text { Cast and cured } \\
\text { at } 1^{\circ} \mathrm{C}\end{array}$ & $\begin{array}{c}250 \mathrm{~mm} \mathrm{x} \\
190 \mathrm{~mm} \mathrm{x} \\
75 \mathrm{~mm} \\
\text { slabs }\end{array}$ & $\begin{array}{c}\text { Similar procedures as } \\
\text { above study except } \\
\text { for the early age } \\
\text { drying }\end{array}$ \\
\hline $\begin{array}{l}\text { Scaling } \\
\text { of } 300 \\
\text { mm } \\
\text { specimen }\end{array}$ & $\begin{array}{l}3 \text { slabs; } 2 \text { with fly ash } \\
\text { and } 1 \text { without fly ash }\end{array}$ & $\begin{array}{l}\text { Cast and cured } \\
\text { at } 1^{\circ} \mathrm{C} \text { ambient } \\
\text { temperature }\end{array}$ & $\begin{array}{c}300 \mathrm{~mm} \mathrm{x} \\
300 \mathrm{~mm} \mathrm{x} \\
900 \mathrm{~mm} \\
\text { slabs }\end{array}$ & $\begin{array}{c}\text { Role of various } \\
\text { surface treatments } \\
\text { and salt applications } \\
\text { also studied } \\
\end{array}$ \\
\hline $\begin{array}{l}\text { Micro- } \\
\text { structure } \\
\text { study }\end{array}$ & $\begin{array}{l}2 \text { - lab specimens } \\
\text { with and without fly } \\
\text { ash; } 2 \text { - field } \\
\text { specimens with and } \\
\text { without fly ash }\end{array}$ & $\begin{array}{l}\text { Lab concrete- } \\
\text { cured at } 10^{\circ} \mathrm{C} \text {, } \\
\text { field concrete- } \\
\text { cured at min. } \\
12^{\circ} \mathrm{C} \\
\end{array}$ & $\begin{array}{l}6 ” \times 12 ” \\
\text { cylinders } \\
2.5 ” \times 15 ” \\
\text { cores }\end{array}$ & $\begin{array}{c}\text { SEM specimens were } \\
\text { prepared after } 7 \text { days } \\
\text { of curing }\end{array}$ \\
\hline
\end{tabular}

$1 ”=25 \mathrm{~mm}$ approximately

\subsubsection{Bleeding of Concrete and Effect of Evaporation Rate at Low Temperature}

At lower temperatures, the presence of fly ash can lead to slower setting and the resulting longer bleeding time of concrete can be an issue. Therefore, a bleeding test was performed as per ASTM C232 for low temperature $\left(1^{\circ} \mathrm{C}\right)$ cured concrete with different slump mixtures, with and without fly ash. A greater depth of concrete can have a higher bleeding; therefore, 6” x 12” (150 mm x $300 \mathrm{~mm}$ ) cylinders were prepared for a bleeding test, to better represent the field conditions. Three specimens were prepared for the 
concrete, with and without fly ash, having slumps of 1”, 2” and 4” each. The slump was increased by increasing the water reducer only (constant w/cm of 0.44 ). Additionally, after finishing photographs of specimens at different intervals were taken for better visual comparison.

Additional 6” x 12” specimens with a 2-inch slump were prepared for an early age evaporation study. The mass of these specimens was monitored continuously. Specimens were exposed to a constant wind speed of $9 \mathrm{mph}$ (14.5 kph) immediately after finishing. Wind speed of $9 \mathrm{mph}$ was selected because it falls in the range of the average wind speed for most regions of Indiana. The mass loss with time for specimens with and without fly ash was then compared.

\subsubsection{Scaling of 75-mm Deep Specimens Cured at Low Temperature}

To study the effect of the mixing and curing temperatures on scaling, $250 \mathrm{~mm} \mathrm{x}$ 190 mm x 75 mm (10” x 7.5” x 3”) specimens were prepared and cured at 1 and $10^{\circ} \mathrm{C}$. The specimen preparation was very much similar to that used for regular scaling specimens described in section 8.2, except for the curing temperature. A set of two scaling specimens was prepared for both temperatures. One specimen in each set was equipped with thermocouples that were placed at $2 \mathrm{~mm}, 4 \mathrm{~mm}, 20 \mathrm{~mm}$ and $30 \mathrm{~mm}$ from the top surface to monitor the temperature of the specimens. The time-temperature data of the thermocouples placed at the center (30 mm from top) of the specimen were used to determine the maturity values. The specimens were stored at cold temperatures ( $35 \pm 5 \%$ $\mathrm{RH})$, until they achieved a flexural strength equivalent to 550 psi. Immediately after that 
they were moved to F-T chamber and exposed to 50 cycles of freezing and thawing with salt solution on the surface.

\subsubsection{Scaling of Concrete With Different Early Age Evaporation (Drying Periods)}

At low temperatures, due to the delayed setting time and a longer bleeding period, early prevention of moisture loss caused by application of a curing compound might pose a threat of accumulation of more bleed water on the surface. Therefore, it is important to know the influence of this surface layer on the scaling results. It is difficult to study this influence by directly applying a curing compound on the surface because, as observed in section 5.3.8 of this study, application of curing compound reduces scaling substantially by creating a barrier to salt penetration. Hence, by covering the surface with plastic lids for different durations, the influence of time of prevention of evaporation (early age drying) on scaling was studied.

Total of eight scaling specimens were prepared and cured at a low temperature $\left(1^{\circ} \mathrm{C}\right)$. The specimen preparation was identical to those described in the previous section. Each set of 2 specimens was covered with plastic lids for 30 minutes, 2 hours, 4 hours, and 15 hours after final finishing of the specimens. Thirty minutes was selected as the earliest time because as per the INDOT specification (Section 504.04) the curing compound should be applied within 30 minutes of final finishing or as soon as the surface water disappears. Moreover, 15 hours was selected as the maximum duration because the initial setting time of the concrete containing fly ash at low temperature $\left(1^{\circ} \mathrm{C}\right)$ was observed to be in the same range. Figure 9.2 shows one of the parts of the slab covered after 30 minutes, while the second part was not yet covered with the lid. These 
specimens also were cured at low temperature until they achieved flexural strength of 550 psi, then they were moved to F-T room for scaling study.

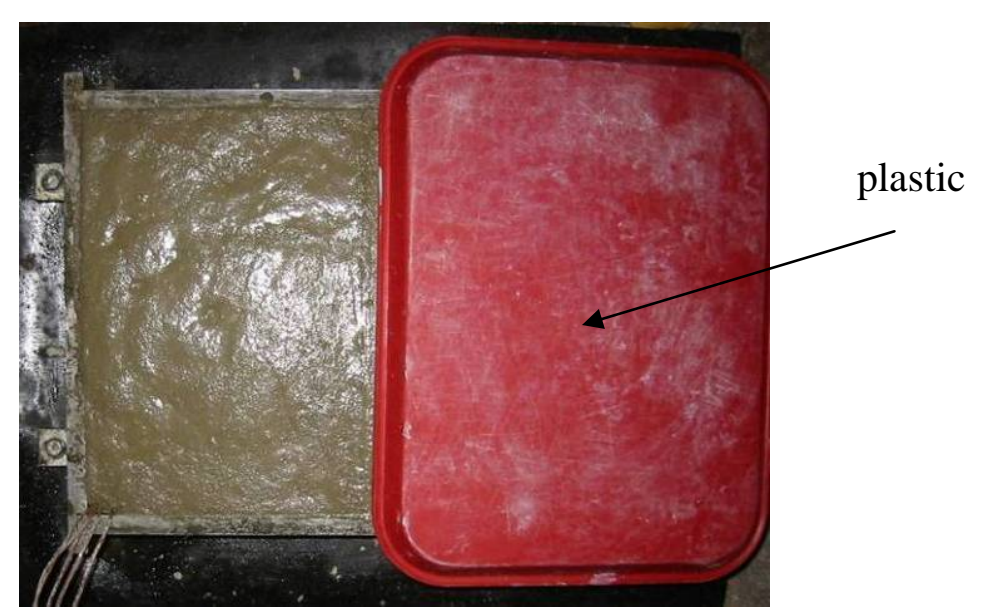

Figure 9.2: Picture showing covered (right) and uncovered segment (left) of scaling specimen

\subsubsection{Scaling and Other Relevant Studies for 300-mm Deep Specimens}

The smaller size of the laboratory specimens resulted in setting times, bleeding, and scaling that might not represent the actual condition of the pavement. In an attempt to generate similar behavior similar to that which may be experienced in the actual pavement, large size (300-mm deep) specimens also were prepared and tested.

\subsubsection{Selection of Test Parameters}

The present pavement thickness in Indiana varies from $225 \mathrm{~mm}$ to $375 \mathrm{~mm}$ (9” to 15”), so 300-mm (12”) thick specimen was selected for this study. The length and width of the specimen were kept constant at $900 \mathrm{~mm}$ x $300 \mathrm{~mm}$. The forms were insulated on all sides with 50 -mm thick Styrofoam ${ }^{\mathrm{TM}}$ sheets, to represent a segment of real pavement 
having considerably large dimensions and a single direction of heat flow. Additionally, a one-inch thick layer of coarse aggregates (cooled at $1^{\circ} \mathrm{C}$ ) was placed at the bottom of the mold to simulate the actual subgrade conditions. Total of two wooden forms were built and equipped with wheels attached to the base for ease of transport. Additionally, a wooden stick was installed in the center of the base for attachment of thermocouples to be placed at various depths in the specimen.

The original surface area of the slab (900 mm x $300 \mathrm{~mm}$ or $419 \mathrm{in}^{2}$ ) was larger than the minimum requirement in ASTM C672 $\left(75 \mathrm{in}^{2}\right)$ for a scaling study. Therefore, it was decided to divide the slab surface into three segments. This allowed for three different surface finish/preparations to be studied for scaling resistance simultaneously using a single specimen. The three parts were each $300 \mathrm{~mm}$ x $300 \mathrm{~mm}$ (12” x 12”) to obtain the following surface conditions; trowel-finished without curing compound (representing the worst case scenario), trowel-finished with curing compound, and tinned with curing compound (identical to field condition).

\subsubsection{Specimen Preparation}

The mixing procedure was identical to the procedure described in section 8.2. Using one batch of concrete $\left(1.8 \mathrm{ft}^{3}, 0.05 \mathrm{~m}^{3}\right)$, half of the mold was filled in the vicinity of the concrete mixer. The mold was then wheeled out to the cold room. A second batch of concrete was then prepared and immediately after mixing, the concrete pan was taken into the cold room to complete the process of casting. A needle vibrator was used for the vibration, at an angle of $20^{\circ}$ such that it penetrated the whole layer. The surfaces were screeded and final trowel finishing was performed after one hour. The fresh properties of 
the concrete then were measured and it was confirmed that desired slump and air content were obtained. The Figure 9.3 shows the specimen preparation for the large size specimen.
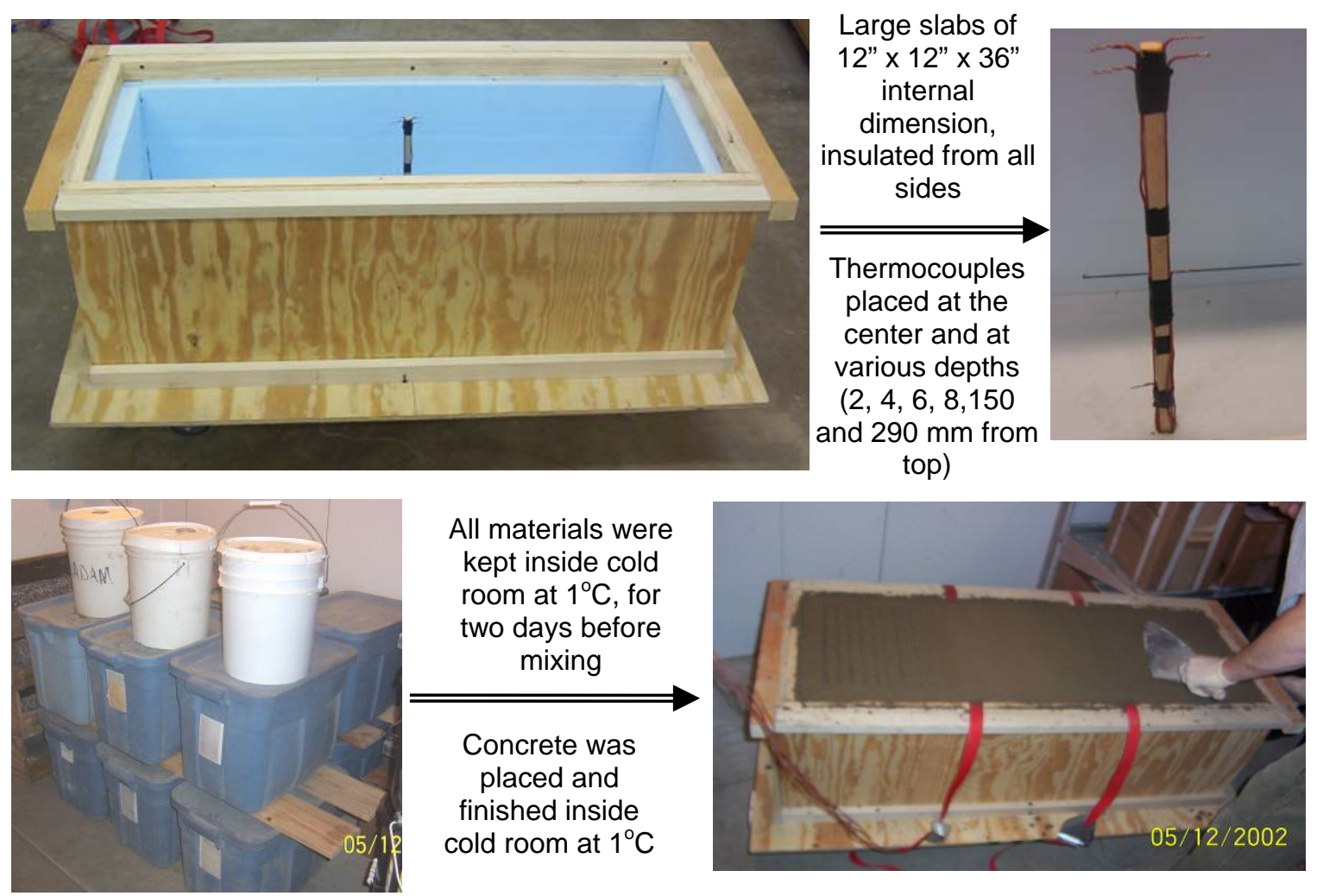

Figure 9.3: Process of preparation of large size specimen

Thermocouples were attached to a wooden stick in order to closely monitor the temperature at various depths and to obtain a useful temperature profile. Four thermocouples were placed close to the surface $(2,4,6$, and $8 \mathrm{~mm}$ from the top), two at the center of the specimen (150 mm from top) and two at the bottom (290 mm from top). Care was taken while placing and finishing the concrete to see that the locations of the thermocouples was not changed. 
After finishing the entire slab with a normal trowel finish, $1 / 3^{\text {rd }}$ of the surface was tinned using standard hand tining tool. Then another third of the trowel finished slab was covered with plastic lid, as soon as the surface moisture disappeared. The areas not covered with the plastic lid were then covered with the liquid curing compound. To simulate the worst case, application rate of $4.0 \mathrm{~m}^{2} / 1$ was maintained, which is less than minimum specified rate of the INDOT specification $\left(3.7 \mathrm{~m}^{2} / \mathrm{l}\right)$.

To determine maturity, continuous temperature monitoring was conducted. Before exposing these slabs to the F-T cycles, it was essential to create a leak-proof dike on the surface. Therefore, 18 - 24 hours of exposure at $23^{\circ} \mathrm{C}\left(73.4^{\circ} \mathrm{F}\right)$ was incorporated in the maturity calculations for curing the epoxy and the sealant used to prepare dike on the concrete surface. Based on these calculations, at the appropriate time the specimen was taken out of the cold room and kept at room temperature. Waterproof epoxy was applied on all edges, where the reservoir dike was supposed to be placed. A reservoir made with Styrofoam $^{\mathrm{TM}}$ sheets was placed on this surface, and a silicon caulk was used to bond the surface and seal all the interfaces. Based on the time-temperature data, as soon as the specimens achieved a maturity equivalent to flexural strength of 550 psi (3.8 MPa), they were moved to the F-T room. Figure 5.4 below shows the results of the calculations for prediction of the flexural strength with a typical temperature profile for the control specimen. 


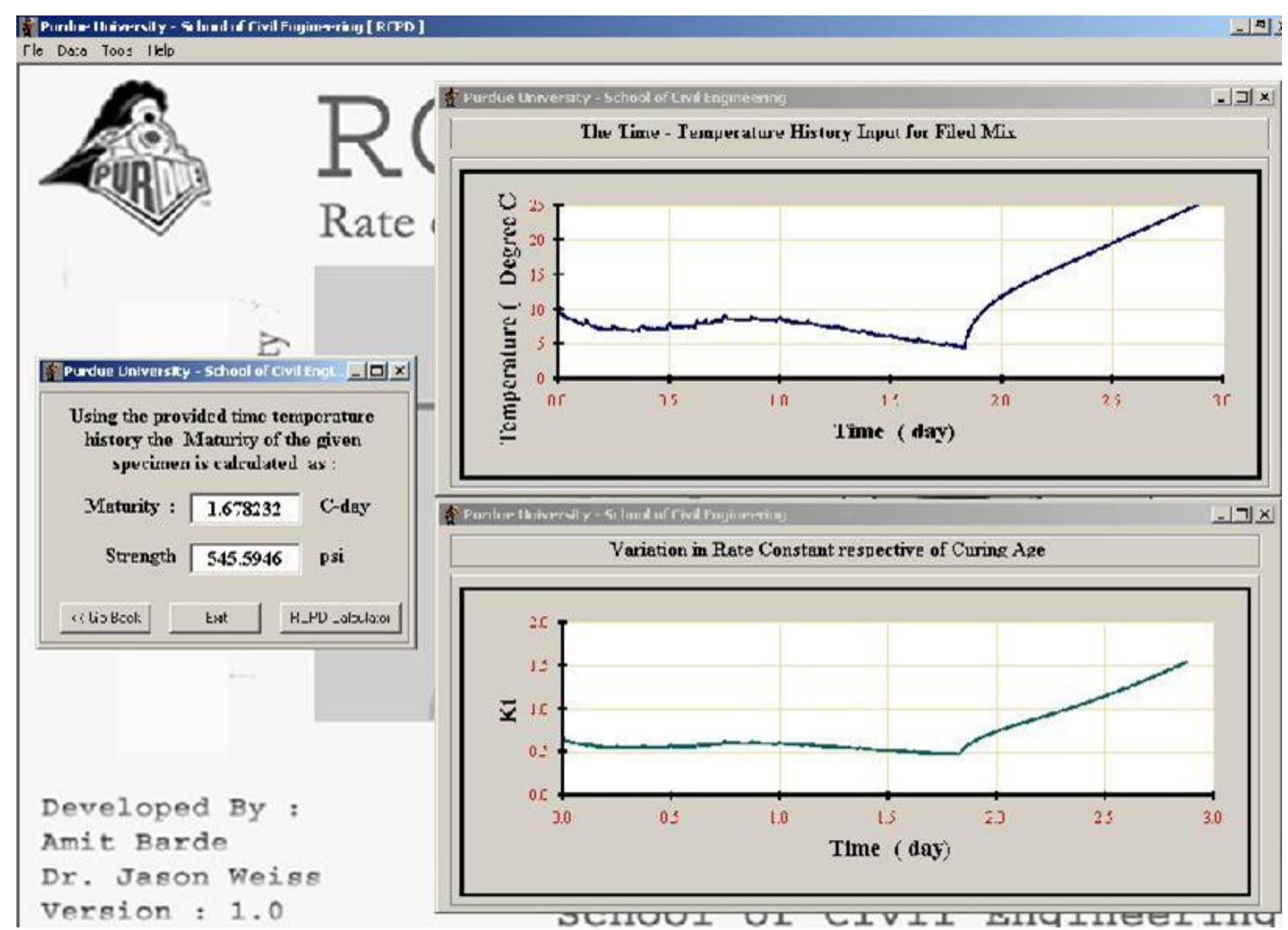

Figure 9.4: Results of calculations for prediction of flexural strength for control mixture

Three $300 \mathrm{~mm}$ deep slabs were prepared, including two specimens containing fly ash and one control specimen. The details of prepared specimens can be found in Table 9.2. Control specimen (control) and one of the fly ash specimens (fly ash 2) were tested with the usual procedure of applying salt solution to the surface before exposing specimens to F-T cycles. To verify whether the time of application of the de-icing salt can make any difference in scaling, $3 \%$ salt was applied to the surface of the second slab containing fly ash (fly ash 1) after first exposing its surface to a known quantity of frozen water. Thus, adding salt solution to the surface before the first freezing cycle, one 
specimen was treated with the salt after the first freezing of water on the surface, which helped to simulate field application of de-icing salt.

Table 9.2: Details of 300-mm deep specimens prepared for lower temperature study

\begin{tabular}{|c|c|c|c|}
\hline Specimen size & $\begin{array}{l}\text { Mix type, Source, } \\
\text { (ID) }\end{array}$ & Application of salt & $\begin{array}{l}\text { Condition } \\
\text { simulated }\end{array}$ \\
\hline $\begin{array}{l}300 \mathrm{~mm} \times 300 \\
\mathrm{~mm} \times 900 \mathrm{~mm} \\
\left(1^{\prime} \times 1^{\prime} \times 3^{\prime}\right)\end{array}$ & $\begin{array}{l}\text { Fly ash - 1" slump, } \\
\text { 7.0\% air (fly ash1) }\end{array}$ & $\begin{array}{l}\text { Salt applied after first } \\
\text { freezing }\end{array}$ & $\begin{array}{l}\text { Effect of de-icing } \\
\text { salt application }\end{array}$ \\
\hline $\begin{array}{l}300 \mathrm{~mm} \times 300 \\
\mathrm{~mm} \times 900 \mathrm{~mm} \\
\left(1^{\prime} \times 11^{\prime} \times 3^{\prime}\right)\end{array}$ & $\begin{array}{l}\text { Fly ash - 1" slump, } \\
\text { 6.5\% air (fly ash2) }\end{array}$ & $\begin{array}{l}\text { Salt solution kept on } \\
\text { surface before first } \\
\text { freezing }\end{array}$ & $\begin{array}{l}\text { Effect of anti- } \\
\text { icing with low } \\
\text { salt concentration }\end{array}$ \\
\hline $\begin{array}{l}300 \mathrm{~mm} \times 300 \\
\mathrm{~mm} \times 900 \mathrm{~mm} \\
\left(1^{\prime} \times 1^{\prime} \times 3^{\prime}\right)\end{array}$ & $\begin{array}{l}\text { Control - 1” slump, } \\
\text { 6.5\% air (control) }\end{array}$ & $\begin{array}{l}\text { Salt solution kept on } \\
\text { surface before first } \\
\text { freezing }\end{array}$ & $\begin{array}{l}\text { Effect of anti- } \\
\text { icing with low } \\
\text { salt concentration }\end{array}$ \\
\hline
\end{tabular}

\subsubsection{Porosity Determination in Field and Laboratory Specimens}

To study the influence of low temperature curing on surface porosity, a microstructure study was performed for some of the laboratory and field specimens cured at low temperature. The laboratory specimens were obtained from the surface of the 6" $\mathrm{x}$ 12” (150 mm x $300 \mathrm{~mm}$ ) cylinders having a 1” slump, prepared for the bleeding study. For comparative purposes, a microstructure study was also performed on specimens of obtained from a few cores, removed from the actual pavement section that were placed on October 15 - 16, 2003 (E \& B Paving, Rochester, Indiana). October 15 is the last date on which fly ash can be used for pavement construction in Indiana. The pavement was cored within 7 days after placement and a 1"-thick disc was cut from the surface of the core and stored in the acetone for at least 3 days to stop further hydration. The 1 ” $\mathrm{x} 1$ ” $\mathrm{x}$ 1” sample was then cut from the disc and embedded in the epoxy following the procedure 
described in section 8.2.2. After polishing, SEM images were acquired (at 100x magnification) throughout the surface and bulk of the concrete. After processing of the images, the ratio of the average porosity of the surface to that of bulk was obtained for each specimen.

\subsection{Observations and Results}

This section will report the observations and results of various low temperature curing studies. Along with this, further data and observations from literature are presented to substantiate the results obtained in this study and to explore potential limitations of the 900-mm deep specimen study used.

\subsubsection{Setting Time Measurement at Low Temperature}

As mentioned in the previous section, the setting time of the concrete with and without fly ash was measured at low temperature $\left(1^{\circ} \mathrm{C}\right)$ using the standard ASTM C403 procedure. Additionally, the setting time of the concrete containing fly ash was measured at $23^{\circ} \mathrm{C}$. The results for the setting times determination are plotted in Figure 9.5. According to ASTM C403, initial and final setting time of concrete is defined as time when pressure required for 1” penetration reaches to 500 and 4000 psi (3.4 MPa and 27.6 $\mathrm{MPa}$ ), respectively. The results presented in Figure 9.5 were used to tabulate the initial and final setting times reported in Table 9.3 for fly ash concrete. For comparison, this Table also includes the values of setting times for plain concrete that were obtained in another set of experiments. 


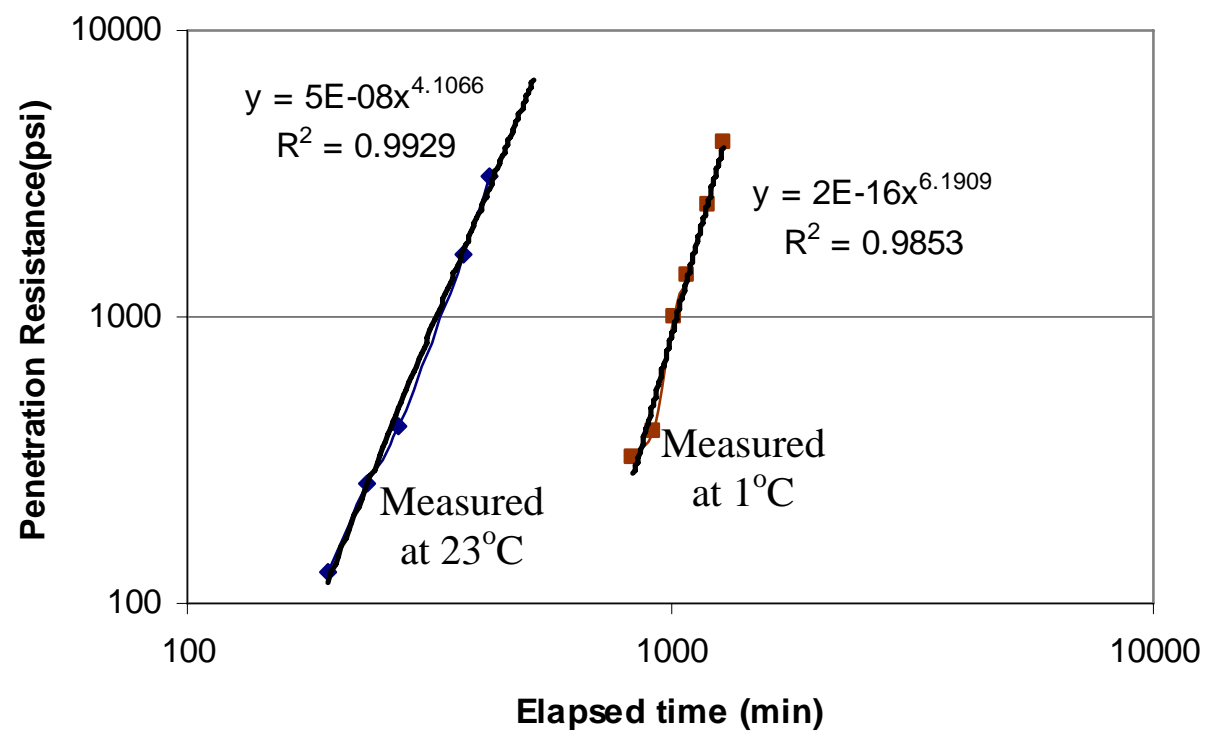

Figure 9.5: Data for setting time of concrete containing fly ash at $23^{\circ} \mathrm{C}$ and $1{ }^{\circ} \mathrm{C}$

Table 9.3: Results for initial and final setting time

\begin{tabular}{|c|c|c|c|}
\hline Properties & $\begin{array}{c}\text { Fly ash concrete at } \\
\mathbf{1}^{\mathbf{0}} \mathbf{C} \text { (hours) }\end{array}$ & $\begin{array}{c}\text { Plain concrete at } \\
\mathbf{1}^{\mathbf{0}} \mathbf{C} \text { (hours) }\end{array}$ & $\begin{array}{c}\text { Fly ash concrete at } \\
\mathbf{2 3}^{\mathbf{0}} \mathbf{C} \text { (hours) }\end{array}$ \\
\hline Initial setting time & 15.6 & 10 & 4.5 \\
\hline Final setting time & 21.8 & 14.5 & 7.5 \\
\hline
\end{tabular}

These results indicate that for concrete exposed to low temperatures, the addition of fly ash increases the initial and final setting times by almost $50 \%$ when compared to plain concrete. Moreover, the setting times of fly ash concrete cast at $1^{\circ} \mathrm{C}$ are almost three times that of similar concrete prepared at $23^{\circ} \mathrm{C}$.

It should be noted that the actual setting times for field concrete setting times might be considerably lower, even at low ambient temperatures, because of higher heat of hydration generated in the large pavement sections. This issue is important for late season construction, as excessively long setting times could influence the amount and 
rate of bleeding of the concrete. The results of the study of bleeding at low temperatures for normal and fly ash concretes are discussed below.

\subsubsection{Bleeding of Concrete and Effect of Evaporation at Low Temperature}

The 6" x 12" specimens were prepared with 1", 2" and 4" slump in order to measure the amount of bleed water at low temperatures. However, it was found that no measurable quantity of bleeding water could be collected from either the fly ash mix or the control mix, even with the 4" slump specimens. This can be attributed to the fact that all mixtures used constant $\mathrm{w} / \mathrm{cm}$ of 0.44 and the increase in slump was achieved by addition of water reducer. In the absence of a quantifiable water accumulation, photographs taken at regular intervals, were used to show the difference in the apparent surface moisture bleeding of the fly ash and the control specimen. Sample photographs taken for 2-in. slump specimen (representing concrete that can be realistically placed using slip-forming technique) are shown in Figure 9.6.

Figure 9.6 shows that for specimens with similar slump, the surface of samples containing fly ash has a wetter appearance than the surface of control specimens. Thus, the effect of delayed setting and an increased period of bleeding are distinctly visible in the concrete containing fly ash. However, there is no sizeable accumulation of water on the surface and thus, it was difficult to measure the quantity of bleeding water for such specimens as per standard ASTM procedure.

To quantify the bleeding indirectly, the rate of evaporation was measured for fly ash and control specimens of 2” slump exposed to a constant wind speed of $9 \mathrm{mph}$ (14.5 kmph). Mass losses were measured at regular intervals and plotted as a total water loss in 
Figure 9.7. It can be seen that the total water loss for the control specimen was higher than for the fly ash specimen.
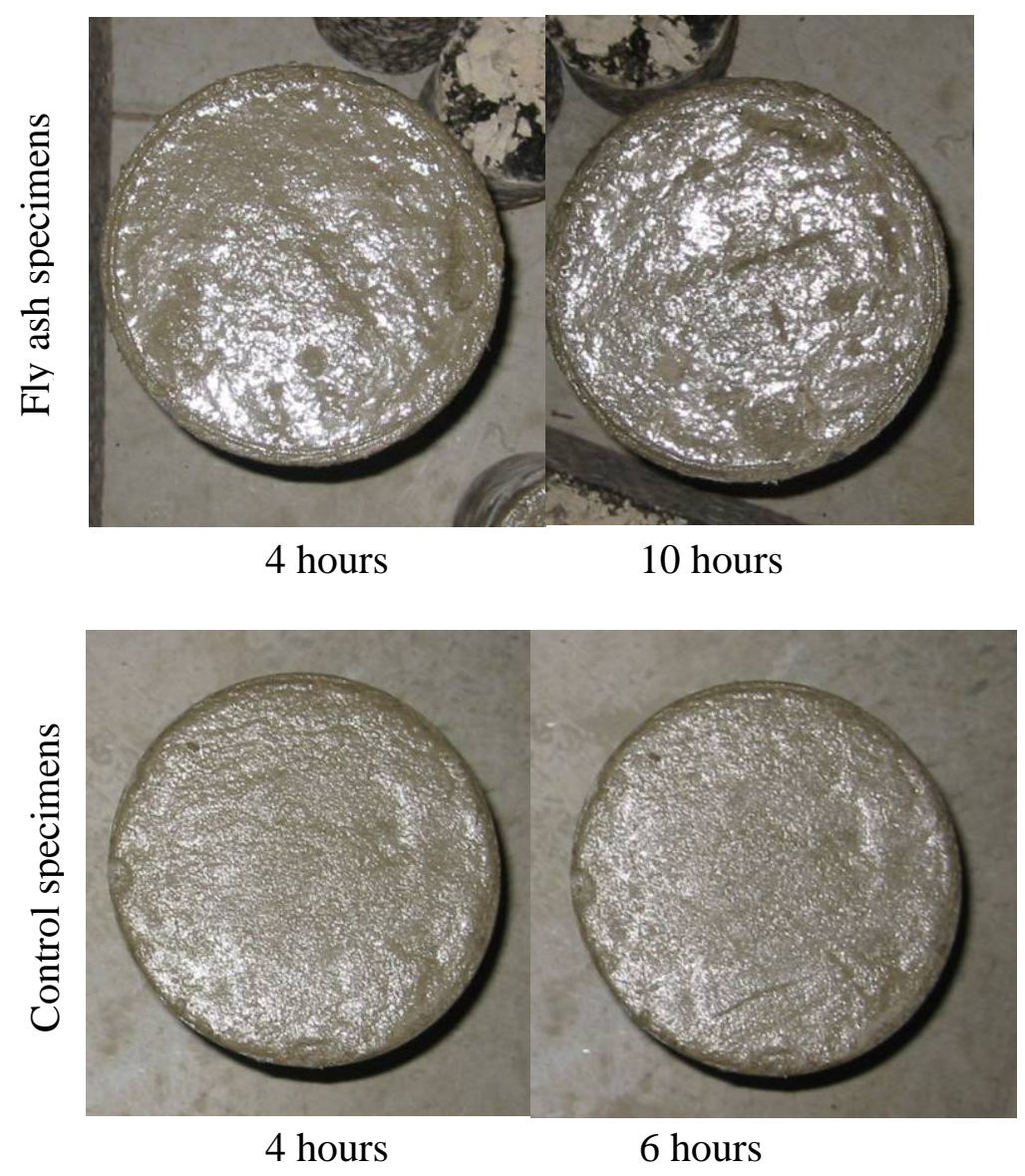

Figure 9.6: Surface of 6”x 12” cylinders at various intervals after finishing 


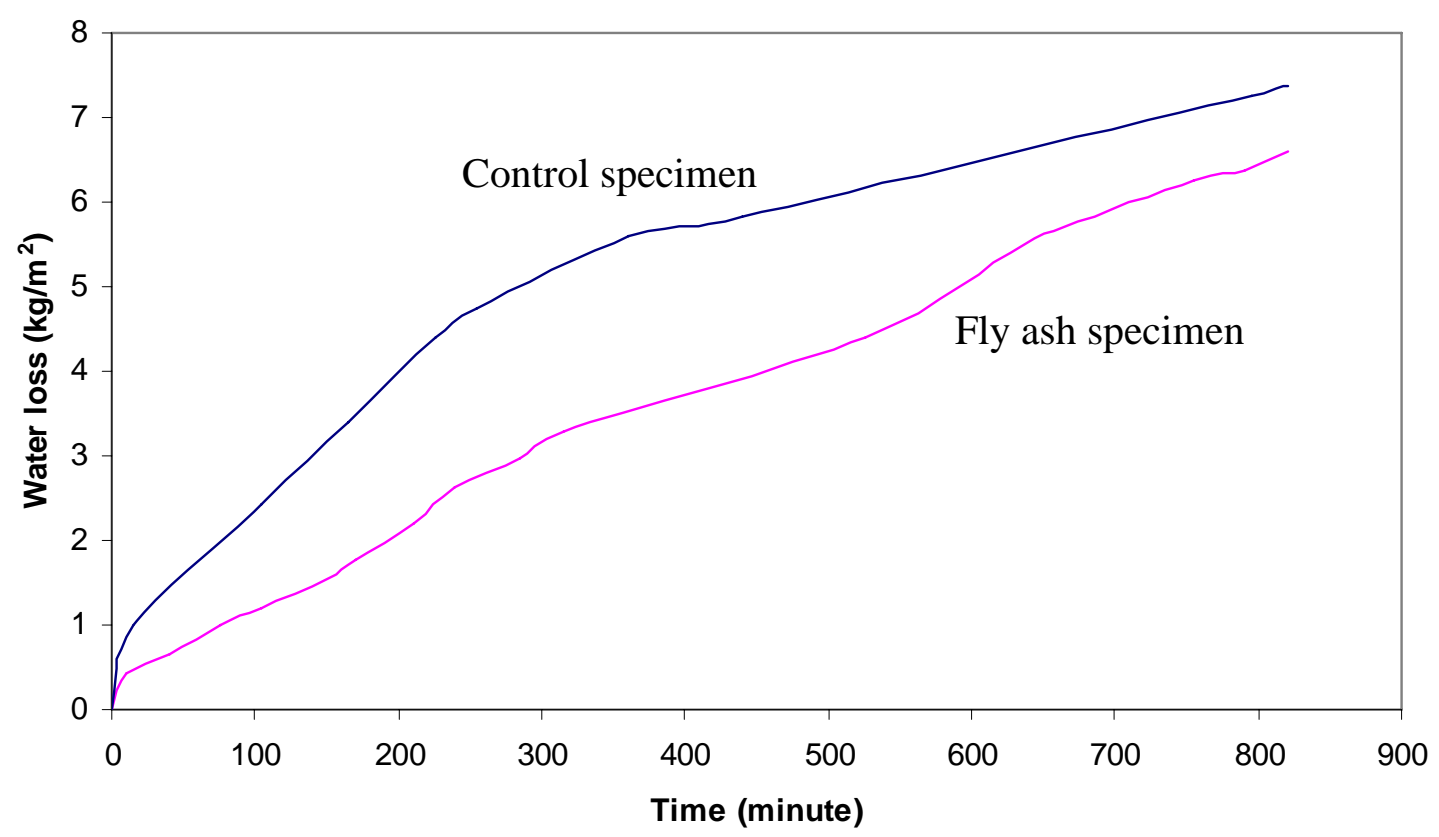

Figure 9.7: Loss of water versus time with constant wind effect of 9 mph for fly ash and control specimens

From this data and the photos of specimens, it can be inferred that the rate of evaporation, and thereby the rate of bleeding, of the control specimen was significantly higher than the fly ash specimen during the first few hour after placement. As the control specimen approached its initial setting time, the rate of evaporation reduced significantly. However, for the fly ash specimen, a constant rate of evaporation was observed for a longer period. However, the total weight loss in the specimens after one day was very similar for both specimens. This indicates that in the case of the fly ash concrete, due to the delayed setting time, the bleeding time also increases. It has been previously reported (Fox, 2004) that the spherical shape and smaller size of the fly ash particles will slow down the rate of bleeding and thereby the rate of evaporation in the fly ash concrete. In 
summary, despite their "wetter" appearance, the overall bleeding of the fly ash concretes were not considerably different from that of plain concrete.

\subsubsection{Scaling of Normal Size Specimens Cured at Low Temperature}

This section describes the scaling results of a set of two specimens, cast and cured at $1^{\circ} \mathrm{C}$ and $10^{\circ} \mathrm{C}$, respectively. Additionally, these results were compared to the corresponding specimen cured at $23^{\circ} \mathrm{C}$ previously described in Chapter 4 (3 day moist cured and 1 day dried). Thus, the scaling results for concrete with and without fly ash cured at three different temperatures and exposed to the F-T cycles after acquiring flexural strength of 550 psi are described herein.

For better comparison of the results for concrete with and without fly ash, Figure 9.8 shows the difference in the scaling results for specimens cured at different temperatures. To get better resolution of this trend, the scaled mass was obtained by deducting the minimum values for that particular mixture from all individual results. For fly ash concrete, a decrease in the curing temperature appeared to cause a decrease in scaling, while for the control specimen scaling increased when there was a decrease in the curing temperature. However, one should keep in mind that there is an intrinsic variability associated with scaling test results and the very weak trend observed may be an artefact. 


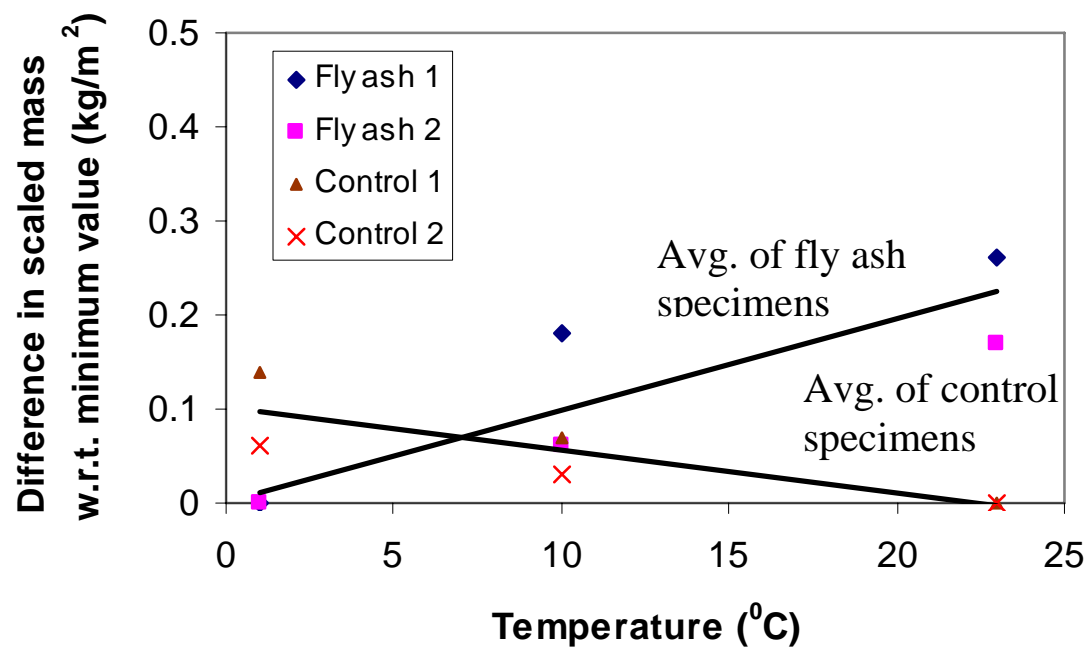

Figure 9.8: Scaling results for concrete cured at different temperatures

These results are consistent with the PCA outdoor study scaling results reported by Stark et al. (2002). On the other hand, Hadchiti et al. (1988), who studied concrete containing different types of fly ash at different curing temperatures, could not find any particular correlation between the curing temperature and scaling. In present study and in the case of Stark et al. (2002), only one cement and fly ash combination was studied, so the trend could be different when different cement and fly ash combinations are studied. Finally, as described earlier 75-mm (3.5-in.) deep specimen might not represent actual field conditions at low temperatures and so a similar study using 900-mm (35-in.) deep specimens was performed, the results of which are described in the section 9.3.5. For this particular case, considering all of the above results, the following reasoning could be hypothesized for the observed behavior. 


\subsubsection{Scaling of Concrete With Different Early Age Drying Periods}

Since concrete containing fly ash has longer setting times and bleeding periods, there is greater chance that water cab accumulate on the surface when evaporation is prevented through the application of a curing compound. To study this, the influence of the time of membrane application on prevention of moisture loss after $(0.5,2,4$, and 15 hours after final finishing) on scaling of specimens was studied. Figure 9.9 shows the results of this study. In this case, the difference in the scaled mass for these specimens is shown with respect to the minimum scaled mass value for better resolution of the effect.

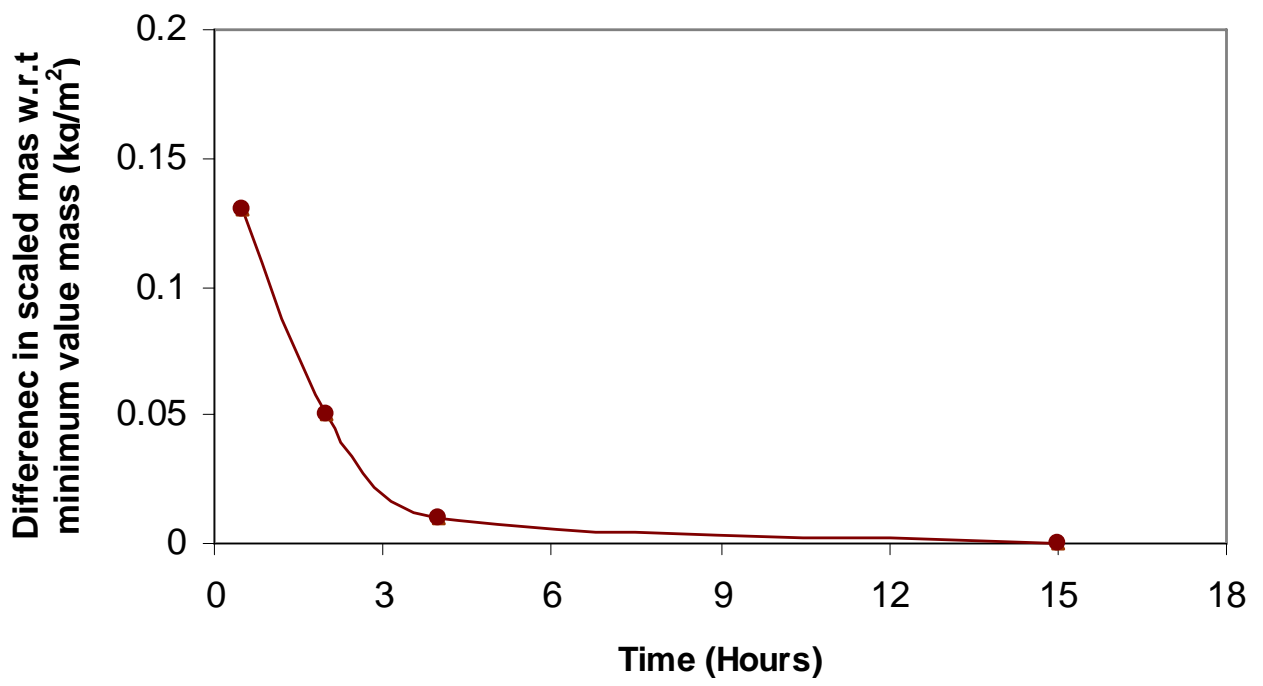

Figure 9.9: Time of prevention of evaporation after finishing versus scaled mass

As expected, with an increase in the time of membrane application (prevention of moisture loss), the scaling decreased. It was visually observed that in specimens that have been covered with curing membrane at 0.5 or 2 hours after finishing, surface started crumbling and flaking off within the first 2 - 3 cycles of freeze and thaw. The damaged surface layer was extremely thin and concrete appeared to be dusty. Thus, the treatment 
that reduces surface evaporation at low temperatures seems to have an effect of forming a very thin highly porous surface layer. The total scaled mass for this layer does not seem to be more than $0.15 \mathrm{~kg} / \mathrm{m}^{2}$. Thus, it can be inferred that even though early application of a curing compound during the low temperature season might pose some potential problems, but the magnitude of scaling is not very significant. Moreover, actual pavements contain tines, which will increase the rate of evaporation.

Based on this study it was revealed that a weak surface layer caused by the accumulation of bleeding water had a little influence on the scaling results when there was no external evaporation barrier applied to the concrete. Hence, to improve the scaling performance of a particular concrete, specifically at low temperatures, it appears that it is not advisable to apply a curing compound until the surface water film (sheen) is completely is gone.

\subsubsection{Low Temperature Curing of Large Size Specimens}

This section describes results of scaling performance of concrete with and without fly ash for $900 \mathrm{~mm}$ x $300 \mathrm{~mm}$ x $300 \mathrm{~mm}$ deep specimens. To see how well these specimens simulate pavement temperatures in the field, they were compared with data from the LTPP database.

\subsubsection{Setting Time, Bleeding and Flexural Strength of Large Size Specimens}

Table 9.2 described details of three $300 \mathrm{~mm}$ deep specimens that were evaluated in this study. To determine setting time and maturity of these specimens, their temperatures were monitored using the thermocouples. Figure 9.10 shows the time 
temperature profile before moving them into the F-T chamber. Unlike in the case of small specimens, it can be seen that although fresh concrete was exposed to an ambient temperature of $1^{\circ} \mathrm{C}$, even the surface of the specimens experienced temperature in the range of $8-10^{\circ} \mathrm{C}$ due to the effect of heat of hydration. The scratch hardness test was used to determine approximate setting time of concrete inside large molds. The approximate setting time of the fly ash mix was estimated as 8 hours and 40 minutes, while for the control mix it was estimated 5 hours 20 minutes. From the data and visual observations, for large size specimens, due to an overall higher temperature inside the specimen, the setting time was noted to be almost half the setting time of the small size specimen (for both the fly ash and the control) in the same ambient temperature. Thus, the size effect significantly influences the results, specifically at low temperature.

The bleeding of concrete in the large size specimens was not as distinctly visible as in the case of the smaller size specimen. Due to the quicker setting of concrete, there was an overall lower bleeding time fore these specimens. However, even in this case the surface of the fly ash concrete was found to be wetter for a little longer period of time than the control specimen. Therefore, it can be said that for actual pavement, because a quicker initial setting time is possible, bleeding would not be as important an issue as in the case of the small size specimens. 


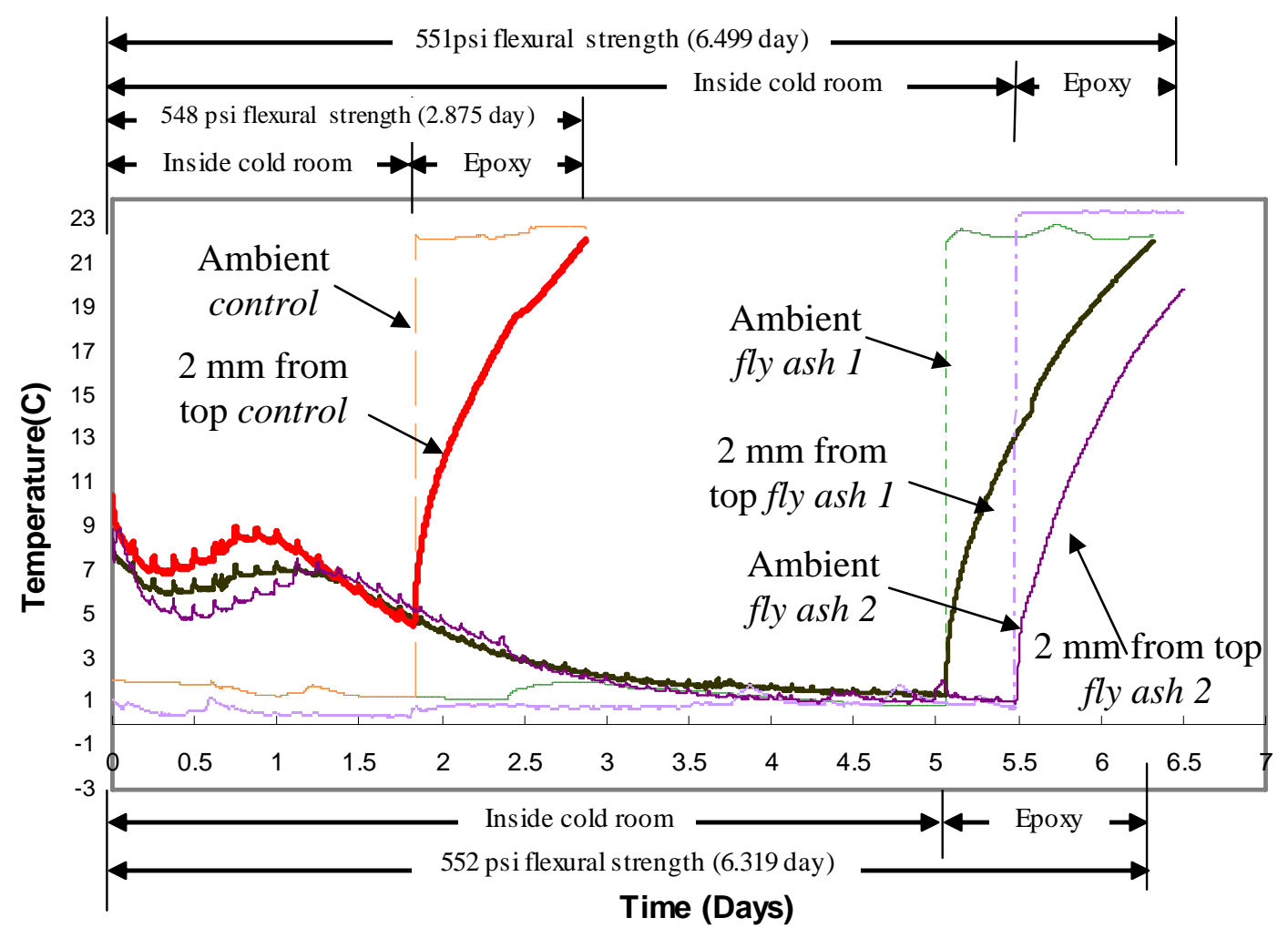

Figure 9.10: Time temperature profile for all the specimens immediately after casting until they were moved to F-T room

As mentioned earlier, based on time temperature data flexural strength at various ages was predicted. Figure 9.10 shows the time for epoxy curing and the time when the specimens were moved to the F-T room and the flexural strength based on the temperature data. The time to achieve the flexural strength of 550 psi (3.8 MPa) was almost double for the concrete containing 20\% fly ash in comparison to the control mix. Note that this is in the laboratory condition where the effect of wind or solar radiation is not present. This duration may increase when the wind is present, which will help reduce the difference between the air and the surface temperatures. On the other hand, this 
duration might decrease in the presence of solar radiation, due to the fact that daytime pavement temperatures can rise much higher than the air temperature (Rawhouser, 1945).

\subsubsection{Scaling Results for Large Size Specimens}

After the desired flexural strength was attained, one of the specimens (fly ash 1) was kept inside the F-T room. To simulate an actual de-icing treatment, a known quantity of water was first frozen on its surface. Following this, enough salt was added to form $3 \%$ solution which was then ponded for a continuous 50 F-T cycles. No scaling was observed in this case at the end of 50 cycles on any of the three surfaces. Figure 9.11 shows all three surfaces of this specimen after 50 cycles, indicating no scaling.

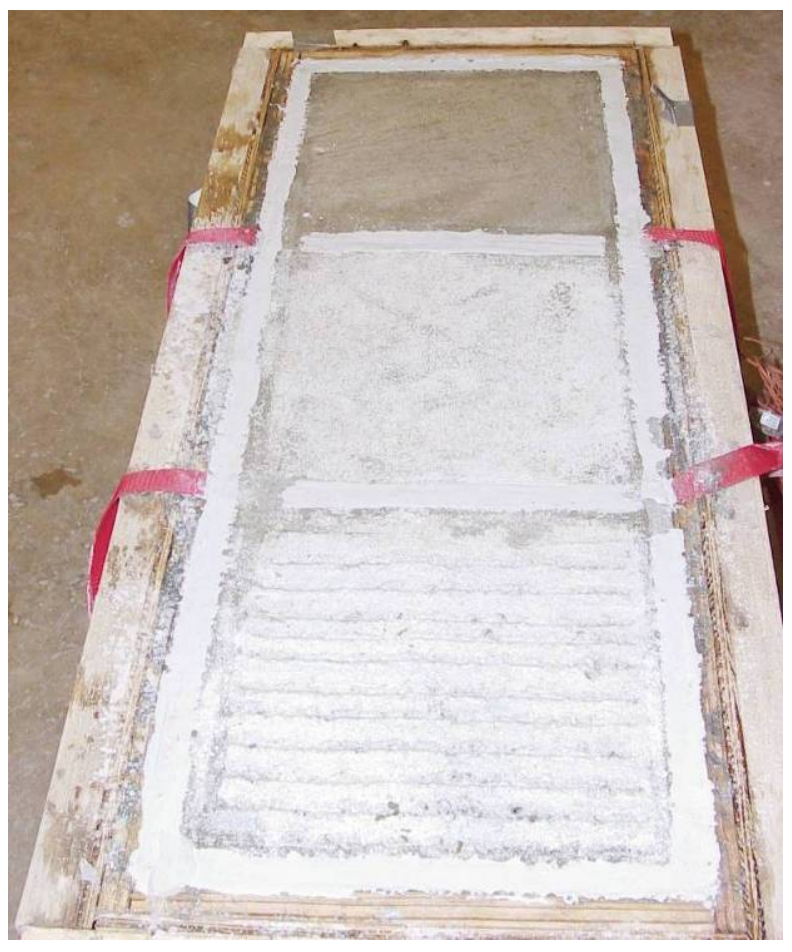

Figure 9.11: Surfaces of the fly ash 1 specimen after 50 F-T cycles 
Although the exact reason for the absence of scaling is difficult to establish, it can perhaps be attributed to the less permeable microstructure (result of slower setting), specific method of salt solution application, the temperature effect in larger specimens, or the combined effect of all. Therefore, in the second phase two more specimens (fly ash 2 and control) were prepared (see Table 9.2). In this case, the salt was applied on the bare surface (without prior freezing of pure water) and then the specimens were exposed to 50 cycles of freezing and thawing. Similar to fly ash 1 specimen, none of these two specimens showed any signs of scaling. These specimens were equipped with thermocouples to monitor their temperature. Details of the temperature data collected are discussed in the next section.

\subsubsection{Study of Temperature Variation with Freeze-Thaw Cycles Inside the Specimens}

Figure 9.12 shows the temperature profile inside different specimens along with the temperature of the F-T room. Thermocouples were placed inside the specimens and also in the surface salt solution. The temperature profiles obtained from the different locations are shown in this Figure.

It was observed that although the temperature of the room dropped to $-15^{\circ} \mathrm{C}\left(5^{\circ} \mathrm{F}\right)$, the temperature inside the 300 -mm deep specimen did not fall below $-5^{\circ} \mathrm{C}$, even at location of $2 \mathrm{~mm}$ below the surface. In fact, even the temperature of water (or solution) ponded on the surface was not dropping below $-3^{\circ} \mathrm{C}\left(26.6^{\circ} \mathrm{F}\right)$. 


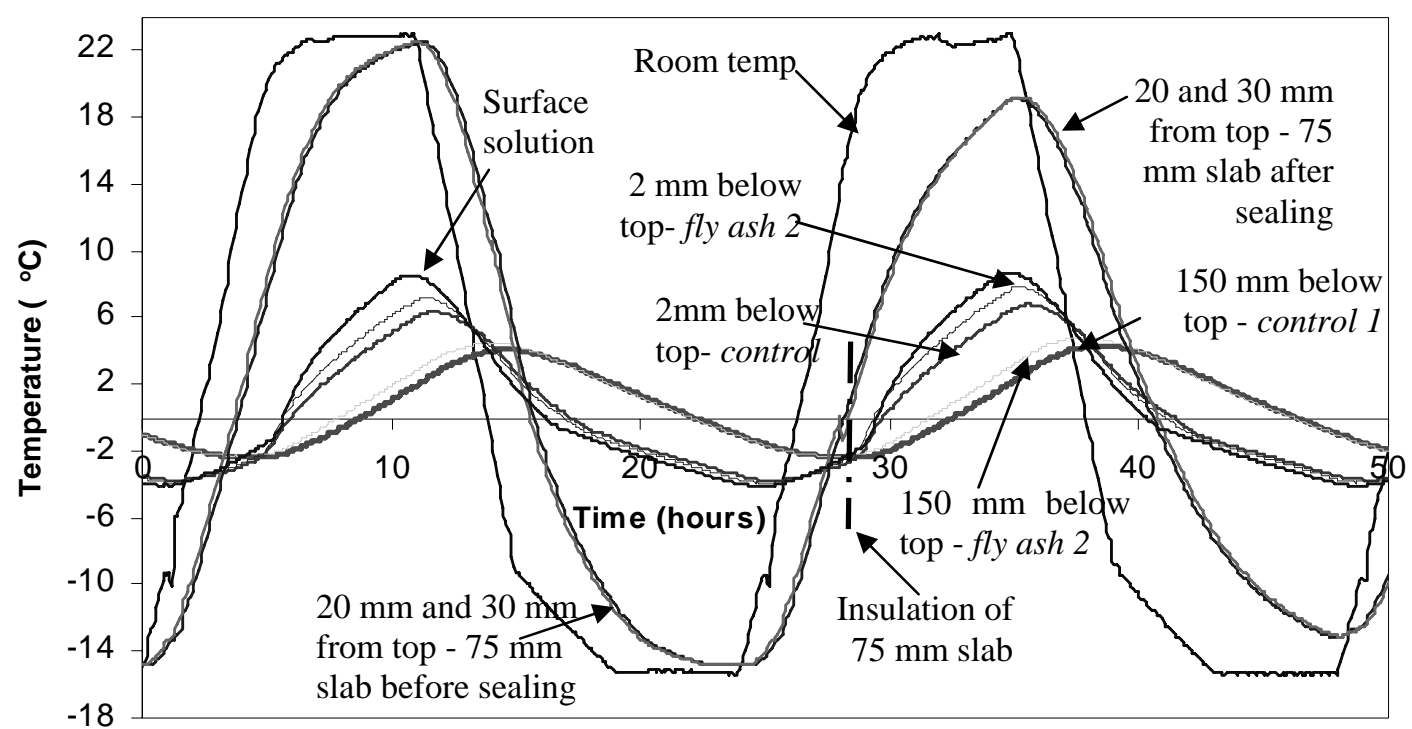

Figure 9.12: Time temperature profile for F-T room and respective temperature profile obtained using thermocouples placed at different locations

To compare these results with those obtained from 75-mm deep specimens used for all the scaling study, temperature profile of one 75-mm thick slab for thermocouples located $20 \mathrm{~mm}$ (0.8”) and $30 \mathrm{~mm}$ (1.2”) deep from the top was added to Figure 9.12. In the first 28 hours this small slab was kept without any insulation (multi direction heat flow), and achieved minimum temperature of $-15^{\circ} \mathrm{C}\left(5^{\circ} \mathrm{F}\right)$ with a little time lag when compared to the temperature of the room. Since the 300-mm deep specimens were insulated from all but one side, an attempt was made to simulate similar conditions for smaller slabs as well. This was achieved by using $50-\mathrm{mm}$ Styrofoam ${ }^{\mathrm{TM}}$ sheets on all the sides except top (single direction heat flow). The time, at which the insulation was applied, (approximately at 28 hours) is shown with a dotted line in the Figure 9.12.

It can be seen that after insulating, the specimen reached the minimum temperature of $-13^{\circ} \mathrm{C}\left(8.6^{\circ} \mathrm{F}\right)$. Hence, it can be said that when heat flow is linear, from 
only the top surface of the specimen, the overall rate of heat transfer reduces but the size of the specimen still dominates.

\subsubsection{Actual Temperature Profiles in Concrete Pavements}

The laboratory studies showed that for $300 \mathrm{~mm}$ deep specimens, because of the very high thermal mass, a significant lag was observed between the air and surface temperature. Therefore, it was important to know how well these results matched with the actual pavement behavior. Using the database provided by Long Term Pavement Performance (LTPP, 2003) for plain jointed concrete pavement of 89 different states, graphs were plotted for the time-temperature profiles during the low temperature seasons. For each pavement, the time-temperature data of the thermocouples placed inside the concrete pavement, the air temperature and the positions of the thermocouples were obtained from different data files. Then, for the particular time period, all of the data was associated and plotted. In most of the pavements under study, the top thermocouple (important for scaling damage) had stopped working before the first winter, including pavements in Indiana. Therefore, Indiana’s latest pavement temperature data (September 1995), was plotted in Figure 9.13. Additionally, to study the behavior during severe winter, data for the province of Quebec is plotted in Figure 9.14. 


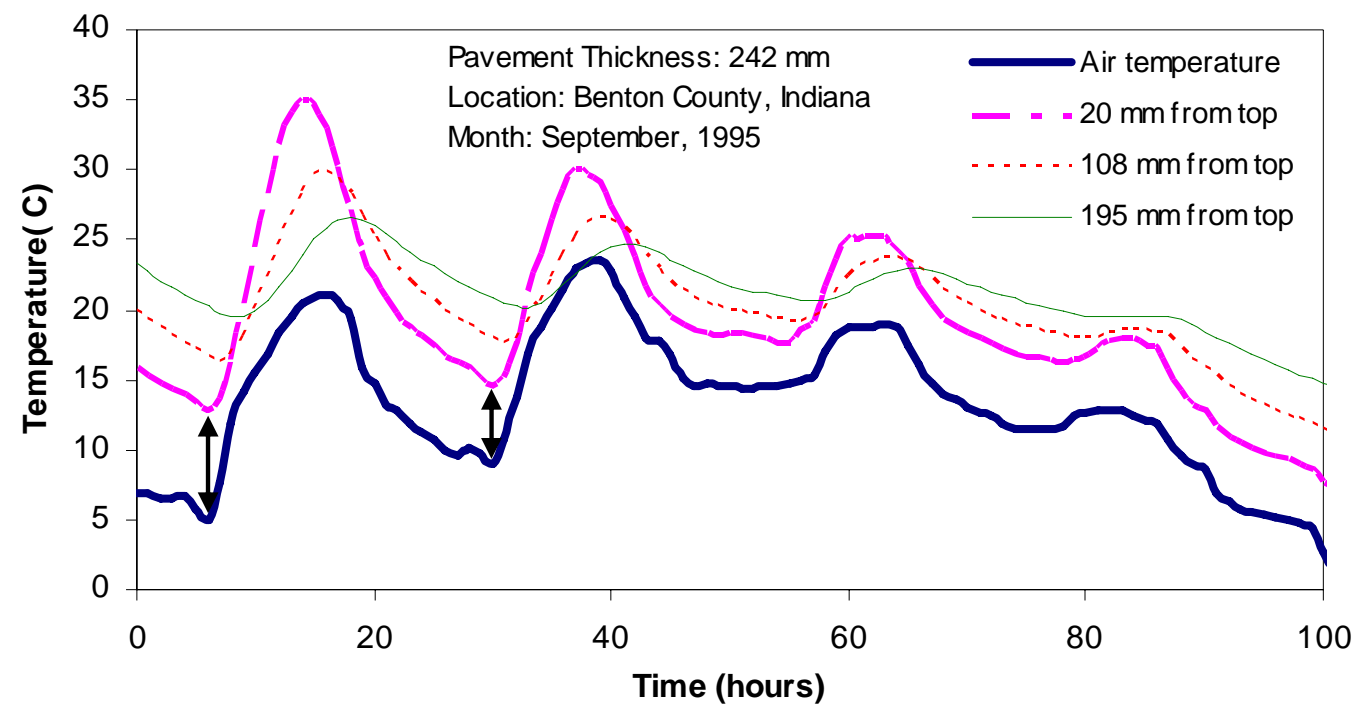

Figure 9.13: Time temperature profile in PCC pavement in Indiana

The following observations can be made from both of Figures, which can be considered useful for this study. The significant time lag (7 hours) that was observed in the 300-mm (12-in.) deep specimen (prepared to simulate actual field conditions), less pronounced in the actual pavements. The main dominating factor here could be considered as the effect of wind, which promotes very quick heat transfer by removing the static air from the surface and subsequently reduces the total time of cooling (or heating) substantially. 


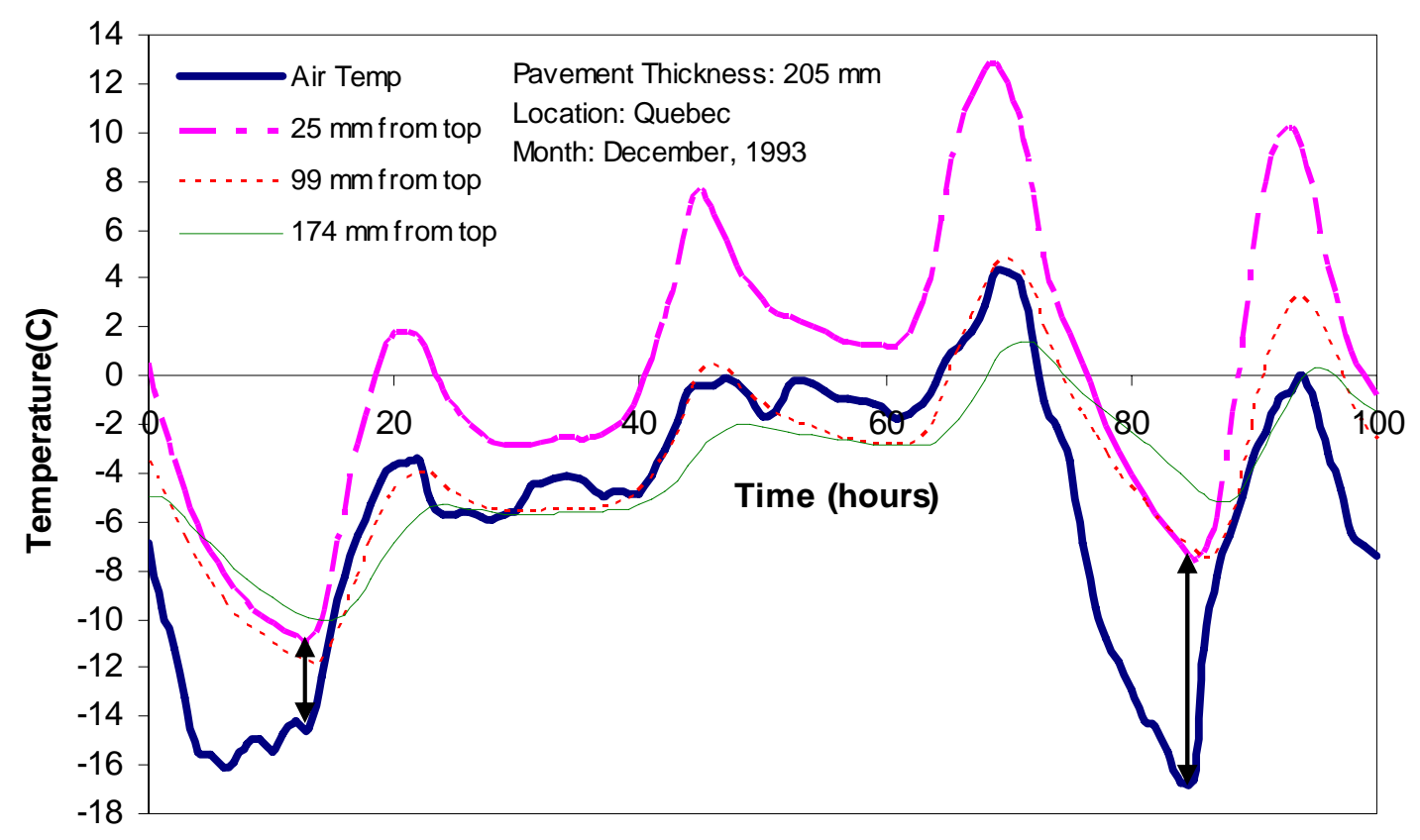

Figure 9.14: Time-temperature profile in PCC pavement in Quebec, Canada

It can be noted in both figures that during the daytime, because of solar radiation (peak at approximately each 24 hours), the concrete surface temperature is higher than the ambient temperature. Solar radiation can increase the surface temperature of concrete up to 10 to $15^{\circ} \mathrm{C}\left(50^{\circ}\right.$ to $\left.59^{\circ} \mathrm{F}\right)$ compared to the mean air temperature (Rawhouser, 1945) and wind speed increases the rate of cooling significantly. The effects of solar radiation would increase the number of freeze thaw cycles at concrete surface even when the air temperature remains constantly in the sub-zero state. In Figure 9.14, it can be seen that for only one thawing in the air, three thaw periods occurred in the surface of the concrete during the same time. This may create a durability concerns regarding freeze-thaw damage in the concrete. On the other hand, this might be considered less detrimental for scaling damage because scaling damage is more dependent on achieving minimum 
temperature than number of F-T cycles. For accurate prediction of the temperature in the pavement information related to solar radiation, wind speed, precipitation, and sub-base temperature is therefore, required in addition to the air temperature.

For the purpose of this study, it was important to establish the difference between the air temperature and the surface temperature in the actual pavement. To get an approximate estimate, the time-temperature profile of the surface and air were obtained, using the LTPP database covering 8 - 10 years of data for three pavements. In most cases, at least $5^{\circ} \mathrm{C}$ difference was observed in the air temperature and the surface temperature for all the minimum temperatures encountered. Due to effect of solar radiation this difference was consistently maintained in most cases, even with a constant sub-zero air temperature for present 3 - 4 days.

\subsubsection{Scaling Results After Lowering Minimum Temperature}

In order to lower the minimum temperature inside the specimen, three fans were installed on the three sides of the slab at different elevations. The average wind speed in the center of the specimen where thermocouple was placed was found to be $9.0 \mathrm{mph}$ (14.5 kmph). The rate of heat transfer increased in this situation and Figure 9.15 below shows the minimum temperature achieved inside the slab before and after installation of fans. The minimum surface temperature also increased from $-5^{\circ} \mathrm{C}$ to $-11^{\circ} \mathrm{C}\left(23^{\circ} \mathrm{F}\right.$ to $12.2^{\circ} \mathrm{F}$ ) in the presence of wind. 


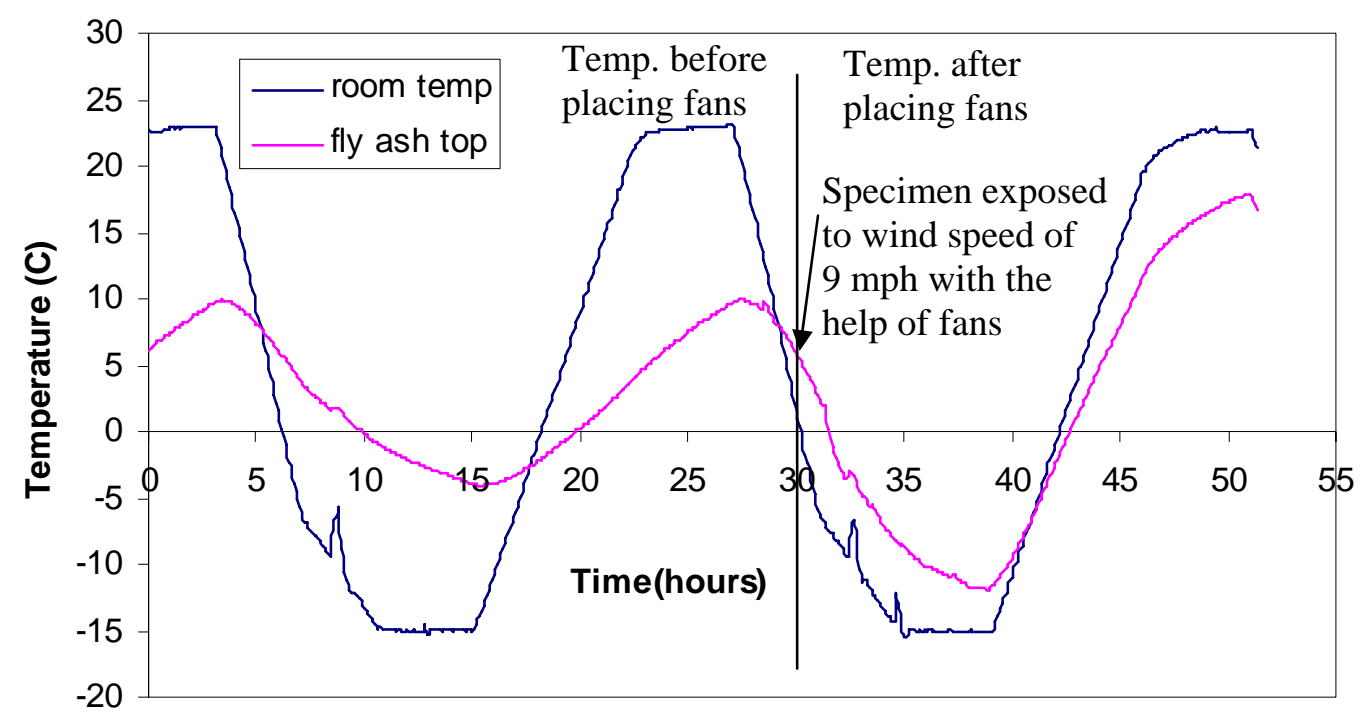

Figure 9.15: Effect of wind in the rate of heat transfer in the large slab

It can be seen from Figure 9.15 that in the presence of a fan, the rate of cooling increased significantly and the time required to attain a certain temperature reduced significantly. This slab was exposed to 10 freeze thaw cycles with this lowered minimum temperature, however still no scaling was observed. The reason could be probably be attributed to an improvement in the strength due to continual hydration, heat absorption capacity of 300 -mm deep specimen, or insufficient $\left(-11^{\circ} \mathrm{C} / 12.2^{\circ} \mathrm{F}\right)$ minimum surface temperature to create any kind of scaling damage. Influence of low temperature curing on surface and bulk porosity for laboratory and field specimens is described in the next section. Further insight about thermal massing effects (heat absorption capacity) and other probable reasoning about absence of scaling in 300-mm deep specimen or actual pavement are given in the next chapter. 


\subsubsection{Porosity Determination in Field and Laboratory Specimens}

Microstructure study was performed for field and laboratory concretes exposed to low temperatures to determine the ratios of surface to bulk porosity. Out of several images obtained at 100x magnification, from the surface and bulk of the specimens, the ratios of the average surface to bulk porosity were obtained for the laboratory and the field specimens with and without fly ash. Figure 9.16 shows the representative image for each type of concrete from the surface and bulk regions. It can be seen that the surface of fly ash concrete for the field and laboratory specimens looks denser than the surface of corresponding control specimens. This supports the previous argument about the effect of reduction of rate of bleeding for fly ash concrete, which helps in improving scaling performance of concrete, specifically at low temperatures, in comparison to the control specimens. Moreover, it can be seen that for fly ash concrete in the laboratory and field specimens, no unusual air content was observed even in the surface region, hence detrimental effect carbon content of fly ash on surface air concentration does not seem to be present at all. 


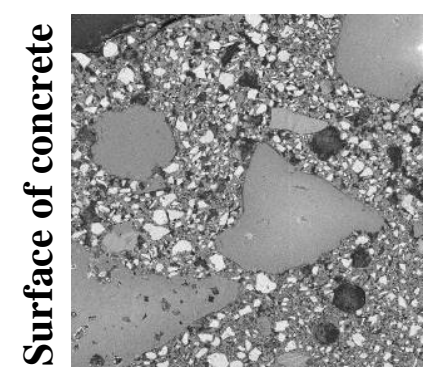

Field Control

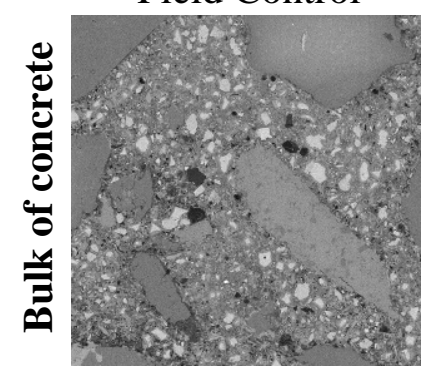

Field Control

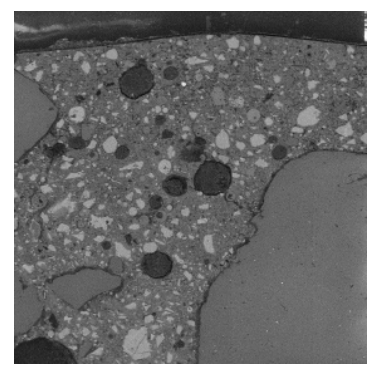

Field Fly ash

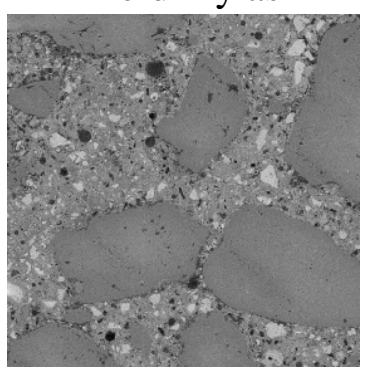

Field Fly ash

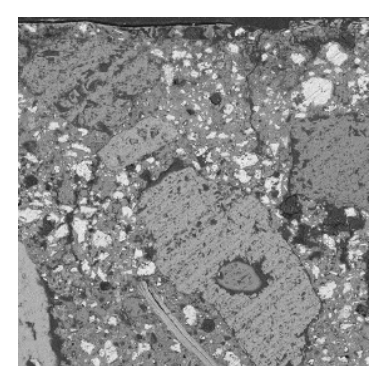

Lab Control

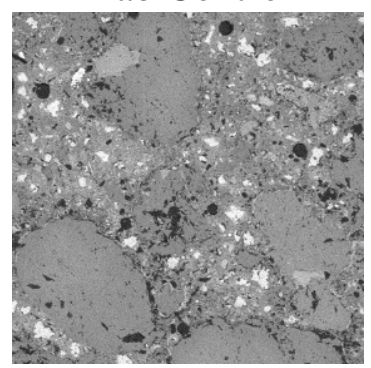

Lab Control

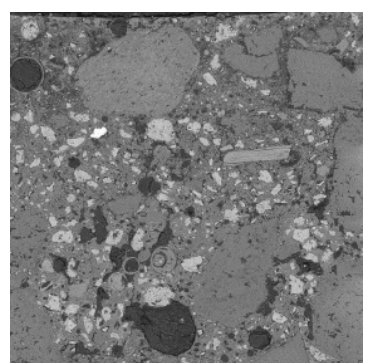

Lab Fly ash

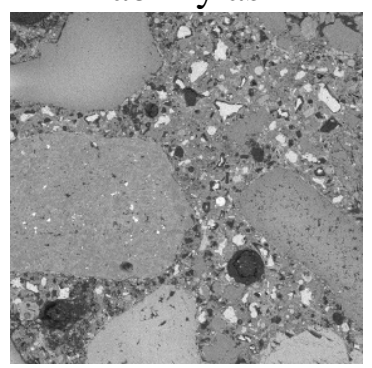

Lab Fly ash

Figure 9.16: Representative images for different concrete cured at low temperature

Figure 9.17 summarizes the results of the ratio of surface to bulk average porosity for all four cases. It was very consistently seen in all the images studied that ratio of surface to bulk porosity of fly ash specimens was less than the respective control specimens, which is evident in the average results also. This was even evident in the scaling results of the low temperature study (unlike the control specimens) as the scaling performance of the fly ash concrete was improved with a decrease in temperature. 


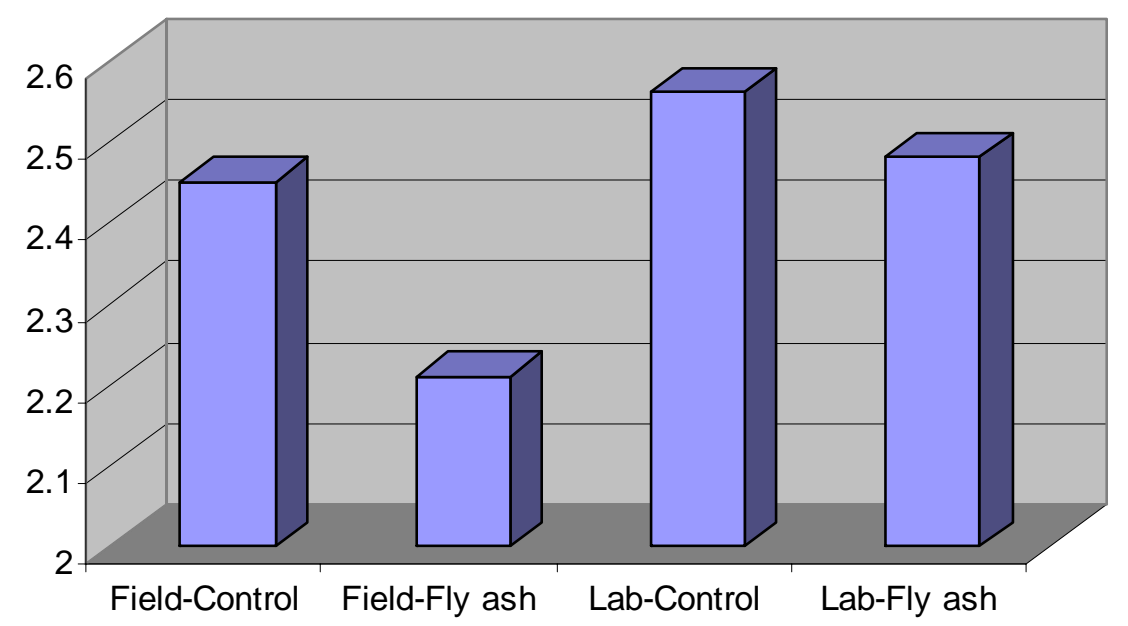

Figure 9.17: Ratio of surface to bulk porosity for different concrete

All of the above results confirm that at low temperature the fly ash concrete with lower slump can develop better microstructure (denser) than normal temperature cured concrete. Hence, there should not be any direct negative implication for using fly ash at low temperature in pavement construction, for climatic conditions similar to Indiana. These are deductions based on the specimens studied but, as mentioned earlier, this behavior is sensitive to material properties and might change with the type of cement and fly ash. Moreover, an increase in slump could also change these results significantly. However, at least it can be said that, certainly the effect of low temperature curing is not detrimental in terms of scaling performance of fly ash concrete when simulating the actual pavement conditions. Further results, described in the next chapter will address the issue of the discrepancy between the laboratory and field scaling performance of fly ash concrete. 


\subsection{Summary}

Study of low temperature mixing and curing resulted in the following observations.

- Low temperature curing could influence significantly the setting time of concrete containing fly ash.

- There is no detrimental effect of low temperature curing on the scaling performance of fly ash concrete. In the current study, improvement in the surface microstructure and the scaling results was observed for concrete containing fly ash.

- The notion of higher bleeding and lower strength gain for the fly ash concrete, leading to poor durability performance does not seem to confirm with the various studies performed. 


\title{
CHAPTER 10: DISCREPANCIES BETWEEN LABORATORY RESULTS AND FIELD OBSERVATIONS RELATING TO SCALING OF CONCRETE CONTAINING SCM
}

\begin{abstract}
10.1. Introduction
Chapter 9 concluded that there is no significant influence of curing temperature on the scaling of concrete containing fly ash or SCM (Supplementary Cementitious Materials). The laboratory tests on the influence of the conditioning periods on scaling revealed that even after 56 days (i.e., 28 days of moist curing and 28 days of drying) concrete containing fly ash can scale more than the control mixture. This would suggest that the pavements containing fly ash even constructed before October $15^{\text {th }}$ could be prone to scaling damage. However, in reality, scaling of mixtures containing fly ash is rarely observed in Indiana (Byers, 2003). In addition, studies on the scaling conducted in the laboratory and the field indicate that the laboratory procedure is far more severe than concrete may be exposed to in the field for the climatic conditions similar to state of Indiana.
\end{abstract}

This chapter attempts to address the discrepancy between the laboratory results and field performance of concrete containing SCM in regard to scaling and discusses possible reasons for such discrepancy. To address the source of this discrepancy, first a brief literature review was performed. In addition, a telephone survey was conducted to ascertain the experience of the twelve neighboring states with respect to the scaling of concrete containing SCM. Five parameters were suggested to be responsible for the 
difference between the laboratory and field performance. Finally, risk analysis was used to determine the probability of scaling in concrete for climatic conditions of Indiana.

\subsection{Literature Review Expressing Discrepancy Between Laboratory and Field}

\section{Performance for Scaling of Concrete Containing SCM}

Many researchers have determined that the scaling resistance of concrete containing SCM is higher than that of plain OPC concrete, when studied in the laboratory using standard laboratory procedure ASTM C 672. On the other hand, although many concrete pavements in the United State contain SCM, no major case of scaling has been reported in the field (at least for typical replacement levels of cement with fly ash). Very little correlation was observed between the two data sets. Field scaling results obtained by many researchers (Afrani and Rogers, 1994 and Hooton and Boyd, 1997) have shown satisfactory performance despite poor laboratory results for concrete containing slag. Despite severe scaling damage observed in laboratory, Bouzoubaâ (2002) reported satisfactory performance of the side-walks made up of High Volume Fly ash concrete (HVFA), after four winters with more than 400 cycles of freezing and thawing combined with numerous applications of deicing salts. Thus, it can be concluded that ASTM C 672 is a very severe test that may underestimate deicing salt scaling resistance of HVFA concrete in actual field applications. Thomas (1997) performed extensive field survey of scaling resistance of fly ash concrete pavement to ascertain long term performance. The results of this survey are summarized in Figure 10.1. 


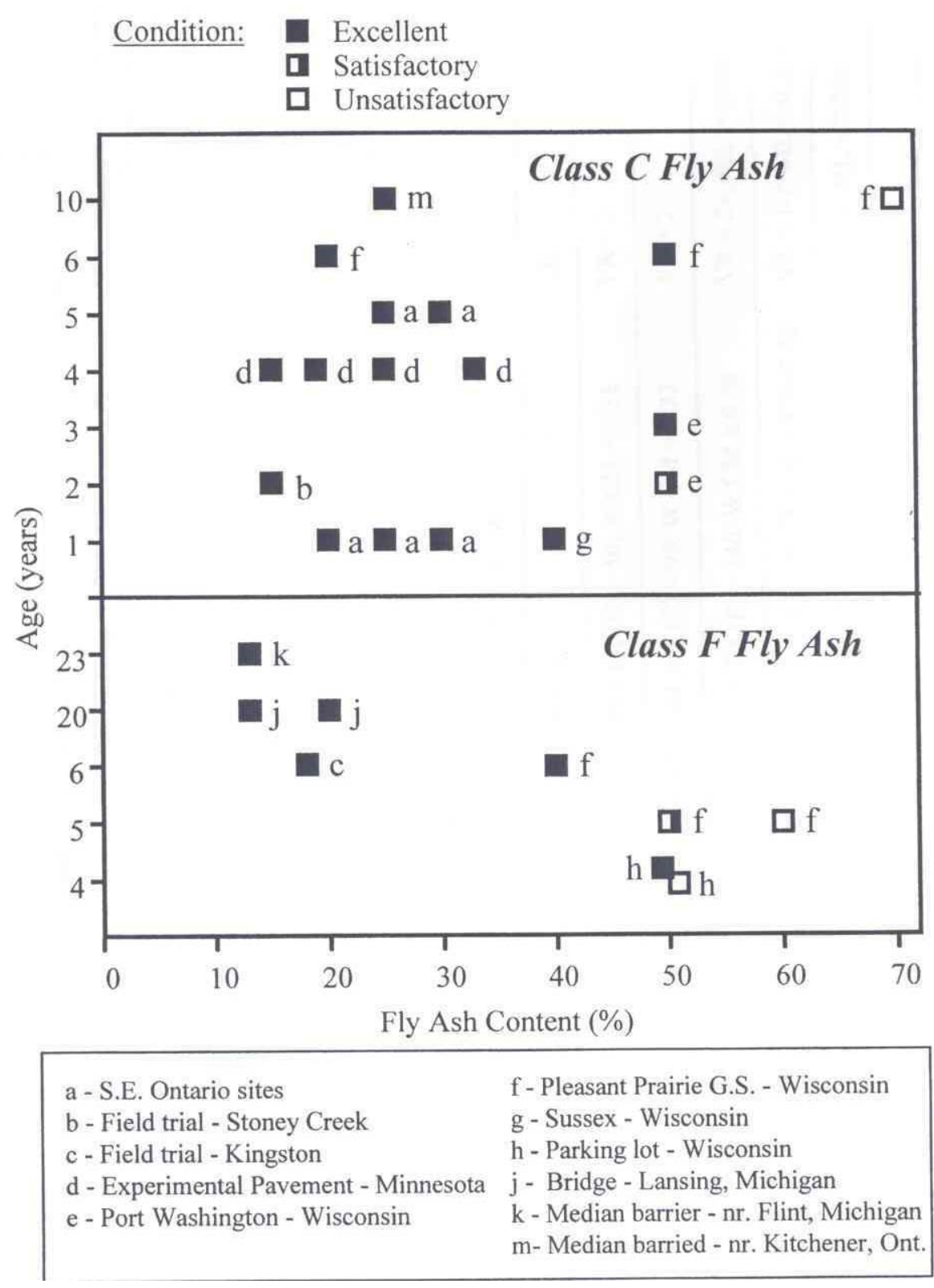

Figure 10.1: Results from field observation of scaling of concrete containing fly ash (Thomas, 1997)

It is evident that most concrete containing fly ash performed well in very severe climates even after several years of exposure. Only a few pavements with very high 
replacement levels of fly ash had shown some surface scaling damage. Figure 10.2 provides images presenting excellent field performance of 27 and 12 years old concrete pavements.

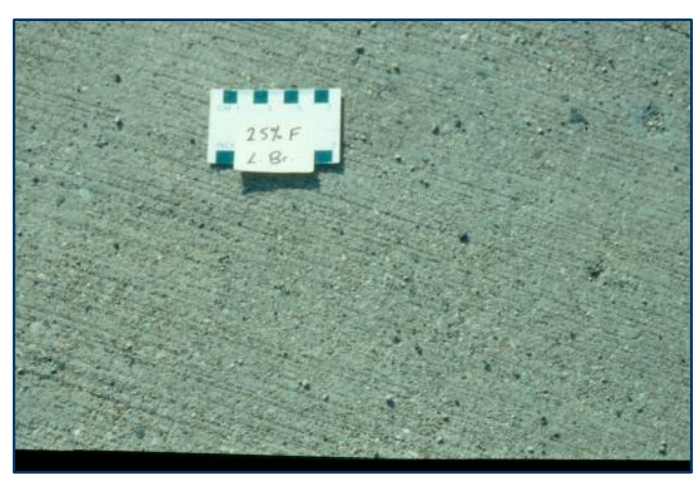

(a)

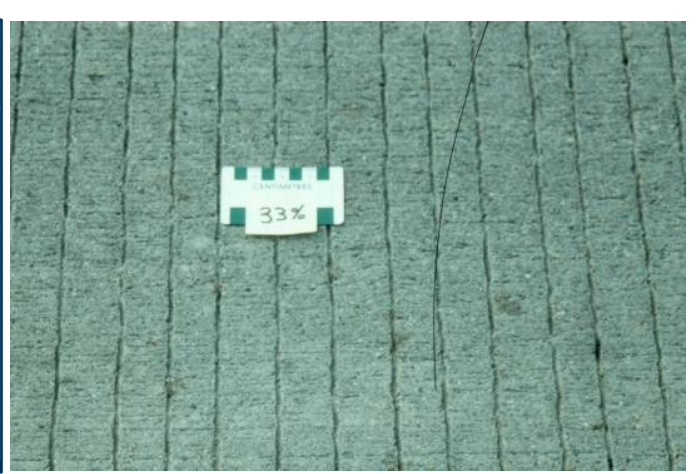

(b)

Figure 10.2: (a) Lansing bridge constructed in 1977 with $20 \%$ class $\mathrm{F}$ fly ash, and (b) U.S. Highway 52 constructed in 1992 with 33\% fly ash (Thomas, 2000)

\subsection{Survey of Field Performance of Concrete Containing SCM in Different States}

\section{Relating to Issues of Scaling}

It is well known that scaling is highly dependent on local environmental conditions including minimum air temperature, frequency of precipitation and the number of freeze-thaw cycles (Studer, 1993 and Jacobsen et al., 1997B). Therefore it is important to collect the information about field performance of pavements surrounding Indiana. A telephone survey was conducted to collect information regarding use of supplementary materials, in late fall construction season, from the twelve states neighboring Indiana. The states were chosen based on climatic and geographical similarities as shown in Figure 10.3. Most of the states selected for the survey are located 
at the same or at higher latitudes from Indiana. Additionally, the state of Kansas was also selected due to extensively reported scaling problems.

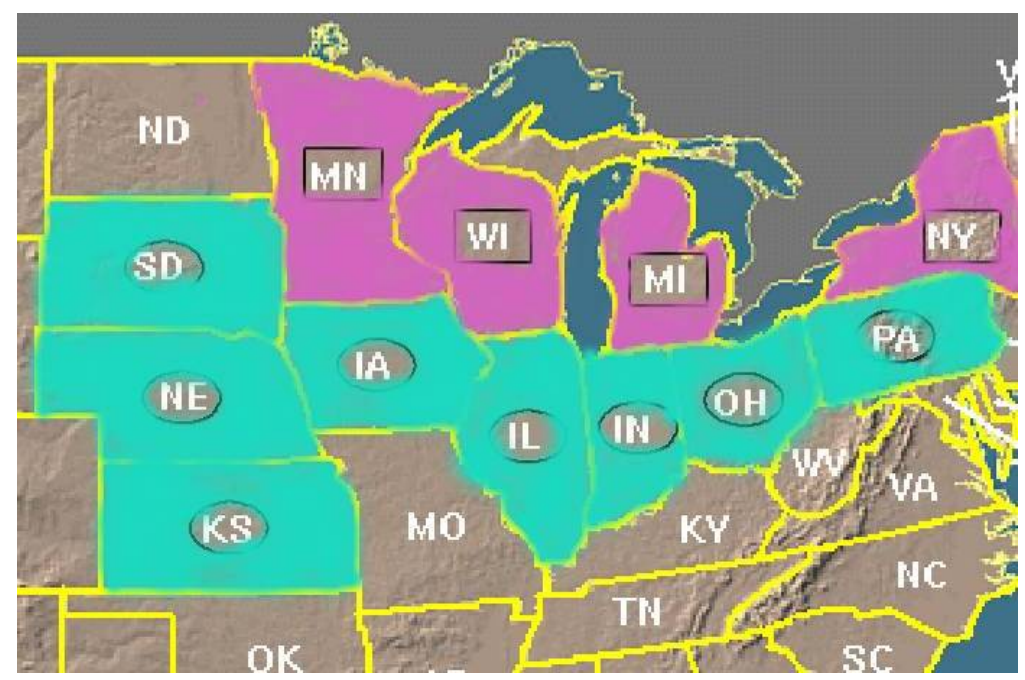

Figure 10.3: States selected for scaling problem survey

A brief summary of all the information collected is shown in Table 10.1. Additionally, any specific measure taken by the state for construction during late fall/low temperature season is also reported. This Table is not an exhaustive list of all the details on scaling. However, in general most of the states that had the potential of having some information about scaling were contacted and hence, the information collected should give a good "average" indication of the problem. 
Table 10.1: Summary of information on scaling obtained from 12 states surrounding Indiana

\begin{tabular}{|c|c|c|c|c|}
\hline $\begin{array}{c}\text { State \& } \\
\text { Contact } \\
\text { Person (see } \\
\text { references for } \\
\text { details) }\end{array}$ & $\begin{array}{l}\text { Restriction } \\
\text { on use of fly } \\
\text { ash /slag }\end{array}$ & $\begin{array}{l}\text { Scaling problem } \\
\text { due to fly ash } \\
\text { (reasons for } \\
\text { general scaling) }\end{array}$ & $\begin{array}{c}\text { Report } \\
\text { available } \\
\text { (type of the } \\
\text { report) }\end{array}$ & $\begin{array}{l}\text { Pavement } \\
\text { Surface } \\
\text { Treatments } \\
\text { for late fall }\end{array}$ \\
\hline $\begin{array}{l}\text { Indiana } \\
\text { (Mr. Zink, E \& } \\
\text { B Paving) }\end{array}$ & $\begin{array}{l}\text { Yes } \\
\left(\text { October } 15^{\text {th }}-\right. \\
\left.\text { April } 1^{\text {st }}\right)\end{array}$ & None & $\begin{array}{l}\text { YES (one } \\
\text { study done in } \\
\text { late fall with } \\
\text { fly ash) }\end{array}$ & $\begin{array}{l}\text { Normal curing } \\
\text { compound }\end{array}$ \\
\hline $\begin{array}{l}\text { Illinois } \\
\text { (Mr. Dirks, } \\
\text { IDOT) } \\
\text { (Mr.Voigt, } \\
\text { ACPA) }\end{array}$ & $\begin{array}{l}\text { No } \\
\text { (Removed } \\
\text { since 2002) }\end{array}$ & None & No & $\begin{array}{l}\text { Application of } \\
2 \text { coats of } \\
\text { linseed oil }\end{array}$ \\
\hline $\begin{array}{l}\text { Iowa } \\
\text { (Mr. Henson, } \\
\text { Iowa DOT) }\end{array}$ & $\begin{array}{l}\text { No } \\
\text { (Removed } \\
\text { since 1997) }\end{array}$ & $\begin{array}{l}\text { None (one } \\
\text { problem mainly } \\
\text { due to finishing } \\
\text { issue) }\end{array}$ & No & $\begin{array}{l}\text { Normal curing } \\
\text { compound }\end{array}$ \\
\hline $\begin{array}{l}\text { Kansas } \\
\text { (Mr. Latorella, } \\
\text { ACPA) }\end{array}$ & No & $\begin{array}{l}\text { None (some } \\
\text { problems with } \\
\text { high volume slag } \\
\text { concrete) }\end{array}$ & No & $\begin{array}{l}\text { Normal curing } \\
\text { compound }\end{array}$ \\
\hline $\begin{array}{l}\text { Nebraska } \\
\text { (Mr. } \\
\text { Woolstrum, } \\
\text { DOT) }\end{array}$ & No & None & No & $\begin{array}{l}\text { Until } 6 \text { months } \\
\text { after } \\
\text { construction } \\
\text { no salt } \\
\text { application }\end{array}$ \\
\hline $\begin{array}{l}\text { South Dakota } \\
\text { (Mr. Crow, } \\
\text { ACPA) }\end{array}$ & $\begin{array}{l}\text { No } \\
\text { (replacement } \\
\text { of } 18 \% \text { only) } \\
\end{array}$ & None & No & $\begin{array}{l}\text { Normal curing } \\
\text { compound }\end{array}$ \\
\hline $\begin{array}{l}\text { Wisconsin } \\
\text { (Mr. Parry, } \\
\text { WisDOT) }\end{array}$ & $\begin{array}{l}\text { No } \\
\text { (Removed } \\
\text { since 1994) }\end{array}$ & $\begin{array}{l}\text { None (one major } \\
\text { problem with } \\
\text { high volume slag } \\
\text { concrete } \\
\text { constructed in } \\
\text { summer) }\end{array}$ & No & $\begin{array}{l}\text { Normal curing } \\
\text { compound }\end{array}$ \\
\hline
\end{tabular}


Table 10.1 continued

\begin{tabular}{|c|c|c|c|c|}
\hline $\begin{array}{c}\text { State \& } \\
\text { Contact } \\
\text { Person (see } \\
\text { references for } \\
\text { details) } \\
\end{array}$ & $\begin{array}{l}\text { Restriction } \\
\text { on use of fly } \\
\text { ash /slag }\end{array}$ & $\begin{array}{c}\text { Scaling } \\
\text { problem due to } \\
\text { fly ash (reasons } \\
\text { for general } \\
\text { scaling) }\end{array}$ & $\begin{array}{c}\text { Report } \\
\text { available } \\
\text { (type of the } \\
\text { report) }\end{array}$ & $\begin{array}{l}\text { Pavement } \\
\text { Surface } \\
\text { Treatments } \\
\text { for late fall }\end{array}$ \\
\hline $\begin{array}{l}\text { Minnesota } \\
\text { (Mr. Snyder \& } \\
\text { Mr. Zeller, } \\
\text { CPAM) }\end{array}$ & No & $\begin{array}{l}\text { None (six year } \\
\text { back one major } \\
\text { problem due to } \\
\text { aggregates) }\end{array}$ & $\begin{array}{l}\text { Yes (showing } \\
\text { effects of bad } \\
\text { const. } \\
\text { practices on } \\
\text { scaling) }\end{array}$ & $\begin{array}{l}\text { Application of } \\
2 \text { coats of } \\
\text { linseed oil, } \\
\text { during late fall } \\
\text { replacement of } \\
\text { fly ash } 1: 4 / 3^{\text {rd }}\end{array}$ \\
\hline $\begin{array}{l}\text { Michigan } \\
\text { (Mr. Branch, } \\
\text { DOT) }\end{array}$ & $\begin{array}{l}\text { Yes } \\
\left(\text { October } 1^{\text {st }}-\right. \\
\left.\text { April } 1^{\text {st }}\right)\end{array}$ & $\begin{array}{l}\text { None (Some } \\
\text { problems due to } \\
\text { improper curing) }\end{array}$ & No & $\begin{array}{l}\text { Normal curing } \\
\text { compound }\end{array}$ \\
\hline $\begin{array}{l}\text { Ohio } \\
\text { (Mr. Struble } \\
\text { DOT) }\end{array}$ & $\begin{array}{l}\text { Yes } \\
\text { (October } 15^{\text {th }}- \\
\left.\text { April } 1^{\text {st }}\right)\end{array}$ & $\begin{array}{l}\text { None (one } \\
\text { problem on } \\
\text { bridge deck with } \\
\text { fly ash ) }\end{array}$ & No & $\begin{array}{l}\text { Normal curing } \\
\text { compound }\end{array}$ \\
\hline $\begin{array}{l}\text { Pennsylvania } \\
\text { (Mr. } \\
\text { Malashkie, } \\
\text { DOT) }\end{array}$ & No & None & None & $\begin{array}{l}\text { Linseed oil } \\
\text { was being } \\
\text { used but not } \\
\text { any more }\end{array}$ \\
\hline $\begin{array}{l}\text { New York } \\
\text { (Mr. Streeter, } \\
\text { DOT) }\end{array}$ & No & $\begin{array}{l}\text { Yes (one major } \\
\text { problem in fall } \\
2003 \text { ) }\end{array}$ & $\begin{array}{l}\text { Yes } \\
\text { (problems in } \\
\text { most bridge } \\
\text { decks) } \\
\end{array}$ & $\begin{array}{l}\text { Normal curing } \\
\text { compound }\end{array}$ \\
\hline
\end{tabular}

The results obtained from individual states are discussed in more detail below.

Indiana: In Indiana, fly ash and ground granulated blast furnace slag (GGBFS) are not allowed in pavements construction from October $15^{\text {th }}$ to April $1^{\text {st }}$. Therefore, hardly any documented evidence for the use of these materials in cold climates in concrete pavement construction is available. One of such exception was a test segment of US24 was constructed between Wabash and Huntington Indiana by E \& B Paving (1999), in which fly ash was used after October $15^{\text {th }}$. In this study related to maturity, fly ash was used till November $10^{\text {th }}$ and up to minimum temperatures of $-1.5^{\circ} \mathrm{C}\left(29.3^{\circ} \mathrm{F}\right)$ and 
rising. After four years of service, that pavement did not show any major signs of scaling on that segment (Zink, 2004). As far as scaling of plain concrete is concerned, some dusting and scaling was observed on US231 pavement constructed during late fall (Nantung, 2003). The reason for the scaling was sudden drop in temperature (high rate of freezing) during night time, which caused formation of weak surface layer. Therefore, this was not the typical scaling generated due to application of deicer salts, but more like dusting where weak surface layer came off quickly. It was extrapolated from this experience that fly ash concrete would be more susceptible to this kind of problems due to slower setting; however, previous chapter confirmed that there is no detrimental effect of low temperature curing on concrete containing fly ash.

Illinois: In 2001 IDOT removed the restrictions on use of fly ash and GGBFS in cold weather conditions. Even before that, fly ash was allowed to be used in a few projects in Chicago during late fall season, but required with special permission. No major problem of scaling has been reported with IDOT. As a precautionary measure, it is specified that two coats of boiled linseed oil $\left(50 \operatorname{yard}^{2} / 1\right)$ shall be used on all the pavements constructed in late fall season (October $15^{\text {th }}$-April $15^{\text {th }}$ ). It is strongly believed that such treatment protects the pavement very well from freeze-thaw and scaling damage for the first winter (Dircks, 2004).

Iowa: Since 1997 Iowa removed the restriction on the use of fly ash and GGBFS during the late fall construction season. No major problem of scaling has been observed in the state so far, (Henson, 2004). Normal white pigment based curing compound is used for curing during late fall season. 
Kansas: Due to abundance of highly reactive aggregates, state of Kansas has major problems with alkali-silica reaction (ASR). To combat this issue, minimum 30\% to $40 \%$ of GGBFS is being used in normal pavement construction. This addition of high volume of slag has created some problems of mortar flaking and scaling in last 5 to 6 years. Scaling has been observed for concrete constructed throughout the year, irrespective of season of construction (Latorella, 2004). Hardly any case of scaling was observed for concrete containing $20-25 \%$ SCM placed during late fall construction season. It is reported that good finishing and curing practices had helped in improving scaling resistance of concrete incorporating high volumes of GGBFS.

Nebraska: In Nebraska, it is common to use blended cement that contain class F fly ash. Most of the pavements are being constructed with this type of cement since the restriction on use of fly ash for late fall construction has been removed. As one of the precautionary measures it is specified that salt should not be applied on newly constructed pavement for at least 6 months after construction. If there is a serious safety concern then salt can be applied earlier, but still no scaling has been observed in such cases (Woolstrum, 2004). Normal white pigment based curing compound is being applied on the pavement and no sealing of the pavement is done for the late fall season.

South Dakota: There is no restriction on the use of fly ash as far as the construction season is concerned. The maximum replacement of fly ash by weight of cement is $18 \%$ with $1: 1$ replacement. No major problems of scaling have been reported in the state (Crow, 2004). No other specific measures are specified for concrete protection during winter. 
Minnesota: Fly ash is being used year round, however during the late fall construction season the replacement level of fly ash is increased from 1:1 to 1:4/3. This effectively increases the total cementitious material in concrete. Also, as an additional precautionary measure, a Linseed oil based curing compound is specified for winter construction. Regarding scaling observation, one major problem of scaling was observed (on 28 slabs up to 3 years old) during the winter of 1996 - '97. A detailed study was performed on these slabs by obtaining various field samples and acquiring construction history through surveys. A report (Snyder, 1998) summarizing the results concluded that along with unusual severity of winter, several other factors like non-durable aggregates, air loss due to longer transit time, over finishing, retempering of mix and inadequate curing were the major factors causing wide spread scaling problem. One of the minor factors was the late fall construction season but there was no specific evidence of scaling due to addition of fly ash in such case. Moreover, it should be noted that all scaling incidents were observed for slabs thinner than $200 \mathrm{~mm}\left(8^{\prime \prime}\right)$. In general, however, even in the severe climate of Minnesota the problem of scaling of pavement essentially does not exist. One of the reasons for good scaling resistance of concrete pavement in that state may be the use very low average w/cm of 0.37 specified by Minnesota DOT and the use of low slump. Additionally, machine finishing of these pavements along with higher thickness seem to help in improving scaling resistance.

Wisconsin: Wisconsin has no restriction on use of fly ash or slag since 1994, when they started using maturity as a tool for strength predictions. Up to $30 \%$ fly ash is being used in the field and no major problems of scaling have been observed relating late fall construction season. One problem of scaling was reported on Loomis Road in 
suburban Milwaukee for concrete containing GGBFS that was placed in summer. A detailed study as to the reasons for this poor performance was conducted and submitted by the ACPA (Voigt, 1999). This pavement was constructed in the summer of 1998 and during the first winter most of the concrete with slag (50\% replacement) scaled significantly in comparison to plain concrete. GGBFS concrete had met 28 day strength criteria and later petrography study showed that hardened concrete had air content within specification. The main reasons for scaling were assumed to be lower control over slump of mixture containing slag and improper finishing. Moreover, when almost all laboratory studies have shown that high replacement of cement (50\%) with fly ash or slag would cause excessive scaling, it is not very surprising to have moderate scaling of high volume slag concrete in the field when one or two other factors aggravated the situation.

Michigan: Similar to Indiana, Michigan also has restriction on use of fly ash/slag during late fall construction season. The use of fly ash and slag is prohibited in the Upper Peninsula starting from October $1^{\text {st }}$ and in the Lower Peninsula starting from October $15^{\text {th }}$ until April $1^{\text {st }}$ of the continuing year. A few cases of scaling have been observed which are mainly attributed to poor construction practices. Not a single case has been attributed to use of fly ash or slag (Branch, 2004). In the case of pavements, normal water based curing compound is being used during winter for curing.

Ohio: Ohio is the third state other than Indiana and Michigan, in which there is still a seasonal restriction on use of fly ash and slag. They also have limited experience as far as use of fly ash or GGBFS during late fall is concerned. So far, scaling was observed in one case on a bridge deck in which fly ash was used during late fall construction season (Struble, 2004). Several other incidents of scaling were reported in 
the Cleveland area, but all of them were normal concrete and they scaled mainly due to late fall construction or insufficient air content.

Pennsylvania: In Pennsylvania, there are no restrictions on use of fly ash and slag during late fall construction season. In the past there was a requirement of using linseed oil for sealing of concrete during winter construction but now this restriction has been removed (Malashkie, 2004). Specifications are mainly based on air temperature and various curing guidelines are provided for various temperatures ranges. No major problems of scaling have been reported thus far.

New York: There are no restrictions on the use of fly ash and slag during winter construction and ternary blends of fly ash and silica fume are very common in the high performance concrete mixtures placed during winter. During the winter of 2002 - '03 numerous cases of concrete scaling were observed in bridge decks, side-walks and other flat works in western New York. This was one of the most extreme winters for western New York with precipitation 33\% higher than average and number of freeze-thaw cycles $60 \%$ higher than normal. A report submitted by Mr. Streeter (Streeter, 2003) points out that one of the major reason for bridge deck scaling was late season placement, which did not allow concrete to dry before it was exposed to de-icing salts, which caused scaling even after sufficient curing of the bridge decks. However, not a single pavement showed scaling. Attempt to provide explanations for this behavior is presented in section 10.5.1.

In summary, it can be said that overall a few problems of scaling of concrete containing moderate (up to $30 \%$ ) amounts of fly ash were actually observed in the field. In cases where problems occurred they were mostly attributed to poor construction practices or high volume replacement of cement by supplementary materials. It should 
be noted that all four states which reported some problems of scaling (Minnesota, Wisconsin, Michigan and New York) are situated at higher latitude than Indiana. These states have average minimum temperature about $5-10^{\circ} \mathrm{C}$ lower than the average Indiana temperature, which could be one of the reasons for higher instances of scaling.

Another important finding of this survey is that when scaling was observed, it was mostly observed in the thin slabs and bridge decks, not in pavements. This implies that thickness of the pavement and construction procedures would have strong influence on scaling resistance.

\subsection{Parameters Responsible for Discrepancy Related to Fresh Concrete}

There are certain parameters, which can influence fresh properties of concrete. Several parameters influencing properties of fresh concrete may be responsible for the observed differences between scaling performance of concrete cast in the laboratory and concrete placed in the field. The two major parameters suggested in this section are early age evaporation and finishing of concrete. In the field, due to effect of wind and solar radiation, rate of evaporation can be much higher then that in the corresponding laboratory specimen. This can create significant difference in surface porosity of both concretes. The other parameter is machine (slip form paver) finishing of concrete in comparison to normal hand/trowel finishing in the laboratory. This finishing could also change scaling resistance of surface significantly. 


\subsubsection{Influence of Early Age Evaporation on Scaling and Surface Porosity}

The porosity of concrete surface could be dependent on the cumulative effect of bleeding and evaporation. Specimens with higher amounts of bleeding and lower evaporation loss can develop highly porous surface layer due to the high localized w/cm. To understand the role of surface pore structure and porosity in scaling mechanism, specimens with different amount of evaporation losses were studied.

\subsubsection{Specimen Preparation and Experimental Procedure}

The 1-in. (25-mm) slump mixture proportion shown in Table 7.1 was used to prepare three slab specimens with the dimension of $380 \mathrm{~mm}$ x $190 \mathrm{~mm}$ x $75 \mathrm{~mm}(15$ " x 7.5 " $\mathrm{x} 3$ "). The specimens were prepared following the same procedure as that used to prepare the normal scaling specimens (section 8.2). After finishing, all specimens were weighed and initial mass was recorded. After weighing, one of the slabs was stored under the plastic lid until the time at which it was demolded ( $24 \pm 2$ hours after casting). The other two specimens were placed in an environmentally controlled chamber for 6 hours. The temperature of the chamber was $30^{\circ} \mathrm{C}\left(86^{\circ} \mathrm{F}\right)$ with an average humidity of $45 \%$. Fans within the chamber aided in the evaporation of surface bleed water. One specimen was subjected to an average wind velocity of $27.3 \mathrm{kph}(17 \mathrm{mph})$ and the other to $14.5 \mathrm{kph}(9 \mathrm{mph})$ over the top surface. Details of specimen and water loss are given in Table 10.2. After 6 hours they were kept under plastic sheet until they were demolded (24 \pm 2 hours).

At the end of 24 hours, all three specimens were weighed once again and loss of water was determined. At the time of demolding each slab was weighed again and cut to 
half using a diamond bladed saw to create two $75 \mathrm{~mm}$ x $190 \mathrm{~mm}$ x $250 \mathrm{~mm}(3$ " x 7.5" x 10 ”) test specimens. These specimens were then placed in moist curing room $(98 \pm 2 \%$ $\mathrm{RH}$ ), for two more days and following that they were kept for 3 more days in constant humidity room $(50 \pm 5 \% \mathrm{RH})$ for drying. One half of each slab was used to perform standard scaling test and the other half was used to prepare two SEM specimens for microstructural study.

Table 10.2: Mass of specimens before and after evaporation

\begin{tabular}{|c|c|c|c|c|c|c|c|}
\hline $\begin{array}{c}\text { Specimen } \\
\text { ID }\end{array}$ & $\begin{array}{c}\text { Size of the } \\
\text { specimens } \\
(\mathrm{mm})\end{array}$ & $\begin{array}{c}\text { Wind } \\
\text { speed at } \\
\text { surface } \\
(\mathrm{kph})\end{array}$ & $\begin{array}{c}\text { Initial } \\
\text { Mass } \\
(\mathrm{kg})\end{array}$ & $\begin{array}{c}\text { Final } \\
\text { Mass } \\
(\mathrm{kg})\end{array}$ & $\begin{array}{c}\text { Loss of } \\
\text { water in } \\
24 \mathrm{hrs} . \\
(\mathrm{kg})\end{array}$ & $\begin{array}{c}\text { Loss per } \\
\text { area } \\
\left(\mathrm{kg} / \mathrm{m}^{2}\right)\end{array}$ & $\begin{array}{c}\text { No. of } \\
\text { SEM } \\
\text { specimens }\end{array}$ \\
\hline $3-3$-ah & $\begin{array}{c}250 \times 190 \times \\
75\end{array}$ & 27.3 & 31.59 & 31.16 & 0.43 & 4.53 & 2 \\
\hline $3-3$-am & $\begin{array}{c}250 \times 190 \times \\
75\end{array}$ & 14.5 & 33.74 & 33.32 & 0.42 & 4.47 & 1 \\
\hline $3-3$-an & $\begin{array}{c}250 \times 190 \times \\
75\end{array}$ & 0 & 31.96 & 31.97 & 0.01 & -- & 2 \\
\hline
\end{tabular}

$1 \mathrm{~kg}=2.2 \mathrm{lb} ; 25.4 \mathrm{~mm}=1$ "; $1 \mathrm{kph}=0.62 \mathrm{mph}$

Notation "3-3" represents moist curing and drying duration, respectively. Additionally, the specimens were given the following suffixes: "ah" - high evaporation, "am" - medium evaporation, and "an" - no evaporation. Scaling test was performed on these specimens using the same test procedure as described in section 8.3.2.

\subsubsection{Results from Scaling Study of Evaporation Samples}

The results of scaling study for specimens exposed to different wind speeds (i.e., evaporation rates) at early ages are shown in Figure 10.4. It can be seen that with increase in wind speed, the total scaled mass decreased significantly. This, once again, 
confirms that for very short moist curing and drying period (i.e., at very early ages, less than 10 days) the amount of moisture in the surface layer and the degree to which it influences microstructure is an important parameter influencing scaling.

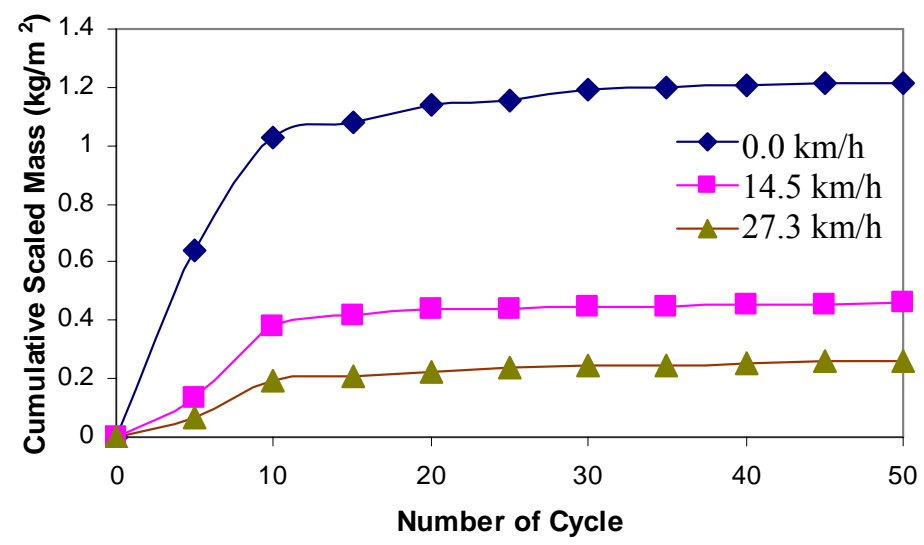

Figure 10.4: Total mass scaled for samples exposed to different wind velocities

Figures 10.5(a) and (b) show cumulative scaled mass versus wind velocity and versus total water loss, respectively. From Figure 10.5(b) it seems that rate of evaporation would have exceeded the bleeding rate for the specimen (3-3-ah) subjected to $27.3 \mathrm{~km} / \mathrm{h}(17 \mathrm{mph})$ wind speed (as indicated by the vertical drop in the trend line), while that may not be the case for specimen (3-3-am) subjected to $14.5 \mathrm{~km} / \mathrm{h}(9 \mathrm{mph})$ wind speed. It can be hypothesized that in specimen 3-3-ah high wind speed could have caused quick water loss by the generation of higher capillary stresses. This higher capillary stresses could have helped in generating a denser microstructure. Therefore, water loss being the same, lower scaling was observed in the specimen 3-3-ah compared to specimen 3-3-am. Thus effect of evaporation might provide a good explanation for the absence of scaling observed in the actual pavements at early or later ages. 


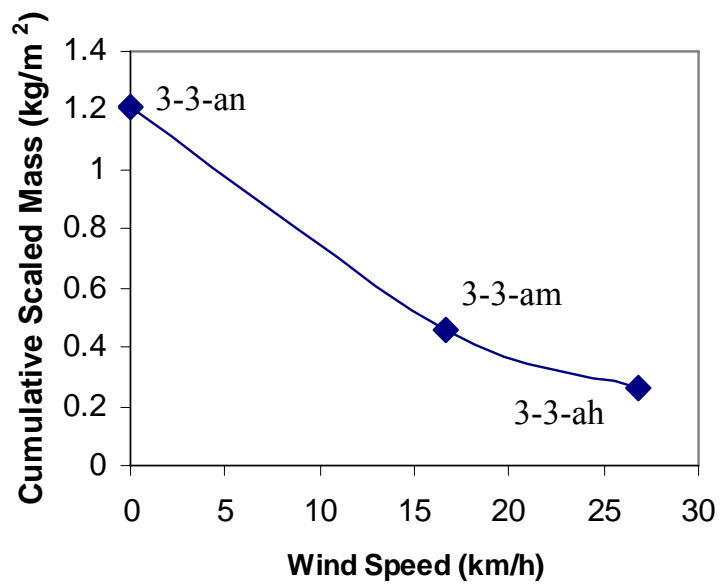

(a)

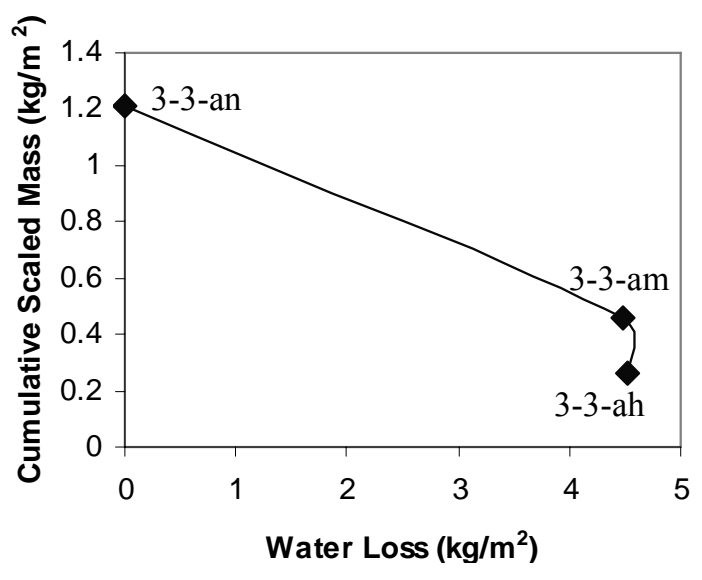

(b)

Figure 10.5: (a) Scaled mass for different wind speeds and (b) scaled mass for different total water loss

Higher wind speed (i.e., higher rate of evaporation) at very early ages will create changes in surface microstructure during plastic stage and could help in developing better tensile strength at the surface. During this period, because of restraint provided by the form or by the concrete below the surface, there are chances of plastic shrinkage cracking occurring on the surface. At the same time, the continuous evaporation would help in reducing capillary porosity. To confirm this hypothesis detailed microstructural analysis was performed with evaporation samples as described in the next section.

\subsubsection{Microstructural Study of Evaporation Samples}

A series of SEM specimens (two for each evaporation rate) were prepared following procedure described in section 8.2.2. Images of microstructure were collected and analyzed to obtain porosity gradients. The values of individual porosities were normalized against the minimum (or bulk porosity) and are plotted in Figure 10.6. 
Surprisingly, for all three cases, the ratio of surface to bulk porosity was almost in the same range.

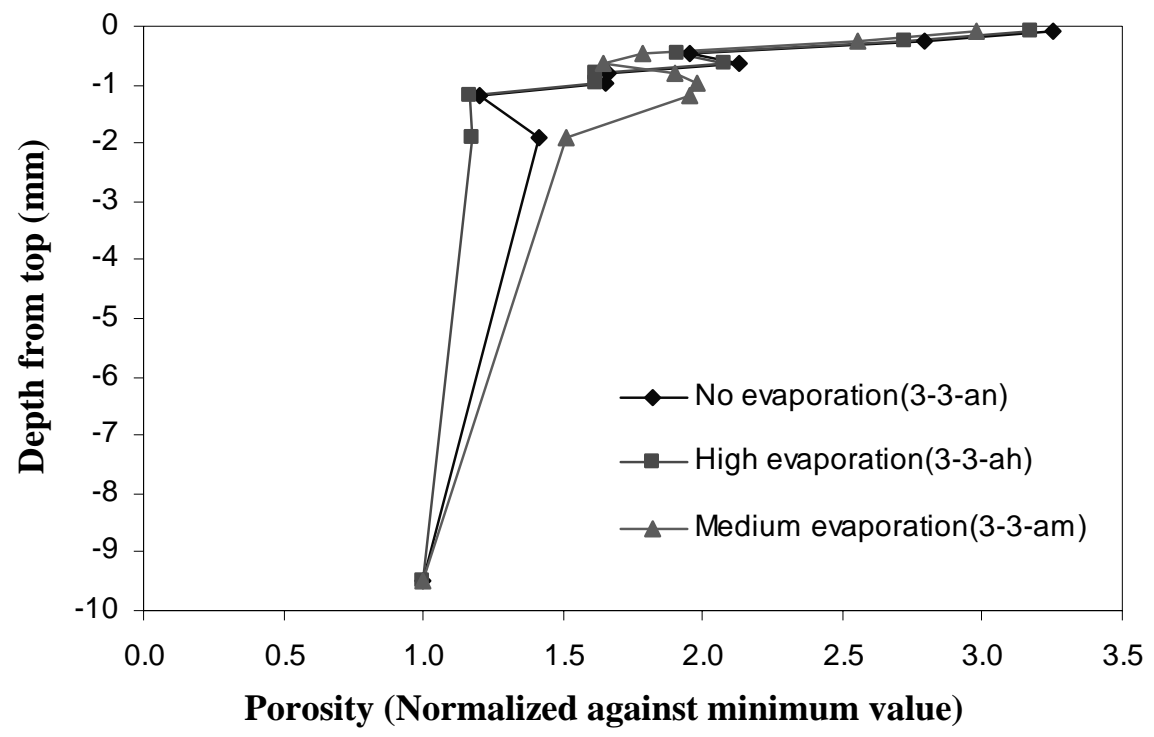

Figure 10.6: Porosity gradient for evaporation specimens, normalized against minimum value

During image acquisition it was observed that higher amount of cracking was presented in the samples subjected to high evaporation, while minimal or no cracking was observed in the specimen without any evaporation losses. The crack widths were found to be higher for the sample 3-3-ah than for sample 3-3-am. Since all these specimens were exposed to similar sample preparation, it can be said that these cracks would not have formed during oven drying or any other sample preparation procedures. In addition, these cracks are only visible in the surface region of the specimen. Thus, it can be said that these cracks are most likely plastic shrinkage cracks formed during evaporation from the surface. To confirm these observations and to find true capillary porosity the following procedure was adopted. 

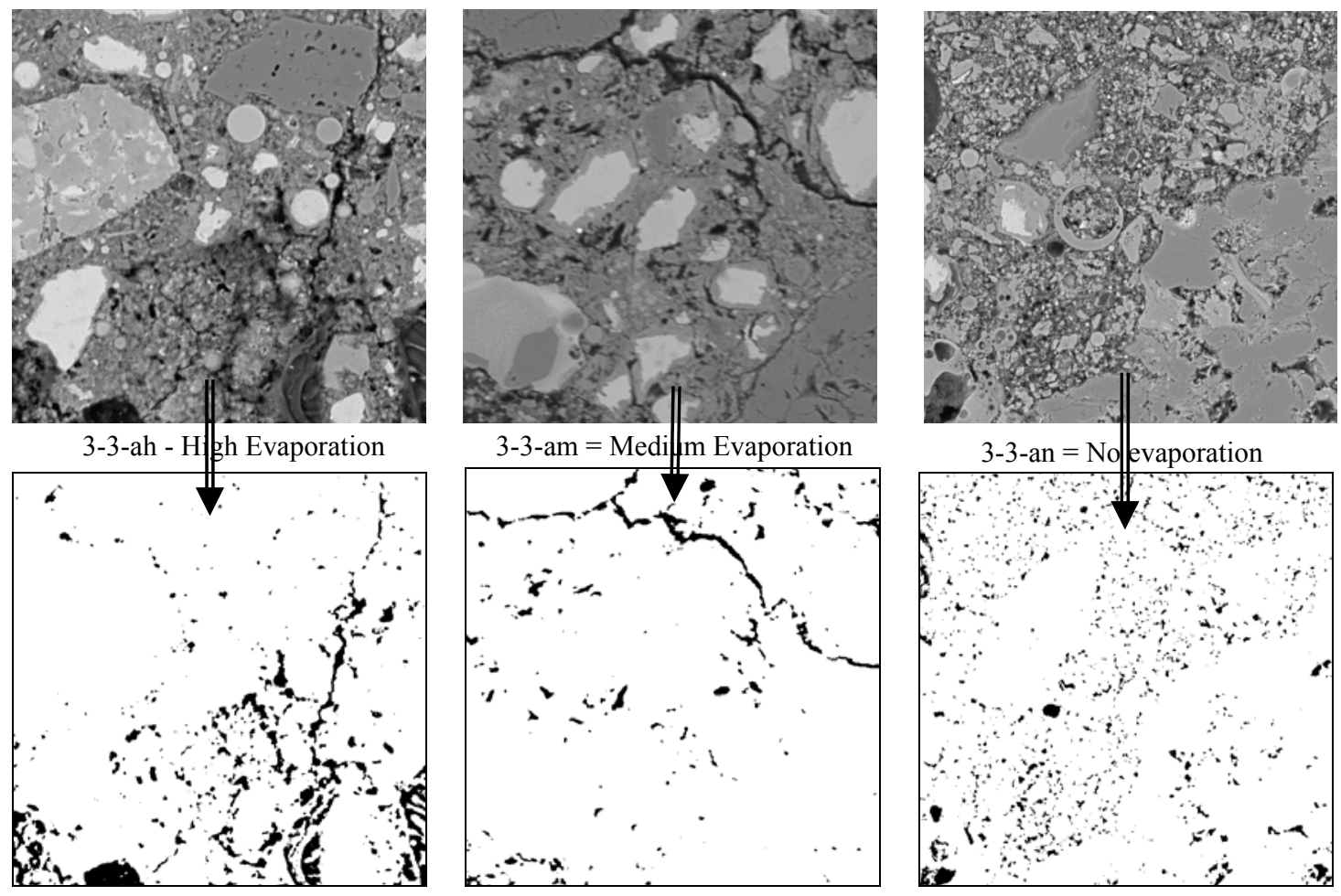

Figure 10.7: Segmentation of images at lower threshold

Figure 10.7 shows typical images obtained from three specimens. The images were segmented at lower brightness threshold value (60 to 65) to distinguish the distinct features. It can be easily seen that cracks are more pronounced in the case of specimen 33-ah, than in the specimen 3-3-am. Moreover, in both of these specimens the matrix is comparatively denser while in the case of specimen 3-3-an, no cracks are observed and the matrix has more distributed pores (capillary porosity). It is believed that higher capillary porosity and lower tensile strength of this matrix is responsible for higher F-T and scaling damage. Thus, although total porosity would be similar for all the three specimens, the strength of the matrix would be different, and therefore scaling performance was different. To eliminate the effect of plastic shrinkage cracking and 
localized difference in air voids, porosities of the images were obtained by eliminating these features with different filters and paint tools. This modified porosity gradients for 3-3-an and 3-3-ah specimens are plotted in Figure 10.8.

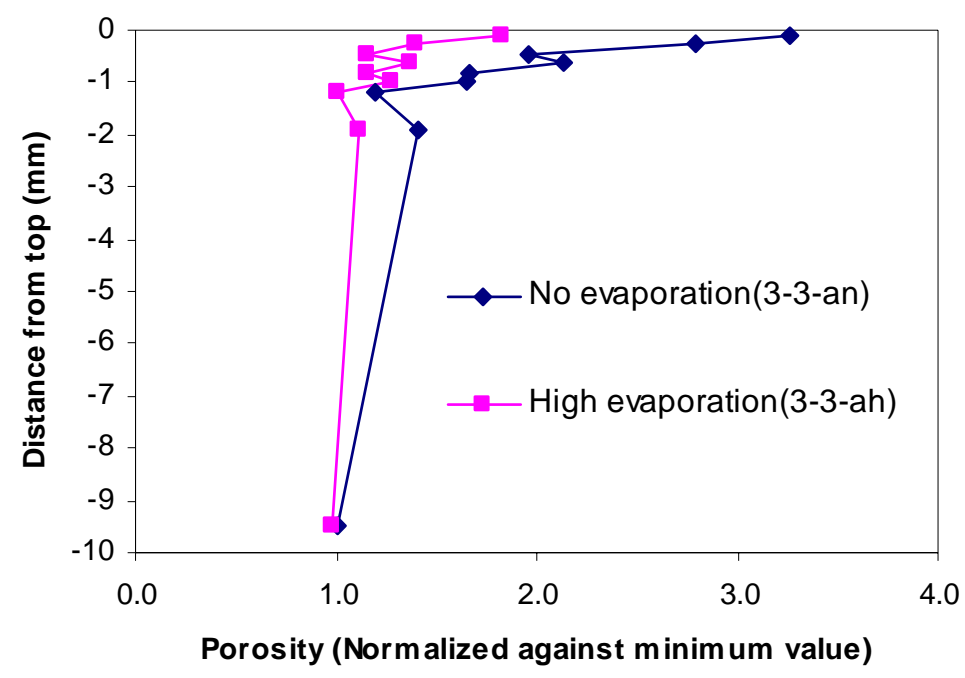

Figure 10.8: Modified porosity gradients for high and no evaporation specimens

Figure 10.8 shows that surface capillary porosity of the specimen 3-3-an is almost twice the capillary porosity of the specimen 3-3-ah. Therefore, it can be hypothesized that young field concrete exposed to wind and solar radiation would have higher evaporation rates. This will result in removal of remove excess water from the surface and will reduce potential for scaling damage as compared to laboratory specimens.

\subsubsection{Finishing Operation- Hand Finishing Versus Machine Finishing}

Based on the literature review and the survey of the DOT representatives, it was realized that finishing could influence scaling results significantly. There is not much difference in scaling results of concrete with different types of hand finishing (Luther et al., 1994) but certainly, machine finishing seems to improve scaling resistance in 
comparison with manually-finished concrete (Thomas, 1997). It is difficult to assess this influence experimentally, so data from literature review and survey was used.

Slip-form paving or machine finishing could help in improving scaling resistance due to following reasons. For proper slip-form paving operation slump should be limited to maximum of 2" $(50 \mathrm{~mm})$ and hence, the overall bleeding in the concrete could be reduced. Additionally, due to machine finishing there are very few chances of retempering of the surface with additional water thus, making the surface weaker due to a local increase in the $w / \mathrm{cm}$ ratio. At the same time, in the case of manually-finished concrete there are chances of over-finishing, which can influence air void structure of concrete surface. Moreover, tines created in the actual pavement would additionally help in increasing the evaporation rate and thereby could make the surface denser. The microstructural study of the simulated field and laboratory samples confirmed that field surface tend to be less porous than comparative laboratory specimen. To support these reasoning three different finding in this regard are mentioned below.

As mentioned earlier, extensive study was carried out in Minnesota to determine reasons for poor durability performance of exterior slabs during the winter of 1996-97 (Snyder, 1998). This study revealed that $85 \%$ of the total problems were scaling problem. After detailed investigation it was realized that out of total scaling problems $61 \%$ problems were associated with improper finishing of the concrete. However, not a single problem was in the pavement constructed with slip form paver. This shows importance of finishing, and highlights the fact that poor manual finishing practices can lead to increased scaling. 
Pigeon (1996) studied the effects of surface microstructure on scaling resistance. He studied different wooden trowel finished surface and compared them with sawed surface. He consistently found wooden trowel finished surface more prone to scaling in comparison to sawed surface. Microstructural study confirmed that there is a significant layer of high porosity observed in the hand finished laboratory specimens. Based on this study, it was concluded that poor finishing of the laboratory specimen is the main reason for apparent discrepancies in scaling performance of field and laboratory concrete containing SCM.

In field performance survey of fly ash concrete, Thomas (2000) investigated various slabs and parking garages with scaling problems. He studied 20 different field cases where he found scaling problems in concrete placed and finished by hand in comparison to machine finished concrete. One such case (a parking slab in Wisconsin) is shown in Figure 10.9.

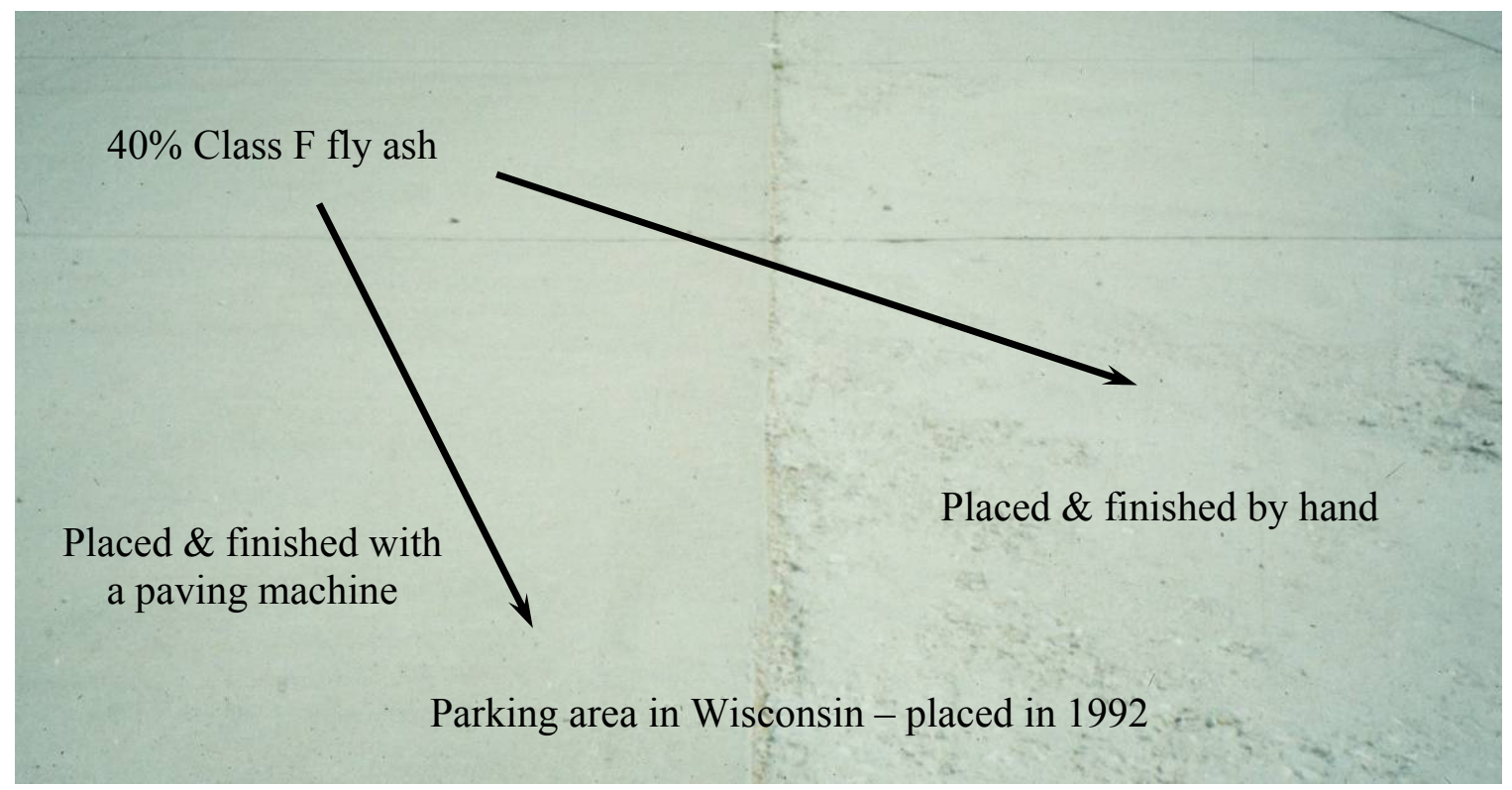

Figure 10.9: Parking slab with differential scaling performance (Thomas, 2000) 
From this Figure it is evident that the portion of the slab placed and finished manually showed very poor resistance to scaling while machine finished segment did not show any scaling. Thus, it can be concluded that the finishing operations conducted by slip form paver is one of the important parameter in improving scaling resistance of concrete, with and without SCM.

\subsection{Parameters Responsible for Discrepancy Related to Hardened Concrete}

There are several parameters which could influence the scaling performance of concrete in the hardened stage. One of these parameters (already considered in the previous chapter) is the size of the specimen. Second parameter is the number of consecutive F-T cycles and intermittent drying. Third parameter is the actual procedure for application of salt solution on the pavement, which is very much different from the procedure followed in ASTM C 672. The influence of these parameters is discussed in detail in the next section.

10.5.1. Influence of Size of the Specimen on Minimum Surface Temperature, Rate of Freezing and Scaling

The size of specimen used in the laboratory study (75 $\mathrm{mm}$ x $190 \mathrm{~mm} \times 250 \mathrm{~mm})$ is considerably smaller in comparison to actual pavement section. In previous chapter using (300-mm deep specimens), it was shown that large thermal mass and single direction heat flow could change scaling behavior. For large size specimens, the rate of freezing and minimum surface temperature observed are different from that observed in the corresponding small specimens even at the same ambient temperature. Therefore, 
further study was performed with different sizes of specimens to determine the influence of size of specimen on rate of freezing and scaling.

\subsubsection{Specimen Preparation and Experimental Procedure}

For this study, mold previously prepared for 300-mm deep specimens, were used. Each mold was partitioned vertically (using 2-inch thick Styrofoam ${ }^{\mathrm{TM}}$ sheets) to create total of three slabs. The area of the each slab was $11 " \mathrm{x} 11 "\left(0.078 \mathrm{~m}^{2}\right)$, which is much higher than minimum area $\left(75 \mathrm{in}^{2}\right.$ or $0.048 \mathrm{~m}^{2}$ ) specified by ASTM C 672. A wooden pole was installed at the center of the each slab and thermocouples were attached to it at various depths. Figure 10.10 shows both molds with partitions and thermocouples pole installed. To create slabs with different thicknesses (ranging from 55 to $245 \mathrm{~mm}$ ), paper waste was used to fill up the bottom portions of the molds so that the top of all the slabs was at the same level, as shown in the section in Figure 10.10.

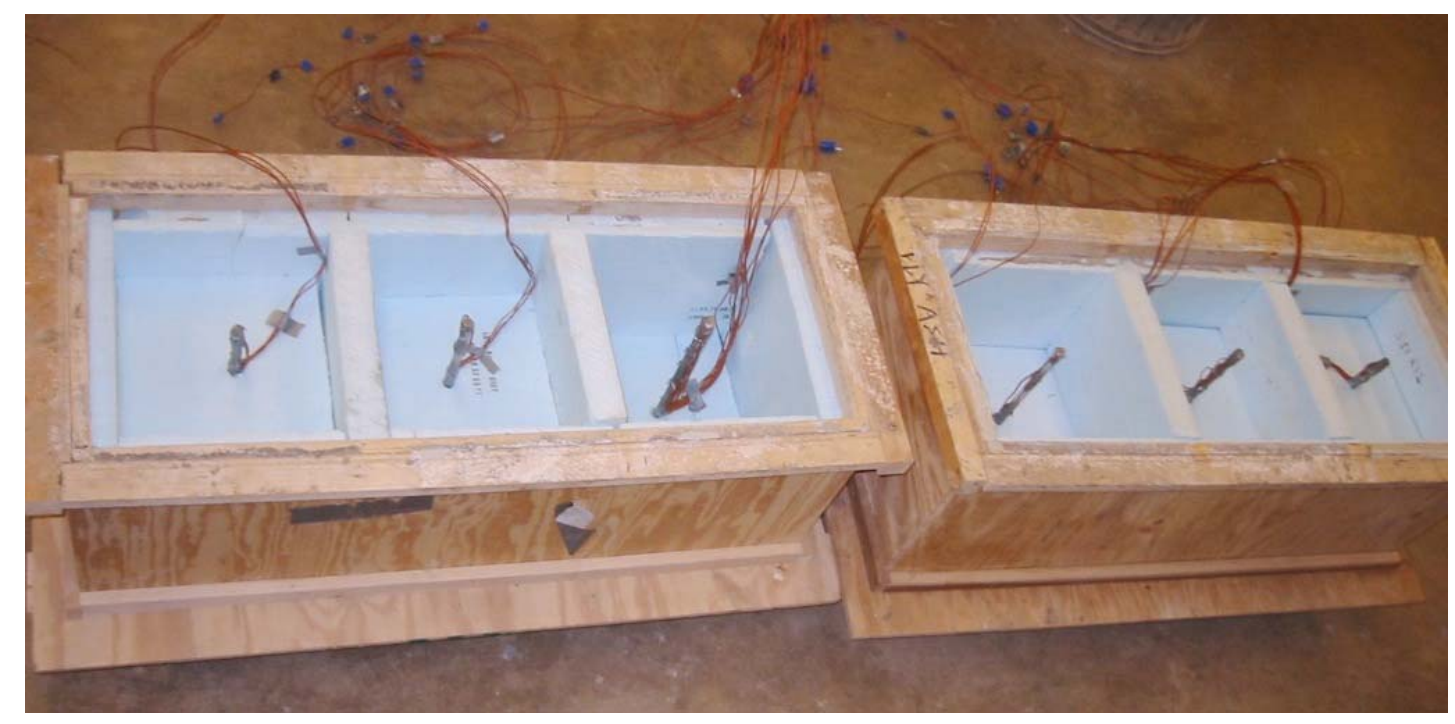

Figure 10.10: Partitioned mold for size effect study 
After partitioning, all joints were sealed using duct tape. Three to nine thermocouples (depending on the depth of the slab) were attached to each central pole using duct tape to obtain the temperature profile at various locations within the slab. All the thermocouple wires were "channeled" out from the mold and into one corner of each slab. Details regarding the number and position of thermocouples for specimens of various depths are shown in Table 10.3. The depth of the each partition was kept 1" $(25 \mathrm{~mm})$ deeper than the specified specimen depth mentioned in the Table. The bottom 1 " of each slab was filled with coarse aggregates (cooled to $1^{\circ} \mathrm{C}$ or $33.8^{\circ} \mathrm{F}$ ) to simulate boundary conditions at the bottom of a field slab. Form release agent was applied on all the sides. Figure 10.11 shows one of the molds, in its final stage before casting the concrete.

The mixture proportions shown in Table 7.1 for $25 \mathrm{~mm}$ (1") slump specimen were used in this study. All aggregates were stored in $1^{\circ} \mathrm{C}$ room 48 hours prior mixing. The mixing, casting and finishing was also identical to large size specimen study, as described in section 9.2.6.2. Slabs were stored in the cold room $\left(1^{\circ} \mathrm{C}\right)$, until they achieved maturity equivalent to $550 \mathrm{psi}(3.8 \mathrm{MPa})$ at which point they were moved to F-T chamber for 50 cycles of freezing and thawing with salt solution on the surface. Temperature data was collected continuously throughout the test; two additional thermocouples were placed to measure the room temperature. 

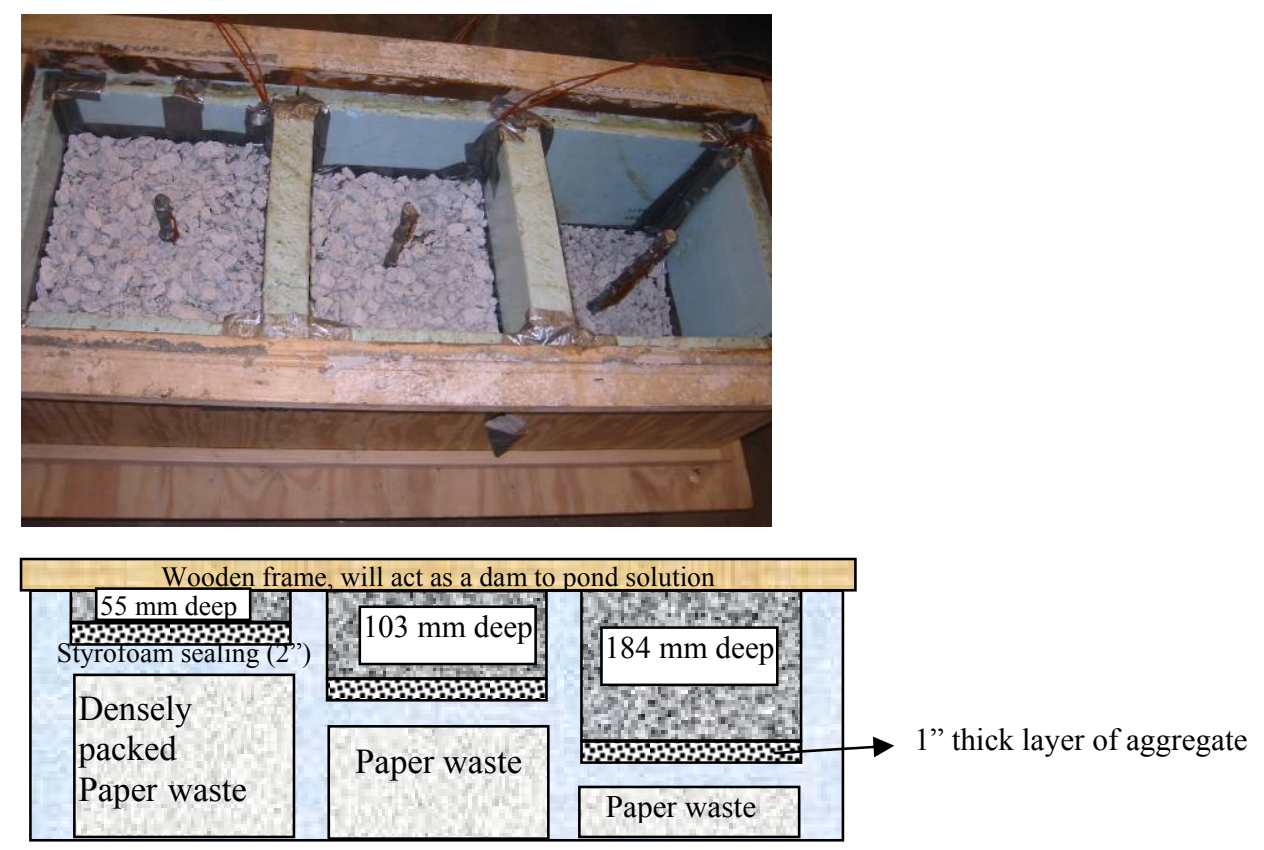

Cross section of the mold

Figure 10.11: Final mold before mixing, with 1" thick base of aggregates

Table 10.3: Summary of specimens and results of size effect study

\begin{tabular}{|c|c|c|c|c|c|}
\hline $\begin{array}{l}\text { Depth of } \\
\text { specimen } \\
(\mathrm{mm})\end{array}$ & $\begin{array}{c}\text { No. and positions of } \\
\text { thermocouples from } \\
\text { top (mm) }\end{array}$ & $\begin{array}{c}\text { Minimum } \\
\text { temp. at } 2 \\
\left.\text { mm ( }{ }^{\circ} \mathrm{C}\right) \\
\end{array}$ & $\begin{array}{c}\text { Maximum } \\
\text { temp. at } 2 \\
\text { mm ( }\left({ }^{\circ} \mathrm{C}\right) \\
\end{array}$ & $\begin{array}{l}\text { Avg. rate of } \\
\text { freezing } \\
\left({ }^{0} \mathrm{C} / \mathrm{hr}\right)\end{array}$ & $\begin{array}{l}\text { Scaling } \\
\text { results } \\
\left(\mathrm{kg} / \mathrm{m}^{2}\right)\end{array}$ \\
\hline 55 & $5(2,8,20,40$ and 50$)$ & -11.5 & 15.2 & -2.0 & 0.25 \\
\hline 81 & $3(2,30$ and 75$)$ & -10.1 & 15.1 & -1.88 & 0.15 \\
\hline 103 & $5(2,10,30,60$ and 100$)$ & -8.6 & 12.5 & -1.58 & None \\
\hline 130 & $3(2,60$ and 125$)$ & -7.2 & 12.0 & -1.43 & None \\
\hline 184 & $3(2,75$ and 180$)$ & -6.9 & 11.0 & -1.38 & None \\
\hline 245 & $\begin{array}{c}8(2,8,20,40,75,125 \\
180 \text { and } 240)\end{array}$ & -6.6 & 11.3 & -1.35 & None \\
\hline $\begin{array}{l}\text { Room } \\
\text { temp. }\end{array}$ & $\begin{array}{c}2 \text { (near surface of the } \\
\text { each specimen) }\end{array}$ & -15.9 & 22.4 & -2.95 & ----- \\
\hline
\end{tabular}




\subsubsection{Results and Data Analysis - Laboratory Study}

Figure 10.12 shows the temperature profiles ( $2 \mathrm{~mm}$ below the surface) for all six lab specimens along with the temperature of the F-T room. Minimum and maximum temperatures for all these slabs along with computed average rate of freezing are given in Table 10.3. The scaling results after application of $50 \mathrm{~F}-\mathrm{T}$ cycles for all the slabs are also given in the same Table.

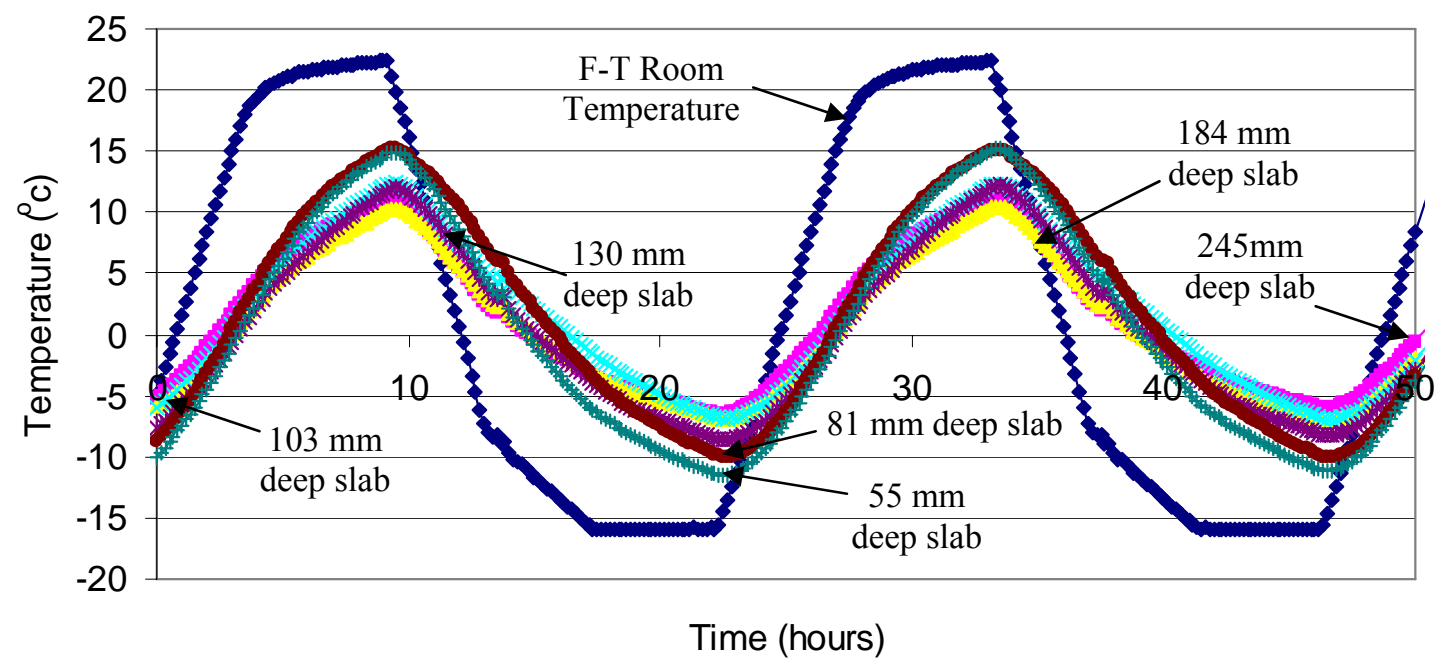

Figure 10.12: F-T cycle temperatures (room and $2 \mathrm{~mm}$ below surface of all six specimens)

It can be seen that for specimens with depths ranging from $55 \mathrm{~mm}$ to $245 \mathrm{~mm}$ $\left(2.5^{\prime \prime} \times 9.5\right.$ "), the minimum temperature of the surface region ranges from -11.5 to $-6.6^{\circ} \mathrm{C}$ (11.3 to $\left.20.1^{\circ} \mathrm{F}\right)$ for ambient minimum temperature of $-15.9^{\circ} \mathrm{C}\left(3.4^{\circ} \mathrm{F}\right)$. This confirms previous observations that the difference between surface and air temperature increases with the increase in size of the specimen. Moreover, results show that scaling (very minor) was only observed in for the specimens in which surface temperature dropped below than $-10^{\circ} \mathrm{C}\left(14^{\circ} \mathrm{F}\right)$. These results confirm the finding of Lindmark (1999) that 
scaling of the concrete is highly dependent on minimum temperature that surface attains, and duration of time for which it attains this temperature. Therefore, size of the pavement being very large in comparison to the laboratory specimen, chances of scaling will be reduced in each case when the minimum surface temperature stay above $-10^{\circ} \mathrm{C}$. The typical rate of freezing observed in the simulated pavement segment exposed to the elements is further described in the next section dealing with the outdoor study.

One more important observation was made from analysis of the temperature data from these slabs, instrumented with thermocouples. Figure 10.13 shows temperature profile of thermocouples placed in 81-mm (3.2") and 245-mm (9.6") thick slab at $2 \mathrm{~mm}$ and $75 \mathrm{~mm}$ from the surface for each specimen along with the temperature profile of the F-T room.

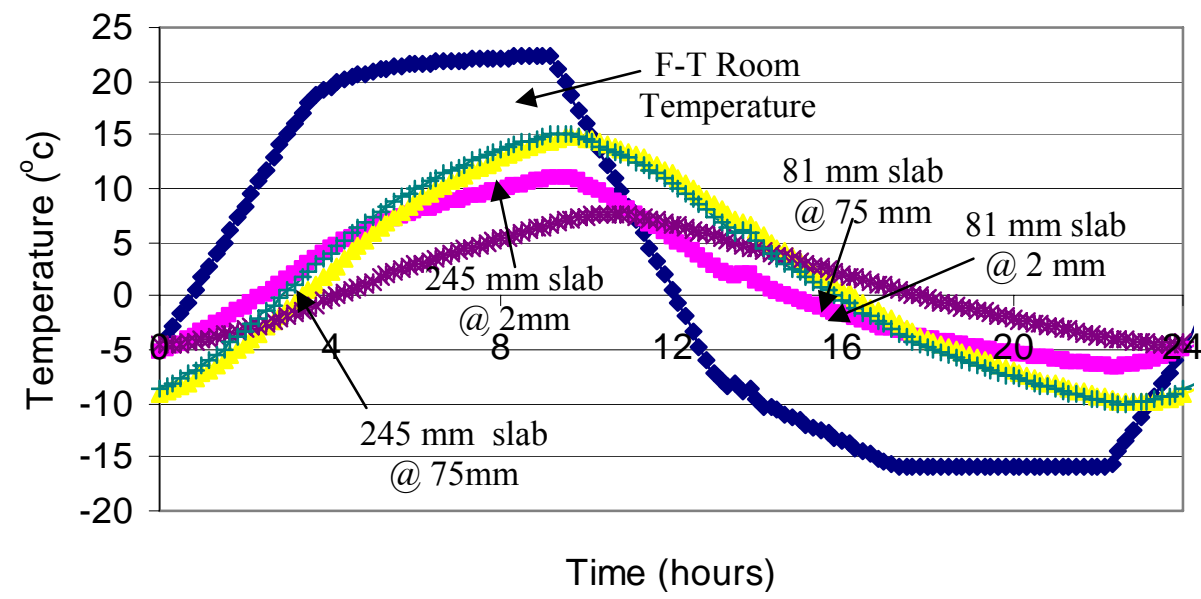

Figure 10.13: Thermal massing effect of large size specimens

From the Figure it is evident that for a small size $(81 \mathrm{~mm})$ specimen the rates of freezing at $2 \mathrm{~mm}$ and $75 \mathrm{~mm}$ are the same, while for large size $(245 \mathrm{~mm})$ specimen rates of freezing at 2 and $75 \mathrm{~mm}$ are significantly different. Thus, because of higher heat absorbing capacity of the large size specimen, differential rate of freezing is observed in 
the surface region. Freezing front moves down slowly from top towards bulk of the specimen. This could be another reason why scaling is observed in the laboratory specimen, while field specimen of similar concrete does not scale.

It has been observed that presence of excess surface water on the surface is essential to cause scaling problem. Verbeck and Klieger (1957) found that when samples were frozen in damp condition, i.e., with no liquid present on the surface, there was no scaling. Similar observation was made by Lindmark (1999). This is one of the very few phenomena which has been observed and accepted by all researchers who studied scaling. Fagerlund (1977) proposed that in sound concrete, moisture uptake during freezing and increased degree of saturation is the major cause of scaling.

Based on above observations, in the case of small size specimen, similar rate of freezing of bulk and surface regions may lead to higher moisture uptake. On the other hand, for large size specimens, surface freezes much faster then the bulk of the concrete. This phenomenon, even in the presence of salt solution provides less time for water uptake. Moreover, freezing will progress downward with time, which can cause moisture movement further downward and away from the surface. Thus, chances of having high degree of saturation in the surface region, and thereby generating detrimental forces, are much lower for larger specimens than for smaller specimens. In summary, the change in rate of freezing is one another important parameter that can help in resolving the discrepancy between laboratory and field scaling performance of concrete. 


\subsubsection{Study of the Cumulative F-T Cycles and Intermediate Drying}

During conditioning period study and low temperature curing study, one common observation was made from all different specimens. None of the specimens, including those which experienced severe scaling showed any scaling damage until completion of three continuous F-T cycles. This indicates that scaling does not happen in one F-T cycle, but that it takes 2 - 3 continuous cycles to initiate scaling in well air entrained concrete. This is consistent with other findings (Jacobsen et al., 1997A) that filling of air voids with water during freezing is one of the major reasons for scaling of virgin concrete. They suggested that due to pumping effect, degree of saturation of surface region increases thus, making air voids inefficient in consecutive cycles that cause damage to the surface. Fagerlund (1977) described the mechanisms of water uptake in the air pores during freezing and has shown how the air pores are inactivated after long period of continuous water storage. All these results provide indirect evidence that in sound concrete scaling does not initiate in 1 - 2 cycles.

At this point it is important to know what kind of freezing temperatures are observed for actual pavement when surface of the pavement is wet or has excessive moisture. To determine time of wetness and number of corresponding freezing cycles, following approach was used.

\subsubsection{Number of Wetting Events and Freezing Temperature for Indiana}

Information related to pavement wetness and corresponding temperature can be useful to determine the probability of initiation of scaling process generation in the climate of Indiana. The computer program "Conclife", developed by National Institute of 
Standards and Technology (NIST) was used to determine the number of wetting events and corresponding subzero temperatures for four different locations in Indiana. The model is based on a one-dimensional finite difference scheme and includes heat transfer by conduction, convection, and radiation. Environmental conditions are varied by using the Typical Meteorological Year (TMY2) data files available from the National Renewable Energy Laboratory. Based on the weather data available in these files and the developed heat transfer model, both the surface temperature and the time-of-wetness of the concrete are computed for typical pavement and bridge deck structures. The time-ofwetness includes both precipitation and condensation on the concrete surface. Wetting may not represent all the times saturation but if there is no wetting there will not be any saturation during that duration for pavement. Thus, this approach will represent the worst case scenario for available data. The results for following four different locations are obtained for Indiana: South Bend, Fort Wayne, Indianapolis and Evansville. Data for all the locations is summarized in Table 10.4.

Table 10.4: Data for freezing and wetting event for a typical year

\begin{tabular}{|c|c|c|c|c|}
\hline $\begin{array}{c}\text { Location for } \\
\text { Indiana }\end{array}$ & $\begin{array}{c}\text { Total } \\
\text { number of } \\
\text { wetting } \\
\text { events }\end{array}$ & $\begin{array}{c}\text { Total } \\
\text { number of } \\
\text { freezing } \\
\text { events }\end{array}$ & $\begin{array}{c}\text { Total number of } \\
\text { wetting event with } \\
\text { sub zero pavement } \\
\text { temperature }\end{array}$ & $\begin{array}{c}\text { Minimum } \\
\text { temperature } \\
\text { while pavement } \\
\text { was wet }\end{array}$ \\
\hline South Bend & 227 & 100 & 2 & -0.96 \\
\hline Fort Wayne & 220 & 100 & 10 & -6.97 \\
\hline Indianapolis & 221 & 90 & 11 & -6.04 \\
\hline Evansville & 254 & 69 & 4 & -4.07 \\
\hline
\end{tabular}


The data indicate that Fort Wayne is the location with maximum number of possible freezing events and with the lowest minimum temperature. Therefore, more complete set of data for Fort Wayne is plotted in Figure 10.14.

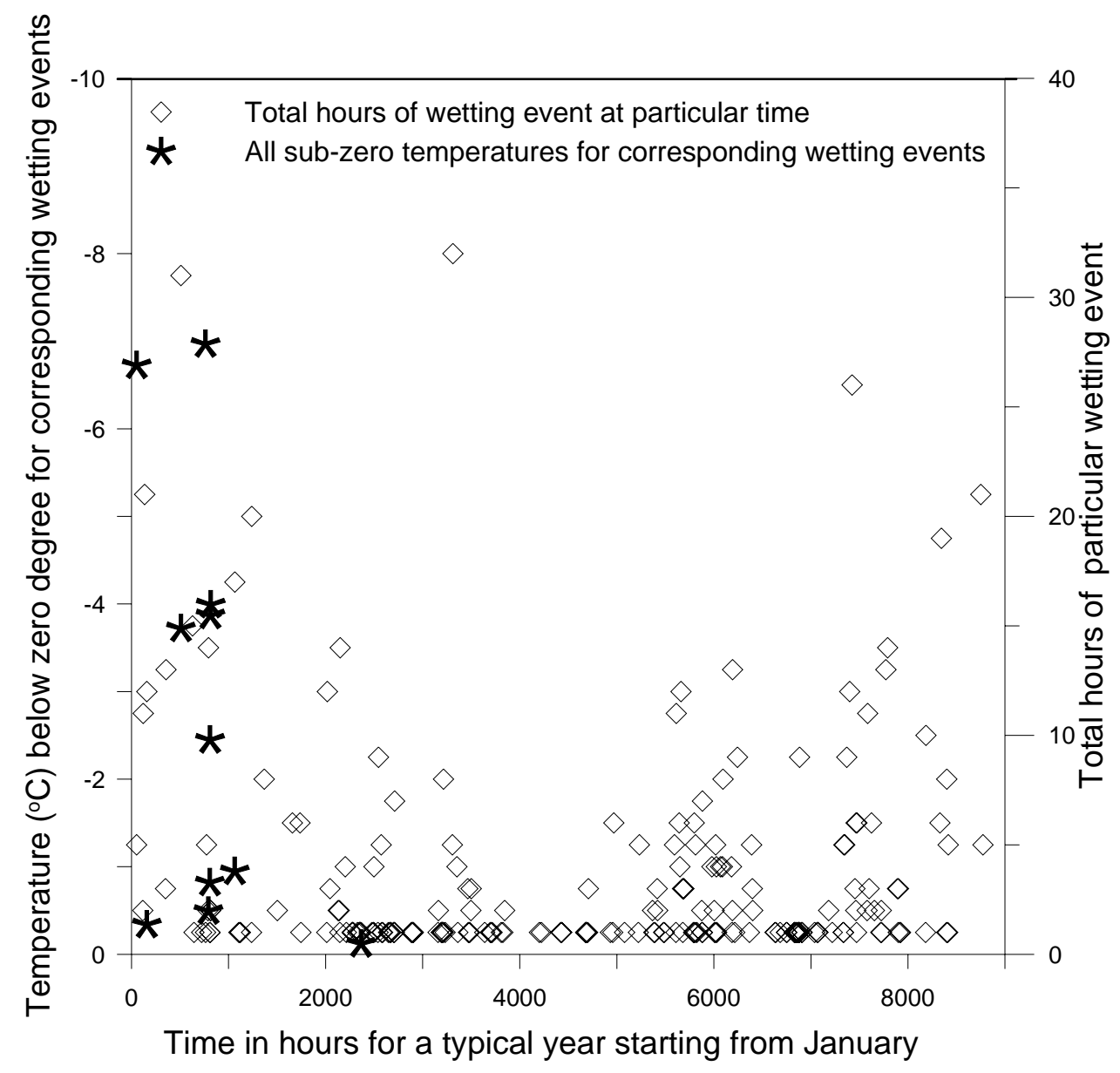

Figure 10.14: Total hours of wetting event at each time with sub-zero temperature

From Figure 10.14, it can be said that lowest minimum surface temperature is about $-7^{\circ} \mathrm{C}\left(19.4^{\circ} \mathrm{F}\right)$, which based on the evidence presented earlier, might not be low enough to initiate scaling in the pavement. It should be noted here that the Typical Metrological Data represent normals over a period of 30 years, so the record minimum 
temperatures might be significantly lower than the reported temperatures. For this reason, the total time of wetness during the freezing events was given more importance in this study. Analysis of the data indicates that the maximum duration of wetness observed during freezing was 30 hours, which is less then 2 days. It is very unlikely to observe more then $2 \mathrm{~F}-\mathrm{T}$ cycles (with minimum air temperature being less then -12 to $-15^{\circ} \mathrm{C}$, i.e., 10.4 to $5^{\circ} \mathrm{F}$ ) during this time frame.

Based on the above data it can be said that it is hardly possible that concrete will undergo 2 - 3 continuous F-T cycles with salt solution on surface in the field and this could be another reason for apparent discrepancy between laboratory and field scaling performance. Thus, to substantiate this argument and see how concrete would perform in laboratory in presence of realistic F-T cycles, study of intermittent drying was done. Additionally, importance of early age evaporation was already described earlier in the chapter. Therefore, to generate the most realistic F-T performance of $250 \mathrm{~mm} \mathrm{x} 190 \mathrm{~mm}$ x $75 \mathrm{~mm}(10 " x$ 7.5” x 3") specimens in laboratory, combined influence of both these parameters was studied along with their individual effects as described in the next section.

\subsubsection{Preparation of the Specimens and Experimental Procedure}

The mixture proportion used in this study was identical to the mixture proportion of $25 \mathrm{~mm}$ (1") slump concrete, shown in Table 7.1. As the original supply of cement and fly ash was exhausted, new shipment of (nominally) same material was secured from the same sources again. Total of four scaling slabs were prepared in this study following the procedure described in section 8.2. Out of the four slabs, two were exposed to early age 
evaporation, the same way as described in section 10.4.1.1 with wind speed of $9 \mathrm{mph}$ on the surface. All slabs were cut in to halves and eight scaling specimens were prepared using the same procedure as described in section 8.2.

All eight slabs were conditioned in the laboratory for 3 days, during which period they were covered with plastic lid and plastic sheets. They were then moved to F-T chamber and ponded with salt solution. After two F-T cycles, four out of these eight slabs (two slabs to be exposed to wind of $9 \mathrm{mph}$ and two subjected to non-wind evaporation) were removed from the F-T room during the thawing period. The solution was removed and surfaces of the specimens were washed thoroughly. After washing the specimens were moved back into the chamber. Two of these specimens were exposed to constant wind effect of $9 \mathrm{mph}(14.5 \mathrm{kmph})$ with the help of two fans for 24 hours. Weight of the specimens was measured at the end of drying period. After one drying cycle, once again $3 \%$ solution of sodium chloride was applied to the surface and again the specimens were exposed to 2 continuous cycles of F-T with solution on the surface. Thus, these four specimens were exposed to 1 dry cycle after 2 wet cycles for total of 75 cycles, while other four specimens were exposed to continuous $50 \mathrm{~F}-\mathrm{T}$ cycles. To create consistent drying effect, during each drying cycle specimens were exposed to wind for 24 to 28 hours until the mass of the specimen was close to the mass recorded earlier (within \pm 10 grams). For intermittently dried specimens scaled mass after 75 cycles was compared to scaled mass collected after 50 cycles of other four specimens. This helped in comparing equivalent amount of wet cycles in all specimens. Results of this study are reported below. 


\subsubsection{Results and Data Analysis}

Surprisingly, for all eight specimens, significant reduction in scaled mass (compared with earlier results) was observed, with maximum scaling of only $0.3 \mathrm{~kg} / \mathrm{m}^{2}$. This reduction can be attributed to variability in materials. Effect of variability of materials on scaling was discussed in detail in Chapter 7. To study the effect of intermittent drying and evaporation independent of materials parameters, the scaled mass is normalized with respect to minimal value. Figure 10.15 below shows results of this study.

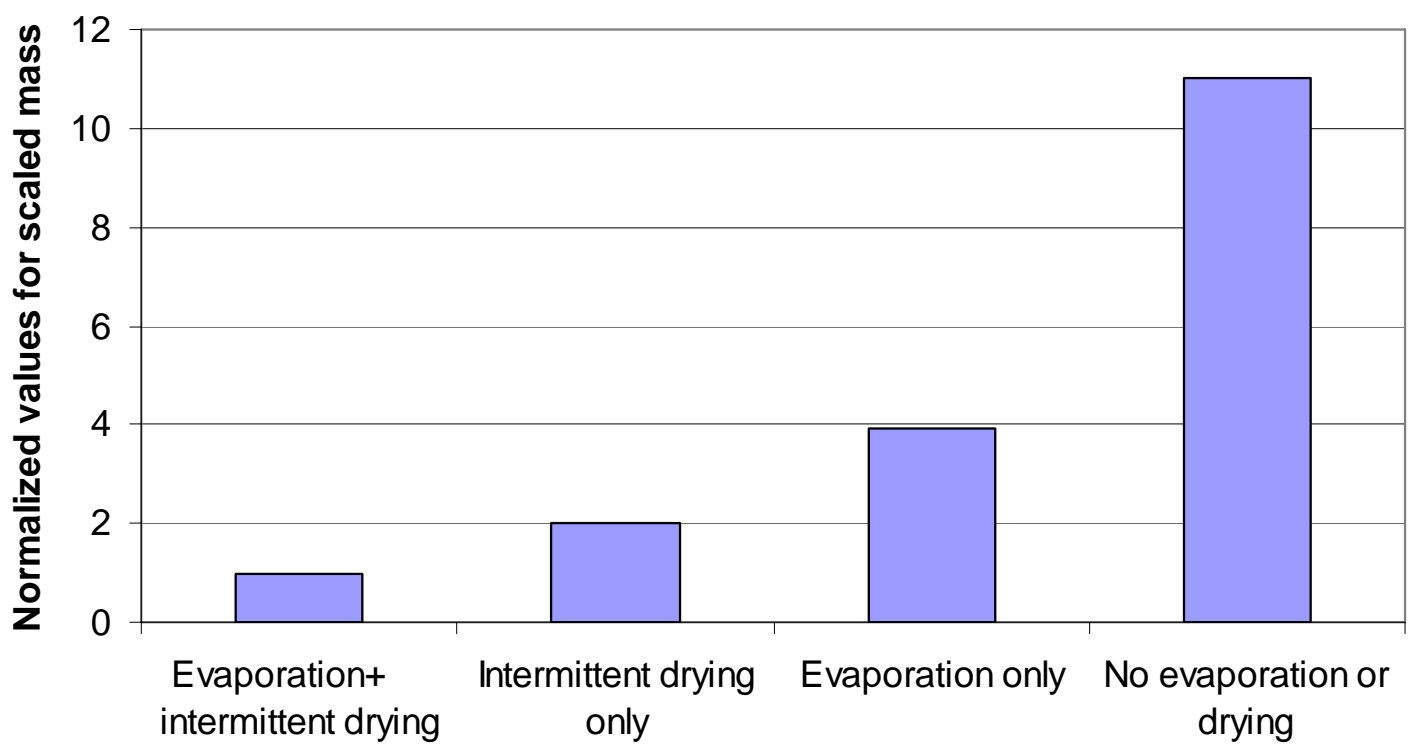

Figure 10.15: Results of evaporation and intermittent drying study

From Figure 10.15 it can be said that the scaled mass of the specimens, with the combined effect of intermittent drying and early age evaporation, is 11 times lower then the scaled mass specimen exposed to continuous F-T cycles (normal scaling cycle), prepared from the same mixture. Even just intermittent drying could reduce scaled mass to $1 / 5^{\text {th }}$ of normal scaling specimen. Thus, when laboratory specimens were exposed to 
environmental conditions likely to be encountered in Indiana, significant reduction in scaling was observed. This phenomenon could also be largely dependent on mixture proportion or composition of materials. As the required number of cycles to initiate scaling may vary (from 2 to 4), depending on type of air void structure formed in the particular concrete.

\subsubsection{Current Practices for the Use of De-icing Salts}

In the literature summary (section 2.4.3), it was evident that maximum scaling can be observed for salt concentration of 2 to $4 \%$. Lindmark (1999) further studied this aspect and mentioned that this pessimum solution is dependent on minimum surface temperature and eutectic point of a particular salt. In our study, with minimum temperature of $\mathrm{F}-\mathrm{T}$ cycle being $-15.9^{\circ} \mathrm{C}\left(3.4^{\circ} \mathrm{F}\right), 5 \%$ was observed as the concentration after which no freezing was observed in the solution and thereby no scaling could be observed. This was evident from the study of high salt concentration effect in section 8.3.3. Also in Indiana, typical minimum temperatures are similar to that used in the laboratory studies. This suggests that scaling in the field can only be expected when salt concentration is in the range of 1 to $5 \%$.

Based on current de-icing practices mentioned in the section 2.4.3, it is possible that the salt concentrations used in the field may be higher than the pessimum concentrations thus reducing the risk of scaling damage.

Having knowledge of these important parameters responsible for discrepancy between laboratory and field scaling results, risk analysis (Monte Carlo simulations) 
techniques can be used to calculate the probability of scaling in Indiana climate. The results of such simulations are presented in the next section.

\subsection{Determination of Probability of Scaling in the Field}

From the experiments described earlier, it is clear that there are several parameters which have influence on the scaling performance of concrete containing SCM. All these parameters contribute to certain extent to scaling resistance or generation of detrimental forces. Due to complex nature of scaling mechanism, most of these parameters can not be combined mathematically to develop a model for scaling with reasonable accuracy (Lindmark, 1999). In such situation, to assess the possibility of scaling for field concrete pavement, risk analysis approach can be used. This approach can give the probability of occurrence of an event that could initiate scaling in the concrete pavement. Thus, first an event is defined which is responsible for causing scaling and then effect of various parameters (salt concentration, surface finishing or materials composition) is incorporated through various probability distribution functions.

\subsubsection{Determination of Detrimental Event that Could Cause Scaling in Concrete}

\section{Pavement}

Based on intermittent drying study it is clear that it takes 2 to 3 F-T cycles with salt solution on surface to initiate scaling in the sound concrete. This study revealed that for concrete exposed to only 2 consecutive wet cycles, scaling could be reduced 11 times, but this can be dependent on type of materials and air void structure. To simulate the worst case scenario, for purpose of this study it was assumed that only two cycles could 
be required to initiate the scaling. Thus, selecting 2 days as the detrimental event not only helped in representing the worst case scenario but also allowed to account for some relaxation incorporation of any unforeseen parameters, which could contribute to scaling. Other parameters associated with this modeling effort are described below.

Minimum surface temperature: It has been proved in the size effect study that scaling in the concrete doesn't happen until surface temperature drops below $-10^{\circ} \mathrm{C}$ $\left(14^{\circ} \mathrm{F}\right)$. To achieve surface temperature of $-10^{\circ} \mathrm{C}$, air temperature should be in the range of $-15^{\circ} \mathrm{C}\left(5^{\circ} \mathrm{F}\right)$, (assuming lag of $\left.-5^{\circ} \mathrm{C}\right)$. In presence of high wind this lag might decrease and hence to represent the worst case scenario the required minimum air temperature was assumed to be $-12^{\circ} \mathrm{C}\left(10.4^{\circ} \mathrm{F}\right)$.

Maximum surface temperature: To develop pumping effect and to increase the degree of saturation by progressive filling of air voids thawing is essential. Thus, concrete surface temperature should be allowed to reach at least to $0^{\circ} \mathrm{C}\left(32^{\circ} \mathrm{F}\right)$. Due to solar radiation, the surface temperature might become higher than air temperature (3 to $5^{\circ} \mathrm{C}$ difference can be assumed as seen between the surface and the air temperatures). Also, in presence of salt solutions concrete surface might thaw at temperature lower than $0^{\circ} \mathrm{C}$. Thus, considering both these factors the maximum temperature during cycle was assumed to be $-6^{\circ} \mathrm{C}\left(21.2^{\circ} \mathrm{F}\right)$.

Precipitation: Along similar lines and, with the above temperature requirement, it is important for the pavement to have sufficient surface moisture. For the pavement on which traffic is present, it is rarely possible that precipitation or snow that accumulated at one time will remain present for two consecutive cycles. Either due to safety concern or due to thawing, surface moisture of single precipitation won't be available during the 
second cycle. Thus, moisture needed for the second cycle must come in the form of new precipitation (precipitation value during both freezing cycles should be higher than 0.0 ").

Daily weather observations (minimum and maximum temperature and precipitation) are collected at hundreds of locations or "stations" throughout Indiana. Most of these data are edited, and then published several months later by the National Climatic Data Center (NCDC). These data for all the locations of Indiana is available online and can be downloaded freely from NCDC website (http://www.ncdc.noaa.gov) or from local Purdue website http://shadow.agry.purdue.edu/sc.obs-geog.html. For this study data from five locations in northwestern Indiana were selected. These five locations were selected based on high precipitation and lower minimum temperature values. Data for 30 years period (1963 to 1993) for all these locations was collected. This data is available in a standard format, but to simplify the analysis and to isolate the typical values, a data program was written using $\mathrm{C}++$. This program helped in quick data analysis by screening large database for specified minimum and maximum temperature and precipitation values, which could be considered detrimental when scaling is concerned. Figure 10.16 shows a window of this program along with input parameters and results displayed for Lowell, Indiana. Using this program and parameters decided above, number of detrimental events for all the five locations for over 30 years of period were determined. Table 10.5 shows the data with month wise number of detrimental events for all five locations considered. 


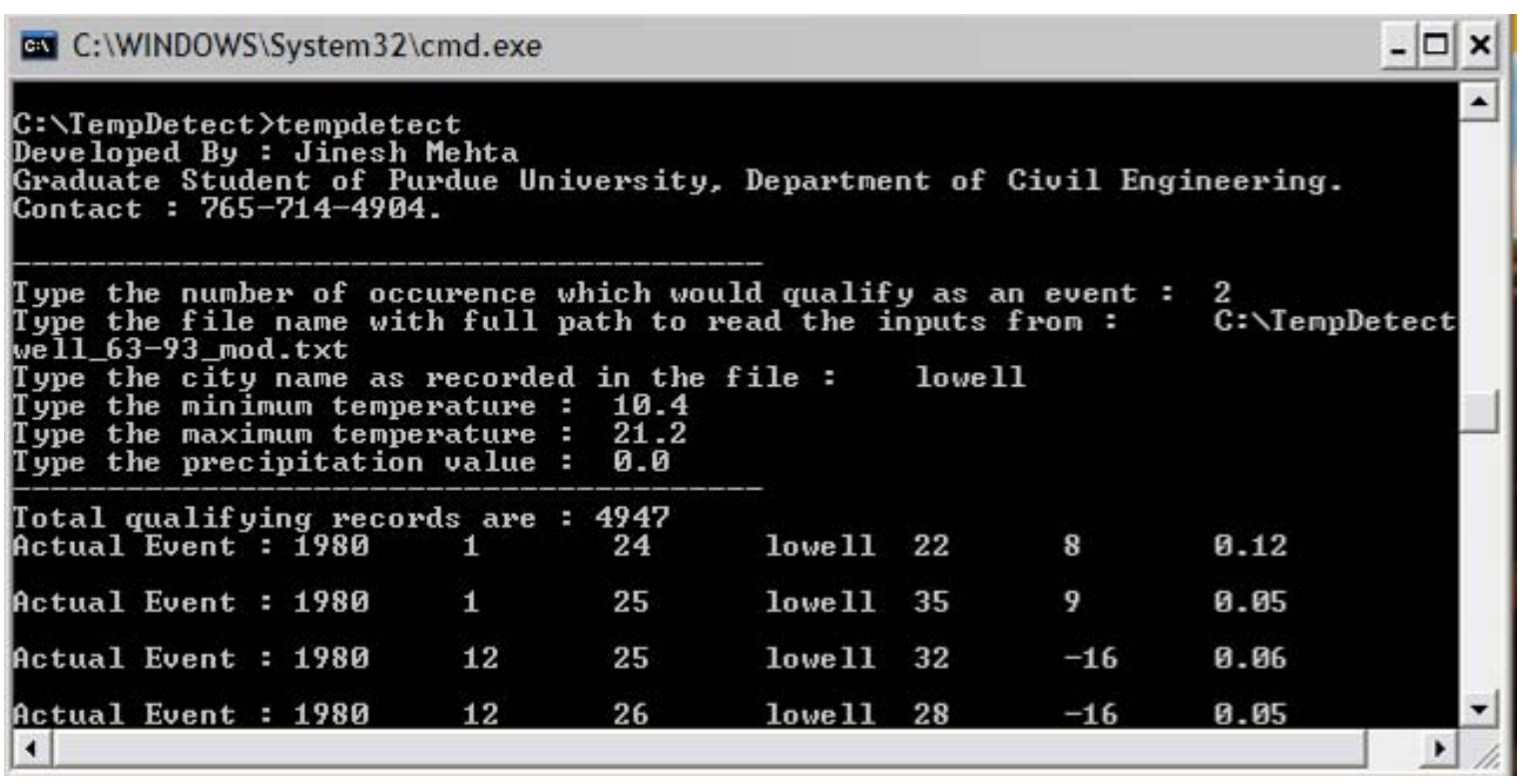

Figure 10.16: Snapshot of the program prepared for data analysis for event determination

Table 10.5: Determination of number of events for different locations

\begin{tabular}{|c|c|c|c|c|c|c|c|}
\hline \multirow{2}{*}{ Location name } & \multirow{2}{*}{ County } & \multicolumn{6}{|c|}{$\begin{array}{c}\text { Month wise observed number of detrimental events } \\
\text { Definition:2 consecutive days during 1963 to 1993 having } \\
\text { Min. temp. } \leq-12^{\circ} \text { C, Max temp. }-6{ }^{\circ} \text { C, Precip. }>0.0 "\end{array}$} \\
\cline { 3 - 8 } & & Oct & Nov & Dec & Jan & Feb & Mar \\
\hline Michigan city & La Porte & 0 & 2 & 1 & 3 & 0 & 1 \\
\hline Wanatah sand & Porter & 0 & 1 & 2 & 2 & 2 & 1 \\
\hline Lowell & Lake & 0 & 1 & 0 & 4 & 1 & 2 \\
\hline North Judson & Starke & 0 & 0 & 1 & 5 & 2 & 1 \\
\hline Winamac & Pulaski & 0 & 1 & 1 & 0 & 4 & 0 \\
\hline \multicolumn{2}{|c|}{ Monthly mean value } & 0 & 1 & 2 & 3 & 2 & 1 \\
\hline
\end{tabular}

Note: The events counted are based on only the error free available data points in the database. 
10.6.2. Monte Carlo Simulation and Risk Analysis for Scaling Probability Determination

For scaling to occur in the field, parameters (surface salt concentration, scaling resistance of concrete) other than severe weather condition (occurrence of the detrimental event) are also important. Thus, total of three different parameters were used to determine the probability of scaling. Importance of severe weather (occurrence of detrimental event) for determination of scaling is shown in above study. Based on observed data for all the locations in Table 10.5, the probability distribution for this factor is given in Table 10.6. For other two selected factors, reasoning is given below.

Salt concentration: It has been clear from literature review and study of current practices that pessimum salt concentration, which could cause scaling, may not occur in each case of application of salt. It has been proved that in no case scaling would initiate when surface salt concentration is higher than $6-7 \%$ for Indiana climate. It is well known that average application rate for different salts are in the range of $25-30 \%$. Therefore considering this factor and based on monthly average consumption of salts, month wise probability distribution for pessimum concentration is given in Table 10.6. To represent the worst case scenario, the mean values selected are higher then possible mean values.

Scaling resistance: It has been shown that for concrete pavements, due to lower slump and higher thickness (higher thermal mass), scaling resistance is substantially higher than the resistance of a thin concrete section. To incorporate this aspect into risk model, it is important to determine chances of having poor scaling resistance of concrete even with such a large heat absorption capacity. For thick concrete pavement poor scaling resistance can be attributed to the problems in air void structure due to improper 
vibration, finishing or presence of deleterious materials. Probability of such cases in typical pavement construction with good quality control is very rare. Therefore, a uniform probability distribution of 0 to 0.2 is given to this factor. Table 10.6 gives probability distribution parameters assigned to each factor for all the months studied.

Table 10.6: Probability distribution assigned to each factor under study

\begin{tabular}{|c|c|c|c|c|c|c|c|}
\hline Factor (type of & Distribution & \multicolumn{6}{|c|}{ Month wise assigned probability distributions } \\
\cline { 3 - 8 } probability dist.) & parameters & Oct. & Nov. & Dec. & Jan. & Feb. & Mar. \\
\hline (A) No. of events & Mean & 0 & 1 & 2 & 3 & 2 & 1 \\
\cline { 2 - 8 } (Normal dist.) & S.D. & 0 & 0.33 & 0.67 & 1 & 0.67 & 0.33 \\
\hline (B) Pessimum salt & Mean & 0 & 0.3 & 0.5 & 0.5 & 0.5 & 0.25 \\
\cline { 2 - 8 } conc. (Normal dist.) & S.D. & 0 & 0.1 & 0.16 & 0.16 & 0.16 & 0.08 \\
\hline (C)Scaling resistance & Minimum & 0 & 0 & 0 & 0 & 0 & 0 \\
\cline { 2 - 9 } (Uniform dist.) & Maximum & 0.2 & 0.2 & 0.2 & 0.2 & 0.2 & 0.2 \\
\hline
\end{tabular}

Using above parameters, risk analysis was performed to determine probability of all these factors, occurring at the same time using simple probability multiplication rule. Probability of scaling P(S) = P (A) x P (B) x P (C). Then using @ Risk 4.5 ${ }^{\mathrm{TM}}$ software, risk analysis was performed by taking all the three factors as variable (A), (B) and (C). The results of simulation for each month along with summary statistics, showing probability in \%, are shown in Figure 10.17. The simulation settings are shown in Table 10.7 .

Table 10.7: Simulation settings for Monte Carlo simulation

\begin{tabular}{|c|c|c|c|c|c|}
\hline $\begin{array}{c}\text { Workbook } \\
\text { Name }\end{array}$ & $\begin{array}{c}\text { Number of } \\
\text { Simulations }\end{array}$ & $\begin{array}{c}\text { Number of } \\
\text { Iterations }\end{array}$ & $\begin{array}{c}\text { Number } \\
\text { of Inputs }\end{array}$ & $\begin{array}{c}\text { Number } \\
\text { of Outputs }\end{array}$ & Sampling Type \\
\hline risk_analysis.xls & 1 & 10000 & 25 & 14 & Monte Carlo \\
\hline
\end{tabular}




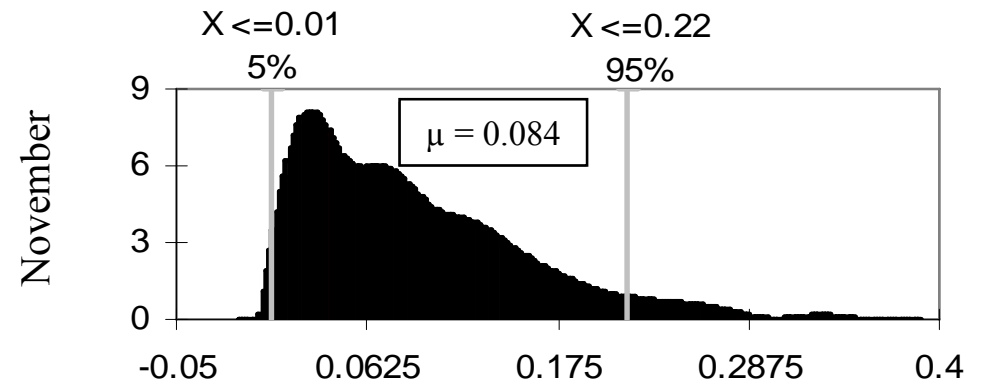

\begin{tabular}{|l|l|}
\hline Statistic & Value \\
\hline Minimum & 0.0000 \\
\hline Maximum & 0.3880 \\
\hline Mean & 0.0837 \\
\hline Std Dev & 0.0665 \\
\hline
\end{tabular}
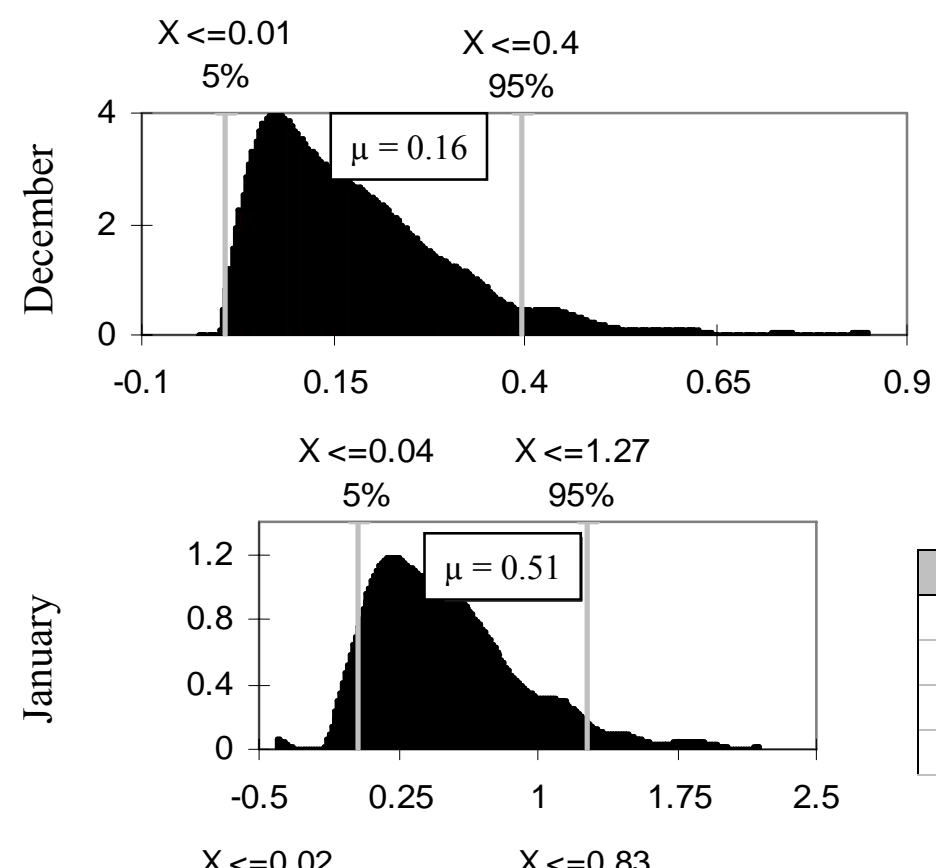

\begin{tabular}{|l|r|}
\hline Statistic & Value \\
\hline Minimum & 0.0000 \\
\hline Maximum & 2.1935 \\
\hline Mean & 0.5118 \\
\hline Std Dev & 0.3942 \\
\hline
\end{tabular}

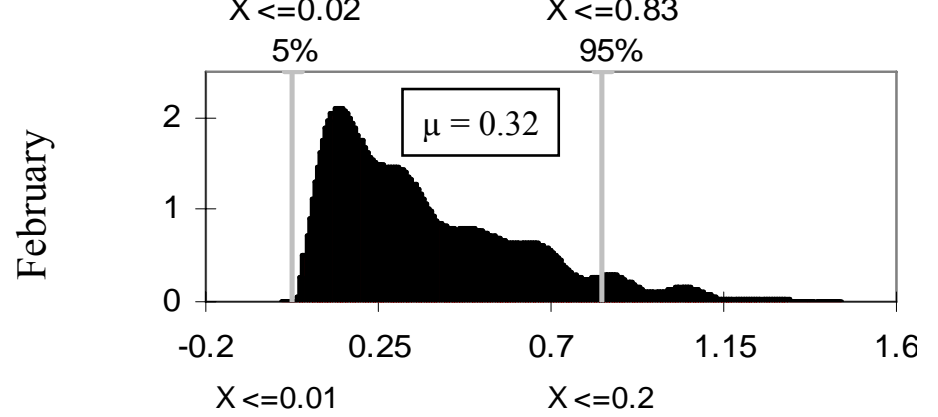

\begin{tabular}{|l|r|}
\hline Statistic & Value \\
\hline Minimum & 0.0000 \\
\hline Maximum & 1.4541 \\
\hline Mean & 0.3173 \\
\hline Std Dev & 0.2609 \\
\hline
\end{tabular}

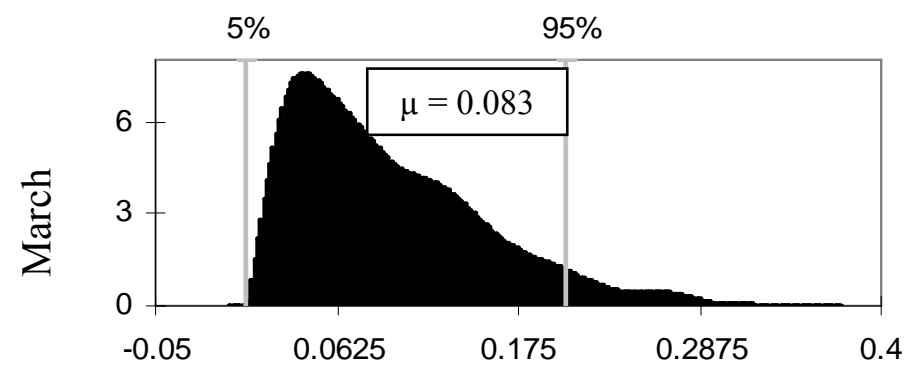

\begin{tabular}{|l|c|}
\hline Statistic & Value \\
\hline Minimum & 0.0000 \\
\hline Maximum & 0.3746 \\
\hline Mean & 0.0827 \\
\hline Std Dev & 0.0635 \\
\hline
\end{tabular}

Figure 10.17: Summary of simulation results, with $\%$ of probability for all months 
Based on these results it can be said that maximum probability of occurring of one event, which could initiate scaling in the concrete pavement, is $0.51 \%$ for the month of January. Therefore it can be said that, statistically, only one out of 196 pavements would have experienced conditions sufficient to initiate scaling. It should be noticed that this is just the probability of initiation of scaling; there are chances are that such pavements will never go through number of cycles required to cause substantial scaling damage. Therefore, this risk model supports the finding of survey showing absence of scaling in sound field pavements.

To see how well this model correlate to general scaling issue, the factor of high scaling resistance (factor $\mathrm{C}$ ), was eliminated from the analysis. Thus, this should represent regular flat slab, being constructed with proper quality control. Once again probability for all the months were determined and highest probability of month of January is shown in Figure 10.18.

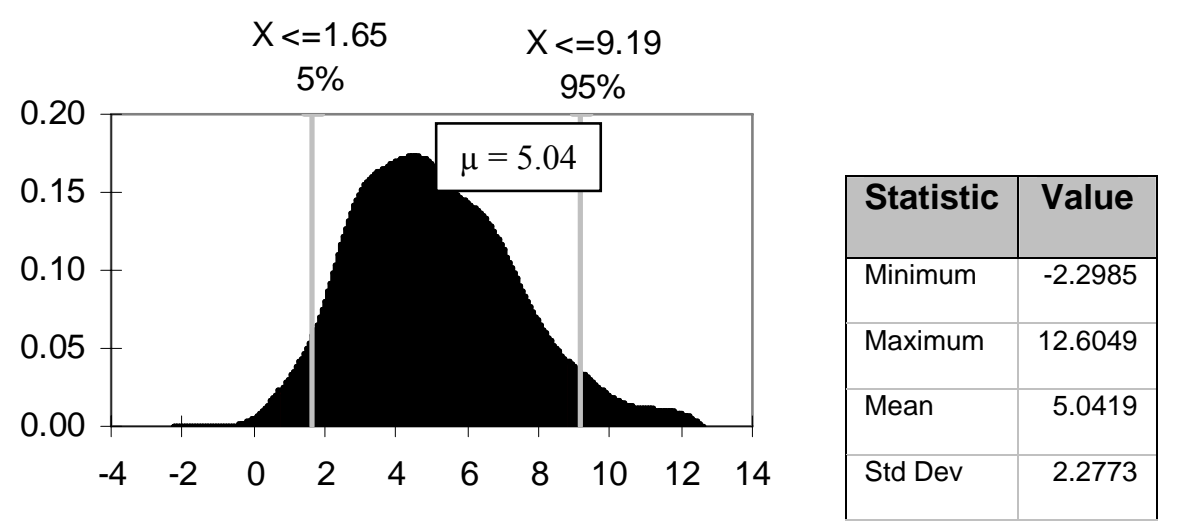

Figure 10.18: Simulation results showing probability for scaling for flat works 
From this Figure it is evident that for normal sections, even in outside weather probability of scaling is high (one out of 20 concrete would show some scaling damage). This sounds a reasonable number based on survey results. Thus, it seems that results of risk analysis gave reasonable output, which can be used to determine probability of scaling in the field for particular location.

\subsection{Summary}

In summary, it can be said that, based on literature review and survey, scaling of concrete pavement is a rare phenomenon for low a replacement values of SCM. Therefore, the laboratory procedure (ASTM C 672) is too severe to study the scaling performance of concrete, specifically those containing fly ash or slag. A total of five major reasons were identified, which could lead to discrepancy between laboratory and field performance.

- Early age evaporation in the field reduces surface porosity and ultimately, makes field concrete more resistant to scaling.

- Finishing of pavement with slip-form paver and tinning operations reduces chances of accumulation of water in the surface region and increases in its strength.

- High heat absorption capacity and differential rate of freezing likely to be present in the large pavement sections, reduces potential for scaling.

- Short-duration of F-T cycles reduces chances achieving of high degree of saturation in the surface region.

- Salt concentrations in the field are often higher than the pessimum scaling concentration. 
At the end, results of risk analysis confirmed that probability of scaling in concrete pavement is very low. These results are mainly applicable to pavements with maximum $20-25 \%$ replacement values of SCM. 


\section{CHAPTER 11: SUMMARY, CONCLUSIONS AND RECOMMENDATIONS}

\subsection{Introduction}

This research addresses several issues raised concerning the scaling of concrete containing fly ash and provides insight towards understanding the mechanism, and scaling performance of concrete with and without fly ash.

This chapter provides an overall summary of the study including the result of an extensive literature review, analysis of experimental results, and information gathered during survey of several state agencies. Individual conclusions from each segment of the study are described. Conclusions are linked together to determine the relative influence of all parameters studied. Finally, overall conclusions are provided along with brief guidelines for the various issues related to the low temperature construction season.

\subsection{Summary and Conclusions from Experimental Studies}

\subsubsection{Materials Selection and its Influence on Scaling Performance}

Chapter 7 summarized the experimental studies and observations on the influence of various material parameters on the scaling performance of concrete. A study of pastes containing different binders revealed that it is unlikely that excessive amounts of low density fly ash particles will be present in the near-surface zone of typical pavement mixtures. It was also confirmed that the presence of deleterious sand particles could lower scaling resistance of concrete. In summary, a systematic detailed study should be 
pursued in the future to develop better understanding of dependency of scaling performance on material properties.

\subsubsection{Studies of Different Conditioning Periods and Slumps}

In Chapter 8 the influence of conditioning periods and slump on the scaling results was studied. Based on the study of six different moist curing and six different drying periods (36 specimens), it can be said that 7 days moist curing and 2-3 days of drying are the optimum with respect to achieving the best scaling resistance. For $63 \mathrm{~mm}$ slump specimens, 3 days of moist curing proved to be the most beneficial. The microstructural study confirmed that at early ages the surface of the laboratory concrete could have an increased porosity which can lead to scaling during in the first few F-T cycles. A salt penetration study confirmed that the effect of salt concentration profile is more important for specimens conditioned for a longer time.

\subsubsection{Influence of Low Temperature Curing on Early Age Properties and Scaling}

From the study on the influence of low temperature mixing and curing (Chapter 9), the following summary could be made: when cured at low temperature, the setting time of concrete with and without fly ash, could increase as much as three times its initial value. At low temperatures concrete containing fly ash exhibited longer period of bleeding and a slower rate, which reduced the potential for water accumulation at the surface. Therefore, no detrimental effect due to low temperature curing on the scaling performance of fly ash concrete was observed. A large size (300-mm deep) specimen study was important for the simulation of the field conditions. The notion of higher 
bleeding and lower strength gain for fly ash concrete due to slower setting, and its detrimental effects on durability performance, were not confirmed in the various studies performed.

\subsubsection{Discrepancy Between Laboratory Scaling Results and Field Observations}

A literature review and survey of various DOT concluded that scaling of concrete pavement rarely occurs for concrete with low replacement values of SCM. However, several cases of scaling of laboratory concrete were also reported. Therefore, the laboratory test procedure (ASTM C672) can be considered too severe to study the scaling performance of concretes, especially, those containing fly ash or slag. There were five major reasons identified, that could cause such a discrepancy between laboratory and field performance. First, early age evaporation observed in the field reduces surface porosity and makes field concrete more resistant to scaling. The second major parameter is finishing of the pavement. The slip-form paving and the tinning operations can result in the formation of a pavement with a stronger surface due to increased rate of evaporation. The third and fourth parameters were high heat absorption capacity of thicker sections and shorter durations of F-T cycles with the period of intermittent drying occur in the field in comparison to laboratory exposure. Finally, the chances of attaining a pessimum concentration of salts along with a quarter inch of water on the surface while freezing are too low. The results of risk analysis confirmed that probability of scaling in concrete pavement is very low. 
11.2.5. Summary and Conclusion Derived from Linking Together all the Parameters

\section{Studied}

Figure 11.1 is presented to show relative importance of various parameters studied on the scaling performance of concrete. This Figure shows the possible percentage improvement in scaling resistance for each parameter studied. This schematic was prepared by considering independent effect of that particular parameter, while keeping everything else constant. For example, it was observed that with change in conditioning periods alone, scaled mass of particular mixture was reduced by as much as 40\%, therefore, in Figure 11.2, 40\% improvement in scaling performance is suggested for the conditioning periods. The percentage values obtained here are based on experimental results; however, certain approximations were made to determine independent effect of a few parameters.

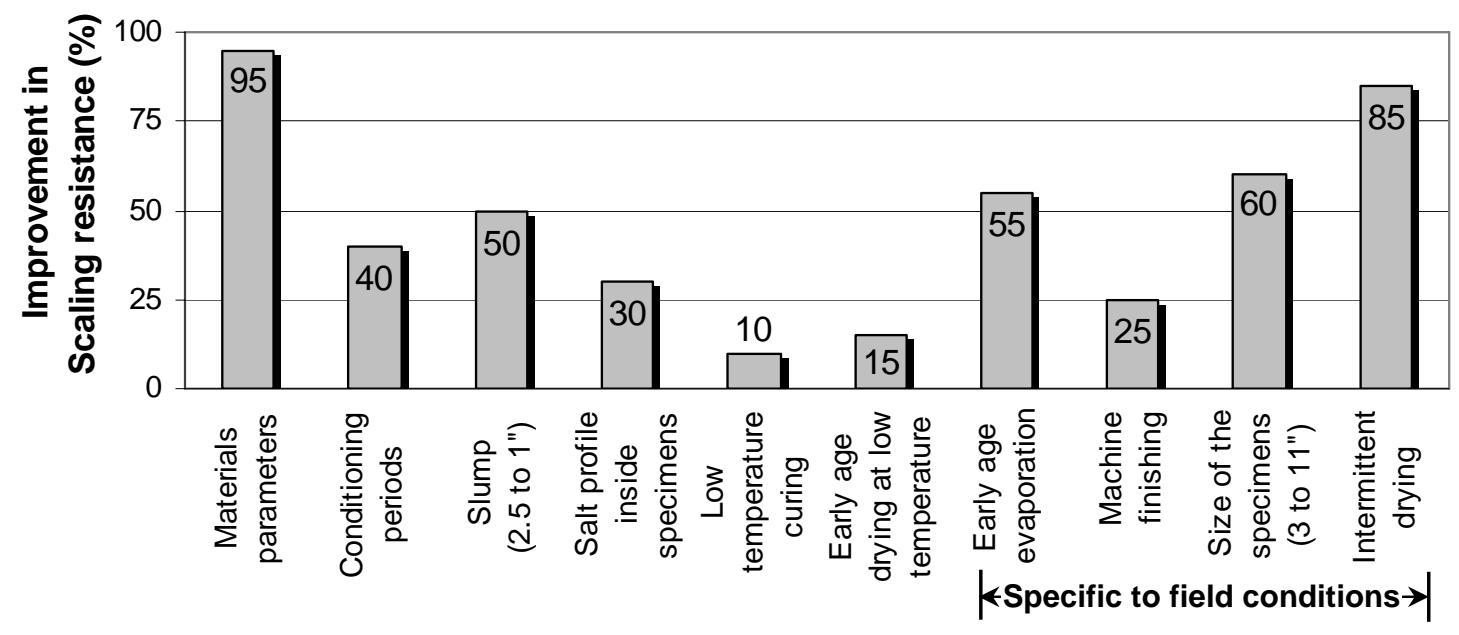

Figure 11.1: Relative importance of all parameters studied

As shown in the Figure 11.1, the most significant parameter influencing the scaling performance of concrete was the type of cementitious materials. In the first part 
of this study (Chapters 1 - 5), it was shown that by changing the cement and fly ash combination, the change in scaled mass varied from 0.3 to $3.0 \mathrm{~kg} / \mathrm{m}^{2}$. The high dependency of scaling on materials could be one of the reasons for reduced repeatability (variability of 25\%), of the test ASTM C 672 with even the same concrete (Marchand et al., 1996).

The second most important parameter found based on the results of the entire study is intermittent drying, which is also one of the major causes for the discrepancy between laboratory and field performance. When concrete was exposed to one intermittent drying cycle after two wetting cycles, $85 \%$ reduction in the scaled mass was observed. This helped to explain the severity of laboratory study being too high in comparison to observed field exposure conditions.

The third important parameter, the conditioning period, also changed the scaling resistance. Moist curing could reduce the surface porosity by effectively filling the capillary porosity with hydration products. Mild drying could help in drying of air voids and increase the scaling resistance. Therefore, by selecting optimum periods of moist curing and dryings, scaling resistance could be improved up to $70 \%$. The optimum period for 1" slump mixture studied was 7 days of moist curing and 2 - 3 days of drying.

Another parameter that was observed to influence the scaling behavior was the ability of concrete to absorb heat, which was related to the size of the specimen. The influence of size of the specimens was described in both Chapters 9 and 10. Study of 300-mm deep specimens illustrated that a change in thickness of the specimens from 75 $\mathrm{mm}$ to $300 \mathrm{~mm}$, can result in a $60 \%$ improvement in scaling resistance. 
The decrease in slump (63 to $25 \mathrm{~mm}$ ) of the specimens and early age evaporation can improve scaling resistance by 50 and 55\%, respectively, which directly relates to the amount of bleeding water accumulated in the surface region. The microstructural study showed that a thin layer $(0.7$ to $1.0 \mathrm{~mm})$ of high porosity could be created in high slump specimens. Therefore, the surface region could be made more dense and more scaling resistant by either decreasing the slump (and thereby reducing overall bleeding) or by early age evaporation.

It is difficult to control the salt concentration front for any particular pavement but in the case of laboratory studies with different drying periods, the salt penetration profile can be changed, which can change the scaling results up to $30 \%$.

The finishing of the concrete is also one of the most important parameters influencing scaling. Based on literature review it can be said scaling resistance of the concrete can be improved by $25 \%$ by proper finishing operations.

Early age drying was studied to determine the appropriate time of application of curing compound. It was observed that drying of specimen until the surface moisture evaporates is beneficial in scaling resistance (15\% increase). The role of low temperature curing was also found beneficial and improved scaling resistance by $10 \%$ for concrete containing fly ash.

\subsection{Overall Conclusions from the Research Project}

Based on the study of scaling of concrete containing fly ash, it can be recommended that the use of supplementary cementitious materials at current replacement levels and using current INDOT temperature guidelines can be extended 
throughout the year for climatic conditions of Indiana for pavement construction. The reasons for this conclusion are evident in the entire study and are also briefly discussed below.

- The first part of this study (Chapters 1 - 5) showed that adequate F-T resistance can be obtained when concrete has a compressive strength of at least 3500 psi (24.1 MPa) and has low amounts of freezable water in addition to minimum air contents of $6 \%$ and air-void spacing less than 0.008” (0.203 mm).

- In regard to scaling, the ASTM C672 was found to be too severe and does not represent the climatic conditions observed in Indiana. Risk analysis indicated that the overall probability of scaling to initiate in any typical pavement in Indiana is very low.

- The scaling resistance of concrete is likely to be higher in actual pavement in comparison to the corresponding laboratory specimens. This can be attributed to low slump, better finishing with slip form paver, and the more favorable temperature profile developed during freezing due to a higher depth of specimens.

- Out of the total of seven different combinations of cementitious materials studied in this research, only one combination showed a scaled mass higher than the specified limit when studied as per ASTM C 672. Moreover, when the second shipment of the same worst performing combination of materials was obtained from the same source, no scaling was observed even in the laboratory study. This indicates that the probability of getting the worst performing combination is very low. 
- The worst performing combination that showed severe scaling damage in the laboratory, did not show any scaling when attempt was done to simulate the actual field conditions in the laboratory.

- Information obtained from the survey showed that out of 12 states having similar or more sever climatic conditions than Indiana, 9 states allow the use of fly ash or slag throughout the entire year. None of these states reported any major scaling problems of in connection with late fall construction season in the case of concrete pavement.

Based on this study, it seems that present INDOT specification is adequate to provide good F-T and scaling resistance for concrete pavement. However, a few more guidelines are provided here that might help in ensuing even better performance of concrete as far as F-T durability and scaling is concerned.

It should be noted here that this study exclusively addressed concrete pavements only. Therefore, the recommendation and guideline is also exclusively for normal pavement constructed with a slip-form paver.

\subsubsection{Guidelines for Materials, Mixing and Slump of Concrete}

The INDOT specification (Section 901) provides a guideline for selection of various materials for PCC construction. These guidelines appear adequate for providing good F-T and scaling resistance for concrete. In addition, the following few additional precautions could help to improve concrete performance.

- Care should be taken to reduce the chances of variability in cementitious materials in the same project, and adjustments should be made to avoid variability in air content and other fresh properties due to changes in materials. 
- With current limit for loss on ignition being 3\%, concrete containing fly ash seem to have similar air content as plain concrete. However, air content being one of the most important parameter with respect to scaling and F-T resistance, careful observations of air content in fresh concrete should be made, and unexpected air loss due to higher carbon content in the fly ash should be strictly avoided.

- For low temperatures, care should be taken to maintain the desired low slump. It has been observed that at low temperatures due to the increased effectiveness of the water reducer the slump increases. Therefore, regular adjustments in the quantity of the water reducer should be made to achieve consistently low slump values. This might require trial batching at several temperatures.

- The current slump requirement for slip formed concrete is $30 \mathrm{~mm}$ (1.25”) to $75 \mathrm{~mm}$ (3”) (Section 502.04), which seem to work fine for adequate F-T performance. However, reducing the maximum slump requirement to $50 \mathrm{~mm}$ (2”) might help in providing better scaling resistance and more consistency in the performance, specifically for low temperature construction seasons.

\subsubsection{Guidelines for Placement, Finishing and Curing}

Section 504 of INDOT specification provides a guideline for finishing and curing of concrete. Based on survey information, application of usual curing compound seems to be working for even low temperature cured concrete with supplementary materials. In addition, a few more guidelines are suggested below based on this study.

- The practice of "sprinkling” the surface with water to ensure better finishing should be avoided, especially during the low temperature construction seasons. Hand 
finishing and retempering of the surface should be avoided. Moreover, overworking should be avoided to prevent formation of excessive layer of mortar and water at the top surface.

- The best time for application of the curing compound would be as soon as the surface moisture evaporates, or as soon as marring of the concrete does not occur. This time for low temperature construction seasons for concrete containing fly ash could be significantly longer than for plain concrete, depending on the wind speed and temperature.

- The application rate of the curing compound $\left(3.7 \mathrm{~m}^{2} / \mathrm{l}\right)$ seems to be satisfactory to ensure good scaling resistance at early ages. Extra care should be taken to maintain uniformity and flawless application, specifically for the late fall construction season.

\subsubsection{Temperature Guidelines}

Current INDOT weather limitations (502.11) seem to be adequate for low temperature construction seasons. The following suggestions are offered based on this study:

- When fly ash is used at very low temperature $\left(2^{\circ} \mathrm{C}-5^{\circ} \mathrm{C}\right.$ or $\left.35.6^{\circ}-41^{\circ} \mathrm{F}\right)$, the setting time and time to attain a flexural strength equivalent to 550 psi (3.8 MPa) might increases significantly in comparison to a mixture without fly ash. Therefore, careful estimation will be required for saw cutting or opening the pavement to traffic.

- The use of SCM should not be allowed when the air temperature drops below $4^{\circ} \mathrm{C}$ $\left(39^{\circ} \mathrm{F}\right)$ without consent of the engineer. In the special cases when concrete is placed at lower than the specified temperature, the placing temperature should be raised to at 
least $13^{\circ} \mathrm{C}$ or more (ACI 306). The ingredients may be heated to attain the desired minimum placing temperature. When the aggregates are free of frozen water, it is usually easier to heat only the mixing water, but when the air temperature is consistently below $0^{\circ} \mathrm{C}\left(32^{\circ} \mathrm{F}\right)$, aggregates should also be heated. Care should be taken when water at temperature above $60^{\circ} \mathrm{C}\left(140^{\circ} \mathrm{F}\right)$ is used as this may lead to the formation of small cement clumps or flash setting. Detailed guidelines to achieve different placing temperatures are provided in ACI 306 "Guide for Cold Weather Concreting”.

- ACI 306 specifies that the concrete should be protected after placing such that temperature of $10^{\circ} \mathrm{C}$ or more is maintained to achieve reasonable setting time and strength gain. The maximum allowable temperature drop in the first 24 hours after the end of protection should be $28^{\circ} \mathrm{C}\left(82.4^{\circ} \mathrm{F}\right)$. This guideline can be useful to avoid thermal cracking as well as being considered important for better F-T and scaling resistance. Therefore, careful monitoring of the temperature should be done, and protection should be removed only when drastic changes in ambient temperature are not expected. 


\section{LIST OF REFERENCES}

ASTM Standard Designation C 1074, Standard Practice for Estimating Concrete Strength by the Maturity Method, The American Society for Testing and Materials, 1998.

ASTM Standard Designation C 215, Standard Test Method for Fundamental Transverse, Longitudinal, and Torsional Frequencies for Concrete Specimens, The American Society for Testing and Materials, 1997.

ASTM Standard Designation C 231, Standard Test Method for Air Content of Freshly Mixed Concrete by the Pressure Method, The American Society for Testing and Materials, 1997.

ASTM Standard Designation C 305, Standard Practice for Mechanical Mixing of Hydraulic Cement Pastes and Mortars of Plastic Consistency, The American Society for Testing and Materials, 1999.

ASTM Standard Designation C 39, Standard Test Method for Compressive Strength of Cylindrical Concrete Specimens, The American Society for Testing and Materials, 2001.

ASTM Standard Designation C 457, Standard Test Method for Microscopical Determination of Parameters of the Air-Void System in Hardened Concrete, The American Society for Testing and Materials, 1998.

ASTM Standard Designation C 618, Standard Specification for Coal Fly Ash and Raw or Calcined Natural Pozzolan for Use as a Mineral Admixture in Concrete, The American Society for Testing and Materials, 2001.

ASTM Standard Designation C 666, Standard Test Method for Resistance of Concrete to Rapid Freezing and Thawing, The American Society for Testing and Materials, 1997.

ASTM Standard Designation C 672, Standard Test Method for Scaling Resistance of Concrete Surfaces Exposed to Deicing Chemicals, The American Society for Testing and Materials, 1998.

ASTM Standard Designation C 78, Standard Test Method for Flexural Strength of Concrete (Using Simple Beam with Third-Point Loading), The American Society for Testing and Materials, 2000. 
Attiogobe, E. K., "Predicting Freeze-Thaw Durability of Concrete - A New Approach", ACI Materials Journal, V.93, No.5, Sep - Oct 1996, pp. 457-464.

Ballim, Y., "Curing and The Durability of OPC, Fly ash and Blast-Furnace Slag Concretes”, Materials and Structures, Vol.26, 1993, pp. 238-244.

Barde, A. "Early Age Flexural Behavior of Cementitious Systems and Factors Affecting Maturity Based Predictions” M.S.C.E thesis, Purdue University, 2004

Baroghel-Bounty, "Durability of Concrete with 20 to 120 Mpa Strength”, Concrete under severe weather conditions, Vol 4, 1995.

Barrow, R.S., Hadchiti, K.M., Carrasquillo, P.M., Carrasquillo, R.L., “Temperature Rise and Durability of Concrete Containing Fly Ash”, ACI Special Publication SP-114, pp.331-348. Edited by V. M. Malhotra. American Concrete Institute, Trondheim, Norway, 1989.

Bentz, D.P., Ehlen, M.A., Ferraris, C.F., Garboczi, E.J., "Sorptivity-Based Service Life Predictions for Concrete Pavements", $7^{\text {th }}$ International Conference on Concrete Pavements - Orlando, FL, USA, Sep 2001.

Berry, E.E., Hemmings, R.T., Zhang, M.H., Cornelius, B.J., Golden, D.M., "Hydration in High Volume Fly Ash Concrete Binders”, ACI Materials Journal, Vol.91, No.4, Jul Aug 1994, pp. 382-388.

Bilodeau, A., Carette, G.G., Malhotra, V.M., Langley, W.S., "Influence of Curing and Drying on the Salt Scaling Resistance of Fly Ash Concrete", ACI Special Publication SP126, pp.201-228. Edited by V.M. Malhotra. American Concrete Institute, Detroit, 1991.

Bilodeau, A. and Malhotra, V.M. "Concrete Incorporating High Volumes of ASTM Class F Fly Ashes: Mechanical Properties and Resistance to De-Icing Salt Scaling and to Chloride- Ion Penetration" ACI Special Publication SP-132, Vol. 1, 1992, pp. 319-349 (ed.: V.M. Malhotra).

Bilodeau A. Shivasundaram, V., Painter, K.E. and Malhotra V. M. "Durability of Concrete Containing High Volume of Fly Ash from Sources in The US", ACI Materials Journal, January-February 1994, pp. 3-12

Bouzoubaâ, N., Zhang, M. H., and Malhotra, V. M., "Mechanical Properties and Durability of Concrete Made with High-Volume Fly Ash Blended Cements Using a Coarse Fly Ash”, Cement and Concrete Research, Vol.31, No.10, Oct 2001, pp. 13931402.

Bouzoubaâ, N., Fournier B., Golden D. M. and Malhotra (2002), V. M. "Mechanical Properties and Durability of Concrete Made with High-Volume Fly Ash Blended Cement 
Produced in Cement Plant” ACI Materials Journal, V. 99, No. 6, November-December 2002, pp.560-567.

Branch, Douglas (Michigan Department of Transportation, 517322 1652), "Personal Communication” February 2004.

Browne, F. P. and Cady P. D.,” Deicer Scaling Mechanism in Concrete”, American Concrete Institute special publication SP-47, pp. 101-119, 1975.

Butler, W., Baweja, D., "Long - Term Durability of Fly Ash Concretes in Civil Engineering Structures" Concrete Durability, ACI Special Publication SP 100, Vol. 1, pp. 519-540. Edited by John. M. Scanlon. American Concrete Institute, Detroit, 1987.

Byres, M., "Personal Communication”, Study Advisory Committee Meeting, July 7, 2003.

Nantung, Tommy, “Personal Communication”, Study Advisory Committee Meeting, July 7, 2003

Cable J. “Personal Communication”, Telephone conversations, February 2004.

Carino, N.J, "The Maturity Method", Handbook on Non Destructive Testing of Concrete, CRC Press, 1991, pp.101-146.

Carino, N.J., Lew, H.S., "Temperature Effects on Strength-Maturity Relations of Mortar”, ACI Journal, Proceedings, V.80, No.3, May - Jun 1983, pp. 177-182.

Carino, N.J., Lew, H.S., Volz, C.K., "Early Age Temperature Effects on Concrete Strength Prediction”, ACI Journal, Vol.80, No.10, Mar - Apr 1983, pp. 93-101.

Chengju, G., "Maturity of Concrete: Method for Predicting Early-Age Strength”, ACI Materials Journal, Vol.86, No.4, Jul - Aug 1989, pp. 341-353.

Cohen, M.D., Zhou, Y., Dolch, W.L., "Non-Air-Entrained High-Strength Concrete - Is it Frost Resistant? ”, ACI Materials Journal, Vol.89, No.2, Jul - Aug 1992, pp. 406-415.

Cohen, M.D., Olek, J., "Silica fume in PCC: The Effects of Form on Engineering Performance”, Concrete International, Nov 1989, pp. 43-47.

Collepardi, M., Marcialis, A., and Turriziani, R., "Penetration of Chloride Ions into Cement Pastes and Concretes", Journal of American Ceramic Society, V. 53, pp 534-535, 1972. 
Diamond S., Sheng Qizhong and Olek J., (1989) "Evidence for Minimum Pozzolanic Reaction in a Fly ash Cement During the Period of Major Strength Development" Materials Research Society Symposium Proceedings, Volume-137, pp. 437-446.

Dirks, D. A. (Concrete Engineer, Illinois Department of Transportation, 217782 7208), "Personal Communication”, February 2004.

Fagerlund, G., "Effect of Air Entraining and Other Admixtures on the Salt-scaling Resistance of Concrete" Paper presented at the International seminar on "Some aspects of admixtures and industrial by products on the durability of concrete" Goteburg, Sweden, 33p, 1986.

Fagerlund, G., "Studies of Scaling, the Water Uptake and the Dilation of Mortar Specimens Exposed to Freezing and Thawing in NaCl Solution”, Proceedings of RILEM TC-117 Research Seminar, Lund, Sweden, Edited by G. Fagerlund and M. J. Setzer pp. 36-66, 1992.

Fox, Thomas A.(2004), "Fly Ash in High-Performance Concrete in Transportation Structures" Presentation in TRB - Supplementary Cementing Materials Workshop, TRB 2004 Annual meeting.

Gebler, S.H., Klieger, P., "Effect of Fly Ash on the Durability of Air-Entrained Concrete", Research and Development Bulletin RD090, Portland Cement Association, http://www.portcement.org/pdf_files/RD090.pdf, 1986.

Gifford, P.M., Gillot, J.E., "Freeze-Thaw Durability of Activated Blast Furnace Slag Cement Concrete”, ACI Materials Journal, Vol.93, No.3, May-Jun 1996.

Girodet C., Bosc J. L., Chabannet M., Pera J., (1997) "Influence of Sand on the Freezethaw Resistance of the Mortar Phase of Concrete" Edited by M. J. Setzer and R. Auberg, RILEM Proceedings 34, E \& FN Spon., pp. 53-60.

Girodet C., Chabannet M., Bosc J. L., Pera J., (1997) "Influence of the Type of Cement on the Freeze-thaw Resistance of the Mortar Phase of Concrete” Edited by M. J. Setzer and R. Auberg, RILEM Proceedings 34, E \& FN Spon., pp. 31-40.

Gopalan, M. K., “Sorptivity of Fly Ash Concretes”, Cement and Concrete Research, Vol. 26, No. 8, 1996, pp. 1189-1197

Graveen C., Barde, A., and Weiss, W.J., "Practical Use of Maturity Method: The Role of Variations in Mixture Proportions on Maturity Predictions", Presented at the American Concrete Institute (ACI), Vancouver, Canada, March 2003 
Gunter, M., Bier, T. and Hilsdorf, H., Effects of Curing Type of Cement on the Resistance of Concrete to Freezing in Deicing Salt Solutions”, ACI Special Publication SP-100, Edited by J. Scanlon, pp. 877-899, 1987.

Hall, C., Water Sorptivity of Mortars and Concrete: A Review”, Magazine of Concrete Research, Vol.41, No.147, 1989, pp. 51-61

Hall, C., Yau, M.H.R., "Water Movement in Porous Building Materials IX; The Water Absorption and Sorptivity of Concretes", Building and Environment, Vol.22, 1987, pp.77-82.

Hansen, W. C. (1954), “ Effect of Age of Concrete on its Resistance to Scaling Caused by Using Calcium Chloride for Ice Removal”, Journal of American Concrete Institute, Vol. 50, 1954, pp.341-351.

Hadchiti Karim M., and Carrasquillo Ramon L., "Abrasion Resistance and Scaling Resistance of Concrete Containing Fly Ash” Research report 481-3, University of Texas at Austin, 1988.

Harnik, A. B., Meier, U. and Rosli, A. (1980), "Combined influence of freezing and deicing salt on concrete- Physical aspects", ASTM Special Technical Publication STP691, Edited by P. J. Sereda and G. G. Litvan, pp. 474-484

Henson, Todd (PCC Materials Engineer, Iowa Department of Transportation, 515239 1226), “Personal Communication” February 2004.

Hong, K., Hooton, R.D., "Effects of Cyclic Chloride Exposure on Penetration of Concrete Cover”, Cement and Concrete Research, Vol. 29, 1999, pp.1379-1386.

Hover, K., "Analytical Investigation of the Influence of Air Bubble Size on the Determination of the Air Content of Freshly Mixed Concrete", Cement, Concrete, and Aggregates, Vol.10, No.1, pp.29-34, 1988.

Indiana Climate Page "Website containing processed climatic data for Indiana" http://shadow.agry.purdue.edu/sc.index.html”"

INDOT Specifications "Indiana Department of Transportation Specifications for Contractors" http://www.in.gov/dot/div/contracts/standards/book/sep04/sep.htm, Section 500- Rigid Pavements, 1999 Standard Specification Book.

Issa, Mohsen A., Issa, Mahmoud A., and Hammad, Ahmad M., "Investigation of Popout and Scaling in Concrete Driveways”, Concrete International, Vol. 16, pp. 63-66, Aug. 1994. 
Isaac, Afrani and Chris, Rogers (1994), "The Effects of Different Cementing Materials and Curing on Concrete Scaling”, Cement Concrete and Aggregates, Vol. 16, No. 2, Dec. 1994, pp. 132-139.

Jacobsen, S., Marchand, J., Boisvert, L., Pigeon, M., Sellevold, E.J., "Frost Deicer Salt Scaling Testing of Concrete: Effect of Drying and Natural Weathering”, Cement, Concrete and Aggregates, Vol.19, No.1, 1997, pp. 8-16.

Jacobsen, S., Saether, D.H., Sellevold, E.J., "Frost Testing of High Strength Concrete: Frost/Salt Scaling at Different Cooling Rates”, Materials and Structures, Vol.30, pp. 3342, Jan - Feb 1997.

Jain, M.K., Pal, S.C., "Utilization of Industrial Slag in Making High Performance Concrete Composites”, The Indian Concrete Journal, Jun 1998, pp. 307-315.

Jackson, F. H. (1958), “Long-Time Study of Cement Performance in Concrete- Chapter 11: Report on the Condition of Three Test Pavements after 15 Years of Service,” Journal of American Concrete Institute, 29[12] pp. 1017-1032.

Janseen D. J., (1997) "The Influence of Material Parameters on Freeze-thaw Resistance With and Without Deicing Salt” Edited by M. J. Setzer and R. Auberg, RILEM Proceedings 34, E \& FN Spon., pp. 3-10.

Jansen, Daniel C., Palmquist Shane M., Swan Christopher, Al-Mufarrej Dalia, Arya Behnam, and D'Annunzio Christian O. "Physical Properties of Concrete with Vitrified Coarse Aggregate” ACI Materials Journal, V. 97, No. 3. May-June 2000, pp. 360-366

Kelham, S., “A Water Absorption Test for Concrete”, Magazine of Concrete Research, Vol.40, No.143, Jun 1988, pp. 106-110.

Klieger P. (1955) "Effect of Atmospheric Conditions During the Bleeding Period and Time of Finishing on the Scale Resistance of Concrete” ACI Journal Proceedings, Vol. 52, Nov. 1955, pp. 309-326.

Klieger P. (1957) “Curing Requirements for Scale Resistance of Concrete”, Portland Cement Association 1957, Research Department Bulletin No. 82, RX082.

Klieger P. (2003) "Further Studies on the Effect of Entrained Air on Strength and Durability of Concrete with Various Sizes of Aggregates” Reprint from highway research board bulletin 128, Concrete International, November 2003, pp. 26-45.

Klieger, P., Gebler, S., "Fly Ash and Concrete Durability”, Concrete Durability, ACI Special Publication SP 100, Vol. 1, pp. 1043-1069. Edited by John. M. Scalon. American Concrete Institute, Detroit, 1987. 
Kosmatka, S.H., Kerkhoff, B., Panarese, W.C., "Design and Control of Concrete Mixtures”, Fourteenth Edition, Engineering Bulletin 001, Portland Cement Association.

Lam, L., Wong, Y.L., Poon, C.S., "Degree of Hydration and Gel/Space Ratio of HighVolume Fly Ash/Cement Systems”, Cement and Concrete Research, Vol. 30, 2000, pp. 747-756.

Lane, D.S., Ozyildirim, C., "Combinations of Pozzolans and Ground, Granulated, Blast Furnace Slag for Durable Hydraulic Cement Concrete”, Final Report, VTRC 00-R1, Aug 1999, pp. 1-18.

Langan, B.W., Joshi, R.C., Ward, M.A., "Strength and Durability of Concretes Containing 50\% Portland Cement Replacement by Fly Ash and Other Materials", Canadian Journal of Civil Engineering, Vol. 17, 1990, pp. 19-27.

Langlois, M., Beaupré, D., Pigeon, M., Foy, C., "The Influence of Curing on the Salt Scaling Resistance of Concrete with and without Silica Fume”, ACI Special Publication SP-114, pp.971-990. Edited by V.M. Malhotra. American Concrete Institute, Detroit, 1989.

Latorella, Todd (Director of engineering, Missouri Kansas chapter of ACPA, 913381 2251), “Personal Communication” February 2004

Le Sage De Fontenay, C. and Sellevold E. J., "Ice Formation in Hardened Cement Paste”, ASTM Special Technical Publication STP-691, Edited by P. J. Sereda and G. G. Litvan, pp. 425-438, 1980.

Lilkov, V., Dimitrova, E., Petrov, O.E., "Hydration Process of Cement Containing Fly Ash and Silica Fume: The First 24 Hours”, Cement and Concrete Research, Vol.27, No.4, 1997, pp. 577-588.

Lindmark, Sture. "Mechanics of Salt Frost Scaling of Portland Cement-Bound Materials: Studies and Hypothesis" (Doctoral Thesis), Lund University, 1999. http://www.byggnadsmaterial.lth.se/pdf/TVBM-1017.pdf

Litvan G. G. (1980), "Freeze Thaw Durability of Porous Building Materials, Durability of Building Materials and Components," ASTM Special Technical Publication STP-691, Edited by P. J. Sereda and G. G. Litvan, pp. 455-463.

Litvan G. G. and Meyer A. (1986), "Carbonation of Granulated Blast Furnace Slag Cement Concrete During Twenty Years of Field Exposure”, pp. 1445-1462, ACI Special Publication, SP-91, Edited by V. M. Malhotra, American Concrete Institute, Detroit.

LTPP data "Long term pavement performance database- data for several pavements of United States and Canada” http://www.tfhrc.gov/pavement/ltpp/ltpp.htm, 2003. 
Luther, M. D., Mikols, W. J., Demaio, A. J., and Whitlinger, J. E., "Scaling Resistance of Ground Granulated Blast Furnace Slag Concretes”, ACI Special Publication SP-145-2, pp. 47-84, 1994.

Malashkie, Jerry (Chief of materials testing division, Pennsylvania Department of Transportation, 717787 4246) “Personal Communication”, February 2004.

Malhotra, V.M., "Mechanical Properties and Freezing and Thawing Resistance of NonAir-Entrained, Air-Entrained and Air-Entrained Superplasticized Concrete Using ASTM Test C 666, Procedures A and B”, Cement, Concrete, and Aggregates, Vol.4, No.1, 1982, pp.3-23.

Maltais, Y., Marchand, J., "Influence of Curing Temperature on Cement Hydration and Mechanical Strength Development of Fly Ash Mortars", Cement and Concrete Research, Vol.27, No.7, 1997, pp.1009-1020.

Manmohan, D., Mehta, P.K., "Influence of Pozzolanic, Slag, and Chemical Admixtures on Pore Size Distribution and Permeability of Hardened Cement Pastes”, Cement, Concrete and aggregates, Vol.3, No.1, pp 63-67, 1981.

Marchand J., Maltais Y., Machabee Y., Talbot C., and Pigeon M., (1997) “Effects of Fly Ash on Microstructure and Deicer Salt Scaling Resistance of Concerete” Edited by M. J. Setzer and R. Auberg, RILEM Proceedings 34, E \& FN Spon., pp. 11-20.

Marchand, J., Pigeon, M., Boisvert, J., Isabelle. H.L., Houdusse, O., “Deicer Salt Scaling Resistance of Roller-Compacted Concrete Pavements Containing Fly Ash and Silica Fume”, ACI Special Publication SP 132, pp.151-178. Edited by V.M. Malhotra. American Concrete Institute, Istanbul, Turkey, 1992.

Marchand, J., Pleau, R., Pigeon, M., "Precision of Tests for Assessment of Deicer Salt Scaling Resistance of Concrete”, Cement, Concrete and Aggregates, Vol.18, No.2, 1996, pp.85-91.

Marchand, J., Pleau, R., Gagne, R., "Deterioration of Concrete Due to Freezing and Thawing”, Materials Science of Concrete IV, 2000, pp. 283-354.

Marchand J., Sellevold E. J., Pigeon M., “The Deicer Salt Scaling Deterioration of Concrete an Overview.” ACI Special Publication SP-145, pp. 1-45, 1994.

Martys, N.S., Ferraris, C.F., “Capillary Transport in Mortars and Concrete”, Cement and Concrete Research”, Vol. 27, No.5, 1997, 747-760.

Marzouk, H.M., Hussein, A., "Properties of High Strength Concrete at Low Temperatures”, ACI Materials Journal, Vol.87, No.2, Mar - Apr 1990, pp. 167-171. 
Marzouk, H.M., Hussein, A., "Effect of Curing Age on High-Strength Concrete at Low Temperatures”, Journal of Materials in Civil Engineering, Vol.7, No.3, Aug 1995, pp. 160-167.

McCarter, W.J., "Influence of Surface Finish on Sorptivity of Concrete”, Journal of Materials in Civil Engineering, Vol. 5, No.1, Feb 1993, pp. 130-136.

McIntosh, J.D., “The Effect of Low-Temperature Curing on the Compressive Strength of Concrete”, Proc. Rilem Symp. On Winter Concreting, Danish Institute for Building Research Copenhagen, Session BII, Copenhagen 1956

Mehta, P.K., “ Pozzolanic and Cementitious By-Products in Concrete- Another Outlook”, ACI Special Publication SP- 114, pp. 1-43, Edited by V. M. Malhotra, American Concrete Institute, Trondheim, Norway, 1989.

Mehta, P.K., Monteiro, P.J.M., “Concrete, Microstructure, Properties and Materials”, Indian edition, 1997.

Mehta, J. "Scaling Resistance of Fly Ash Concrete for Late Fall Paving Applications" M.S.Thesis., Purdue University, December 2004.

Naik, T.R., Ramme, B.W., Tews, J.H., "Pavement Construction with High Volume Class C and Class F Fly Ash Concrete”, ACI Materials Journal, Vol. 92, March - April 1995, pp. 200-210.

Naik, T.R., Ramme, B.W., Kraus R. N., and Siddique R.,(2003) "Long-Term Performance of High-Volume Fly Ash Concrete Pavements” ACI Materials Journal, V. 100, No. 2, March-April 2003, pp. 150-155.

Naik, T.R., Singh, S.S., Hossain, M.M., “Abrasion Resistance of High-Strength Concrete Made with Class C fly ash”, ACI Materials Journal, Vol.92, No.67, Nov-Dec 1995, pp.649-659.

Naik, T., Singh, S.S., "Influence of Fly Ash on Setting and Hardening Characteristics of Concrete Systems”, ACI Materials Journal, Vol.94, No.5, Sep - Oct 1997, pp. 355-360.

Naik, T.R., Singh, S.S., and Ramme Bruce (1998) "Mechanical Properties and Durability of Concrete Made with Blended Fly Ash” ACI Materials Journal, Vol. 95, No. 4, JulyAugust 1998, pp. 454-462.

Naik, T., Singh, S.S., "Superplasticized Structural Concrete Containing High Volumes of Class C Fly Ash”, Journal of Energy Engineering, Vol.117, No.2, Aug 1991, pp. 87-96. 
Nasser, K.W., Lai, P.S.H., "Resistance of Fly Ash Concrete to Freezing and Thawing”, ACI Special Publication SP-132, pp.205-226. Edited by V.M. Malhotra. American Concrete Institute, Istanbul, Turkey, 1992.

Neville, A.M., “Properties of concrete”, Fourth Edition, 1996.

Neuwald A., Krishnan A., Weiss J., Olek J., Nantung T., "Concrete Curing and its Relationship to Measured Scaling in Concrete Containing Fly Ash” TRB 2003 Annual Meeting Presentation

Okamoto, P.A., Whiting, D., "Use of Maturity Method and Pulse Velocity Techniques to Predict Strength Gain of Rapid Concrete Pavement Repairs During Curing Period”, Transportation Research Record 1458, 1994, pp. 85-90.

Ozturan T., Bastopcu M. E., "Effects of Curing on Durability of Fly Ash Concrete” ACI Special Publication 212, June 2003, pp. 353-368.

Ozyildirim, C., "Laboratory Investigation of Low-Permeability Concretes Containing Slag and Silica Fume”, ACI Materials Journal, Vol.91, No.2, Mar - Apr 1994, pp. 197202.

Parry, Jim, (Physical and chemical tests supervisor, Wisconsin Department of Transportation, 608246 7939), “Personal Communication”, February 2004.

Parsons, W. H., Johnson, W. H. (1944), "Factors Affecting the Thermal Expansion of Concrete Aggregate Materials,” Proceeding American Concrete Institute, Vol. 40, pp. 457-466.

Pearson, J. C., "A Concrete Failure Attributed to Aggregate of Low Thermal Coefficient,” Proceedings, American Concrete Institute, Vol. 38, 1942, pp. 29-34.

Pigeon, M., Pleau, R., Aitcin, P.C., "Freeze Thaw Durability of Concrete with and Without Silica Fume in ASTM C666 (Procedure A) Test Method: Internal Cracking Versus Scaling”, Cement, Concrete, and Aggregates, Vol. 8, No.2, 1976, pp. 76-85.

Pigeon, M., Prevost, J., Simard, J.M., "Freeze-Thaw Durability vs. Freezing Rate”, Journal of American Concrete Institute, Vol.82, 1985, pp. 684-692.

Pigeon, M., Gagne, R., Foy, C., "Critical Air-Void Spacing Factors with Low Water to Cement Ratio Concretes with and without Condensed Silica Fume”, Cement and Concrete Research, Vol.17, 1987, pp. 896-906.

Pigeon, M., Talbot, C., Marchand, J., Hornain, H., "Surface Microstructure and Scaling Resistance of Concrete”, Cement and Concrete Research, Vol.26, No.10, 1996, pp. 15551566. 
Pigeon, M., Perraton, D. and Pleau, R. "Scaling Test of Silica Fume Concrete and the Critical Spacing Factor Concept”, ACI Special Publication SP-100, Edited by J. Scanlon, pp.1155-1182, 1987.

Pinto, R.C.A., Hover, K.C., “Application of Maturity Approach to Setting Times”, ACI Materials Journal, Vol.96, No.6, Nov-Dec 1999, pp. 686-691.

Powers, T. C. (1945), “A Working Hypothesis for Further Studies of Frost Resistance of Concrete”, Proceeding American Concrete Institute, Vol. 41, 1945, pp. 245-272

Powers, T.C. (1949), “The Air Requirement of Frost-Resistant Concrete”, Proceedings, Highway Research Board, V.29, 1949, pp.184-202, and Discussion, pp.203-211.

Powers, T.C. (1953), Helmuth, R. A. "Theory of Volume Changes in Hardened PortlandCement Paste during Freezing”, Proceedings, Highway Research Board, V.32, 1953, PCA Bulletin 46, 1953.

Ramezanianpour, A.A., Malhotra, V.M., "Effect of Curing on the Compressive Strength, Resistance of Chloride-Ion Penetration and Porosity of Concretes Incorporating Slag, Fly Ash or Silica Fume”, Cement and Concrete Composites, Vol.17, 1995, pp.125-133.

Rodway, L.E., "Effect of Air-Entraining Agent on Air-Void Parameters of Low and High Calcium Fly Ash Concretes”, Cement, Concrete, and Aggregates, Vol. 10, No.1, 1998, pp.35-38.

Rosli, A. and Hanrik A. B., "Improving the Durability of Concrete to Freezing and Deicing Salts”, Durability of building materials and components, ASTM Special Technical Publication STP-691, Edited by P. J. Sereda and G. G. Litvan, pp. 464-473, 1980.

Roy, D.M., "Fly Ash and Silica Fume Chemistry and Hydration”, ACI Special Publication SP-114, pp.117-138. Edited by V. M. Malhotra. American Concrete Institute, Trondheim, Norway, 1989.

Sarkar, S.L., Baalbaki, M., Aiticin, P.C., "Microstructural Development in High Strength Concrete Containing a Ternary Cementitious System” Cement Concrete and Aggregates, Vol.13, No.2, 1991, pp.81-87.

Saucier, F., Pigeon, M., Cameron, J., “Air Void Stability-Part V: Temperature, General Analysis, and Performance Index”, ACI Materials Journal, Vol.88, 1991, pp.25-36.

Sellevold, E. J. and Farstad, T., "Frost/Salt Testing of Concrete: Effect of Test Parameters and Concrete Moisture History”, Nordic Concrete Research, Vol. 10, pp. 121138, 1991. 
Setzer M. J., "Basic Phenomena of Frost Action”, Proceedings of RILEM TC-117 Research Seminar, Lund, Sweden, Edited by G. Fagerlund and M. Setzer pp. 5-17.

Setzer M. J. "Action of Frost and Deicing Chemicals: Basic Phenomenon and Testing” freeze-Thaw durability of concrete, RILEM proceedings 30, 1997.

Sharma, R.L., Pandey, S.P, "Influence of Mineral Additives on the Hydration Characteristics of Ordinary Portland Cement “, Cement and Concrete Research, Vol. 29, 1999, pp. 1525-1529.

Slate, F. O., "Chemical Reactions of Indiana Aggregate in Disintegration of Concrete," Proceedings American Society of Testing Materials, Vol. 49, 1949, pp. 954-961.

Snyder, M. J., "Protective Coatings to Prevent Deterioration of Concrete by Deicing Chemicals”, National cooperative highway research program report 16, Highway Research board of the division of engineering and industrial research, National academy of science, national research council, 1965.

Snyder, Mark, (Concrete Paving Association of Minnesota) "An Evaluation of Concrete Flatwork Durability Problems in Minnesota”, Aggregate and Ready-mix Association of Minnesota, April 1998.

Streeter D. (Materials Bureau, New York State Department of Transportation, 518457 5956), “Personal Communication” January 2004.

Struble, Bryan, (Concrete Engineer, Ohio Department of Transportation, 614275 1325), "Personal Communication”, February 2004.

Studer W., "Internal Comparative Tests on Frost Deicing Salt Resistance” freeze-Thaw durability of concrete, RILEM proceedings 30, 1997.

Sturrup, V.R., Hooton, D.R., Clendenning, T.G., "Durability of Fly Ash Concrete”, ACI Special Publication SP-79, pp.71-86. Edited by V.M. Malhotra. American Concrete Institute, Detroit, 1983.

Stark David C., Kosmatka Steven H., Farny James A., and Tennis Paul D., (2002), "Performance of concrete specimen in the PCA outdoor test facility", Research Development Bulletin No. RD 124.

Stark J., Eckart A., Ludwig H. M., (1997) "Influence of $\mathrm{C}_{3} \mathrm{~A}$ Content on Frost and Scaling Resistance of Concrete" Frost Resistance of Concrete, Edited by M. J. Setzer and R. Auberg, RILEM Proceedings 34, E \& FN Spon., pp. 100-110. 
Swenson, E.G., “CBD-116. Durability of Concrete Under Winter Conditions”, Canadian Building Digest, http://www.nrc.ca/irc/cbd/cbd116e.html, 1969.

Tan, X., Pu, X., "Strengthening Effects of Finely Ground Fly ash, Granulated Blast Furnace Slag, and their Combination”, Cement and Concrete Research, Vol.28, No.12, 1998, pp. 1819-1825.

Tank, R.C., Carino, N.J., "Rate Constant Functions for Strength Development of Concrete”, ACI Materials Journal, Vol.88, No.1, Jan - Feb 1991, pp. 74-83.

Thomas, M.D.A. "Laboratory and Field Studies of Salt Scaling in Fly Ash Concrete" Frost Resistance of Concrete, Edited by M. J. Setzer and R. Auberg, RILEM Proceedings 34, E \& FN Spon., pp. 21-30.

Thomas, M.D.A, Mathews, J.D., "Effect of Curing on Durability of Fly Ash Concrete”, Transportation Research Record 1458, 1994, pp. 99-108.

Thomas, M.D.A., Shehata, M.H., Shashiprakash, S.G., Hopkins, D.S., Cail, K., "Use of Ternary Cementitious Systems Containing Silica Fume and Fly Ash in Concrete”, Cement and Concrete Research, Vol.29, 1999, pp.1207-1214.

Thomas, M.D.A. (2000), “Deicer Salt Scaling Resistance of Fly Ash Concrete- The Lab. vs. the Field”, Presentation in ACI fall 2000 convention.

Uomoto, T., Kobayashi, K., "Effect of Curing Temperature and Humidity on Strength of Concrete Containing Blast Furnace Slag Admixture”, ACI Special Publication SP 114, pp. 1345-1364. Edited by V. M. Malhotra. American Concrete Institute, Trondheim, Norway, 1989.

Verbeck, G. and Klieger, P. "Studies of “salt” scaling of concrete”, Highway Research Board Bulletin, $\mathrm{N}^{0} 150$, Washington D. C. 1957, pp. 1-17.

Virtanen J., “ Field Study on the Effects of Additions on the Salt Scaling Resistance of Concrete” Nordic Concrete Research, Vol. 9, pp. 197-212 (1990).

Voigt G. (Chief operating officer, Illinois Department of Transportation, 847966 2272), “Personal Communication” January 2004

Wainwright and Ait-Aider H., "The Influence of Cement Source and Slag Additions on the Bleeding of Concrete" Cement and Concrete Research, Vol. 25, No. 7, pp. 14451456, 1995.

Whiting, D., Dziedzic, W., “Chloride Permeability of Rigid Concrete Bridge Deck Overlays”, Transportation Research Record 1234, pp. 24-29. 
Whiting David, “Strength and Durability of Residential Concretes Containing Fly Ash" Portland Cement Association, Research and Development Bulletin RD0099.01T, 1989

Whiting, D., “Deicer Scaling Resistance of Lean Concretes Containing Fly Ash”, ACI Special Publication SP-114, pp. 340-371, 1989.

Wimpenny, D.E., Ellis, C., Reeves, C.M., Higgins, D.D., “The Development of Strength and Elastic Properties in Slag Cement Concretes Under Low Temperature Curing Conditions”, ACI Special Publication SP-114, pp.1283-1306. Edited by V. M. Malhotra. American Concrete Institute, Trondheim, Norway, 1989.

Wong, Y.L., Lam, L., Poon, C.S., Zhou, F.P., “ Properties of Fly Ash-Modified Cement Mortar-Aggregate Interfaces”, Cement and Concrete Research, Vol.29, 1999, pp.19051913.

Woolstrum, George (Portland Cement Concrete And Physical Test Engineer, Nebraska Department of Roads, 402479 4791) “Personal Communication” February 2004.

Zeller, M. (Director of Engineering services, Concrete Paving Association of Minnesota, 763-561-0402) “Personal Communication”, February 2004.

Zink R. (E \& B Paving, Rochester, Indiana, 574223 4644), “Cold Weather Concrete Field Study”, Submitted to INDOT Materials and Test Division, 2000. 
APPENDIX A - MIXTURE PROPORTION FOR CONCRETE PREPARATION 
Table A1: Mixture proportion for concrete preparation

\begin{tabular}{|l|c|}
\hline Cement & $515 \mathrm{lb} / \mathrm{yd}^{3}$ \\
\hline Water & $226 \mathrm{lb} / \mathrm{yd}^{3}$ \\
\hline Fine Aggregate (SSD) & $1485 \mathrm{lb} / \mathrm{yd}^{3}$ \\
\hline Coarse Aggregate (SSD) & $1665 \mathrm{lb} / \mathrm{yd}^{3}$ \\
\hline Water Reducer & $1256 \mathrm{ml}$ \\
\hline Air Entraining Agent & $134 \mathrm{ml}$ \\
\hline Cement & $515 \mathrm{lb} / \mathrm{yd}^{3}$ \\
\hline
\end{tabular}

Note: 1 . Water to cementitious $(\mathrm{w} / \mathrm{cm})$ ratio for mortar and paste mixtures $=0.41$

2. Water to cementitious $(\mathrm{w} / \mathrm{cm})$ ratio for concrete mixtures $=0.44$ 
APPENDIX B - STRENGTH DATA FOR MORTARS 
Table B1: Strength data for mixture M01

\begin{tabular}{|c|c|c|c|c|c|c|}
\hline \multicolumn{7}{|c|}{ M01 (Lonestar cement + Rockport fly ash) } \\
\hline \multicolumn{2}{|r|}{ ( 0.5 day) } & \multicolumn{3}{|c|}{ (1.5 day) } & \multirow[b]{2}{*}{ T1 (lbs) } & \multirow[b]{2}{*}{ Strength (psi) } \\
\hline & T23 (lbs) & Strength (psi) & T10 (lbs) & Strength (psi) & & \\
\hline 1 & 2582 & 645.5 & \begin{tabular}{|r|}
4508 \\
\end{tabular} & \begin{tabular}{|r|}
1127 \\
\end{tabular} & & \\
\hline 2 & 2556 & 639 & 4413 & 1103.25 & & \\
\hline 3 & 2591 & 647.75 & 4018 & 1004.5 & & \\
\hline \multicolumn{2}{|c|}{ Avg } & \multicolumn{3}{|r|}{1078.25} & & \\
\hline \multirow{2}{*}{\multicolumn{2}{|c|}{ (1 day) }} & & & & & \\
\hline & & Strength (psi) & T10 (lbs) & Strength (psi) & T1 (lbs) & Strength (psi) \\
\hline 1 & 9514 & 2378.5 & 2723 & $\begin{array}{r}680.75 \\
\end{array}$ & 235 & 58.75 \\
\hline 2 & 9108 & 2277 & 2658 & 664.5 & 217 & 54.25 \\
\hline 3 & 9808 & 2452 & 2771 & 692.75 & 238 & 59.5 \\
\hline \multicolumn{2}{|c|}{ Avg } & 2369.17 & & 679.33 & & 57.50 \\
\hline \multirow{2}{*}{\multicolumn{2}{|c|}{$\begin{array}{l}\text { ( } 3 \text { day) } \\
\text { T23 }\end{array}$}} & & & & & \\
\hline & & Strength (psi) & \begin{tabular}{|l|l} 
T10 (lbs) \\
\end{tabular} & Strength (psi) & T1 (lbs) & Strength (psi) \\
\hline 1 & 15250 & 3812.5 & 11200 & 2800 & 6151 & 1537.75 \\
\hline 2 & 16620 & 4155 & 11790 & 2947.5 & 6086 & 1521.5 \\
\hline 3 & 15270 & 3817.5 & 12280 & 3070 & 6102 & 1525.5 \\
\hline \multicolumn{2}{|c|}{ Avg } & 3983.75 & & 2873.75 & & 1528.25 \\
\hline \multirow{2}{*}{\multicolumn{2}{|c|}{$\begin{array}{l}\text { ( } 7 \text { day) } \\
\text { T23 }\end{array}$}} & & & & & \\
\hline & & Strength (psi) & T10 (lbs) & Strength (psi) & T1 (lbs) & Strength (psi) \\
\hline 1 & 19240 & 4810 & \begin{tabular}{|r|}
15760 \\
\end{tabular} & \begin{tabular}{|r|}
3940 \\
\end{tabular} & 11490 & 2872.5 \\
\hline 2 & 20220 & 5055 & 17130 & 4282.5 & 12500 & 3125 \\
\hline 3 & 17530 & 4382.5 & 15440 & 3860 & 11950 & 2987.5 \\
\hline \multicolumn{2}{|c|}{ Avg } & 4749.17 & & 4027.50 & & 2995.00 \\
\hline \multirow{2}{*}{\multicolumn{2}{|c|}{$\begin{array}{l}\text { ( } 28 \text { day) } \\
\text { T23 }\end{array}$}} & & & & & \\
\hline & & Strength (psi) & \begin{tabular}{|l|} 
T10 (lbs) \\
\end{tabular} & \begin{tabular}{|l|} 
Strength (psi) \\
\end{tabular} & \begin{tabular}{|l|}
$\mathrm{T} 1$ (lbs) \\
\end{tabular} & Strength (psi) \\
\hline 1 & 24210 & 6052.5 & $\begin{array}{r}22880 \\
\end{array}$ & 5720 & 19020 & \\
\hline 2 & 25540 & 6385 & 23620 & 5905 & 23250 & 5812.5 \\
\hline 3 & 24730 & 6182.5 & 23530 & 5882.5 & 21520 & 5380 \\
\hline \multicolumn{2}{|c|}{ Avg } & 6206.67 & & 5835.83 & & 5596.25 \\
\hline \multicolumn{2}{|r|}{ (90day) } & & & & & \\
\hline & T23 & Strength (psi) & T10 (lbs) & Strength (psi) & T1 (lbs) & Strength (psi) \\
\hline \multicolumn{7}{|c|}{ 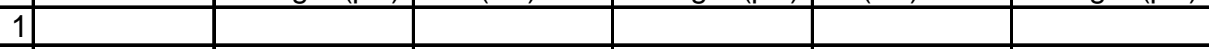 } \\
\hline \multirow{2}{*}{\multicolumn{2}{|c|}{\begin{tabular}{l|l}
2 \\
3
\end{tabular}}} & & & & & \\
\hline & & & & & & \\
\hline
\end{tabular}

T23 (lbs)- Failure load in lbs for specimens cured at $23^{\circ} \mathrm{C}$ T10 (lbs)- Failure load in lbs for specimens cured at $10^{\circ} \mathrm{C}$ $\mathrm{T} 1$ (lbs)- Failure load in lbs for specimens cured at $1{ }^{\circ} \mathrm{C}$ Strength (psi) - Compressive strength in psi 
Table B2: Strength data for mixture M02

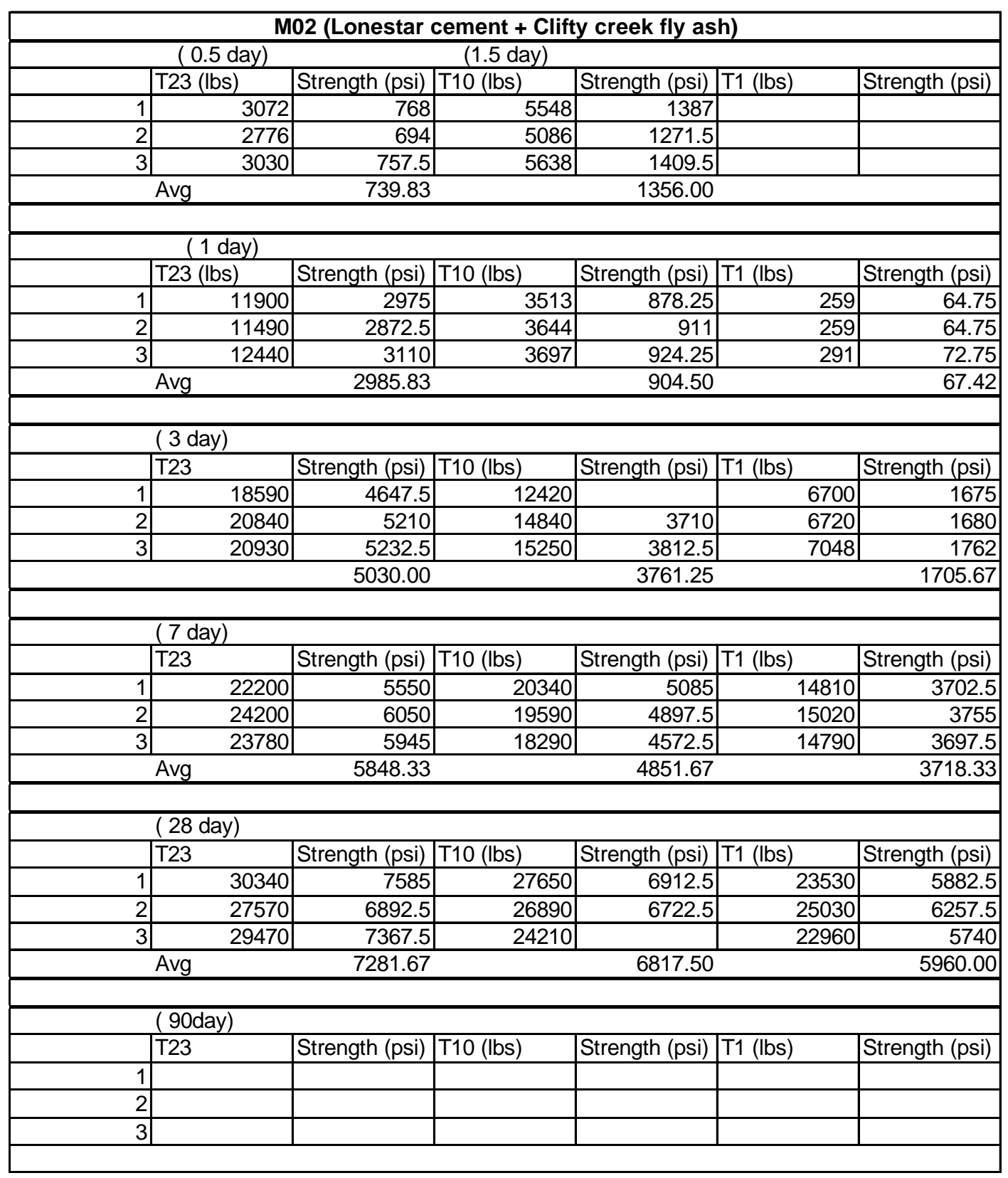


Table B3: Strength data for mixture M03

\begin{tabular}{|c|c|c|c|c|c|c|}
\hline \multicolumn{7}{|c|}{ M03 (Lonestar cement + Miami Fort fly ash) } \\
\hline \multicolumn{3}{|c|}{ ( 0.5 day) } & \multicolumn{4}{|c|}{ ( 0.5 day) } \\
\hline & T23 (lbs) & Strength (psi) & T10 (lbs) & Strength (psi) & T1 (lbs) & Strength (psi) \\
\hline 1 & 3449 & 862.25 & 303 & 101.00 & & \\
\hline 2 & 3334 & 833.50 & 272 & 90.67 & & \\
\hline 3 & 3584 & 896.00 & 287 & 95.67 & & \\
\hline \multicolumn{2}{|c|}{ Avg } & \multicolumn{2}{|l|}{863.92} & \multicolumn{2}{|l|}{95.78} & \\
\hline \multicolumn{7}{|c|}{ ( 1 day) } \\
\hline \multicolumn{2}{|c|}{ T23 (lbs) } & Strength (psi) & T10 (lbs) & Strength (psi) & T1 (lbs) & Strength (psi) \\
\hline 1 & 8152 & 2038 & 3535 & 1178.33 & 641 & 213.67 \\
\hline 2 & 8790 & 2197.5 & 3408 & 1136.00 & 770 & 256.67 \\
\hline 3 & 8763 & 2190.75 & 2882 & & & \\
\hline \multicolumn{2}{|c|}{ Avg } & \multicolumn{2}{|l|}{2142.08} & \multicolumn{2}{|l|}{1157.17} & 235.17 \\
\hline \multicolumn{7}{|c|}{ ( 3 day) } \\
\hline & T23 & Strength (psi) & T10 (lbs) & Strength (psi) & T1 (lbs) & Strength (psi) \\
\hline 1 & 12150 & 3037.5 & 11570 & 2892.5 & 7537 & 1884.25 \\
\hline 2 & 13190 & 3297.5 & 11730 & 2932.5 & 6465 & 1616.25 \\
\hline 3 & 12620 & 3155 & 12420 & 3105 & 7663 & 1915.75 \\
\hline \multicolumn{2}{|c|}{ Avg } & \multicolumn{2}{|l|}{3167.5} & \multicolumn{2}{|l|}{2912.50} & 1805.42 \\
\hline \multicolumn{7}{|c|}{ ( 7 day) } \\
\hline \multicolumn{2}{|c|}{ T23 } & Strength (psi) & T10 (lbs) & Strength (psi) & \begin{tabular}{|l|} 
T1 (lbs) \\
\end{tabular} & Strength (psi) \\
\hline 1 & 14440 & 3610 & 13820 & 3455 & \begin{tabular}{|r|}
11810 \\
\end{tabular} & 2952.5 \\
\hline 2 & 12820 & & 14380 & 3595 & 11790 & 2947.5 \\
\hline 3 & 14990 & 3747.5 & 17080 & & 14140 & \\
\hline \multicolumn{2}{|c|}{ Avg } & \multicolumn{2}{|l|}{3678.75} & \multicolumn{2}{|l|}{3525.00} & 2950.00 \\
\hline \multicolumn{7}{|c|}{ ( 28 day) } \\
\hline \multicolumn{2}{|c|}{ T23 } & Strength (psi) & T10 (lbs) & Strength (psi) & T1 (lbs) & Strength (psi) \\
\hline 1 & 20608 & 5152 & 21970 & 5492.5 & \begin{tabular}{|r|}
20500 \\
\end{tabular} & 5125 \\
\hline 2 & 20810 & 5202.5 & 21890 & 5472.5 & 20480 & 5120 \\
\hline 3 & 20406 & 5101.5 & 22050 & 5512.5 & 20460 & 5115 \\
\hline \multicolumn{2}{|c|}{ Avg } & 5152.00 & & 5492.50 & & 5120.00 \\
\hline \multicolumn{7}{|c|}{ (90day) } \\
\hline \multicolumn{2}{|c|}{ T23 } & Strength (psi) & T10 (lbs) & Strength (psi) & \begin{tabular}{|l|} 
T1 (lbs) \\
\end{tabular} & Strength (psi) \\
\hline 1 & 25490 & & 22430 & 5607.5 & \begin{tabular}{|r|}
23960 \\
\end{tabular} & 5990 \\
\hline 2 & 22940 & 5735 & 23510 & 5877.5 & 20360 & \\
\hline 3 & 22940 & 5735 & 18880 & & 23590 & 5897.5 \\
\hline & Avg & 5735.00 & & 5742.50 & & 5943.75 \\
\hline
\end{tabular}


Table B4: Strength data for mixture M04

\begin{tabular}{|c|c|c|c|c|c|c|}
\hline \multicolumn{7}{|c|}{ M04 (Lonestar cement + Will county fly ash) } \\
\hline & \multicolumn{2}{|l|}{ ( 0.5 day) } & \multicolumn{4}{|c|}{ ( 0.5 day) } \\
\hline & T23 (lbs) & Strength (psi) & T10 (lbs) & Strength (psi) & T1 (lbs) & Strength (psi) \\
\hline 1 & 2559 & 639.75 & 81 & 20.25 & & \\
\hline 2 & 2451 & 612.75 & 71 & 17.75 & & \\
\hline 3 & 2513 & 628.25 & 56 & 14 & & \\
\hline \multicolumn{2}{|c|}{ Avg } & \multicolumn{2}{|l|}{626.92} & \multicolumn{2}{|l|}{17.33} & \\
\hline \multicolumn{7}{|c|}{ ( 1 day) } \\
\hline \multicolumn{2}{|r|}{ T23 (lbs) } & Strength (psi) & T10 (lbs) & Strength (psi) & T1 (lbs) & Strength (psi) \\
\hline 1 & 8252 & 2063 & 3532 & 883.00 & 315 & 78.75 \\
\hline 2 & 7903 & 1975.75 & 4305 & 1076.25 & 270 & 67.50 \\
\hline 3 & 8768 & 2192 & 3226 & 806.50 & 342 & \\
\hline \multicolumn{2}{|c|}{ Avg } & \multicolumn{2}{|l|}{2076.92} & \multicolumn{2}{|l|}{921.92} & 73.13 \\
\hline \multicolumn{7}{|c|}{ ( 3 day) } \\
\hline \multicolumn{2}{|c|}{ T23 } & Strength (psi) & T10 (lbs) & Strength (psi) & T1 (lbs) & Strength (psi) \\
\hline 1 & 13720 & 3430 & 11850 & & 6007 & 1501.75 \\
\hline 2 & 13460 & 3365 & 9174 & 2293.5 & 5378 & 1344.5 \\
\hline 3 & 14390 & 3597.5 & 9068 & 2267 & 4561 & \\
\hline \multicolumn{2}{|c|}{ Avg } & \multicolumn{2}{|l|}{3397.5} & \multicolumn{2}{|l|}{2293.50} & 1423.13 \\
\hline \multicolumn{7}{|c|}{ ( 7 day) } \\
\hline \multicolumn{2}{|c|}{ T23 } & Strength (psi) & T10 (lbs) & Strength (psi) & T1 (lbs) & Strength (psi) \\
\hline 1 & 13660 & & 14110 & 3527.5 & 12700 & 3175 \\
\hline 2 & 15040 & 3760 & 14610 & 3652.5 & 12120 & 3030 \\
\hline 3 & 15880 & 3970 & 17590 & & 13175 & 3293.75 \\
\hline \multicolumn{2}{|c|}{ Avg } & \multicolumn{2}{|l|}{3865.00} & \multicolumn{2}{|l|}{3590.00} & 3166.25 \\
\hline \multicolumn{7}{|c|}{ ( 28 day) } \\
\hline & T23 & Strength (psi) & T10 (lbs) & Strength (psi) & T1 (lbs) & Strength (psi) \\
\hline 1 & 19145 & 4786.25 & 20480 & 5120 & 19800 & 4950 \\
\hline 2 & 19145 & 4786.25 & 20000 & 5000 & 19600 & 4900 \\
\hline 3 & 19205 & 4801.25 & 20840 & 5210 & 19820 & 4955 \\
\hline \multicolumn{2}{|c|}{ Avg } & \multicolumn{2}{|l|}{4791.25} & \multicolumn{2}{|l|}{5110.00} & 4935.00 \\
\hline \multicolumn{7}{|c|}{ (90day) } \\
\hline \multicolumn{2}{|c|}{ T23 } & Strength (psi) & T10 (lbs) & Strength (psi) & T1 (lbs) & Strength (psi) \\
\hline 1 & 22510 & 5627.5 & 24000 & 6000 & 20040 & 5010 \\
\hline 2 & 22530 & 5632.5 & 23320 & 5830 & 21650 & 5412.5 \\
\hline 3 & 22510 & 5627.5 & 22085 & 5521.25 & 20070 & 5017.5 \\
\hline & Avg & 5629.17 & & 5783.75 & & 5146.67 \\
\hline
\end{tabular}


Table B5: Strength data for mixture M05

\begin{tabular}{|c|c|c|c|c|c|c|}
\hline \multicolumn{7}{|c|}{ M05 (Lehigh cement + Rockport fly ash) } \\
\hline \multicolumn{3}{|c|}{ ( 0.5 day) } & \multicolumn{4}{|c|}{ ( 0.5 day) } \\
\hline & T23 (lbs) & Strength (psi) & T10 (lbs) & Strength (psi) & T1 (lbs) & Strength (psi) \\
\hline 1 & 3004 & 751 & 127 & 31.75 & & \\
\hline 2 & 2951 & 737.75 & 136 & 34 & & \\
\hline 3 & 2989 & 747.25 & 149 & 37.25 & & \\
\hline \multicolumn{2}{|c|}{ Avg } & \multicolumn{2}{|l|}{745.33} & \multicolumn{2}{|l|}{34.33} & \\
\hline \multicolumn{7}{|c|}{ ( 1 day) } \\
\hline \multicolumn{2}{|c|}{ T23 (lbs) } & Strength (psi) & T10 (lbs) & Strength (psi) & T1 (lbs) & Strength (psi) \\
\hline 1 & 9176 & 2294 & 2377 & $\begin{array}{r}594.25 \\
\end{array}$ & 195 & 48.75 \\
\hline 2 & 8315 & 2078.75 & 2552 & 638 & 209 & 52.25 \\
\hline 3 & 8249 & 2062.25 & 2555 & 638.75 & 206 & 51.5 \\
\hline \multicolumn{2}{|c|}{ Avg } & \multicolumn{2}{|l|}{2145.00} & \multicolumn{2}{|l|}{623.67} & 50.83 \\
\hline \multicolumn{7}{|c|}{ ( 3 day) } \\
\hline & T23 & Strength (psi) & T10 (lbs) & Strength (psi) & T1 (lbs) & Strength (psi) \\
\hline 1 & 13050 & 3262.5 & 10160 & 2540 & 5582 & 1395.5 \\
\hline 2 & 13400 & 3350 & 12410 & 3102.5 & 5335 & 1333.75 \\
\hline 3 & 11320 & 2830 & 11020 & 2755 & 4809 & 1202.25 \\
\hline \multicolumn{2}{|c|}{ Avg } & \multicolumn{2}{|l|}{3147.50} & \multicolumn{2}{|l|}{2799.17} & 1310.50 \\
\hline \multicolumn{7}{|c|}{ ( 7 day) } \\
\hline & T23 & Strength (psi) & T10 (lbs) & Strength (psi) & T1 (lbs) & Strength (psi) \\
\hline 1 & 16770 & 4192.5 & 12930 & $\begin{array}{r}3232.5 \\
\end{array}$ & 11630 & 2907.5 \\
\hline 2 & 16540 & 4135 & 13310 & 3327.5 & 11360 & 2840 \\
\hline 3 & 13520 & & 15120 & & 10810 & 2702.5 \\
\hline \multicolumn{2}{|c|}{ Avg } & \multicolumn{2}{|l|}{3902.50} & \multicolumn{2}{|l|}{3446.67} & 2816.67 \\
\hline \multicolumn{7}{|c|}{ ( 28 day) } \\
\hline \multicolumn{2}{|c|}{ T23 } & Strength (psi) & T10 (lbs) & Strength (psi) & T1 (lbs) & Strength (psi) \\
\hline 1 & 20050 & 5012.5 & 20590 & 5147.5 & 18040 & 4510 \\
\hline 2 & 20330 & 5082.5 & 19770 & 4942.5 & 12100 & \\
\hline 3 & 19250 & 4812.5 & 19930 & 4982.5 & 18130 & 4532.5 \\
\hline \multicolumn{2}{|c|}{ Avg } & \multicolumn{2}{|l|}{4969.167} & \multicolumn{2}{|l|}{5024.167} & 4521.250 \\
\hline \multicolumn{2}{|r|}{ (90day) } & & & & & \\
\hline \multicolumn{2}{|c|}{ T23 } & Strength (psi) & T10 (lbs) & Strength (psi) & T1 (lbs) & Strength (psi) \\
\hline 1 & 21860 & 5465 & 25870 & $\begin{array}{r}6467.5 \\
\end{array}$ & 17730 & \\
\hline 2 & 23440 & 5860 & 20430 & & 21310 & 5327.5 \\
\hline 3 & 21630 & 5407.5 & 24410 & 6102.5 & 21790 & 5447.5 \\
\hline & Avg & 5577.50 & & 6285 & & 5387.5 \\
\hline
\end{tabular}


Table B6: Strength data for mixture M06

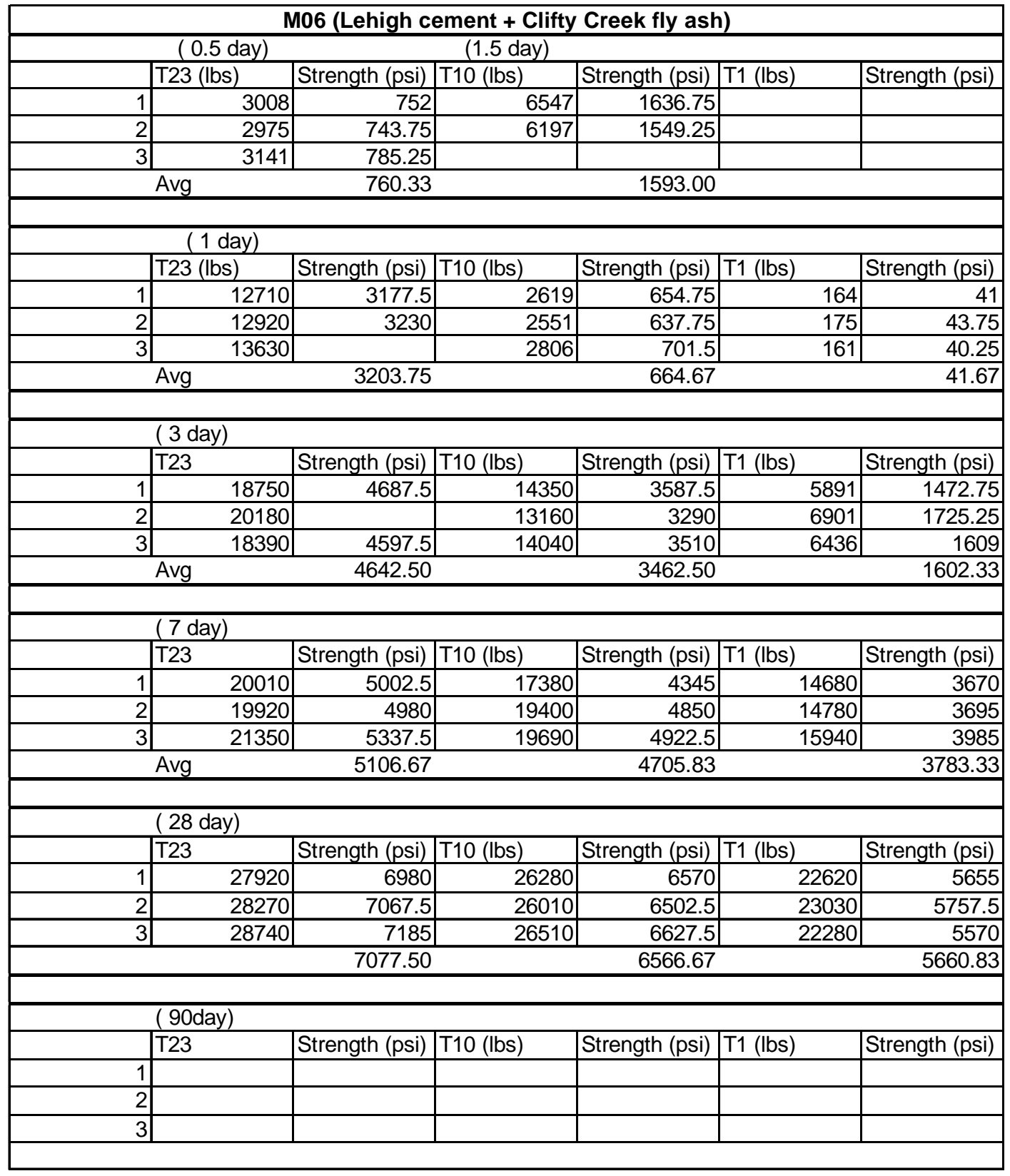


Table B7: Strength data for mixture M07

\begin{tabular}{|c|c|c|c|c|c|c|}
\hline \multicolumn{7}{|c|}{ M07 (Lehigh cement + Miami Fort fly ash) } \\
\hline \multicolumn{3}{|c|}{ ( 0.5 day) } & \multicolumn{4}{|c|}{ ( 0.5 day) } \\
\hline & T23 (lbs) & Strength (psi) & \begin{tabular}{|l|l} 
T10 (lbs) \\
\end{tabular} & Strength (psi) & T1 (lbs) & Strength (psi) \\
\hline 1 & 3613 & 903.25 & 288 & 72 & & \\
\hline 2 & 3710 & 927.5 & 279 & 69.75 & & \\
\hline 3 & 3304 & 826 & 276 & 69 & & \\
\hline \multicolumn{2}{|c|}{ Avg } & \multicolumn{2}{|l|}{885.58} & \multicolumn{2}{|l|}{70.25} & \\
\hline \multicolumn{7}{|c|}{ ( 1 day) } \\
\hline \multicolumn{2}{|c|}{ T23 (lbs) } & Strength (psi) & \begin{tabular}{|l|l} 
T10 (Ibs) \\
\end{tabular} & Strength (psi) & T1 (lbs) & Strength (psi) \\
\hline 1 & 9025 & 2256.25 & 2848 & 712 & 399 & 99.75 \\
\hline 2 & 8491 & 2122.75 & 2675 & 668.75 & 370 & 92.5 \\
\hline 3 & 9083 & 2270.75 & 2783 & 695.75 & 429 & 107.25 \\
\hline \multicolumn{2}{|c|}{ Avg } & \multicolumn{2}{|l|}{2216.58} & \multicolumn{2}{|l|}{692.17} & 99.83 \\
\hline \multicolumn{7}{|c|}{ ( 3 day) } \\
\hline \multicolumn{2}{|r|}{ T23 } & Strength (psi) & \begin{tabular}{|l|l|} 
T10 (Ibs) \\
\end{tabular} & Strength (psi) & \begin{tabular}{|l|} 
T1 (lbs) \\
\end{tabular} & Strength (psi) \\
\hline 1 & 13830 & 3457.5 & 11760 & \begin{tabular}{|r|}
2940 \\
\end{tabular} & 7083 & 1770.75 \\
\hline 2 & 14190 & 3547.5 & 11550 & 2887.5 & 7780 & 1945 \\
\hline 3 & 16150 & & 13380 & & 8214 & 2053.5 \\
\hline \multicolumn{2}{|c|}{ Avg } & \multicolumn{2}{|l|}{3502.50} & \multicolumn{2}{|l|}{2913.75} & 1923.08 \\
\hline \multicolumn{7}{|c|}{ ( 7 day) } \\
\hline \multicolumn{2}{|c|}{ T23 } & Strength (psi) & T10 (lbs) & Strength (psi) & \begin{tabular}{|l|} 
T1 (lbs) \\
\end{tabular} & Strength (psi) \\
\hline 1 & 19590 & 4897.5 & 17350 & 4337.5 & \begin{tabular}{|r|}
14150 \\
\end{tabular} & \\
\hline 2 & 19580 & 4895 & 18040 & 4510 & 12490 & 3122.5 \\
\hline 3 & 17190 & & 16400 & 4100 & 12000 & 3000 \\
\hline \multicolumn{2}{|c|}{ Avg } & \multicolumn{2}{|l|}{4896.25} & \multicolumn{2}{|l|}{4315.83} & 3061.25 \\
\hline \multicolumn{7}{|c|}{ ( 28 day) } \\
\hline \multicolumn{2}{|c|}{ T23 } & Strength (psi) & \begin{tabular}{|l|l} 
T10 (Ibs) \\
\end{tabular} & Strength (psi) & \begin{tabular}{|l|} 
T1 (lbs) \\
\end{tabular} & Strength (psi) \\
\hline 1 & 22940 & 5735 & 21710 & $\begin{array}{r}5427.5 \\
\end{array}$ & 19650 & 4912.5 \\
\hline 2 & 20670 & 5167.5 & 20710 & 5177.5 & 20440 & 5110 \\
\hline 3 & 22380 & 5595 & 19930 & 4982.5 & 21240 & 5310 \\
\hline \multicolumn{4}{|c|}{5499.17} & \multicolumn{2}{|l|}{5195.83} & 5110.83 \\
\hline \multicolumn{7}{|c|}{ (90day) } \\
\hline \multicolumn{2}{|c|}{ T23 } & Strength (psi) & \begin{tabular}{|l|l|} 
T10 (lbs) \\
\end{tabular} & Strength (psi) & \begin{tabular}{|l|} 
T1 (lbs) \\
\end{tabular} & Strength (psi) \\
\hline 1 & 24330 & 6082.5 & 24840 & 6210 & 24900 & 6225 \\
\hline 2 & 24170 & 6042.5 & 24690 & 6172.5 & 23240 & 5810 \\
\hline 3 & 26660 & 6665 & 23740 & 5935 & 23010 & 5752.5 \\
\hline & Avg & 6263.33 & & 6105.83 & & 5929.17 \\
\hline
\end{tabular}


Table B8: Strength data for mixture M08

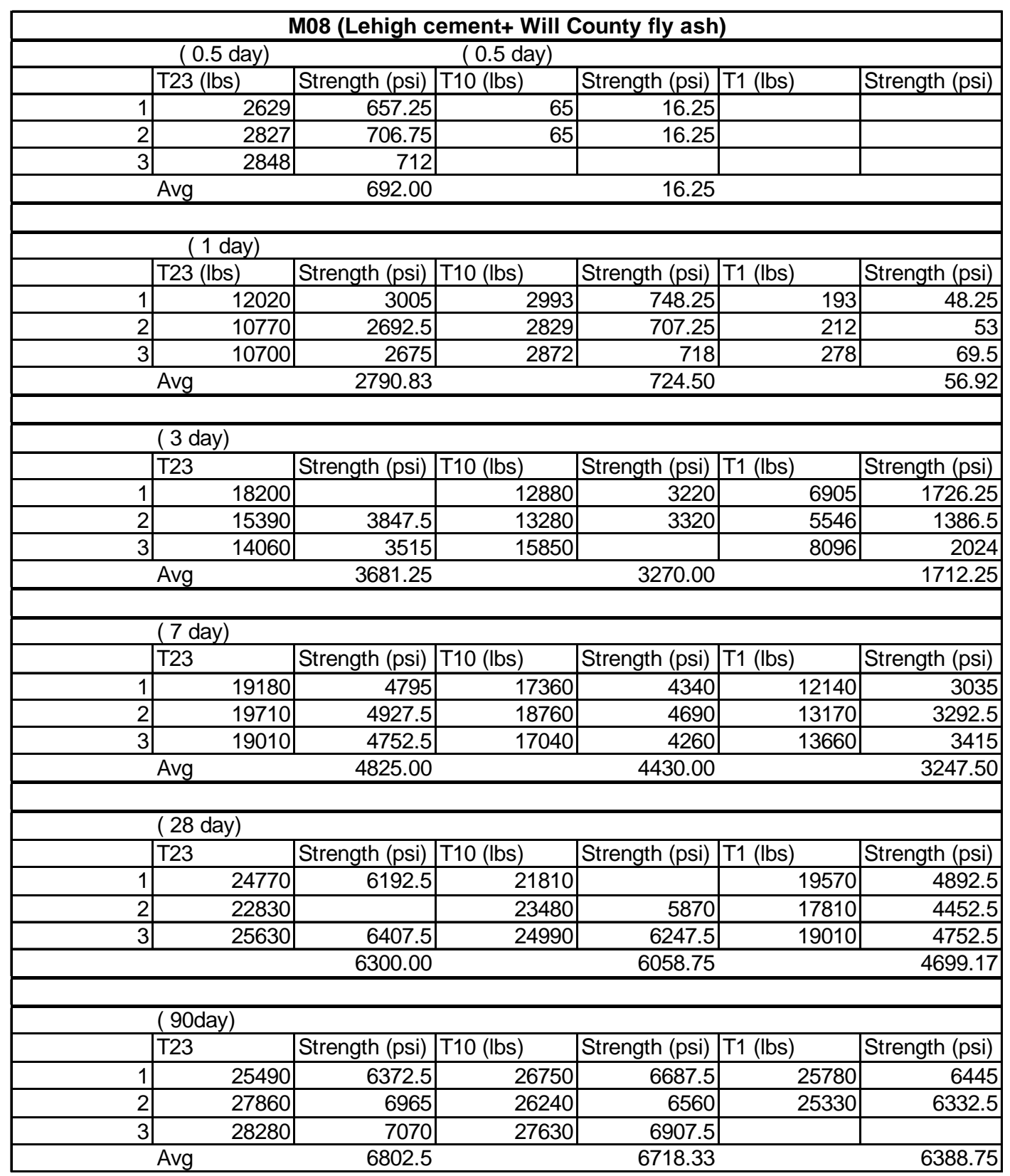


Table B9: Strength data for mixture M09

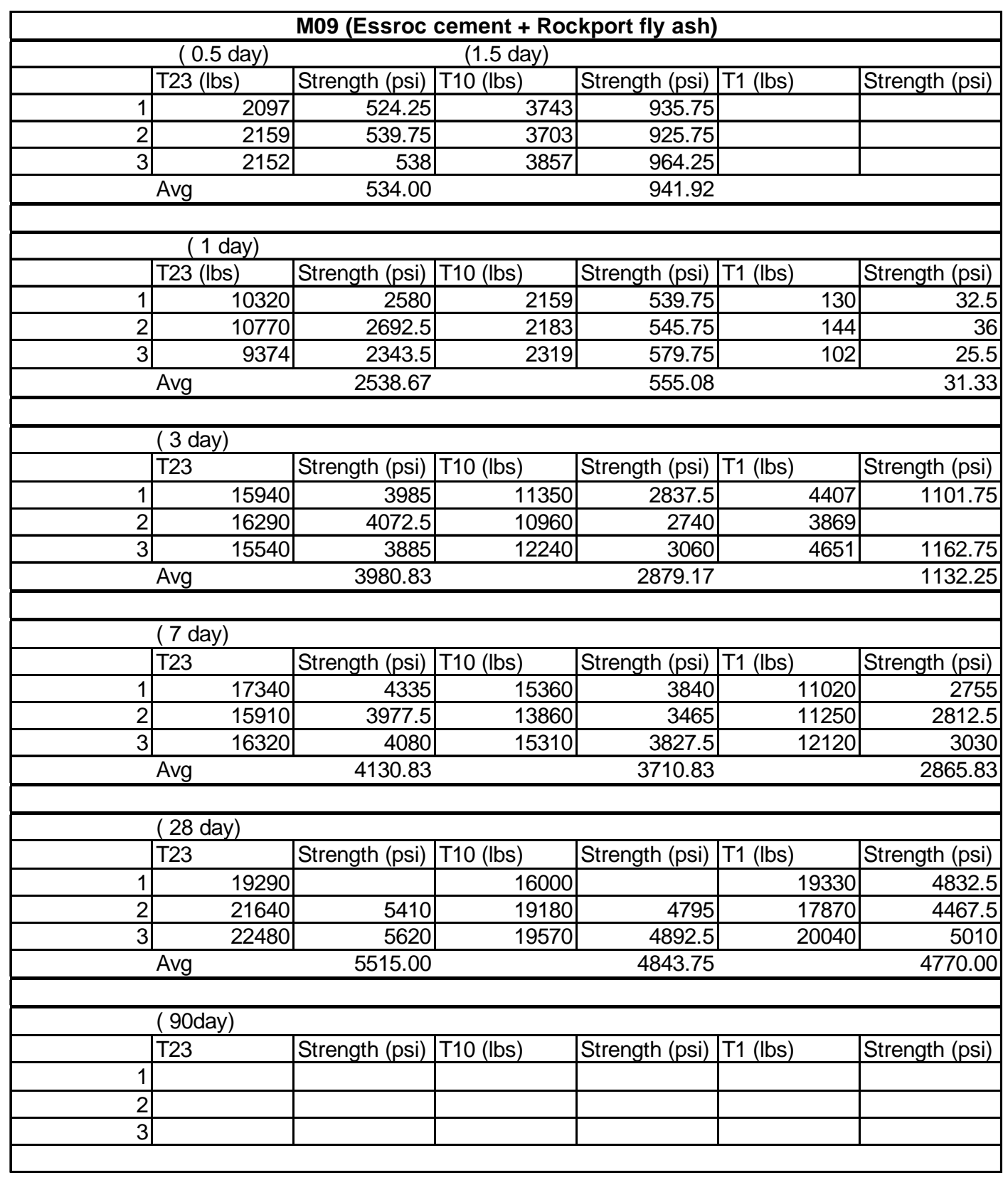


Table B10: Strength data for mixture M10

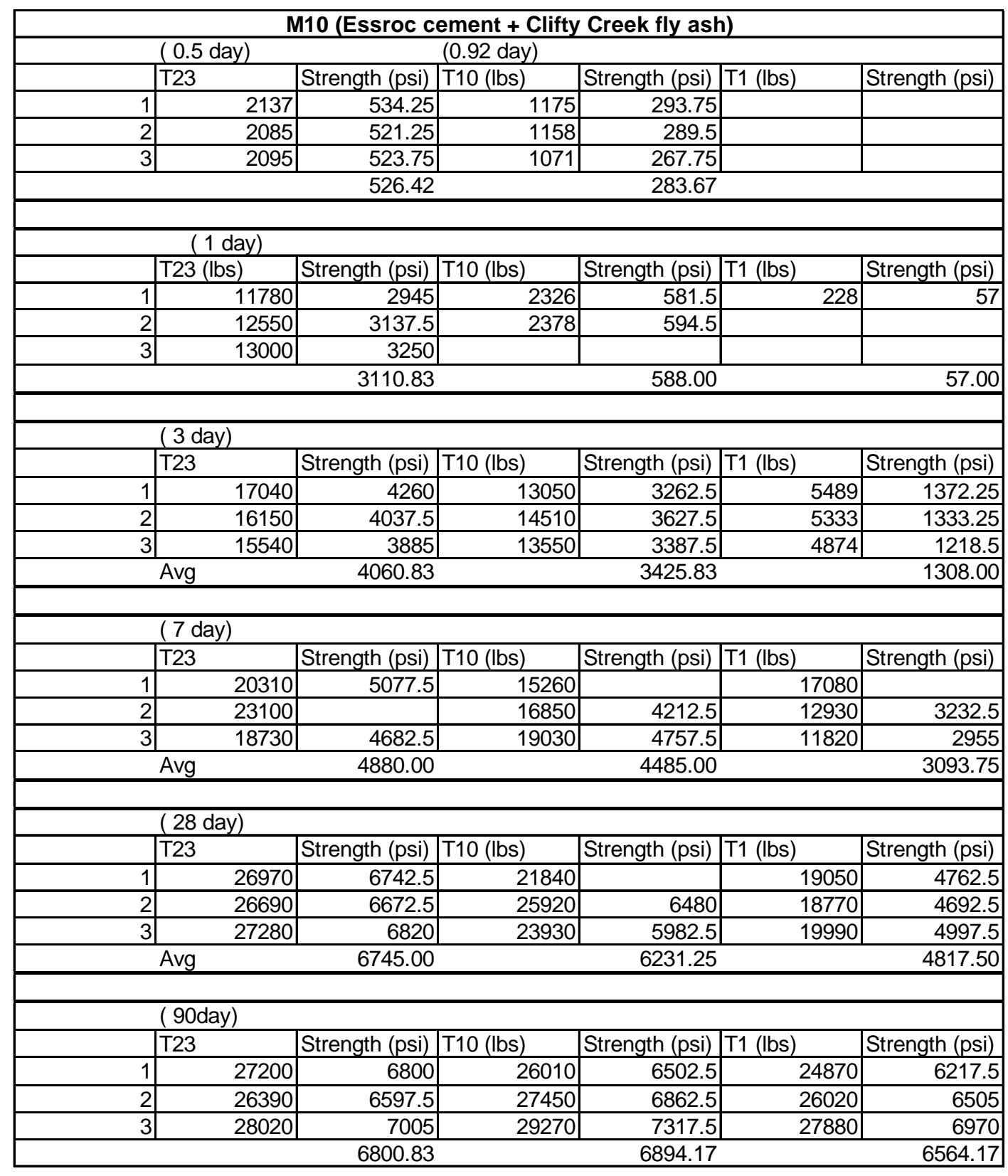


Table B11: Strength data for mixture M11

\begin{tabular}{|c|c|c|c|c|c|c|}
\hline \multicolumn{7}{|c|}{ M11 (Essroc cement + Miami Fort fly ash) } \\
\hline \multicolumn{3}{|c|}{ ( 0.5 day) } & \multicolumn{4}{|c|}{ ( 0.5 day) } \\
\hline & T23 (lbs) & Strength (psi) & \begin{tabular}{|l|l|} 
T10 (lbs) \\
\end{tabular} & Strength (psi) & T1 (lbs) & Strength (psi) \\
\hline 1 & 2333 & 583.25 & 4175 & 1043.75 & & \\
\hline 2 & 2403 & 600.75 & 3809 & 952.25 & & \\
\hline 3 & 2536 & 634 & 3798 & 949.5 & & \\
\hline \multicolumn{4}{|c|}{606} & \multicolumn{2}{|l|}{981.83} & \\
\hline \multicolumn{7}{|c|}{ ( 1 day) } \\
\hline & T23 (lbs) & Strength (psi) & T10 (Ibs) & Strength (psi) & T1 (lbs) & Strength (psi) \\
\hline 1 & 10350 & 2587.5 & 2067 & 516.75 & 315 & 78.75 \\
\hline 2 & 10560 & 2640 & 2109 & 527.25 & & \\
\hline 3 & 10480 & 2620 & & & & \\
\hline \multicolumn{2}{|c|}{ Avg } & \multicolumn{2}{|l|}{2615.83} & \multicolumn{2}{|l|}{522.00} & 78.75 \\
\hline \multicolumn{7}{|c|}{ ( 3 day) } \\
\hline & T23 & Strength (psi) & \begin{tabular}{|l|l|} 
T10 (lbs) \\
\end{tabular} & Strength (psi) & T1 (lbs) & Strength (psi) \\
\hline 1 & 13550 & 3387.5 & \begin{tabular}{r|}
8390 \\
\end{tabular} & 2097.5 & 3358 & 839.5 \\
\hline 2 & 11200 & & 7715 & 1928.75 & 3352 & 838 \\
\hline 3 & 13620 & 3405 & 9368 & 2342 & 3519 & 879.75 \\
\hline \multicolumn{2}{|c|}{ Avg } & \multicolumn{2}{|l|}{3396.25} & \multicolumn{2}{|l|}{2122.75} & 852.42 \\
\hline \multicolumn{7}{|c|}{ ( 7 day) } \\
\hline \multicolumn{2}{|c|}{\begin{tabular}{l|l} 
& T23 (lbs) \\
\end{tabular}} & Strength (psi) & \begin{tabular}{|l|} 
T10 (lbs) \\
\end{tabular} & Strength (psi) & T1 (lbs) & Strength (psi) \\
\hline 1 & 16090 & 4022.5 & $\begin{array}{r}12960 \\
\end{array}$ & 3240 & 11850 & 2962.5 \\
\hline 2 & 17350 & 4337.5 & 12530 & 3132.5 & 12240 & 3060 \\
\hline 3 & 15150 & 3787.5 & 14010 & 3502.5 & 12040 & 3010 \\
\hline \multicolumn{2}{|c|}{ Avg } & \multicolumn{2}{|l|}{4049.17} & \multicolumn{2}{|l|}{3291.67} & 3010.83 \\
\hline \multicolumn{7}{|c|}{ ( 28 day) } \\
\hline \multicolumn{2}{|r|}{ T23 (lbs) } & Strength (psi) & \begin{tabular}{|l|} 
T10 (lbs) \\
\end{tabular} & Strength (psi) & T1 (lbs) & Strength (psi) \\
\hline 1 & 21190 & 5297.5 & \begin{tabular}{|l|}
19120 \\
\end{tabular} & 4780 & 19130 & 4782.5 \\
\hline 2 & 21370 & 5342.5 & 21010 & 5252.5 & 17280 & 4320 \\
\hline 3 & 21970 & 5492.5 & 21410 & 5352.5 & 17580 & 4395 \\
\hline \multicolumn{4}{|c|}{5377.5} & \multicolumn{2}{|l|}{5128.33} & 4499.17 \\
\hline \multicolumn{7}{|c|}{ (90day) } \\
\hline \multicolumn{2}{|c|}{\begin{tabular}{l|l} 
& T23 (lbs) \\
\end{tabular}} & Strength (psi) & \begin{tabular}{|l|} 
T10 (lbs) \\
\end{tabular} & Strength (psi) & T1 (lbs) & Strength (psi) \\
\hline 1 & 23590 & 5897.5 & 20160 & 5040 & 21830 & 5457.5 \\
\hline 2 & 25370 & 6342.5 & 23140 & 5785 & 22080 & 5520 \\
\hline 3 & 24740 & 6185 & 21450 & 5362.5 & 21370 & 5342.5 \\
\hline & Avg & 6141.67 & & 5395.83 & & 5440.00 \\
\hline
\end{tabular}


Table B12: Strength data for mixture M12

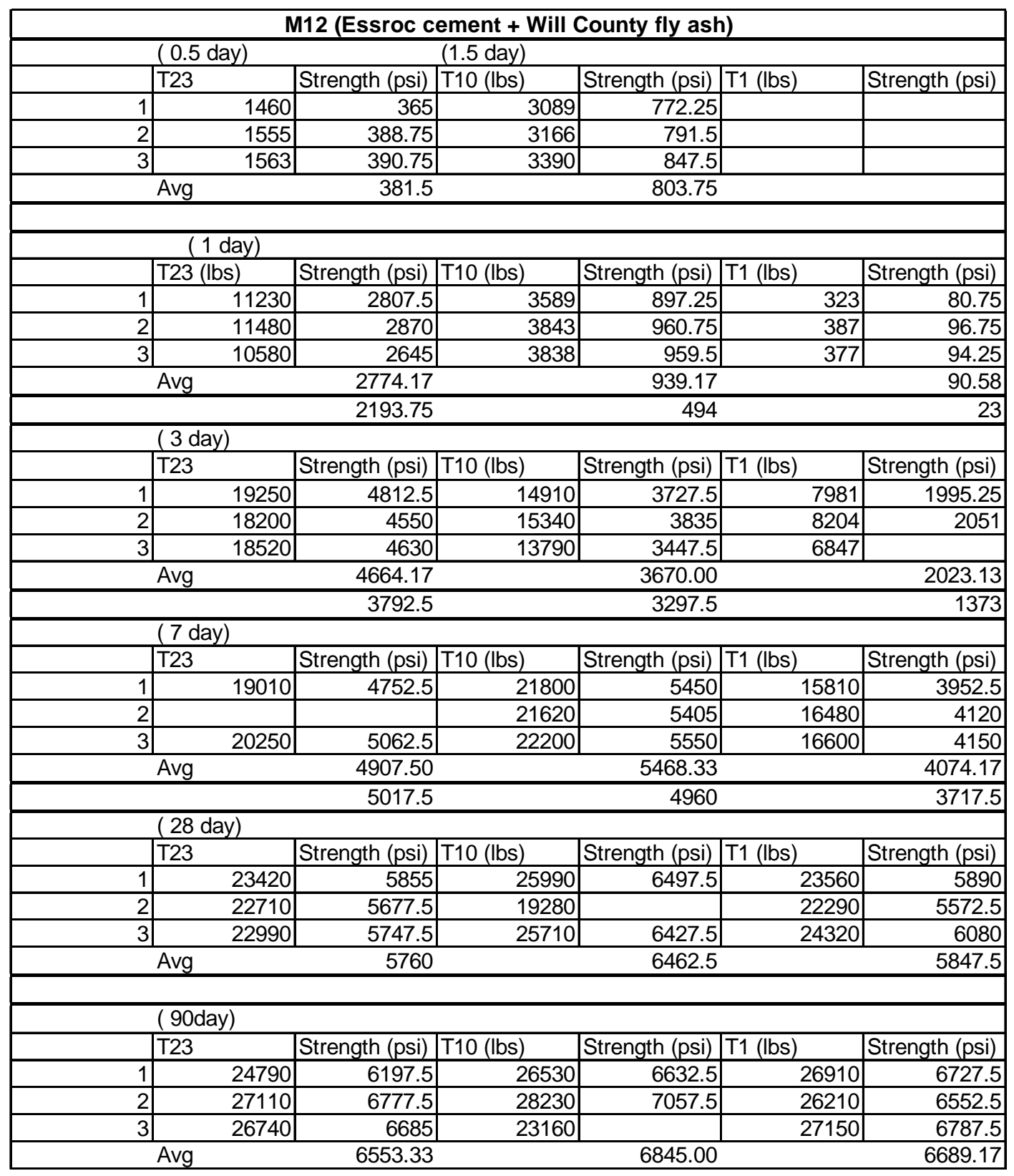


Table B13: Strength data for mixture M13

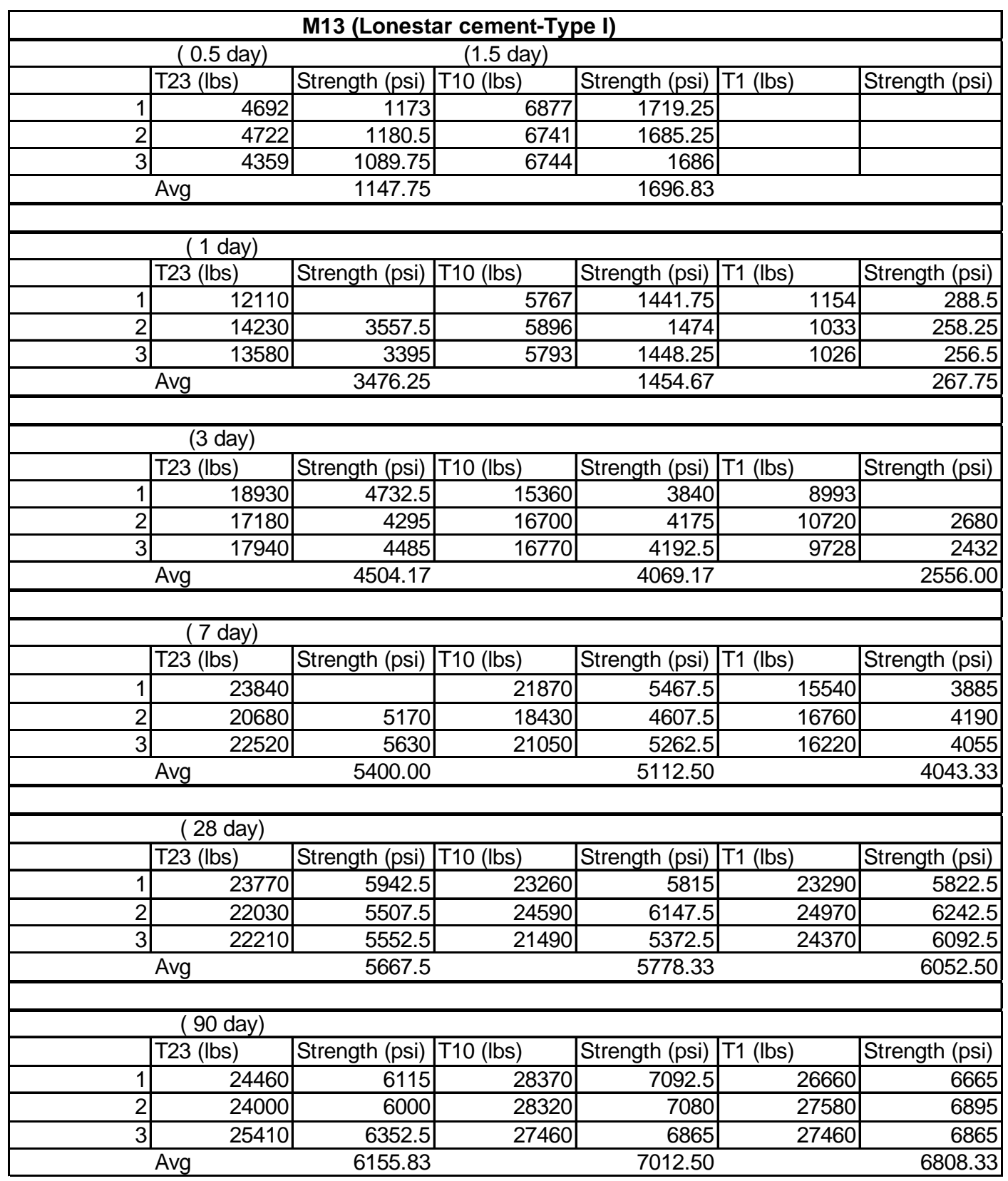


Table B14: Strength data for mixture M14

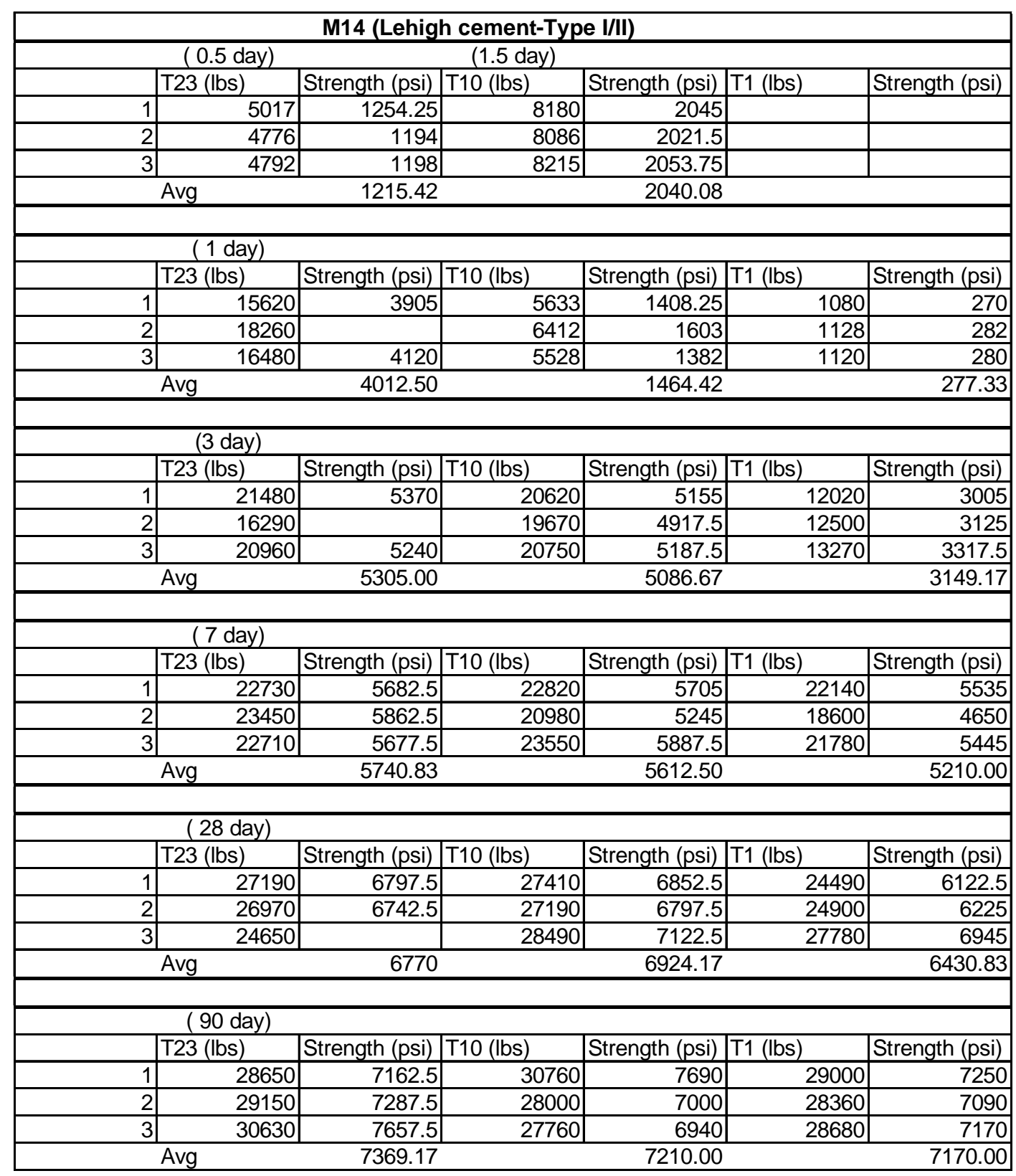


Table B15: Strength data for mixture M15

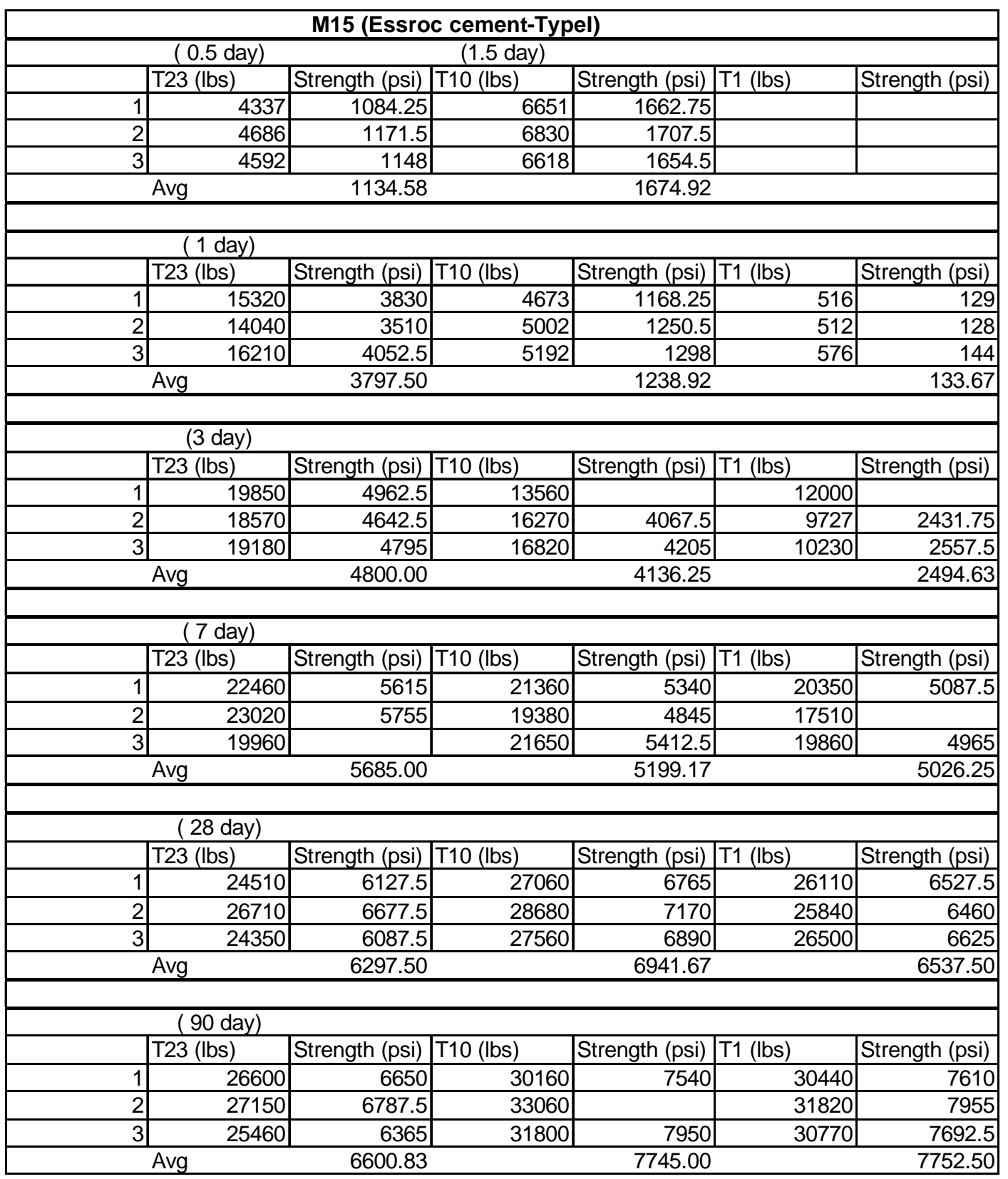


Table B16: Strength data for mixture M16

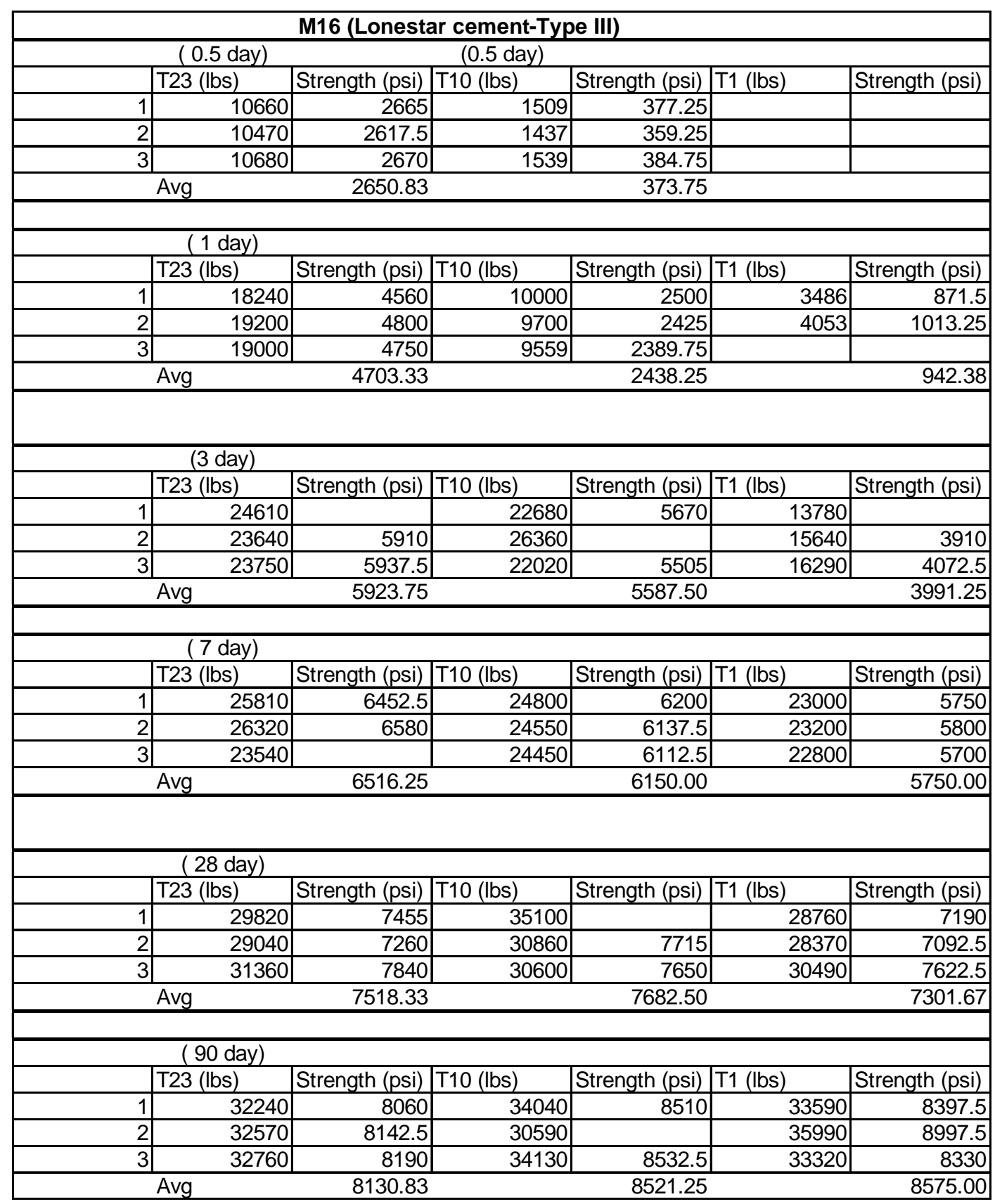


Table B17: Strength data for mixture M17

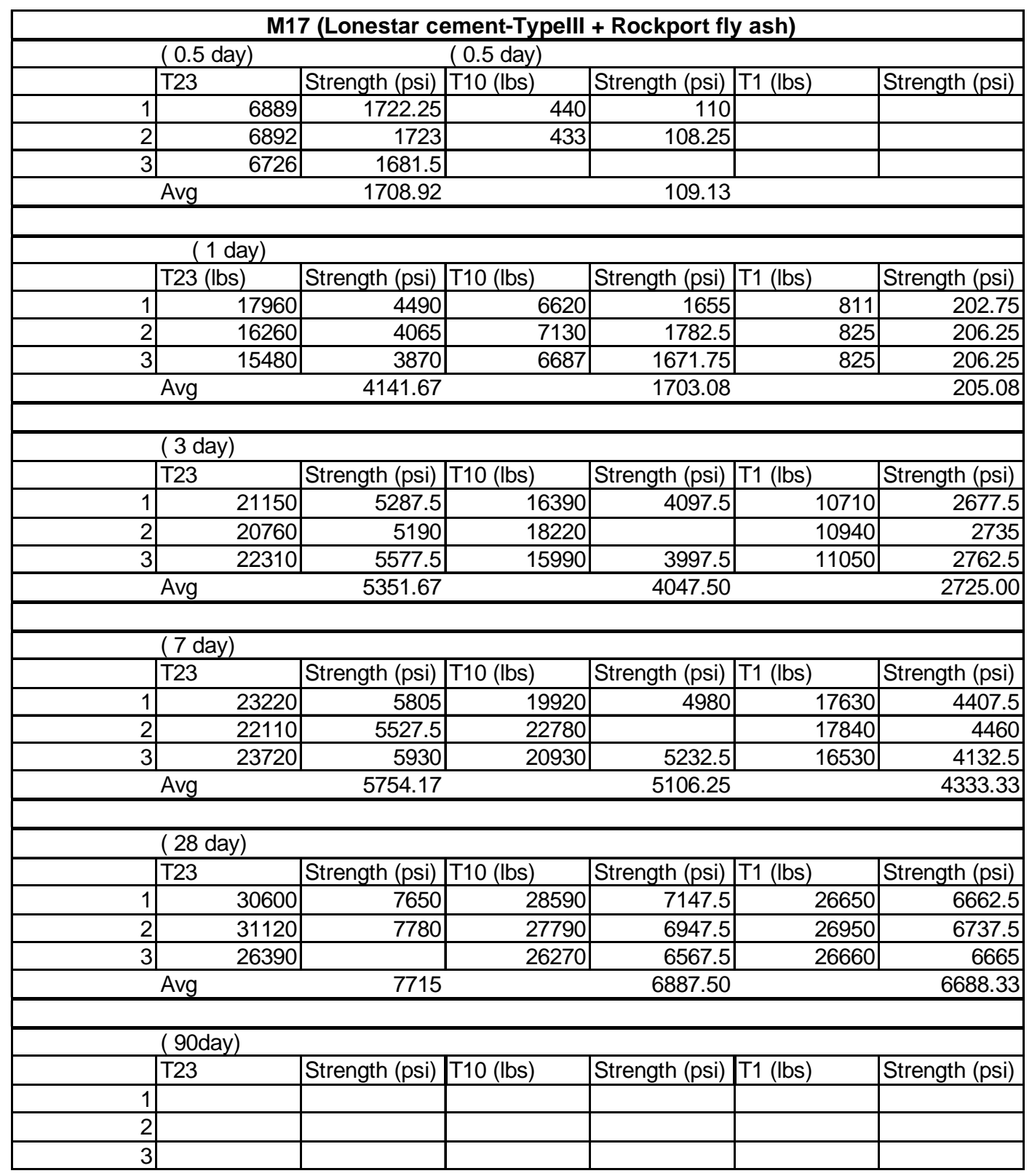


Table B18: Strength data for mixture M18

\begin{tabular}{|c|c|c|c|c|c|c|}
\hline \multicolumn{7}{|c|}{ M18 (Lonestar cement -TypellI + Clifty Creek fly ash) } \\
\hline & \multicolumn{2}{|l|}{ ( 0.5 day) } & \multicolumn{4}{|c|}{ ( 0.5 day) } \\
\hline & T23 (lbs) & Strength (psi) & T10 (lbs) & Strength (psi) & T1 (lbs) & Strength (psi) \\
\hline 1 & $\begin{array}{r}7712 \\
\end{array}$ & 1928 & 540 & 135 & & \\
\hline 2 & 7815 & 1953.75 & 513 & 128.25 & & \\
\hline 3 & 8305 & 2076.25 & 523 & 130.75 & & \\
\hline \multicolumn{2}{|c|}{ Avg } & \multicolumn{2}{|l|}{1986.00} & \multicolumn{2}{|l|}{131.33} & \\
\hline \multicolumn{7}{|c|}{ ( 1 day) } \\
\hline & T23 (lbs) & Strength (psi) & T10 (lbs) & Strength (psi) & T1 (lbs) & Strength (psi) \\
\hline 1 & $\begin{array}{r}17590 \\
\end{array}$ & 4397.5 & 9532 & 2383 & 800 & 200 \\
\hline 2 & 18660 & 4665 & 8988 & 2247 & 800 & 200 \\
\hline 3 & 16380 & 4095 & 9180 & 2295 & & \\
\hline \multicolumn{2}{|c|}{ Avg } & \multicolumn{2}{|l|}{4385.83} & \multicolumn{2}{|l|}{2308.33} & 200.00 \\
\hline \multicolumn{7}{|c|}{ ( 3 day) } \\
\hline \multicolumn{2}{|r|}{ T23 (lbs) } & Strength (psi) & T10 (lbs) & Strength (psi) & T1 (lbs) & Strength (psi) \\
\hline 1 & 24450 & 6112.5 & 18400 & 4600 & 14500 & 3625 \\
\hline 2 & 22700 & 5675 & 17880 & 4470 & 14200 & 3550 \\
\hline 3 & 23510 & 5877.5 & 19590 & 4897.5 & 13300 & 3325 \\
\hline \multicolumn{2}{|c|}{ Avg } & \multicolumn{2}{|l|}{5888.33} & \multicolumn{2}{|l|}{4655.83} & 3500.00 \\
\hline \multicolumn{7}{|c|}{ ( 7 day) } \\
\hline & T23 (lbs) & Strength (psi) & T10 (lbs) & Strength (psi) & T1 (lbs) & Strength (psi) \\
\hline 1 & 28810 & 7202.5 & 25930 & 6482.5 & 20200 & 5050 \\
\hline 2 & 28310 & 7077.5 & 26540 & 6635 & 19950 & 4987.5 \\
\hline 3 & 27610 & 6902.5 & 26380 & 6595 & 19850 & 4962.5 \\
\hline \multicolumn{2}{|c|}{ Avg } & \multicolumn{2}{|l|}{7060.83} & \multicolumn{2}{|l|}{6570.83} & 5000.00 \\
\hline \multicolumn{7}{|c|}{ ( 28 day) } \\
\hline & T23 (lbs) & Strength (psi) & T10 (lbs) & Strength (psi) & \begin{tabular}{|l|} 
T1 (lbs) \\
\end{tabular} & Strength (psi) \\
\hline 1 & 31870 & 7967.5 & 29100 & 7275 & 28480 & 7120 \\
\hline 2 & 33710 & 8427.5 & 27720 & 6930 & 28070 & 7017.5 \\
\hline 3 & 24350 & & 32510 & & 29390 & \\
\hline \multicolumn{2}{|c|}{ Avg } & \multicolumn{2}{|l|}{8197.50} & \multicolumn{2}{|l|}{7102.50} & 7068.75 \\
\hline \multicolumn{7}{|c|}{ (90day) } \\
\hline & T23 & Strength (psi) & T10 (lbs) & Strength (psi) & T1 (lbs) & Strength (psi) \\
\hline \multicolumn{7}{|c|}{ 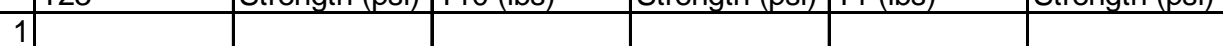 } \\
\hline \multicolumn{7}{|c|}{2} \\
\hline 3 & & & & & & \\
\hline
\end{tabular}


Table B19: Strength data for mixture M19

\begin{tabular}{|c|c|c|c|c|c|c|}
\hline \multicolumn{7}{|c|}{ M19 (Lonestar cement-Typelll + Miami Fort fly ash) } \\
\hline & & \multicolumn{4}{|c|}{$(0.5$ day) } \\
\hline & $\frac{\text { ( } 0.5 \text { day) }}{\text { T23 (lbs) }}$ & Strength (psi) & T10 (lbs) & Strength (psi) & T1 (lbs) & Strength (psi) \\
\hline 1 & 7211 & 1802.75 & 573 & 143.25 & & \\
\hline 2 & 6311 & & 585 & 146.25 & & \\
\hline 3 & 6914 & 1728.5 & 591 & 147.75 & & \\
\hline \multicolumn{2}{|c|}{ Avg } & 1765.63 & \multicolumn{3}{|c|}{145.75} & \\
\hline \multirow{2}{*}{\multicolumn{2}{|c|}{$\begin{array}{c}\text { ( } 1 \text { day) } \\
\text { T23 (lbs) }\end{array}$}} & & & & & \\
\hline & & Strength (psi) & T10 (lbs) & Strength (psi) & T1 (lbs) & Strength (psi) \\
\hline 1 & 15980 & 3995 & $\begin{array}{r}7532 \\
\end{array}$ & 1883 & 1329 & 332.25 \\
\hline 2 & 14990 & 3747.5 & 7010 & 1752.5 & 1439 & 359.75 \\
\hline 3 & 16340 & 4085 & 7841 & 1960.25 & 1308 & 327 \\
\hline \multicolumn{2}{|c|}{ Avg } & 3942.50 & & 1865.25 & & 339.67 \\
\hline \multicolumn{2}{|r|}{ ( 3 day) } & & & & & \\
\hline \multicolumn{2}{|c|}{ T23 (lbs) } & Strength (psi) & \begin{tabular}{|l|l} 
T10 (lbs) \\
\end{tabular} & Strength (psi) & \begin{tabular}{|l|} 
T1 (lbs) \\
\end{tabular} & Strength (psi) \\
\hline 1 & 23270 & 5817.5 & 20390 & \begin{tabular}{|r|}
5097.5 \\
\end{tabular} & 12200 & 3050 \\
\hline 2 & 24150 & 6037.5 & 20080 & 5020 & 11360 & 2840 \\
\hline 3 & 22010 & 5502.5 & 18970 & 4742.5 & 11750 & 2937.5 \\
\hline \multicolumn{2}{|c|}{ Avg } & 5785.83 & & 4953.33 & & 2942.50 \\
\hline \multirow{2}{*}{\multicolumn{2}{|c|}{$\begin{array}{l}\text { ( } 7 \text { day) } \\
\text { T23 (lbs) }\end{array}$}} & & & & & \\
\hline & & Strength (psi) & T10 (lbs) & Strength (psi) & T1 (lbs) & Strength (psi) \\
\hline \multirow{3}{*}{\begin{tabular}{l|} 
\\
2 \\
3
\end{tabular}} & 24270 & 6067.5 & $\begin{array}{r}24970 \\
\end{array}$ & $\begin{array}{r}6242.5 \\
\end{array}$ & 17160 & 4290 \\
\hline & 22780 & 5695 & 22520 & 5630 & 19100 & 4775 \\
\hline & 22960 & 5740 & 24490 & 6122.5 & 19700 & 4925 \\
\hline \multicolumn{2}{|c|}{ Avg } & 5834.17 & & 5998.33 & & 4663.33 \\
\hline \multicolumn{2}{|r|}{ ( 28 day) } & & & & & \\
\hline \multicolumn{2}{|r|}{\begin{tabular}{l|l} 
T23 (lbs) \\
\end{tabular}} & Strength (psi) & T10 (lbs) & Strength (psi) & T1 (lbs) & Strength (psi) \\
\hline 1 & 28080 & 7020 & \begin{tabular}{|l|}
29640 \\
\end{tabular} & 7410 & 27730 & $\begin{array}{r}6932.5 \\
\end{array}$ \\
\hline 2 & 26460 & & 29820 & 7455 & 26130 & 6532.5 \\
\hline \multirow[t]{2}{*}{$3 \mid$} & 28240 & 7060 & 28750 & 7187.5 & 27580 & 6895 \\
\hline & & 7040 & & 7350.83 & & 6786.67 \\
\hline \multicolumn{2}{|r|}{ (90day) } & & & & & \\
\hline & $\mathrm{T} 23$ & Strength (psi) & T10 (lbs) & Strength (psi) & T1 (lbs) & Strength (psi) \\
\hline \multicolumn{2}{|c|}{\begin{tabular}{l|l}
1 & \\
\end{tabular}} & & & & & \\
\hline \multirow{2}{*}{\multicolumn{2}{|c|}{$\begin{array}{l}2 \\
3\end{array}$}} & & & & & \\
\hline & & & & & & \\
\hline
\end{tabular}


Table B20: Strength data for mixture M20

\begin{tabular}{|c|c|c|c|c|c|c|}
\hline \multicolumn{7}{|c|}{ M20 (Lonestar cement-Typelll +Will county fly ash) } \\
\hline \multicolumn{3}{|c|}{ ( 0.5 day) } & \multicolumn{4}{|l|}{ ( 0.5 day) } \\
\hline & T23 & Strength (psi) & T10 (lbs) & Strength (psi) & $\mathrm{T} 1$ (lbs) & Strength (psi) \\
\hline 1 & 7146 & 1786.5 & 372 & 93 & & \\
\hline 2 & 7541 & 1885.25 & 405 & 101.25 & & \\
\hline 3 & 6906 & 1726.5 & 411 & 102.75 & & \\
\hline \multicolumn{2}{|c|}{ Avg } & \multicolumn{2}{|l|}{1799.42} & \multicolumn{2}{|l|}{99.00} & \\
\hline \multicolumn{7}{|c|}{ ( 1 day) } \\
\hline & T23 (lbs) & Strength (psi) & T10 (lbs) & Strength (psi) & T1 (lbs) & Strength (psi) \\
\hline 1 & 15320 & 3830 & 6927 & 1731.75 & 824 & 206 \\
\hline 2 & 15400 & 3850 & 7061 & 1765.25 & 821 & 205.25 \\
\hline 3 & 16170 & 4042.5 & 7203 & 1800.75 & 855 & 213.75 \\
\hline \multicolumn{2}{|c|}{ Avg } & \multicolumn{2}{|l|}{3907.50} & \multicolumn{2}{|l|}{1765.92} & 208.33 \\
\hline \multicolumn{7}{|c|}{ ( 3 day) } \\
\hline & T23 & Strength (psi) & T10 (lbs) & Strength (psi) & T1 (lbs) & Strength (psi) \\
\hline 1 & 19650 & 4912.5 & 18750 & 4687.5 & 12200 & 3050 \\
\hline 2 & 20220 & 5055 & 18910 & 4727.5 & 12470 & 3117.5 \\
\hline 3 & 20490 & 5122.5 & 18870 & 4717.5 & 10940 & 2735 \\
\hline \multicolumn{2}{|c|}{ Avg } & \multicolumn{2}{|l|}{5030.00} & \multicolumn{2}{|l|}{4710.83} & 2967.50 \\
\hline \multicolumn{7}{|c|}{ ( 7 day) } \\
\hline & T23 & Strength (psi) & T10 (lbs) & Strength (psi) & T1 (lbs) & Strength (psi) \\
\hline 1 & 23230 & 5807.5 & 23340 & 5835 & 20790 & 5197.5 \\
\hline 2 & 25300 & 6325 & 23610 & 5902.5 & 21620 & 5405 \\
\hline 3 & 22350 & 5587.5 & 26750 & & 21570 & 5392.5 \\
\hline \multicolumn{4}{|c|}{5906.67} & \multicolumn{2}{|l|}{5868.75} & 5331.67 \\
\hline \multicolumn{7}{|c|}{ ( 28 day) } \\
\hline & T23 & Strength (psi) & T10 (lbs) & Strength (psi) & T1 (lbs) & Strength (psi) \\
\hline 1 & 28950 & 7237.5 & 27070 & 6767.5 & 27020 & 6755 \\
\hline 2 & 26360 & 6590 & 29710 & 7427.5 & 28480 & 7120 \\
\hline 3 & 26720 & 6680 & 24180 & & 30460 & 7615 \\
\hline \multicolumn{4}{|c|}{6835.83} & \multicolumn{2}{|l|}{7097.50} & 7163.33 \\
\hline \multicolumn{7}{|c|}{ (90day) } \\
\hline & T23 & Strength (psi) & T10 (lbs) & Strength (psi) & T1 (lbs) & Strength (psi) \\
\hline \multicolumn{7}{|c|}{ 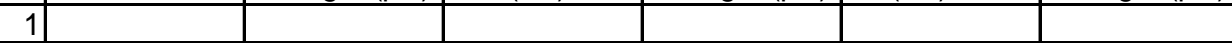 } \\
\hline \multicolumn{7}{|l|}{2} \\
\hline 3 & & & & & & \\
\hline
\end{tabular}


Table B21: Strength data for mixture M21

\begin{tabular}{|c|c|c|c|c|c|c|}
\hline \multicolumn{7}{|c|}{ M21 (Lonestar cement + Holnam slag) } \\
\hline & \multicolumn{2}{|l|}{ ( 0.5 day) } & \multicolumn{4}{|c|}{0.94 day } \\
\hline & T23 (lbs) & Strength (psi) & T10 (lbs) & Strength (psi) & T1 (lbs) & Strength (psi) \\
\hline 1 & 3886 & 971.5 & 2530 & 632.5 & & \\
\hline 2 & 4091 & 1022.75 & 2551 & 637.75 & & \\
\hline 3 & 4130 & 1032.5 & 2661 & 665.25 & & \\
\hline \multicolumn{2}{|c|}{ Avg } & \multicolumn{2}{|l|}{1008.92} & \multicolumn{2}{|l|}{645.17} & \\
\hline \multicolumn{7}{|c|}{ ( 1 day) } \\
\hline \multicolumn{2}{|c|}{ T23 (lbs) } & Strength (psi) & \begin{tabular}{|l|l|} 
T10 (lbs) \\
\end{tabular} & Strength (psi) & T1 (lbs) & Strength (psi) \\
\hline 1 & 11360 & 2840 & 4724 & 1181 & 965 & 241.25 \\
\hline 2 & 10180 & 2545 & 4666 & 1166.5 & 956 & 239 \\
\hline 3 & 11480 & 2870 & 4829 & 1207.25 & 908 & 227 \\
\hline \multicolumn{2}{|c|}{ Avg } & \multicolumn{2}{|l|}{2751.67} & \multicolumn{2}{|l|}{1184.92} & 235.75 \\
\hline \multicolumn{7}{|c|}{ ( 3 day) } \\
\hline \multicolumn{2}{|c|}{ T23 (lbs) } & Strength (psi) & \begin{tabular}{|l|} 
T10 (lbs) \\
\end{tabular} & Strength (psi) & T1 (lbs) & Strength (psi) \\
\hline 1 & 17890 & 4472.5 & 13260 & 3315 & 8068 & 2017 \\
\hline 2 & 17910 & 4477.5 & 12370 & 3092.5 & 8224 & 2056 \\
\hline 3 & 18060 & 4515 & 14200 & & 8025 & 2006.25 \\
\hline \multicolumn{2}{|c|}{ Avg } & \multicolumn{2}{|l|}{4488.33} & \multicolumn{2}{|l|}{3203.75} & 2026.42 \\
\hline \multicolumn{7}{|c|}{ ( 7 day) } \\
\hline \multicolumn{2}{|c|}{\begin{tabular}{l|l} 
T23 (lbs) \\
\end{tabular}} & Strength (psi) & \begin{tabular}{|l|} 
T10 (lbs) \\
\end{tabular} & Strength (psi) & T1 (lbs) & Strength (psi) \\
\hline 1 & 23030 & 5757.5 & \begin{tabular}{r|}
17660 \\
\end{tabular} & 4415 & 14630 & 3657.5 \\
\hline 2 & 23680 & 5920 & 18550 & 4637.5 & 14210 & 3552.5 \\
\hline 3 & 22330 & 5582.5 & 18780 & 4695 & 14330 & 3582.5 \\
\hline \multicolumn{2}{|c|}{ Avg } & \multicolumn{2}{|l|}{5753.33} & \multicolumn{2}{|l|}{4582.50} & 3597.50 \\
\hline \multicolumn{7}{|c|}{ ( 28 day) } \\
\hline \multicolumn{2}{|c|}{ T23 (lbs) } & Strength (psi) & T10 (lbs) & Strength (psi) & T1 (lbs) & Strength (psi) \\
\hline 1 & 28620 & 7155 & 28280 & 7070 & 21270 & 5317.5 \\
\hline 2 & 25820 & 6455 & 27380 & 6845 & 23010 & 5752.5 \\
\hline 3 & 27440 & 6860 & 27520 & 6880 & 22760 & 5690 \\
\hline \multicolumn{2}{|c|}{ Avg } & \multicolumn{2}{|l|}{6823.33} & \multicolumn{2}{|l|}{6931.67} & 5586.67 \\
\hline \multicolumn{7}{|c|}{ (90day) } \\
\hline & \begin{tabular}{|l|l|} 
T23 (lbs) \\
\end{tabular} & Strength (psi) & T10 (lbs) & Strength (psi) & T1 (lbs) & Strength (psi) \\
\hline 1 & 28880 & 7220 & 28670 & $\begin{array}{r}7167.5 \\
\end{array}$ & 29170 & \begin{tabular}{|l|}
7292.5 \\
\end{tabular} \\
\hline 2 & 30000 & 7500 & 30450 & 7612.5 & 27300 & 6825 \\
\hline 3 & 29940 & 7485 & 29150 & 7287.5 & & \\
\hline & Avg & 7401.67 & & 7355.83 & & 7058.75 \\
\hline
\end{tabular}


Table B22: Strength data for mixture M22

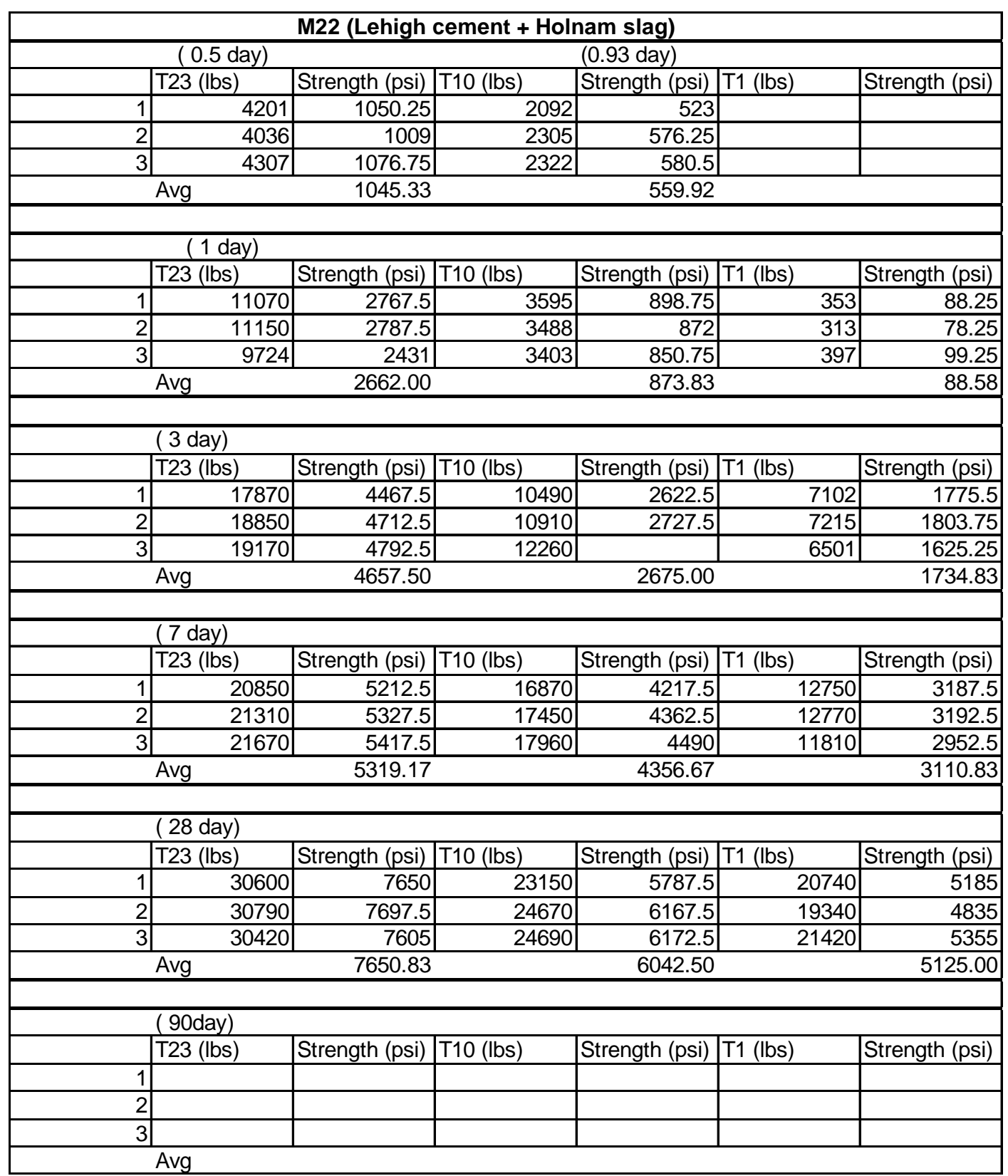


Table B23: Strength data for mixture M23

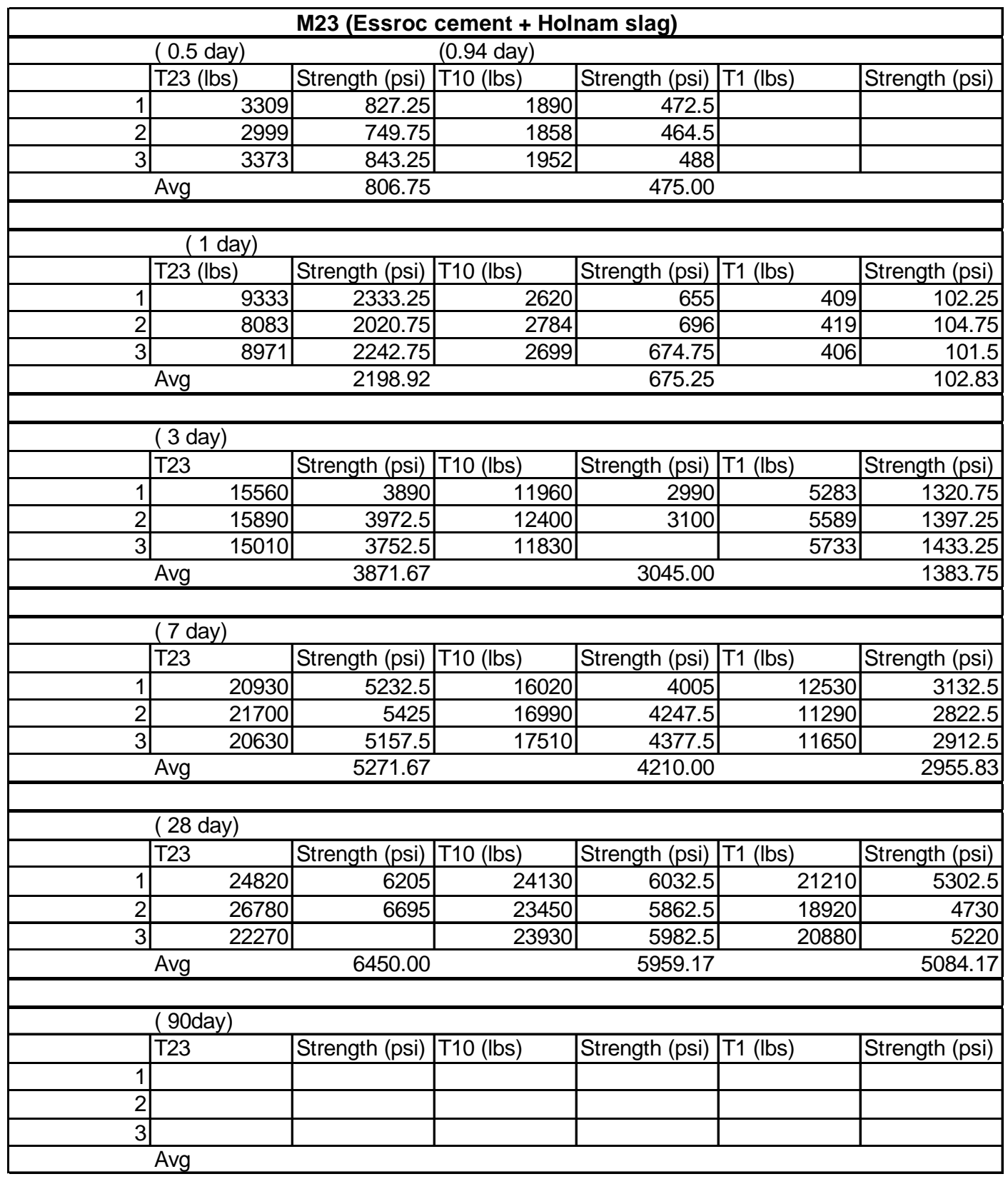


Table B24: Strength data for mixture M24

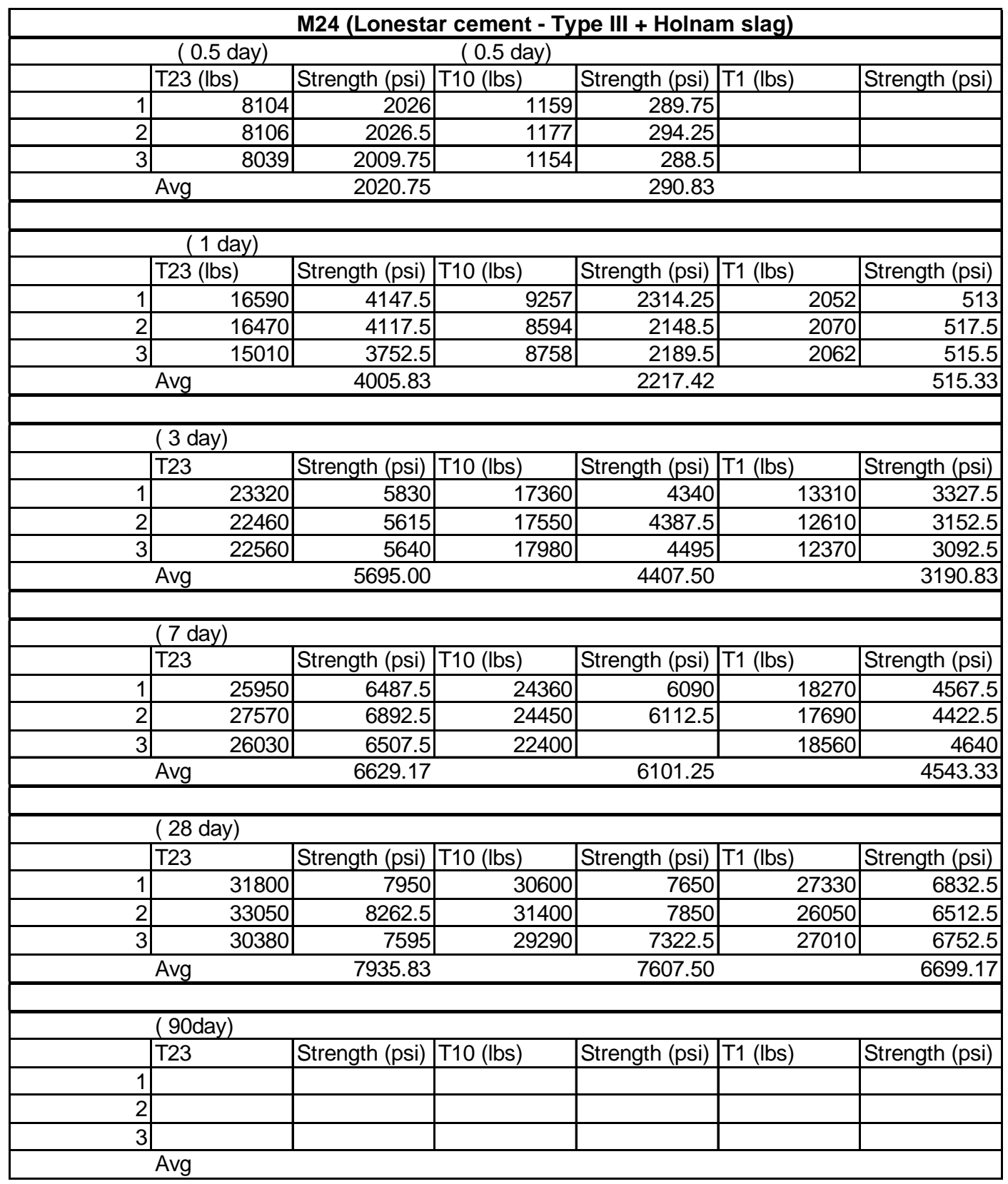


APPENDIX C - PICTURES OF SCALED SURFACES 
Table C1: Conditioning periods for concrete slabs subjected to salt scaling tests

\begin{tabular}{|c|c|c|c|c|}
\hline Conditioning & \multicolumn{4}{|c|}{ Specimen No. } \\
\hline & $3 \& 4$ & $7 \& 8$ & $\mathrm{CC} 1 \& \mathrm{CC} 2$ & $\mathrm{CC} 5$ \& CC6 \\
\hline $\begin{array}{c}\text { Moist Curing }\left(21^{\circ} \mathrm{C}\right. \\
@ 100 \% \mathrm{RH})\end{array}$ & 3 days & 14 days & 3 days & 14 days \\
\hline & & & & \\
\hline $\begin{array}{c}\text { Drying }\left(20^{\circ} \mathrm{C} @ 50\right. \\
\% \mathrm{RH})\end{array}$ & 3 days & 14 days & 3 days & 14 days \\
\hline
\end{tabular}




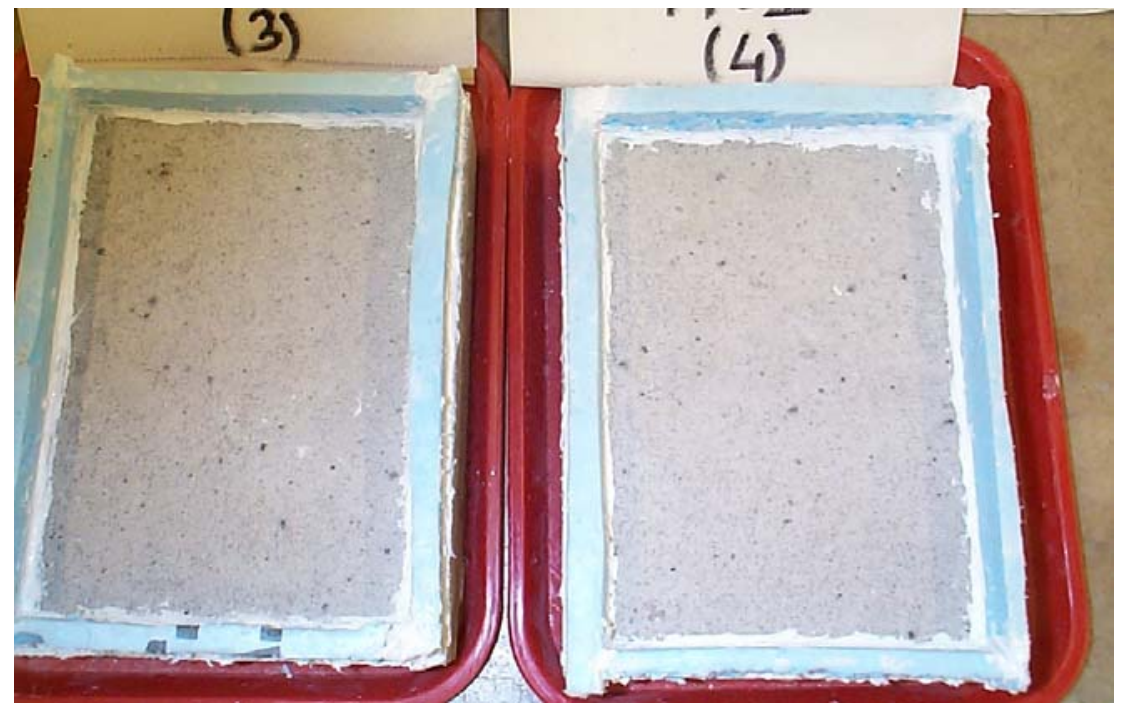

Figure C1: C01 (Lonestar cement) conditioned for 6 days

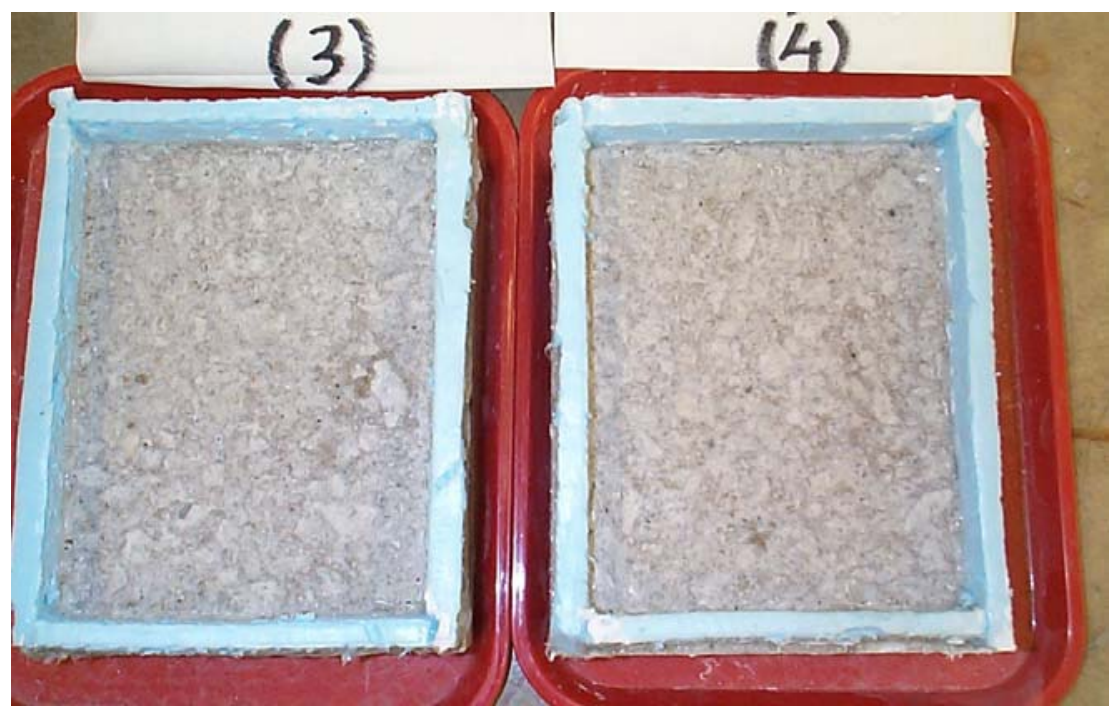

Figure C2: C02 (Lonestar cement + Rockport fly ash) conditioned for 6 days 


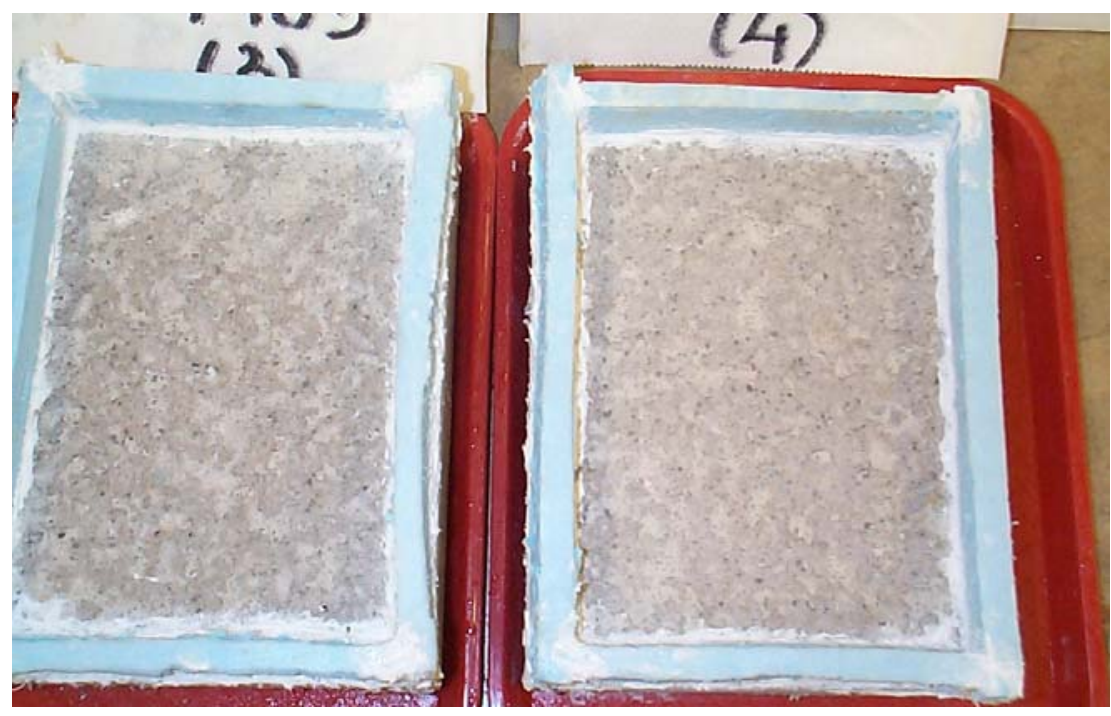

Figure C3: C03 (Lonestar cement + slag) conditioned for 6 days

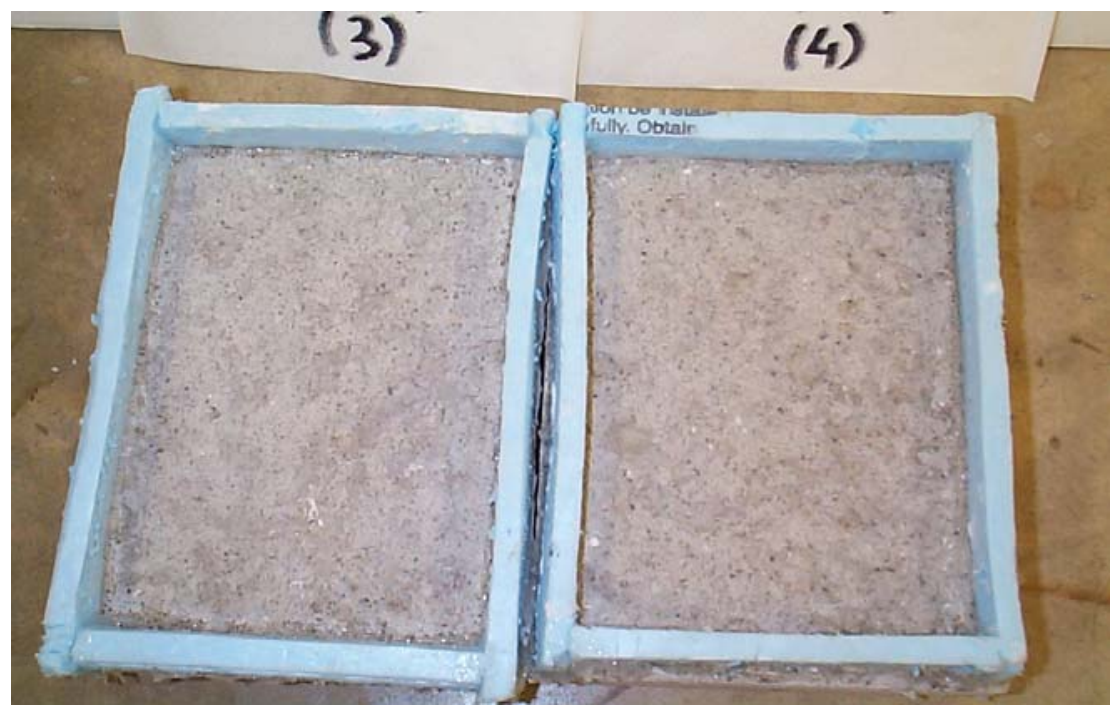

Figure C4: C04 (Lehigh cement + Rockport fly ash) conditioned for 6 days 


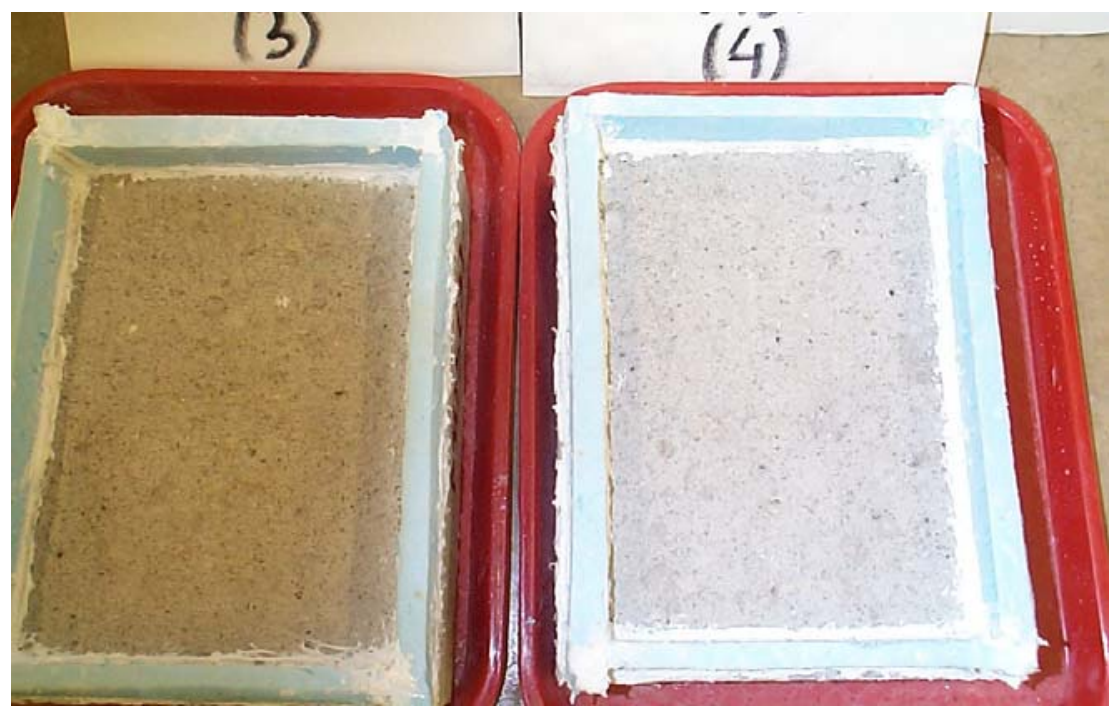

Figure C5: C05 (Lehigh cement + Miami Fort fly ash) conditioned for 6 days

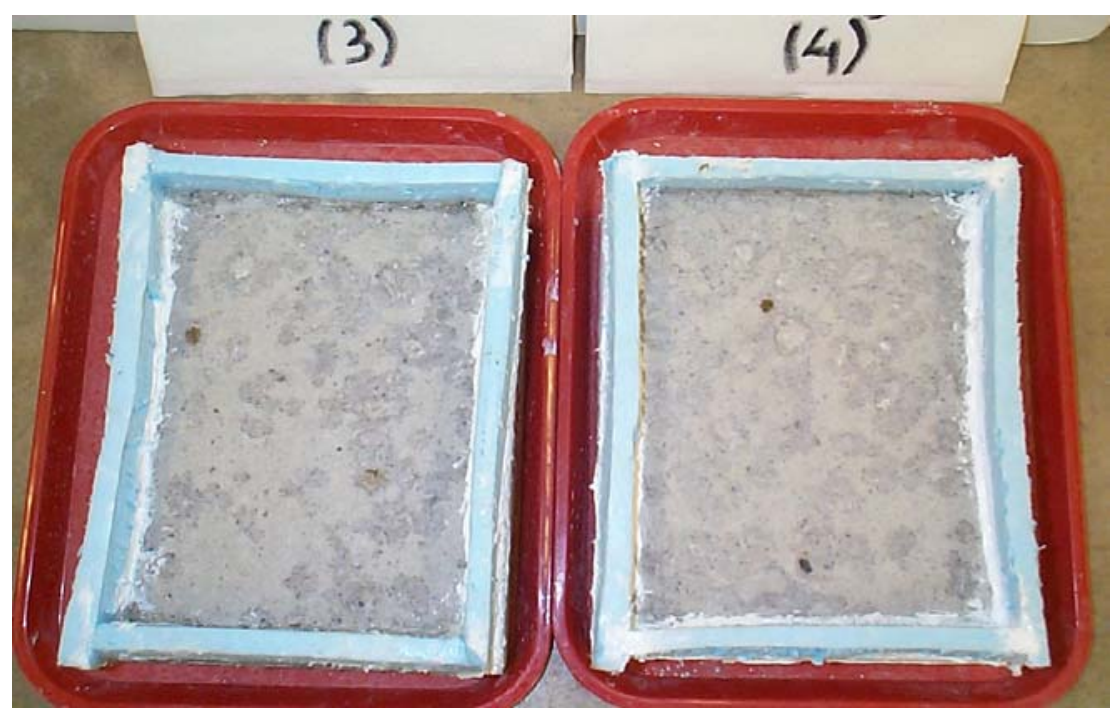

Figure C6: C06 (Essroc cement + Clifty Creek fly ash) conditioned for 6 days 


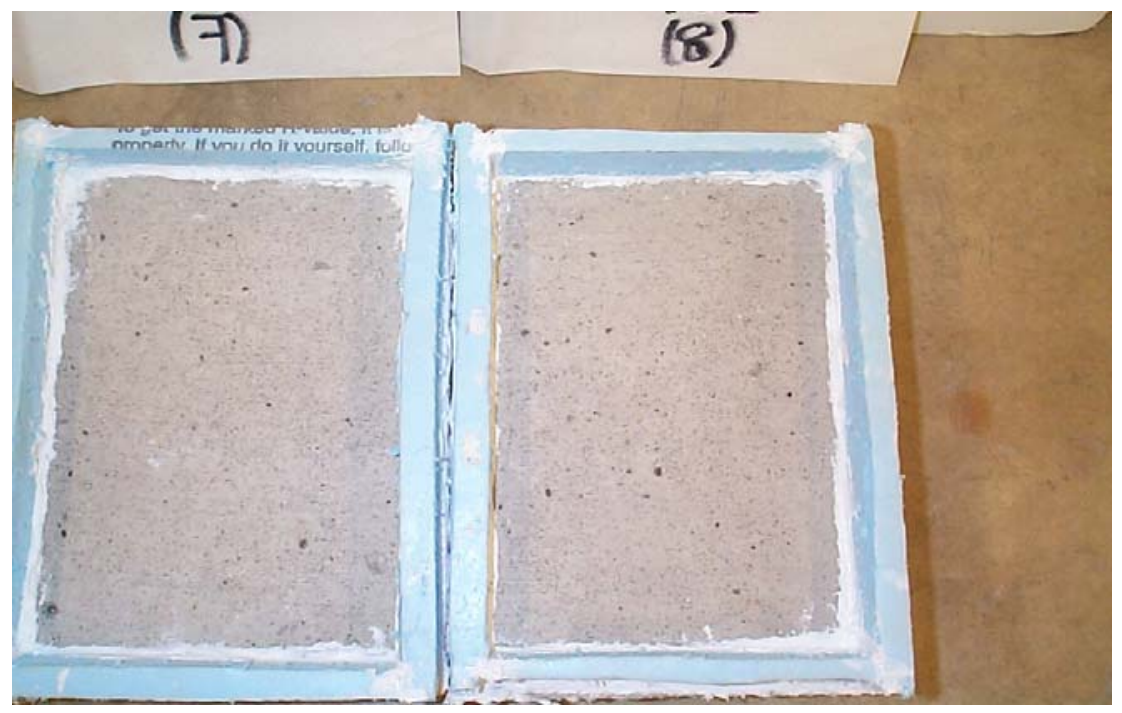

Figure C7: C01 (Lonestar cement) conditioned for 28 days

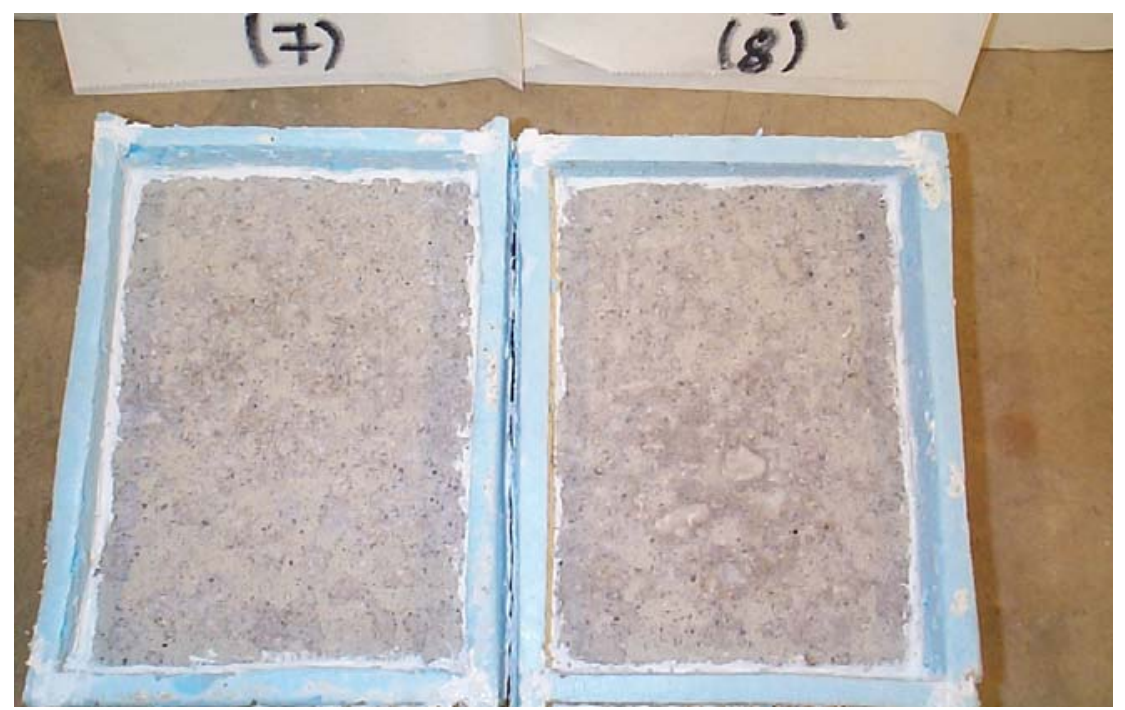

Figure C8: C02 (Lonestar cement + Rockport fly ash) conditioned for 28 days 


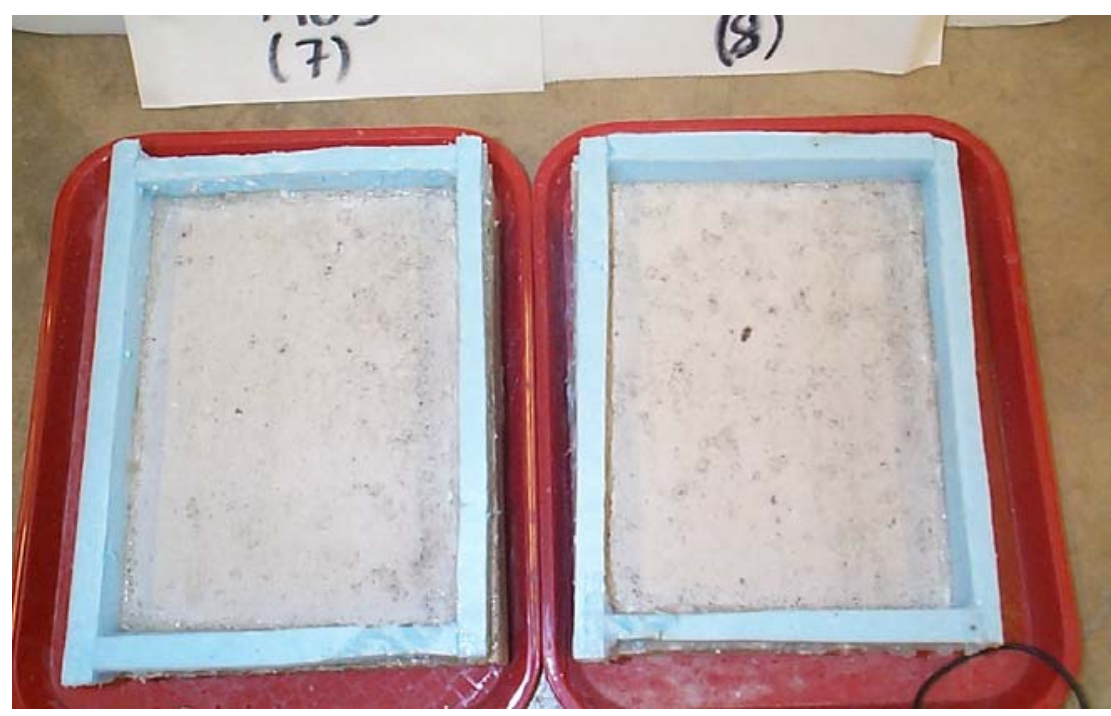

Figure C9: C03 (Lonestar cement + slag) conditioned for 28 days

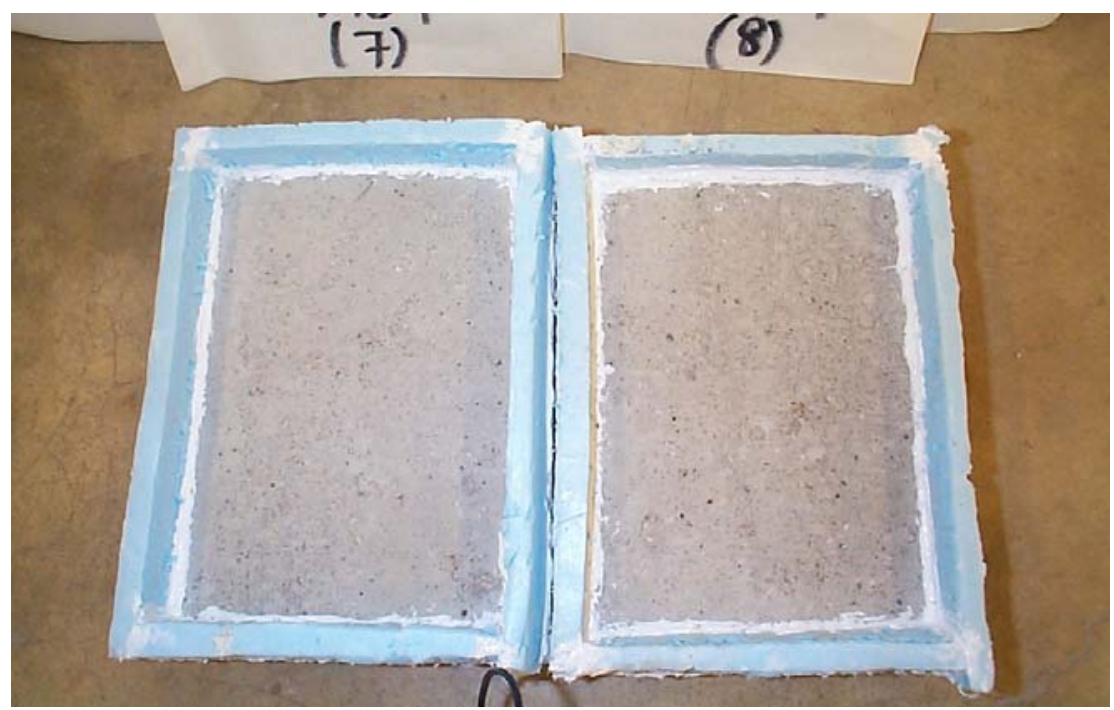

Figure C10: C04 (Lehigh cement + Rockport fly ash) conditioned for 28 days 


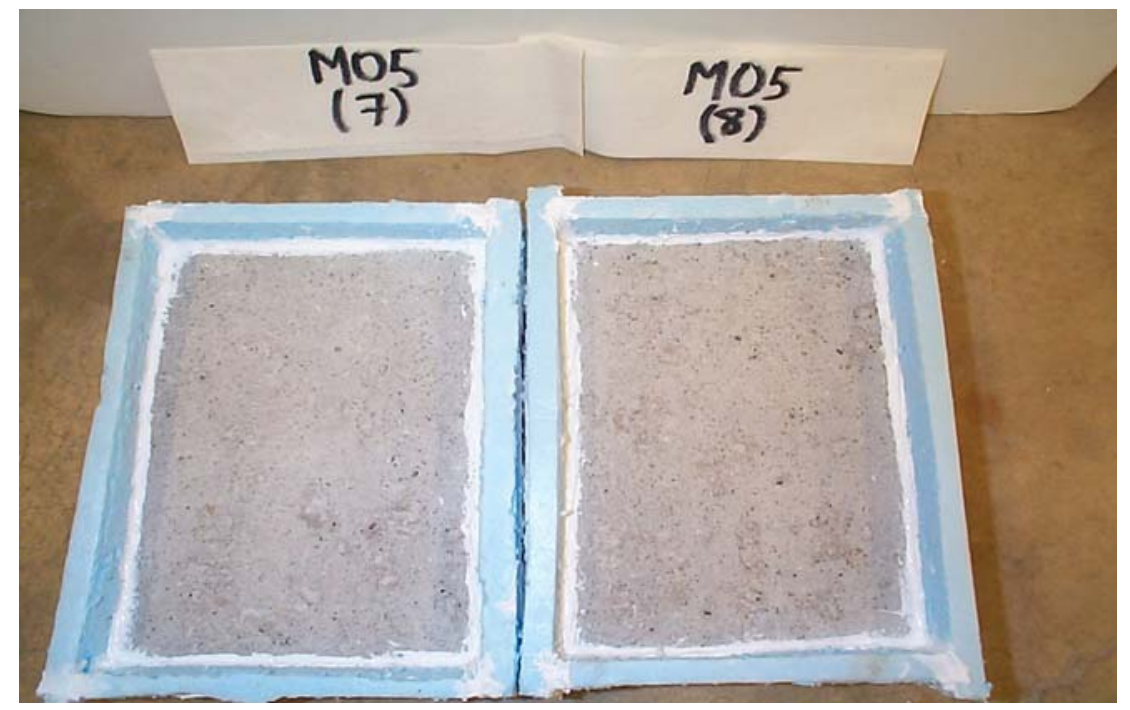

Figure C11: C05 (Lehigh cement + Miami Fort fly ash) conditioned for 28 days

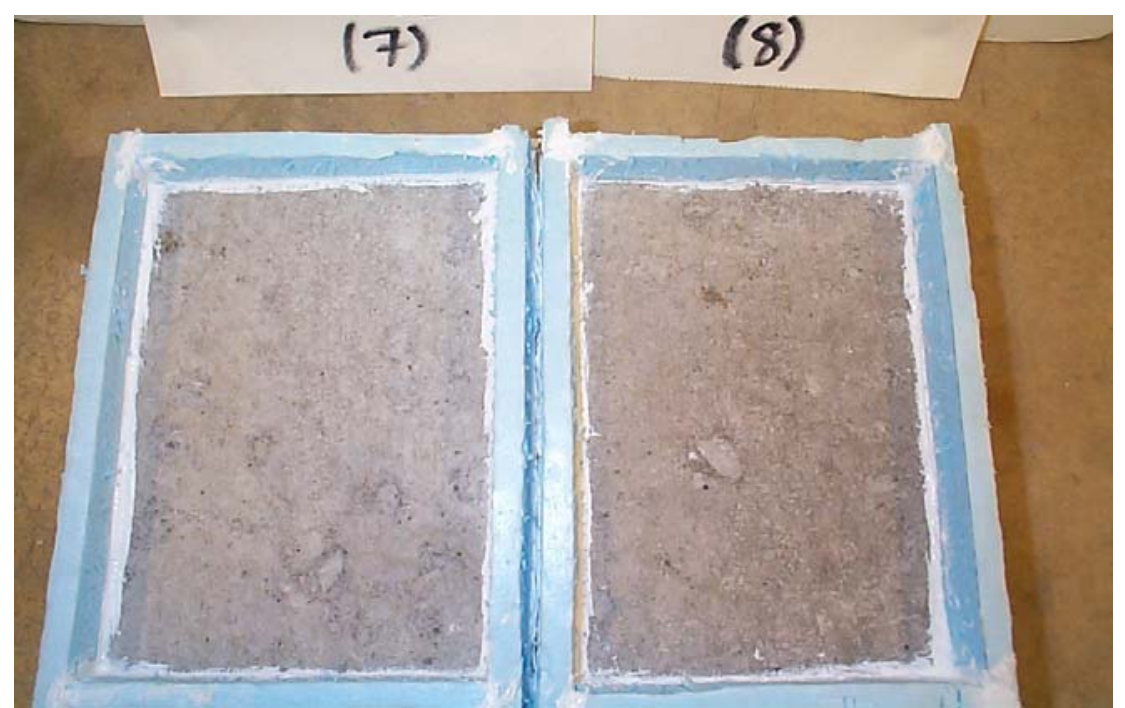

Figure C12: C06 (Essroc cement + Clifty Creek fly ash) conditioned for 28 days 


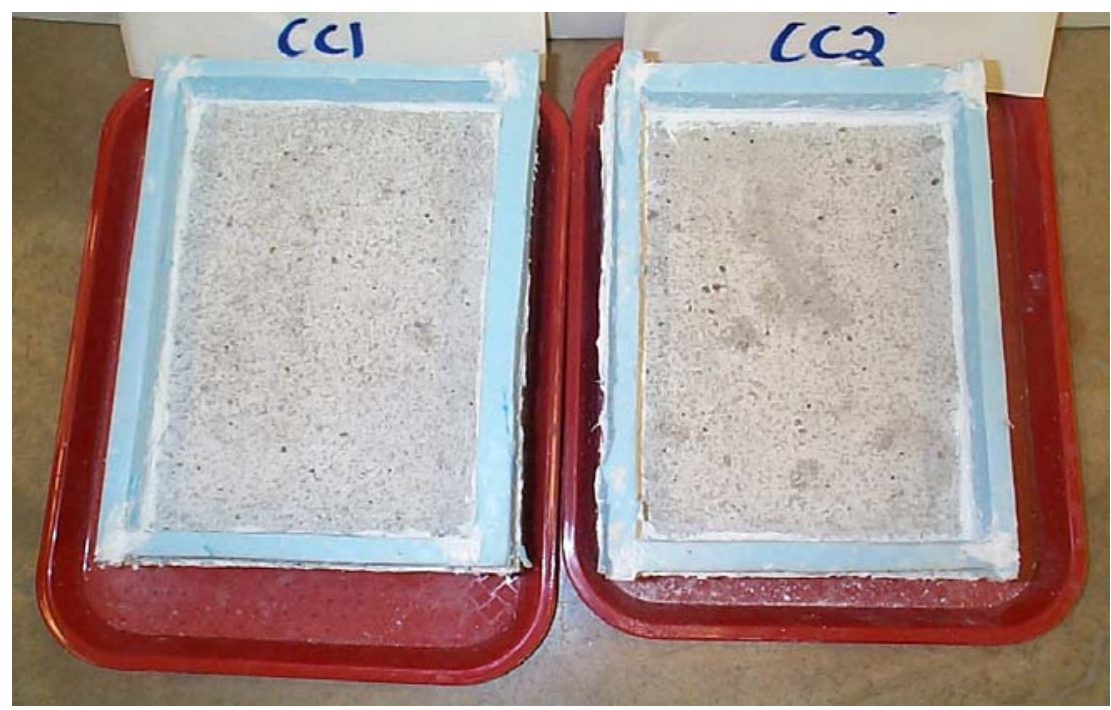

Figure C13: C01 (Lonestar cement) with curing compound conditioned for 6 days

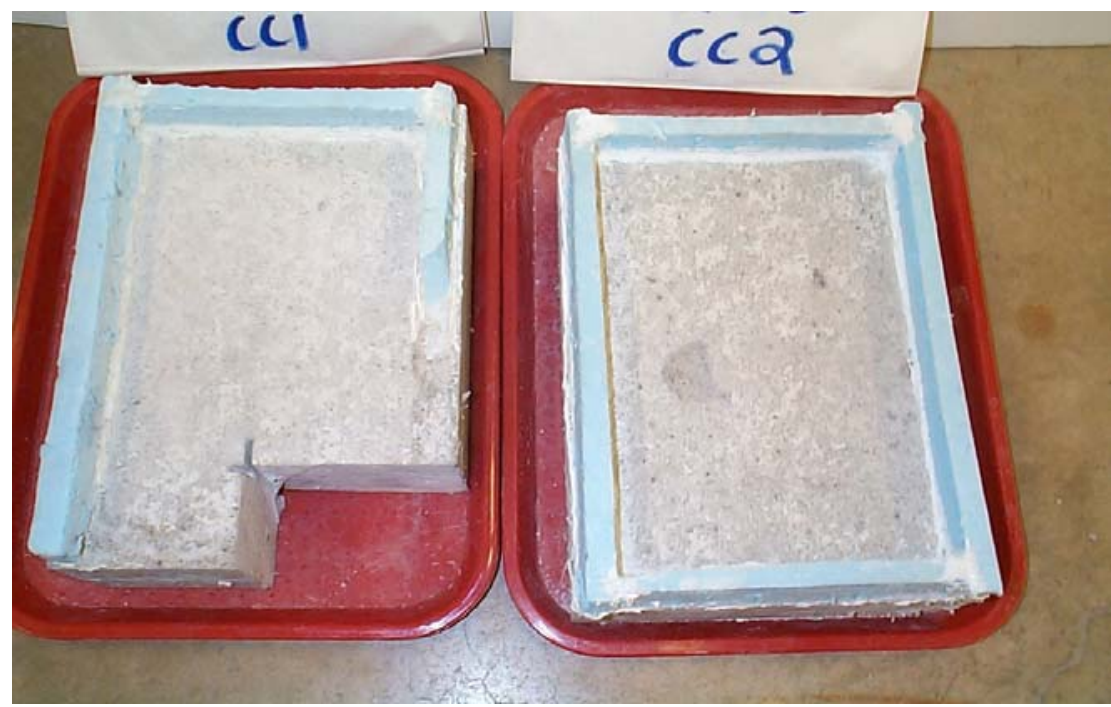

Figure C14: C02 (Lonestar cement + Rockport fly ash) with curing compound conditioned for 6 days 


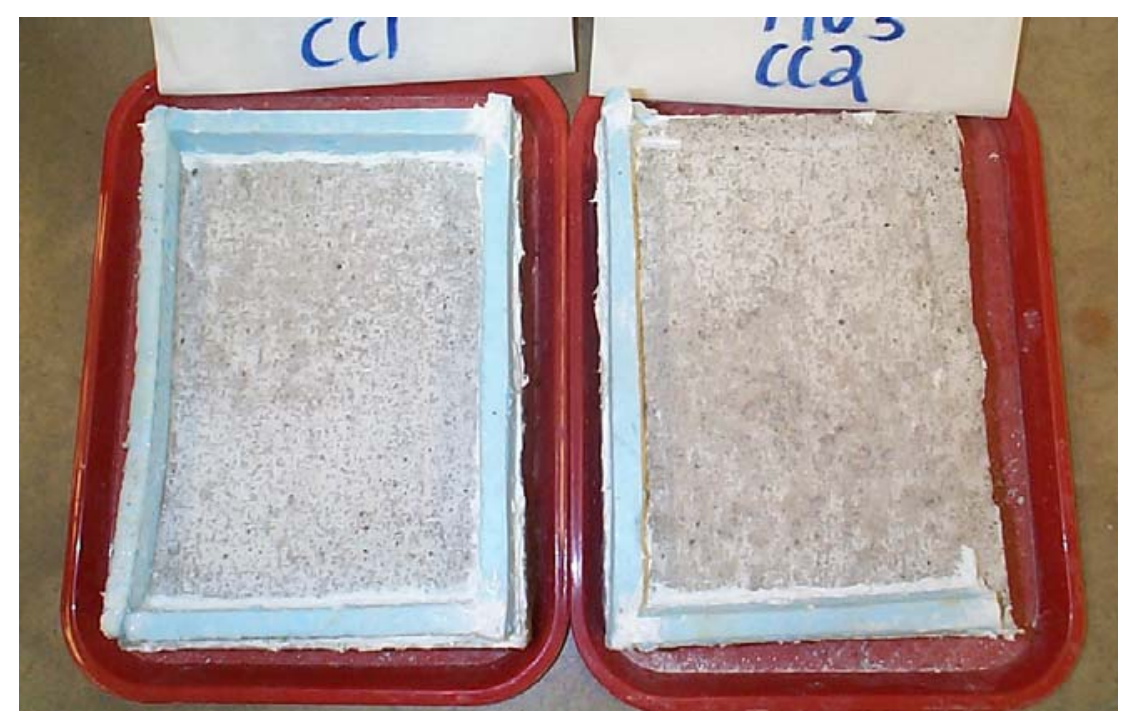

Figure C15: C03 (Lonestar cement + slag) with curing compound conditioned for 6 days

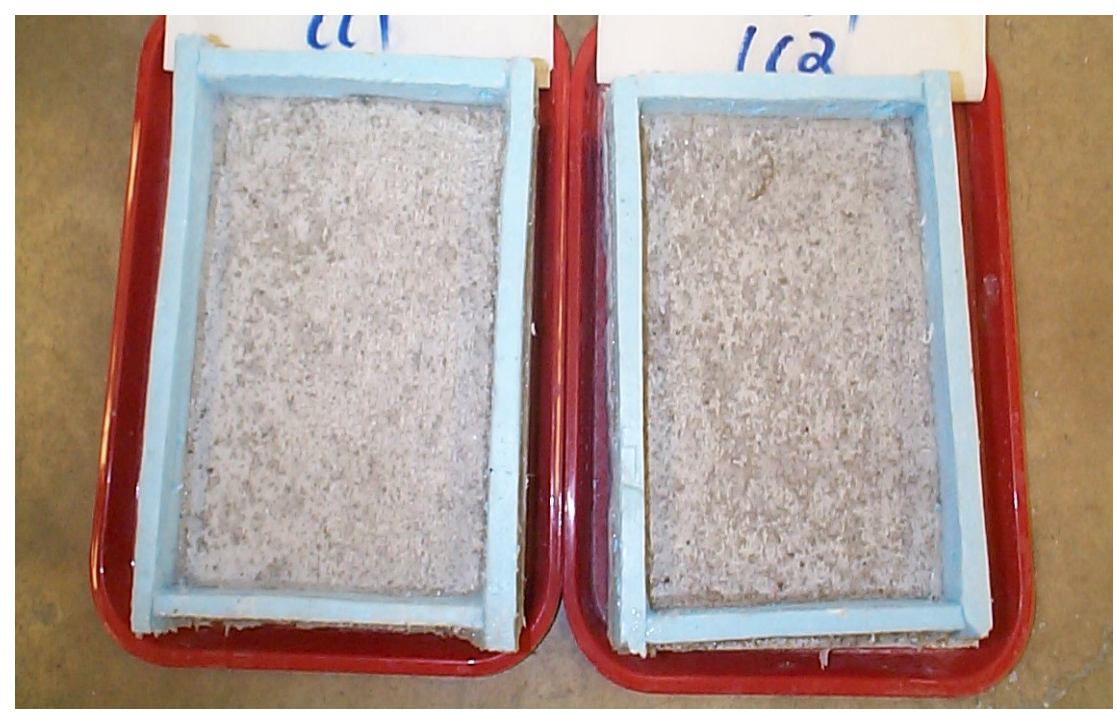

Figure C16: C04 (Lehigh cement + Rockport fly ash) with curing compound conditioned for 6 days 


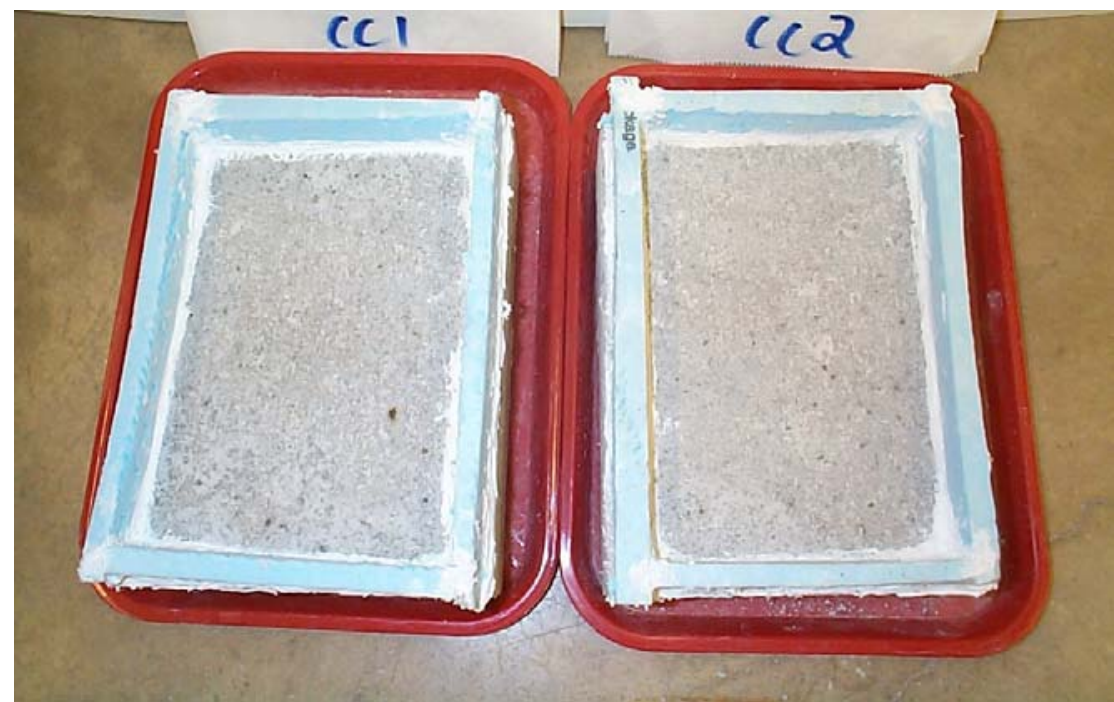

Figure C17: C05 (Lehigh cement + Miami Fort fly ash) with curing compound conditioned for 6 days

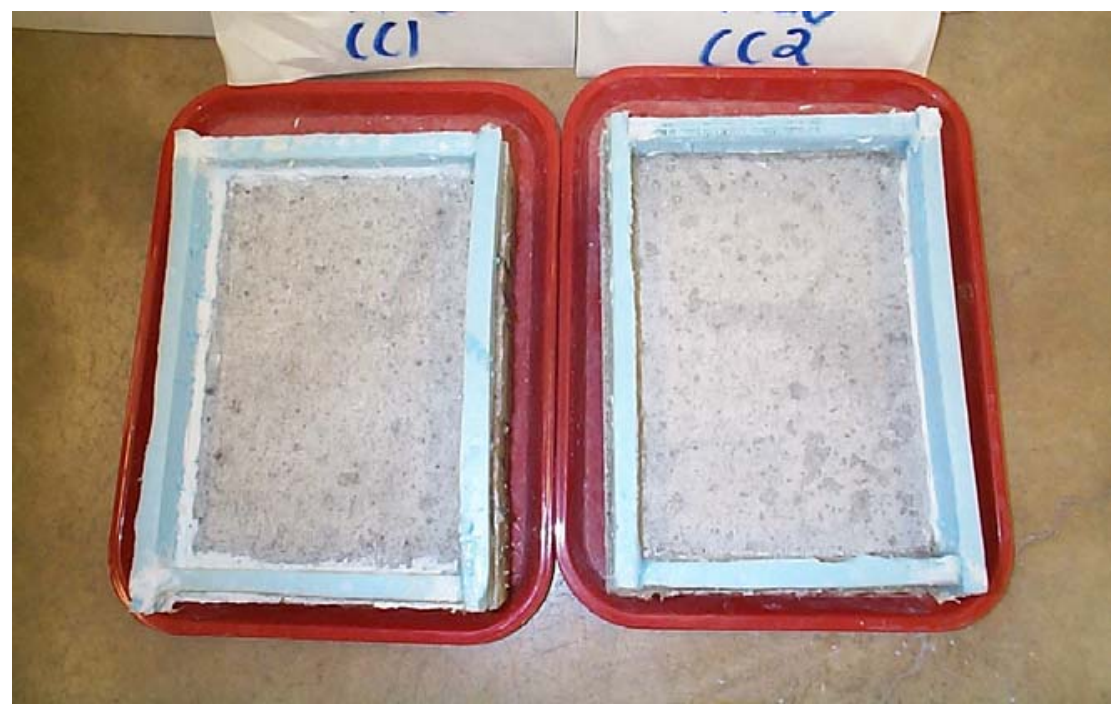

Figure C18: C06 (Essroc cement + Clifty Creek fly ash) with curing compound conditioned for 6 days 


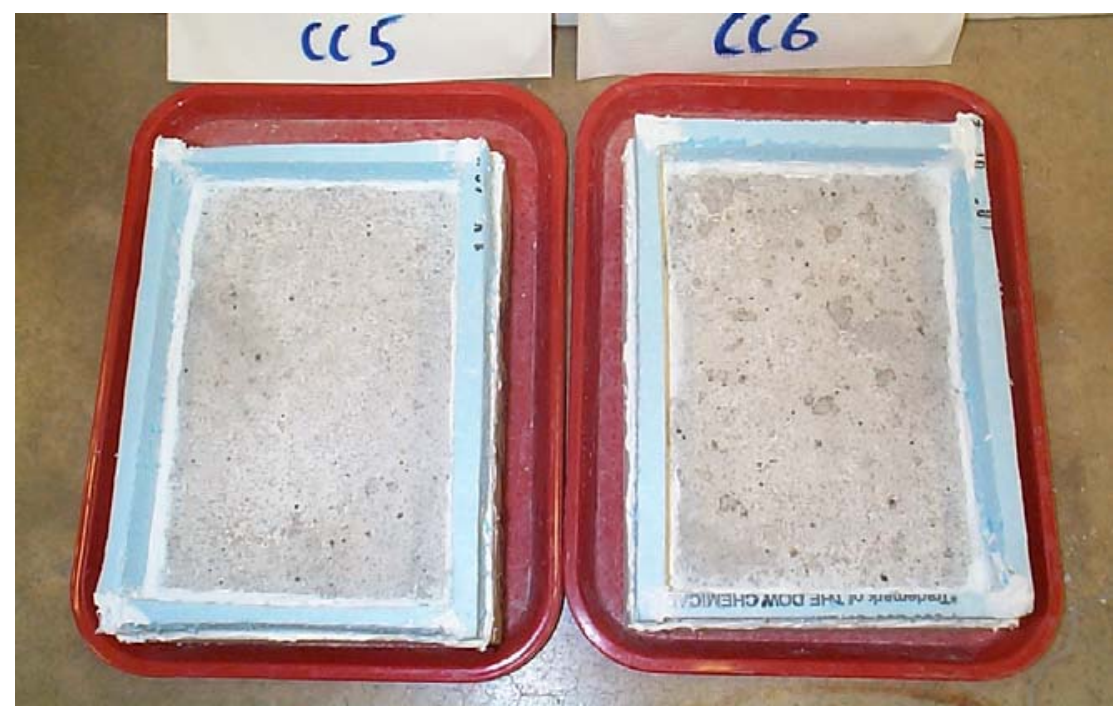

Figure C19: C01 (Lonestar cement) with curing compound conditioned for 28 days

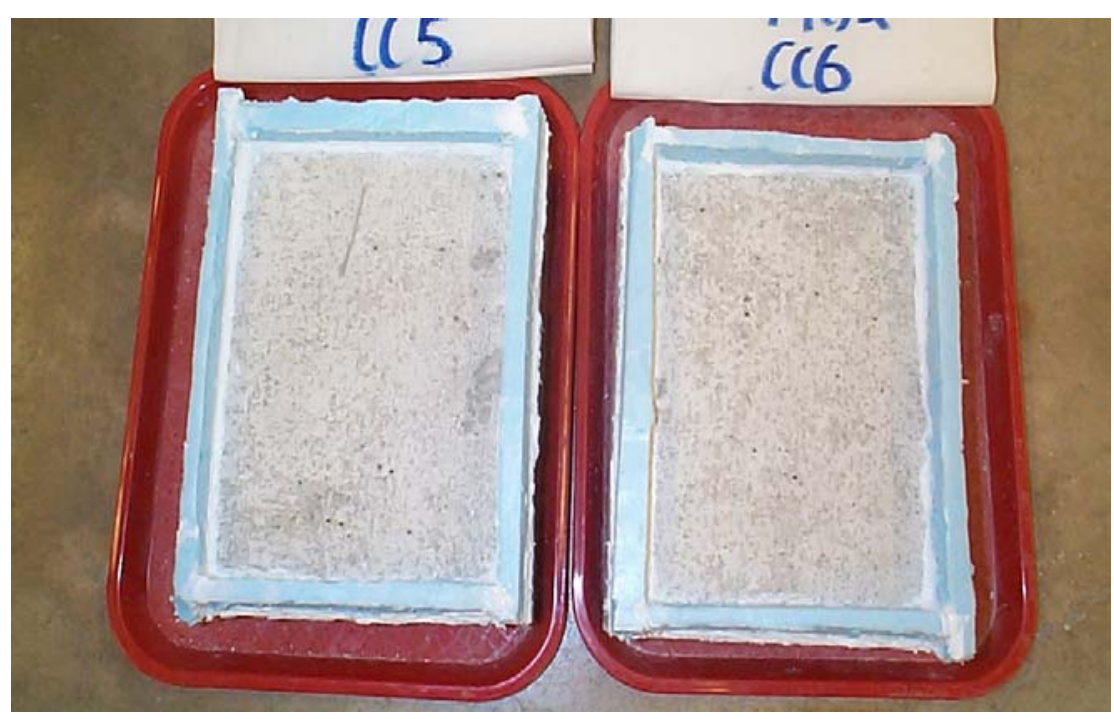

Figure C20: C02 (Lonestar cement + Rockport fly ash) with curing compound conditioned for 28 days 


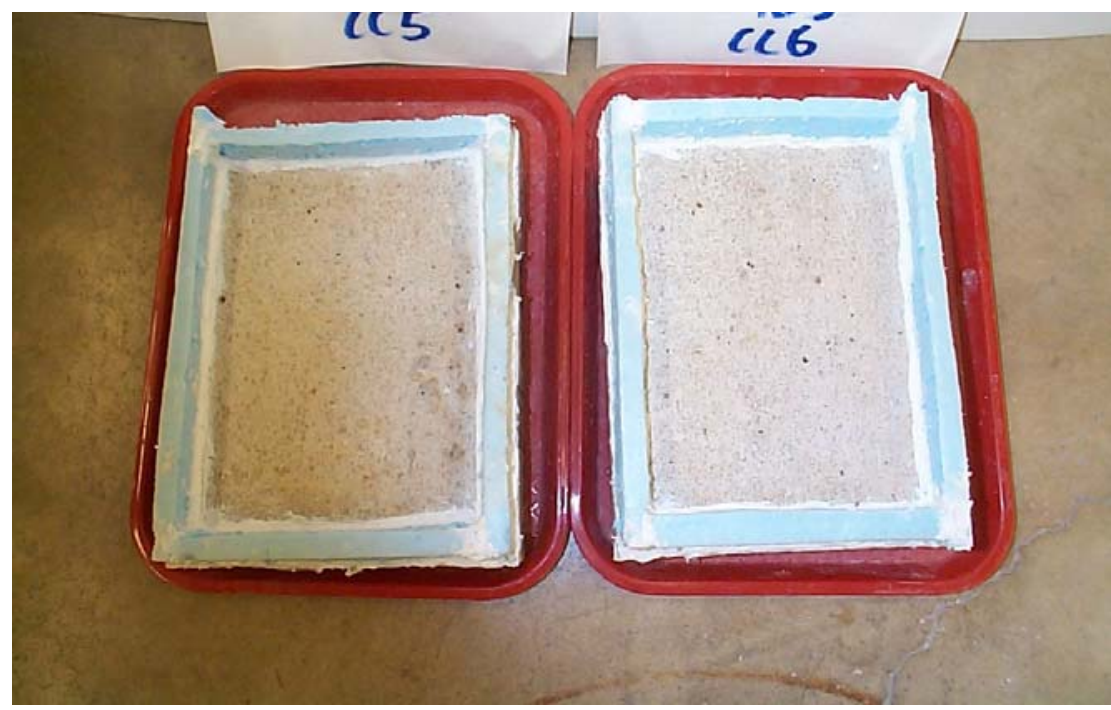

Figure C21: C03 (Lonestar cement + slag) with curing compound conditioned for 28 days

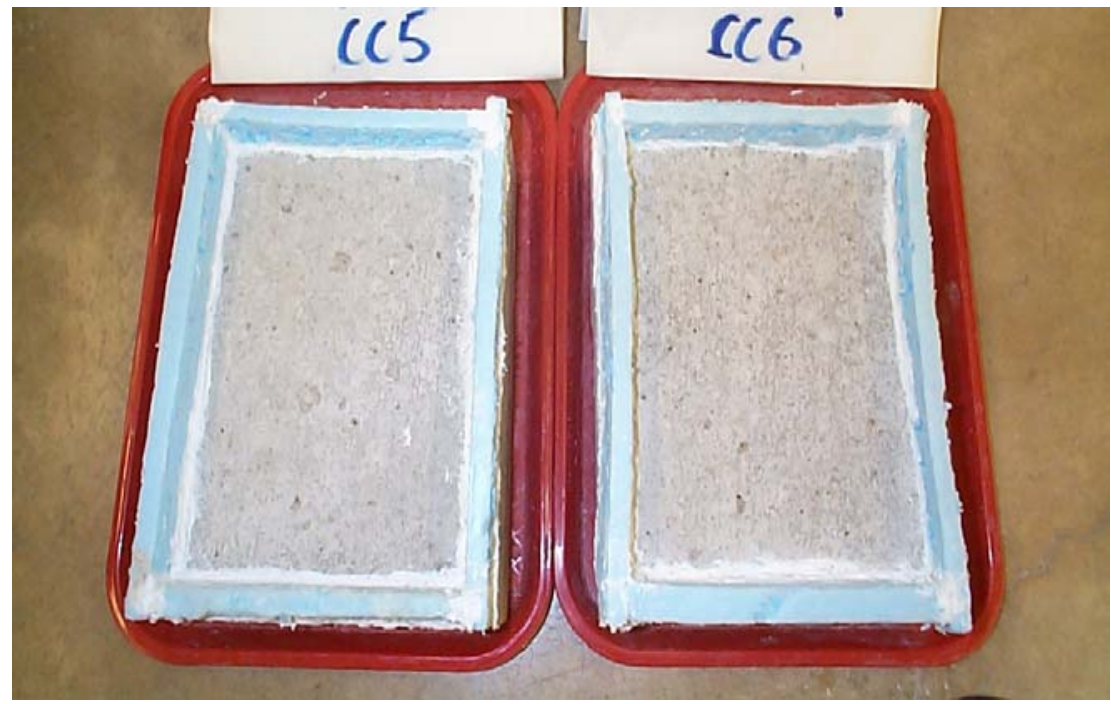

Figure C22: C04 (Lehigh cement + Rockport fly ash) with curing compound conditioned for 28 days 


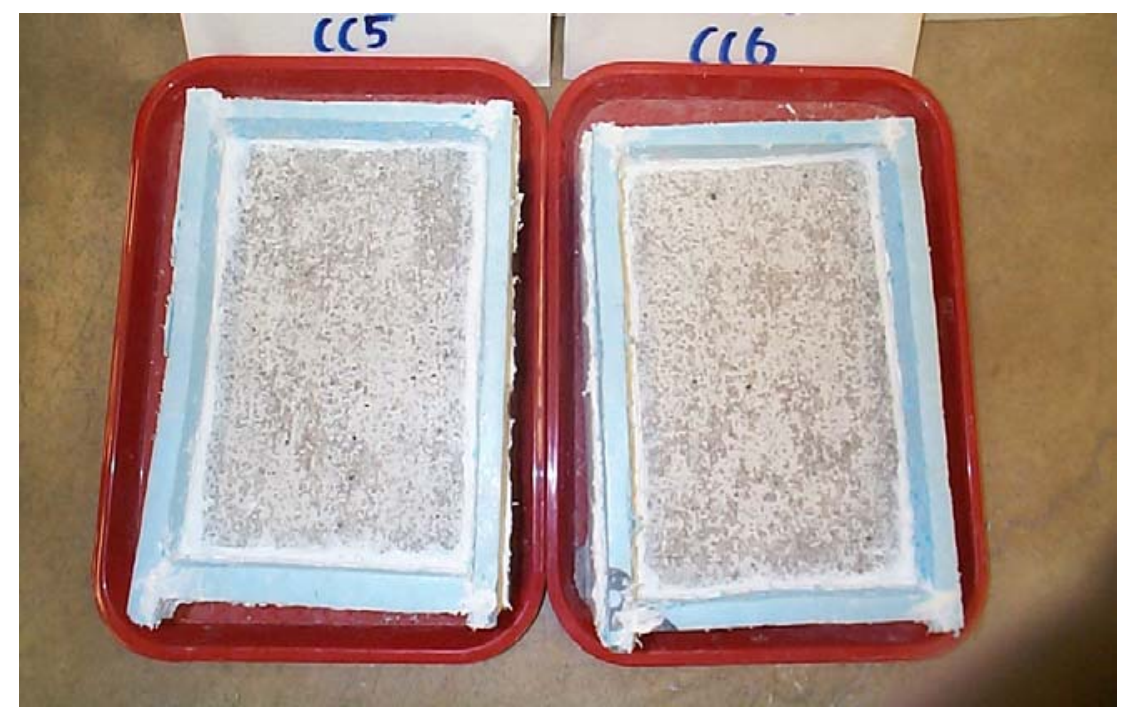

Figure C23: C05 (Lehigh cement + Miami Fort fly ash) with curing compound conditioned for 28 days

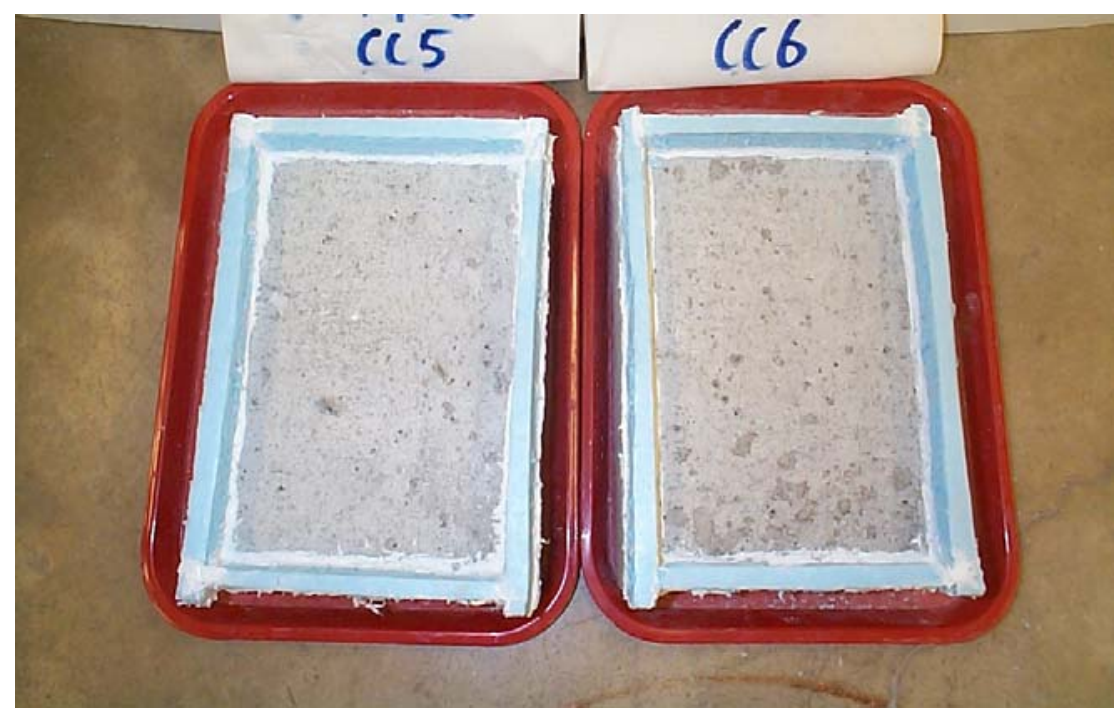

Figure C24: C06 (Essroc cement + Clifty Creek fly ash) with curing compound conditioned for 28 days 